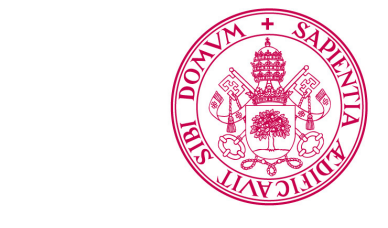

Universidad deValladolid
PROGRAMA DE DOCTORADO EN INVESTIGACIÓN

TRANSDISCIPLINAR EN EDUCACIÓN

\title{
LAS FORMACIÓN DE COMPETENCIAS TRANSVERSALES DOCENTES EN LA FORMACIÓN INICIAL DEL PROFESORADO DE EDUCACIÓN FÍSICA
}

Presentada por José Luis Aparicio Herguedas

para optar al grado de

Doctor por la Universidad de Valladolid

\author{
Dirigida por: \\ Dr. Antonio Fraile Aranda \\ Dr. Carlos Velázquez Callado
}





\section{AGRADECIMIENTOS}

A Antonio por el cariño y comprensión mostrada, la dedicación continuada para mi formación y la disposición constante para entenderme y ayudarme. Agradezco las experiencias compartidas de docencia e investigación, aprendiendo en ellas una forma de pensar y proceder que sin duda redundaron en un mejor conocimiento de la profesión docente e investigadora. Las numerosas conversaciones en escenarios diversos supusieron puntos de inflexión en el autoconocimiento personal y profesional que han marcado un cambio en mi perfil.

A Carlos por el apoyo incondicional mostrado, el afecto de su actitud y la comunicación abierta en todo momento para optimizar el proceso de realización de mi tesis y la lectura paciente de cuanto se iba desarrollando.

A mis amigos colombianos de Medellín, William, Juan David, José Roberto, Albeiro, Néstor Guillermo, Sandra, Pacho y cuantos me ayudaron a realizar mi pasantía con tanto cariño y generosidad. Agradezco los valiosos momentos formativos en el IUEF de la Universidad de Antioquia y otras universidades colombianas que supusieron un voto de confianza. Agradezco también el cariño y la amistad regalada presente en eventos, reflexiones compartidas y experiencias diversas.

Al Vicerrectorado de Investigación de la Universidad de Valladolid por las ayudas económicas prestadas para la realización de la presente tesis, asistencia a congresos y jornadas formativas y pasantías, contribuyendo activamente al desarrollo de mi formación investigadora.

Especialmente a Raquel por el apoyo incondicional, la paciencia, el ánimo y el inmenso cariño mostrado, suponiendo la energía vital para persistir y arriesgar, afrontar los retos, superar los malos momentos y aprovechar los buenos. 
Tesis doctoral realizada con el soporte de un contrato predoctoral FPI para personal de investigación en formación de la Universidad de Valladolid, Vicerrectorado de Investigación (Convocatoria 2015-2019), en conexión con el proyecto I+D+i: "Las competencias docentes en la formación inicial del profesorado de educación física". Convocatoria de noviembre de 2013 del Programa Estatal de Investigación, Desarrollo e Innovación Orientada a los Retos de la Sociedad, en el marco del Plan Estatal de Investigación Científica y Técnica y de Innovación 2013-2016. Referencia: EDU 201342024-R. Duración: 3 años (2014-2016). 


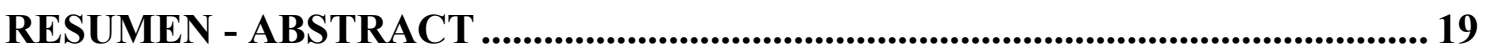

1. INTRODUCCIÓN ............................................................................................. 21

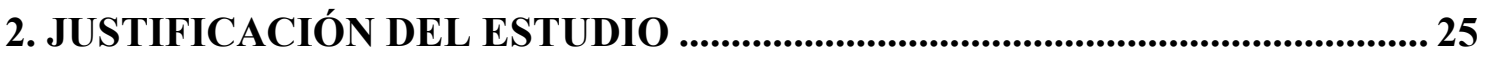

3. MARCO TEÓRICO-CONCEPTUAL .........................................................29

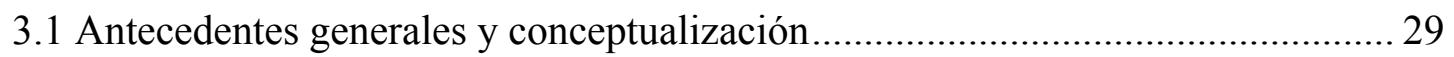

3.1.1 Tratamiento histórico de las competencias.................................................... 30

3.1.1.1 La eficacia profesional a través de la competencias................................ 31

3.1.1.2 Competencias en la convergencia hacia EEES........................................ 35

3.1.2 Competencias profesionales: conceptualización .......................................... 42

3.1.2.1 Perspectiva dinámica, integradora y de mercado ..................................... 43

3.1.2.2 Perspectiva socio-crítica: en búsqueda del sentido humanista de las

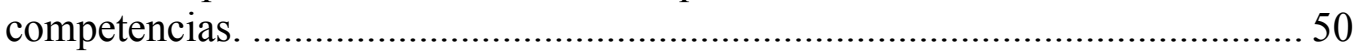

3.2 La cultura profesional del profesorado de Educación Física en España ............... 57

3.2.1 Evolución del espacio profesional de la EF en España ................................... 58

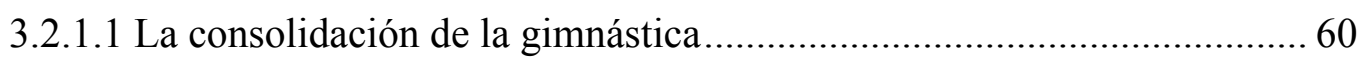

3.2.1.2 La formación de "profesores especiales" ................................................ 62

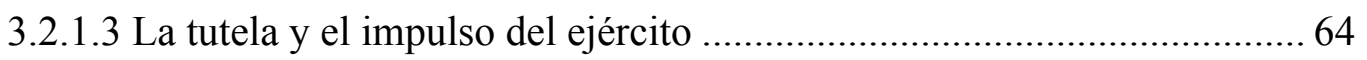

3.2.1.4 La función y los valores de la EF del régimen franquista ......................... 66

3.2.1.5 De camino hacia la transición................................................................. 69

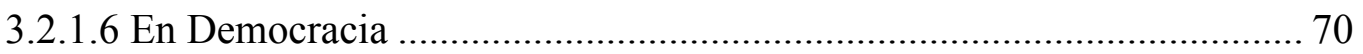

3.2.2 Enfoques competenciales en la tradición de la Formación Inicial del

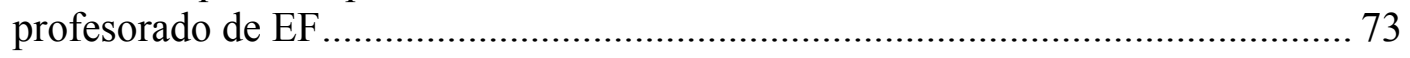

3.2.2.1 El modelo tradicional (o academicista) .................................................. 74

3.2.2.2 El modelo técnico ……………….................................................... 75

3.2.2.3 El modelo de formación hacia la práctica ................................................ 77

3.2.2.4 El modelo social-transformativo …………………............................ 79

3.3 Las competencias genéricas o transversales en la formación del profesorado de

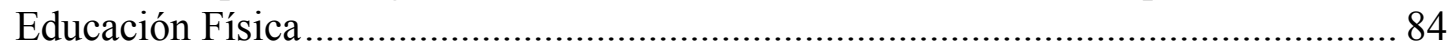

3.3.1 Competencias Instrumentales .................................................................. 91

3.3.1.1 Conocimientos de informática aplicada al ámbito de la EF ................... 92

3.3.1.1.1 Conceptualización ....................................................................... 92

3.3.1.1.2 Competencia digital en la formación del profesorado de Educación

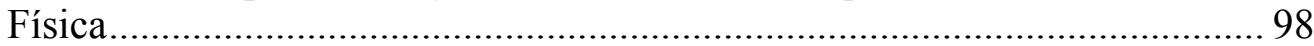

3.3.1.1.3 Metodologías que facilitan la adquisición y desarrollo de la competencia tecnológica. 
3.3.1.2 Conocimiento de una Lengua Extranjera

3.3.1.2.1 Conceptualización

3.3.1.2.2. La Enseñanza de la Lengua Extranjera en la formación inicial del profesorado de Educación Física

3.3.1.2.3 Una metodología que facilita el conocimiento de una LE desde el área de EF

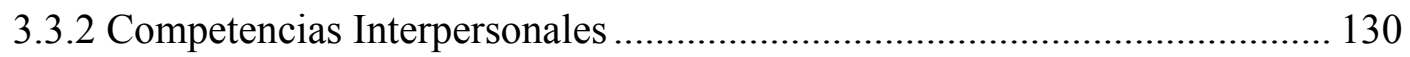

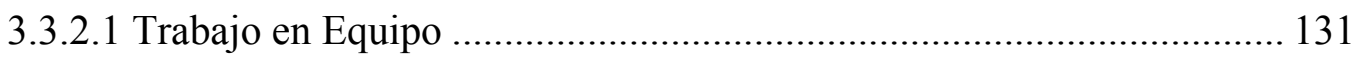

3.2.1.1 Trascendencia del trabajo en equipo en las organizaciones

3.3.2.1.2 Conceptualización: ¿qué significa realmente trabajar en equipo?. 133

3.3.2.1.3 Componentes del trabajo en equipo: los big five del trabajo en equipo

3.3.2.1.4 Presencia del desarrollo de la competencia para el trabajo en equipo en la formación inicial del profesorado de Educación Física.

3.3.2.1.5 Metodologías que facilitan la adquisición y desarrollo de la competencia para el trabajo en equipo ................................................... 150

3.3.2.2 Habilidades en las relaciones interpersonales .................................. 154

3.3.2.2.1 De la Inteligencia emocional y social a las competencias emocionales y sociales.

3.3.2.2.2 Las competencias emocionales y sociales en la formación del profesorado de EF.

3.3.2.4.5 Metodologías que facilitan la adquisición y desarrollo de las habilidades en las relaciones interpersonales

3.4. La evaluación formativa

3.4.1 Conceptualización: ¿qué es evaluar?.....

3.4.2 Evaluación Formativa para la implicación de los estudiantes en su desarrollo competencial.

3.4.3 Medios, técnicas e instrumentos de evaluación

3.4.4 Experiencias de Evaluación Formativa en la Formación del Profesorado de $\mathrm{EF}$

4. OBJETIVOS DE LA INVESTIGACIÓN .............................................................. 197

5. METODOLOGÍA DE LA INVESTIGACIÓN................................................. 201

5.1. Los referentes teóricos de la metodología de investigación ............................. 201

5.1.1 Enfoque metodológico de la investigación................................................ 201

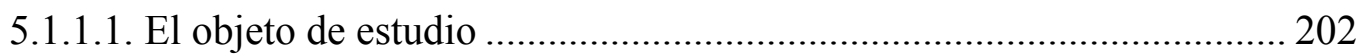

5.1.1.2 El método mixto de investigación ...................................................... 202

5.1.1.3 Aspectos característicos del método mixto .......................................... 204

5.1.1.3.1 El referente filosófico ................................................................ 205 
5.1.1.3.2. Propósitos del método mixto 206

5.1.1.3.3. Ventajas e inconvenientes del método mixto ............................. 207

5.1.1.3.4 El proceso metodológico mixto ................................................... 208

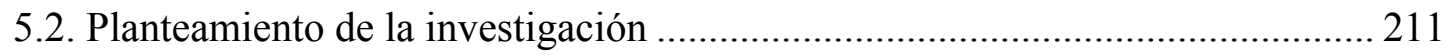

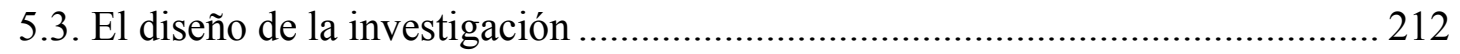

5.3.1 Diseño de la metodología de investigación .............................................. 212

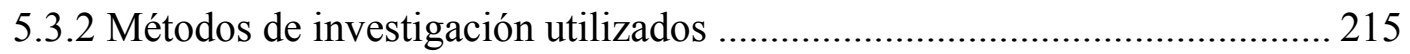

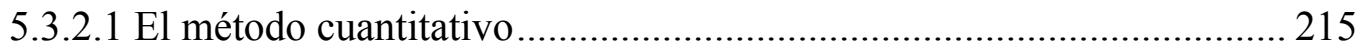

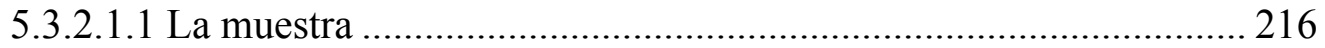

5.3.2.1.2 Instrumento de recogida de datos .............................................. 219

5.3.2.1.3 Análisis estadístico de los datos ................................................. 221

5.3.2.1.4 Rigor científico ............................................................................. 223

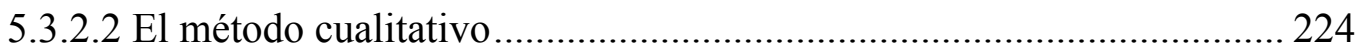

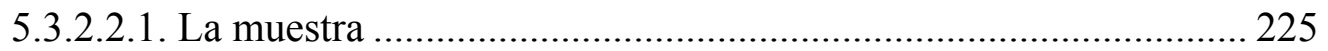

5.3.2.2.2 Instrumento de recogida de datos .............................................. 226

5.3.2.2.3. Análisis de datos cualitativos ................................................... 231

5.3.2.2.4. Criterios de rigor en la investigación cualitativa ......................... 242

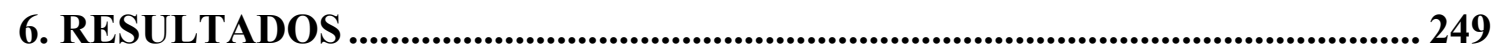

6.1. Conocer el grado de ayuda formativa recibida a lo largo de la formación inicial del profesorado de Educación Física, para el desarrollo de las competencias

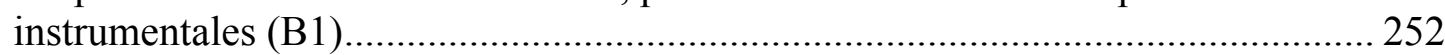

6.1.1 Conocer cómo influye el "género" a la hora de considerar la ayuda formativa recibida durante la formación, para el desarrollo de las competencias

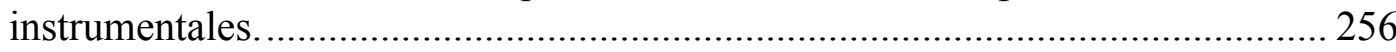

6.1.2 Conocer cómo influye el "tipo de estudios de Educación Física" cursados a la hora de considerar la ayuda formativa recibida durante la formación para el

desarrollo de las competencias instrumentales............................................... 270

6.2. Conocer el grado de ayuda formativa recibida a lo largo de la formación inicial del profesorado de Educación Física, para el desarrollo de las competencias

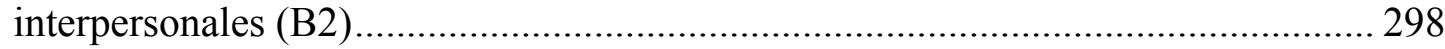

6.2.1. Conocer cómo influye el "género" de los estudiantes a la hora de considerar la ayuda formativa recibida a través de las materias cursadas para el desarrollo de las competencias interpersonales.

6.2.2. Conocer cómo influye el "tipo de estudios de Educación Física" cursados por los estudiantes, a la hora de considerar la ayuda formativa recibida para el desarrollo de las competencias interpersonales.

6.3. Conocer si existe una relación entre el uso de metodologías activas y la presencia de la evaluación formativa respecto de la percepción de desarrollo de competencias que tienen los estudiantes tras su formación. 
6.4. Conocer si existe una relación entre el uso de los instrumentos de evaluación utilizados respecto de la percepción de desarrollo de competencias que tienen los estudiantes tras su formación.

6.5. Conocer si existe una relación entre las formas de calificación utilizadas respecto a la percepción de desarrollo de competencias que tienen los estudiantes tras su formación.

7.1 ¿Cuál es la percepción de los estudiantes de Educación Física sobre la ayuda formativa recibida durante su formación para el desarrollo de sus competencias instrumentales (B1), desde la perspectiva de género y de la titulación cursada? ..... 377

7.2 ¿Cuál es la percepción de los estudiantes de Educación Física sobre la ayuda formativa recibida durante su formación para el desarrollo de sus competencias interpersonales (B2), desde la perspectiva de género y de la titulación cursada? .... 385

7.3 ¿Qué relación existe entre el uso de metodologías activas y de evaluación formativa respecto de la percepción de desarrollo de competencias instrumentales e interpersonales (B1/B2) que tienen los estudiantes de Educación Física tras su formación?

7.4 ¿Qué relación existe entre el uso de los instrumentos de evaluación aplicados durante la formación inicial respecto de la percepción de desarrollo de competencias instrumentales e interpersonales que tienen los estudiantes de Educación Física tras su formación?

7.5 ¿Qué relación existe entre las formas de calificación utilizadas durante la formación cursada respecto de la percepción de desarrollo de competencias instrumentales e interpersonales que tienen los estudiantes de Educación Física tras su formación?

8. CONCLUSIONES

9. DEBILIDADES Y FORTALEZAS DEL ESTUDIO

10. LINEAS DE INVESTIGACIÓN FUTURAS.

Anexo 1. Cuestionario de competencias docentes de los estudiantes

Anexo 2. Guión realizado para el desarrollo del Grupo de Discusión 1

Anexo 3. Guión realizado para el desarrollo del Grupo de Discusión 2

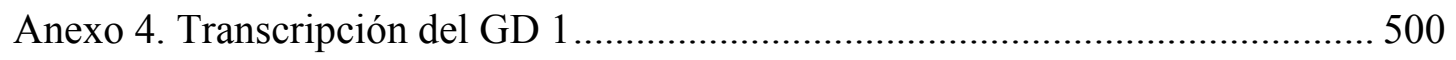

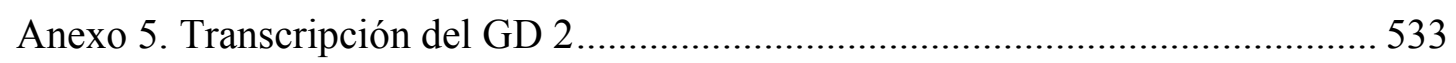


Tabla 3. 1 Evolución normativa punto de partida de los planes de estudios de referencia para este estudio (elaboración propia) ............................................................... 42

Tabla 3. 2 Características de la perspectiva integradora y dinámica de las competencias profesionales (Cano, 2005; Marín, 2009) …..................................................... 50

Tabla 3. 3 Características de la perspectiva sociocrítica de las competencias profesionales a partir de Contreras (2010), Díez Gutiérrez (2009), Fraile (2004a, 2004b), Martínez Bonafé (2004), Pérez Gómez (2010), Villardón-Gallego (2015)

Tabla 3. 4 Capacidades básicas que facilitan el desarrollo de la autonomía para el aprendizaje (Monereo y Pozo, 2003).

Tabla 3. 5 Presencia de las competencias en los títulos de Grado MEPEF y CAFyD (Libros Blancos, ANECA, 2005a, 2005b).

Tabla 3. 6 Presencia de las competencias transversales en los "verifica" del título de Grado MEPEF (en las 12 facultades de Educación analizadas).

Tabla 3. 7 Presencia de las competencias transversales en los "verifica" del título de Grado CAFyD (en las 7 facultades CAFyD analizadas)

Tabla 3. 8 Aspectos metodológicos que han de estar presentes en la capacitación tecnológica docente (Resta y Semenov, 2004)

Tabla 3. 9 Tratamiento de la competencia digital presente en el Proyecto Tunning y Libros Blancos de los títulos de Grado MEPEF y CAFyD (ANECA, 2005a, 2005b)

Tabla 3. 10 Dimensiones a considerar en la formación tecnológica (Arwa et al., 2012; Ferrari, 2013; Krumsvik, 2008; Llorente, 2008) 103

Tabla 3. 11 Problemas críticos surgidos durante el desarrollo de trabajos grupales ... 152

Tabla 3. 12 Diversificación de las competencias emocionales a partir de Goleman, Boyatzis y McKee (2002).

Tabla 3.13 Aspectos que han de estar presentes en la formación práctica de las habilidades interpersonales (García et al., 2014; Mireya y Filella, 2016; érezEscoda et al., 2013; Ribes, 2011; Saarni (2000)......

Tabla 3.14 Diferencias entre evaluación y calificación (Hamodi et al., 2005) ........... 175

Tabla 3.15 Medios e instrumentos de evaluación (Hamodi et al. 2015) 185

Tabla 5. 1 Fortalezas de los métodos cuantitativo y cualitativo (Jhonson y Turner, 2003)

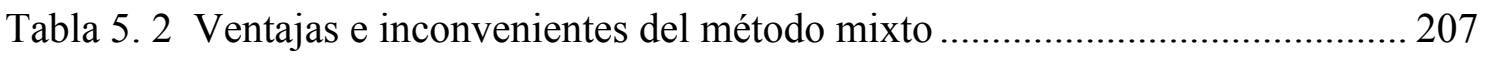

Tabla 5. 3 Estructura del cuestionario: preguntas e ítems ........................................ 220

Tabla 5. 4 Valores asignados a las variables nominales del cuestionario (Gutiérrez et al., 2011) 
Tabla 5. 5 Principales propósitos de la investigación cualitativa (Maxwell, 1998) .... 225

Tabla 5. 6 Tratamiento de los criterios de rigor científico 247

Tabla 6. 1 Valores asignados a las variables nominales del cuestionario (Gutiérrez et

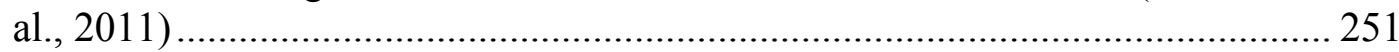

Tabla 6. 2 Ítems del cuestionario que integran B1 (competencias instrumentales) .... 252

Tabla 6. 3 Descriptivos para B1 y sus ítems (todos los estudiantes) 253

Tabla 6. 4 Relación de códigos que explican el significado de la formación cursada y su contribución para el desarrollo de P1.29

Tabla 6. 5 Relación de códigos que explican el significado de la formación cursada y su contribución para el desarrollo de P1.28 ........................................................ 255

Tabla 6. 6 Valores de la variable MB1 en relación a la variable factor "género" ....... 256

Tabla 6. 7 Diferencias en la percepción de los estudiantes hombres y mujeres en relación a MB1

Tabla 6. 8 Valores de promedio obtenidos para P1.29 y P1.28 en relación a la variable factor "género".....

Tabla 6. 9 Diferencias en la percepción de los estudiantes hombres y mujeres sobre P1.29

Tabla 6. 10 Estudio comparativo entre estudiantes hombres y mujeres sobre los códigos que explican el funcionamiento de la formación recibida para el desarrollo de P1.29 260

Tabla 6.11 Diferencias en la percepción de los estudiantes hombres y mujeres sobre $\mathrm{P} 1.28$

Tabla 6. 12 Estudio comparativo entre estudiantes hombres y mujeres sobre los códigos que explican el funcionamiento de la formación recibida para el desarrollo de $\mathrm{P} 1.28$

Tabla 6. 13 Valores de la variable MB1 en relación a la variable factor "tipo de estudios de EF" cursados

Tabla 6. 14 Diferencias en la percepción de los estudiantes MEPEF y CAFyD en relación a MB1

Tabla 6. 15 Valores de promedio obtenidos para P1.29 y P1.28 en relación a la variable factor "tipo de estudios de EF" cursados

Tabla 6. 16 Diferencias en la percepción de los estudiantes MEPEF y CAFyD sobre P1.29

Tabla 6.17 Valores de promedio obtenidos para P1.29 en relación a la variable factor "facultades MEPEF".

Tabla 6. 18 Prueba Kruskal-Wallis para P1.29 y variable factor "facultades MEPEF"

Tabla 6. 19 Resultados del análisis post hoc entre P1.29 y la variable factor "facultades MEPEF" (comparadas de dos en dos) 
Tabla 6. 20 Valores de promedio obtenidos para P1.29 en relación a la variable factor "facultades CAFyD"

Tabla 6. 21 Prueba Kruskal-Wallis para P1.29 y variable factor "facultades CAFyD"

Tabla 6. 22 Resultados del análisis post hoc entre P1.29 y la variable factor "facultades CAFyD" (comparadas de dos en dos) 281

Tabla 6. 23 Estudio comparativo entre estudiantes MEPEF y CAFyD sobre los códigos que explican el funcionamiento de la formación recibida para el desarrollo de P1.29 282

Tabla 6. 24 Diferencias en la percepción de los estudiantes MEPEF y CAFyD sobre $\mathrm{P} 1.28$ 286

Tabla 6. 25 Valores de promedio obtenidos para P1.28 en relación a la variable factor "facultades MEPEF".

Tabla 6. 26 Prueba Kruskal-Wallis para P1.28 y variable factor "facultades MEPEF"

Tabla 6. 27 Resultados del análisis post hoc entre P1.28 y la variable factor "facultades MEPEF" (comparadas de dos en dos)

Tabla 6.28 Valores de promedio obtenidos para P1.28 en relación a la variable factor "facultades CAFyD" 291

Tabla 6. 29 Prueba Kruskal-Wallis para P1.28 y variable factor "facultades CAFyD"

Tabla 6. 30 Resultados del análisis post hoc entre P1.28 y la variable factor "facultades CAFyD" (comparadas de dos en dos)

Tabla 6.31 Estudio comparativo entre estudiantes MEPEF y CAFyD sobre los códigos que explican el funcionamiento de la formación recibida para el desarrollo de P1.28.

Tabla 6. 32 Ítems del cuestionario que integran B2 (competencias interpersonales).. 298

Tabla 6. 33 Descriptivos para B2 y sus ítems (todos los estudiantes).

Tabla 6. 34 Relación de códigos que explican el significado de la formación cursada en relación al desarrollo de $\mathrm{P} 1.30$ 300

Tabla 6. 35 Relación de códigos que explican el significado de la formación cursada en relación al desarrollo de P1.31 302

Tabla 6. 36 Valores de la variable MB2 en relación a la variable factor "género" ..... 303

Tabla 6. 37 Diferencias en la percepción de los estudiantes hombres y mujeres en relación a MB2

Tabla 6. 38 Valores de promedio obtenidos para P1.30 y P1.31 en relación a la variable factor "género". 305

Tabla 6. 39 Diferencias en la percepción de los estudiantes hombres y mujeres sobre $\mathrm{P} 1.30$ 
Tabla 6. 40 Estudio comparativo entre estudiantes hombres y mujeres sobre los códigos que explican el funcionamiento de la formación recibida en relación al desarrollo de P1.30

Tabla 6. 41 Diferencias en la percepción de los estudiantes hombres y mujeres sobre $\mathrm{P} 1.31$

Tabla 6. 42 Estudio comparativo entre estudiantes hombres y mujeres sobre los códigos que explican el funcionamiento de la formación recibida en relación al desarrollo de P1.31

Tabla 6. 43 Valores de la variable MB2 en relación a la variable factor "tipo de estudios de EF" cursados

Tabla 6. 44 Diferencias en la percepción de los estudiantes hombres y mujeres en relación a MB2

Tabla 6. 45 Valores de promedio obtenidos para P1.30 y P1.31 en relación a la variable factor "tipo de estudios de EF" cursados

Tabla 6. 46 Diferencias en la percepción de los estudiantes MEPEF y CAFyD sobre $\mathrm{P} 1.30$

Tabla 6. 47 Valores de promedio obtenidos para P1.30 en relación a la variable factor "facultades MEPEF".

Tabla 6. 48 Prueba Kruskal-Wallis para P1.30 y variable factor "facultades MEPEF"

Tabla 6. 49 Resultados del análisis post hoc entre P1.30 y la variable factor "facultades MEPEF" (comparadas de dos en dos)

Tabla 6. 50 Variables de promedio obtenidos para P1.30 en relación a la variable factor "facultades CAFyD"

Tabla 6. 51 Prueba Kruskal-Wallis para P1.30 y variable factor "facultades CAFyD"

Tabla 6. 52 Resultados del análisis post hoc entre P1.30 y la variable factor "facultades CAFyD" (comparadas de dos en dos)

Tabla 6. 53 Estudio comparativo entre los estudiantes MEPEF y CAFyD sobre los códigos que explican el funcionamiento de la formación recibida para el desarrollo de P1.30

Tabla 6. 54 Diferencias en la percepción de los estudiantes MEPEF y CAFyD sobre P1.31

Tabla 6. 55 Valores de promedio obtenidos para P1.31 en relación a la variable factor "facultades MEPEF". 338

Tabla 6. 56 Prueba Kruskal-Wallis para P1.31 y variable factor "facultades MEPEF"

Tabla 6. 57 Resultados del análisis post hoc entre P1.31 y la variable factor "facultades MEPEF" (comparadas de dos en dos)

Tabla 6. 58 Valores de promedio obtenidos para P1.31 en relación a la variable factor "facultades CAFyD" 
Tabla 6. 59 Prueba Kruskal-Wallis para P1.31 y variable factor "facultades CAFyD"

Tabla 6. 60 Resultados del análisis post hoc entre P1.31 y la variable factor "facultades CAFyD" (comparadas de dos en dos) ................................................................. 343

Tabla 6.61

Tabla 6. 62 Relación entre el uso de metodologías activas y utilización de evaluación formativa y la percepción de ayuda formativa recibida para el desarrollo de las competencias instrumentales e interpersonales.

Tabla 6. 63 Relación entre el uso de metodologías activas y utilización de evaluación formativa y la percepción de ayuda formativa recibida para el desarrollo de P1.28, P1.29, P1.30 y P1.31

Tabla 6. 64 Relación entre los instrumentos de evaluación y la percepción de ayuda formativa recibida para el desarrollo de P1.28

Tabla 6. 65 Coocurrencia de códigos sobre los instrumentos de evaluación y la percepción de ayuda formativa recibida para el desarrollo de P1.28

Tabla 6. 66 Relación entre los instrumentos de evaluación y la percepción de ayuda formativa recibida para el desarrollo de P1.29 ................................................ 360

Tabla 6.67 Coocurrencia de códigos sobre los instrumentos de evaluación y la percepción de ayuda formativa recibida para el desarrollo de P1.29.

Tabla 6. 68 Relación entre los instrumentos de evaluación y la percepción de ayuda formativa recibida para el desarrollo de P1.30

Tabla 6. 69 Coocurrencia de códigos sobre los instrumentos de evaluación y la percepción de ayuda formativa recibida para el desarrollo de P1.30

Tabla 6.70 Relación entre los instrumentos de evaluación y la percepción de ayuda formativa recibida para el desarrollo de $\mathrm{P} 1.31$

Tabla 6. 71 Coocurrencia de códigos sobre los instrumentos de evaluación y la percepción de ayuda formativa para el desarrollo de P1.31

Tabla 6. 72 Relación entre la forma de calificar y la percepción de ayuda formativa recibida para desarrollar $\mathrm{P} 1.28$

Tabla 6. 73 Coocurrencia de códigos sobre la forma de calificación y la percepción de ayuda recibida formativa para desarrollar P1.28

Tabla 6.74 Relación entre la forma de calificar y la percepción de ayuda formativa recibida para desarrollar P1.29

Tabla 6. 75 Coocurrencia de códigos sobre la forma de calificar y la percepción de ayuda formativa recibida para desarrollar P1.29

Tabla 6. 76 Relación entre la forma de calificar y la percepción de ayuda formativa recibida para desarrollar $\mathrm{P} 1.30$

Tabla 6. 77 Coocurrencia de códigos sobre la forma de calificar y la percepción de ayuda formativa recibida para desarrollar P1.30.

Tabla 6.78 Relación entre las formas de calificar y la percepción de ayuda formativa recibida para desarrollar $\mathrm{P} 1.31$ 
Tabla 6. 79 Coocurrencia de códigos sobre las formas de calificación y la percepción de ayuda formativa recibida para desarrollar P1.31 y sus capacidades de adaptarse y ayudarse

Tabla 6. 80 Coocurrencia de códigos sobre las formas de calificación y la percepción de ayuda formativa recibida para desarrollar P1.31 y sus capacidades de comunicar y colaborar....

Tabla 6. 81 Coocurrencia de códigos sobre la forma de calificar y la percepción de ayuda formativa recibida para desarrollar P1.31 en sus capacidades de negociar y pedir ayuda

\section{INDICE DE FIGURAS}

Figura 1. 1. Estructura en capítulos de la tesis doctoral 24

Figura 3. 1. Principales líneas de acción procedentes de los comunicados europeos sobre la Formación Superior

Figura 3. 2. Enfoque competencial de la perspectiva dinámica integradora (Cano et al, 2014; Le Boterf, 2001; Perrenoud, 2008).

Figura 3. 3. Enfoque competencial desde las perspectiva socio-crítica (Contreras, 2010)

Figura 3. 4. Principales hitos históricos de la formación de la Educación Física en España (Pastor Pradillo, 1997)

Figura 3. 5. Modelos formativos en la formación del profesorado de Educación Física en España (Fraile, 2004b; Fraile, 2018; Romero-Cerezo, 2004).

Figura 3. 6. Modelos metodológicos presentes en las guías docentes de las asignaturas tecnológicas en los planes formativos de los grados MEPEF y CAFyD

Figura 3. 7. Modelos metodológicos presentes en las guías docentes de las asignaturas ELE en los planes formativos de los grados MEPEF y CAFyD .

Figura 3. 8. Instrumentos de evaluación presentes en las guías docentes de las asignaturas ELE en los planes formativos de los grados MEPEF y CAFyD ....... 129

Figura 3. 9. Los big five del trabajo en equipo (Salas et al., 2005) ............................ 141

Figura 3. 10. Mecanismos de coordinación de los big five (Salas et al., 2005) ............ 144

Figura 5. 1. Modelos generales de diseño metodológico mixto para estatus iguales ... 209

Figura 5. 2. Modelos generales de diseño metodológico mixto para estatus distintos. 209

Figura 5. 3. Esquema del diseño de investigación y detalle de la triangulación de resultados

Figura 5. 4. Distribución de la muestra en función de la titulación de Educación Física cursada

Figura 5. 5. Distribución de la muestra según el género 
Figura 5. 6. Distribución de la muestra atendiendo a las franjas de edad

Figura 5. 7. Distribución de la muestra considerando las facultades de Educación y universidades de procedencia

Figura 5. 8. Distribución de la muestra considerando las facultades de Ciencias de la Actividad Física y del Deporte y universidades de procedencia.

Figura 5. 9. Red de la categoría Conocimiento de una Lengua extranjera y sus códigos

Figura 5. 10. Red de la categoría Conocimientos de informática aplicados al ámbito de

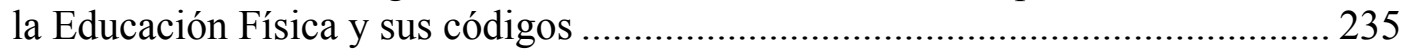

Figura 5. 11. Red de la categoría Trabajo en equipo y sus códigos ........................... 236

Figura 5. 12. Red de la categoría Habilidades en las relaciones interpersonales y sus

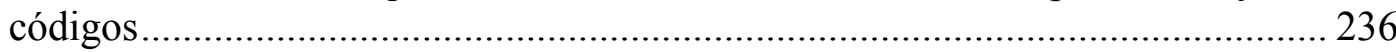

Figura 5. 13. Redes de las categorías Metodologías activas y Evaluación formativa y sus códigos

Figura 5. 14. Red de la categoría Instrumentos de evaluación y sus códigos .............. 237

Figura 5. 15. Red de la categoría Formas de calificación y sus códigos ...................... 238

Figura 5. 16. Redes de las categorías Sexo y Tipo de estudios de Educación Física

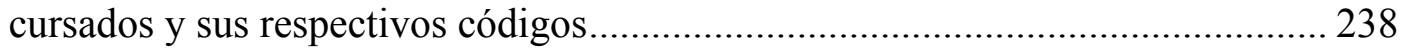

Figura 5. 18. Tabla de coocurrencia de códigos (Software Atlas.ti) ............................ 240

Figura 5. 19. Red semántica de citas (hipervínculos) ................................................. 241

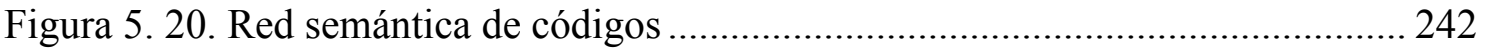

Figura 6. 1. Frecuencias en las respuestas en relación a P1.28 …............................... 255

Figura 6. 2. Percepción media de los estudiantes hombres y mujeres en relación al grado de ayuda formativa recibida para el desarrollo de MB1 .................................... 257

Figura 6. 3. Representación gráfica de las medias de tendencia central de P1.29 y P1.28, integradas en B1, considerando la variable factor "género"............................... 258

Figura 6. 4. Red semántica del grupo de mujeres que explica las experiencias formativas relacionadas con la adquisición y desarrollo de P.129. 261

Figura 6. 5. Red semántica del grupo de hombres que explica las experiencias formativas relacionadas con la adquisición y desarrollo de P1.29

Figura 6. 6. Red semántica del grupo de mujeres que explica las experiencias formativas relacionadas con la adquisición y desarrollo de P1.28.

Figura 6. 7. Red semántica del grupo de hombres que explican las experiencias formativas relacionadas con la adquisición y desarrollo de P1.28

Figura 6. 8. Percepción media de los estudiantes de los grupos MEPEF y CAFyD en relación al grado de ayuda formativa recibida para el desarrollo de MB1 ........... 271

Figura 6. 9. Representación gráfica de las medias de tendencia central de P1.29 y P1.28, integradas en B1, considerando la variable factor "tipo de estudios de EF" cursados 
Figura 6. 10. Representación gráfica de los valores de promedio obtenidos para P1.29 en relación a la variable factor "facultades MEPEF"

Figura 6. 11. Representación gráfica de los valores de promedio obtenidos para P1.29 en relación a la variable factor "facultades CAFyD"

Figura 6. 12. Red semántica del grupo de estudiantes CAFyD que explica las experiencias formativas relacionadas con la adquisición y desarrollo de P1.29 .. 283

Figura 6. 13. Red semántica del grupo de estudiantes MEPEF que explica las experiencias formativas relacionadas con la adquisición y desarrollo de P1.29 .. 284

Figura 6. 14. Representación gráfica de los valores de promedio obtenidos para P1.28 en relación a la variable factor "facultades MEPEF" ....................................... 288

Figura 6. 15. Representación gráfica de los valores de promedio obtenidos para $\mathrm{P} 1.28$ en relación a la variable factor "facultades CAFyD"

Figura 6. 16. Red semántica del grupo de estudiantes MEPEF que explica las experiencias formativas relacionadas con la adquisición y desarrollo de P1.28 .. 295

Figura 6. 17. Red semántica del grupo de estudiantes CAFyD que explica las experiencias formativas relacionadas con la adquisición y desarrollo de P1.28 .. 297

Figura 6. 18. Frecuencias en las respuestas en relación a P1.30 ................................. 300

Figura 6. 19. Frecuencias en las respuestas en relación a P1.31 _............................... 301

Figura 6. 20. Percepción media de los estudiantes hombres y mujeres en relación al grado de ayuda formativa recibida para el desarrollo de MB2 ........................... 304

Figura 6. 21. Representación gráfica de las medidas de tendencia central de P1.30 y P1.31 considerando la variable factor "género" 305

Figura 6. 22. Red semántica del grupo de estudiantes mujeres que explica las experiencias formativas relacionadas con la adquisición y desarrollo de P1.30 .. 308

Figura 6. 23. Red semántica del grupo de estudiantes hombres que explica las experiencias formativas relacionadas con la adquisición y desarrollo de P1.30 .. 311

Figura 6.24. Red semántica del grupo de estudiantes mujeres que explica las experiencias formativas relacionadas con la adquisición y desarrollo de P1.31 .. 315

Figura 6. 25. Red semántica del grupo de estudiantes hombres que explica las experiencias formativas relacionadas con la adquisición y desarrollo de P1.31 .. 317

Figura 6. 26. Percepción media de los estudiantes de los grupos MEPEF y CAFyD en relación al grado de ayuda formativa recibida para el desarrollo de MB2 ........... 320

Figura 6. 27. Representación gráfica de las medidas de tendencia central de P1.30 y P1.31 considerando la variable factor "tipo de estudios de EF" cursados. 322

Figura 6. 28. Representación gráfica de los valores de promedio obtenidos para P1.30 en relación a la variable factor "facultades MEPEF"

Figura 6. 29. Representación gráfica de los valores de promedio obtenidos para $\mathrm{P} 1.30$ en relación a la variable factor "facultades CAFyD" 328

Figura 6. 30. Red semántica del grupo de estudiantes CAFyD que explica las experiencias formativas relacionadas con la adquisición y desarrollo de P1.30 .. 332 
Figura 6.31. Red semántica del grupo de estudiantes MEPEF que explica las experiencias formativas relacionadas con la adquisición y desarrollo de P1.30 .. 335

Figura 6. 32. Representación gráfica de los valores de promedio obtenidos para P1.31 en relación a la variable factor "facultades MEPEF"

Figura 6. 33. Representación gráfica de los valores de promedio obtenidos para P1.31 en relación a la variable factor "facultades CAFyD"

Figura 6.34. Red semántica del grupo de estudiantes CAFyD que explora las experiencias formativas relacionadas con la adquisición y desarrollo de P1.31 .. 345

Figura 6. 35.Red semántica del grupo de estudiantes MEPEF que explica las experiencias formativas relacionadas con la adquisición y desarrollo de P1.31 .. 346 



\section{RESUMEN - ABSTRACT}

\section{Resumen}

La presente investigación trata de conocer cómo la formación que se presta a los futuros docentes de Educación Física, ayuda al desarrollo de las competencias transversales o genéricas presentes en los planes formativos de formación del profesorado. Dada la naturaleza mixta del método de investigación utilizada se han considerado cinco preguntas de investigación de partida para conocer en profundidad el objeto central del estudio, que redundan a su vez en cinco objetivos: (1) conocer el grado de ayuda formativa recibida, para el desarrollo de sus competencias instrumentales. (2) conocer el grado de ayuda formativa recibida para el desarrollo de sus competencias interpersonales. (3) conocer si existe una relación entre el uso de metodologías activas y de evaluación formativa respecto de la percepción de desarrollo de competencias que tienen los estudiantes tras su formación. (4) conocer si existe una relación entre el uso de los instrumentos de evaluación respecto de la percepción de desarrollo de competencias que tienen los estudiantes tras su formación. (5) conocer si existe una relación entre las formas de calificación utilizadas durante la formación inicial respecto a la percepción de desarrollo de competencias que tienen.

La respuesta a los objetivos se realizó a través de un estudio mixto, cuantitativo y cualitativo. La muestra de participantes del estudio cuantitativo fue de 1173 estudiantes de los grados universitarios de Maestro en Educación Primaria (mención Educación Física) y Ciencias de la Actividad Física y del Deporte procedentes de 19 facultades españolas. Se utilizó un cuestionario sobre competencias docentes y evaluación formativa. El estudio cualitativo se desarrolló mediante la realización de dos grupos de discusión con estudiantes representantes de las dos titulaciones de referencia y facultades de procedencia. Los resultados evidencian una mayor ayuda prestada al desarrollo de competencias interpersonales como el trabajo en equipo y las habilidades en las relaciones interpersonales. En relación a las metodologías activas y la evaluación formativa se confirma una mayor aportación de estas al desarrollo de competencias interpersonales mediante instrumentos como los exámenes y presentaciones orales y trabajos grupales, así como una mayor presencia de la calificación participada a partir de la coevaluación y autoevaluación desarrollada entre los estudiantes y/o entre estos con el docente. 


\section{Abstract}

The present research tries to know, how the formation that is lent to the future teachers of Physical Education, helps to the development of the transversal or generic competences present in the formative plans of formation of the professorate. Given the mixed nature of the research method used, five initial research questions have been considered in order to gain an in-depth knowledge of the central objective of the study, which in turn have five objectives. (1) Know the degree of formative help received, for the development of their instrumental competence. (2) Know the degree of formative help received for the development of their interpersonal competence. (3) Know if there is, a relationship between the use of active methodologies and formative evaluation with respect to the perception of development of competence students have after their training. (4) Know if there is, a relationship between the use of assessment instruments with respect to the perception of development of competence students have after their training. (5) Know if there is, a relationship between the forms of qualification used during the initial training with respect to the perception of development of competence they have.

The response to the objectives was carried out through a mixed, quantitative and qualitative study. The sample of participants of the quantitative study was of 1173 students of the university degrees of Teacher in Primary Education (mention Physical Education) and Physical Activity and Sports Sciences coming from 19 Spanish faculties. A questionnaire on teaching competence and formative evaluation was used. The qualitative study was developed by holding two discussion groups with students representing the two reference degrees and faculties of origin. The results show a greater help given to the development of interpersonal competence such as teamwork and interpersonal competence. In relation to the active methodologies and the formative evaluation confirms a greater contribution of these to the development of interpersonal competence through instruments such as exams and oral presentations and group work, as well as a greater presence of the qualification participated from the coevaluation and self-evaluation developed among the students and among these with the teache. 


\section{INTRODUCCIÓN}

La formación inicial del profesorado de Educación Física (FIPEF) ha de promover una capacitación técnica y humanista transferible al mundo laboral, de tal forma que permita dar respuestas a las necesidades contextualizadas del alumnado de Educación Primaria y Secundaria en los centros educativos de inserción profesional. Esto conlleva una preocupación por que los estudios superiores faciliten la capacitación docente más allá del tratamiento de los contenidos disciplinares establecidos en los planes de estudios. También en los programas formativos de las titulaciones conducentes al ejercicio docente de la Educación Física (EF), se explicita la necesidad de comenzar a desarrollar una serie de competencias de dominio necesario para abordar las funciones docentes futuras (Buscá y Campllonch, 2008; Díaz del Cueto, 2013; PazoHaro y Tejada-Mora, 2012).

Las competencias profesionales suponen un conjunto de recursos personales y externos que, de forma integrada, facilitan la intervención docente, pudiendo dar mejores respuestas a las necesidades y problemas del complejo contexto educativo. Su desarrollo se prevé a lo largo de toda la vida profesional del docente en conexión con la formación continua, pero su toma de conciencia, adquisición y primeros atisbos de desarrollo toma su inicio en la formación inicial (Tejada y Navío, 2005; Tobón, 2007; Zabalza, 2012; Villardón-Gallego, 2015).

Actualmente, este planteamiento competencial de la formación superior comienza desde la implantación del Espacio Europeo de Educación Superior (EEES), en el que se desarrollan aspectos de importancia para ello como la necesidad de desarrollar procesos de enseñanza y aprendizaje centrados en el estudiante, siendo este también constructor de su propio aprendizaje. Además urge a organizar la formación desde las competencias profesionales en las dimensiones específicas y transversales o genéricas, recogiendo en las primeras aquellas que facilitarían el conocimiento teórico- 
práctico de la disciplina de especialización (EF) y en las segundas otras de suma importancia para el desarrollo de las anteriores.

Por ejemplo, este es el caso de la competencia comunicativa sin la cual sería más difícil el desarrollo de los procesos interactivos de enseñanza-aprendizaje entre el docente y su alumnado, o competencias tan básicas y necesarias en su capacitación docente como la planificación y organización de la enseñanza, trabajar en equipo, establecer buenas relaciones interpersonales, adaptarse a los diversos y complejos contextos profesionales, hacer uso de la tecnología como apoyo de los procesos de enseñanza y aprendizaje, el compromiso ético, la capacidad crítica o el aprendizaje autónomo acorde las propias necesidades.

Pero además, su gestión requiere de cambios en los procesos formativos establecidos, fundamentalmente relacionados con los aspectos metodológicos y de evaluación, siendo las metodologías activas y los sistemas de evaluación formativa y compartida, alternativas que pueden favorecer el desarrollo competencial de los futuros docentes de EF, conviviendo la gestión de los conocimientos disciplinares con la adquisición de distintas capacidades que dimensionan la capacitación y cualificación docente.

Desde este planteamiento general, subyace la esencia de la presente Tesis Doctoral, estructurada mediante siete capítulos que abordan esta dimensión de la formación del profesorado de EF (figura 1.1). En el primer capítulo, introducción y justificación del estudio, se avanzan los aspectos relevantes que se abordan en el estudio así como se pretende dar cuenta y justificar la relevancia del tema de la investigación.

En el segundo capítulo, se aborda el marco teórico-conceptual en el que se recogen los principales antecedentes y preceptos conceptuales que dan sustento al presente trabajo de investigación. La primera sección da cuenta de los antecedentes y nociones principales. La segunda revisa la evolución de la cultura profesional del 
profesorado de EF a nivel nacional. Una tercera sección muestra el estudio en profundidad de las competencias transversales o genéricas objeto de investigación. La cuarta sección define los principales preceptos, características y estudios relevantes sobre la evaluación formativa en la FIPEF.

En el cuarto capítulo, se establecen los objetivos y preguntas de investigación que guían el estudio, respondiendo mediante una metodología mixta (quinto capítulo) que integra un estudio cuantitativo y uno cualitativo, especificando sobre ambos la muestra, los procedimientos así como los instrumentos de recogida de información y los procesos de análisis de los datos obtenidos.

En el sexto capítulo se presentan de forma integrada los resultados de ambos estudios, combinando los cuantitativos con los cualitativos, siendo los últimos el complemento de los primeros a fin de contrastarlos y corroborarlos.

En el séptimo capítulo se establece la discusión de los resultados encontrados en la investigación realizada y en el octavo las conclusiones más relevantes del estudio, junto con la presentación de la fortalezas y limitaciones, así como de las posibilidades de investigación a futuro.

Finalmente se presentan las referencias bibliográficas y los anexos que complementan el estudio realizado. 




Figura 1. 1. Estructura en capítulos de la tesis doctoral 


\section{JUSTIFICACIÓN DEL ESTUDIO}

El objeto de investigación de la presente tesis se preocupa por los primeros momentos formativos del profesorado de Educación Física, a sabiendas de su importancia para tomar conciencia sobre su desarrollo competencial para el futuro ejercicio como docentes. También para observar como formadores, lo decisivo de la formación a ofrecer pensando en la influencia capital de todos los elementos que la estructuran, conocimientos, actividades de enseñanza y aprendizaje, metodologías docentes y evaluación, que sin duda desde un carácter holístico, son las ayudas formativas que se prestan para impulsar el desarrollo competencial de los estudiantes, y que serán más o menos válidas en la medida en la que más les ayude en su capacitación profesional (Yániz, 2008).

Lleixá, Robert y Batalla (2008), valoran la formación inicial del profesorado en su capacidad de ayudar a identificar las necesidades de la comunidad educativa a fin de que el profesorado se prepare y capacite para intervenir sobre ella. Zabalza (2012) reclama a la formación inicial del profesorado la integración de teoría y práctica para activar las competencias de los estudiantes, a fin de que sean estas las herramientas docentes que aplicar en su presente formativo y futuro profesional, superando el modelo tradicional, intelectual y academicista de la formación superior y abrazando otro modelo alternativo, en el que se piense sobre los planteamientos didácticos de las materias y sus contenidos para que redunden en su capacitación como docentes.

El profesorado de EF hace frente en escenarios profesionales complejos a una gran diversidad de situaciones en el propio contexto de aula (micro) y en el contexto de centro (macro), atendiendo las necesidades de aprendizaje de su alumnado pero también otras exigencias profesionales (gestión de centro, atención a las familias, formación continua, participación en equipos de trabajo multidisciplinar, atención a la diversidad). Esto justifica la necesidad de ser formado en aquellas competencias que le permitan abordar esas situaciones dando respuesta a los retos y problemas que se derivan de ellas. 
Para Villardón-Gallego (2015), las competencias genéricas o transversales facilitan la integración en la formación personal y profesional de aquellas capacidades y recursos que permiten precisamente afrontar esos retos, permitiendo saber adaptarse a diferentes contextos, organizar y planificar la docencia, tomar decisiones, resolver problemas, trabajar en equipo, ser autocrítico y crítico, liderar equipos, tener iniciativa, ser sensible a la diversidad y a la multiculturalidad. Parece razonable querer conocer en qué medida la FIPEF presta las ayudas formativas que los estudiantes de EF requieren para adquirir y desarrollar estas competencias, considerando en dicha formación la forma en la que se abordan las materias, las metodologías docentes utilizadas y las formas de evaluación aplicadas.

El desarrollo competencial en la formación del profesorado es un tema a debate frecuente y son diversos los estudios preocupados por conocer la percepción de los estudiantes en torno a sus competencias adquiridas a partir de los estudios cursados, encontrando habitualmente una importante brecha mostrada entre el impulso creciente de competencias de tipo interpersonal y la pobreza formativa constante de las de tipo instrumental, especialmente para el caso de la competencia lingüística y tecnológica (ANECA, 2005b; ANECA, 2007; Conchado y Carot, 2013; Cuervo, Alonso y Sabadell, 2013; Fernández-Batanero, 2012; Flores Aguilar et al., 2014; Hamodi, Moreno-Murcia y Barba, 2018; Marín-Díaz, Latorre-Medina y Blanco-Encomienda, 2010; Pazo-Haro y Tejada-Mora, 2012; Raposo-Rivas, 2006; Romero, Castejón, López-Pastor y Fraile, 2017).

No obstante este tipo de iniciativas investigadoras se encuentran inmersas en un sistema formativo universitario todavía más preocupado por la transacción de la información a través de medios tradicionales de formación y evaluación, lo que parece no terminar de integrar una verdadera formación competencial para la inserción profesional.

Esta línea temática de investigación adquiere importancia en las siguientes medidas: 
Inicialmente queriendo ahondar en la percepción que tienen los estudiantes de EF en relación a la ayuda formativa recibida para la adquisición y desarrollo de sus competencias transversales, especialmente en los tipos instrumentales e interpersonales, poniendo en tensión aquellas que favorecen la tecnificación (instrumentales) y las que favorecen la interacción y la reflexión (interpersonales). Y además ahondando en las estructuras formativas de los contenidos de aprendizaje para averiguar lo que aportan al desarrollo competencial de los estudiantes.

Pretendiendo conocer los sistemas metodológicos aplicados en su formación y en qué medida pudieran influir en la adquisición y desarrollo de las competencias transversales docentes de los estudiantes. Esto a sabiendas de que desde el proceso de convergencias de Bolonia, momento de gran impulso competencial para la formación superior, se apostaba por una dinamización de los contenidos de los aprendizajes a adquirir, mediante nuevas fórmulas metodológicas que tomaran al estudiante como centro de atención del proceso de enseñanza y aprendizaje.

Buscando conocer la influencia en el desarrollo de las competencias objeto de estudio de los sistemas de evaluación aplicados durante la formación cursada, junto con los instrumentos de evaluación y sistemas de calificación habituales. Pretendiendo contrastar los planteamientos evaluadores aplicados en la FIPEF y su relación con la adquisición y desarrollo de las competencias objeto de estudio.

Tal y como se ha avanzado, de esta forma en relación a las competencias transversales docentes, instrumentales, interpersonales, objeto de investigación, se pretende conocer si los esfuerzos formativos realizados en la FIPEF ayudan en su adquisición y desarrollo, considerando las dinámicas de las materias que conforman los planes de estudios, pero también las metodologías y sistemas de evaluación aplicados en integrados en la formación. Su conocimiento en detalle pasa por indagar sobre las vivencias, experiencias formativas, pensamientos y reflexiones de los estudiantes que permitan comprender de qué forma se han podido ir adquiriendo y desarrollando las 
competencias transversales objeto de estudio, en virtud de las materias desarrolladas en la formación y los procesos metodológicos y de evaluación experimentados.

La presente tesis contribuye en el contexto de la literatura especifica en la profundización y esclarecimiento de la ayuda formativa que se presta en la FIPEF mediante las dinámicas formativas que se desarrollan para ello, aportando información específica sobre su contribución al desarrollo de las competencias transversales docentes (específicamente las de tipo instrumental e interpersonal).

Su peculiaridad y difícil evaluación, hacen que la aportación específica que se hace al respecto ayude a comprender de qué forma se están gestionando las materias que forman parte de la FIPEF para conocer si existe contribución al desarrollo de este tipo de competencias y cómo se pueden mejorar los procesos de enseñanza $\mathrm{y}$ aprendizaje para optimizar su desarrollo, que ya la literatura específica considera de especial relevancia para la inserción profesional.

Se espera recoger información que ayude a entender cómo los procesos formativos que se prestan actualmente en la FIPEF, tales como los planteamientos didácticos de las materias, los recursos metodológicos así como los aspectos de evaluación, influyen en la adquisición y desarrollo de las competencias transversales docentes de los estudiantes y de qué forma. 


\section{MARCO TEÓRICO-CONCEPTUAL}

A lo largo de este capítulo, se abordan los principales referentes conceptuales sobre el universo competencial en la formación superior, partiendo de una primera sección en la que recogemos el origen en el contexto internacional, su llegada al EEES y su desarrollo y expansión en este contexto, hasta instalarse en el escenario formativo español; además se desarrollan las principales corrientes que explican desde diferentes perspectivas, tanto su conceptualización como su proyección y sentido. En la segunda sección se realiza un recorrido histórico sobre los hitos primordiales que marcaron la configuración de la cultura profesional del profesorado de EF en España, así como los principales enfoques competenciales que se fueron desarrollando históricamente, evolucionando hasta llegar a modelos actuales. En la sección tercera se recogen los principales fundamentos sobre las competencias objeto de estudio, competencias genéricas o transversales en la FIPEF, ahondando en las de tipo instrumental, abordando específicamente el conocimiento tecnológico aplicado a la EF y el conocimiento de una lengua extranjera, y las de tipo interpersonal, estudiando en profundidad el trabajo en equipo y las habilidades en las relaciones interpersonales. Finalmente se dedica la última sección a la evaluación formativa de competencias, desarrollando sus principales fundamentos e investigaciones, realizadas en el contexto de la FIPEF así como su impacto en su adquisición y desarrollo.

\subsection{Antecedentes generales y conceptualización}

El tratamiento competencial en el ámbito formativo no es un concepto nuevo, sino más bien ya explorado en escenarios relacionados con la formación para el empleo, vinculado este hecho a la necesidad natural de acercar el mundo de la producción y el mundo de la formación. Es por ello que se revisan algunos hitos en contextos internacionales y nacionales que marcaron esta perspectiva y fueron un punto de partida para la llegada a la formación superior de estos planteamientos. 
El enfoque competencial para la formación superior en Europa, impulsado tras el proceso de Bolonia, ha producido un movimiento de los paradigmas clásicos que la fundamentaban. Se revelaron diversos aspectos esenciales para conseguir el cambio como el papel activo y protagonista del estudiantado en el desarrollo de su propia formación, el rol guía y orientador de los docentes y los nuevos enfoques metodológicos y de evaluación. En definitiva, una nueva perspectiva formativa que busca facilitar la empleabilidad en los cambiantes escenarios socioeconómicos, sin dejar a un lado el tratamiento de los conocimientos que se integran en un nuevo planteamiento en donde están presentes también las capacidades, las experiencias, los valores y la propia disposición responsable de las personas en los procesos formativos que inician.

Se presentan los antecedentes históricos que fueron el germen del tratamiento competencial en la actualidad en los sectores profesionales y formativos, así como desde la perspectiva de este último, los inicios del cambio que marcó el nacimiento del nuevo EEES.

\subsubsection{Tratamiento histórico de las competencias}

Los orígenes de la perspectiva competencial en la formación surgen en entornos empresariales en los que se buscaba la máxima capacitación y cualificación de los trabajadores y profesionales, para afrontar las exigencias cada vez más intensas del mercado. Además este pensamiento en la traslación al sector profesional de la formación, revela una voluntad por conquistar nuevos planteamientos docentes alternativos a los tradicionales, abordando el desempeño profesional docente considerando no solo los dominios sobre los conocimientos, sino también sobre otras herramientas que optimizaran la práctica profesional y por ende, redundara en mejores resultados de aprendizaje para el alumnado de destino.

Se abordan a continuación, dos hitos sobre los que se fue consolidando la perspectiva competencial en la formación docente: los cambios en la formación del 
profesorado en el contexto norteamericano de los años 70 y las reformas de los 90 en relación a la formación preuniversitaria y universitaria en el contexto internacional.

Estos hechos traen consigo una nueva era de reformas vinculadas en Europa a la formación superior, allanando el camino a un proceso de cambio en la construcción del nuevo EEES.

\subsubsection{La eficacia profesional a través de la competencias}

Hablar de competencias supone necesariamente considerar su origen productivista y mercantilista ampliamente extendido en el mundo empresarial norteamericano o en el sector público británico de los 80 (Chomsky, 1986). Desde esta perspectiva se planteaban como la adecuación entre los resultados pretendidos por las empresas y el perfeccionamiento de los empleados, requiriendo de estos capacidades que les cualificaran para hacer frente a las exigencias cambiantes de los roles, funciones, tareas y responsabilidades a desempeñar (Gimeno Sacristán, 2008). Se abría, por tanto, una perspectiva de competencias contribuyentes a la eficacia en la ejecución de la tarea.

Son dos los hechos históricos que hicieron germinar en el sector profesional de la educación una idea creciente de formación competencial.

El primero surge en los años setenta, con la reforma de la formación inicial del los docentes de educación primaria norteamericanos a través de iniciativas de algunas universidades y colleges, como el programa Performance of Competency-Based Teacher Education Programs (programas de educación docente basados en la competencia o el rendimiento) con la convicción de desarrollar propuestas para seleccionar modelos innovadores de capacitación profesional del profesorado que se apartaran del modelo tradicional y habitual de formación del profesorado. Así como incluir performances, prácticas alternativas de enseñanza o realizaciones competenciales 
del docente. Se trataba de desarrollar habilidades didácticas aisladas que se aplicaran a situaciones docentes en el aula, adaptándose del mundo empresarial indicadores de rendimiento o de comportamiento que mejoraran el proceso de aprendizaje.

De esta manera se destacaban estrategias didácticas como el análisis de las tareas, la orientación al alumnado, la revalorización del trabajo de campo, la estructuración de contenidos en módulos abiertos y flexibles, y funciones de investigación (Burms y Klingstedt, 1981; Houston, 1974). Surge así en este momento un modelo de competencia técnico-profesional, conductista y fundamentado en la descripción de las competencias a desarrollar, en virtud del análisis de la tarea involucrada en la docencia y de las habilidades necesarias para realizarla.

Pronto se reconoce como insuficiente enumerar una lista de estrategias didácticas, competencias y destrezas y practicarlas aisladamente, dado que se piensa es imprescindible reunirlas en unidades lógicas para entrenarlas y adquirirlas (Martínez Rodríguez, 2008).

En España, en los años setenta, se divulgó el enfoque competencial en la formación inicial docente en el ámbito de la teoría pedagógica, bajo una reveladora propuesta separada del conductismo más convencional (Gimeno Sacristán, 2009; Imbernón, 1994) y donde se abordaba el carácter situacional del entrenamiento (las competencias se han de aplicar en contextos de situación real) para poder detectarlas, hacer su seguimiento y evaluarlas. Las competencias en este sentido sólo pueden ser manifestadas en las actuaciones docentes en el desempeño profesional Para ello, se planificaban sistemáticamente y redactaban en términos de conducta observable, con criterios evaluables en relación a la propia acción individual docente.

Para algunos autores como Eraut (1994) este enfoque desatiende lo relacionado con el contexto sociocultural y los avances en la teoría del aprendizaje menos psicológica, equiparando la formación del profesorado con la preparación técnica de un trabajador de industria, en la que su especialización está tan delimitada que requiere de 
muchos otros que completen la realización de una tarea; así aparece reflejada esta visión taylorista y fordista a modo ilustrativo en el largometraje Modern Times (Chaplin, 1936).

Pero es en esta década, y desde el punto de vista pedagógico, cuando también se valoraba, casi proféticamente, que ser competente se extendía más allá de la mera justificación de superación de los contenidos formativos desde los tradicionales mecanismos de evaluación, planteando que el éxito en la formación no es ninguna garantía de eficacia en el desempeño profesional (McClelland, 1973), lo que hace pensar que ser competente supone reconocer que, para el ejercicio profesional, es necesario contar también con cualidades y características personales que permitan afrontar los retos profesionales. Estas cualidades podrían ser desde capacidades para negociar y alcanzar acuerdos, hasta formas alternativas de valorar y encarar los problemas o ciertas dotes de liderazgo para gestionar grupos.

El segundo hito, las reformas desarrolladas a partir de los años noventa en la formación profesional preuniversitaria y universitaria, en países de Europa, Australia y Estados Unidos, abren otra modalidad de entrenamiento competencial para reducir la brecha existente entre las exigencias del mercado laboral y las necesidades formativas para afrontarlas.

Esto apunta hacia un modelo de formación para el trabajo y la consiguiente regulación de la cualificación profesional, buscando el acuerdo entre empleadores, políticos y administradores de la educación (Aitken, 1993). Se retoma para ello el modelo americano conductual de competencias de los setenta, fundamentado principalmente en la tarea. Pese a que para ciertos autores (Achtenhagen y Grubb, 2001) este modelo competencial no encajaba en ambientes laborales complejos (como la educación o la sanidad), que requieren flexibilidad para resolver problemas y por tanto de un planteamiento formativo competencial más holístico; este modelo formativo basado en competencias fue creciendo y extendiéndose hacia un gran número de países (Gonczi, 1997). 
En la actualidad, en la sociedad del siglo XXI, la formación basada en competencias continúa siendo en el ámbito de la educación superior un tema pedagógico clave ya que vincula empresa, conocimiento, empleabilidad y ciudadanía (González y Wagenaar, 2003) con autonomía profesional, interactividad con grupos, manejo y dominio de herramientas y efectividad para abordar creativamente los desafíos profesionales del mercado laboral (DeSeCo, 2005; OECD, 2001).

Variables sin duda esenciales que permiten comprender la relación de la formación inicial de los titulados universitarios con las exigencias del mercado laboral y de la sociedad. En este sentido, el documento publicado por la Unión Europea, Focus on the Structure of Higher Education in Europe 2006/2007, se apoya en las competencias como componentes de la acreditación profesional y seguro de la calidad de las titulaciones para acercar formación a empleo.

Pero la estructuración de la formación inicial docente, mediante una red de competencias que sostengan su práctica profesional futura, sigue envuelta en un halo de dudas, desacuerdos y problemas teórico-prácticos que se enraízan en las propias dificultades surgidas en la conceptualización del término, su imprecisión, ambigüedad y difícil praxis y sobre todo evaluación (De la Orden Hoz, 2011).

De esta forma, el universo de competencias en el ámbito universitario aparece para armonizar la formación conducente a la cualificación en consonancia con las necesidades del mercado laboral; todo en favor de contribuir a afrontar un nuevo orden socioeconómico que se impone y se mantiene en Europa en los comienzos del siglo XXI. Será el proyecto Tuning (González y Wagenaar, 2003) el que muestre el espectro competencial necesariamente a abordar en la formación superior, diversificando las competencias que han de desarrollarse en este contexto en dos grupos, específicas y transversales o genéricas, conteniendo en este último las de carácter instrumental, interpersonal y sistémico imprescindibles para la empleabilidad (Villardón, 2015). 
Brown y Pickford (2007) consideran básico y fundamental el tratamiento en la formación superior de competencias transversales como la comunicación y la escucha activa, la gestión de las emociones y de las relaciones interpersonales, el trabajo en equipo y la cooperación, así como la capacidad de resolver conflictos y problemas y el liderazgo. Por su parte, en la formación del profesorado de EF, Fraile (2018), por ejemplo, valora el desarrollo de estas y otras competencias en la FIPEF aportando alternativas metodológicas para su desarrollo, como el coaching o la Programación Neurolingüística (PLN) para desarrollar el autoconocimiento personal, la gestión emocional, las relaciones interpersonales, la capacidad crítica y autocrítica, sin duda competencias imprescindibles para el desarrollo profesional docente.

\subsubsection{Competencias en la convergencia hacia EEES}

La presencia de las competencias en el contexto de la educación superior, que ha dado un vuelco a la universidad en las últimas décadas, se presenta desde algunos hitos singulares (Yániz, 2008). Uno de ellos es la Conferencia Mundial de París de Educación Superior de la Unesco en 1998, donde se presentaban las competencias como un conjunto de herramientas para conseguir el acercamiento de la educación superior a las necesidades y demandas de la sociedad, profesionalizando la formación universitaria y contribuyendo con ello a elevar el nivel de vida de la ciudadanía (Unesco, 1998). Desde esta perspectiva, la educación superior podría ganar en eficacia y configurarse con el mundo empresarial como un tándem para abordar los retos del orden socioeconómico imperante y preparar a los ciudadanos para los nuevos desafíos del siglo XXI. El enfoque competencial de la formación superior permitiría por tanto a los estudiantes conformarse como agentes activos en la construcción de la sociedad del conocimiento, para adaptarse de forma flexible a los rápidos cambios y demandas sociales, $\mathrm{y}$ desempeñarse eficazmente en el, cada vez más dinámico y complejo, mercado laboral (Sánchez, López y Fernández, 2010). 
Pero sensibilizarse con las exigencias del nuevo orden socioeconómico y formar profesionales desde el ámbito universitario, supone repensar el nuevo papel que asumen los conocimientos; no tanto, a retener sino a comprender, asumir, seleccionar, procesar y aplicar para reconocer los modelos emergentes de empleo, las nuevas exigencias de los desempeños profesionales o los nuevos perfiles a promover. Estaríamos ante el fin de los saberes tradicionales de hecho, frente a un nuevo modelo formativo basado en competencias clave, en cuanto capacidades asentadas en conocimientos, experiencias, valores y disposiciones que una persona desarrolla cuando se compromete con las prácticas educativas a lo largo de su vida y ya desde la educación general obligatoria (Eurydice, 2002).

Un aspecto más que merece ser destacado es el establecimiento del ideario y los documentos fundacionales que vinculan el marco común de las cualificaciones con el ámbito universitario en el contexto del nuevo EEES.

Ya con la Declaración de la Sorbona (1998), pero sobre todo, a partir de la Declaración de Bolonia (1999), junto con una serie de documentos en conjunto (Comunicado de Praga, 2001; Comunicado de Berlín, 2003; Comunicado de Bergen, 2005) se cristaliza la voluntad común de crear y desarrollar un EEES, asumiendo los retos expresados hasta el momento e introduciendo las competencias, en un intento de aproximar conocimientos y habilidades a contextos socio-laborales reales en relación a las características propias de un determinado puesto de trabajo y, todo también, desde la libre circulación de estudiantes y titulados a lo largo de los países miembros.

Mediante la Declaración de la Sorbona (1998), la Declaración de Bolonia y de Praga $(1999,2001)$ se aboga por la armonización de una arquitectura de la educación superior europea, atractiva para los estudiantes europeos y de otros continentes así como para académicos e investigadores. Para ello, los ministros competentes en materia de educación superior acordaron ocho líneas esenciales de acción (figura 3.1). 
Adoptar de un sistema

de titulaciones

reconocibles y

comparables

Promover la movilidad

entre estudiantes,

docentes y otro

personal
Implementar un

sistema estructurado

en dos ciclos

universitarios

principales

Promover la

cooperación europea

en el control de la

calidad
Establecer un sistema

de créditos ECTS

(European Credit

Transfer System)

Potenciar el

aprendizaje

permanente
Promocionar las

instituciones europeas

de educación superior
Promover el Espacio

Europeo de Educación

Superior

Figura 3. 1. Principales líneas de acción procedentes de los comunicados europeos sobre la Formación Superior

De esta manera, los títulos comienzan a ser entendidos desde una perspectiva profesionalizadora y para la empleabilidad, pretendiendo acercar potenciales perfiles técnicos a empleadores y responder conjunta y más exitosamente a las necesidades y demandas del mercado de trabajo (Riesco González, 2008).

Como consecuencia del nuevo planteamiento de la educación superior y su reajuste al nuevo ritmo de cambio de la sociedad, surge el Proyecto Tuning (González y Wagenaar, 2003) con la intención de sintonizar las estructuras de educación superior europeas con el nuevo marco socio-económico que se vive. De esta forma se cree necesario que la política social y económica europea vaya acompañada de una política de educación superior. Es así como se consolida la asociación entre educación superior, mercado y empleabilidad.

El Proyecto Tuning contribuye de esta forma a la creación del nuevo EEES, hecho que se refleja en el común esfuerzo de sus representantes (100 instituciones europeas de educación superior de 26 países), en el espíritu de búsqueda del consenso, en el respeto a las diversidades y peculiaridades de los estados y en la concreción de puntos comunes de acuerdo en relación a los resultados de aprendizaje, las 
competencias, habilidades y destrezas, que permitan que tal espacio sea real y que, los estudiantes y profesionales puedan moverse por él fácilmente y desde un referente también común: la calidad.

Así mismo centra su mirada en las estructuras educativas y en los contenidos y no en los sistemas educativos, responsabilidad de cada uno de los países miembros, haciendo un enorme esfuerzo de sintonización gracias al trabajo desarrollado y coordinado por las universidades y sus representantes, junto con más de cien reconocidos expertos europeos. Pero la contribución a un EEES supone definir algunos aspectos base para cimentar dichos puntos comunes. Tuning destaca la importancia de los resultados de aprendizaje y el valor de las competencias en las estructuras formativas comunes a consensuar.

Los resultados del aprendizaje suponen las competencias, en donde se incluyen conocimientos, habilidades y destrezas, actitudes y aptitudes que en definitiva, se espera que al final de su proceso de aprendizaje el estudiante desarrolle, domine y sepa demostrar para garantizar la profesionalidad futura de sus actuaciones. Las competencias se plantean no solo con carácter específico, sino también genéricas, transversales o independientes de las materias. Se establece de esta forma una nueva manera en Europa de entender y abordar la educación superior, con una renovada perspectiva competencial y profesionalizadora de cara a la integración social y laboral de los estudiantes (Pol, Moreno y Oliver, 2009).

La Universidad como institución, la reestructuración de sus titulaciones de grado y postgrado y la reorganización del sistema europeo de transferencia y acumulación de créditos (ECTS), se encaminan, en conexión directa con las necesidades y demandas sociales, hacia el nuevo ritmo socioeconómico de un mercado de trabajo cambiante y con la exigencia de facilitar la movilidad entre estudiantes y trabajadores en un territorio común, para garantizar el acceso y la promoción en el mercado laboral. 
Con el fin de desarrollar los objetivos para la concreción de un EEES, el Proyecto Tuning se desdobla en dos fases: una primera fase (2000-2002) y una segunda (2003-2004), estableciéndose cuatro líneas de trabajo: las competencias genéricas o transversales; las competencias específicas; el papel del sistema de créditos (ECTS) y el enfoque de enseñanza-aprendizaje y evaluación, con la garantía y control de calidad.

Pero más allá de Europa, el Proyecto Tuning se acercó también a las estructuras de educación superior latinoamericanas, fruto nuevamente de una necesidad de convergencia. Todo surge en la IV Reunión de Seguimiento del Espacio Común de Enseñanza Superior de la Unión Europea, América Latina y el Caribe (UEALC) en la ciudad española de Córdoba, en octubre de 2006, donde los representantes latinoamericanos que participaban en el encuentro, tras escuchar los resultados del Proyecto Tuning Europa, se interesaron en la posibilidad de desarrollar una experiencia paralela. Desde ese momento, se empezó a preparar la propuesta que fue presentada por un grupo de universidades europeas y latinoamericanas ante la Comisión Europea.

La propuesta Tuning para América Latina es una idea intercontinental, un proyecto que se nutrió de aportes de académicos europeos y latinoamericanos, en donde se respondía a la misma idea de consenso en las estructuras de las titulaciones, aun sabiendo que actores y realidad no podrían ser nunca los mismos (Beneitone et al., 2007). Al igual que el Proyecto Tuning Europa, en América Latina y Caribe, se busca en las competencias los puntos comunes de referencia para un marco común intercontinental en educación superior.

Distintas experiencias, como la desarrollada por la Red Urel (Red de Universidades regionales de Latinoamérica) para compartir los avances que van sucediendo en la formación superior en Europa y España, a consecuencia de los cambios acaecidos desde el proceso de Bolonia, han permitido abordar y reflexionar sobre las exigencias y cambios también llegados a Latinoamérica como consecuencia del impacto de la economía global, de la restructuración del mercado y de los consecuentes cambios sociales (Fraile, 2006a; 2009). Dichos cambios se relacionarían 
con la nueva forma de organización de las estructuras universitarias, el avance de las cada vez más consolidadas fórmulas de educación a distancia como consecuencia del empuje de las tecnologías de la información y comunicación, la necesidad de incrementar los estudios de postgrado, el aumento de la movilidad de estudiantes y egresados entre universidades y países o la incorporación de la cultura de la evaluación de la calidad a la universidad (Galarza, 2004).

El Proyecto Tuning es el modelo sobre el que se asienta en España la nueva filosofía de organización de los estudios universitarios conforme el nuevo EEES, teniendo en cuenta el enfoque de aprendizaje basado en competencias, siendo la Agencia Nacional de Evaluación de la Calidad (ANECA) la encargada de adaptar, orientar y supervisar el diseño de las nuevas titulaciones universitarias (De Miguel et al., 2005).

Desde este modelo, las nuevas estructuras formativas en relación a las necesidades socioeconómicas y de mercado laboral, reconocidas tanto por el ámbito universitario como por el mundo empresarial, son la base sobre las que fundamentar el perfil del egresado universitario y las competencias a adquirir por éste en su formación inicial. Por ello, el factor metodológico es clave para integrar las necesidades reales del contexto y los contenidos competenciales adecuados, mediante los diseños de perfiles académico-profesionales lo más competente posibles, para abordar las exigencias de los contextos profesionales en los que incorporarse (De Miguel, 2005a).

Tal factor metodológico en el proceso de convergencia europea, se fundamenta también desde un punto de vista formativo, en la necesidad de dar la vuelta al modelo de enseñanza tradicional centrado en el docente, para llegar a un modelo centrado en el aprendizaje autónomo del estudiante. Se acepta así el principio por el que se entiende que los aprendizajes eficaces (realmente competenciales) se alcanzan cuando el estudiante se implica y se responsabiliza de la organización y desarrollo de sus labores formativas y académicas y aceptando, además, que la sociedad del conocimiento exige 
una adaptación permanente a nuevos saberes, hecho que conlleva una búsqueda personal de conocimientos con carácter atemporal.

Es por ello, que tanto la formación básica como la formación superior han de procurar aportar las bases y herramientas competenciales para que se inicie y mantenga a lo largo de toda la vida esa búsqueda personal. Estaríamos hablando del desarrollo de un tipo de competencias inmediatamente anteriores a las de desarrollo profesional, llamadas propedéuticas o básicas (Zabalza, 2012) y que establecerían un marco previo de conocimientos y habilidades esenciales, para afrontar otros más específicos en procesos formativos superiores y extendidos a lo largo de la vida.

En este sentido las autoridades europeas han ido exhortando hacia su desarrollo de forma que todos los ciudadanos fuesen instruidos en estas competencias clave para vivir y trabajar en la nueva sociedad de la información, prestando especial atención a aquellas competencias necesarias para la empleabilidad (tecnológicas, idioma extranjero trabajar en equipo, habilidades sociales) y cristalizándose en el Marco Europeo de referencia sobre las Competencias Clave para el Aprendizaje a lo largo de la vida, así como en los programas específicos Education and Training 2010 y Education and Training 2020.

En España, los principios del proceso de convergencia europea fueron cristalizándose a través de la creación de numerosas disposiciones legales para hacer posible la transición hacia los nuevos estudios de educación superior (Ortega Navas, 2010), incluyendo el enfoque competencial en el ADN de las enseñanzas conducentes a la obtención de los nuevos títulos universitarios.

Este hecho ha ido desarrollándose en la ordenación legal de las enseñanzas universitarias oficiales en España (RD1393/2007): “los planes de estudios conducentes a las obtención de un título deberán tener en el centro de sus objetivos la adquisición de competencias por parte de los estudiantes, ampliando, sin excluir el enfoque basado en contenidos y horas lectivas" (p.2). 
Consecuentemente, para el caso de las titulaciones de Grado de Maestro de Educación Primaria, mención EF (MEPEF) y Ciencias de la Actividad Física y del Deporte (CAFyD), son sus Libros Blancos elaborados por la ANECA (ANECA, 2005a, 2005b) el punto de partida para orientar los planes de estudios universitarios, aunque particularmente con ciertos matices en cada universidad. Se describe a continuación la evolución normativa que ha favorecido el diseño competencial de los actuales planes de estudios en España (tabla 3.1).

Tabla 3.1

Evolución normativa punto de partida de los planes de estudios de referencia para este estudio (elaboración propia)

\section{Desarrollo normativo del enfoque competencial en la formación superior}

Real Decreto 1044/2003, de 1 de agosto, por el que se establece el procedimiento para la expedición por las universidades del Suplemento Europeo al Título (RD/1044/2003)

Real Decreto 1125/2003, de 5 de septiembre, por el que se establece el sistema europeo de créditos y el sistema de calificaciones en las titulaciones universitarias de carácter oficial y validez en todo el territorio nacional $(\mathrm{RD} / 1125 / 2003)$

Real Decreto 49/2004, de 19 de enero, sobre homologación de planes de estudios y títulos de carácter oficial y validez en todo el territorio nacional (RD/49/2004)

Real Decreto 55/2005, de 21 de enero, por el que se establece la estructura de las enseñanzas universitarias y se regulan los estudios universitarios de Grado ( $\mathrm{RD} / 55 / 2005)$

Libro Blanco del título de Grado en Magisterio (ANECA, 2005a)

Libro Blanco del título del título de Ciencias de la Actividad Física y del Deporte (ANECA, 2005b)

Real Decreto 1393/2007, de 29 de octubre, por el que se establece la ordenación de las enseñanzas universitarias oficiales (RD1393/2007)

Memoria de verificación del Título de Grado en Magisterio (Orden ECI/3857/2007)

Real Decreto 1027/2011, de 15 de julio, por el que se establece el Marco Español de Cualificaciones para la Educación Superior (RD/1027/2011)

Memoria de verificación del título de Grado de Ciencias de la Actividad Física y del Deporte (Resolución/SGU/2018)

\subsubsection{Competencias profesionales: conceptualización}

Desarrollar un único concepto de competencia es ardua tarea a sabiendas de que el término está atravesado por numerosos elementos que la configuran, aportados desde distintas corrientes ideológicas. A lo largo de la sección se irán desentrañando dos 
perspectivas que dimensionaron y caracterizaron el universo competencial en el plano formativo. Una primera perspectiva integradora y de mercado, subrayando el concepto de integración de diversos elementos para su conceptualización como conocimientos, habilidades, destrezas, capacidades, valores, actitudes que en su movilización, permiten responder a las exigencias profesionales. Un segundo modelo, socio-crítico, que insta hacia posiciones formativas en las que prevalezca el sentido humanista aplicado al desarrollo competencial de los estudiantes.

\subsubsection{Perspectiva dinámica, integradora y de mercado}

En la conceptualización del término competencia de algunos autores (Tejada y Navio, 2004) se observa el peculiar atractivo que este concepto posee aún, incluso a sabiendas de las dificultades para definirlo y actualizarlo, así como de la diversidad de corrientes conceptuales que van surgiendo. También lo expresa en este sentido Le Boterf (1996), apuntando a que la necesidad de definirlo aumenta con la necesidad de usarlo, reconociendo que su conceptualización se encuentra todavía en un proceso de fabricación.

Cercana a planteamientos de eficacia profesional y preocupada por el rendimiento en el puesto de trabajo (que las tareas se hagan bien y rápido) y que prescinde del elemento situacional para el desempeño profesional, se abre a partir de la década de los 60 una idea de ejercicio profesional que requiere de la cualificación en situación, para hacerse profesionalmente responsable de una acción que se quiera plantear a modo de solución a una problemática a resolver (Corominas et al., 2006). Para ello, y desde este momento, las capacidades y habilidades intelectuales y materiales para desempeñarse profesionalmente adquieren la máxima importancia.

En las últimas décadas, las cualidades para enfrentarse con éxito a los retos de la profesión docente han experimentado un gran cambio, pasando de ser consideradas las habilidades intelectuales prioritarias, a compartir importancia con otras conducentes a saber adaptarse a nuevas circunstancias y saberse relacionarse o trabajar conjuntamente con un amplio equipo de profesionales (Corominas, 2001). Desde una cosmovisión 
neoliberal, se despliega un modelo formativo basado, además de en conocimientos, también en destrezas, habilidades y capacidades útiles para el mundo empresarial. El individuo, al final de su vida académica y desde esta perspectiva, es una fuerza de trabajo flexible y adaptativa tanto como requiere el mercado de trabajo cambiante e incierto (Díez Gutiérrez, 2008; 2015; 2018).

Las competencias profesionales se han asociado habitualmente al dominio de habilidades o destrezas, lo que conlleva una cierta imprecisión terminológica, ya que si hablamos del manejo de aisladas habilidades, privamos de altura de miras y sentido holístico al propio hecho competencial.

Las habilidades o destrezas son características perceptivas, motoras, intelectuales, interactivas, activadas para la realización de una acción laboral, pretendiendo con ellas dar solución a los problemas y retos que de esa actividad profesional se derivan; los conocimientos, el saber hacer o las actitudes $\mathrm{y}$ comportamientos son parte de las habilidades que se despliegan al abordar los desafíos del ejercicio profesional (Corominas, 2001).

Pero la idea de simple cualificación profesional en virtud del aprendizaje y dominio de ciertos conocimientos, habilidades y destrezas, no termina de calar en el mundo empresarial. Aquí se hace uso de un término más complejo para designar la capacidad de un profesional para componer de forma propia y personal y habilitar en virtud de las circunstancias laborales, el mejor paquete de actuaciones para cuyo desarrollo y despliegue está debidamente cualificado y capacitado, lo que le permite responder con éxito a dichas circunstancias laborales: hablamos de las competencias (Delors, 1996).

Suponen la capacidad para combinar conocimientos, habilidades, destrezas y cualidades personales que integran un saber, un saber hacer, un saber ser y saber estar, procedentes de la cualificación y capacitación que da la formación y la experiencia, para habilitarlas en situación (Zagalaz, 2007). Así, la competencia reside en la capacidad 
para movilizar los recursos y dirigirlos hacia un determinado problema complejo a resolver en situación (Cano, Portillo y Puigdellívol, 2014; Tejada, 2005). En este sentido la estrategia formativa desde la perspectiva dinámica se muestra en la figura 3.2.

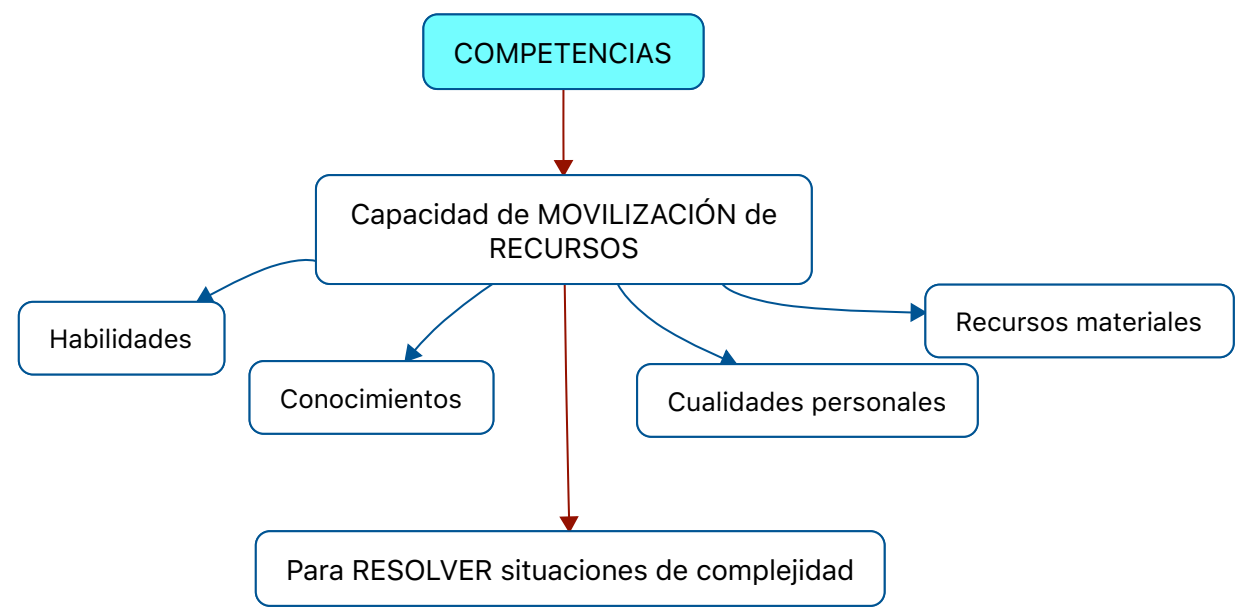

Figura 3. 2. Enfoque competencial de la perspectiva dinámica integradora (Cano et al, 2014; Le Boterf, 2001; Perrenoud, 2008)

Tal movilización implica considerar que el mero dominio de los conocimientos y habilidades técnicas no son suficientes, si no se saben aplicar y transferir en el momento conveniente (Perrenoud, 2008), lo que exige también una actualización de lo que se sabe y se sabe hacer en situación, para revelar el paso del mero saber y saber hacer, al ser efectivamente competente (Le Boterf, 2001). Se habla entonces de saber combinar y aplicar conocimientos y habilidades prácticas junto con adoptar actitudes, valores éticos y habilidades interactivas para lograr una acción eficaz en relación a la exigencia de la tarea a realizar (OECD, 2005).

Si se aplica analógicamente tal consideración al ejercicio de la profesión docente, la formación inicial del profesorado se entiende como un hecho y tiempo trascendente para ayudar a los futuros docentes a hacer una transición formativo-laboral competencialmente apropiada, contribuyendo finalmente a configurar los perfiles profesionales adecuados para interpretar y responder a las nuevas y diversas realidades 
educativas, surgidas por la aceleración de los últimos cambios sociales (Esteve Zaragoza, 2006).

Se constituye, por tanto, como un momento formativo clave para comprender y aprender que las competencias son capacidades para manejarse también en contextos de aprendizaje, ayudando a interrelacionar constantemente teoría con práctica, e impulsando su aplicación para la identificación y resolución de situaciones problema de la práctica profesional docente presente y futura (Zabalza, 2012).

Este planteamiento formativo competencial integrador contrasta con un modelo tradicionalista de formación del profesorado, cuya base formativa ha sido profundamente intelectual y valedora de un conocimiento estático y academicista (Bolívar, 2008). Caracterizado también por su lejanía con respecto a las necesidades reales de la escuela y de los nuevos perfiles profesionales docentes demandados (más adaptativos, empáticos y cooperativos), poniendo en circulación perfiles, en muchos casos, poco flexibles e insuficientemente adaptativos como para hacer frente a la complejidad viva, real y en constante evolución de los centros educativos.

El dinamismo es en la actualidad una de las principales dimensiones del conocimiento, y la velocidad con la que la información fluye y se multiplica hace que esta se quede rápidamente obsoleta. Además, la especialización y segmentación del conocimiento, dificulta en los futuros docentes una visión global y completa de la realidad educativa, lo que les impide interpretarla y responder activamente a sus demandas y necesidades.

Los futuros profesores, a lo largo de su formación inicial, han de saber identificar qué les reclama la comunidad educativa en sus diversos contextos, debiendo saber aplicar selectivamente las competencias precisas para ejercer consecuentemente (Lleixá et al., 2008). La actual sociedad del conocimiento y los nuevos escenarios educativos requieren de profesionales con altas capacidades de aprendizaje, de actualización, adaptación, flexibilización y de resolución de problemas complejos 
(Tejada, 2005) para actuar de manera eficaz en su dimensión ciudadana y profesional. Para ello se hace necesario un planteamiento de educación superior que forme para la ciudadanía y prepare profesionales capaces de afrontar los desafíos de la sociedad presente y futura (Yániz, 2007).

En el III Simposium Iberoamericano de Docencia Universitaria, Gairín et al. (2004) definieron las competencias profesionales que los futuros docentes podrían adquirir en su formación inicial, como funciones a desarrollar tras su periodo formativo. Dichas funciones se diversificarían en capacidades para reconocer los problemas de la profesión docente, detectarlas en situaciones simuladas y reales y saber establecer soluciones a los mismos (Villa y Poblete, 2007). Para ello arguyen que las competencias podrían agruparse en torno a dos ejes: un primer grupo de competencias transversales, generales o comunes en el desempeño de cualquier profesión y un segundo grupo de competencias específicas o propias de la especificidad de una materia o disciplina.

En este sentido plantean que ser competente supone ser capaz de dar respuesta activa y efectiva a los problemas complejos del aula, movilizando, seleccionando, ordenando y aplicando algo más que meros conocimientos y recursos pedagógicos. Un docente en su ambiente profesional diario necesitará movilizar también recursos de carácter inter e intrapersonal como habilidades sociales, regulación emocional, habilidades comunicativas, capacidad de trabajo cooperativo, sensibilización crítica con los problemas del entorno sociocultural o capacidad autocrítica para revisar constantemente su praxis de aula (Fraile y Aparicio, 2015), gestionando hábilmente todo, para poder hacer frente a los retos que su grupo clase le obliga a afrontar cada día en el proceso de enseñanza-aprendizaje que lidera.

Surge una perspectiva competencial ciertamente dinámica (Lleixà et al., 2008) que busca la capacidad de movilización, orquestación, transferencia o encaje, de recursos personales y profesionales para dar respuesta a problemas concretos en contextos específicos. 
Este planteamiento pasa no solo por la movilización a la carta de todos los recursos en función de la situación a la que se enfrenta el docente con sus alumnos, sino también por la movilización de sus esquemas de pensamiento para abrirse a la innovación y proponer múltiples soluciones a diversos problemas. En este sentido, el docente puede enfrentarse de manera eficiente a problemas actuales como los derivados de la atención a la diversidad, los diferentes ritmos de aprendizaje o el tratamiento de la interculturalidad, haciendo de su profesión un ejercicio más comprometido socialmente con su centro educativo (Carreras y Perrenoud, 2005).

Este modelo más dinámico de competencias es también denominado modelo de competencias de tercer nivel (Aubrun y Orifiamma, 1990) y están conformadas, además de por las capacidades vinculadas al saber y al saber hacer, por otras transversales que se podrían clasificar en cuatro grupos: (1) competencias referidas a comportamientos profesionales y sociales (como la toma de decisiones o la asunción de responsabilidades), (2) competencias referidas a actitudes (como la forma de tratar a los demás, el compromiso adquirido con los otros o la responsabilidad personal y social), (3) competencias relacionadas con las capacidades creativas (como la originalidad y capacidad de riesgo en la toma de decisiones, o la capacidad de propuesta de soluciones a los demás), y (4) competencias de actitudes existenciales y éticas (como la capacidad de análisis y reflexión sobre la propia práctica docente o la capacidad de compromiso ético y social en el contexto socio-educativo desde el que se trabaja).

Se pueden advertir entonces ciertas capacidades comunes a todas las definiciones de competencia abordadas, como son las capacidades de movilizar, orquestar, transferir o ajustar, que se cruzan con algunos aspectos de necesario dominio y manejo personal y profesional como son los conocimientos, saberes, habilidades, destrezas, técnicas, valores y actitudes. Todos retrotraen a núcleos esenciales de la psicología, de la educación, de la sociología o de la ética.

Efectivamente, el manejo combinatorio de todos estos elementos, y su despliegue en el puesto docente a modo de equipamiento personal, capacitan a un 
individuo para actuar con eficacia en su desempeño profesional, haciendo posible que desde su formación inicial, con la formación permanente y hasta la práctica profesional, pueda dar el salto del saber y saber hacer, al "ser capaz de" (Tejada, 2005). Por ello las prácticas formativas profesionales en contextos reales de trabajo suponen una óptima oportunidad para poner en tensión el "saber y saber hacer" con respecto al "ser capaz de" y "ser (efectivamente) competente" en el desempeño profesional de las tareas y funciones docentes.

Así, pensando en el futuro, el docente de EF va a poder valorar y hacer evolucionar su idea de capacitación si pone en contraste su proceso de adquisición de conocimientos con una práctica real profesional que le llegaría, bien mediante su experiencia de prácticas formativas (Practicum) en donde ejercer las funciones docentes en el contexto propio de su área en un centro educativo real o bien, a través de experiencias profesionales diversas en contextos educativos no formales. Tales experiencias de contraste serán la forma efectiva de percibir el "ser capaz de" y el "ser competente para". Como apunta Tejada (2005) la mejor manera de desarrollar las competencias es desde la acción, relacionando formación y experiencia y no sustituyendo una por otra; superando el "saber hacer" (saber imitar) por el "saber actuar", aprendiendo a crear y aplicar medidas adecuadas y ajustadas a las contingencias encontradas en el día a día del aula (Tejada, 2009).

Para Cano (2005) y Martin (2009) algunas características que permiten entender el planteamiento integrador y dinámico de las competencias profesionales son las siguientes (tabla 3.2.). 
Tabla 3.2

Características de la perspectiva integradora y dinámica de las competencias profesionales (Cano, 2005; Marín, 2009)

Características del planteamiento integrador de las competencias

\begin{tabular}{ll}
\hline $\begin{array}{l}\text { Presentan un carácter } \\
\text { teórico-práctico }\end{array}$ & $\begin{array}{l}\text { Partiendo de saberes académicos y habilidades aprendidas, éstos } \\
\text { se entienden desde la práctica en un contexto real profesional. }\end{array}$ \\
\hline $\begin{array}{l}\text { Muestran un carácter } \\
\text { aplicativo }\end{array}$ & $\begin{array}{l}\text { Las competencias tienen su ser en la aplicabilidad y en la } \\
\text { transferibilidad. }\end{array}$ \\
\hline $\begin{array}{l}\text { Manifiestan un carácter } \\
\text { contextualizado }\end{array}$ & $\begin{array}{l}\text { Movilizar una competencia supone una aplicación a una situación } \\
\text { determinada a resolver, aunque para ello y por analogía se } \\
\text { consideren experiencias anteriores. }\end{array}$ \\
\hline $\begin{array}{l}\text { Ofrecen un carácter } \\
\text { reconstructivo }\end{array}$ & $\begin{array}{l}\text { Las competencias que se adquieren en la formación inicial han de } \\
\text { ser practicadas en contextos y situaciones reales, a fin de poder ser } \\
\text { revisadas, repensadas y reconstruidas. }\end{array}$ \\
\hline $\begin{array}{l}\text { Disponen de un } \\
\text { carácter combinatorio } \\
\text { o integrador }\end{array}$ & $\begin{array}{l}\text { Ser competente supone movilizar tanto conocimientos y saberes, } \\
\text { como habilidades, técnicas y destrezas, así como valores, actitudes } \\
\text { yabilidades sociales, que de manera combinada permiten una } \\
\text { intervención sobre una situación problema, en un contexto real, } \\
\text { con intencionalidad efectiva. }\end{array}$ \\
\hline $\begin{array}{l}\text { Muestran un carácter } \\
\text { interactivo, dinámico }\end{array}$ & $\begin{array}{l}\text { Ser competente no se entiende desde la actuación solitaria sino de } \\
\text { forma contextualizada y en interacción con los demás. }\end{array}$ \\
\hline
\end{tabular}

\subsubsection{Perspectiva socio-crítica: en búsqueda del sentido humanista de las competencias.}

Aunque de forma general la comunidad académica fue valorando los principios del proceso de convergencia europea y considerando el EEES como una gran oportunidad de cambio para la universidad, surge una corriente académica crítica que observa cómo la educación superior se pone al servicio del mercado laboral y de las exigencias y necesidades del mundo empresarial, siendo las competencias la herramienta para hacerlo (Laval, 2004). Igualmente observan cómo paulatinamente se va abandonando el principio de cambiar la sociedad desde la universidad para hacerla más humana, justa, equitativa, posicionándose más como un instrumento útil a los cambios que se están produciendo en la economía y que no son tan justos, equitativos y comprensivos con la sociedad (Díez Gutiérrez, 2009). 
La educación humanista, con su pretensión de universalidad y emancipación intelectual de ayudar a ubicar en la sociedad a personas reflexivas y críticas, queda truncada por la aparición de una nueva era neoliberal productora de profesionales intelectualmente muy cualificados al servicio de la economía y de la empresa (Díez Gutiérrez, 2008) y en búsqueda en la educación superior, de las competencias que les son útiles (Laval, 2004).

De esta manera, se pasa de un modelo formativo universitario desde donde se proyectaban hacia la sociedad personas reflexivas, a un modelo nuevo donde se busca el desarrollo de personas trabajadoras adaptativas, polivalentes y eficaces para atender las nuevas exigencias de un mercado laboral cambiante e incierto, en una estrategia neoconservadora que reclama la excelencia profesional exclusivamente para atender los intereses del propio mercado (Martínez Bonafé, 2004).

En este sentido, aparece un nuevo lenguaje en el ámbito de la educación. El lenguaje de la mercantilización que penetra en las instituciones educativas. Un nuevo lenguaje que para Laval (2004) se hace presente también en la escuela. En definitiva una McDonaldización (Ritzer, 2007) cuyos tentáculos alcanzan la escuela.

Así, el vínculo de dependencia de la educación a la economía se muestra también en el leguaje educativo, de forma que el profesor es un "gestor" de aula o un "mediador" del aprendizaje, la educación es "excelencia", el aprendizaje se asocia a "rendimiento" y éste se asocia a su vez a la consecución "eficaz" de objetivos.

En definitiva, una nueva lógica se abre paso: la del saber que se vincula claramente con el trabajo y el consumo, dos características esenciales de un modelo económico neoliberal que se instala también en la vida socio-educativa y que, en ocasiones, hace que el profesional de la docencia se aliene de su propio trabajo, abstraído de toda realidad e inundado por su actividad productiva y los productos de esa actividad, pudiendo perder el sentido crítico-reflexivo de su autonomía docente (Martínez Bonafé, 2013). Así, el colectivo docente observa el surgimiento con gran 
fuerza de un modelo competencial proveniente de los órganos administrativos superiores y burocráticos de la ordenación educativa (Perrenoud, 2000), que impide su libre desarrollo profesional, imponiendo múltiples decisiones sobre sus programaciones sin que tomen parte en ellas, estandarizando su actuación y dejando a un lado su conocimiento experiencial acumulado, sus concepciones, sus creencias y sus cualidades personales (Elliott, 2005).

Se abre así un debate profundo con espíritu crítico que hace por un lado, repensar las competencias en la formación inicial del profesorado en un contexto de sociedad convulsa en lo socio-cultural, enmarcada en una auténtica revolución del conocimiento y de la información y sujeta a las presiones de las reglas del mercado (Rodríguez Martínez y Díez Gutiérrez, 2014); y por otro, reflexionar sobre el tratamiento planificador y metodológico que permita su vivencia y desarrollo de una forma más holística y menos fragmentada (Gimeno Sacristán, 2008a) y adoptar el docente un punto de vista en la forma de ver a los estudiantes no como productos predecibles, sino como personas, ciudadanos y futuros profesionales (Angulo Rasco, 2008). De no ser así, se corre el riesgo de acabar redefiniendo los programas de formación del profesorado como una suma de competencias imprescindibles al final de clases, seminarios y cursos, así como una traducción de su formación en conocimientos prácticos y competencias, estandarizando, tecnificando y taylorizando dicha formación (Laval, 2004).

No es tanto el concepto de competencia lo que está en juego. Aceptando que las competencias tienen una fuerte base intelectual fundamentada en los conocimientos y saberes teórico-prácticos (Cano, 2005; Cano et al., 2014; Corominas, 2001; Tejada, 2005; Zabalza, 2012), el reto radica en el tipo de conocimientos, saberes y experiencias de aprendizaje que se priorizan en los planes formativos para formar a un futuro profesorado, que se apasione con el ejercicio profesional comprometido de la educación. 
Un conocimiento que en su difusión desde la universidad, repercuta pedagógicamente en una sensibilización hacia problemáticas sociales, locales, globales y cuyo tratamiento redunde en la búsqueda activa de soluciones. Lo que implica tanto un ejercicio de conocimiento del saber, como de selección, utilización, actualización, aplicación a contextos específicos, para adaptarse $\mathrm{y}$ aprender permanentemente (Villardón-Gallego, 2015). Esto obliga a repensar en la FIPEF la conexión entre la formación académica y la formación práctica en los centros escolares (Practicum) para garantizar el desarrollo de experiencias de aprendizaje atractivas, integradas, permitiendo poner en juego y de forma reflexiva, crítica y autónoma, las competencias que se pretenden desarrollar en los futuros docentes (Rodríguez Martínez y Díez Gutiérrez, 2014).

Alcanzar un enfoque competencial más holístico y menos fragmentado para la FIPEF supone admitir la necesidad de establecer una rica y constante interacción entre teoría y práctica, utilizando la investigación-acción cooperativa como estrategia pedagógica, atendiendo a planteamientos metodológicos más activos y colaborativos, conectados con la realidad profesional docente y los centros escolares y en búsqueda constante de la reflexión en la práctica (Fraile, 2004a; Pérez Gómez, 2010). En este sentido Hortigüela, Pérez-Pueyo y López-Pastor (2015) y Hortigüela, Pérez-Pueyo y Fernández-Río (2016) mostraron cómo la utilización de metodologías activas, más abiertas y participativas junto con modelos alternativos de evaluación optimizaban el desarrollo competencial de sus estudiantes y les hacían más conscientes de la realidad educativa de inserción profesional.

Ser competente supone trascender el mero sentido de eficacia en el desempeño de una tarea encomendada, para pasar a un estado tendente a analizar, contrastar, reflexionar y evaluar también la propia práctica docente en debate triangular abierto con la institución escolar de referencia, empleadora y la propia institución académica, formadora. Así, un currículum fundamentado en competencias incita a la experimentación por los estudiantes de una formación contextualizada, transformadora de la realidad, inclusiva y constructora de futuro para todos. 
Algunos aspectos que pueden ayudar a clarificar esta visión más crítica y reflexiva de las competencias docentes en la formación inicial vienen de la mano de ciertos planteamientos relacionados con el pensamiento práctico (Schön, 1983, 1987) y la comprensión de la formación docente como un proceso de reconstrucción conceptual y continua de las formas de comprender, actuar y representar, a la luz de lo que cada futuro docente vivencia en relación con los contextos y personas que inundan su existencia personal y profesional, durante todo su proceso formativo inicial $\mathrm{y}$ permanente. Tales aspectos son los siguientes:

- La práctica docente no ha de considerarse como un hecho lineal consecuencia natural de la formación teórica, sino como un escenario complejo y cambiante, en el que necesariamente se producen situaciones a observar, contrastar, investigar, debatir y reformular. Con lo que las competencias docentes se tornan en capacidades vivas, en potencial proceso de evolución, cambio constante, reconstrucción y deconstrucción.

- Práctica y teoría en eterna interacción, se conforman como un bucle en continuo movimiento que expande el conocimiento, transforma la realidad y transforma también al propio docente en formación ya que éste interactúa con la realidad (cuando contrasta y reflexiona triangularmente en contacto con ella, con su propio yo docente y con la realidad académica formante).

- Aprender supone reconstruir y reestructurar constantemente la red de saberes que se van tejiendo en relación a las experiencias, interacciones y significados que se ponen en tensión con las realidades formativas (Pérez Gómez, 2010), para ser transformado por ellas $\mathrm{y}$ hacer crecer la proyección personal $\mathrm{y}$ profesional como docente.

- El pensamiento práctico puede ser el lugar para comprender la integración de los saberes y los conocimientos, las habilidades, destrezas y técnicas y los elementos emotivos y motivacionales que dirigen la labor docente.

Por todo ello, siguiendo a Contreras (2010) se propone desde esta perspectiva socio-crítica una estrategia para la formación del profesorado (figura 3.3) fundamentada en el desarrollo de las competencias contenidas en los planes de estudios, en clave de 
saberes, habilidades, capacidades, valores, actitudes y actividades prácticas que redunden en experiencias constantes de transformación personal y profesional para ayudar en su incorporación a cada identidad docente y constituirse como profesionales reflexivos únicos. Por ello y siguiendo a Imbernón (1994) la cuestión no es aprender los estándares, los estereotipos y las técnicas que definen el aprendizaje del oficio del docente de EF, sino sentar los cimientos de una cultura profesional que contribuye activamente a la transformación social; esto supone reconocer lo que se debe saber, lo que se puede enseñar, cómo se puede hacer y porqué es necesario hacerlo de un determinado modo y en un lugar concreto.

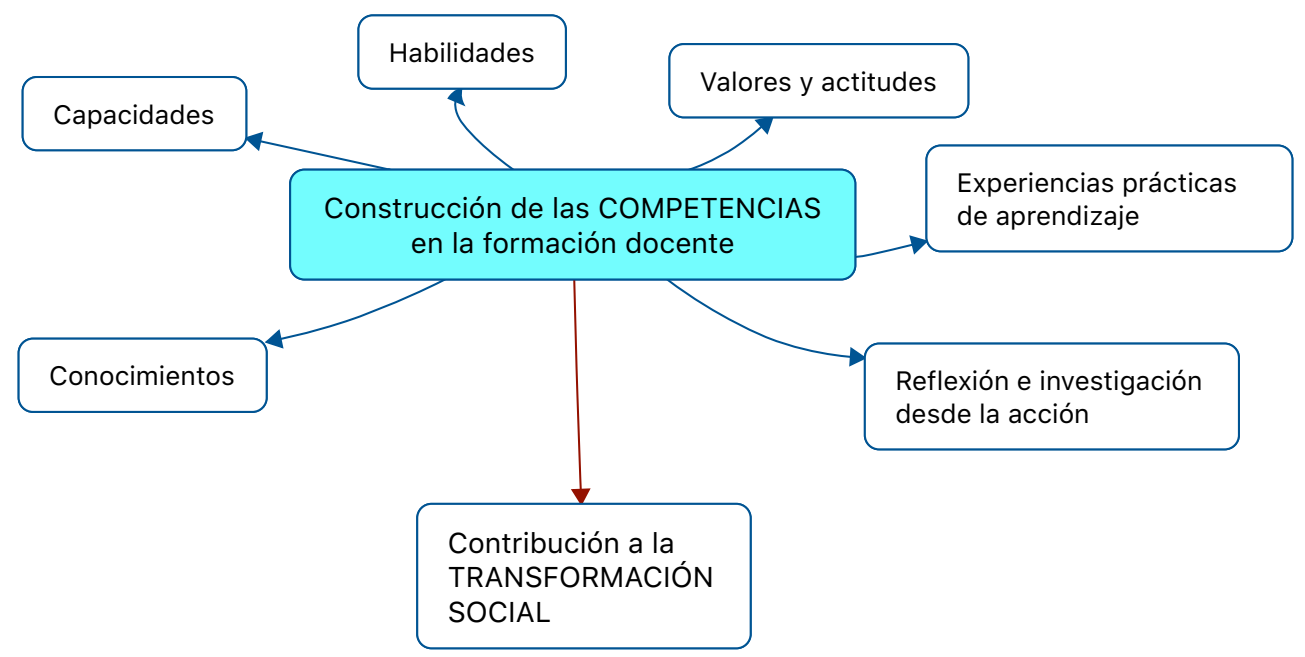

Figura 3. 3. Enfoque competencial desde las perspectiva socio-crítica (Contreras, 2010)

Se trata de la necesidad de eliminar la frontera entre lo que se sabe (saber, saber hacer) y lo que se es (Larrosa, 1996), en virtud del planteamiento de verdaderas experiencias que afecten a los futuros docentes, les impliquen subjetivamente y les transformen en lo profundo de la unidad indisoluble personal y profesional de lo que comienzan a ser, ayudándoles a comprender y valorar que la práctica pedagógica, en cuanto base sustancial del ejercicio docente, es algo nunca resuelto a priori, sino en constante evolución, que interpela y hace repensar constantemente si las actuaciones (docentes) desarrolladas fueron o no las más adecuadas y si ayudaron a cambiar en cierta medida el entrono socio-educativo en el que se interviene. 
Es por ello necesario que desde una perspectiva crítica en la formación superior se ayude a valorar la necesidad de actuar como profesionales transformativos (Freire, 1986) sobre la realidad particular de cada día. Se trata de encadenar desde la docencia en la universidad y con el fin de que se proyecte al ejercicio profesional futuro, una conciencia sobre la propia práctica docente en clave de conexión y de repercusión activa en el entorno social cercano, aunque también sea necesario, para ello, poner en tela de juicio las circunstancias sociopolíticas del momento (Flecha, 1998).

Así, las competencias a incorporar en la formación inicial del profesorado deben suponer un corpus teórico-práctico inacabado, que interpele constantemente a los estudiantes y que se enraíce en su ser personal y profesional, para proyectarse en una práctica pedagógica más reflexiva, sensible y verdaderamente presente y expuesta a la realidad de aula y social en la que interactuar (Van Manen, 2003).

De acuerdo con Fraile (2004b), (Villardón-Gallego, 2015) y Yániz (2007) es urgente establecer un modelo de formación inicial del profesorado que proyecte en el perfil profesional, competencias no solo pensadas para resolver problemas en el contexto laboral (pensamiento de mercado), sino también pensadas para desarrollar mujeres y hombres de ciudadanía comprometida con la desigualdad social y la sensibilización con los problemas sociales cercanos y lejanos (algunos de impacto mundial).

En definitiva, un modelo formativo basado en un tipo de competencias más transversales que favorezcan efectivamente la inserción laboral en el mercado actual, pero como docentes y ciudadanos críticos que pueden transformar la realidad y que la entienden en clave inclusiva o constructora de futuro para todas las personas, en clave de justicia social.

Se muestran en la tabla 3.3 de forma resumida los aspectos característicos del planteamiento socio-crítico de las competencias. 
Tabla 3.3

Características de la perspectiva sociocrítica de las competencias profesionales a partir de Contreras (2010), Díez Gutiérrez (2009), Fraile (2004a, 2004b), Martínez Bonafé (2004), Pérez Gómez (2010), Villardón-Gallego (2015)

\section{Características del planteamiento socio-crítico humanista de las competencias}

\begin{tabular}{ll}
\hline $\begin{array}{l}\text { Transformación social y } \\
\text { compromiso ciudadano }\end{array}$ & $\begin{array}{l}\text { La formación competencial docente se plantea desde un principio de } \\
\text { contribución al cambio, la transformación social y la ciudadanía } \\
\text { comprometida. }\end{array}$ \\
\hline Educación humanista & $\begin{array}{l}\text { Se considera esencial la formación para las competencias reflexiva y } \\
\text { crítica. }\end{array}$ \\
\hline Sensibilización social & $\begin{array}{l}\text { La formación competencial se orienta hacia la sensibilización hacia } \\
\text { problemáticas sociales (locales, globales) implicando la búsqueda } \\
\text { activa de soluciones desde la educación. }\end{array}$ \\
\hline $\begin{array}{l}\text { Interacción teoría y } \\
\text { práctica }\end{array}$ & $\begin{array}{l}\text { Se insta hacia un modelo de formación competencial desde la } \\
\text { investigación sobre la acción docente. }\end{array}$ \\
\hline $\begin{array}{l}\text { Superación del sentido } \\
\text { de eficacia }\end{array}$ & $\begin{array}{l}\text { Ser competente supone ser capaz de experimentar, analizar, contrastar, } \\
\text { reflexionar y evaluar la propia práctica docente. }\end{array}$ \\
\hline Pensamiento práctico & $\begin{array}{l}\text { Las competencias son capacidades vivas que evolucionan, cambian, se } \\
\text { reconstruyen y deconstruyen desde la interacción con el contexto, } \\
\text { haciendo crecer la proyección personal y profesional docente. }\end{array}$ \\
\hline $\begin{array}{l}\text { Transformación } \\
\text { personal y profesional }\end{array}$ & $\begin{array}{l}\text { Se orientan los saberes, habilidades, capacidades y valores que } \\
\text { configuran las competencias docentes hacia experiencias de } \\
\text { transformación personal y profesional. }\end{array}$ \\
\hline
\end{tabular}

\subsection{La cultura profesional del profesorado de Educación Física en España}

El desarrollo de la cultura profesional del profesorado de EF en España requiere del descubrimiento de los momentos históricos que han ido configurando el sector que se conoce en la actualidad. A lo largo del tiempo se han ido poniendo los límites para acotar el espacio profesional del colectivo, que ha ido cambiando conforme las necesidades y demandas surgentes de los cambios sociopolíticos atravesados.

Se presentan los principales hitos históricos que muestran el nacimiento de la figura del profesorado de EF en España, así como la formación y evolución de su espacio profesional, mostrando cómo los perfiles que se fueron configurando atendieron 
las necesidades y demandas del momento, construyéndose paulatinamente el basto campo profesional que hoy se conoce y atiende.

También se presentan los principales enfoques competenciales que fueron desarrollándose en la tradición formativa del profesorado de EF, desde un modelo academicista tradicional en los orígenes, basado en el conocimiento científico y su transmisión, pasando por otros tecnológicos, otros basados en la práctica y también social-transformativos, que reconociendo la desigualdad social, adopta una visión situada de la docencia de la EF, crítica y reivindicativa en favor de los grupos sociales con mayores necesidades socio-educativas, interviniendo desde el área en este sentido.

\subsubsection{Evolución del espacio profesional de la EF en España}

Para conocer cómo se ha ido produciendo el desarrollo competencial del profesorado de EF, es necesario reconocer y apuntalar su espacio y su cultura profesional que, en los últimos cien años, ha ido evolucionando no sin la generosidad, superación, renuncias y vocación de un profesorado que se fue forjando, aun teniendo en contra una prolongada instrumentalización política y un tratamiento discriminatorio de su propia especialidad (Pastor Pradillo, 2004a).

El espacio profesional en la EF supone cada uno de los contextos susceptibles de intervención profesional cuyos límites se van construyendo, atendiendo a las cambiantes necesidades sociales, las nuevas demandas, los campos de actuación tradicionales y emergentes, el marco normativo que define las actuaciones y las condiciones y la creación de un sector o corporación que represente a los miembros de la profesión (Pastor Pradillo, 2004b).

Siguiendo a Bernard (1980) y teniendo como fondo el conocimiento y control del cuerpo y el movimiento, esta evolución sufrió momentos en los que en ocasiones prevaleció la preocupación del sentido estético corporal; otras en la que el estado 
reclamaba su dominio en aras al sentido patrio y de imagen de progreso del país y en otras ocasiones, será el sentido de desarrollo físico quien prevalezca, por la necesidad creada de potenciación del cuerpo como instrumento para el rendimiento deportivo.

En tanto se van configurando estas versiones a lo largo de los siglos XIX y XX, se irá construyendo y reclamando, por parte de la sociedad, una nueva figura de técnico capaz de hacer factible la consecución de tales demandas y objetivos. Estos hechos irán marcando su construcción profesional y dotándole de un bagaje histórico que le irán configurando como un profesional emergente.

Es necesario por todo ello, comprender este proceso de construcción del perfil del docente de EF quien, fruto de la herencia social y cultural española y de las opciones de actividad física a la que se irá adscribiendo en esta etapa histórica moderna, irá enfrentándose a nuevos retos y, por tanto, evolucionando en la apropiación de los aspectos nucleares del área de conocimiento y de su aplicación pedagógica, administrando los nuevos valores, costumbres, prácticas y técnicas, y acrecentando un perfil profesional que da respuestas a las particularidades históricas que el contexto le demanda (Pastor Pradillo, 1997). Se desarrollan a continuación ciertos hitos (figura 3.4) que, al margen de las pesadumbres por las que atraviesa la EF en el ámbito formativo, se consideran referentes históricos para comprender el proceso de su institucionalización educativa y por tanto, la configuración de la cultura profesional de sus docentes. 


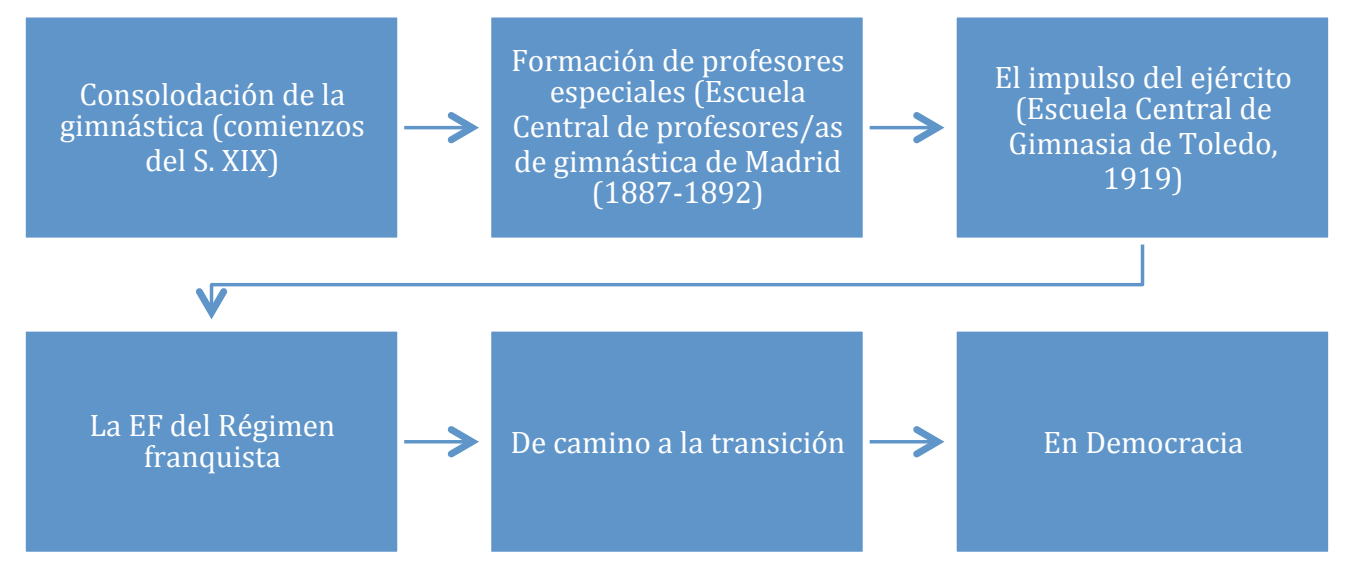

Figura 3. 4. Principales hitos históricos de la formación de la Educación Física en España (Pastor Pradillo, 1997)

\subsubsection{La consolidación de la gimnástica}

Es en los comienzos del siglo XIX cuando se considera que las prácticas gimnásticas más cercanas a la recreación, el espectáculo y el circo no deben ser confundidas con una verdadera gimnástica, cuyo fin es el robustecimiento de la salud y el fortalecimiento de la sociedad y la raza, en aras a la consecución del destino patrio de las naciones. Así mismo, el estado toma las riendas de la responsabilidad de la infancia, herencia de los cambios sociales y políticos de la Revolución Francesa, compartida con los progenitores, perdiendo protagonismo la iglesia en su influencia en la gestión de la educación. En España, las influencias de Rousseau con su postulado de educación natural del niño, del pestalozzismo, con la reivindicación de la EF como parte de un modelo de desarrollo integral formado por lo moral, lo intelectual y lo corporal, apoyada en lo artístico y expresivo (Pestalozzi, 1986), hacen que vaya tomando forma una nueva disciplina escolar, la gimnástica y de ella, vaya evolucionando la formulación del concepto de EF en el contexto español (Pastor Pradillo, 1997).

En aras al robustecimiento del cuerpo y del espíritu de la nación, el estado toma en cuenta los valores de la gimnástica para incidir en la definición del nuevo ciudadano; 
ciertas influencias que van calando en la configuración del concepto de EF en España a través de la gimnástica, vienen de la mano de cuatro escuelas europeas, como la Alemana de Guts Muths; Sueca y los métodos gimnásticos de Ling; Inglesa, con aportaciones importantes en juegos y deportes, y Francesa con Amorós y la consolidación en París del Gimnasio Civil y Militar de París, a imagen y semejanza del que dirigió en Madrid años atrás aplicando el método pestalozziano y ya como reconocido pedagogo (García Carretero, 1990; Langlade y Langlade, 1983).

Fruto de todas estas aportaciones sobre la gimnástica, el concepto de EF en España se irá configurando y en ello priorizando algunos aspectos que irán conformando su identidad. Tales aspectos se relacionarán con una preocupación constante por el fortalecimiento del cuerpo, su robustez y la preparación de una juventud higiénica y moralmente sana, considerando desde los primeros momentos de la infancia, tiempos y espacios para la ejercitación y el fortalecimiento corporal al aire libre (Rousseau, 2007; Vigarello, 2005). También se considerarán como columna vertebral de la educación moral, higiénica e intelectual, como apuntábamos de inspiración pestalozzista, para facilitar además del desenvolvimiento corporal, el pensamiento y el comportamiento, afirmando que la gimnástica no solamente embellece el ser, sino que también lo perfecciona, regulariza y anima (Pastor Pradillo, 2007).

Con todo ello, desde 1847, con la instrucción del Ministerio de Comercio, Instrucción y Obras que modificaba los planes de estudio vigentes, hasta 1883, con el Real Decreto sancionado por el Rey Alfonso XII, por el que se establecía la obligatoriedad de la gimnástica en el sistema educativo, se consigue que su concepto, atención y gestión de un vuelco, hasta el extremo de ser necesaria la creación de una Escuela Central de Profesores y Profesoras de Gimnástica de Madrid. El objetivos es proveer de docentes suficientemente capacitados para hacer frente al desarrollo de la nueva disciplina. Y este podría ser el punto de comienzo oficial del ejercicio profesional de la EF (Pastor Pradillo, 1997, 2004a, 2004b). 
El modelo de formación inicial que se crea, cercano a posiciones higiénicas y dirigido por profesionales médicos y civiles, tendrá como resultado la formación de profesionales más cerca de la práctica motriz que desde una base científica teórica, no contemplando una perspectiva pedagógica y recreando un enfoque formativo tradicional, desde el que el egresado, ya en su rol docente, tiende a reproducir su propio modelo formativo: aprender para transmitir lo aprendido (Contreras, 1992; Fraile, 2004b). Así lo considera Pastor Pradillo (1997), instando al profesorado para que sea ejemplo de sus estudiantes y que estos a su vez lo sean de su alumnado una vez egresados, ejerciendo la perfección de la ejercitación motriz y pidiendo tal perfección a los propios estudiantes.

Estos hechos marcaron definitivamente el comienzo del proceso de institucionalización de la educación física así como los inicios de los primeros profesionales formados y capacitados para ejercer la profesión docente desde la nueva disciplina.

\subsubsection{La formación de "profesores especiales"}

Aunque un impulso progresista fue decisivo para su fundación, la Escuela Central de Profesores y Profesoras de Gimnástica de Madrid, con el objetivo de formar profesores y profesoras de gimnástica, una vez egresados, con destino exclusivo en el ámbito de la docencia en el nivel secundario (perdiéndose la oportunidad de destinar profesionales a otros cuerpos docentes como la primaria), no reflejaba en sus enseñanzas tal progresismo, más bien pecaba de exceso de intelectualismo y deficiente formación pedagógica y didáctica.

Sus objetivos eran del todo de corte anatómico-fisiológicos y las actividades formativas de tipo gimnástico, basadas en la excesiva utilización de aparatos e instrumentos gimnásticos (de inspiración en la gimnástica alemana y francesa). Además estaban ausentes las perspectivas expresivas o rítmicas, $\mathrm{u}$ otras de inspiración británica en lo relacionado con la presencia de juegos, deportes o actividades en la naturaleza, 
que la Institución Libre de Enseñanza en España ya promovían a nivel pedagógico, a la par que en Francia lo hacía Coubertin y en Inglaterra Thomas Arnold (López Fernández, 2002; Pastor Pradillo, 1997; Zorrilla, 2002).

De esta forma, las nuevas tendencias educativas del momento, de la mano de la Institución Libre de Enseñanza (con prácticas formativas como centro de la formación, innovaciones educativas, avances en los proyectos educativos y alternativas pedagógicas en un intento por abrir los ojos a otros países) no se reflejaban tan deseadamente en el planteamiento de tal institución formativa, que se posicionaba más cercana a orientaciones militaristas y que no recibía más apoyo político institucional en un momento socio-político convulso, que el del reducido sector progresista (López Fernández, 2002).

Poco tiempo después, en 1892, el centro fue clausurado y algunas cuestiones, como el concepto de EF (para los detractores políticos calificado de dudoso), los planteamientos metodológicos, la escasez de egresados (considerados como profesores especiales), las reivindicaciones de monopolio de las funciones docentes por profesionales de la medicina y de las ciencias, frente a los nuevos y excluidos titulados en Gimnástica, complicaron el proceso de institucionalización de la disciplina en el ámbito educativo. También influyó la insuficiente identidad aún como profesión diferenciada, la ausencia de orientación profesional de los contenidos de los planes formativos, así como la habilitación de docentes sin suficiente formación. Estos hechos contribuyeron al reinado de cierto caos, con presencias y ausencias de la materia en la educación secundaria durante algunos periodos de tiempo.

La formación inicial del profesorado se aborda en la República desde la voluntad de dignificación del ejercicio docente (Anguita 1997; Contreras, 1992), que, con el Decreto de 29 de septiembre de 1931, se cristaliza en la unificación de categorías, igualdad de salarios, nuevo plan de formación de maestros y la firme convicción de que para una nueva escuela el maestro es el mejor precursor. Así, en la nueva formación de 
maestros en las Escuelas Normales, aparece la asignatura "Educación Física y juegos infantiles".

Respecto a la formación del profesorado que debía ejercer en bachillerato, en 1934, con la reforma del plan de estudios de 1903 y sus modificaciones de 1931 y 1932 , que consideraban para el bachillerato la presencia de la EF como materia a impartir, se sustituye en el nuevo plan la EF por juegos y deportes, dejando de tener carácter de disciplina y asumiendo un carácter exclusivamente de ejercitación práctica.

Tal vacío en el currículo de bachillerato no coincidía con la importancia que se le pretendía otorgar a la EF en el momento. Por ello el gobierno republicano, sensible a esta situación, decide crear a partir de 1933 una red de escuelas (encabezada por la Escuela de Formación del Profesorado de Educación Física en la Universidad de Madrid, adscrita a las facultades de Medicina y Filosofía y Letras) para formar al profesorado de $\mathrm{EF}$, con un planteamiento formativo teórico-práctico, en el que el aprendizaje de los fundamentos científicos de la EF (médicos, anatómicos, fisiológicos) y el adiestramiento y la ejercitación en deportes y juegos fueran su leitmotiv.

El otro gran impulso a la EF por el gobierno del momento se encuentra en la creación, en 1935, de la Junta Nacional de Educación Física que, mediante Decreto de 24 de abril, encarna la voluntad política de que la EF esté presente en todos los niveles de enseñanza, desde un planteamiento no tan militarista (común en Europa), sino más humano y liberal, para difundir el verdadero valor educativo de la ejercitación corporal en una novedosa propuesta de formación integral del individuo.

\subsubsection{La tutela y el impulso del ejército}

La tradición en la preparación física y gimnástica del personal militar de la Escuela Central de Gimnasia de Toledo (fundada en 1919), extendió con el tiempo sus objetivos al ámbito civil y se convirtió en inspiración de la EF y de la evolución del 
perfil de sus docentes. Prueba de ello fueron las diversas promociones de profesores de EF que salieron de sus aulas y cuyo perfil exclusivamente masculino, en estos años anteriores al régimen (1936), mostraba un planteamiento prioritariamente anatómico del ejercicio físico y de su enfoque metodológico, junto con un objetivo finalmente ético y patriótico (Pastor Pradillo, 2004a).

Aunque la EF desde esta orientación castrense resultaba eficaz para el mundo militar, definió un perfil muy ambiguo para la EF civil, no facilitando demasiado el desarrollo profesional del profesorado de EF. No obstante, también es necesario reconocer la labor desarrollada por el ejército para sentar las bases de unos rasgos que fueron forjando el carácter docente del profesorado de EF, más allá del perfil meramente militarista; asentando rasgos como la vocación formadora, así como la tecnificación y capacitación para saber hacer uso del ejercicio físico como instrumento transmisor de valores, haciendo resurgir el cuerpo de las últimas posiciones a las que la educación le había relegado.

En este momento inmediatamente anterior al estallido de la guerra civil y de la llegada del régimen, se hicieron más intensas las reivindicaciones de disciplinas como la medicina y la educación, quienes reclamaban para sí el regreso de la EF y también de su carácter civil (Pastor Pradillo, 2002), que parecía monopolizado por el sistema castrense, quien planteaba la disciplina desde un currículum eminentemente anatómicofisiológico, exigiendo como requisito a los candidatos haber cursado algunas asignaturas de la carrera de medicina. (López Fernández, 2002).

La línea formativa de referencia era del tipo biomédica, siendo la higiene y la salud la principal fundamentación de la formación de profesorado de EF en este periodo republicano. Pero en consonancia con el carácter liberal del momento político, se empiezan a atisbar objetivos sociales y pedagógicos, buscando asentar un modelo formativo del profesorado contrario al militarizado influyente e imperante hasta el momento. Su recorrido y desarrollo será breve (no hubo ninguna promoción saliente) debido al estallido de la Guerra Civil y al proyecto que desarrollará posteriormente el 
régimen franquista sobre la $\mathrm{EF}$, su misión, utilidad, planteamiento ideológico y formativo.

\subsubsection{La función y los valores de la EF del régimen franquista}

Con el fin de la Guerra Civil, los sectores políticos del bando nacional se integran en lo que se denominó el Movimiento Nacional. De ellos, a la Falange Española (a través de la Delegación Nacional de Educación Física y Deportes, creada a través de Decreto de 22 de febrero de 1941) le fueron concedidas las competencias y el control de la EF y el deporte, dada su tradición de gestión del ocio y la recreación en contextos educativos formales y no formales. Así, la EF se proyecta desde un movimiento político y se evidencia en ella el carácter ideológico que la configura.

A los sectores cercanos a la Iglesia Católica se les cedió el control del Ministerio de Educación y la educación reglada. De esta forma el adoctrinamiento de las nuevas generaciones quedaba perfectamente asegurado siendo la Falange Española Tradicional (FET) y las Juntas de Ofensiva Nacional Socialista (JONS), a través de sus diferentes Delegaciones Nacionales (Frente de Juventudes, Sección Femenina o Delegación Nacional de Deportes). Estos se harían cargo de las diferentes situaciones y contextos de la educación física, desbaratando definitivamente los niveles de avance en lo educativo alcanzados hasta el momento.

Son las delegaciones nacionales del Frente de Juventudes y de la Sección Femenina a quienes se confía la EF, en los ámbitos formal y no formal, para hacer de ella el "aparato pedagógico del franquismo" (Escolano, 2010), con el fin de impulsar la ideología y valores del régimen y con ellos la reconstrucción nacional y la cohesión social. Son dichas delegaciones y movimientos políticos quienes aprobarán los planes para el desarrollo de la EF y los ejecutarán en el ámbito de sus correspondientes jurisdicciones, aunque sea el Ministerio de Educación Nacional quien se reserva la competencia de dictar las normas necesarias para facilitar el diseño y el desarrollo de tales planes, conforme establecía la Ley 77/1961 de 23 de diciembre de EF. 
La EF se proyecta desde el régimen a partir de un nuevo replanteamiento de ejercicio físico para un doble fin: para la misión individual de preservar y salvar el alma y para la misión católica como nación en el mundo.

En este sentido, los grandes valores que se la atribuyen permanecen, para diversos sectores durante los cuarenta años de existencia del franquismo, fundamentándose en la versión ética de la raza hispánica, la versión dualista de la educación integral el servicio de la actividad física hacia la espiritualidad de las personas y la instrumentalización de la EF para forjar el carácter de la juventud y para transmitir actitudes cívicas, patrióticas y políticas. La EF se alinea así con los valores de nación imperantes en el momento y se convierte en una de las piezas claves para el control ideológico de la sociedad.

Tanto el Frente de Juventudes como la Sección Femenina, competentes en la EF escolar, crean en virtud del Decreto de 2 de septiembre de 1941, las Academias Nacionales "José Antonio" (ANJA) (masculina) e "Isabel La Católica" (femenina) con el fin de formar inicialmente, no tanto a perfiles docentes de EF, sino más bien a mandos o instructores de juventudes (López Fernández, 2002), definiendo un perfil técnico con algunas características y competencias peculiares (Pastor Pradillo, 2004a) como:

- Utiliza un método que permita vincular la EF al movimiento espiritual hispánico que se persigue.

- No busca profesionalizarse pues se alejaría de la auténtica misión orientadora de valores espirituales de la $\mathrm{EF}$.

- Hace uso de la gimnasia sueca como modelo metodológico de actividad física.

- No busca su especialización deportiva, pues la verdadera EF que se requiere no exalta algunos valores contrarios al régimen como la excesiva pasionalidad de algunos deportes.

- Asume un perfil que promueve un modelo de EF sacrificado y ascético aunque adornado de un estilo estético del movimiento. 
- Promueve ser ejemplo de formación moral, política y religiosa.

Más adelante se evolucionó hacia un replanteamiento de la formación impartida por la ANJA para la instrucción de instructores y mandos, para acercarse a la titulación oficial de maestro de primera enseñanza. Es así como se crea la Escuela de Magisterio "Miguel Blasco Vitela", adscrita a la Escuela Normal de Magisterio "Pablo Montesino", egresando de ellas maestros con el título de primera enseñanza con la especialidad de EF expedido por el Ministerio de Educación y la Secretaría General del Movimiento.

En 1961 se reconoce a la ANJA como la entidad competente para expedir directamente el título de profesor de EF. Para el sector femenino, las alumnas de la Escuela Nacional "Isabel la Católica" se adscribirán a partir de 1958 en la Escuela Nacional de Especialidades "Julio Ruiz de Alda" al crearse dentro de ella las Escuela Nacional de Educación Física Femenina.

El profesorado de EF es preparado técnicamente para destilar política en su práctica diaria como funcionarios al servicio del Movimiento. Su selección y desarrollo profesional dependerá definitivamente del Movimiento y de la Delegación Nacional, conformándole como uno de los colectivos más activos del régimen (Contreras,1992). $\mathrm{Su}$ formación técnica se enmarca en el modelo gimnástico neosueco, con mayor peso de los aspectos biomédicos, higiénicos, militaristas que los educativos y atravesada por los ideales y valores políticos del régimen.

Es a partir de la Ley de Educación Física de 1961, que confirma la existencia de las escuelas de formación del profesorado de EF, cuando se establece también la creación de una nueva escuela para dotar al profesorado de una titulación específica para la impartición de la disciplina, naciendo en 1963 mediante Decreto 1321/1963 de 3 de junio, el Instituto Nacional de Educación Física (INEF). 
La formación inicial de maestros cuenta también con preparación para la impartición de la EF escolar en todos los planes de estudios durante este periodo (Planes de 1942, 1945 y 1950). Su preparación se fundamentaba en el desarrollo de contenidos sobre teoría de la EF, anatomía y fisiología, juegos y deportes, teniendo cierto protagonismo la fase práctica de la formación, debido en gran medida al planteamiento higiénico de la EF aunque enmascarando verdaderamente un ideario político que configura al maestro como uno de los principales valedores propagandísticos de los valores e ideales de la España Nacional-Católica (Contreras, 1992).

El ejercicio de enlazar la EF con la política y la ideología suponía buscar el perfecto perfil docente, moralmente formado, para llevar con naturalidad a los estudiantes, discípulos, hacia el diálogo, el ejemplo o la anécdota doctrinal, siendo él por su parte, modelo permanente del buen falangista.

Para ello la búsqueda de perfiles adecuados para tal misión requería de una selección cuidadosa desde el punto de vista de su formación política, moral y religiosa (Pastor Pradillo, 2000).

Más adelante, en los años 50, herencia de la importancia de la higiene y la moralidad imperante hasta el momento, se señalan dos puntales formativos sobre los que sostener las dos facetas física y moral del concepto de EF que todo docente ha de promover: la anatomía y fisiología por una parte y la psicología y la ética por otra, sin las cuales el docente de EF asumiría un rol de mero entrenador y practicante de especialidades físico-deportivas.

\subsubsection{De camino hacia la transición}

En este camino, el planteamiento político, aunque en esencia sigue siendo mantenedor de los ejes autoritarios del régimen, parece acercase a posiciones más 
tecnócratas, en las que aun apreciándose cierta neutralidad, no deja de seguir asentando el estado de la situación tal y como se venía fraguando desde el final de la Guerra Civil.

Tal evolución llega también a la educación, promoviéndose la Ley 14/1970 de 4 de agosto, General del Educación y Financiamiento de la Reforma Educativa, lo que trae consigo un modelo propio del perfil profesional del maestro de enseñanza primaria que se refleja en los nuevos planes de estudios que posteriormente se regularían mediante Decreto 1381/1972, de 25 de mayo, y que anteriormente pasarían por el proceso de integración de las Escuelas Normales en Escuelas Universitarias (Decreto 2498/1971, de 17 de septiembre). Pero no es hasta 1977 cuando entre las directrices para configurar los planes de estudios de las Escuelas Universitarias del Profesorado de Educación General Básica (EGB), aparece la Didáctica de la EF como materia común.

El profesorado de enseñanzas medias se formará en el INEF, quien establecerá desde su constitución un equilibrio formativo de tipo técnico, científico y práctico, estableciendo cuatro itinerarios conducentes a la obtención de cuatro títulos: profesor de Educación Física y Deportes (cuatro años de formación), Instructor de Educación Física y Deportes (dos años de formación), Entrenador deportivo y Maestro-instructor en Educación Física (formación a través de un curso, para Maestros de Primera Enseñanza ya titulados).

\subsubsection{En Democracia}

En lo referente a la formación del profesorado de EF que iría a integrarse en el cuerpo de profesores de Educación General Básica (EGB), se observa una tendencia de acercamiento a posiciones más didácticas y pedagógicas (psicoeducativas) y menos anatómico-fisiológicas. Pero esta tendencia se fundamenta en la encrucijada política que a partir de 1976 se produce en España. Una inflexión que viene de la necesidad de caminar hacia un nuevo modelo sociopolítico democrático sin exclusiones y a través del cambio y la conciliación. Desde la transición hacia ese modelo y la fundación de un nuevo marco educativo, los urgentes retos que se abordan son la definición, el 
reconocimiento y la protección de los principios y valores esenciales para la educación, junto como el establecimiento de una estructura para su aplicación (Mayordomo Pérez, 2003).

Tales retos obligan a la exploración de caminos como la dotación al sistema educativo de una nueva orientación política, la adecuación de los proyectos a las necesidades, la puesta en evidencia de las esperanzas e inquietudes, el despliegue de nuevas prácticas profesionales, como base política plural y de consenso, para transitar en la búsqueda hacia un pacto escolar que permitan la construcción del marco jurídico de la educación, uno de los objetivos fundamentales a alcanzar en la transición hacia la democracia.

Este proceso democratizador va avanzando y recalando en la política de inversiones en educación para facilitar la escolarización, la gestión democrática de las instituciones, el nuevo estatus profesional docente y la introducción de nuevos principios pedagógicos facilitadores de la nueva convivencia, afianzándose a través de los Pactos de la Moncloa (MEC, 1979) de gran repercusión en política educativa. Esto trajo consigo en relación al espacio profesional docente, un nuevo estatus del profesorado, que ampara los derechos de asociación, expresión y reunión, así como la legalización de la participación sindical, la estabilidad del empleo y la reglamentación de la acceso a la función docente.

En paralelo, caben destacar importantes avances en el desarrollo profesional docente y en la nueva cultura que se va a ir desarrollando en las aulas. La influencia de los movimientos de renovación pedagógica, con la publicación de revistas especializadas y la inclusión de nuevos modelos formativos para el profesorado, van a ir evidenciando la inquietud hacia una nueva cultura docente. Reflexiva, colaborativa y con una vocación democrática, dicha cultura se muestra en consonancia con la nueva comprensión política de formación humana, expresada en clave de convivencia y virtudes éticas, en aras a abrazar un modelo de formación política plural que prepara a los jóvenes para el ejercicio de la ciudadanía democrática, tal y como se revela en la 
Orden Ministerial de 29 de noviembre de 1976 (MEC, 1976). Así, el profesorado, en una nueva cultura profesional emergente, se alinea con la necesidad de asumir una conducta y actitud que promuevan los valores fundamentales de la convivencia mediante la reflexión, el diálogo y la participación activa con el alumnado, según se proyecta en la Orden Ministerial de 30 de junio de 1977 (MEC, 1977).

Con la entrada en vigor de la Ley Orgánica General del Sistema Educativo (LOGSE) de 3 de octubre de 1990, y hasta la actualidad, se desarrolla un modelo de formación inicial del profesorado en el que se reivindica un perfil profesional del maestro de EF como mediador en el aprendizaje de su alumnado, lo que exige de un ejercicio docente comprometido y responsable con la sociedad y como profesional que reflexiona, investiga e innova para con su propia práctica (Gil Madrona, 1999).

La influencia desde los 70 de algunos movimientos pedagógicos en el profesorado en activo encuadrados en el paradigma de la indagación orientada o crítico (Anguita, 1997), han podido contribuir a sembrar de nuevas perspectivas didácticas y pedagógicas el planteamiento de la EF escolar, su utilidad, métodos y el advenimiento de un perfil profesional docente más cualificado.

En lo que al perfil del egresado de INEF se refiere, el instituto, con centros en Madrid y Barcelona, experimenta una reformulación del título y del currículo activada mediante Real Decreto 790/1981, cuyo plan de estudios común para ambas sedes aprobado por Orden de 20 de julio de 1981, válido también para la nueva sede de Granada en funcionamiento a partir de 1982, incorpora una orientación clara hacia el ejercicio docente como salida profesional, con aproximaciones a la figura de entrenador mediante las maestrías en especialidades deportivas.

Desde 1987, con la creación del INEF de Galicia, León, Las Palmas y La Coruña, y ya a partir de su plan de estudios, se comienzan a explorar otros perfiles profesionales no docentes como el de gestor deportivo o técnico de alto rendimiento. La orientación de la formación inicial de titulados en EF planteada en INEF evoluciona 
desde modelos higiénico-médicos, hasta modelos más didácticos, recreativos, de rendimiento y de gestión, para trascender la tendencia exclusiva hacia la docencia de la EF, allanando el camino también a nuevos campos profesionales y yacimientos de empleo tendentes a la orientación de la EF hacia la salud o hacia la recreación (López Fernández, 2002).

\subsubsection{Enfoques competenciales en la tradición de la Formación Inicial del profesorado de EF}

A partir del análisis de la cultura profesional del profesorado de EF y de los acontecimientos históricos que fueron marcando su carácter, podríamos reconocer (aunque a veces no en estado puro) los diferentes enfoques pedagógicos que se fueron aplicando a la formación inicial del profesorado de EF reconstruyendo su tradición formativa. Se observan esencialmente cuatro modelos formativos (Fraile 2004b; Fraile, 2018; Romero-Cerezo, 2004) que desarrollamos a continuación: (1) el modelo tradicional, (2) el modelo técnico, (3) el modelo de formación hacia la práctica y

finalmente, (4) el modelo social-reconstruccionista desde los que podemos establecer un paralelismo entre cada una de estas tradiciones formativas y su particular visión competencial profesional subyacente (figura 3.5). 


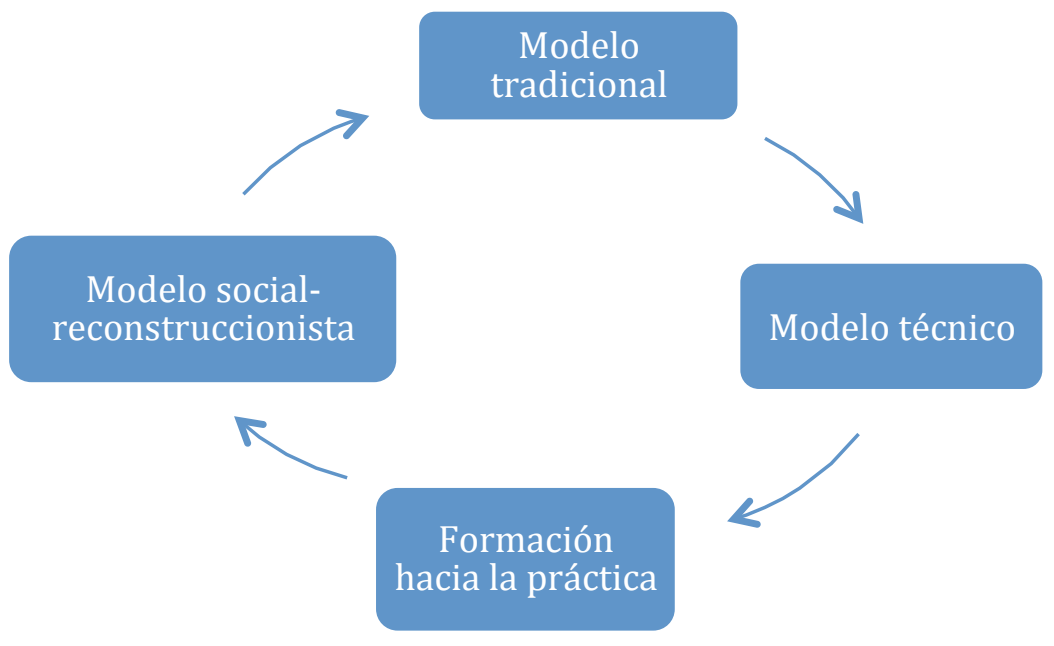

Figura 3. 5. Modelos formativos en la formación del profesorado de Educación Física en España (Fraile, 2004b; Fraile, 2018; Romero-Cerezo, 2004)

\subsubsection{El modelo tradicional (o academicista)}

Partiendo de una visión empírica y analítica de búsqueda de la verdad, el modelo academicista se fundamenta en un planteamiento basado en el conocimiento científico como elemento base para entender y describir la realidad (Aguerrondo, 2009). Pretende formar desde el conocimiento científico para que el futuro docente se enfrente a la realidad del aula, siendo el aprendizaje de los conocimientos para su transmisión posterior su principal cometido (Fraile, 2004b). De esta forma, el docente de EF, en su práctica profesional, va a tener un referente científico claro desde el que comparar su praxis de aula y desde donde observar si es o no eficaz en la transmisión del conocimiento a su alumnado.

Ejercer competentemente desde esta perspectiva, pasa por convertirse en experto en descubrir la teoría de la EF para después pedir la reproducción exacta de lo anteriormente informado. Se es más eficaz si se consiguen altas cotas de reproducción de lo transmitido. El profesorado se preocupa de poner a prueba, desde su dominio intelectual del conocimiento científico, el saber del alumnado, observando así su propia eficacia profesional y la adecuación entre original y reproducción. Las competencias que dominan el modelo son puramente academicistas, teóricas y fundamentadas en el 
conocimiento a transmitir. A mayores conocimientos mayor sensación de competencia y eficacia profesional.

De cara al estudiante, el docente prima más el ejercicio de reproducir que el de comprender, dando por verdad que existe alineamiento entre reproducir y comprender si lo que se reproduce es lo que se espera y se transmitió con anterioridad. Así, si el alumnado se alinea intelectualmente con el profesorado y sus exigencias académicas, se alcanzará el logro para ambos y, por tanto, el docente podría llegar a la conclusión de que su desempeño ha sido efectivamente exitoso.

Este modelo formativo busca que los docentes puedan transmitir conocimientos científicos y culturales desde el área de EF a los estudiantes para dotarlos de una formación centrada en el dominio de conceptos y estructuras disciplinares, haciendo uso de una metodología directiva y asumiendo los docentes un rol de mediador entre el alumnado y los conocimientos a informar (Fraile, 2018). Los contenidos (prescritos inicialmente) no se contextualizan y su reproducción mediante una prueba de evaluación final, son el único garante de su aprendizaje y comprensión.

La fase de prácticas formativas se plantea desde una perspectiva finalista, siempre que la fase teórica de la disciplina esté superada, admitiendo que los estudiantes ya disponen del suficiente bagaje teórico como para abordar la realidad del aula que el proceso de prácticas favorece. Este planteamiento formativo finalista adolece de la posibilidad de contrastar la experiencia con los conocimientos teóricos, estableciendo dos estancias formativas contiguas pero inconexas y no desarrollando cauces de reflexión que permitan contribuir a resolver los problemas derivados de la práctica en el aula.

\subsubsection{El modelo técnico}

El enfoque formativo basado en la sociedad del conocimiento se redefine agregándole una connotación activa. Aun partiendo de la base empírica desde la que entender y explicar la ciencia, se apunta hacia un planteamiento más operativo sobre la 
realidad, esto es, resolver problemas. Desde este planteamiento, se forman docentes de EF preparados para la resolución eficaz de problemáticas del área a partir del dominio de las competencias propias y específicas de la EF (conocimientos, habilidades y destrezas).

De esta manera, los futuros docentes, tras los aprendizajes derivados del periodo formativo inicial, deberían ser capaces de demostrar los conocimientos y habilidades adquiridas, dominar la materia a enseñar y las estrategias psicopedagógicas y metodológicas a emplear y su saber hacer en la praxis diaria de aula.

La mecanización desde la repetición de estas capacidades le hacen competente para desarrollar su tarea de enseñar desde la exclusividad de su materia, para gestionar desde ella su aula o para seleccionar recursos óptimos que apoyen el proceso de enseñanza-aprendizaje que lidera. Los futuros docentes se convierten en reproductores de capacidades, estrategias, habilidades, destrezas o métodos que dominan los expertos a los que se otorga el perfil de docente-modelo a seguir y que imparten sus disciplinas en los centros de formación del profesorado. En ningún momento se cuestionan si la diversidad de capacidades, destrezas, habilidades o métodos aprendidos y listos para reproducir, son los más adecuados a sus características personales y profesionales, a las del alumnado en los centros educativos o a los múltiples contextos en donde se irá a ejercer en el futuro (Romero-Cerezo, 2004).

La eficacia de su tarea se evidenciará a través del feedback que establezca entre el rendimiento del alumnado y la enseñanza desarrollada, de manera que se observará más competente cuanto mejores resultados obtenga su alumnado y mayor número de evidencias encuentre a partir de las evidencias reproducidas. Desde esta perspectiva, ser competente supone reproducir los conocimientos, técnicas y estrategias específicas aprendidas a lo largo de la formación para re-exponiéndolas en la práctica, intentar resolver cuantos problemas surgen durante la misma.

La finalidad del modelo formativo se relaciona con el dominio de la competencia motriz para, una vez instruido, transmitirla de nuevo en diferentes 
contextos educativos. Es por ello que los contenidos relacionados con las bases anatómicas y fisiológicas o el aprendizaje motor son prioritarios para el asentamiento de las bases formativas de los futuros docentes. A modo de crítica se ponía en tela de juicio la capacidad del profesorado de programar conocimientos más allá de los motrices, ya que planteamientos formativos tecnicistas no suelen considerar tratamientos transversales como la educación en valores o interdisciplinares como los aprendizajes resultado de la colaboración entre distintas áreas del currículum (Tinning, 1992).

Son conocidas en España ciertas propuestas técnico-didácticas (Sánchez Bañuelos, 1984) que revelan algunas variables propias de este modelo formativo, que ayudan a optimizar el proceso mecanizado de formación y por tanto contribuyen a la máxima eficacia en la tarea docente:

- Dominio y control de los tiempos para captar la atención del alumnado, su disposición y organización en las sesiones.

- El manejo de las situaciones de interacción y de feedback en los diferentes momentos del desarrollo de las sesiones, obteniendo suficiente información como para distinguir al alumnado más apto y menos apto.

- La garantía de la optimización de los aprendizajes mediante el control del tiempo realmente útil de las sesiones.

\subsubsection{El modelo de formación hacia la práctica}

Se posiciona en el panorama formativo como una alternativa al modelo tradicional, encaminando su fin y sentido hacia la formación práctica. Se dirige desde la tradición simbólica e interpretativa hacia la descripción e interpretación de los fenómenos sociales experimentados a partir de la comprensión, la significación y la acción. Desde la realidad educativa, este modelo formativo, que se basa en la tradición interpretativa, tiene como fin último hacer inteligible la acción, descubriendo y describiendo sus significados dentro del propio contexto socio-educativo en el que tiene lugar. Es por eso que el perfil de profesorado subyacente al modelo es considerado 
como un profesional investigador en el aula, para el que la indagación, la reflexión y la autocrítica han de ser capacidades referentes para su práctica de aula (Fraile, 2004a; Stenhouse, 1984).

Se busca en la formación del futuro docente optimizar sus capacidades de pensamiento, reflexión y resolución de problemas, transcendiendo la acción rutinaria para alcanzar la acción creativa (Fraile, 2004b). Supone para el ejercicio profesional la posibilidad de pensar en clave de excelencia y no de suficiencia, lo que supone ser competente ejerciendo de forma excelente las responsabilidades y tareas propias de su puesto de trabajo dentro de la organización escolar.

Se considera al docente como un profesional que piensa y decide sobre las situaciones de enseñanza que desarrolla; la conducta que pone de manifiesto está influida y determinada por los procesos de pensamiento y reflexión que desarrolla (García Ruso, 2003; 2004).

Así, en este modelo formativo, se observa un enfoque alternativo a la visión tradicional de la figura del docente de EF que domina el arte de enseñar como máxima expresión de su práctica. De esta forma se apuesta por un punto de vista reflexivo y creativo que en la formación inicial vaya asentando los cimientos de un perfil docente que piensa, siente, escucha, dialoga, contrasta y ejerce la crítica. Esto le convierte en un agente de cambio social que le posiciona en el aula desde la investigación y la acción. También le orienta a actuar en favor de los intereses humanos y sociales, vivir su praxis en comunidad y de forma colaborativa para trascender el individualismo, hacer del pensamiento divergente y creativo el motor para la construcción de nuevas ideas e interactuar con el alumnado de su contexto valorando la diversidad (Imbernón, 1994; Romero-Cerezo, 2004).

De esta manera, el futuro profesorado de EF puede ser ayudado en su formación inicial a superar el planteamiento técnico y rutinario de su ejercicio profesional para alcanzar un estadio más creativo, reflexivo, innovador, cooperativo y funcional que le 
permita analizar los problemas y establecer estrategias adecuadas para su resolución, enfrentándose con versatilidad a la realidad compleja y cambiante del aula en la que va a ejercer su profesión y adecuando sus aportaciones y soluciones, desde el propio juicio y criterio personal fruto de la indagación constante de su propia acción.

\subsubsection{El modelo social-transformativo}

A partir de este modelo, se busca formar a los estudiantes para que puedan atender en un futuro, en el ejercicio de su profesión, a una sociedad diversa e inmersa en la desigualdad social. Para ello han de adoptar una visión contextualizada, situada, crítica, reivindicativa y posicionada en favor de los grupos sociales más desfavorecidos y con mayores necesidades socio-educativas, para contribuir a su inclusión y para garantizar su no discriminación.

Desde una posición crítica (Freire, 1978, 1990, 1998; Giroux, 1983; Pascual, 2000) se define el objeto final de la educación como la formación de las personas para transformar la sociedad en un lugar más equilibrado y justo, priorizando las soluciones ideológicas, prácticas y creativas que permiten repensar y realizar los cambios personales y sociales necesarios para alcanzar una esfera de convivencia y prosperidad mejor para todos, más en clave de compromiso ético y de contextualización social y cultural, que puramente academicista transmisora de conocimientos. Estos avances se irán cristalizando en modelos de tercera vía para el cambio educativo, en donde la responsabilidad del liderazgo educativo también recae sobre el profesorado, participando en redes profesionales que ayudan al desarrollo profesional y a la motivación para ser agentes de cambio también (Giddens, 1998, 2001, 2004).

Reconocer, experimentar y reflexionar sobre el contexto de vida social, política y económica permite aterrizar en la realidad social y de aula para contribuir, mediante una práctica docente crítica, empática y democrática, a la mejora de las condiciones de aprendizaje del alumnado procedente de diversidad de situaciones, contextos y orígenes. 
Entre las características de la tradición crítica, reconstructiva y transformadora que se encuentran en el núcleo de este modelo formativo (Carr y Kemmis, 1988; Giroux, 1990; McLaren, 1995) y por la que se intenta comprender la relación entre los valores, los intereses y las acciones que están presentes en las prácticas educativas, destacamos:

- Localiza las situaciones sociopolíticas que no permiten alcanzar los objetivos educativos.

- El docente puede ser capaz de desvirtuar y cuestionar los planteamientos educativos sancionados oficialmente, confrontando los esquemas dominantes.

- El docente se posiciona como un intelectual que reflexiona y es capaz de transformar su praxis en pro de la búsqueda del empoderamiento de la capacidad crítica de los estudiantes.

- Se hace uso de la crítica para que los estudiantes alcancen a vislumbrar las problemáticas sociales.

- El punto de partida es una visión dialéctica de la realidad.

- Pretende desarrollar un pensamiento autorreflexivo a partir de la conexión entre la teoría y la práctica, lo que supone un saber a un nivel superior, más allá del saber tradicional, un saber que integra el conocimiento con su puesta en práctica (Aguerrondo, 2009).

- Busca la autonomía del sujeto para desde ella poder desarrollar la construcción social de este como ciudadano.

- Busca compensar las desigualdades atendiendo a la diversidad y ofreciendo oportunidades para todos.

Todo este constructo exige por tanto al futuro docente salir del "yo" frente al "ellos", para alcanzar el "nosotros" (Goleman, 2006) imprescindible en toda tendencia empática activa y desde la que trabajar en favor de los intereses y necesidades educativas del alumnado.

Tal ejercicio es una interesante aproximación a la representación de las competencias transversales del docente (González y Wagenaar, 2003) en su fase de formación inicial. Algunas son de especial interés como la apreciación de la diversidad 
y de la multiculturalidad, la capacidad de trabajo en equipo con grupos diversos, el espíritu de liderazgo, el reconocimiento de considerar las relaciones interpersonales en la interacciones diarias de aula, el desarrollo del espíritu crítico y autocrítico durante el ejercicio indagador sobre la propia practica, la capacidad de comunicación verbal y no verbal, la capacidad para generar ideas nuevas y resolver problemas o la apreciación de otras culturas y costumbres (Yániz, 2008).

Sin duda, todas ellas confluyen en un aspecto esencial previo para poder manejarlas y desarrollarlas: la autonomía en el aprendizaje, o "la capacidad para tomar decisiones que permitan al estudiante regular su propio aprendizaje para aproximarlo a una meta determinada dentro de su contexto de aprendizaje" (Monereo, 2001, p. 12). Esta base requiere prepararlo para que sea consciente de la realidad en la que vive y en la que ejercerá su profesión, de las decisiones que toma, de los conocimientos y valores que pone en juego y del modo que necesita para afrontar las dificultades que se encuentra (Villardón-Gallego, 2015).

Se presentan algunas capacidades básicas que permiten desarrollar la autonomía para el aprendizaje y que llevan consigo implicaciones para el ejercicio docente (Monereo y Pozo, 2003) (tabla 3.4). 
Tabla 3.4

Capacidades básicas que facilitan el desarrollo de la autonomía para el aprendizaje (Monereo y Pozo, 2003)

\section{Capacidades}

Consideraciones esenciales

\begin{tabular}{ll}
\hline Capacidad de pensar & $\begin{array}{l}\text { Requiere de la capacidad de reflexión, aspecto a contener en } \\
\text { el núcleo de las actividades de aprendizaje a desarrollar en la } \\
\text { formación. }\end{array}$
\end{tabular}

Capacidad de comunicar

Se detiene en la argumentación para avalar las posiciones, convencer o informar, acciones presentes en las actividades de aprendizaje en la educación superior.

\begin{tabular}{ll}
\hline Capacidad de cooperar & $\begin{array}{l}\text { Requiere de la gestión del conocimiento contrastándolo con } \\
\text { los demás. }\end{array}$ \\
\hline Capacidad de empatizar & $\begin{array}{l}\text { Faculta para gestionar las propias emociones coordinándolas } \\
\text { con las de los demás. }\end{array}$ \\
\hline Capacidad de crítica & $\begin{array}{l}\text { Construye el propio punto de vista desde fuentes de } \\
\text { conocimiento diversas y plurales. }\end{array}$ \\
\hline Capacidad para automotivarse & $\begin{array}{l}\text { Consigue que el carácter externo de la motivación se } \\
\text { interiorice, logrando que el motor del aprendizaje y de toda } \\
\text { actividad se aloje en la propia persona. }\end{array}$ \\
\hline
\end{tabular}

Este planteamiento competencial situacional, supone descubrirse en situación para construir y deconstruir los conocimientos. El ejercicio competente en este sentido va más allá de la aplicación de conocimientos a una situación; supone ser capaz de organizar la actividad docente adaptándose a las características de la situación en virtud de la experiencia y la práctica personal y profesional. Conocer y experimentar la profesión docente desde diversos contextos y ser capaz de adaptar el ejercicio profesional a estos constituye, en esencia, el desarrollo dinámico de cada competencia, haciendo posible que a través de la actividad y de su revisión reflexiva e indagatoria el futuro docente sea capaz de ir construyendo sus propias competencias (Jonnaert, Barrette, Masciotra y Yaya, 2008).

El docente de EF, desde este planteamiento formativo, aprenderá a hacer uso de una didáctica más flexible y diversa. Sabrá partir de un alumnado dispar, con intereses, necesidades, capacidades diferentes y cambiantes, para configurarse como un profesional sensible con la realidad del alumnado y con sus problemas, reflexivo, crítico, innovador y audaz para plantear nuevas ideas, nuevas fórmulas de intervención 
socioeducativa, nuevos métodos, y nuevas prácticas de EF que contribuyan a mejorar la calidad de las vidas del alumnado con el que interviene.

De esta manera deberá ejercer, desde un modelo de enseñanza comprometida ante las situaciones problemáticas, una práctica que lleve consigo el cambio, la mejora, la reconstrucción posible de la realidad y el posicionamiento personal y profesional efectivo ante ello (Fraile, 2004b).

Esta perspectiva supone un golpe crítico al planteamiento puramente academicista o tecnicista de las funciones docentes, poniendo en alza un modelo de desarrollo profesional que pasa por reivindicar la investigación desde la acción, la reflexión y la autocrítica sobre la praxis o contemplar la posibilidad de cambiar de rumbo en el propio ejercicio profesional, en función de la realidad educativa cambiante a la que nos podamos enfrentar. Y esto trasciende al modelo formativo tradicional que prepara futuros docentes académicamente brillantes, dignificando con ello el perfil de un profesorado de EF que también ejerce como agente transmisor de valores positivos como el juego limpio, la ayuda mutua, la igualdad, la colaboración para alcanzar objetivos comunes, la cesión en pro del bien común, la paz y en definitiva valores personales y grupales que ponen en relación a la persona con la vivencia de su propio cuerpo con los demás y con la realidad (Velázquez Buendía, 2013), viviendo y haciendo experimentar valores transformativos para una sociedad más democrática y justa.

Finalmente, es necesario entender que las tradiciones de formación inicial del profesorado que han influido en la formación del profesorado de EF en España, no se excluyen unas de otras. Por el contrario, lejos de una visión parcelada, un espíritu de complementariedad (Fraile, 2004b) en los planes formativos es enormemente ventajoso pues de él depende la optimización de los instrumentos formativos de cada una de ellas, para poder ofrecer un mejor y enriquecedor proceso de enseñanza y aprendizaje para los futuros docentes. Las situaciones diversas y cambiantes del aula, han de ser abordadas por el profesorado de EF apoyándose en los elementos característicos de cada una para poder ejercer más eficazmente. 


\subsection{Las competencias genéricas o transversales en la formación del profesorado de}

Educación Física

Como se ha ido mostrando, desde la Convergencia de Bolonia en 1999 y la creación del EEES, el sentido formativo de los estudios universitarios se ve atravesado por una visión utilitarista desde la que enfrentarse al mundo del trabajo, tomando como ejes vertebradores de los procesos formativos iniciales, las competencias y las habilidades. Así, una red de competencias específicas y transversales, se extiende en las titulaciones universitarias en el contexto europeo, para posibilitar la empleabilidad a los estudiantes y facilitar su tránsito al mundo del trabajo (González y Wagenaar, 2003).

Las competencias específicas son siguiendo a Tobón (2005) aquellas consideradas como propias para el desarrollo de una determinada profesión. Su elevado nivel de especialización requiere de la puesta en marcha de programas formativos específicos y técnicos para su adquisición y desarrollo.

Por su parte, las competencias transversales o genéricas, presentes en todos los planes formativos y al ejercicio de cualquier profesión, incluyen un conjunto de habilidades cognitivas, capacidades y actitudes consideradas inestimables por la sociedad el conocimiento y caracterizando la forma de actuar de las personas en su desempeño profesional y personal (Corominas, 2001; González Maura y González Tirado, 2008; Villardón-Gallego, 2015).

Se diversifican en tres grupos (González y Wagenaar, 2003; Rodriguez y Vieira, 2009): (1) instrumentales; (2) interpersonales; (3) sistémicas. Las habilidades, capacidades y actitudes que las estructuran se espera sean integradas en las materias formativas de cada titulación universitaria junto con sus conocimientos y destrezas específicas, garantizando su adquisición y ayudando en su desarrollo. Estos tipos aparecen expresados en el Real Decreto 1393/2007 que regula la ordenación de las enseñanzas universitarias oficiales en España. 
Que los estudiantes hayan desarrollado aquellas habilidades de aprendizaje necesarias para emprender estudios posteriores con un alto grado de autonomía"; “[...] puedan transmitir información, ideas, problemas y soluciones a un público tanto especializado como no especializado"; "[...] posean habilidades de aprendizaje que les permitan continuar estudiando de un modo que habrá de ser en gran medida autónomo”; “[...] sepan aplicar sus conocimientos y enfrentarse a la complejidad de formular juicios, incluir reflexiones sobre responsabilidades sociales y éticas vinculadas a la aplicación de sus conocimientos y juicios”; “[...] sepan aplicar los conocimientos adquiridos y su capacidad de resolución de problemas en entornos nuevos o poco conocidos dentro de contextos más amplios (multidisciplinares) relacionados con su área de estudio (p.2021).

Para Armengol, Castro, Jariot, Massot y Sala (2011) en relación al ejercicio docente, las competencias genéricas o transversales se estructuran también en tres bloques, instrumentales, emocionales y sociales. Para el manejo de competencias instrumentales se espera en los estudiantes que dominen y promuevan los conocimientos y habilidades necesarias para poder llevar a la práctica su ejercicio docente; entre ellas destacan capacidades como la de análisis y síntesis de la información, la expresión de las ideas con claridad, el dominio tecnológico aplicado al sector educativo y la innovación metodológica y de evaluación.

Para el desarrollo de las emocionales, se espera que los estudiantes consigan regular para el ejercicio de la docencia la dimensión afectiva. Entre ellas destacan capacidades como la regulación emocional en las relaciones profesionales, la adaptación flexible y superación de situaciones estresantes y adversas y el reconocimiento de las limitaciones y confianza en las fortalezas propias.

Finalmente, para el manejo de las competencias sociales (Le Boterf, 2001), el saber ser profesional, se espera consigan aprender a cooperar entre sí, aplicando la comunicación y el entendimiento para gestionar conjuntamente, con sus compañeros, los problemas y retos que se les presentan. Tal es el caso de capacidades como el trabajo en equipo, el compromiso ético, la búsqueda y aportación de soluciones alternativas a 
los retos que se plantean en el ejercicio docente así como la capacidad de iniciativa personal.

Bunk (1994) considera que las competencias transversales facilitan desarrollar aspectos metodológicos como la capacidad de transferir a la práctica los conocimientos y habilidades aprendidos; aspectos sociales, para la comunicación y la interacción social $\mathrm{y}$ aspectos de colaboración grupal, participativos, para tomar decisiones y asumir responsabilidades.

Delors (1996) y Villardón-Gallego (2015) apuntan a la trascendencia de la formación de habilidades generales en la universidad para facilitar la empleabilidad, la movilidad y la adaptación a distintos entornos laborales, como requisito esencial para saber afrontar los cambios en el mercado laboral. Los Libros Blancos de los títulos de Grado MEPEF y CAFyD (ANECA, 2005a, 2005b) que orientan el desarrollo de los planes formativos para las universidades, contienen diversas competencias transversales.

Se resumen a continuación tras la comparativa realizada las competencias transversales que son comunes en ambos títulos (tabla 3.5). 
Tabla 3.5

Presencia de las competencias en los títulos de Grado MEPEF y CAFyD (Libros

Blancos, ANECA, 2005a, 2005b)

Grupo de Competencias

Libros Blancos de los títulos de Grado MEPEF y CAFyD

(ANECA 2005a, 2005b)

\begin{tabular}{|c|c|}
\hline \multirow{8}{*}{ INSTRUMENTALES } & Organización y planificación \\
\hline & Comunicación oral y escrita en lengua materna \\
\hline & Toma de decisiones \\
\hline & Resolución de problemas \\
\hline & Análisis y síntesis \\
\hline & Gestión de la información \\
\hline & Conocimientos de informática aplicados a la especialidad \\
\hline & Conocimiento de una lengua extranjera (LE) \\
\hline \multirow{7}{*}{ INTERPERSONALES } & Trabajo en equipo \\
\hline & Habilidades en las relaciones interpersonales \\
\hline & Reconocimiento a la diversidad y a la multiculturalidad \\
\hline & Compromiso ético \\
\hline & Trabajo en un equipo de carácter interdisciplinar \\
\hline & Razonamiento crítico \\
\hline & Trabajo en un contexto internacional \\
\hline \multirow{8}{*}{ SISTÉMICAS } & Adaptación a situaciones nuevas \\
\hline & Iniciativa y espíritu emprendedor \\
\hline & Creatividad \\
\hline & Motivación por la calidad \\
\hline & Aprendizaje autónomo \\
\hline & Sensibilidad hacia temas medioambientales \\
\hline & Conocimientos de otras culturas y costumbres \\
\hline & Liderazgo \\
\hline
\end{tabular}

La concreción de las competencias profesionales en los planes formativos de las titulaciones conducentes al ejercicio profesional de la EF, en cada una de las universidades del territorio nacional se realiza en virtud de la verificación que realiza la ANECA (agencia adscrita al Ministerio competente en materia de Educación), a través de su programa "Verifica" http://www.aneca.es/Programas-deevaluacion/VERIFICA/Verificacion-de-Grado-y-Master). 
Las universidades pueden presentar ante la ANECA las memorias de verificación de sus títulos a fin de ser aprobados y validados por esta, para lo cual deberán recoger aspectos como: 1) la descripción del título; 2) la justificación; 3) competencias a desarrollar; 4) acceso y admisión de los estudiantes; 5) planificación de las enseñanzas (denominación, créditos ECTS, tipos de asignaturas, temporalidad, competencias e indicadores competenciales o resultados de aprendizaje, actividades y metodología, sistemas de evaluación y resumen de los contenidos); 6) recursos y materiales; 7) resultados esperados; 8) gestión de la calidad; 9) calendario de implantación. Una vez aprobada la titulación, cada guía docente de cada materia contendrá estos aspectos mostrando coherencia así con la memoria de verificación

La tipificación de competencias transversales presentes en los Libros Blancos, se recoge también en los "verificas" de cada plan de estudios de las titulaciones MEPEF y CAFyD de las facultades de origen de los estudiantes participantes en este estudio (facultades MEPEF de Albacete Barcelona, Córdoba, Granada, Madrid, Murcia, Santander, Segovia, Sevilla, Tenerife, Valencia y Valladolid; facultades CAFyD de Huesca, León, Murcia, Sevilla, Vic y Vitoria). A continuación se presentan de forma sintetizada las competencias instrumentales, interpersonales y sistémicas presentes en los "verificas" de las titulaciones analizadas, correspondientes a los grados MEPEF y CAFyD de las facultades mencionadas, así como la frecuencia de repetición de cada una de ellas.

El estudio realizado muestra la presencia, para el caso de las facultades MEPEF, de diecisiete competencias transversales de las que ocho son instrumentales, seis interpersonales y tres sistémicas presentes en catorce grupos de asignaturas comunes (tabla 3.6), siendo las más presentes en las materias a cursar la toma de decisiones, la resolución de problemas y el trabajo en equipo. 
Tabla 3.6

Presencia de las competencias transversales en los "verifica" del título de Grado MEPEF (en las 12 facultades de Educación analizadas)

Bloque de competencias

Competencias

Frecuencia

\begin{tabular}{|c|c|c|}
\hline \multirow{8}{*}{ INSTRUMENTALES } & Toma de decisiones & 13 \\
\hline & Resolución de problemas & 11 \\
\hline & Gestión de la información & 4 \\
\hline & Análisis y síntesis & 3 \\
\hline & Organización y planificación & 3 \\
\hline & $\begin{array}{l}\text { Conocimientos de informática relaticos al } \\
\text { ámbito de estudio }\end{array}$ & 3 \\
\hline & $\begin{array}{l}\text { Comunicación oral y escrita en lengua } \\
\text { materna }\end{array}$ & 1 \\
\hline & Conocimiento de una LE & 1 \\
\hline \multirow{6}{*}{ INTERPERSONALES } & Trabajo en equipo & 14 \\
\hline & $\begin{array}{l}\text { Reconocimiento de la diversidad y la } \\
\text { multiculturalidad }\end{array}$ & 3 \\
\hline & Sensibilidad hacia temas medioambientales & 3 \\
\hline & Habilidades en las relaciones interpersonales & 1 \\
\hline & Trabajo en equipo de carácter interdisciplinar & 1 \\
\hline & Compromiso ético & 1 \\
\hline \multirow{3}{*}{ SISTÉMICAS } & Creatividad & 2 \\
\hline & Adaptación a situaciones nuevas & 1 \\
\hline & Conocimiento de otras culturas y costumbres & 1 \\
\hline
\end{tabular}

Para los verificas del segundo grupo de facultades (CAFyD) (tabla 3.7), se reconocen once competencias transversales, de las que tres son instrumentales e interpersonales respectivamente y cinco son sistémicas presentes en treinta y tres grupos de materias. En relación a su frecuencia se observa que el análisis y síntesis y el trabajo en equipo son dos de las más repetidas. 
Tabla 3.7

Presencia de las competencias transversales en los "verifica" del título de Grado $C A F y D$ (en las 7 facultades CAFyD analizadas)

Bloque de competencias

Competencias

Frecuencia

- Desarrollar y mostrar en su aplicación una alta capacidad de análisis y de síntesis de la información relativa al campo de conocimiento y profesional

- Gestionar con eficacia y eficiencia la información procedente de diferentes fuentes integrando sus aspectos relevantes para el cumplimiento de los objetivos propuestos

- Resolver con eficacia y eficiencia problemas inherentes a su campo de conocimiento y profesional utilizando estrategias y técnicas adecuadas $\mathrm{y}$, si procede, innovadoras

- Mostrar disposición y habilidad para el trabajo en equipo

- Transmitir información, ideas, problemas y soluciones a un público tanto especializado como no especializado

INTERPERSONALES - Adoptar y mostrar una actitud favorable a la búsqueda de la calidad en el desempeño de sus funciones profesionales, sea cual sea su ámbito de acción e intervención, incluyendo un alto nivel sistemático de reflexión crítica sobre su propia práctica profesional.

- Desarrollar habilidades y estrategias que incidan en la capacidad para trabajar en forma autónoma.

- Organizar y planificar propuestas de acción, programas y actividades propias de su campo profesional en sus diferentes ámbitos de aplicación y desarrollo

- Ajustar las propias capacidades, los recursos y SISTÉMICAS condiciones del entorno para adaptarse a nuevas situaciones en las que debe aplicar conocimientos $\mathrm{y}$ habilidades profesionales.

- Aplicar los conocimientos adquiridos en los procesos de formación en la práctica profesional, en diferentes contextos y situaciones

- Mostrar capacidad de aprender nuevos conocimientos y habilidades a lo largo de su vida profesional y personal. 
Todo indica que el enfoque competencial en la formación del profesorado de EF estaría más presente y diversificado en la titulación MEPEF, aunque el trabajo en equipo sería una competencia común y altamente presente en las dos titulaciones.

Son diversos los estudios que muestran la percepción del grado de desarrollo de las competencias genéricas en los estudiantes de formación del profesorado coincidiendo en mostrar una acusada diferencia entre el mínimo desarrollo a partir de la formación cursada de competencias instrumentales, especialmente para los casos del conocimiento de una LE y de informática aplicada al ámbito de estudio y un desarrollo superior para aquellas de tipo interpersonal como el trabajo en equipo y las habilidades para las relaciones interpersonales (Álvarez, Iglesias y García, 2008; ANECA, 2005b; ANECA, 2007; Conchado y Carot, 2013; Gallardo, 2006; Gutiérrez, Hortigüela, Peral y Pérez-Pueyo, 2018; Marín-Díaz et al., 2010; Martínez y González, 2019; Michavila, Martínez, Martín-González, García-Peñalvo y Cruz-Benito, 2018; Pazo-Haro y TejadaMora, 2012; Romero et al., 2017). Dada la presencia de esta brecha en la literatura, se decide en el contexto de estudio de esta tesis, profundizar en este fenómeno a fin de buscar respuestas que ayuden a fortalecer a futuro su desarrollo competencial en la formación superior.

\subsubsection{Competencias Instrumentales}

La presencia de las competencias del tipo instrumental en la formación inicial del profesorado de EF permite garantizar aquellas de corte metodológico, ayudando a planificar las acciones y controlar los tiempos. Adquiere especial relevancia para el ámbito de la EF, ya que los aprendizajes dispuestos hacia el alumnado lo son en base a un espacio distinto al convencional (cancha deportiva, patio escolar) y un tiempo a controlar y manejar, tomando decisiones y resolviendo problemas en este escenario (Blázquez, 2016).

Pero especialmente son de interés para este estudio las competencias conocimiento y utilización de las tecnologías de la información y comunicación (TIC) 
aplicadas al ámbito de la EF (por ejemplo manejo de herramientas tecnológicas y aplicaciones (App), empleadas durante el proceso de enseñanza y aprendizaje en EF) y también el conocimiento de una LE, que permite interactuar en contextos internacionales, manejar documentación en distintos idiomas, así como afrontar los nuevos contextos escolares bilingües de inserción profesional (Area, 2004; Villa y Poblete, 2007).

\subsubsection{Conocimientos de informática aplicada al ámbito de la EF}

Se aborda esta competencia revisando diferentes aspectos que la conceptualizan y caracterizan, su presencia en la FIPEF examinando las dimensiones que han de formar parte de la formación básica para su desarrollo, explorando además los principales estudios que dan cuenta de su desarrollo formativo en la percepción del estudiantado de EF y de su importancia en el contexto profesional. Así mismo se abordan diversas metodologías que presumiblemente facilitan su adquisición y desarrollo. Se pretende así dar cuenta de los aspectos más importantes que forman parte del desarrollo de la competencia tecnológica, buscando respuestas en los planteamientos formativos frecuentemente desarrollados para indagar en qué medida ayudan a su adquisición y desarrollo.

\subsection{Conceptualización}

En la actualidad, la presencia de la tecnología en la sociedad ha cambiado absolutamente la percepción de la comunicación entre las personas. La tecnología es la palanca necesaria para desarrollar las transformaciones en el mundo contemporáneo. Además la globalización y los cambios económicos han acelerado la incorporación del manejo de tales tecnologías al ámbito formativo. Su presencia permanente ha desatado una revolución en todas las dimensiones humanas, cambiando estilos de vida, generando nuevas relaciones, y estableciendo una nueva forma de pensar y de conocer el mundo (Arias, Torres y Yáñez, 2014; Carneiro, Toscano y Díaz, 2009; Cózar y Roblizo, 2014). 
De acuerdo con Kelly (2005), todo lo que se ha creado e inventado es tecnología, viviendo en un ecosistema tecnológico en donde se ha naturalizado el uso de lo creado hasta extenderlo a todas las facetas de la vida.

La tecnología es la forma de explorar las posibilidades que la humanidad se da a sí misma para, diversificándose, socializándose y expandiéndose, explorar los límites de su propia existencia; forma parte de nuestro camino evolutivo permitiendo descubrir quienes somos y mejorar la propia presencia en el mundo.

En los últimos años se ha producido un gran auge en la literatura científica donde se ha debatido sobre la forma de incorporación de la tecnología al ámbito educativo. A pesar de los importantes avances que se han conseguido en Europa, tal y como se señala alguno de los Informes Eurydice (2004), también se muestran algunas lagunas en los efectos que se esperaban, pues son numerosos los casos en los que se introdujeron las tecnologías, aunque haciéndolas convivir con planteamientos metodológicos y curriculares tradicionales.

Balanskat, Blamire y Kefala (2006), Maroto Sánchez (2007) y Teo, Chai, Hung y Lee (2008) consideran en este sentido que la introducción de la tecnología en la educación ha tenido más bien un carácter marginal, pues no ha conseguido contribuir de forma socioconstructivista tanto como se esperaba a la generación de los aprendizajes y su consumo masivo se ha producido más fuera de los contextos educativos que dentro. Este aspecto también es recogido por García, Gros y Escofet (2012) quienes observaron entre los estudiantes universitarios encuestados una percepción de uso de la tecnología más en clave comunicativa, de relación y lúdica en ámbitos extra académicos.

Los estudios de Monedero Moya (1999), Cabero (2003), Raposo Rivas (2004) y Ferreres (2016) manifiestan el sentir del profesorado de EF en activo y del estudiantado en formación en relación a su competencia digital. En este sentido (1) realizan un 
manejo técnico básico y un uso más en domicilio que en el centro educativo, pero con poca formación para su incorporación a los procesos de enseñanza y aprendizaje y mucha menos para la producción de medios; (2) su uso es mínimo en el aula, tan solo para la presentación de contenidos; además depende de la predisposición e iniciativa del docente o de las condiciones meteorológicas; (3) su aplicación con el alumnado solo se relaciona con la orientación para la búsqueda de información; (4) su grado de manejo técnico varía en función de la novedad de la tecnología que se incorpora al mercado; (5) su edad es un factor de preocupación en relación al interés por la incorporación de las herramientas TIC a la tarea docente, a menor edad mayor preocupación por su incorporación.

Diversas investigaciones sobre capacitación digital del profesorado (Llorente, 2008; Maroto Sánchez, 2007; McVee, Bailey y Shanahan, 2008; Prendes, Castañeda y Gutiérrez, 2010; Raposo-Rivas, Fuentes y González, 2006; Tello y Aguaded, 2009) revelan el olvido de la incorporación en su formación de las dimensiones didáctica y pedagógica, estando más presente en todo caso la formación para el manejo técnico instrumental. Esto se aprecia en una mayor atención en la formación superior en el conocimiento y manejo de herramientas informáticas tradicionales para la elaboración y presentación de productos académicos (procesadores de textos del tipo Word, Excel; presentaciones visuales del tipo Power Point y Prezi; uso de correo electrónico), lentos avances paralelamente en el uso para la docencia (Zempoalteca, Barragán, González y Guzmán, 2017) o en el uso en forma de herramientas electrónicas y software específicos para trabajar en equipo virtual (Google docs) (Arias et al., 2014).

En este sentido, y de acuerdo con Zabalza (2011), es todavía escaso el impacto transformador que ha supuesto la introducción en las aulas universitarias de los medios tecnológicos clásicos (vídeo, proyectores, fotografía). Aunque parece facilitan mucho la transmisión de la información, no han mostrado apenas poder de transformación del modelo y del rol docente, ya que su uso generalmente se ha planteado y sigue planteándose más en clave de trasmisión directa de la información a través de la magistralidad, lo que revela un modelo formativo en la formación del profesorado 
todavía transaccional más que interactivo, incluyendo a demás de la presentación de la información también la evaluación.

Algunas de estos aspectos mencionados están detrás de las percepciones tan ínfimas que los estudiantes en su formación inicial consideran en relación a la formación recibida para el desarrollo de esta competencia (Carot et al., 2011; SarcedaGorgoso y Rodicio-García, 2018). No obstante, en otros casos se considera suficiente, en cuanto se aporta una idea general no de forma pormenorizada pero si básica como para conocer algunas herramientas didácticas o sistemas de comunicación personal y virtual en situaciones individuales y colectivas (González et al., 2010).

La educación del alumnado del siglo XXI requiere por tanto de la capacitación del profesorado para la ocupación de nuevos roles docentes que, lejos de ser ya la única fuente del conocimiento, ocupa ahora un papel más bien de mediador para presentar los contenidos, ser guía y orientador, investigador o tutor virtual (Goodyear, Salmon, Spector, Steeples y Tickner, 2001). Así, la competencia digital del docente se ha convertido en una valiosa herramienta que requiere de formación y actualización constante, considerando para ello el dominio de diversas áreas de la competencia digital como las presentes en el modelo noruego presentado por Krumsvik (2008), en donde el docente se ha de formar en tres niveles: (1) formación digital básica (uso de herramientas TIC, capacidad de búsqueda de información y manejo tecnológico); (2) posibilidades del uso didáctico de las TIC; (3) uso para el autoaprendizaje permanente.

Por ello, la formación para el desarrollo didáctico de la competencia digital en el profesorado ha de abordar aspectos tales como el uso de las TIC aplicadas a su área de conocimiento o disciplina, la vinculación del uso de las TIC en diferentes espacios educativos y manejo de las TIC para la planificación y organización del aula (Cebrián de la Serna, 2003). Por su parte, Martínez (2002) considera necesaria además la incorporación a la formación digital de una actitud y aptitud intercultural, puesto que en el mundo global la forma de comunicación entre emisores y receptores se produce en espacios distintos y entre culturas distintas. 
Consiguientemente, siguiendo a Resta y Semenov (2004), se condensan a continuación los aspectos metodológicos que se han de incorporar al desarrollo de la formación de la competencia digital en la capacitación del profesorado (Tabla 3.8). Es destacable el valor de la reflexión y el debate como aspectos de evaluación formativa cuyo valor está presente en técnicas como la autoevaluación y la coevaluación (Hamodi, 2015), que permiten el desarrollo de la competencia digital de forma responsable pensando en su aplicación en el ejercicio profesional futuro.

Tabla 3.8

Aspectos metodológicos que han de estar presentes en la capacitación tecnológica docente (Resta y Semenov, 2004)

\section{Incorporaciones metodológicas para la formación docente}

(1) Las posibilidades de desempeño profesional fundamentadas en el conocimiento y las habilidades sobre su disciplina, han de ser la base sobre las que incorporar la tecnología para su desarrollo, y no tanto en el uso de los hardware y software descontextualizados de la especialización disciplina

(2) Se requiere de contar con los recursos TIC necesarios y el tiempo de exploración de las posibilidades didácticas que entrañan

(3) Son necesarios los tiempos de reflexión y debate sobre las posibilidades para el aprendizaje que revelan las experiencias con el uso de las TIC aplicadas a la propia disciplina, así como sus posibilidades para la construcción de nuevos escenarios de aprendizaje

(4) Es imprescindible considerar que no hay un solo nivel de desarrollo en el manejo de las TIC aplicadas a la educación, sino que existen diversos niveles que van reclutando diversas capacidades, en virtud de las necesidades que se van abordando

(5) Resulta esencial presentar las TIC como herramientas para el cambio educativo, facilitando que las intervenciones docentes se produzcan desde otros enfoques más ricos e interactivos en beneficio del alumnado

Además, el desarrollo competencial digital en la formación inicial del profesorado no solo requiere del establecimiento de los contenidos y los procedimientos metodológicos en dicha formación, sino también de los aspectos que han de ser considerados como mínimos para evaluar el grado de adquisición y desarrollo formativo de la competencia digital. Un ejemplo de sistematización de estándares para la verificación del desarrollo competencial digital en la formación del profesorado es el que propone la Sociedad Internacional para la Tecnología Educativa (Llorente, 2008), 
que estableció una organización de bloques de estándares para dar cuenta de la incorporación y desarrollo de la tecnología en la práctica docente.

- Conoce la tecnología y la usa adaptándose a las circunstancias docentes mediante su uso.

- Diseña y planifica entornos de aprendizaje haciendo uso de recursos tecnológicos (creación de escenarios pedagógicos asistidos por la tecnología para atender las necesidades de su alumnado; localización e incorporación de nuevos recursos tecnológicos considerados como útiles para el aprendizaje de su alumnado; previsión de los recursos tecnológicos necesarios a incorporar a las actividades de aprendizaje.

- Aplica de forma didáctica la tecnología para facilitar los aprendizajes de su alumnado (abordando tecnológicamente los contenidos disciplinares, empleando la tecnología para aplicar métodos, activos, centrados en el alumno y favoreciendo su uso creativo).

- Evalúa los aprendizajes haciendo uso de recursos tecnológicos.

- Aumenta su productividad pedagógica a partir del uso de herramientas tecnológicas (toma de decisiones, reflexiona mejor sobre su práctica para mejorar, aprende de forma continua, se comunica con colegas, madres y padres).

- Usa la tecnología intencionalmente también para el desarrollo de adaptaciones curriculares y para ejemplificar ante su alumnado la utilización ética de la misma.

A pesar de los esfuerzos investigadores y formativos por difundir la necesidad de capacitación digital en los programas de formación de maestros en España, algunos estudios como los de Cózar, Hernández, Hernández, De Moya y Guerrero (2002) y Cózar y Roblizo (2014) manifiestan que la competencia digital ha quedado parcialmente relegada a un tratamiento transversal en algunas materias. Este hecho se ha agudizado tras la frecuente desaparición de asignaturas especializadas de diversos programas formativos de las titulaciones del Grado de Maestro, quizá por la libertad de las instituciones universitarias para el diseño de la formación (no obstante se mantienen algunas asignaturas que aún orientan específicamente en la competencia digital). En el 
estudio de Cózar y Roblizo (2014) los estudiantes encuestados responden, ante la pregunta sobre la formación recibida a lo largo de sus estudios para el desarrollo de su competencia digital, con "muy poco "y "nada" en un $65 \%$ de los encuestados, aunque su actitud hacia la incorporación a su formación y utilidad presente y futura es bastante positiva .

\subsection{Competencia digital en la formación del profesorado de Educación Física}

La importancia de desarrollar la competencia digital en la FIPEF es reconocida tanto por los profesionales en ejercicio como por los propios estudiantes, tal y como ya se mostró en los trabajos de Centeno y Cubo (2013) y ya antes Fernández, Hinojo y Aznar (2002) en los que los estudiantes encuestados reconocían las posibilidades tecnológicas para el desarrollo de los conocimientos, aunque en relación a la formación inicial recibida, una mayoría común percibía que era insuficiente. Consecuentemente respecto a la necesidad de formarse, los estudiantes reconocían necesitar una capacitación más específica, mostrando una importante disposición para ello (70\%).

En el mismo sentido también concluyeron Raposo-Rivas et al. (2006) al comprobar cómo los estudiantes de EF en magisterio encuestados percibían que las materias teórico-prácticas cursadas ofrecían poca o ninguna aportación tecnológica vinculadas al ámbito educativo, reconociendo además que ya se portaba un bagaje tecnológico e informático básico que se aplicaba en los ámbitos personales y académicos, como también mostraron Pino y Soto (2010). Contrariamente San Nicolás, Vargas y Area (2012) mostraron resultados más favorables hacia la adquisición y dominio de la competencia digital en la percepción de los estudiantes encuestados a partir de la formación cursada.

Por su parte Romero et al. (2017) mostraron moderadas valoraciones de los estudiantes de EF encuestados en relación a sus conocimientos de informática aplicados a la disciplina, tras los estudios cursados, siendo los estudiantes de EF en magisterio los 
que obtuvieron comparativamente valoraciones más altas que los estudiantes de $\mathrm{EF}$ en CAFyD.

Desde el Proyecto Tuning (González y Wagenaar, 2003) y los Libros Blancos de los títulos de grado MEPEF y CAFyD (ANECA, 2005a; 2005b) se insta a la formación de los estudiantes de EF en las competencias digitales (tabla 3.9). Se muestran a continuación las competencias recogidas y a desarrollar en este sentido en los documentos mencionados.

Tabla 3.9

Tratamiento de la competencia digital presente en el Proyecto Tunning y Libros Blancos de los títulos de Grado MEPEF y CAFyD (ANECA, 2005a, 2005b)

\section{Competencia Digital}

Capacidad para utilizar TIC (e-learning) e integrarlas en entornos de aprendizaje.

Habilidades básicas de manejo de ordenador.

Habilidades para buscar, procesar y analizar información procedente de fuentes diversas.
Documento de origen

Proyecto TUNING

Proyecto TUNING

Proyecto TUNING

Conocer los campos temáticos de interrelación de las ciencias con las otras áreas y en especial en aspectos de educación tecnológica, educación para la salud y educación medioambiental.

Sólida formación científico-cultural $\mathrm{y}$ tecnológica.

ANECA (Grado Magisterio)

Capacidad para utilizar e incorporar adecuadamente en las actividades de enseñanza-aprendizaje las TIC.

ANECA (Grado Magisterio)

Aplicar conocimientos básicos sobre las TIC y su aplicación a un contexto informativo actualizado a fin de conocer los avances de la educación física y el deporte.

Conocimientos de informática relativos al ámbito de estudio.

ANECA (Grado Magisterio)

Saber aplicar las TIC en el ámbito de las

Ciencias de la Actividad Física y del

Deporte.

ANECA (Grado Magisterio)

ANECA (Grado Magisterio) 
tecnológicas de aplicación al entorno formativo físico-deportivo. Siguiendo a Arévalo (2007), la tecnología aplicada a la formación en el sector se diversifica en dos orientaciones. Una primera aplicada a la EF de forma directa, esto es, al uso de herramientas, App, dispositivos móviles a utilizar en el ámbito educativo (Castellano y Casamichana, 2014; Del Castillo, Herrero, García, Checa y Monjelat, 2012; Dorado y Gewerc, 2017; López, 2018).

Y una segunda perspectiva, que corresponde al aprovechamiento de las funciones de la informática convencional, internet, telecomunicaciones, crear y almacenar información, para compartir y comunicar datos, para presentar contenidos, crear nuevas perspectivas de uso pedagógico, medir resultados fisiológicos, en el ámbito de la actividad física y la salud (Atienza y Gómez-Gonzalvo, 2016; Casey, Goodyear y Armour, 2016, 2017; Molina, Valencia-Peris y Gómez-Gonzalvo, 2016; UsabiagaArruabarrena y Valencia-Peris, 2014).

La revista MIT Technoloy Review (2016) informaba de algunas de las tecnologías actualmente emergentes susceptibles de aplicar al ámbito educativo, como por ejemplo el desarrollo de interfaces para maximizar las posibilidades táctiles o del habla de los dispositivos tecnológicos, lo que implicaba la presencia y fácil normalización en el aula del uso de tablets, relojes inteligentes y dispositivos móviles. No obstante, la peculiaridad del área de EF, encargada de prestar una formación eminentemente práctica a través de la actividad físico-motriz en espacios abiertos, quizá haya sido una razón de peso, tal y como exponen Villacazán, Contreras y Villalba (2017), por la que las plataformas, entornos virtuales de aprendizaje, herramientas on line o App para gestionar el conocimiento, no hayan sido tan desarrolladas para el área. No obstante, por ejemplo, diversas tecnologías como el uso del videojuego, tipo exergames, parece que ya van siendo incorporadas paulatinamente para la dinamización tecnológica del área, permitiendo jugar con el movimiento corporal utilizando consolas y sensores para su desarrollo (Edison, Felipe y Giraldo, 2013) 
En el sector educativo físico-deportivo se comienzan a introducir también en las actividades de aula herramientas de medida y notificación de datos fisiológicos (pulsómetros), geolocalización a través de dispositivos móviles o instrumentos como Geocaching, Neoreader y códigos $Q R$ para las actividades deportivas de orientación en la naturaleza, el uso del vídeo para el trabajo de aspectos técnicos y tácticos del deporte o expresivo-corporales, herramientas digitales para la gestión del aula, presentación y desarrollo de contenidos curriculares, gestión de la evaluación, e-actividades (wikis), la comunicación y la interacción en red.

También el uso de dispositivos móviles y de dispositivos inteligentes personales disponiendo de internet a alta velocidad (m-learning), para acceder a espacios de aprendizaje en línea (e-learning) y entornos virtuales de aprendizaje colaborativa; en definitiva, instrumentos TIC que generan el nacimiento de nuevos escenarios pedagógicos, que buscan el aprovechamiento comunicativo, interactivo, informativo, cooperativo, creativo e innovador de la aplicación de tales herramientas tecnológicas para el aprendizaje (Arévalo, 2016; Caballero, Domínguez y Arjona, 2016; CastroLemus y Gómez, 2016; Monguillot, González, Guitert y Zurita, 2014; Pérez y Pérez, 2013; Quintero, Jiménez y Area, 2016, 2018)

Si lo que se pretende es transmitir y experimentar en los procesos de enseñanzaaprendizaje, conocimientos flexibles y adaptados a las necesidades de la sociedad, conformando éstos los cimientos competenciales en un marco de educación democrática (Fraile, 2004c, 2006a; Martínez, 2010), es lógico pensar que la competencia digital vaya estando cada vez más presente en cada una de las etapas formativas, dada su creciente importancia social, condicionando consecuentemente dichos procesos de enseñanzaaprendizaje. Es necesario por ello, pensando en la formación del profesorado de EF, contar con ciertos criterios que ordenen las decisiones sobre el uso tecnológico: (Arévalo, 2007), por ejemplo, (1) priorizando la práctica como base para el aprendizaje tecnológico (aprender haciendo); (2) decidiendo sobre las herramientas TIC que aplicadas al área de EF generen aprendizajes más profundos y más significativos pensando en la práctica de aula futura; (3) haciendo prevalecer la utilidad educativa de las herramientas a conocer y utilizar, más que sus virtudes propiamente tecnológicas. 
Por ello, el desarrollo de la competencia digital en la FIPEF requiere de la atención a dimensiones más allá del mero dominio de las herramientas tecnológicas que, como se ha detallado, son cada vez más numerosas y cambiantes con respecto a la velocidad de surgimiento de nuevas necesidades, problemáticas y demandas.

Por lo tanto, se apuesta por un modelo formativo de desarrollo de la competencia digital que requiere de la predisposición para expresarse y comunicar, generar producciones creativas y responsables, publicar, difundir y compartir la información generada, hacer uso de diversos soportes tecnológicos y dispositivos con diferentes lenguajes y formas, para aplicar al aula potenciando con ellos pedagogías emergentes que tengan en primer lugar al alumnado y su mejor aprendizaje (Adell y Castañeda, 2012; Arévalo, 2016; Gewerc, Montero, Pernas y Alonso, 2011).

En este sentido, Casey et al. $(2016,2017)$ se preocupan por que la comunidad de profesionales de la EF atienda en mejor medida a los aspectos pedagógicos de la enseñanza de la tecnología, buscando con ello co-construir, probar y evaluar nuevas formas de utilización de las TIC para optimizar el aprendizaje de los estudiantes en la FIPEF, optimizar la docencia del profesorado y desarrollar un mejor aprovechamiento en la propia acción de la EF de los recursos digitales susceptibles de aprender y aplicar (aprovechamiento en contexto), reflexionando sobre su uso y re-pensando sus posibilidades pedagógicas, compartiendo sus ventajas y discutiendo sobre los inconvenientes.

Estos aspectos sin duda hablan de un modelo formativo en el que la evaluación para su desarrollo se aproxima a sistemas formativos y compartidos, implicando a los estudiantes en los procesos evaluadores y que sin duda activan y hacen uso de la capacidad crítica, mejoran la autonomía personal y la responsabilidad para optar por las mejores opciones tecnológicas que explorar y usar en su práctica docente durante la formación (López-Pastor y Pérez-Pueyo, 2017). 
Considerando las recomendaciones del Proyecto DIGCOMP (Ferrari, 2013) para la formación de la competencia digital, los planteamientos de Area, Gutiérrez y Vidal (2012) para la alfabetización digital, junto con las propuestas de Krumsvik (2008) y Llorente (2008), se establecen las siguientes dimensiones (tabla 3.10) que deberían formar parte del proceso formativo para el desarrollo de la competencia digital susceptible de aplicar a la FIPEF.

Tabla 3.10

Dimensiones a considerar en la formación tecnológica (Arwa et al., 2012; Ferrari, 2013; Krumsvik, 2008; Llorente, 2008)

\section{Dimensión formativa de la Competencia Digital \\ Dimension formativa}

\begin{tabular}{|c|c|}
\hline \multirow{3}{*}{ Dimensión instrumental } & $\begin{array}{l}\text { - Saber utilizar los dispositivos y recursos digitales (hardware y } \\
\text { software) para identificar necesidades y problemas y aplicar } \\
\text { medidas de resolución creativas y eficaces }\end{array}$ \\
\hline & $\begin{array}{l}\text { - Considerar la disposición y uso de los dispositivos y recursos } \\
\text { digitales en función de su valor para la significatividad de los } \\
\text { aprendizajes de sus alumnos }\end{array}$ \\
\hline & $\begin{array}{l}\text { - Promover actividades de aprendizaje sin perder el carácter motriz } \\
\text { propio del área, cuyos soportes tecnológicos doten de mayor } \\
\text { riqueza y significatividad a los aprendizajes que se esperan se } \\
\text { desarrollen }\end{array}$ \\
\hline \multirow[t]{2}{*}{ Dimensión intelectual } & $\begin{array}{l}\text { - Saber buscar, seleccionar, comprender y evaluar la información } \\
\text { mediante el uso de recursos digitales, así como crear otra nueva a } \\
\text { partir de las búsquedas realizadas }\end{array}$ \\
\hline & $\begin{array}{l}\text { - Identificar las propias carencias digitales y buscar los recursos } \\
\text { para superarlas }\end{array}$ \\
\hline \multirow[t]{2}{*}{ Dimensión ética } & $\begin{array}{l}\text { - Adquirir e interiorizar, para transmitir, valores inspirados en el } \\
\text { compromiso ético cuando se hace uso de los recursos digitales. }\end{array}$ \\
\hline & - Proteger a las personas, a los datos y a los dispositivos \\
\hline \multirow{3}{*}{$\begin{array}{l}\text { Dimensión } \\
\text { comunicativa }\end{array}$} & $\begin{array}{l}\text { - Saber expresarse, comunicarse, } \\
\text { colaborativamente en los diversos entornos y escenarios virtuales }\end{array}$ \\
\hline & - Compartir e intercambiar información en beneficio mutuo \\
\hline & $\begin{array}{l}\text { - Crear escenarios pedagógicos asistidos por tecnología, para } \\
\text { favorecer el encuentro interactivo, la cooperación y la } \\
\text { comunicación }\end{array}$ \\
\hline Dimensión emocional & $\begin{array}{l}\text { - Aplicar el autocontrol emocional en el uso de los recursos } \\
\text { tecnológicos, priorizando la creación de relaciones positivas con } \\
\text { los usuarios de la Red }\end{array}$ \\
\hline
\end{tabular}

\section{Indicadores competenciales}

- Saber utilizar los dispositivos y recursos digitales (hardware y software) para identificar necesidades y problemas y aplicar digitales en función de su valor para la significatividad de los

- Promover actividades de aprendizaje sin perder el carácter motriz arrollen

- Saber buscar, seleccionar, comprender y evaluar la información 
Quintana (2000), en el mismo sentido, establece para la formación de la competencia tecnológica cuatro dimensiones susceptibles de poder ser desarrolladas en la capacitación docente. En la primera dimensión, instrumental, se prevé el desarrollo del conocimientos y uso de equipos informáticos convencionales, uso de software y programas para el procesamiento y presentación de la información. En la segunda, cognitiva, se desarrollan aspectos formativos relacionados con la selección y uso de la tecnología de impacto en el sector educativo. En la tercera, profesional, se avanza en el uso de los programas informáticos y las App para la gestión de las clases, el seguimiento y evaluación del alumnado, la gestión académica, la formación permanente y la participación en proyectos de innovación a nivel de centros educativos. Finalmente en la cuarta dimensión, didáctico-metodológica, se afrontan aspectos de creación de unidades de programación y actividades de aprendizaje que incorporen el uso de las TIC y su presencia cotidiana en el aula, para el desarrollo de los procesos de enseñanza y aprendizaje y para facilitar la comunicación, la expresión y acceso al currículum de todo el alumnado.

Especialmente la dimensión didáctico-metodológica es destacada por Carreiro da Costa (2006) considerando la necesidad de robustecerla en la FIPEF, precisamente por sus potencialidades didácticas para la creación de escenarios alternativos de aprendizaje en EF. Para ello insta al uso de los dispositivos y recursos multimedia y las posibilidades de internet. No obstante, este interés académico parece contrastar con el interés profesional del profesorado de $\mathrm{EF}$, que muestra un grado medio de interés en lo relacionado con la incorporación en los procesos de enseñanza y aprendizaje en el aula de la tecnología (Fernández Berrueco y Sánchez-Tarazaga, 2014).

Pero paradójicamente es precisamente esta preocupación y predisposición de uso didáctico, uno de los aspectos que valoran en positivo los estudiantes sobre sus docentes (Bullock, 2004). Ferreres (2016) informa que la preocupación de los docentes va siendo cada vez mayor, reconociendo y aceptando paulatinamente su integración como contenido transversal facilitador de la creación de mejores aprendizajes, aunque no se traduzca todavía en mayor uso pedagógico con su alumnado, debido fundamentalmente a la escasa capacitación para llevar a cabo esta integración. Además, Díaz Barahona 
(2012) considera que el profesorado de EF encuestado en su estudio muestra cierta inseguridad en el manejo de las TIC pensando que el alumnado está mucho más capacitado que él, lo que implica no hacer demasiado uso tecnológico en el aula.

García-Valcárcel y Martín del Pozo (2016) y Roblizo y Cózar (2015) muestran cómo los estudiantes encuestados para su estudio dicen conocer y utilizar durante su formación, la tecnología, esencialmente para la edición de textos y documentos y la creación de presentaciones visuales para realizar exposiciones orales: editores de texto, hojas de cálculo, creadores de presentaciones, programas de edición de imagen (Paint, PhotoShop, Gimp), vídeo (Windows media maker) y audio (Audacity, Nuendo), así como aquellas que favorecen la búsqueda de información en la red, redes sociales y mensajería electrónica. No obstante, reconocen, aunque sí las conocen, no haber utilizado durante la formación inicial herramientas especializadas para uso didáctico (códigos $Q R$, realidad aumentada como las App de geolocalización, editores de páginas web, webquest, cazatesoros, lifestreaming, Lectores RSS, plataformas y software educativos, gamificación). Entienden la preferencia por el uso de herramientas para la realización de presentaciones visuales, debido a la importancia que consideran tienen como apoyo visual para la comprensión de los contenidos en el aula así como para favorecer la motivación y la participación de su futuro alumnado.

Para Carrasco, Abraldes y Gómez (2012), por ejemplo, aprender a crear y manejar webquest desde la formación, conecta con la realidad profesional en tanto dota a los estudiantes de una herramienta de aplicabilidad a la realidad de las aulas, con la que diversificar las posibilidades de aprendizaje del alumnado desde la creación tecnológica.

Pero, en general, esta carencia práctica es verdaderamente significativa si atendemos a que los estudiantes encuestados lo son precisamente de formación del profesorado. Contrasta con la creciente relevancia de las TIC en la práctica profesional docente futura que pasará sin duda por el manejo de la tecnología aplicada a la docencia en situaciones de creación, evaluación y adaptación en relación a su práctica de aula 
(Prendes, Castañeda y Gutiérrez, 2010; Roig y Pascual, 2012; Romero, Gisbert y Carrera, 2009).

Laurillard (2002) encontró que la reducción del potencial pedagógico de las TIC en la formación universitaria se debía a la falta de práctica tecnológica del profesorado universitario, en cuya formación no estuvo presente la tecnología y, por tanto, su desarrollo en su práctica actual es lenta. Por su parte Mishra y Koehler (2006) mostraron que la velocidad de los cambios tecnológicos no favorece el aprendizaje lo suficientemente rápido del profesorado universitario; esto le impide mantenerse al día, conservando tan solo aquellos conocimientos y herramientas de uso cotidiano como los sistemas operativos y los sistemas de procesamiento de la información, aspecto que en el mejor de los casos incorporan a su práctica docente, perpetuando la dimensión instrumental de dicha formación en su alumnado.

Este hecho permite entender en parte las carencias formativas del profesorado de EF, mostrando un nivel básico en el uso de la tecnología (Almerich et al., 2005; Cabero y Llorente, 2006). En sus estudios se muestra que los hombres conocen y manejan a nivel de usuario normal el sistema operativo, los procesadores de texto, las hojas de cálculo, así como el uso de Internet para la búsqueda de información. Las mujeres presentan conocimientos a nivel de usuario normal en el manejo de procesadores de texto y hacen uso de Internet para buscar información y como fuente de comunicación.

En el mismo sentido, Gisbert, Espuny y González (2011) encontraron paralelamente que los estudiantes encuestados consideraban poseer conocimientos TIC iniciales básicos, de uso instrumental, adquiridos en su formación pasada o en su vida personal, con lo que no valoraban la insistencia sobre ellos. Más bien demandaban establecer nuevos espacios formativos en los que incorporar y aplicar estas o nuevas estrategias tecnológicas para facilitar su adquisición y desarrollo, o la solución a posibles lagunas que pudieran existir sobre su manejo y aplicabilidad de cara a su práctica docente futura. 
En relación a la formación recibida sobre el conocimiento y uso de aplicaciones y herramientas específicas, los estudios de García et al. (2012) y Gutiérrez, Palacios y Torrego (2010) establecen que, tanto los estudiantes hombres como las mujeres encuestadas, reconocen ciertos aprendizajes realizados (webquest, pizarras digitales, podcast) pero dudosas posibilidades de aplicación a la función docente. En esta línea se muestran también los resultados de Gabarda, Rodríguez y Moreno (2017) sobre la creación de contenidos digitales del estudiantado encuestado, mostrando un escaso desarrollo formativo como para ser capaces de crear contenidos digitales. En este sentido, Roblizo y Cózar (2015) mostraron cómo las estudiantes encuestadas para su estudio, hacían un mayor uso que los hombres de las herramientas tecnológicas básicas vinculadas a la realización de trabajos académicos.

También en relación a la formación recibida, la participación en el Practicum facilitó el aprendizaje y utilidad de las TIC en situaciones reales de ejercicio profesional (Sarceda-Gorgoso y Rodicio-García, 2018). Prat, Camerino y Coiduras (2014) encontraron que fue en la formación continua, durante el ejercicio profesional, en mayor medida que en la inicial en la que el profesorado de EF adquirió las competencias TIC y su aplicación al aula de EF, siendo esta formación por tanto la que mejor capacita para el manejo de las herramientas tecnológicas. Estos autores reconocen no obstante que la incorporación de las TIC al área de EF es relativamente reciente, tal es el ejemplo de la realidad aumentada, códigos $Q R$ para el desarrollo de las actividades físicas en la naturaleza (Castro-Lemus y Gómez, 2016).

No obstante, la actitud de los estudiantes hacia el aprendizaje y uso de las herramientas digitales educativas o aplicables a la gestión del área de EF es positiva y abierta a aprender y practicar, aunque se reconoce que la formación recibida es escasa, poco especializada, en ocasiones alejada de las demandas de la realidad escolar y escasamente aplicadas en las situaciones formativas durante los estudios cursados (Ortega, 1999; Ortega y Fuentes, 2003; Romero, et al., 2009). Este aspecto puede deberse, en opinión de Roig y Pascual (2012), a la percepción de los estudiantes de falta de conexión de las herramientas TIC aprendidas con respecto a la realidad docente futura. 
Contrariamente, en los trabajos de Blasco, Mengual y Roig (2011) con estudiantes de EF se observa que estos, tras la formación recibida tecnológica aprendida, se encuentran en su mayoría en las etapas de familiarización y confianza con ella y sus posibilidades didácticas considerando su validez y su productividad. Esto evidencia no solo el reconocimiento de la utilidad de las TIC aprendidas sino su valor de potencialidad pedagógica para su futuro como docentes (Morales, 2001).

\subsection{Metodologías que facilitan la adquisición y desarrollo de la competencia tecnológica}

En relación a la forma de adquirir la competencia tecnológica en la formación inicial del profesorado de EF, se reconoce que, tal y como plantean Romero et al. (2017), se suele realizar mediante la interacción con el profesorado que maneja las TIC y que transmite el conocimiento y la habilidad de uso de forma interactiva, buscando la participación activa y protagonista del estudiantado, tal y como apuntan también Hamodi, López-Pastor y López-Pastor (2015), lo que revela un modelo de evaluación formativa en el que los estudiantes también se implican construyendo su propio aprendizaje desde la acción.

Cózar y Roblizo (2014) también destacan el valor comunicativo que se establece entre el profesor y el estudiantado en favor de la adquisición de las TIC mientras se hace uso de ellas en las experiencias formativas. Sin duda se trata de la tendencia hacia la utilización de un modelo metodológico más activo, creativo, dialógico y lúdico (Ferrés y Piscitelli, 2012; McKeachie y Svinicki, 2006; Pessoa, Hernández y Muñoz, 2015), en el que la adquisición y desarrollo de la competencia tecnológica pasa por el protagonismo y papel crucial del estudiante, utilizando la tecnología en la propia acción y estando integrada en todo el programa de la materia impartida (Adams-Becker, Cummins, Davis, Hall-Giesinger y Ananthanarayanan, 2017; Cabero y Llorente, 2006). Este aspecto aparece valorado por los estudiantes de magisterio de todas las menciones encuestados (incluida EF) en el estudio de Morales, Trujillo y Raso (2015), destacando un $48 \%$ de ellos la necesidad de cambiar las metodologías tradicionales por otros 
procesos de enseñanza más activos y un 58\%, requiriendo adoptar en tales procesos, un papel más protagonista y responsable frente al aprendizaje y utilización de las TIC e indicando del profesorado, su participación más en un rol de orientador durante el proceso.

Esta demanda se debe posiblemente, tal y como señala Monguillot (2015), a la falta de cierta comprensión aún de la importancia de la tecnología en el hecho educativo, en donde lo nuclear no es la tecnología en sí misma, sino la metodología con la que manejarla en clave de aprovechamiento educativo, integrando con ella tanto el contenido curricular de la EF, el conocimiento de sus posibilidades pedagógicas y el conocimiento de la propia tecnología aplicada en situación. La EF es una disciplina que con el tiempo y buen hacer de sus profesionales, ha ido incorporando para su desempeño, metodologías activas, sin duda impulsoras de un verdadero desarrollo competencial de los estudiantes, sorteando la sedentarización del consumo tecnológico habitual en la sociedad, para incorporarle la riqueza de la movilidad, la presencialidad y la interactividad. No hay que olvidar que la EF es pedagogía motriz donde el aprendizaje se realiza haciendo y reflexionando sobre ello (Barahona, 2012).

Por ello se, entiende que para el desarrollo de la competencia tecnológica está prevista, en una gran mayoría de los planes formativos de las dos titulaciones de grado analizados, un tipo de asignatura que parece la específicamente directa para desarrollar los aprendizajes tecnológicos (su denominación no difiere demasiado en unos casos u otros: "Educación y TIC", "TICS aplicadas a la educación", "Recursos en educación y TIC", "Educación mediática y aplicaciones didácticas TIC", "Las TIC en el contexto organizativo e interactivo del centro escolar", "TIC para al actividad física y el deporte", "Nuevas tecnologías aplicadas a la actividad física y el deporte").

A partir del estudio realizado de las guías docentes de las materias dispuestas para la formación de la competencia tecnológica en las titulaciones MEPEF y CAFyD de las 19 facultades de procedencia de los participantes en este estudio (facultades MEPEF de Albacete Barcelona, Córdoba, Granada, Madrid, Murcia, Santander, 
Segovia, Sevilla, Tenerife, Valencia y Valladolid; facultades CAFyD de Huesca, León, Murcia, Sevilla, Vic y Vitoria), se observaron, en relación a los procedimientos metodológicos previstos en ellas, esencialmente dos fórmulas comunes: la presentación de los contenidos por parte del docente, en clave de clase magistral, conviviendo con métodos caracterizados por la participación del estudiante en el desarrollo de los contenidos tecnológicos y expresados en formas como el trabajo grupal (TG), el aprendizaje basado en problemas $(\mathrm{ABp})$ y proyectos $(\mathrm{ABP})$ o el estudio de casos (figura 3.6).

Esto evidencia una importante preocupación por los docentes por la participación e implicación activa de sus estudiantes, en el aprendizaje y uso de los contenidos tecnológicos objeto de estudio.

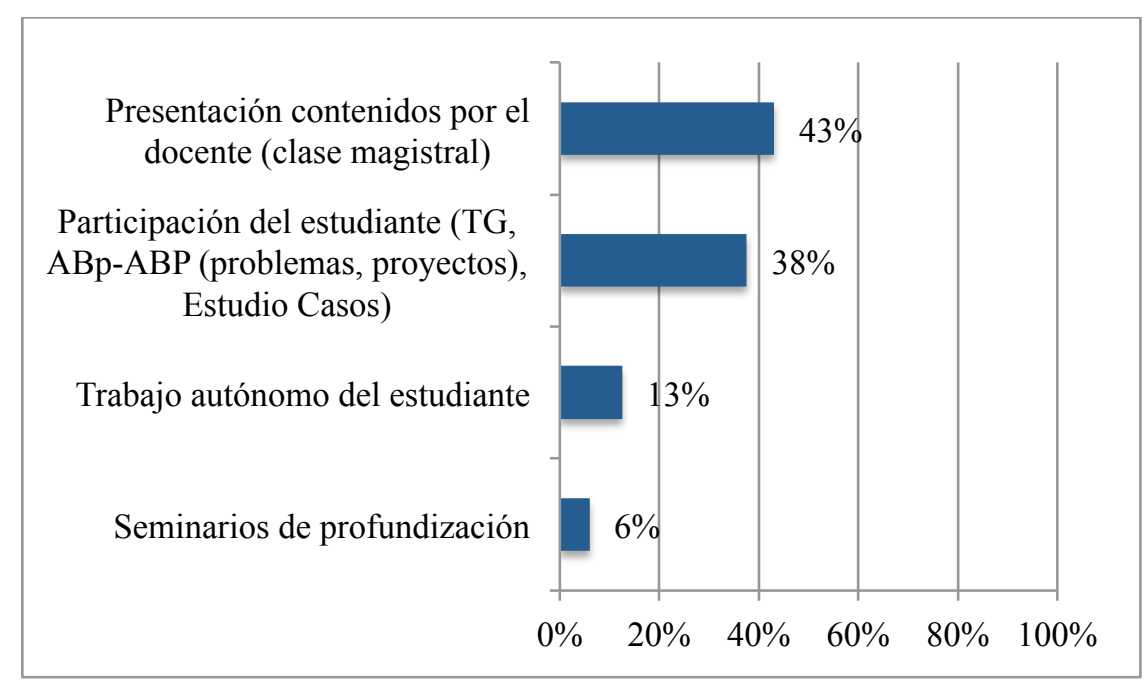

Figura 3. 6. Modelos metodológicos presentes en las guías docentes de las asignaturas tecnológicas en los planes formativos de los grados MEPEF y CAFyD

Barahona (2012) considera que se pueden aplicar algunas de las metodologías activas hoy más conocidas e innovadoras que impliquen la participación de los estudiantes, siendo susceptibles de utilizar activando el uso además de las herramientas TIC; tal es el caso del aprendizaje colaborativo mediante el desarrollo de TG, el ABp, el aprendizaje ubícuo y el estudio de casos. Así, Sosa y Palau (2018) proponen el uso del flipped classroom (FL) como la metodología que, invirtiendo el modelo tradicional de clase y haciendo uso del tiempo de aula para desarrollar aspectos experimentales y 
prácticos en el uso de la tecnología para un fin determinado, permita solventar problemas de forma interactiva, guiando el docente dicho proceso (Bergmann y Sams, 2012; Wanner y Palmer, 2015).

Se trata de un modelo de aprendizaje colaborativo cuya finalidad es el aprendizaje competencial real con los demás, en un escenario creado para favorecer además la responsabilidad personal y grupal, cambiando el rol de los estudiantes y del profesorado (Turón, Santiago y Díez, 2014). Un estudio reciente de Sargent y Casey (2019) reveló que el uso del FL entre el profesorado de EF en ejercicio optimizó el tiempo en el aula en el que su alumnado se mostraba más tiempo físicamente activo, siendo un método que apoya metodológicamente el desarrollo del proceso de enseñanza y aprendizaje.

Los resultados de algunas experiencias realizadas en la formación superior, avalan la idoneidad de este modelo formativo para el desarrollo de la competencia tecnológica de los estudiantes (Basso-Aranguiz, Bravo-Molina, Castro-Riquelme y Moraga-Contreras, 2018; Kong, 2015; Sosa y Palau, 2018; Zainuddin y Halili, 2016), siendo frecuente durante el desarrollo de tales experiencias, el aprendizaje y el uso de herramientas tecnológicas habituales en el ejercicio profesional docente, de creación y presentación de contenidos como MoviMaker, Google drive, Dropbox, Power Point, Prezi; de difusión del contenido como Wordpress; de búsqueda de información mediante Youtube; de comunicación como Gmail, Outlock, Facebook, Twitter, Whatsapp; de evaluación como Kahoot.

El ABp se apoya en el problema o en el reto (Perrenoud, 2012), como punto de partida para la adquisición, desarrollo y aplicación de competencias para su resolución (integrando los conocimientos y habilidades que se van aprendiendo), siendo los estudiantes desde un papel de profesionales activos y aplicando herramientas TIC, los que intentan resolverlo en un escenario de actividades auténticas y reales dentro y fuera del aula (Aristizábal y Cruz, 2018; Barrett, 2005; Barrows, 1986; Sagástegui, 2004). 
Se considera uno de los métodos del "aprendizaje situado" más eficaces para el desarrollo competencial, que toma como punto de partida que el conocimiento es situado y forma parte del contexto y su cultura y, por tanto, no puede despegarse de este, aprendiendo y haciendo en él más en el sentido del "cómo" que en el sentido del “qué", encontrando en la tecnología un apoyo cada más presente en la sociedad de la información y de la comunicación (Arévalo, 2016; De Vargas, 2006). En este sentido, Robledo, Fidalgo y Arias (2015) mostraron que el ABp es un método con gran potencial para estimular el desarrollo de competencias en los estudiantes en la formación superior, aunque especialmente el método de casos, para resolver problemas y situaciones dadas, correlacionaba de forma especialmente positiva con el desarrollo de la competencia tecnológica en la consideración de los estudiantes encuestados en su estudio.

De la misma manera y en clave situacional, destaca también el aprendizaje ubicuo y su relación directa con la tecnología, en cuanto posibilidad de acceder a la información en cualquier momento, circunstancia, necesidad o problemática a resolver; de forma que el aprendizaje pueda realizarse en diversos lugares y contextos tal y como se hace hoy en la vida real y además de forma continua a lo largo de la vida (Burbules, 2012). Para ello toma recursos tecnológicos, tutoriales de youtube, acceso a redes inalámbricas mediante telefonía móvil, realidad aumentada mediante útiles de geolocalización, dispositivos audiovisuales y redes sociales entre otros para hacer frente a los retos planteados. El mismo autor destaca en la relación tecnológica profesoradoestudiantes que lejos de distinguirse se complementan, comunican, aprenden conjuntamente, siendo la colaboración un potencial recurso para optimizar las aportaciones de ambos al proceso de aprendizaje.

Algunas experiencias didácticas realizadas con estudiantes de educación física que proponen el uso de herramientas tecnológicas audiovisuales o del tipo webquest, códigos $Q R$, App como Runkeeper y de realidad aumentada, redes sociales, en diversos entornos de aprendizaje planteados para la búsqueda de soluciones a problemas y retos (Aparicio, Fraile y Velasco, 2017; Gallego, Muñoz, Arribas y Rubia, 2016; Monguillot et al., 2014; Prat y Camerino, 2012), revelaron intensos y transferibles aprendizajes 
tecnológicos en climas de elevada motivación y satisfacción durante la realización de las tareas.

No obstante el uso de planteamientos metodológicos alternativos, activos, para favorecer el desarrollo tecnológico de los estudiantes en el contexto de la EF, pasa por reconocer, tal y como consideran Armour (2014), Casey et al. (2016, 2017) y, la consideración de un modelo pedagógico tecnológico que favorezca la conciencia crítica, la reflexión y el aprovechamiento formativo en el ámbito de especialización a fin de hacer las cosas de manera diferente haciendo uso de la tecnología, en lugar de hacer las misas cosas utilizando herramientas tecnológicas llamativas o de moda. Del mismo pensar en la utilización de una pedagogía tecnológica supone reconocer el error como una fuente de aprendizaje, siendo la interacción y la comunicación docente-alumnado y alumnado-alumnado un elemento imprescindible a contener en las fórmulas metodológicas aplicadas para su formación (Quennerstedt, Gibbs, Almqvist, Nilsson y Winther, 2016).

\subsubsection{Conocimiento de una Lengua Extranjera}

Se aborda el conocimiento de una LE revisando diferentes aspectos que la conceptualizan y caracterizan, su presencia en la FIPEF examinando las dimensiones que han de formar parte de la formación básica para su desarrollo, explorando además los principales estudios que dan cuenta de su controvertido tratamiento formativo y de su importancia en el contexto profesional. Así mismo se abordan las principales tendencias metodológicas que facilitan su progreso.

\subsection{Conceptualización}

El conocimiento y dominio de una lengua extranjera (LE), inglés o francés prioritariamente, se ha considerado indispensable tanto por el sector académico como por el profesional, requiriendo de su incorporación a la vida formativa para su traslación posterior a la cada vez más exigente realidad profesional, de ahí su implementación en 
todos los planes formativos (Alonso, Fernández y Nyssen, 2009; Aranda, Puentes y Antequera, 2008; Bartual y Turmo, 2016).

La formación para la competencia en el conocimiento y manejo de una LE ha de ayudar esencialmente al estudiante a ser capaz de comunicarse oralmente y por escrito, y la Universidad ha de facilitar que cada estudiante pueda desarrollar esta competencia, a fin de contribuir a la profundización en sus destrezas idiomáticas en vinculación con sus propios estudios. Por ello, ha de tratar de conseguir no solo que los idiomas se aprendan, sino también que se utilicen en las diferentes materias en donde se apliquen, usando entre otras estrategias la conversación, la búsqueda de información o la elaboración de informes o trabajos (Villa y Poblete, 2007).

En el caso de Europa, el giro hacia las competencias que se fue desarrollando en torno a la construcción del EEES, provocó que la enseñanza de una lengua extranjera (ELE), tuviera que adoptar nuevas metodologías vinculadas al nuevo enfoque competencial, alejándose de las tradicionales a fin de facilitar en el alumnado su desarrollo competencial en clave de manejo de conocimientos, capacidades y habilidades, como resultado visible y palpable de cuanto sabe, comprende y está capacitado para hacer. Todo en favor de cumplir con la vocación profesional de las nuevas titulaciones cuya misión fundamental es la preparación para la incorporación al mundo laboral.

Es lógico pensar que, en este giro formativo en la formación del profesorado, las iniciativas pedagógicas para alcanzar los nuevos objetivos para la ELE cambiaran para conseguir vincular los contenidos formativos con la profesión docente a ejercer, buscar nuevas alternativas para desarrollar los procesos de evaluación y planificar y diseñar detalladamente las actividades de aprendizaje, en consonancia con nuevas fórmulas metodológicas.

De tal manera que, como señalan González (2005) y Ramos (2009a), sea factible conseguir que los idiomas sean utilizados como lenguas vehiculares de comunicación 
para poder desarrollar el currículum educativo, que los docentes en el ejercicio profesional en contextos bilingües, hoy ya desarrollan.

Surge así la necesidad de promover nuevos planteamientos para la ELE pensando en las competencias a alcanzar por los estudiantes desde un enfoque más participativo. Se desarrollan verdaderas aulas comunicativas tanto para aprender acerca de la segunda lengua, como para usarla y poder comunicarse mediante el juego, el trabajo cooperativo, el uso de situaciones interactivas y dialógicas, basadas en la recreación de contextos, situaciones simuladas, en cuanto condiciones imprescindibles para ir adquiriendo y desarrollando la capacidad de comunicación mediante la LE (Benítez, 2007; Corrales Wade, 2009).

El Marco Común Europeo para las Lenguas (MCEL) (2001) surge para dotar una base común para la elaboración de los planes y programas formativos para el aprendizaje de las lenguas en el contexto de Europa, describiendo el objeto de aprendizaje al respecto a fin de poder conseguir los estudiantes comunicarse en alguna de las lenguas del espacio común. Adquiere un sentido centrado en la acción, en tanto considera a los estudiantes como agentes sociales que en situaciones de interacción, asumen tareas y las desarrollan en un contexto y un campo de acción concreto, en constante relación con los demás. El enfoque basado en la acción considera todos los recursos personales y capacidades específicas de la persona, cognitivos, emocionales, volitivos para llegar a comunicarse con los demás mediante el uso de una LE. Para ello insta a la utilización por parte del docente de aquellos recursos formativos como pruebas de expresión y comunicación oral (conversación, debates), listas de control, fichas de observación, así como portafolios que permitan evaluar en la realización de las tareas el dominio lingüístico en situaciones de interacción.

Oxford (1990, 1993) considera que el aprendizaje de una LE requiere de la activación por parte de los estudiantes de determinadas estrategias de aprendizaje en cuanto comportamientos y acciones específicas utilizadas para asimilar y hacer uso de la LE que se aprende. 
Tales estrategias se agrupan en torno a seis dimensiones (siendo las tres primeras las que favorecen directamente el aprendizaje de la LE): memorización, para recuperar la información aprendida; cognitivas, para entender la LE y producir un discurso; compensación, que equilibra el uso de la LE a pesar de los déficits de conocimientos al respecto; metacognitivas, que organizan y coordinan el aprendizaje; afectivas y sociales, de autorregulación emocional y de interacción con los demás.

A este respecto cobra sentido pensar, en consonancia con los planteamientos de Anderson (2008), Lee y Oxford (2008), que los estudiantes que podrían obtener mayores éxitos en el aprendizaje de una LE serían o aquellos que emplearan una variada y extensa lista de estrategias para conseguirlo o los que hicieran una selección de estrategias que mejor les ayudaran a aprender y aplicar la LE que aprenden en contexto. No obstante atendiendo al género, su relación con las estrategias de aprendizaje no está del todo clara. Algunos autores mostraron que el género sí afectaba a la elección y utilización de ciertas estrategias para el aprendizaje de una LE (Green y Oxford, 1995). Así, Hong-Nam y Leavell (2006) encontraron que las mujeres las utilizaban más frecuentemente que los hombres, pero Wharton (2000) encontró una mayor utilización de estas en los hombres.

A partir del MCEL (2001), se considera el nivel de referencia más bajo del uso de una lengua el llamado A1, en el que el alumnado es capaz de interactuar de forma sencilla, preguntando y contestando a preguntas básicas. En el nivel A2 el alumnado ha de poder desenvolverse en situaciones breves de intercambio social, pudiendo realizar así por ejemplo, transacciones sencillas en establecimientos en el extranjero, obtener información básica en oficinas de turismo o ubicarse en el espacio pidiendo información básica. Si se alcanza una participación más activa en las conversaciones en colaboración con el interlocutor, se considera que se está en una situación de A2+. El nivel B1 dota de recursos para ser capaz de mantener interacciones entendibles en situaciones de debate, la expresión de una idea principal sobre un tema que se pretende exponer y resolver problemas cotidianos, haciendo uso de capacidades como la de inicio de una conversación en situaciones sin haberlo previsto, como por ejemplo en aquellas en las 
que haya que interponer una queja, realizar una consulta o pedir información más clara a un interlocutor si no entiende suficientemente lo que quiere decirle.

El nivel B1+ añade a las habilidades anteriores otras como las de intercambio de cantidades de información, por ejemplo siendo capaz de tomar nota cuando alguien expone un punto de vista o describiendo, con cierta precisión, aspectos que le ocurren o explicar de forma resumida una lectura breve realizada dando la opinión al respecto.

En el nivel B2 el estudiante, tras haber transitado formativamente por le nivel intermedio, de forma más avanzada, es capaz de explicar y defender sus opiniones en un debate proporcionando explicaciones, argumentos, ventajas e inconvenientes de su idea, especula sobre las causas y las consecuencias en situaciones hipotéticas. Puede desenvolverse con soltura en un discurso social, conversando con naturalidad y comprendiendo lo que se expone en la conversación, tomar el turno de palabra e intervenir o terminar la conversación, conforme los rigores del idioma, aunque todavía no sutilmente. Además es capaz de tomar conciencia sobre los errores y equivocaciones que comete corrigiéndolos, planifica lo que va a exponer y considera el efecto que produce su mensaje en los interlocutores. Para el nivel B2+ el énfasis se muestra en las habilidades y destrezas de conversación que aplica al discurso social.

El nivel C1 de dominio eficaz de operatividad, se caracteriza por la facilidad para utilizar un repertorio lingüístico extenso, lo que permite una comunicación fluida y espontánea; dispone y aplica numerosos recursos léxicos, seleccionando de entre los que dispone aquellos que son más apropiados y ajustados para afrontar la interacción comunicativa. El último nivel, el $\mathrm{C} 2$, es considerado como de maestría aunque no implica una competencia de hablante nativo de un idioma, sino que evidencia un nivel elevado de precisión y facilidad para la comunicación.

Las actividades de aprendizaje a desarrollar dentro del aula han de ser significativas para los estudiantes, de forma que se identifiquen con ellas, siendo necesario para ello sean aplicables a contextos reales y motivantes (Doman, 2014; 
Dörnyei, 2003). Harmer (2007), a partir del MCEL (2001), considera las actividades de aprendizaje para la ELE de dos tipos: las actividades comunicativas, fundamentadas en la interacción entre el alumnado, y las no comunicativas, en las que este trabaja sin interacción y centrado en la repetición sobre una base de ejercicios de diferente índole, para el aprendizaje de las estructuras del lenguaje.

En las actividades no comunicativas encajarían la utilización de ejercicios de repetición, de práctica, de escucha, de vocabulario a partir del uso diccionario, de gramática, de traducción, de escritura, de autocorrección o audiovisuales, requiriendo el docente considerar una amplia variedad de estas apoyándose si fuera necesario en instrumentos tecnológicos (Eslami-Rasekh y Valizadeh, 2004; González et al., 2015).

Los estudios de Fernández (2014) y Ashouri y Fotovatnia (2010) mostraron la percepción de los estudiantes encuestados por las actividades de producción de vocabulario específico que a su juicio aumentaban su motivación por aprender inglés y facilitaban la significatividad de los aprendizajes, resultando eficaces para abordar las necesidades comunicativas surgidas durante las dinámicas de las actividades. Por su parte, los trabajos de González et. al. (2018) mostraron elevados niveles de motivación hacia el aprendizaje en los estudiantes cuando se aplicaron actividades que contenían el trabajo sobre nuevo vocabulario, asociado a ejercicios de traducción para fijar su adquisición, reconociendo con ello haber aumentado sus posibilidades de expresión de ideas, entender nuevos contenidos y poder escribir al respecto. De la misma manera, las actividades realizadas a partir del uso de recursos audiovisuales resultaron altamente motivantes y eficaces aunque reconociendo que su uso no había sido frecuente a lo largo de las experiencias de aprendizaje de idiomas cursados en la formación superior.

Pero las revelaciones del proyecto Tuning y del Informe Reflex (ANECA, 2007; Carot et al., 2011; González y Wagenaar, 2003) anunciaron la pobre contribución de la universidad española al desarrollo de las habilidades relacionadas con la adquisición, uso y dominio de una LE frente a la demanda creciente de los sectores profesionales, mostrando ciertas deficiencias formativas también en la rama de estudios universitarios 
vinculados a la Educación. De la misma manera, los estudios de Clemente y Escribá (2013), Jiménez, Holgado y Pérez (2007) y Mora (2003) con estudiantes universitarios revelaron paradójicamente la importancia que conceden a esta competencia para su inserción laboral, aunque reconociendo no haber estado a su juicio suficientemente presente durante su formación inicial y, por tanto, menos desarrollada como quisieran. A esta misma conclusión también llegan Mir (2007) y Muñoz-Cantero, Rebollo y Espiñeira (2014) en sus estudios con estudiantes universitarios de formación del profesorado, para los que esta competencia es considerada del todo insuficientemente desarrollada durante la formación inicial.

\subsection{La Enseñanza de la Lengua Extranjera en la formación inicial del profesorado de Educación Física}

A pesar de la importante presencia de esta competencia en la FIPEF (ANECA, 2005a, 2005b; Orden ECI/3857/2007) como consecuencia de las recomendaciones provenientes del proceso de Bolonia (González y Wagenaar, 2003; Unión Europea, 2001) y de la consideración de las competencias clave para el aprendizaje permanente en el marco europeo (Unión Europea, 2006), los estudios realizados al respecto con estudiantes evidencian todavía un importante déficit formativo (Cuervo et al., 2013). Además, tal y como informan De la Maya y Luengo (2015) y Jóver, Fleta y González (2016), existe una reducción de la formación para una LE a niveles mínimos en las menciones no especialistas en LE del título de maestro en el contexto universitario nacional, siendo exiguo el número de créditos sobre el total de la formación prestada, mostrando las autoras del estudio, la insuficiencia de la formación no solo a nivel de conocimientos de la LE sino a nivel de formación en didáctica específica. Este hecho contrasta con la creciente demanda de profesorado con suficiente preparación para afrontar la proliferación de escuelas bilingües, en donde en algunas de las materias cursadas por el alumnado se encuentra integrada la LE, como es caso de la EF.

Según lo considerado por Díaz del Cueto (2013), en el caso del graduado en CAFyD, este ha de manejar durante su formación información científica nacional e 
internacional específica de su ámbito de estudio, para lo que requieren del manejo de competencias comunicativas en una LE. A pesar de ello, para los estudiantes de EF en CAFyD, es el conocimiento de una LE la percibida como peor desarrollada durante los estudios cursados, opinión que en el mismo estudio es compartida por los docentes y egresados encuestados (ANECA, 2005b). Resultado similar se muestra en el trabajo de Romero et al. (2017) donde se observa cómo las competencias en el conocimiento y manejo de una LE no están suficientemente consolidadas.

Los trabajos de Álvarez et al. (2008) Flores Aguilar et al. (2014), Gallardo (2006) y Marín-Díaz et al. (2010), Pazo-Haro y Tejada-Mora (2012) muestran igualmente importantes déficits formativos percibidos por los maestros tras la formación recibida, aunque reconociendo su utilidad profesional en contextos de multiculturalidad. Y tal y como apuntan los estudiantes de formación del profesorado en Madrid y Madrid (2014), es el método aplicado a su formación lo que en todo caso favorecería, cuando es activo y participativo, la mejora de su aprendizaje.

Por su parte Cantón, Cañón y Arias (2013) y Cortina (2011) revelaron, entre los resultados de su estudio con estudiantes MEPEF, que el nivel correspondiente a la competencia para la LE alcanzada correspondía más bien a un nivel A2 y no al esperado $\mathrm{B} 1$, encontrando déficits en la comprensión y expresión oral en donde el nivel alcanzado se acercaba más si cabe al A1. En el segundo estudio no aparecen diferencias en la comunicación oral en relación al género y, este aspecto, como se muestra, tampoco fue desarrollado en etapas educativas anteriores. Además se explicita una desconexión entre el esfuerzo realizado para aprender y la percepción de la funcionalidad comunicativa de lo aprendido, mostrando los estudiantes cierta dosis de desmotivación.

Esta frustración en ocasiones viene determinada por la ausencia de correcciones a los estudiantes, percibiendo que los errores en el uso de la LE, frecuentemente fosilizados y crónicos, no se deshacen ni resuelven y sin embargo se arrastran de una formación a otra (Jiménez, 2004). Para Brown (1994) es el feedback sobre la tarea realizada mediante expresiones y palabras correctoras, pero especialmente el afectivo a 
través del comportamiento kinésico (mirada, gestos faciales, sonrisa), una estrategia clave a prestar por el docente para alentar la participación y el aprendizaje en el alumnado, de forma que este pueda percibir que el docente se interesa en su producción para ayudarle a mejorar.

Saravia y Bernaus (2008) encontraron que los estudiantes de magisterio encuestados menos motivados para el aprendizaje de una LE eran aquellos que habían obtenido niveles más bajos tras la formación recibida, siendo conscientes además de la importancia de esta formación para su desarrollo profesional futuro. En cambio, a medida que su nivel iba mejorando, su desmotivación y ansiedad iba disminuyendo. Este aspecto se confirmó también en otros contextos formativos en los estudios de Pavón (2001) y Madrid (1999), en donde se mostraba la relación entre motivación, rendimiento académico y conciencia instrumental de la LE, que se reconoce actualmente esencial para el ejercicio profesional y en cierta medida, ejerce una presión social en aquellos que tienen más dificultades para su aprendizaje.

Sobre la forma de aprender una LE, los trabajos de García y Jiménez (2015) con estudiantes MEPEF, coincidiendo con otros en contextos internacionales como los de Clark y Trafford (1995), Lee y Oxford (2008), Griffiths (2003), revelaron que las estrategias más utilizadas por las mujeres fueron las metacognitivas y cognitivas. Los hombres utilizaban las metacognitivas (en menor medida que las mujeres) y las de compensación. Sobre las estrategias metacognitivas, las mujeres seleccionaban muy bien el lugar idóneo para el estudio de la LE y trabajaban sobre los contenidos más regularmente que los hombres; en relación a las estrategias cognitivas, las específicas utilizadas por ellas en mayor medida que los hombres fueron la lectura repetitiva, el uso del diccionario, releer los escritos propios y practicar sonidos. En relación a la memorización, siendo una de las estrategias menos utilizada, lo era más en las mujeres que en los hombres, incluyendo estrategias específicas como elaborar listas de palabras a modo de diccionario, repasar y relacionar. Los hombres obtuvieron mejores resultados en la utilización de las estrategias afectivas, como la automotivación y estrategias sociales como consultar dudas al docente (compensación). 
De la misma manera, Gómez, Solaz y Sanjosé (2014) y Jiménez (2004) encontraron un nivel de A2-B1 (básico intermedio) de inglés alcanzado por los estudiantes de magisterio que formaban parte de su trabajo, mostrando estos carencias de comprensión lectora para afrontar textos universitarios en inglés que formaban parte de la formación recibida, abordando su lectura mediante estrategias metacognitivas de resolución de problemas y de reparación como ajustar la velocidad de la lectura para no perder la concentración. Además mostraron una ausencia de hábitos de lectura en inglés, tan solo abordando aquellos textos de lectura obligatoria durante las materias cursadas y déficits en la expresión oral.

En relación a la efectividad de la FIPEF para la enseñanza de una LE, para Ramos (2009b) y Pérez Cañado (2015) es necesario actualizar su capacitación en el uso de una LE, a fin de poder abordar en el futuro ejercicio docente las necesidades de bilingüismo de los centros educativos de destino, debiendo desarrollar aspectos no solamente lingüísticos sino también metodológicos como el uso de estrategias participativas para el desarrollo de destrezas lingüísticas básicas dentro del área de EF, especialmente de compresión y expresión oral, así como saber desarrollar el currículo.

McGuire, Parker y Cooper (2001), Ramos y Ruiz Omeñaca (2010) por su parte defienden la naturaleza privilegiada del área de EF por su interactividad para la vinculación constante entre lenguaje y acción, pudiendo a través del planteamiento de afrontamiento de retos abordarlas el alumnado haciendo uso del la LE como idioma vehicular dentro de una metodología integrada como AICLE (Aprendizaje Integrado de Contenidos y Lengua Extranjera).

Esto es posible debido a la facilidad que la EF como disciplina dispone para la contextualización de los contenidos y de su comprensión, debido a las posibilidades de demostración práctica del profesor y del alumnado entre sí, siendo el cuerpo y el movimiento la esencia de las actividades prácticas de aula para la interacción y la comunicación, pudiendo transferir la competencia desarrollada en la educación no universitaria a la formación superior (Buscà y Capllonch, 2008). Para ello, en la ELE, 
en la formación del profesorado de EF se requiere del desarrollo de experiencias prácticas comunicativas es decir, de actividades interactivas, por ejemplo haciendo uso del juego y diversificando así las posibilidades de aprendizaje (Barrionuevo, 2011; Cerqueiro, 2013; Harmer, 2007).

Además la preparación en la formación del profesorado pasa finalmente por el desarrollo de experiencias de inmersión lingüística y de movilidad a través de programas del tipo Erasmus, a fin de mejorar el conocimiento de una LE y, con suficiente dominio, ser capaces de afrontar también el reto de enseñar la LE (Cuervo, Alonso y Sabadell, 2013). Un mayor dominio y soltura comunicativa facilitan manejar en el aula las habilidades didácticas necesarias para afrontar la docencia bilingüe, para diseñar unidades de programación, elaborar materiales, crear instrumentos de evaluación y utilizar metodologías activas de aprendizaje (Nunan y Lam, 1998). No obstante como apunta Pérez Cañado (2012), las alternativas formativas extra académicas que ofrece la institución universitaria no siempre resultan suficientes pues frecuentemente adolecen de la formación pedagógica que requieren los perfiles docentes para afrontar los retos de la educación bilingüe.

\subsection{Una metodología que facilita el conocimiento de una LE desde el área de EF}

Habitualmente los métodos tradicionales de enseñanza de idiomas, o bien hacían énfasis en el aprendizaje de la gramática como aspecto esencial, como es el caso del método clásico, en el que las reglas gramaticales para la traducción de textos eran el objeto de estudio o bien, como en el caso de los métodos directo y audiolingüe, atendían con más fuerza al uso oral del idioma extranjero que se estaba aprendiendo o a la memorización de diálogos y repetición de estructuras sintácticas. Estas se entendían como la base sobre las que aumentar la fluidez en dicho idioma, aunque se encontraron importantes escollos, como la falta de transferencia de esas estructuras sintácticas a las situaciones de la vida real, en donde no se siguen patrones establecidos (Richards y Rodgers, 2014). 
Frente a estos métodos, surgieron otros como el denominado enfoque natural (Krashen y Terrell, 2000) que buscaba mayores garantías de comprensión de los mensajes por parte de los estudiantes. En este enfoque, el profesorado de idiomas debía minimizar en sus explicaciones la carga léxica a impartir, para apoyarse mejor en otros recursos como los audiovisuales. También métodos como el Total Physical Response se basaban en la prioridad por la compresión oral del alumnado, minimizando la enseñanza de la gramática y los sistemas de memorización de estructuras lingüísticas en base a la repetición, apoyándose más en el diálogo del alumnado con los docentes y de los propios alumnos entre sí (interactividad), para desarrollar una asociación entre la acción desarrollada en el aula y el lenguaje (Larsen-Freeman, 2000).

Los métodos tradicionales no cumplieron suficientemente con el objetivo de enseñar idiomas (Ramos, 2013). Así, surgieron otros, para la enseñanza del inglés específicamente, que se fundamentaban en la integración del idioma en las materias no lingüísticas dentro de un contexto educativo formal (AICLE), teniendo por objeto desarrollar los contenidos de esas materias tomando también sus métodos habituales para su desarrollo.

Algunos como el llamado Inglés basado en el contenido, ESL, (content-based) (Brinton, Snow y Wesche, 1989) se fundamentan en la colaboración práctica entre el profesorado de idiomas y otro profesorado responsable de otras materias: los segundos concretan los bloques de contenidos de sus materias y los primeros preparaban en clave de vocabulario los conceptos esenciales de esas materias que, presumiblemente estudiarían de forma específica en las respectivas materias especializadas. También el Enfoque para el Aprendizaje del Lenguaje Académico Cognitivo (CALLAS) (Chamot y O’Malley, 1994) requiere tanto de la enseñanza de los contenidos del idioma, como de las estrategias metodológicas para garantizar que el alumnado pudiera aprenderlo, lo que facilita presumiblemente un mejor manejo de las destrezas y también en la comprensión de los temas a estudiar en ese idioma, optimizando la realización de acciones de orden superior para el aprendizaje, como la elaboración de redacciones y resúmenes, tomar notas o encarar proyectos prácticos (Ramos, 2009a). 
De la misma manera el English Language Development (ELD) y el Specially Designed Academic Instruction in English (SDAIE) (Freeman y Freeman, 1995) surgen en Estados Unidos para la enseñanza del inglés, como dos métodos complementarios que aúnan el aprendizaje de los contenidos del idioma mediante el uso de estrategias alternativas de enseñanza, facilitando la comprensión a los estudiantes. Especialmente el ELD se piensa para aquellos con importantes limitaciones para adquirir los conocimientos del idioma. Ambos incrementan su efectividad en tanto aumenta la colaboración entre los docentes y se combinan con procedimientos metodológicos que dotan de protagonismo al estudiante, como el trabajo grupal, el aprendizaje basado en problemas, la cooperación y el desarrollo de proyectos (Brown, 2007). En cualquier caso, parece que la ELE promueve un mayor aprendizaje cuando hace uso de metodologías activas, flexibles y abiertas a la colaboración entre docentes y a la implicación y participación de los estudiantes (Bretones, 2008).

Para el área de EF parece que el enfoque metodológico AICLE en los últimos años está teniendo importante presencia y potencial para la enseñanza de una LE de forma integrada, fundamentalmente en las etapas de educación primaria, secundaria y también, aunque en menor medida, en el contexto universitario de formación del profesorado (Clancy y Hruska, 2005; Coral, 2010; Devos, 2012; Molero, 2011; Muñoz, 2007; Ramos y Ruiz-Omeñaca, 2011).

El método AICLE, nomenclatura de la expresión “Aprendizaje Integrado de Contenidos y Lengua Extranjera" (CLIL, Content and Language Integrated Learning; en el ámbito de la universidad ICLHE, Integrating Content and Language in Higher Education) se refiere a la posibilidad de enseñar cualquier disciplina haciendo uso de una LE como vehículo de comunicación, estableciendo equilibradamente una forma de aprender los contenidos de la LE y los de la disciplina en cuestión encontrando en las metodologías abiertas y participativas una forma de provocar interacción y comunicación entre los estudiantes (Doiz, Lasagabaster y Sierra, 2013; Hernando, Hortigüela y Pérez-Pueyo, 2015; Hortigüela, Hernando y Pérez-Pueyo, 2016) 
Se trata de una metodología holística que plantea la enseñanza de una LE desde una propuesta de aprender haciendo, lo que supone, aplicado desde el área de EF, aprovechar la motivación por el movimiento corporal para alcanzar tanto las metas físico-motrices como también las lingüísticas (Vallerand y Rousseau, 2001). Deller y Price (2007) consideran que si en el aula de LE son cuatro capacidades el objeto de enseñanza y aprendizaje y de las producciones a generar por los estudiantes, leer, escribir, escuchar y hablar, a través del método integrado en el aula de EF, las capacidades lingüísticas son el recurso para aprender y practicar los contenidos que se enseñan de forma práctica y experiencial. En este planteamiento metodológico holístico e integrado, encajan la utilización de forma híbrida de métodos participativos en uso en la didáctica de la $\mathrm{EF}$, de forma que su utilización conjunta facilite tanto la consecución de los objetivos didácticos del área como los lingüísticos, ya que la comunicación es más eficiente si se arbitran diferentes metodologías participativas, tal es el caso por ejemplo del TG y el aprendizaje cooperativo (AC) (Coral, 2018).

Para el mismo autor las propuestas en la enseñanza superior para utilizar una LE como lengua vehicular implican, para el caso de la FIPEF, la inclusión de objetivos y resultados de aprendizaje relacionados con la adquisición de estrategias para diseñar tareas de EF desde el enfoque integrado ICLHE, aprendiendo y practicando los contenidos específicos (planificación de la EF escolar; uso de ayudas lingüísticas en la enseñanza y aprendizaje de la EF escolar), mejorando además las capacidades lingüísticas en una LE. En la formación de maestros la importancia del desarrollo de la LE lo es no solo desde el punto de vista de la comunicación, sino también desde la enseñanza.

Esto implica definir la competencia más que el propio conocimiento, es la capacidad de enseñarla dentro de otro campo de conocimiento (Jóver et al., 2016). Coral (2010) propone que la estructuración del proceso de comunicación en la formación se lleve a cabo desde tres dimensiones: 1) el lenguaje del aprendizaje, para analizar el contenido disciplinar y el vocabulario específico; 2) el lenguaje para el aprendizaje, necesario para la gestión de las tareas; 3) el lenguaje espontáneo, no previsto, creativo, surgente de los momentos de aprendizaje y necesario para la gestión de las relaciones interpersonales y de los conflictos. 
Esta metodología integrada ya fue impulsada por la Comisión Europea (1995) y considerada como la más indicada para favorecer el desarrollo del plurilingüismo, siendo: 1) creadora de situaciones de aprendizajes significativas centradas en el alumnado y en la integración de una LE vehículo de una o más disciplinas; 2) contextualizadora en torno a un tema que favorece la colaboración entre el profesorado y los departamentos de adscripción de este y 3) facilitadora del uso de los recursos TIC. Para el ámbito de la EF, se enfatiza la capacidad de resolución de problemas y de aprender a hacer tareas en un contexto natural, el de la acción físico-motriz, motivando a los estudiantes y haciendo uso de la interacción y la comunicación oral (escucha y expresión oral) como medio fundamental para su puesta en práctica (Molero, 2011; Suárez, 2005).

\section{La Red Europea ENLU (European Network for the Promotion of Language} Learning Among All Undergraduates) fue uno de los proyectos seleccionados por la Comisión Europea (ELC/ENLU, 2006) para preparar una acción general de promoción de las lenguas europeas (plurilingïsmo) en el escenario de la universidad. Uno de los aspectos estudiados se relacionaba con la idoneidad de la metodología integrada AICLE/ICLHE para incorporar en la formación superior la interactividad entre los hablantes, dado el carácter metodológico tradicionalmente transaccional de la universidad orientado a la provisión de información, en detrimento del carácter interactivo que hoy requiere la enseñanza y utilización de una LE.

En España, Vez (2006), en un estudio realizado para el Ministerio de Educación y Ciencia en relación al estado de aprendizaje de lenguas en la universidad española, revelaba la necesidad de incorporar métodos integrados, así como la enseñanza de idiomas con fines específicos en aquellas titulaciones de carácter técnico, favoreciendo el uso de terminología especializada pensando en su uso en el escenario laboral, el intercambio estudiantil y profesional. 
El conocimiento de una LE en la FIPEF se realiza mediante una o varias materias específicas a cursar para su desarrollo. El análisis realizado de sus guías docentes en los planes formativos de los dos títulos de grado de las facultades de origen de los estudiantes participantes en este estudio (facultades MEPEF de Albacete Barcelona, Córdoba, Granada, Madrid, Murcia, Santander, Segovia, Sevilla, Tenerife, Valencia y Valladolid; facultades CAFyD de Huesca, León, Murcia, Sevilla, Vic y Vitoria), permitió encontrar algunos rasgos en cuanto a la metodología y la evaluación prevista en ellas. Se evidenciaba una preocupación del profesorado responsable por la interactividad, la comunicación y la participación activa de los estudiantes en el proceso de enseñanza y aprendizaje de la LE, cohabitando esta realidad con la presentación de los conocimientos de la materia por el docente en clave de clases magistrales (figura 3.7). Pero no se refleja esta tendencia participativa en la evaluación, primando aún la previsión de exámenes escritos en diversas modalidades en mayor medida que los instrumentos más participados (figura 3.8). Este aspecto refuerza la idea de Buscá, Rivera y Trigueros (2012), Martínez-Muñoz, Castejón y Santos-Pastor (2012) y RuízGallardo, Ruiz y Ureña (2013) cuando se refieren a la estima que tienen los profesores sobre lo alternativo del proceso de enseñanza y aprendizaje que prevén en las guías docentes de las materias que imparten, frente finalmente a lo restrictivo de los instrumentos de evaluación, fáciles de calificar, que aplican.

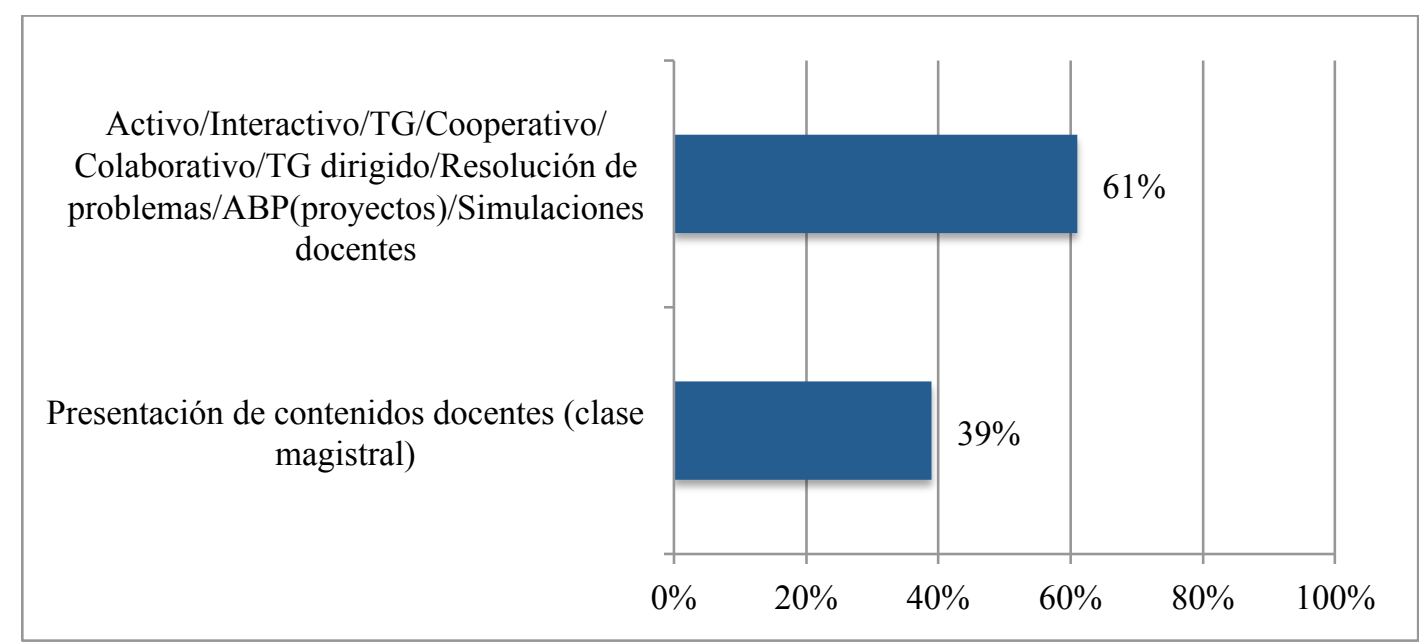

Figura 3. 7. Modelos metodológicos presentes en las guías docentes de las asignaturas ELE en los planes formativos de los grados MEPEF y CAFyD 


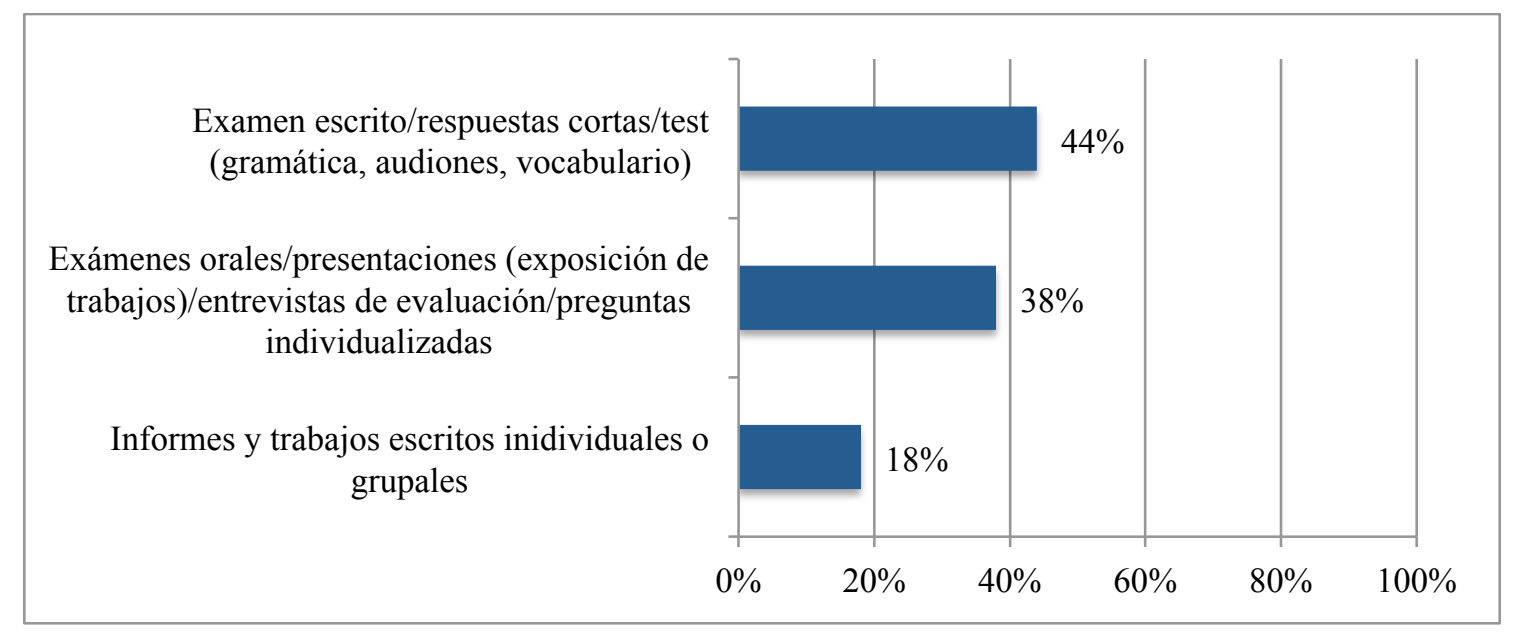

Figura 3. 8. Instrumentos de evaluación presentes en las guías docentes de las asignaturas ELE en los planes formativos de los grados MEPEF y CAFyD

Parece que cada vez va existiendo una mayor generalización de la creencia sobre la necesidad de implementación de una metodología integrada en la formación superior para ayudar a mejorar la competencia en LE en el estudiantado universitario. Los estudios de Dalton-Puffer (2011), Doiz et al. (2013), Lagabaster y Ruiz de Zarobe (2010) y Lasagabaster (2012) verifican esta creencia en base a los resultados positivos recogidos al respecto. Toledo, Rubio y Hermosín (2012), en un escenario universitario plurilingüe de formación del profesorado en donde se puso en marcha la metodología ICLHE, ayudada en algunos casos con métodos activos como el TG o AC, mostraron valoraciones positivas del estudiantado para entender al profesor en clase y la realización de las tareas. Creyeron haber mejorado su nivel de idioma, específicamente en la adquisición de un vocabulario más diverso y técnico y en la comprensión oral y escrita y la expresión oral, sintiéndose más capaces de mantener una conversación en inglés con sus compañeros cuando realizaban las tareas; así como aprovechado el esfuerzo realizado en función de los resultados obtenidos.

Del mismo modo, el no acompañamiento de la evaluación a la intencionalidad metodológica expuesta en las guías docentes, da cuenta de un proceso de enseñanza y aprendizaje que aún diferencia enseñanza y evaluación como dos entidades separadas, 
rasgo muy relacionado con modelos metodológicos tradicionales (Bonson y Benito, 2005; Dochy, Segers y Dierick, 2002).

\subsubsection{Competencias Interpersonales}

Las competencias interpersonales, siguiendo a González y Wagenaar (2003), suponen aquellas capacidades que facilitan la interacción social. Permiten expresar la emocionalidad, entenderse y relacionarse con el entorno social de forma autocrítica y crítica, cooperativa y ética. Para la FIPEF en las dimensiones afectiva y relacional, es necesario promover espacios formativos para activar y desplegar habilidades socioemocionales (Conde y Almagro, 2013) como la autorregulación o la empatía, orientando ante la conflictividad en las relaciones interpersonales, favoreciendo el trabajo en equipo para abordar proyectos comunes, mitigando tensiones y ejercitando la escucha y la toma de posición del otro (Bisquerra y Pérez-Escoda, 2007).

En opinión de Sánchez y Boronat (2014) las competencias interpersonales en la formación del profesorado entran en juego cuando se establecen relaciones grupales para cooperar, siendo la participación, la receptividad, la adaptación, la sutileza, la empatía, la asertividad, el compromiso, la inteligencia emocional, la comunicación, habilidades necesarias para afrontar situaciones en este sentido. Además, la actitud del estudiante hacia el cambio se canaliza en la medida en la que se adquieren y se activan competencias interpersonales como la escucha activa, la comunicación y la receptividad hacia los demás. Es de interés para este estudio conocer de forma más profunda las competencias trabajo en equipo y habilidades en las relaciones interpersonales en relación a su presencia en la FIPEF, dada la conexión entre ellas, siendo necesario para trabajar grupalmente y cooperar afrontar situaciones formativas haciendo uso de las habilidades interpersonales. 


\subsubsection{Trabajo en Equipo}

El trabajo en equipo es una las competencias actualmente mejor valoradas en contextos profesionales y formativos, reconociéndose en ello la importancia que las organizaciones otorgan a la capacidad de las personas para trabajar juntos afrontando cooperativamente los desafíos a afrontar.

Se abordan a continuación, los rasgos que las organizaciones profesionales destacan sobre ella, los aspectos que la definen y distinguen de otros conceptos afines, los componentes que la dimensionan, su dinámica de funcionamiento así como su presencia en la FIPEF y las metodologías que presumiblemente pudieran ayudar a su formación y desarrollo.

\subsubsection{Trascendencia del trabajo en equipo en las organizaciones}

El trabajo en equipo es una de las competencias transversales más valoradas por el mundo de la empresa y en todos los sectores, incluido el formativo (ANECA, 2007). En este sentido, diversas investigaciones revisadas (Cannon-Bowers, Tannenbaum, Salas y Volpe, 1995; Chen, Donahue y Klimoski, 2004; Leach, Wall, Rogelberg y Jackson, 2005; McClough y Rogelberg, 2003) manifiestan la importancia de contar con perfiles de empleados con habilidades para trabajar en equipo, reconociendo que esta competencia es de vital importancia por su efectividad a la hora de abordar las tareas, alcanzar las metas establecidas y resolver colectivamente los problemas encontrados, llevando consigo mejoras en la capacidad competitiva de la organización y en la empleabilidad de los trabajadores.

Así, entidades como el Observatorio de la Innovación en el Empleo (OIE, 2015), dispuso respecto del trabajo en equipo la necesidad de formar en el ámbito de la universidad en esta competencia transversal, ampliamente demandada en el mundo profesional. Informaba además que el trabajo en equipo aún no se desarrolla suficientemente en la formación superior y que la evaluación centrada en los 
conocimientos, no proporciona suficientes y valiosos feedback a los estudiantes, como para hacerles saber si manejan adecuadamente esta competencia, declarando no del todo suficiente por tanto su formación.

Además, sucede frecuentemente que tras la formación cursada los estudiantes manifiestan un alto dominio sobre el trabajo en equipo, pero los egresados ya insertos en el mercado laboral y los empleadores difieren, en razón a la diferente conceptualización que se tiene de la competencia (Barraycoa y Lasaga, 2009).

El mundo global y cambiante requiere de la integración en los equipos de trabajo de diversas visiones, enfoques, opiniones, así como la puesta en funcionamiento de un proceder complejo atravesado por conocimientos y capacidades. En el sector educativo, la participación interdisciplinar e interprofesional para desarrollar proyectos, resolver problemáticas de centro, atender las necesidades del alumnado que más lo necesita, requiere de la capacidad para salir de la individualidad, aunar esfuerzos, y disponerse alineadamente para alcanzar objetivos comunes, integrándose y contribuyendo al trabajo en equipo (Villardón-Gallego, 2015). Consecuentemente, se valora el potencial que desarrollan las experiencias en la formación superior en las que los contenidos se conectan y hacen alusión a situaciones profesionales reales dotándolas de significatividad y funcionalidad (Bricall, 2000).

Por ello se valora el trabajo en equipo como el sistema de organización del trabajo, ya no mecanicista sino orgánico, favorecedor de la comunicación horizontal, la flexibilidad estructural, el aprendizaje colectivo y continuo y la adaptabilidad. Desde esta perspectiva, el equipo es un núcleo de aprendizaje que adquiere, crea y aplica el conocimiento a fin de solucionar sistemáticamente los problemas que se encuentra, experimentar nuevos enfoques de solución, aprender de la propia experiencia y de las experiencias de otros, resistir conjuntamente a las presiones adaptándose unos a otros, cumplir los plazos para la consecución de los objetivos, reconocer y compartir las limitaciones y transferir el conocimiento aprendido a partir de los resultados obtenidos, 
nutriendo al propio equipo y a la organización en la que se inserta (Álvarez, Asensio y García, 2013; Garvin, 1993).

Los estudiantes de EF son cada vez más conscientes de la exigencia por parte del entorno laboral de saber trabajar y resolver problemas de forma colaborativa, en equipo, consensuada y corresponsablemente. Empiezan a considerar que es la forma principal de trabajo en una organización y consideran además que es un sistema que no surge de forma natural, sino intencional. Entienden que condiciona el que la organización prospere y alcance sus objetivos. Tal reconocimiento de la importancia del trabajo en equipo se muestra en los resultados de los estudios de Carot, Conchado, Mora y Vila, 2011, Clemente y Escribá (2013), Fuentes-Abeledo et al. (2008), Pazo-Haro y TejadaMora (2012), González et al. (2010), Pérez 2007, Romero et al. (2011) y Rodríguez, Ibarra y Cubero (2018), Romero, Zagalaz, Romero y Martínez, 2011, en los que se percibe una elevada estimación que conceden los estudiantes, a la formación prestada desde la universidad para desarrollar esta competencia. No obstante, en los estudios de Gutiérrez-García, Pérez-Pueyo, Pérez-Gutiérrez y Palacios-Picos (2011) con estudiantes de EF procedentes de los estudios MEPEF y CAFyD, se revela una percepción sobre la ayuda recibida para su formación no tan halagüeña, a diferencia del profesorado encuestado que sí consideran haber desarrollado acciones formativas para su adquisición.

\subsection{Conceptualización: ¿qué significa realmente trabajar en equipo?}

Existe cierta diversidad terminológica en relación al trabajo en equipo y otros conceptos afines, relacionados con él, que subyacen en los discursos que lo conceptualizan y explican: "trabajo en grupo", "grupos de trabajo", "equipos" o "trabajo en equipo" (Torrelles, Coiduras, Carrera e Isus, 2014).

Además, tal y como se apuntaba anteriormente, existe una percepción o autoimagen de alto grado de desarrollo del trabajo en equipo por parte de los estudiantes, a partir de las numerosas experiencias de trabajo grupal desarrolladas en su 
formación superior, pensando que la formación recibida sí ha facilitado mucho su desarrollo competencial (Escolano-Pérez, Tomás-Aragonés y Herrero-Nivela, 2012), aunque en los trabajos de Conchado y Carot (2013).

Esto muestra cierto desajuste entre el modelo más complejo demandado por el mercado laboral (por ejemplo para el caso de la profesión docente, asociada esta competencia a la necesidad de trabajar de forma compleja con perfiles multidisciplinares), con respecto a lo que se aprende en la formación superior (frecuentemente asociado más a la idea de procedimiento metodológicos de trabajo grupal, de reparto de tareas para desarrollar un producto académico), generando en la mayor parte de los casos, controversia y una difícil transferencia al mundo real (Barraycoa y Lasaga, 2009, 2010).

Un grupo no requiere de aspectos como la sinergia, que un equipo necesita (Clety, 2009); pero el equipo parte de un grupo. Lejos de ser realidades antagónicas, estos términos no hacen sino complementar y proyectar su existencia, a pesar de que estas disquisiciones en ocasiones no sean técnicamente percibidas por el estudiantado.

Formativamente se acude al término "trabajo en grupo" como la justificación de las acciones y tareas que este ha de desarrollar, como afrontar desafíos, resolver problemas, acomodándose este término generalmente en el vocabulario docente como asimilado al de "trabajo en equipo", a pesar de distinguir los docentes que este último representa mucho más que la suma de individuos que trabajan dividiéndose la tarea en partes para refundirlas finalmente (Gámez-Montalvo y Torres-Martín, 2012).

Paralelamente son comúnmente aceptadas en la formación superior algunas metodologías docentes basadas en el trabajo grupal o grupos de trabajo, como revelan los trabajos de Moreno, Quesada y Pineda (2010) y Vallejo (2011). Se recalca la idea de necesidad en el contexto universitario, de trabajar juntos, siendo el grupo el punto de partida de las acciones que se esperan sean desarrolladas, diseñando y produciendo materiales que sean el culmen del trabajo realizado, pero buscando trascender la idea de 
la suma de partes que trabajadas por cada miembro del grupo conforman finalmente un todo (Barraycoa y Lasaga, 2009). Se pretende acercar así más a la idea solidaria de objetivos grupales comunes por encima de los individuales, comunicándose, poniendo en funcionamiento habilidades $\mathrm{y}$ aptitudes, para lograr objetivos reconocidos $\mathrm{y}$ priorizados que se acerquen más a la idea de equipo, tal y como defienden Moreno, Bajo, Moya, Maldonado y Tudela (2007).

El término equipo se define como la unión de dos o más personas que trabajan en cooperación, creando una red de relaciones de interdependencia, estableciendo entre ellas una sinergia y cohesión, con el propósito de trabajar para alcanzar una meta preestablecida (Ros, 2006; Torrelles et al., 2014). Los equipos se desarrollan cuando cada uno de sus miembros participa en la realización de la tarea común, adaptándose a las particularidades del contexto como condicionantes externos influyentes en su rendimiento y eficacia (Kozlowski y Ilgen, 2006).

La interdependencia es, siguiendo a Cletty (2009), el grado en el que los miembros de un equipo deben apoyarse los unos en los otros y tolerarse para cumplir sus tareas de manera eficaz. Un nivel bajo de interdependencia, frecuentemente común en la formación superior, se observa cuando el producto colectivo realizado es fruto tan solo de la suma de producciones individuales aportadas. Una interdependencia más secuencial permite el desarrollo de una producción grupal a partir de las tareas individuales realizadas pero de una manera más ordenada y lineal. Un modelo más recíproco de interdependencia produce, sin embargo, una tarea supervisada por todos los miembros del equipo, que podría ser máxima si se producen intercambios diversos y simultáneos entre sus miembros, discutiendo dicha tarea realizada a partir de las aportaciones de todos, presentando una producción de carácter más multidimensional y mejor ejecutada (Savoie y Brunet, 2000).

Los equipos son entes complejos, dinámicos y adaptativos que se asientan sobre tres niveles de organización que hacen que el trabajo compartido sea realmente eficaz: la organización, el equipo y la persona, siendo esta el factor más importante, puesto que 
de ella depende la puesta a disposición del equipo de sus conocimientos, habilidades y actitudes para adaptarse constantemente a las diversas circunstancias que suceden de una forma eficiente, autónoma y flexible, construyéndose por tanto, la competencia que va desarrollando la persona para trabajar en equipo (Clety, 2009; Torrelles et al., 2011).

Sundstrom, Demeuse y Futrell (1999) definen el equipo como la organización de individuos interdependientes que comparten la responsabilidad de obtener resultados específicos, desarrollando una tarea compartida, para el bien de su organización. Una organización de pertenencia, en cuanto entidad que acuerda el mandato colectivo, fija los objetivos, y estructura los recursos.

El equipo no existe en la medida en que su organización no insta legítimamente a todos sus miembros para realizar una tarea que les atañe. La organización juega así, en opinión de Savoie y Mèndes (1993) y de Rousseau, Aubé y Savoie (2006), un rol de dirección, catalizador para los miembros que conforman el equipo, los instruye y los dispone para la consecución de un objetivo. Un estudio de Livingstone y Lynch (2002) con estudiantes universitarios reveló, tras las experiencias de trabajo grupal realizadas, una preferencia generalizada por parte de los estudiantes por que sus docentes participaran activamente en el proceso, ayudándoles a comprender y minimizar las situaciones de ansiedad, frustración y falta de entusiasmo que se iban generando cuando se ponían en marcha los procesos grupales de trabajo y surgían los conflictos interpersonales.

Un equipo de trabajo se define como la agrupación de dos o más individuos que interactúan socialmente y poseen uno o más objetivos comunes, se reúnen para realizar tareas relevantes conducentes a la consecución del objetivo, manifiestan interdependencias con respecto al flujo de trabajo, las metas y los resultado y asumen diferentes roles y responsabilidades, previamente pactados, a disposición de la tarea a desarrollar para alcanzar la meta común (Hackman y Wageman, 2005; Hollenbeck et al., 1995; Salas, Dickinson, Converse y Tannenbaum, 1992). 
Poblete y García (2004) consideran que lo equipos están compuestos por un número reducido de personas que desarrollan procedimientos acordados y aceptados por todos sus miembros, asumiendo flexiblemente roles y funciones y caracterizados por la calidez en las relaciones interpersonales, la motivación, la ayuda mutua y la confianza.

Borrell (1998) establece para el equipo, tres condiciones esenciales a darse entre sus miembros: (1) sentir la necesidad mutua de compartir habilidades y conocimientos; (2) reconocer la necesidad de complementariedad de perfiles; (3) ser capaz de establecer relaciones de confianza que les permitan la delegación de responsabilidad los unos en los otros, fragmentando el trabajo, con la garantía de que éstos cumplirán con su parte a fin de alcanzar el objetivo común.

A partir del concepto de equipo, en el que el individuo habilita sus conocimientos y capacidades para el fin común, se desarrolla el concepto de "trabajar en equipo" como competencia. En este sentido, Ros (2006) considera que se trata de un estilo para la realización de una actividad académica o laboral, en la que el individuo teje una red de interacciones que inspiran un nuevo espíritu y un nuevo modelo de participación conjunta en la consecución de las tareas, fundamentadas en la confianza, la comunicación, el apoyo mutuo, la interdependencia consciente, positiva, responsable y activa con sus compañeros, que conlleva considerar la misión del equipo también como propia.

Salas y Cannon-Bowers (2001), Salas, Burke, y Cannon-Bowers (2000), Weaver, Rosen, Salas, Baum y King (2010) describen que trabajar en equipo supone desarrollar la capacidad para trabajar conjuntamente, cooperativamente, poniendo en funcionamiento cuantas habilidades interpersonales y comportamientos operativos se requieran, para realizar eficazmente las tareas. Además, requiere reconocer las necesidades de los otros y satisfacerlas, comunicándose de forma eficaz, y coordinándose colectivamente para la acción, inspirándose confianza unos a otros, lo que facilitaría en gran medida tal, como establecen Rousseau et al. (2006), la creación 
de una red de interacciones, relaciones sociales, interdependencias y sinergias positivas para lograr el objetivo preestablecido deseado.

En este sentido, en los estudios de Boned, Rodríguez, Mayorga y Merino (2006), en relación a las competencias que los profesionales de la actividad física y del deporte han de adquirir a lo largo de su formación, es altamente valorada la capacidad para establecer relaciones sociales, aspecto que consideran favorecedor para aprender a trabajar en equipo e integrase en el sector profesional en equipos multidisciplinares.

Para Cannon-Bowers, Tannenbaum, Salas y Volpe (1995), la competencia para el trabajo en equipo incluye el conocimiento de las bases fundamentales de las dinámicas grupales, además de la adopción de un comportamiento en las relaciones interpersonales que optimice la responsabilidad recíproca para con las tareas y para el abordaje de las adversidades.

Villa y Poblete (2007) consideran que el desarrollo de la responsabilidad personal en el proceso de trabajo en equipo se forja en tres momentos. En un primer momento del proceso, los integrantes se comprometen formalmente en la realización de las tareas, cumplir los plazos, asumiendo los objetivos grupales frente a los intereses individuales, reconociendo su prioridad. En un segundo momento, la capacidad de responsabilidad trasciende de la mera participación formal en las tareas encomendadas, para encaminarse hacia el interés por el entendimiento y la armonía entre los componentes del equipo, poniendo todos su potencialidad en pro de que los unos aprendan de los otros y se valoren, confíen, se comuniquen, y actúen constructivamente para afrontar los conflictos del equipo. Finalmente, en un tercer momento, los componentes del equipo plantean iniciativas (liderazgo grupal) para movilizar el compromiso de los demás, administran las tareas de forma que sean factibles para todos, ayudan a conseguir que todos vean que las diferencias son enriquecedoras para el equipo y por tanto, se logren acuerdos para el funcionamiento interno, incorporando al debate las propuestas, ideas e iniciativas de todos sus miembros (Villa y Poblete, 2011). 
En relación a la gestión de las tareas cuando se trabaja en equipo, Kozlowski e Ilgen (2006) consideran que supone el medio para promover las relaciones interpersonales, siendo fuente de objetivos, de organización de roles, de asunción de funciones y abordaje técnico o de cómo proceder. Para Cletty (2009) las tareas del equipo participan claramente en la propia conceptualización del sistema "equipo"; sin tareas no existe equipo. El propio procedimiento de trabajo para su consecución, facilita que sus miembros adquieran, combinen y compartan el conocimiento (de manera interdependiente), obteniendo como resultante una producción a partir de la experiencia de trabajar conjuntamente, construyéndose un sentido cada vez más profundo sobre el equipo del que forman parte sus miembros y sobre sí mismos (Argote, Gruenfeld y Naquin, 2001; Russ-Eft, Preskill y Sleezer, 1997).

En relación al funcionamiento del procedimiento para abordar las tareas, Huber (1991) diferencia en su modelo de aprendizaje cuatro momentos esenciales: (1) el proceso de adquisición del conocimiento por el que el equipo busca y obtiene información, explorando fuentes de información y realizando búsquedas dirigidas; (2) el proceso de distribución de la información entre los miembros del equipo por algunos de sus miembros, debiendo gestionar aspectos como la carga de información distribuida; (3) el proceso de interpretación de la información, de manera que cada miembro del equipo da significado a la información trabajada; finalmente (4) el proceso de almacenamiento y recuperación de la información para su utilización en la creación de nuevas producciones a presentar, es decir, utilización de una memoria grupal o transactiva para adquirir, etiquetar, recopilar y recobrar información en un escenario de interacción constante (Levine, Resnick y Higgins, 1993; Wegner, Erber y Raymond, 1991).

Se puede afirmar, por tanto, que trabajar en equipo es la capacidad que adquieren y desarrollan sus miembros para alcanzar una meta que les une, afrontando abiertamente las contrariedades, discrepancias y problemas críticos que ocurren. Para ello, sus miembros movilizan sus recursos personales buscando además otros externos, a fin de flexibilizar su modelo de trabajo y de interacción, se comunican de forma abierta para adaptarse a las circunstancias específicas de ejecución de las tareas y al 
tiempo limitado de que disponen, combinando el interés por el bien propio con la forma solidaria del bien común (Moreno et al., 2007; Stevens y Campion, 1994; Torrelles et al., 2011).

La capacidad de trabajar en equipo es por tanto, originalmente, una respuesta individual del individuo al equipo al que se asocia. Para ello pone a disposición del equipo sus conocimientos, habilidades y aptitudes a fin de hacer frente a la carga de la tarea que se asume individualmente para el bien común, a la vez que teje redes de relaciones interpersonales que se van optimizando a partir del esfuerzo comunicativo, la interdependencia, la confianza, el apoyo mutuo y la adaptabilidad, a fin de poder hacer frente a las tareas, las adversidades y lograr así alcanzar la meta preestablecida.

\subsection{Componentes del trabajo en equipo: los big five del trabajo en equipo}

Desarrollar la competencia para el trabajo en equipo gira en torno a cinco componentes centrales (Salas, Sims y Burke, 2005) o cinco llaves que es necesario considerar en la formación del individuo al respecto: (1) el liderazgo de equipo; (2) el seguimiento mutuo del desarrollo de la tarea; (3) el comportamiento de apoyo y respaldo recíproco; (4) la adaptabilidad y (5) la orientación de equipo (figura 3.9). 


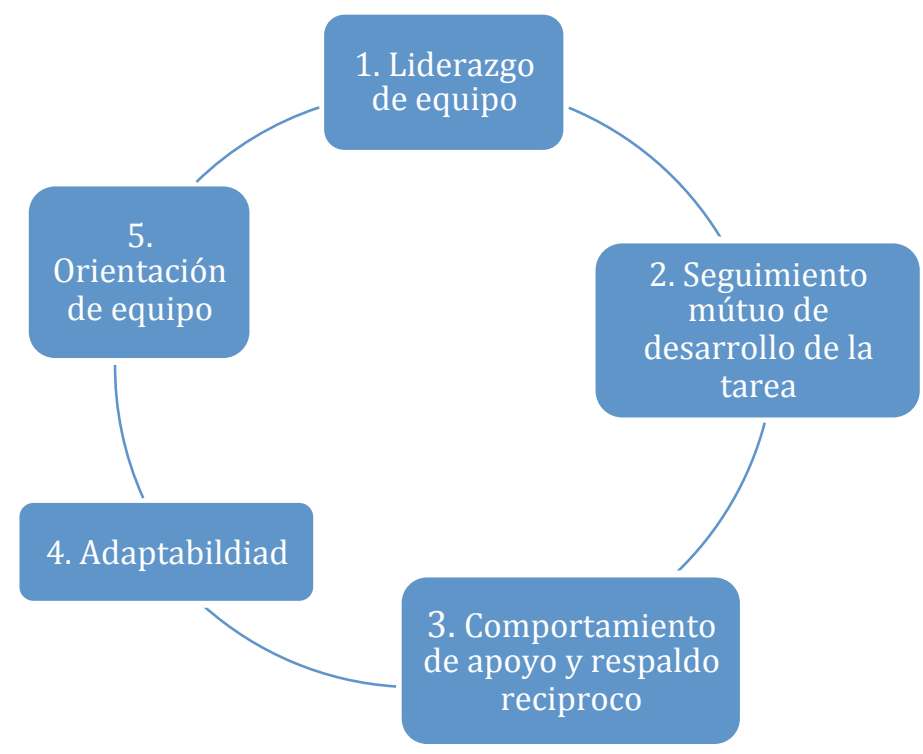

Figura 3. 9. Los big five del trabajo en equipo (Salas et al., 2005)

En relación al (1) liderazgo asumido por los miembros de un equipo o interdependencia positiva (Johnson, Johnson y Holubec, 1999; Pujolás, 2009), es uno de los componentes centrales y de mayor peso, ya que el trabajo en equipo requiere de la aplicabilidad de las funciones y decisiones asumidas entre el equipo para garantizar que el esfuerzo puesto en marcha durante el trabajo realizado sea verdaderamente efectivo para la consecución del objetivo común y de las tareas a desempeñar. Tales funciones se promueven esencialmente, desde una orientación para el desarrollo de la tarea aunque también desde una orientación para las relaciones sociales (Torrado y Arce, 2015). Guían además, la comprensión del objetivo del equipo (modelo mental común), orientan la adaptabilidad y la flexibilidad de sus miembros para hacer frente a potenciales contrariedades surgidas durante el proceso, alentando y promoviendo un clima de equipo, desde el que desarrollar el seguimiento compartido de la tarea, el respaldo, el apoyo y la ayuda a disponer hacia los demás (Salas et al., 2005).

Es posible que para la gestión del liderazgo se generan tensiones entre los miembros de los equipos, cuando es asumido exclusivamente por uno de sus miembros o si estos perciben por parte del líder erigido, demasiada intromisión en la realización de las tareas, tal y como revelan los estudios de Burdett (2007). 
El (2) seguimiento compartido del desarrollo de la tarea supone la capacidad de los miembros del equipo de observar sus comportamientos durante la realización de las tareas, es decir tener la certeza de que el trabajo como equipo se realiza, avanza y fluye.

Aplicar este componente al modus operandi del equipo, supone conocer cuáles son las responsabilidades de los otros miembros y las tareas que han de realizar, para aprender a detectar e identificar lapsos, errores y desviaciones en las acciones que desarrollan el resto de componentes, comunicarse y "ofrecer respuestas y feedback sobre los errores detectados y prevenirlos y subsanarlos" (Salas et al., 2005, pp. 560).

En opinión de Fidalgo-Blanco, Lerís, Sein-Echaluce y García-Peñalvo (2013), los mapas de responsabilidades creados por los miembros de los equipos para visibilizar ante los demás su conocimiento común, facilitan la evaluación ante los propios integrantes de los equipos y ante los docentes. Todo ello requiere compartir un mismo modelo mental sobre la meta a alcanzar, así como del procedimiento a emplear. Para ello es necesario que el equipo conozca las tareas, responsabilidades de los demás y su clima de equipo rezume confianza y cohesión, optimizando la comunicación intragrupal (Del Canto et al., 2009; Díaz-Granados \& Salas, 2008). Tales aspectos son reconocidos como aprendidos en la formación recibida por los estudiantes de EF encuestados en los trabajos de Freire, Teijeiro y Pais (2013).

El (3) comportamiento de respaldo supone incorporar la capacidad de ayudar, suministrando recursos y apoyos cuando se reconoce recíprocamente que existen dificultades para afrontarlas. Su importancia se manifiesta en los resultados del rendimiento del equipo, en los procesos para adaptarse mejor a los entornos y situaciones cambiantes, así como en la capacidad del equipo para reducir la sobrecarga de trabajo en cuanto factor estresante para su eficacia (Salas et al. 2005). Para Marks, Mathieu y Zaccaro (2000), la prestación de ayuda a los miembros del equipo puede administrarse de tres formas: proporcionando feedback a un compañero mediante comentarios verbales que le ayudan a desarrollar su tarea, ayudando al compañero de equipo a realizar su tarea y finalmente, asumiendo y completando la tarea del 
compañero sobrecargado. Estos autores igualmente reconocen una relación directa entre el comportamiento de respaldo y el control mutuo del rendimiento, ya que para prestar ayuda se ha debido supervisar el rendimiento del otro para ratificar que la carga de trabajo aceptada por él es realmente asumible por él mismo o si, por el contrario, requiere de la prestación de apoyos para que pueda ser desarrollada.

La (4) adaptabilidad del equipo (Salas et al., 2005) le permite ser capaz de alterar el curso de una acción y flexibilizar en respuesta a las cambiantes condiciones extra e intra equipo. Esto supone reconocer las desviaciones sobre la acción esperada, reajustar tales acciones, observar cómo los cambios pueden estar alterando los roles asumidos por los miembros del equipo, asumir que se están produciendo dichos cambios y adaptarse en consecuencia a las circunstancias (Kozlowski y Ilgen, 2006).

Algunos trabajos sobre evaluación de la competencia de trabajo en equipo en la formación superior (Del Canto et al., 2009; París, Torrelles y Mas, 2016; Sancho et al., 2009; Viles, Jaca, Campos, Serrano y Santos, 2012) revelan que los estudiantes se implican de forma efectiva en el desarrollo de las tareas asumidas, pero reconocen serias dificultades en su capacidad adaptativa al equipo, lo que incide negativamente en el ambiente de trabajo que se define, por que no se comparten los mismos objetivos, se difiere en la realización de las tareas, en la asunción de las funciones o no se dispone el mismo dominio y despliegue de habilidades sociales resultando estas desequilibradas.

Para Driskell y Salas (1992) y Salas, et al., (2005), la (5) orientación del equipo (de naturaleza actitudinal frente a la naturaleza conductual de los otros cuatro componente centrales analizados) supone la preferencia por trabajar con otros y mejorar el trabajo individual mediante la coordinación, la evaluación y la consideración de los aportes de otros miembros del equipo, trabajando conjuntamente con ellos. La adopción de esta actitud, además de mejorar el esfuerzo y el rendimiento individual, facilita el rendimiento general del equipo, la coordinación y la satisfacción. Los estudios de París et al. (2016) con estudiantes universitarios, en relación a la orientación del equipo, 
revelan que su desarrollo formativo despierta un sentido de integración y promoción de los miembros, así como de cohesión que beneficia al equipo y al trabajo emprendido.

Johnson y Johnson (1999) proponen varios aspectos pedagógicos para orientar y reforzar eficazmente las experiencias prácticas de trabajo grupal y favorecer estos cinco componentes: impulsando la interdependencia positiva para alcanzar el sentido colectivo de equipo, educando en la fuerza del "nosotros" frente al "yo", promoviendo la interacción promotora, favoreciendo entre los miembros del equipo la ayuda mutua en situaciones de dificultad y reforzando en positivo, el trabajo realizado por los compañeros.

Pero estos componentes llevan aparejados ciertos mecanismos de coordinación (Salas et al., 2005) (figura 3.10) necesarios para la interacción entre ellos en la acción; aseguran que los cinco componentes se desarrollen y que la información necesaria se comparta con los miembros del equipo durante el proceso; estos mecanismos son: (A) los modelos mentales compartidos (shared mental models), (B) la confianza mutua (mutual trust), y (C) y la comunicación interconectada (closed-loop communication).

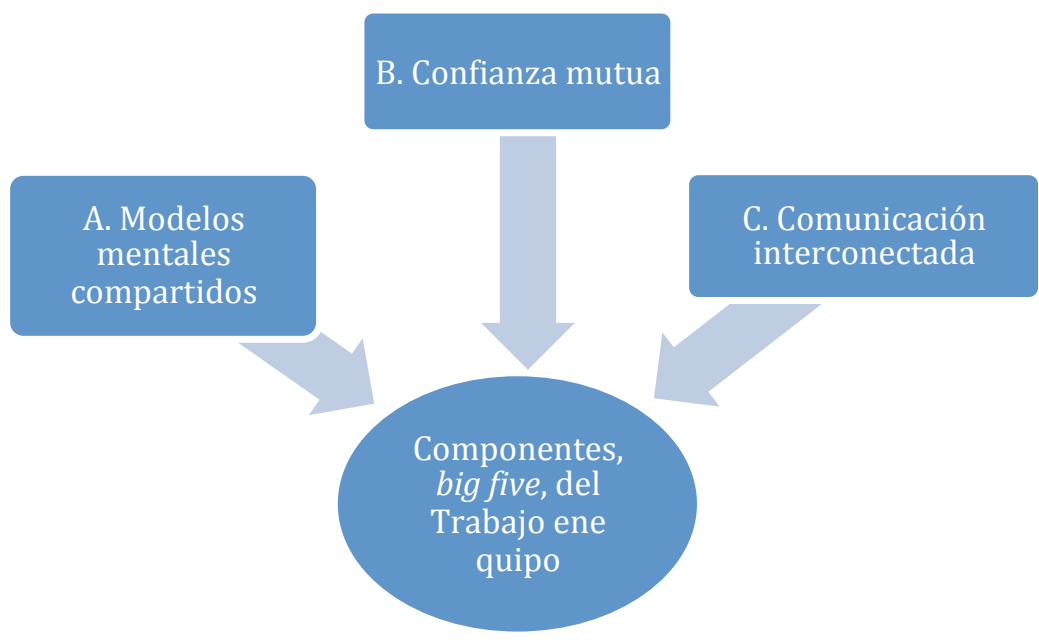

Figura 3. 10. Mecanismos de coordinación de los big five (Salas et al., 2005) 
Poseer (A) un mismo modelo mental en el equipo requiere por parte de sus miembros lograr establecer un entendimiento y una comprensión compartida de los objetivos del equipo y las tareas individuales de cada uno de sus miembros. Permite identificar la meta a alcanzar y priorizarla, organizar y codificar la información, administrar los patrones de respuesta para gestionar las acciones que se ponen en marcha, ayudar en caso de sobrecarga de trabajo y hacer el seguimiento compartido de su rendimiento. Sobre ello, los estudios de Mas, París y Torrelles (2016) con estudiantes de EF en CAFyD revelan que algunas dimensiones competenciales del trabajo en equipo como "actuar siguiendo los objetivos, creando sinergias dentro del equipo" y "realizar las tareas dentro del plan establecido, ajustándolas cuando es necesario", son dimensiones reconocidas en las experiencias de trabajo grupal realizadas, generadoras de discrepancias y tensiones, lo que muestra las dificultades para lograr poseer un mismo modelo mental de equipo.

Para Weber (2002) los equipos cuyo clima interno es de (B) confianza mutua entre sus miembros, descubrirán cómo su proceso de trabajo en equipo podrá alcanzar mayores cotas de éxito, debido fundamentalmente a la protección de los derechos e intereses de todos los miembros del equipo en pro de su mejor participación. Para Bandow (2001) (consultado en Salas et al., 2005) sin suficiente confianza, los miembros del equipo gastarán tiempo y energía para protegerse, controlarse e inspeccionarse unos a otros, en lugar de colaborar para proporcionar ideas para abordar las metas comunes. Además, la confianza también está presente en el uso y validación de la información que hacen los miembros del equipo, de forma que si estos no sienten que se valoran sus aportaciones o que la información que proporcionan no es usada de forma apropiada, seguramente disminuya su disposición a continuar compartiendo información disminuyendo su confianza intragrupal.

El intercambio de información que se establece mediante la (C) comunicación entre los miembros del equipo se convierte en un hecho crucial, sobre todo a medida en que se abordan objetivos en situaciones complejas, ya que no solo se administra la información entre los miembros del equipo para el desarrollo de la tarea, sino también facilita la actualización continua del modelo mental compartido de este. Pero, es posible 
encontrar déficits comunicativos entre los miembros del equipo en conexión con los conflictos interpersonales surgidos, la inadecuada interpretación de los mensajes o el estrés del entorno, que hace que los miembros del equipo se centren exclusivamente en el desarrollo de sus tareas. Estos aspectos requieren de la necesidad de establecer un modelo de comunicación que conecte a todos los miembros del equipo (Díaz-Granados y Salas, 2008).

Para León, Felipe, Iglesias y Marugán (2014) y Rico, Sánchez-Manzanares, Gil, Alcover y Tabernero (2011), la comunicación en el seno del equipo se relaciona directamente con la percepción de sus miembros de responsabilidad e interdependencia entre ellos para el desarrollo de los objetivos, las tareas que les unen y las funciones que asumen para su consecución, ayudando a la coordinación entre sus miembros y siendo fuente de conflicto cuando no se desarrolla de forma asertiva (Del Canto et al., 2009).

Todos estos componentes de lo que técnicamente supone trabajar en equipo, toman sentido si se plantean formativamente de manera práctica y cercana a la función docente, de forma que se garantice a partir de la acción la reflexión sobre su planteamiento complejo, su efectividad para la resolución de problemas, y por ende su valor en alza para la transferencia al ámbito profesional (Gámez y Torres, 2012; Sáiz y Gómez, 2011; Torrelles et al., 2011).

Esto requiere de un modelo formativo que de manera efectiva consiga vincular ámbito académico con ámbito profesional, para significar dicha transferencia, a fin de que el trabajo en equipo experimentado y desarrollado en la formación inicial se acerque al trabajo en equipo profesional (Perrenoud, 2013). En este contexto se pone en marcha en los claustros docentes, en la formación de equipos interdisciplinares para resolver problemas pedagógicos, diseñar y desarrollar proyectos, colaborar con otros docentes de otros centros, así como establecer y afianzar relaciones internacionales mediante proyectos compartidos. 
3.3.2.1.4 Presencia del desarrollo de la competencia para el trabajo en equipo en la formación inicial del profesorado de Educación Física

En el ámbito deportivo, la cooperación para el trabajo en equipo, como aspecto del desarrollo psicosocial de los deportistas, adquiere cada vez mayor importancia para la consecución de los objetivos de participación en los equipos. También para la transferencia de tales capacidades a otros ámbitos como el de la escuela, el instituto o la universidad, surgiendo allí cooperación y práctica deportiva como un tándem necesario para la formación integral del individuo y siendo estos escenarios formativos lugares óptimos para su experimentación y desarrollo (Ruiz y Cabrera, 2004).

También, el área de EF se posiciona como un escenario formativo desde el que abordar tales capacidades, no solo desde la participación motriz, sino desde los vínculos e interrelaciones nacientes en dichas prácticas, que sin duda enriquecen las experiencias y las vivencias de equipo, proyectando y maximizando los valores que emanan de ellas (Devís, 1996), como preocuparse por los compañeros (López-Pastor, Monjas y PérezBrunicardi, 2003) o participar en grupos heterogéneos (Monjas, Ponce y Gea, 2015).

Además, en el contexto docente se muestra cada vez más preocupación porque FIPEF desarrolle iniciativas y prácticas formativas para que los estudiantes adquieran la competencia para la cooperación, como la base sobre la que apoyar la competencia para el trabajo en equipo y poder realizar mejor una transferencia al mundo profesional, mucho más real y acorde a sus expectativas (Perrenoud, 2013). Por ello, dentro del contexto universitario, en los estándares europeos propuestos por Kudláček y Klavina (2010), se establece la necesaria preparación en la formación del profesorado de EF de la competencia para el trabajo en equipo, a fin de poder transferir las capacidades adquiridas al ejercicio profesional donde se requiera, especialmente en escenarios de diversidad, la colaboración con diversos profesionales del entorno.

En el contexto español, el Libro Blanco del título CAFyD (ANECA, 2005b) y el Libro Blanco del título MEPEF (2005a), establecen la formación a través de las diversas 
disciplinas que conforman los títulos de la competencia para trabajar en equipo, mostrando en ambos casos además, la enorme importancia que dan los académicos y profesionales a esta competencia, cobrando por ello el sentido su presencia en la formación para los profesionales del sector.

Así se recoge la formación de esta competencia en los requisitos para la verificación de los títulos universitarios oficiales, que habilitan para el ejercicio de la profesión de Maestro en Educación Primaria (Orden ECI/3857/2007), a fin de poder promover el trabajo cooperativo entre su futuro alumnado, así como poder diseñar, planificar y evaluar en colaboración con otros docentes y profesionales del centro. También en la Resolución de septiembre de 2018 del Consejo de Universidades, por la que se establecen recomendaciones para la propuesta por las universidades de memorias de verificación del título oficial de Grado CAFyD, cobra importancia la formación de esta competencia a fin de poder ser capaz el futuro profesional, de desarrollar un trabajo multidisciplinar en las ocupaciones de su sector profesional.

Esta formación para el profesorado de EF, que se viene realizando en torno al desarrollo de esta competencia, es reconocida en los trabajos de Fuentes-Abeledo, González-Sanmamend y Raposo-Rivas (2008), Gutiérrez et al. (2018) y Martín y Puig (2007), integrando en las experiencias cursadas la formación de habilidades relacionadas con la interacción personal. También estableciendo relaciones de confianza, construyendo las normas de convivencia y compartiendo responsabilidades. De la misma manera discrepando de los puntos de vista, aprendiendo a cambiar de posición a partir de las evidencias presentadas por los compañeros, afrontando constructivamente los conflictos, no perdiendo de vista los objetivos comunes, compartiendo conocimientos y recursos y reflexionando conjuntamente sobre los procesos desarrollados, los resultados obtenidos y las implicaciones personales a partir de las tareas realizadas para el fin común.

No obstante, a pesar de los beneficios, Asún, Rapún y Romero (2019) encontraron en la percepción de sus estudiantes tras la experiencia que recientemente 
realizaron, apreciaciones de tendencia negativa centradas en la complejidad de la propia acción de trabajar en grupo, de la organización interna y de la diversidad de perfiles que integran los grupos con múltiples personalidades, estilos de liderazgo y asunción de responsabilidades, así como de la dificultad en ocasiones de sobrellevar climas de trabajo negativos y de tensión. No obstante, reconocieron conflictos interpersonales sobre los que se implicaron, siendo tolerantes y negociadores para alcanzar acuerdos, contribuyendo así en su resolución, aunque en este sentido, reclamaban mayor supervisión y apoyo del profesorado, asumiendo un rol de acompañante y guía del proceso (Álvarez, 2011; Tardif, 2006).

Para Fraile (2008), las experiencias de trabajo en equipo realizadas con estudiantes de EF en contextos de formación superior favorecieron aspectos como la comunicación intragrupal, reconociéndose como aspecto esencial en la práctica docente real que ayuda en las relaciones interpersonales mantenidas y en la resolución de conflictos y tensiones. También favorecieron la necesidad de poner en práctica habilidades prosociales como la ayuda mutua y otras como la tolerancia, la escucha, la negociación y el consenso.

Además, incrementaron la tendencia cooperativa frente a la competitiva e individualista en la realización de las tareas, desarrollando no solo la responsabilidad individual para la consecución de la tarea asignada, sino también la responsabilidad grupal para con la consecución de las tareas de los compañeros, aprendiendo todos de todo y no solo cada uno de su parte. Para Benito y Cruz (2005) la esencia del desarrollo de la competencia para trabajar en equipo radica en que los estudiantes, cuando trabajen juntos para completar una tarea, tomen conciencia de la necesidad de preocuparse tanto por su aprendizaje como por el de sus compañeros. 


\subsection{Metodologías que facilitan la adquisición y desarrollo de la competencia para}

el trabajo en equipo

En el Proyecto Tuning se reconoce que las metodologías activas empleadas en la formación superior influyen con cierto éxito en el aprendizaje y de forma específica y directa, en la manera de adquirir y desarrollar las competencias. Siguiendo a Barriopedro, López de Subijana, Gómez y Rivero (2016), las metodologías activas que parece mejor conectan con el desarrollo de la competencia para el trabajo en equipo son el TG, que en los últimos años ha evolucionado hacia el $\mathrm{AC}$, sin perjuicio de otras que encierran un estilo metodológico también de tendencia cooperativa como el aprendizaje colaborativo, el ABP o la realización de supuestos y simulaciones prácticas (SantosRego, Lorenzo-Moledo y Priegue Caamaño, 2009). En cualquier caso se requiere, por parte de los docentes, superar los modelos de enseñanza más tradicionales, para optar por un estilo pedagógico y un perfil docente más guía, orientador y dinamizador de las actividades grupales dispuestas para sus estudiantes (Fraile, 2008).

Fernández-Río (2014), Fernández-Río y Méndez-Jiménez (2016) defienden el AC como el modelo de enseñanza y de aprendizaje desde el que los estudiantes actúan como co-aprendices potenciando la interacción e interdependencia positiva de metas lo que facilita el desarrollo de aprender a trabajar en equipo. Pero observan en la hibridación de modelos pedagógicos la consecución de mayor alcance de los mismos, proponiendo por ejemplo por su potencialidad en conjunto algunos como el AC+Educación Deportiva; AC+ Modelo de responsabilidad personal y social (Hellison, 1995); AC+Modelo Comprensivo de Iniciación Deportiva; AC+Modelo de EducaciónAventura.

El TG ha tomado posición en el EEES como una estrategia metodológica básica para la adquisición de habilidades sociales, destrezas de cooperación, de ayuda y de interacción, tal y como describen Molina, Quesada y Pineda (2010). En el Informe Reflex (ANECA, 2007) se mostraron correlaciones positivas entre el TG y la contribución de este al desarrollo de la competencia para el trabajo en equipo. Resulta 
importante para la formación de los estudiantes, porque su dinámica básica de funcionamiento ya se encuentra en cierta medida dispuesta en un proceder similar en el entorno laboral (Vallejo y Molina, 2011). Pero, lejos de ser entendida esta como una mera agrupación de personas, más bien se concibe el TG como una forma de trabajar juntos y colaborar para la consecución de un objetivo, mediante la realización de unas tareas, tomando decisiones y resolviendo problemas, primando más los objetivos del grupo que la suma individual de la aportación de cada uno de los miembros (Moreno et al., 2007).

El TG se ha convertido en una importante tendencia en educación superior promovido por los educadores por sus beneficios pedagógicos, como el aumento de la motivación en los estudiantes, el intercambio de conocimiento y la creencia de que la solución creativa a numerosos problemas complejos requiere de las aportaciones ad hoc de varios individuos (Barfield, 2003; Johnson y Johnson, 2006; McConnell, 2005). En este sentido, el TG se fundamenta en el enfoque constructivista del aprendizaje. El alumnado construye este aprendizaje asumiendo un rol activo en el mismo, en un escenario de interacción, intercambio de ideas y de conocimientos con el resto de componentes del grupo de pertenencia (Escolano-Pérez et al., 2012).

Pero durante la participación en los TG surgen múltiples dificultades (Burdett, 2007) que devienen en ambientes tensionados desde el punto de vista emocional, ya que tal participación supone mucho más que la disposición del mero saber de cada miembro del grupo sobre un tema determinado. Tales situaciones críticas en ocasiones ponen en peligro la tarea a desarrollar y la efectividad de la sinergia grupal, tal y como establecen Del Canto et al. (2009), Jhen y Mannix (2001), Kerr y Brum (1983), Putnam (1997), Sheingold, Hawkins y Char (1984) y Velázquez (2013) y que condensamos en cinco dimensiones en la tabla 3.11 . 
Tabla 3.11

Problemas críticos surgidos durante el desarrollo de trabajos grupales

Problemas críticos presentes en los TG

- Diferencias respecto de las capacidades individuales de los miembros del grupo y los recursos propios a aportar para su consecución: si éstos presentan diferencias destacables en los conocimientos, habilidades, capacidades o recursos propios para llevar a cabo el trabajo, podría surgir el efecto polizón, poniéndose en riesgo la efectividad del equipo, pues unos asumirán naturalmente más carga de trabajo que otros, siendo los que menos asumen, beneficiarios también de los logros grupales, desequilibrando así la sinergia de fuerzas internas del equipo.

- Desequilibrio en las funciones de los roles a desempeñar para abordar el trabajo, pues en clave de capacidades, es posible que los miembros del grupo más capacitados se reserven funciones superiores de toma de decisiones, de organización de recursos, de liderazgo, o de creación e invención, frente a aquellos, por el contrario, que asumen funciones menores, mecánicas, no disponiendo de oportunidades para exponer su sentir.

- Abandono temprano de la realización del trabajo, ante las discrepancias entre los miembros del grupo, el desequilibrio de funciones, o las dificultades para hacer converger la diversidad de capacidades, generando renuncias y volatilizando la cohesión grupal.

- Pugna para hacer prevalecer los criterios, ideas, procedimientos, estrategias de unos miembros del grupo frente a otros, generando un bucle de autodestrucción a partir de la gestión del conflicto.

- Falta de comunicación para abordar las diferencias y discrepancias como consecuencia de los intereses, objetivos distintos.

Otros aspectos tensores del clima de trabajo grupal, y por tanto potencialmente generadores de conflicto, surgen en los grupos por el absentismo de algunos miembros a las reuniones de trabajo (Burdett, 2007), la injerencia de algunos de sus miembros en la tarea de los otros, sintiéndose invadidos o reprobados que no supervisados y respaldados (Salas et al., 2005). También surgen tensiones cuando no existe el seguimiento del rendimiento en la realización de la tarea y algunos miembros no desarrollan su trabajo, provocando un efecto polizón que intoxica las relaciones personales y la eficacia del TG, beneficiándose unos del esfuerzo de los otros, aportando mucho menos (Kerr y Bruun, 1983; Slavin, 2014). Esta conflictividad provoca en numerosas ocasiones una queja generalizada y muestras de poco entusiasmo por repetir experiencias similares, frustración, estafa y preferencia por el trabajo individual (Gámez y Torres, 2012; McConnell, 2005). 
Aguilera (2018), en su trabajo con estudiantes de magisterio, muestra las dificultades experimentadas para abordar las tareas encomendadas en las asignaturas cursadas desde un planteamiento de TG, a partir del esfuerzo desigual que los miembros del equipo aplican al desarrollo de dichas tareas y el número excesivo y poco heterogéneo de los grupos creados. Otras experiencias de trabajo en equipo en el ámbito de la formación del profesorado de EF (Fraile, 2008; Juez, Julián y Fraile, 2009) describen situaciones de conflicto que derivan en el alumnado hacia una tendencia hacia el individualismo, la competitividad, la insuficiencia comunicativa o la ausencia de habilidades para manejarse en situación.

Se plantea por ello el AC como una metodología activa que estructura el trabajo grupal con el objetivo de minimizar dichos problemas, presentando importantes ventajas formativas para desarrollar la competencia para el trabajo en equipo, facilitando que los estudiantes aprendan que las tareas no son el fin sino el medio. Permite también que alcancen las metas académicas y sociales compartidas e interaccionen unos con otros en grupos reducidos y heterogéneos a fin de lograr un cambio en su comportamiento y en la forma de relacionarse. Además promueve la preocupación responsable de unos por otros, movilizando para ello diversas habilidades y actitudes y valorando finalmente (autoevaluación grupal) la calidad del proceso y el trabajo realizado (Velázquez, 2013; 2015).

Johnson y Johnson (1999) condicionan la eficacia del AC, tal y como lo hacen Salas et al. (2005) en relación al trabajo en equipo, a ciertos aspectos (coincidentes), como la interdependencia positiva entre los miembros de los grupos comprendiendo que su disposición y trabajo beneficia a todos sus compañeros, la interacción promotora y comportamiento de respaldo y apoyo, el ejercicio efectivo de la responsabilidad individual, las habilidades en las relaciones interpersonales y el procesamiento grupal, autoevaluación grupal o seguimiento mutuo de las tareas. Por ello, para desarrollar el trabajo en equipo en la formación superior, tiene sentido promover actividades formativas que contengan los cinco componentes presentados por los autores mencionados. De esta forma, se intenta promover no solamente el desarrollo de la tarea de forma eficaz sino garantizando que el trabajo en quipo desarrollado consiga 
desarrollar los aprendizajes en todos y cada uno de los miembros (Velázquez, Fraile y López-Pastor, 2014).

Algunas experiencias, como las de Aramendi, Bujan, Garín y Vega (2014), Feria-Maldueño, Grimaldi-Puyana, Sánchez-Oliver y Alcaraz-Rodríguez (2017), Hernández y Sánchez (2012), Learreta (2005), Vernetta (2013) aplicando el AC a la formación superior, mostraron su eficacia en aspectos de estructura de grupo (organización, objetivos acordados, eficacia del los roles asumidos), de relaciones interpersonales, de comunicación y de funcionamiento grupal, de responsabilidad compartida, tomando decisiones, aceptando la crítica, intercambiando informaciones, realizando las tareas y siguiendo mutuamente su desempeño evaluándolas).

No obstante, es necesario previamente dar pasos iniciales para promover, en el desarrollo de la persona, las habilidades en las relaciones interpersonales y de la comunicación, necesarias para aprender a trabajar en equipo cooperando (Kagan, 2000). Así, estructuras como el puzzle de Aronson (Aronson, Blaney, Stephan, Sikes y Snapp, 1978) pueden ayudar a iniciar procesos de AC, estimulando el manejo de habilidades y actitudes de comunicación interpersonal, de negociación, de cesión, de ayuda mutua y de asunción de responsabilidades, sin duda necesarias para aplicar a situaciones de trabajo en equipo.

\subsubsection{Habilidades en las relaciones interpersonales}

Las relaciones interpersonales toman como punto de partida la regulación de las emociones, por tanto tiene sentido para este estudio abordar la inteligencia emocional (IE) y social (IS) en tanto son parte del desarrollo integral de los individuos. Los docentes emocionalmente inteligentes manejan su emocionalidad por que saben que la convivencia con su alumnado y en general, con la comunidad educativa, está en juego. 
A continuación se abordan los elementos conceptuales más importantes de la IE y la IS, la necesidad de abordarlos desde las competencia emocional (CE) y social (CS) para desarrollar habilidades favorecedoras de las relaciones interpersonales que facilitan la adaptación social y la interacción con los demás.

Se aborda también el estado de la CE y CS en la FIPEF, el desarrollo de las habilidades en las relaciones interpersonales durante la formación, así como las experiencias prácticas que favorecen su adquisición. Diversas experiencias e investigaciones y mencionadas dan cuenta de tal estado formativo. Finalmente se revisan las metodologías que favorecen su adquisición y desarrollo, considerando aquellas que favorecen la interacción personal y el intercambio comunicativo.

\subsection{De la Inteligencia emocional y social a las competencias emocionales y sociales}

Existe un interés por conocer la utilidad de la IE e IS en las diferentes áreas de la vida de las personas, considerándose que influye conjuntamente en el desarrollo personal y social de los individuos (Bar-On, 2000; Goleman, 1998, 2012; Salovey, Stroud, Woolery, y Epel, 2002). En este sentido, varios trabajos con estudiantes universitarios en situaciones de interacción (Extremera y Fernández Berrocal, 2004; Ramos, Fernández-Berrocal y Extremera, 2007; Schutte et al., 2001) verifican las relaciones positivas entre IE e IS y la calidad en las relaciones personales, puntuando positivamente en aspectos como la empatía, mostrando mayores niveles de afectividad y mayor capacidad para tomar la perspectiva del otro en tales situaciones. Además las personas con mayor atención a su emocionalidad parece muestran mayores niveles de preocupación por las emociones de los demás, estando más dispuestos escuchar y prestar ayuda.

Por tanto, la IE y la IS se reconocen como el punto de partida desde el que abordar el crecimiento emocional y social, en tanto supone la capacidad para apreciar, 
entender y regular las emociones propias en las relaciones con los demás, promoviendo su desarrollo y favoreciendo la calidad de esas relaciones sociales. Bisquerra (2005) considera que las relaciones interpersonales que manifiestan en contextos educativos entre el docente y su alumnado están entretejidas de emociones y son la escucha y la empatía, habilidades fundamentales para establecer relaciones prosociales y crear un clima de aula favorable al trabajo en grupo satisfactorio y eficaz. La empatía, ser consciente, entender y apreciar los sentimientos de los otros, es una habilidad esencial para el desarrollo de la profesión docente, pues de ella depende la percepción de las dificultades y los sentimientos del alumnado durante el proceso de aprendizaje que, mediante la comunicación y las habilidades interpersonales, es necesario gestionar. Uno de los aspectos que forman parte de la empatía es, por ejemplo, la capacidad de observar y prestar atención a las personas, en su entorno, sus necesidades, las interacciones entre ellas, que en ocasiones se descuida, imbuidos los docentes en la dinamización de la materia a impartir y no tanto en la dinamización de las personas (Goleman, 2006).

Los docentes emocionalmente inteligentes serían capaces de apreciar, comprender y manejar su propia emocionalidad y también aplicar estas habilidades hacia las emociones de los demás, siendo empáticos y sintonizando con las señales sociales que los demás muestran (Mayer y Salovey, 1997). La IE es por tanto el constructo teórico sobre el que se asienta la capacidad de adaptación social, siendo clave para el desarrollo de la vida socio-emocional de las personas, capacitando para percibir, evaluar y expresar las emociones, conocerse, comprenderse y regularse emocionalmente, facilitando la adquisición de habilidades interpersonales para interactuar en reciprocidad, entenderse y convivir (Mayer y Salovey, 1993).

La capacidad de percepción, valoración y expresión de las emociones supone la precisión con la que las personas identifican, expresan y distinguen sus propios sentimientos y las emociones que muestran los demás (Mayer y Salovey, 1997). La compresión emocional genera un autoconocimiento emocional mediante el que se etiquetan las emociones, se dotan de significado y se comprenden en su complejidad Finalmente la regulación emocional incluye la apertura tanto hacia los sentimientos 
placenteros como desagradables, para reflexionar sobre ellos, manejando las emociones resultantes, moderando las negativas y proyectando las positivas.

Goleman (1998) considera que la práctica de la IE se asienta en base a cuatro dominios: la conciencia de uno mismo, la autogestión, la conciencia social y la capacidad para el manejo de las relaciones, que facilitan las interacciones sociales en ámbitos como el personal, familiar o profesional. Para ello, se requiere ser emocional y socialmente competente, manejando las habilidades subyacentes a tales dominios, como por ejemplo relacionarse con las personas o resolver conflictos en el ámbito del trabajo. Por su parte Goleman, Boyatzis y McKee (2002), a partir de los mismos dominios planteados, establecieron dos competencias emocionales (CE) para abordarlos: competencia personal y competencia social, incluyendo en cada una diversas habilidades socio-emocionales para su desarrollo (tabla 3.12).

Tabla 3.12

Diversificación de las competencias emocionales a partir de Goleman, Boyatzis y McKee (2002)

\section{Competencia personal}

Conciencia de uno mismo

- Conciencia y valoración de uno mismo

- Autoconfianza

\section{Competencia social}

Conciencia social

- Conciencia de la organización de pertenencia

- Servicio
Manejo de las relaciones

- Gestión de los conflictos

- Trabajo en equipo

- Liderazgo

- Establecimiento de vínculos

De acuerdo con Bisquerra y Pérez-Escoda (2007), las CE suponen un conjunto de conocimientos, capacidades, habilidades y actitudes que sirven para comprender, regular y proyectar adecuadamente en las relaciones interpersonales la vida emocional; de la misma manera. Saarni (1998) considera que las CE permiten ser auto-eficaz en la expresión de las emociones en las relaciones sociales, para lo cual se requiere del conocimiento de las propias emociones así como la capacidad para su regulación desde la madurez y los valores éticos incorporados de la propia cultura. Goleman (2012) 
entiende que todas las emociones son sociales, resultando imposible separar la causa de una emoción del ámbito relacional, ya que son las relaciones interpersonales las que movilizan las emociones. Por lo tanto, el autoconocimiento emocional, su regulación y la autogestión emocional se relacionan expresamente con el éxito en la relaciones sociales y el bienestar personal (Bisquerra, 2003).

La competencia social (CS) supone, siguiendo a Gimpel y Merrell (1998) y Merrell (2002), la adopción de comportamientos adaptativos, prosociales y positivos relacionados entre sí a fin de mantener buenas relaciones con las personas. Para ello, se requiere del manejo de las habilidades interpersonales, la aceptación y cumplimiento de las normas de convivencia y el mantenimiento de la conducta prosocial, en forma de comportamientos beneficiosos para los demás como, por ejemplo, la prestación de ayuda.

Kelly (2002) afirma que la formación de las relaciones con los demás parte de un objetivo a alcanzar y para ello se requiere de la puesta en marcha de un repertorio de conductas y capacidades conversacionales y de expresión emocional, que refuercen socialmente tal objetivo.

Las habilidades en las relaciones interpersonales muestran la capacidad de las personas para interrelacionarse satisfactoriamente entre sí, siendo las relaciones resultantes beneficiosas para ellas. Estas habilidades para la mejor socialización, como sugiere León (2009), se aprenden mediante la observación, la práctica, la reflexión y el refuerzo, en forma de comportamientos seleccionados y adecuados al contexto y al interlocutor con quien se desarrolla la interacción. Se expresan con ellas opiniones y emociones que ayudan a mantener y mejorar las relaciones con el interlocutor, resolver situaciones de conflicto y responder a las exigencias de las situaciones sociales de forma efectiva (León, Medina, Cantero y Gil, 1998). Las competencias interpersonales se desarrollan cuando se establecen relaciones grupales de colaboración, promoviéndose la comunicación, la receptividad, la escucha activa, la asertividad, el compromiso, todas favorecedoras del cambio y de la mejora en las relaciones sociales. 
El buen funcionamiento de las habilidades interpersonales en la práctica requiere del consenso social por el que se comparten y aprueban las habilidades interpersonales en las relaciones sociales, de forma que, siguiendo a García (2016) el contexto cultural $\mathrm{y}$ el propio grupo de relación, son quienes validan como adecuados determinados comportamientos en determinadas situaciones y su efectividad con respecto a la consecución de tres metas: alcanzar el objetivo por el que se comienza una relación interpersonal en base a un interés particular, mejorar la relación constituida y mantener finalmente la propia autoestima. Para ello es necesario atender al carácter situacional en tanto en cuanto una misma conducta puesta en funcionamiento en las relaciones sociales, puede ser adecuada o no atendiendo a dicha situación contextual (Ballester y Gil, 2002).

Para Villa Sánchez y Villa Leicea (2007) resulta imprescindible, desde el punto de vista formativo, incorporar en la educación superior situaciones de aprendizaje mediante actividades prácticas formativas, TG o experiencias vicarias como los simulacros (role-playing), que permitan conocer y experimentar diferentes vivencias en las que desarrollar y aplicar las habilidades interpersonales, considerando tales experiencias, como indica Goleman (2012), oportunidades únicas para optimizar esta dimensión.

El desarrollo de experiencias académicas que formen en la práctica de habilidades interpersonales, requieren, siguiendo a Bisquerra (2003; 2007), García, Cabanillas, Morán y Olaz (2014), Mireya y Filella (2016), Pérez-Escoda, Filella, Soldevila y Fondevila (2013), Ribes (2011) y Saarni (2000) la posibilidad de practicar aspectos como la escucha, la atención, el diálogo, el respecto a las diferencias, la expresión verbal y no verbal, la actividad prosocial y la actuación ante situacinoes interactivas de tensión y conflicto. Estos y otros se resumen en la tabla 3.13. 
Tabla 3.13

Aspectos que han de estar presentes en la formación práctica de las habilidades interpersonales (García et al., 2014; Mireya y Filella, 2016; érez-Escoda et al., 2013; Ribes, 2011; Saarni (2000)

\section{Formación práctica de habilidades para las relaciones interpersonales}

(1) El manejo de habilidades básicas para la socialización y la interactividad con los demás que, a modo de convencionalismos, facilitan la interacción: escuchar y mantener la disposición para el diálogo (por ejemplo mediante formalismos sociales como agradecer, saludar y despedirse).

(2) El respeto a los demás: mostrar aceptación y apreciación de las diferencias individuales así como valorar los derechos de todos.

(3) La comunicación receptiva, atendiendo a los canales verbal y no verbal, posibilitando la recepción de los mensajes con mayor precisión.

(4) La comunicación expresiva: iniciando y manteniendo las conversaciones, expresando y comunicando la propia emocionalidad de manera verbal y no verbal, garantizando que los mensajes transmitidos han sido comprendidos.

(5) Las emociones compartidas, siendo consciente de que la naturaleza de las relaciones interpersonales se definen a partir de la sinceridad expresiva y de la reciprocidad en la relación.

(6) El comportamiento pro-social, manteniendo posiciones interactivas de amabilidad, respeto, preocupación, compasión y participación equilibrada en situaciones de intercambio grupal.

(7) La asertividad, para ser capaz de posicionarse ante la presión grupal entre la vehemencia y la pasividad, defendiendo y expresando las propias posiciones, frente a la presión que ejerce el grupo sobre los miembros.

(8) El comportamiento adaptativo que faciliten la independencia en el entorno social.

(9) La actuación ante las situaciones de conflictividad, previniendo, anticipándose o afrontándolos resolutivamente; esto que requiere de identificar las situaciones problema que necesitan de una solución, midiendo los riesgos y los recursos disponibles para el planteamiento de soluciones; ante el conflicto se requiere de la capacidad de negociación, atendiendo los puntos de vista y emociones de los demás, así como ser capaz de pedir ayuda.

(10) La gestión de situaciones emocionales vivenciadas por uno mismo, afrontándolas, para poder prestar atención a las emociones de los demás.

Sin duda las experiencias formativas prácticas que facilitan el debate y la reflexión despiertan una preocupación formativa por aprender a actuar con los demás, entrenando habilidades como la cooperación, la ayuda mutua, la regulación emocional o la responsabilidad personal y grupal (Caprara, Steca, Zelli y Capanna, 2005; Catalano, Berglund, Ryan, Lonczak y Hawkins, 2004; Penner, Fritzsche, Craiger y Freifeld, 1995). Por tanto, en este sentido forman parte de las habilidades prosociales algunas como ayudar, asistir, cuidar y apoyar; dar, prestar, compartir; consolar, confortar; 
reforzar positivamente, confirmar y valorar; escuchar, empatizar, ser solidario, cohesionar, unir; predisponerse positivamente hacia los demás, comprometerse, comprender, informar y ser asertivo; ser capaz de trabajar con el otro, sentir por el otro, atender al otro (Caprara y Steca, 2005; Hay y Cook, 2007; Warneken y Tomasello, 2009).

3.3.2.2.2 Las competencias emocionales y sociales en la formación del profesorado de EF

La necesidad de hacer presente en la FIPEF la adquisición y desarrollo de las CE y CS puede tener su mejor fin en el reconocimiento de su importancia como futuros docentes para crear un clima de aprendizaje para la comunicación, la interacción, la convivencia y la tolerancia en el aula. Tal y como apunta Blázquez (2016), el docente de EF ha de atender en su contexto de trabajo aquellos condicionantes que le permitan crear un clima de aula socializador y facilitador de la buena convivencia y del aprendizaje. El entendimiento en el aula es uno de los elementos imprescindibles para facilitar los aprendizajes y esto depende en gran medida de las relaciones de cercanía que el docente consiga mantener con su alumnado (Valdemoros-San Emeterio y LucasMolina, 2014).

La creación de escenarios educativos en los que las rutinas de aprendizaje sean efectivas requiere del establecimiento de un ambiente emocional de estabilidad, que garantice que las relaciones profesorado-alumnado se asienten sobre el aprendizaje y desarrollo de habilidades socioemocionales que optimicen sus capacidades para relacionarse y convivir más armónicamente, aprender cooperando y fortalecer la cohesión grupal (Conde y Almagro, 2013; Fernández-Berrocal, Extremera y Palomera, 2008; Pesquero et al., 2008).

Para Armengol et al. (2011), las competencias interpersonales (emocionales, sociales) han de formar necesariamente parte del perfil docente a promover en la formación superior, puesto que, en el contacto profesorado-alumnado facilitan saber 
regular constructivamente las relaciones socioafectivas establecidas; y también en el contacto entre compañeros, ya que permiten saber cooperar adoptando un comportamiento basado en la comunicación y el entendimiento. En este sentido, estudios realizados por Allan, Clarke y Jopling (2009) con estudiantes de magisterio, en relación a su consideración de la efectividad de la enseñanza, revelaron que su percepción de eficacia recae en la capacidad que tienen como docentes para establecer una interacción eficaz con su alumnado. Estos términos también se recogen en los trabajos de Zabalza y Zabalza Cerdeiriña (2011) y Fraile (2013), concluyendo cómo de forma habitual se recuerda a los mejores docentes no solo por su dominio disciplinar, sino también por sus habilidades interpersonales en las relaciones profesoradoalumnado, es decir, otras cualidades que facilitan el aprendizaje al alumnado

Algunos trabajos, como los de Alonso (2008) y Fernández-Batanero (2012, 2013) con docentes de EF en ejercicio y estudiantes MEPEF, muestran una importante valoración de las habilidades interpersonales adquiridas durante la formación cursada para la mediación y la intervención en situaciones de interacción grupal y en ocasiones aplicadas a situaciones asociadas conflictos y roces. En definitiva, revelan que interactuar-escuchar-empatizar son habilidades prioritarias para el profesorado de EF. No obstante, esta valoración coexiste con otras que muestran una débil formación docente para desarrollarlas, dada la importancia que adquiere para el ejercicio de su profesión saber gestionar las relaciones con las familias y con el alumnado, regular sus emociones y gestionar las situaciones de estrés y ansiedad (Camacho y Padrón, 2006; Gutiérrez, Pérez y Pérez, 2013).

Boned et al. (2006) mostraron también la relación entre las prácticas de Actividades Físicas en el Medio Natural (AFMN) cursadas en CAFyD por los estudiantes y la necesidad de desarrollo de sus habilidades interpersonales para poder afrontarlas.

Sánchez y Boronat (2014), Barceló y Ruíz-Corbella (2015), González et al. (2010) observaron que los estudiantes de magisterio encuestados, participantes en 
experiencias prácticas de simulacros docentes o en situaciones de prácticas formativas en centros escolares, mostraron niveles aceptables pero mejorables de dominio de habilidades interpersonales como la comunicación, la negociación, la empatía y la asertividad para buscar soluciones conjuntas, cooperando con sus compañeros e interactuando con el alumnado, adaptándose a los cambios, mostrando iniciativa y regulación emocional.

Hamodi et al. (2018) revelaron recientemente que la formación del profesorado de EF, de forma general, contribuía al desarrollo de competencias personales en mayor medida que las específicas. No obstante, encontraron diferencias entre la percepción de desarrollo de este tipo de competencias más en los estudiantes MEPEF que en los CAFyD; estos últimos valorando haber desarrollado más sus competencias específicas a partir de la formación cursada. De forma coincidente, Maulini, Fraile y Cano (2015) encontraron que tales competencias fueron consideradas mejor desarrolladas por los estudiantes MEPEF a partir de la formación que cursaron que en los estudiantes CAFyD, quienes reconocían haber desarrollado en mayor medida las competencias específicas.

A pesar de lo específico de la titulación CAFyD, diversos estudios realizados mostraron ciertos avances competenciales socio-emocionales condicionados al desarrollo de experiencias prácticas, expresivo-corporales grupales y lúdico motrices durante la formación; tales avances fueron especialmente relevantes en aspectos como la percepción, la comprensión y la regulación emocional, beneficiando para las relaciones interpersonales, las capacidades de flexibilidad y adaptación, de afrontamiento de las situaciones de conflicto, de interacción corporal y de colaboración con los demás (Alonso, Gea y Yuste, 2013; De Rueda y López, 2013; Rodríguez, Caja, Parra, Velasco y Terrón, 2013).

En este sentido, un verdadero ejercicio de colaboración para afrontar las dinámicas del trabajo grupal requiere para Marks et al. (2000), Salas et al. (2005) y Johnson y Johnson (1999), de la incorporación de la capacidad de ayudar, activando el 
comportamiento de respaldo e interacción promotora hacia los compañeros, proporcionando feedback verbal o prestando los apoyos para la realización de las tareas.

Las experiencias de Dyson y Grineski (2001) y Eldar (2008), sobre la influencia de las prácticas físicas grupales en el desarrollo de habilidades interpersonales con estudiantes de EF, revelaron el desarrollo y aplicación de habilidades vinculadas a la negociación y al establecimiento de pactos sobre los retos y tareas a desarrollar con sus compañeros, flexibilizando la postura, adaptándose y optimizando así su capacidad de trabajar en grupo y cooperar (Velázquez, 2015). También Boned et al. (2006), mostraban la relación entre las prácticas de AFMN cursadas y el desarrollo de las habilidades para las relaciones interpersonales para afrontarlas.

Ruíz Omeñaca (2008) defiende un modelo formativo que ayude a desarrollar perfiles docentes de EF cuyo papel en las situaciones reales de conflictividad en el aula sea más mediador que árbitro o conciliador. Este rol más dinamizador de la gestión del proceso de conflicto, busca ayudar a re-equilibrar los poderes que surgen entre las personas en conflicto estableciendo en la comunicación, la herramienta para gestionar la solución a los problemas, creando un contexto de libertad y respeto recíproco para ayudar a hacer comprender la situación que protagonizan y la aborden desde una actitud de tolerancia y comunicación, pudiendo llegar ellas mismas, a establecer los acuerdos, cumplirlos y facilitar la recomposición de la convivencia.

En este sentido, la capacidad de comunicación docente resulta vital para mediar y promover situaciones de aprendizaje donde la interacción y la socialización condicionan las capacidades comunicativas (Mérida, 2012) y el uso del lenguaje va más allá de su uso instrumental para transmitir la información, optimizándose para gestionar la interacción didáctica en el aula, con el alumnado, con sus familias y colaborar con equipos docentes interdisciplinares en favor de proyectos comunes (Danielson, 2011; Gauthier, 2006; Imbernón, 2007). 
Un estudio de Gallego y Rodríguez (2014), con estudiantes MEPEF en relación a su capacidad de comunicación, mostraba valoraciones de suficiencia comunicativa tras la formación cursada. Especialmente en las situaciones en las que se requería la escucha, el mantenimiento del diálogo, el argumento, la necesidad de negociación, comprendiendo los mensajes y las reacciones, mostrando un estilo comunicativo asertivo en situaciones de tensión, conservando la calma, respetando la opinión de los demás en atenta escucha, pero emitiendo su mensaje suficientemente comprensible y directo.

Jares (2006) considera que las conductas competitivas y discriminativas presentes en la sociedad, la ausencia de valores para la convivencia, junto con las importantes carencias formativas del profesorado para aprender a abordar desde la formación inicial los conflictos interpersonales, suponen importantes hándicaps que están presentes en el ejercicio docente. Tales carencias formativas es posible que aumenten, en opinión de Lizaso y Reizábal (2016), por la falta general de oportunidades para practicar las habilidades interpersonales en diferentes situaciones didácticas experimentadas durante la formación inicial, lo que puede acarrear una falta de repertorio de habilidades necesarias para afrontar distintas situaciones sociales o una ausencia de cultura aplicativa y adaptativa a cada situación en la interacción profesorado-alumnado.

Por todo ello, en la FIPEF han de estar presentes experiencias prácticas que ayuden a tomar conciencia de la necesidad de desarrollar las propias competencias emocionales y sociales. Los estudios de Soriano-Maldonado y Delgado-Noguera (2011) con docentes de EF en ejercicio revelaban la importancia que dan estos a la experiencias prácticas de conexión con la realidad educativa, prácticas didácticas y de entrenamiento de habilidades para las relaciones interpersonales durante su formación inicial, por su poder interactivo y de reflexión sobre la práctica y que consideraban no haber recibido de forma suficiente. A la luz de su experiencia, estas oportunidades prácticas de conexión con la realidad acercan mejor a los estudiantes a la realidad laboral; una realidad en la que, de forma prioritaria, se requieren habilidades interpersonales como la comunicación y la empatía, imprescindibles para guiar las relaciones profesorado- 
alumnado en el aula y, en gran medida, necesarias para dinamizar y motivar, crear climas favorecedores del aprendizaje y mediar para la solución a los conflictos.

En las investigaciones de Abarca y Sala (2002), los estudiantes de magisterio encuestados reconocen la importancia de las habilidades en las relaciones interpersonales y, más aún, la empatía como pieza clave para su desarrollo personal y profesional. Además, valoran la necesidad de ser adaptativos $\mathrm{y}$ flexibles emocionalmente, para ajustar las propias emociones y comportamientos en relación a las situaciones cambiantes o en contextos de diversidad. No obstante tanto los resultados de los estudios de Pertegal-Felices y Castejón-Costa (2011) como los del Proyecto Reflex (ANECA, 2007), establecen déficits en la adquisición y desarrollo de las competencias socio-emocionales en la formación universitaria de maestros, reconociendo los estudiantes MEPEF, dificultades en la capacidad de negociar y mediar para solucionar problemas y abordar conflictos.

De la misma forma, Jiménez, Holgado y Pérez (2007) muestran la importancia que otorgan los estudiantes MEPEF para su formación a las habilidades en las relaciones interpersonales como competencia docente, considerando imprescindible su manejo para su desarrollo profesional; no obstante, en el estudio se revela que apenas están presentes este tipo de competencias en las materias cursadas. Aparicio y Fraile (2016) mostraron en este sentido como a través de un programa de expresión corporal en la FIPEF se desarrollaron las habilidades para las relaciones interpersonales, lo que evidencia la idoneidad de la EF para tratar este tipo de competencias interpersonales de forma práctica y directa.

Atendiendo al género algunos estudios consultados, como los de revisión temática de Alcalá, Camacho, Giner, Giner e Ibáñez (2006) y Caballero (2004), mostraron ciertas diferencias, sutiles en algunos casos, en las relaciones entre las variables competencia emocional y género, considerando puntos fuertes y débiles en uno u otro grupo. Así, Gartzia, Aritzeta, Balluerka y Barbera (2012) y Denis, Hamarta y Ari (2005) mostraron algunos puntos fuertes en los hombres como la asertividad o en 
las mujeres la sensibilidad para las interacciones personales y la expresión abierta y sincera de las emociones. En este sentido, Alarcón y Guirao (2014) mostraron que la formación superior, aún no facilitando todavía suficientemente el desarrollo de las competencias socioemocionales, proveía el desarrollo en cierta medida de algunas CE en mayor medida en las estudiantes universitarias mujeres que en los hombres, como la resiliencia, el respeto a los demás y el reconocimiento hacia el otro.

Por su parte García et al. (2014), Olaz (2012), Chan, Rogers, Parisotto y Biesanz (2011) y Toussaint y Webb (2005) obtuvieron resultados sobre el desarrollo de la CS en estudiantes universitarios, también de EF, en los que las mujeres mostraban un desarrollo mayor que los hombres en habilidades comunicativas de asertividad, expresión emocional, empatía, sensibilidad y calma.

También los estudios de Rodríguez Mena (2003) y Romero et al. (2011) con estudiantes MEPEF revelaron que, tanto hombres como mujeres, aunque en mayor medida estas últimas, percibían haber desarrollado habilidades como la empatía, la comunicación, la escucha, la iniciativa personal y la expresión emocional, sintiéndose capaces de contribuir al desarrollo de climas afectivos positivos más íntimos. Aunque el primero mostraba también valoraciones iguales en hombres y mujeres para la capacidad para actuar en situaciones de problemas y conflictos, desmitificando la exclusiva fortaleza de los hombres para actuar ante la conflictividad. Por su parte, Molero, Ortega y Moreno (2010), en sus trabajos con estudiantes de EF, revelaron diferencias en la regulación y reparación emocional en favor de las mujeres, no así los de Gartzia et al. (2012), que revelaron un desarrollo de la regulación emocional similar en hombres y mujeres a partir de la formación recibida.

En trabajos similares con estudiantes de EF en CAFyD (De Rueda y López, 2013; Romero-Martín, Gelpi, Mateu y Lavega, 2017) resultaron desarrollados de forma pareja en hombres y mujeres, aspectos como la percepción, la comprensión y la regulación emocional, sin duda necesarios para abordar las relaciones interpersonales, afrontándolas de forma adaptativa y flexible, interactuado, colaborando mejor y 
abordando los conflictos asertivamente, aspecto desarrollado tanto en hombres como en mujeres también en los trabajos de Repetto, Beltrán, Garay-Gordovil y Pena (2006).

3.3.2.4.5 Metodologías que facilitan la adquisición y desarrollo de las habilidades en las relaciones interpersonales

Fernández March (2006) considera que la formación de competencias como las vinculadas a las relaciones sociales requiere de un cambio en el panorama formativo a nivel metodológico, porque necesitan ser aprendidas y experimentadas con sentido, de forma activa e implicada, con tareas reales para que su aprendizaje sea duradero y significativo, asumiendo el protagonismo el estudiante y siendo el docente el guía que acompaña, orienta, dinamiza y evalúa (conjuntamente) el proceso de aprendizaje.

Castejón et al. (2008) y Extremera y Fernández Berrocal (2004) apuntan que el profesorado a lo largo de su formación inicial ha de desarrollar sus habilidades interpersonales por dos razones, porque a futuro las aulas son el escenario de mayor impacto socioemocional para el alumnado y porque con niveles adecuados de IE e IS se abordan con más éxito los problemas y desafíos de aula. Por ello, parece necesario incluir, para su adquisición y desarrollo, metodologías activas como los TG en situaciones cooperativas para trabajar en equipo, que fomenten el desarrollo de las habilidades interpersonales (Dyson, 2001; Goudas y Magotsiou, 2009; Palomero, 2009; Velázquez et al., 2014). Como resultado del trabajo cooperativo, orientado hacia el desarrollo de los TG, se obtienen beneficios socio-emocionales compartidos, siendo esta metodología para ello mucho más efectiva que el trabajo individual (Chickering y Gamson, 1991).

Tales beneficios socioemocionales en forma de habilidades sociales subyacen de la interacción y la comunicación entre los miembros de los equipos que cooperan entre sí, aprendiendo a escuchar, respetar, animar, criticar ideas, mostrar empatía, prestar cuidado y ayuda a los demás, preocupándose por ellos y por su aprendizaje (André, Louvet y Deneuve, 2013; Darnis y Lafont, 2013; Fernández-Río y Velázquez, 2005; Johnson y Johnson, 1994). 
Desde esta perspectiva de TG y de cooperación, por ejemplo, la realización de dinámicas formativas compartidas entre docentes y estudiantes para la planificación, desarrollo y evaluación de proyectos vinculados a las AFMN (acampadas, orientación, escalada, rutas en BTT), en las que los estudiantes no solo participan sino que también contribuyen activamente en su preparación y consecución, favorecen la creación de ambientes más intensos de interacción personal, cohesión grupal y convivencia. Además les permite desplegar habilidades tales como la comunicación, el comportamiento prosocial, la asertividad y la conducta adaptativa, que se requieren especialmente, para afrontar lasa actividades, potenciando fuertemente el desarrollo de las CE y CS (Baena-Extremera y Granero-Gallegos, 2008; Caballero, 2012; GraneroGallegos, Ruíz-Juan y García-Montes, 2005).

A partir de este planteamiento metodológico, Prouty, Panicucci y Collinson (2007), Gómez (2008), Parra y Domínguez (2009) y Santos y Martínez (2011) consideran que entre las habilidades que se ponen en funcionamiento mediante el desarrollo de TG en clave de cooperación están especialmente presentes la empatía, la asertividad, la colaboración y la expresión emocional, aprendiendo a acomodarlas según la situación. Se experimentan además las ventajas de la mediación en situaciones de roce y conflicto entre compañeros, mediante la escucha y el diálogo en un ambiente altamente formativo (Arribas et al., 2008) que ayuda a funcionar a los grupos como una unidad cohesionada (Weinberg y Gould, 1996).

El aprendizaje de conductas sociales en la formación del profesorado requiere de la prestación de oportunidades para practicar comportamientos prosociales y habilidades interpersonales en diferentes situaciones. En tales experiencias han de estar presentes acciones en las que sea posible, tal y como indican Rosales, Caparrós, Molina y Alonso (2013), la expresión de conductas comunicativas verbales y corporales de interacción con los demás, el debate para mostrar las posiciones e identificar diversos estilos de respuestas (pasivas, asertivas, agresivas), la expresión de ideas, sentimientos y deseos, la cooperación y la prestación de ayuda. En este sentido, en los trabajos con estudiantes CAFyD de Goodyear, Casey y Kirk (2014) y Lavega et al. (2012) se desvelaba que, tras 
las experiencias de AC aplicadas a las tareas grupales y de equipo, se lograron mejorar en general habilidades para relacionarse unos con otros y especialmente su motivación así como su compromiso en relación a sus compañeros de grupo.

También las experiencias prácticas grupales de contacto corporal en materias como expresión corporal, activan habilidades prosociales facilitadoras de la cohesión grupal y de la buena convivencia como la prestación de ayuda y la cooperación (Learreta, Sierra y Ruano, 2005; Ruano, 2013).

En esta línea, metodologías como el ABP son para De Miguel (2005b) una fuente de desarrollo de habilidades en las relaciones interpersonales con las que activar situaciones interactivas de convivencia, comunicación, cooperación, responsabilidad individual y grupal, compromiso y respeto a los demás. Se lleva a cabo la realización de un proyecto o programa de intervención profesional, planificando, diseñando, desarrollando y evaluando a partir de los aprendizajes realizados puestos en situación (Fernández March, 2006; Maldonado, 2008). Dicho proyecto se fundamenta en la experimentación, la reflexividad, la cooperación, la comunicación y la interactividad en situaciones y escenarios próximos a la realidad.

Popescu (2012) considera que el ABP se fundamenta en algunos principios de fuerte tradición constructivista. Las interacciones con el medio permiten comprenderlo mejor a partir de la construcción del propio aprendizaje en y desde este y la evolución del conocimiento se relaciona con la capacidad humana de negociación e interacción social. A partir de ellos el protagonismo del aprendizaje recae en los propios estudiantes, que asumen funciones y responsabilidades, pudiendo convivir, trabajando en equipo, colaborando y reflexionando sobre todo cuanto acontece mientras se trabaja en su desarrollo y a partir también de la retroalimentación del profesorado, que asume un rol de orientador y guía experto (Almirall y Besora, 2015; Fernández March, 2006; García-Valcárcel, Basilotta y López, 2014). 
Algunas experiencias ABP de aplicación en el tratamiento de materias como AFMN, dentro de las titulaciones de formación del profesorado de EF compartiendo experiencias con colectivos vulnerables (Arribas et al., 2008; Becerril y Bores, 2015; González-Cabarcos y Mundina-Gómez, 2014), han sido valoradas por los estudiantes como altamente generadoras de relaciones interpersonales más intensas, de comunicación y diálogo, discusión, negociación y acuerdos para tomar decisiones conjuntas y para resolver conflictos en contextos reales de acción.

Este aspecto, en opinión de Carreiro da Costa (2006), configura un perfil docente de EF que es capaz de realizar no solamente tareas micro (enseñanza del área en relación al aula) y meso (en relación al centro) con las interacciones que conlleva, sino también tareas macro, vinculando el centro educativo con la sociedad y la comunidad a la que se acude para interactuar y aprender.

Otros modelos pedagógicos vinculados a la EF han sido tipificados y descritos por Fernández-Río, Calderón, Hortigüela, Pérez-Pueyo y Aznar (2016) y Peiró y Julián (2015) como facilitadores de competencias socio-emocionales como es el caso del modelo de responsabilidad personal y social (Hellison, 1985, 1995) que desarrolla aspectos esenciales para la interacción con los demás como la responsabilidad, el respeto, la reflexividad, la prestación de ayuda, la empatía, el liderazgo, que redundan en la integración social.

\subsection{La evaluación formativa}

Finalmente se pretende dar cuenta en el presente trabajo de lo concerniente a la evaluación formativa en la FIPEF, a sabiendas de que el sistema favorece la adquisición y desarrollo de competencias, tal y como señalan Brown y Pickford (2013), mostrando una manera de evaluar en la que la retroinformación es esencial para que los estudiantes tomen conciencia, en tiempo real, sobre la realización de las tareas encomendadas y puedan realizar ajustes sobre la marcha. Esta toma de conciencia es la premisa clave del modelo, capacitándoles para que puedan realizar su propia revisión en relación a la 
calidad de las tareas que están desempeñando y en el mismo momento en el que las realizan. Sadler (1989) considera necesario, en este sentido, dotarles de la máxima retroinformación para que, a partir de los consejos y comentarios dados, sean capaces de mejorar competencialmente. Esta forma de evaluar contrasta con la tradicional finalista, en la que prima la postinformación sobre lo que ya se ha hecho, dotando a la tarea realizada de un valor informativo al final del proceso de aprendizaje, fundamentalmente con fines de certificación.

Pero ante este ideal cabría preguntarnos para el caso que ocupa cómo es la evaluación en la FIPEF en la actualidad, a fin de observar si la evaluación formativa está de alguna forma presente o si, por el contrario, siguen primando otras fórmulas menos alternativas. Las guías docentes pueden dar cuenta de primeras pistas sobre cómo se desarrolla el plan de evaluación para la superación de las materias específicas que conducen a la obtención de los títulos MEPEF y CAFyD (de 11 y 6 facultades examinadas respectivamente). El análisis realizado sobre las estrategias de evaluación en ellas en relación al título MEPEF permite observar que tan solo alrededor de un 10\% dan cuenta de un modelo de evaluación formativa. En el resto no aparece claramente este modelo de evaluación y sí rasgos que nos hacen pensar fundamentalmente en una evaluación del tipo continua. Para el caso de la titulación CAFyD, el porcentaje de materias que en sus guías despliegan un sistema de evaluación formativa es similar, optándose en otros casos por modelos de evaluación continua o de proceso.

Se irán desarrollando, a lo largo del capítulo, los principales elementos de la evaluación formativa a fin de aclarar su significado, funcionamiento y valor en los procesos de enseñanza y aprendizaje en la formación superior. Del mismo modo se pretende establecer qué aspectos de la evaluación formativa son susceptibles de ayudar al desarrollo competencial de los estudiantes de profesorado de EF durante el desarrollo de su formación, analizando algunas experiencias formativas recientes de evaluación formativa que se han ido desarrollando al respecto en el panorama nacional de la formación superior en la FIEPEF. 


\subsubsection{Conceptualización: ¿qué es evaluar?}

Tradicionalmente, la evaluación fue entendida como el proceso de recogida de información para emitir un juicio de valor al respecto por parte del profesor, considerando este que la objetividad marcada por su buen enseñar era suficiente para valorar dicha información y olvidando el valor didáctico del error como fuente de aprendizaje. Contraria y desafortunadamente se ha extendido el sentido de error como el factor diferenciador entre, por ejemplo, una exitosa ejecución y una defectuosa, siendo esta última consecuencia de la torpeza, incapacidad o insuficiencia responsabilidad del estudiante (Blázquez, 2016).

Para Bonson y Benito (2005) y Dochy et al. (2002) las prácticas de evaluación que responden a un modelo más tradicional se caracterizan por aspectos como: la orientación hacia la acreditación y certificación, la consideración de la enseñanza y la evaluación como actividades separadas, la no incorporación de la reflexión durante la elaboración de los instrumentos de recogida de información (habitualmente test, exámenes) o un control exclusivo del profesorado quien no revela aspectos previos informativos, como los criterios de evaluación o la estrategia de calificación.

Siguiendo a Gimeno Sacristán (1992), este modelo tradicional de evaluación analiza el resultado de las tareas al final del proceso, dotándolas de un valor específico y confundiendo dicho proceso realizado con la calificación aplicada al respecto, entendiendo los estudiantes, finalmente, que la valoración realizada de la tarea o producto entregado es la propia evaluación. Este modelo no considera los estándares establecidos por Gullickson (2007) relacionados con la utilidad, sentido informativo, beneficio para el alumnado y precisión para infundir un juicio de valor sólido.

Así, parece haberse integrado en este modelo de evaluación tradicional una utilización muy similar de los conceptos evaluación y calificación, llegando incluso a asimilarse confusamente uno en el otro (Álvarez, 2005; Fernández-Balboa, 2006; 
Santos Guerra, 2003), dando por hecho que evaluar es calificar, examinarse y pasar por controles, entregas y selecciones.

Por ello, todo apunta a que las prácticas evaluativas de los procesos de aprendizaje han podido ser sustituidas por prácticas calificativas finales, siendo para el evaluador y el evaluado la nota final alcanzada el aspecto más importante de todo el proceso de aprendizaje (López-Pastor, 2004). Queda por tanto asumir, tal y como indican Dochy et al. (2002), el reto de alcanzar y extender una nueva cultura de evaluación, superando la tradicional del examen, observando nuevas estrategias y criterios (Gessa, 2011) para afrontar las exigencias del EEES y la formación desde una perspectiva competencial (Florido, Jiménez y Santana, 2008), hecho que parece ir paulatinamente en evolución (Palacios y López-Pastor, 2013).

Hamodi, López-Pastor y López-Pastor (2015) diferencian los conceptos de evaluación y calificación, en tanto esencialmente el primero es un proceso de recogida, análisis y juicio de cierta información aportada por el alumnado, para tomar decisiones al respecto; sin embargo, la calificación es definitoriamente una acción de conversión del juicio emitido sobre la información recogida, en forma de valor o nota alfanumérica. Algunos aspectos diferenciadores más al respecto se presentan resumidos en la tabla 3.14 . 
Tabla 3.14

Diferencias entre evaluación y calificación (Hamodi et al., 2005)

Evaluación

Calificación

Se trata de un proceso de recogida de información para analizar, emitir juicio sobre ella y tomar decisiones

Se trata de la acción de transformación y materialización del juicio emitido en forma de valor alfanumérico

Su desarrollo es prolongado durante todo el tiempo $\mathrm{Su}$ aplicación $\quad$ es puntual, circunstancial $\mathrm{y}$ de duración del proceso de enseñanza aprendizaje

Funciones de la evaluación: 1) Formadora (se aprende durante el proceso de enseñanza y aprendizaje); 2) Reguladora (facilita la mejora del aprendizaje durante el proceso para alumnado y profesorado); 3) Pedagógica (visibiliza el progreso de aprendizaje del alumnado); 4) Comunicadora (mediante el feedback entre profesorado y alumnado-alumnado); 5) Creadora de determinados ambientes y climas de aula

\section{generalmente sumativa y final}

Funciones de la calificación: 1) Certificadora (constata ante el entorno social el alcance de los objetivos previstos); 2) Selectiva (de los perfiles mejores y peores conforme los estándares establecidas); 3) Comparativa (de resultados interalumnado e inter-profesorado); 4) De control normativo (obligado cumplimiento por parte del docente de calificar a su alumnado)

Atendiendo al planteamiento conceptual de evaluación dispuesto anteriormente, por tanto, lo que adquiere verdadera importancia es el proceso de enseñanza y aprendizaje, en donde se van adquiriendo y desarrollando los elementos definitorios de las competencias a aprender y, que la misma evaluación en clave de proceso, permite observar, distinguir y corregir, a fin de que los estudiantes puedan reconducir su actuación con mayor diligencia actuando con mayor competencia.

Este planteamiento nos sirve para dar el paso hacia un modelo de evaluación menos tradicional, más formativo y garantista de la toma de conciencia compartida profesorado y alumnado, tanto de lo que se ha aprendido, como de la forma en la que se han realizado tales aprendizajes (Álvarez, 2005). A ello se añade el cómo se aplica lo aprendido a la acción, para dar soluciones adaptadas al contexto, movilizando lo aprendido, que es sin duda, la esencia del enfoque competencial de la formación (Le Boterf, 2001). En este sentido, el protagonismo de los estudiantes es esencial, saliendo del modelo de aprendizaje, que pivotaba en torno a los contenidos y al docente, para entrar en otro que pone en el centro del proceso de enseñanza y aprendizaje al estudiante, lo que obliga a la realización de cambios estructurales en los planteamientos evaluativos en la formación superior (Sonlleva, Martínez y Monjas, 2018). 


\subsubsection{Evaluación Formativa para la implicación de los estudiantes en su desarrollo competencial}

De acuerdo con Villardón (2006), si para la adquisición y el desarrollo de competencias se requiere de la participación activa e implicación del alumnado, es lógico pensar que durante el proceso de evaluación cobre sentido la misma implicación y participación activa de este, configurando dentro del proceso de enseñanza y aprendizaje una misma forma de entender el papel de los estudiantes. Es por ello que la evaluación desde la perspectiva de Barrientos y López-Pastor (2017) tenga pedagógicamente una función no solo acreditativa, sino también formativa en cuanto fuente de aprendizaje para ellos. Este aspecto es esencial para Berraza (2007) si lo que se pretende es ayudarles en su desarrollo competencial a lo largo de su formación, con lo que los modelos de evaluación formativa y compartida se adecúan a este interés.

Así, han de formar parte de la evaluación las propias actividades en las que se movilicen los recursos, conocimientos y habilidades por parte del alumnado, la continuidad del proceso de enseñanza y aprendizaje para facilitar el alcance de mejoras competenciales (Delgado, 2006), la información prestada hacia el alumnado, pre y retroinformativa durante el desarrollo de las actividades. Así mismo la inclusión de la reflexión como base para la toma de conciencia y mejora competencial y la autoevaluación de sus propios límites, permitiéndoles emitir juicios de valor sobre los aprendizajes alcanzados y habilidades aplicadas. Además, han de formar parte también aspectos como la evaluación entre iguales o evaluación por pares, enseñando y estimulando su uso para fortalecer así el desarrollo del pensamiento crítico en situaciones de interacción (Keppell, Au, Ma y Chan, 2006).

Esto hace necesario, tal y como plantean Herrington y Herrington (1998), tratar para la evaluación de competencias: 1) el diseño y planificación del escenario sobre el que el alumnado operará y se desempeñará competencialmente a partir de los aprendizajes a realizar, 2) el diseño de actividades y tareas que impliquen desafíos complejos y poco estructurados a fin de desplegar sobre su consecución las 
competencias a adquirir y desarrollar, y 3) la previsión de las evidencias a recoger garantizando que en ellas se refleja la existencia de aprendizajes adquiridos y aplicados.

Todo apunta a que estas exigencias para optimizar la formación de competencias pueden ser parte de un sistema de evaluación formativa y continua (Denton, 2014), desde el que prestar y obtener información sobre el estado de aprendizaje del alumnado, centrándose en él y en sus necesidades y redundando todo en mejoras constatables, sobre los aprendizajes que va realizando (Boston, 2002; Hanna y Dettmer, 2004).

Así, la evaluación formativa se presenta como un sistema de evaluación cuyo fin es optimizar los procesos de enseñanza y aprendizaje, que los estudiantes aprendan más a partir de los errores y que el profesorado perfeccione su práctica docente, integrándose esta en tales procesos (López-Pastor, 2012). No sirve tanto para seleccionar a las personas que actúan con competencia en la realización de ciertas tareas y trabajos, sino más bien para promover tales competencias entre todos los estudiantes, siendo esta la verdadera dimensión formativa de la evaluación (Hall y Burke, 2003; Kaftan, Buck y Haack, 2006; Sluijsmans, Dochy y Moerkerke, 1998).

Por ello, para su eficacia ha de ser válida, fiable, consistente, justa, inclusiva, controlable, auténtica, exigente, motivadora, eficiente, transparente e informativa mediante el uso de la retroinformación o el feedback (Brown y Pickford, 2013; Hall y Burke, 2003; Kaftan, Buck y Haack, 2006; Sluijsmans, Dochy y Moerkerke, 1998).

Existen diversos estudios en los que se muestra la influencia de los procesos de evaluación formativa aplicados en la formación inicial del profesorado y la promoción de determinadas competencias, especialmente si se ponen marcha procesos metodológicos que lleven consigo la interacción (Brown y Glasner, 2003; Buscá et al., 2012; Delgado y Oliver, 2009; Dochy et al., 2002; Silva y López-Pastor, 2015). Dicha influencia es mayor y eficaz para el desarrollo de competencias interpersonales cuando se activan situaciones de aprendizaje colaborativo y de comunicación interpersonal (Arribas, Carabias y Monreal, 2010; Atienza, Valencia-Peris, Martos-García, López- 
Pastor y Devís-Devís, 2016; Fraile, Aparicio, Asún y Romero, 2018; Hamodi et al., 2018; Hortigüela, Pérez-Pueyo y Abella, 2015; Martínez-Mínguez, 2016). En menor medida se observa influencia para el caso de competencias instrumentales, al igual que han mostrado recientemente los trabajos de Cañadas (2018) y Gallardo-Fuentes, LópezPastor y Carter-Tuhillier (2018).

La revisión de los trabajos de Cañadas (2018), William y Thompson (2007), William y Leahy (2015) y Gibbs (2006) permiten definir a continuación algunas estrategias para promover en la evaluación formativa, que garantizan una mejor adquisición y desarrollo de las competencias promovidas en la formación:

1. Verificar con el alumnado los objetivos de aprendizaje y los estándares de evaluación, así como las técnicas y actividades pensadas para ello, escenarios de desarrollo de tales actividades, tiempos de duración y agentes de evaluación, ayudando de esta forma a que este tome conciencia de todo ello, que estará presente en el proceso de enseñanza y aprendizaje. La especificación de estos referentes permitirá que el alumnado monitorice y supervise su propio trabajo.

2. Diseñar y presentar actividades y tareas que permitan poner en práctica los elementos que conforman las competencias (capacidades intelectuales y técnicas, recursos materiales, actitudes y habilidades interactivas) (Cano, Portillo y Puigdellívol, 2014; OCDE, 2005) para tomar decisiones, resolver problemas y ser eficaz en la exigencia determinada por la actividades propuestas. Esto lleva al docente a equilibrar la carga de trabajo necesaria para su desarrollo, asegurando el éxito, la significatividad de los aprendizajes y la creación de un clima óptimo para ello, aspectos que parece sí son reconocidos por los estudiantes de EF encuestados como ventajas de los procesos de evaluación formativa experimentadas (Gallardo-Fuentes, López-Pastor y CarterTuhillier, 2018; Romero, Castejón, López-Pastor y Fraile, 2017).

3. Dotar de suficientes feedback informativos durante el proceso de enseñanza y aprendizaje como para garantizar que los errores se reduzcan, tal y como proponen 
Asún, Aparicio, Romero y Fraile (pendiente) acercando los resultados que se van obteniendo a los estándares de evaluación que se prevén sean alcanzados. Para Nicol y Milligan (2006) el feedback ayuda competencialmente a distinguir el buen del mal desempeño en la realización de las actividades, facilita el desarrollo de la reflexión (para el reconocimiento de todo lo que lastra su aprendizaje, despertando preguntas que le ayudan a avanzar) y de la autoevaluación (para desarrollar estrategias de desarrollo personal y profesional a utilizar desde el momento presente y proyectándose hacia el futuro). De la misma manera, anima al aumento de las interacciones docente-estudiantes a fin de regular y mejorar el aprendizaje (Higgins, Hartley y Skelton, 2002) aumentando la motivación por aprender del estudiantado (Pieron, 1999).

Son diversos los tipos de feedback que en la literatura revisada facilitan los aprendizajes de los estudiantes en el contexto de la FIPEF. Los de tipo verbal, utilizados por el docente, parece generan en sus estudiantes mejores resultados que los del tipo no verbal (Amoros y Horn, 2000; Koka y Hein, 2005). Askew y Lodge (2000) consideran tres tipos: 1) los mensajes directos del profesorado a estudiantes para ayudarles a aprender, 2) los referidos a la conexión entre las experiencias previas y las nuevas, y 3) el discurso que distribuye equitativamente el poder entre el docente y sus estudiantes sobre el aprendizaje que están realizando y cómo han de hacerlo para optimizarlo.

Por otro lado, atendiendo a la naturaleza del efecto retroinformativo, se establecen varios tipos (Moreno-Murcia, Huéscar, Peco, Alarcón y Cervelló, 2013; Pieron, 1999), los de carácter positivo o aprobador, negativo o reprobador específicamente sobre las actividades y tareas desempeñadas, los que tienen un efecto motivador, orientado más a la persona que a la tarea y los de tipo neutro o correctivo.

La efectividad del feedback, para Gibbs y Simpson (2004), pasa por centrarlo en la realización de las actividades que realiza el estudiante y no en su ser ni en sus características personales. También pasa por asegurar la comprensión de los mensajes, en relación a lo que están realizando y facilitar la consecución de los estándares de aprendizaje sobre los objetivos educativos previstos. Para Boud y Molloy (2013), Nicol 
y McFarlane-Dick (2006) el feedback efectivo hace uso de la conversación con los estudiantes a fin de involucrarlos sobre los aprendizajes generados, implicándolos en su propia supervisión y autoevaluación, instándoles a la responsabilidad de la planificación de sus aprendizajes para extenderlo a lo largo de la vida; además promueve la motivación y la autoestima del estudiante. También Spiller (2009) considera que la inmediatez del feedback ayuda a reconocer más fácilmente los aspectos a mejorar para transferir rápidamente la corrección a otras tareas. Villardón (2006), en relación a la cantidad y calidad de feedback, considera su prestación con cierta frecuencia y suficiente detalle, tan pronto como para no perder la utilidad del mismo durante el proceso de aprendizaje, indicando aquello en lo que se va progresando en forma de conversaciones y discusiones, huyendo de las calificaciones.

4. Favorecer la participación de los estudiantes en el propio aprendizaje y en el de sus compañeros, mediante el uso de algunas técnicas favorecedoras para ello.

La autoevaluación (self-assessment) se refiere a la evaluación que los estudiantes hacen sobre sus propias actuaciones y trabajos, bien sobre sí mismos como individuos o como grupo (Hamodi, 2016). Con ella se pretende alejar de los juicios emitidos por los docentes para dar paso en cierta forma independiente, a la propia reflexión que lleve a la autoevaluación, a fin de promover la valoración sobre el estado de sus aprendizajes para reorientarlo, mejorarlo y transferirlo (López-Pastor, 2012; McDonald, Boud, Francis y Gonzci, 2000).

También pretende aprender a autorregular su propio aprendizaje detectando las dificultades y buscando alternativas para superarse (Hamodi et al., 2015). Mas (2011) considera que entre las responsabilidades sobre la evaluación del docente universitario en la formación que imparte está la de promover procesos de autoevaluación entre sus estudiantes, orientando esta hacia la toma de conciencia de sus aprendizajes.

Para Fraile (2010) algunos beneficios de la autoevaluación pasan por el desarrollo en los estudiantes de principios universales de honradez, dignidad así como 
de capacidades imprescindibles para la vida personal y profesional como la autocrítica, la autonomía y la responsabilidad personal. Sin ellos la toma de conciencia no existe y el valor de la misma desaparece del proceso de enseñanza y aprendizaje, perdiendo su potencialidad educadora. La naturaleza evolutiva de las competencias, estando en constante proceso de desarrollo, requiere de un proceso de evaluación verdaderamente formativa que. a modo de diagnóstico, permita ir actualizando los aprendizajes, renovándolos y aplicándolos en un contínuum, siendo para Brown y Glasner (2003) la autoevaluación la técnica más eficaz. En este sentido dan cuenta Romero, Asún y Chivite (2016), cuyo trabajo con estudiantes de EF mostraba cómo los procesos de autoevaluación promovidos, activaron reflexivamente la capacidad para aunar los conocimientos adquiridos en la formación teórico-práctica, para aplicarlos y transferirlos en la resolución de problemas, en situaciones prácticas expresivo motrices.

La coevaluación (peer-assessment) o evaluación entre iguales o pares es, para López-Pastor (2006), una técnica de evaluación entre alumnos, susceptible de ser aplicada en actividades en las que la participación puede ser tanto individual como grupal. En el caso de los TG, el riesgo de disolución de las responsabilidades individuales no es tal, pudiendo valorar tanto los aspectos individuales de participación en las actividades, como las aportadas al grupo. La coevaluación es, por tanto, una forma de evaluación participativa y pactada entre el docente y su alumnado y entre el propio alumnado entre sí que, en diversas calidades y cantidades de colaboración, realizan una valoración conjunta y negociada de las tareas realizadas (Bovill y Bulley, 2011).

Para Quesada, García y Gómez (2016) la coevaluación tiene una parte de autoevaluación sobre la tarea realizada y otra de contraste con el propio docente $u$ otro alumnado, discutiendo al respecto, dialogando, explicando, argumentando, interactuando, comunicándose, no solo en relación a la valoración de la tarea realizada y los contenidos y habilidades aplicadas, sino también respecto de la autorregulación de sus aprendizajes, surgiendo una idea más exacta y ajustada del grado competencial de realización de la tarea. 
Fraile et al. (2018) mostraron cómo un proceso de evaluación formativa en donde se desarrollaba la coevaluación con estudiantes de EF en MEPEF y CAFyD, promovía y mejoraba competencias de utilidad para el funcionamiento de los equipos de trabajo como la comunicación y el liderazgo, así como la competencia emocional, reguladora de los flujos relacionales entre los miembros de dichos equipos.

Varios trabajos realizados con estudiantes en su formación inicial (Gómez y Quesada, 2017; López-Pastor, Pérez-Pueyo, Barba y Lorente-Catalán, 2016; Moreno, Candela y Bañuelos, 2019) mostraron cómo las estrategias de coevaluación ayudaron, a partir de la retroalimentación ofrecida, al aprovechamiento de los errores para pensar sobre ellos, ser más conscientes, reflexionar y aprender. También en contextos de Practicum, ayudaron a tomar conciencia sobre el grado de desarrollo de competencias transversales como la comunicación, la adaptación a situaciones nuevas o la reflexión sobre las interrelaciones del grupo clase para la intervención docente (MartínezMínguez, 2017).

La evaluación compartida (co-assessment) supone el proceso de diálogo que el docente desarrolla con su alumnado sobre la evaluación de los aprendizajes en el proceso de enseñanza y aprendizaje. Se fundamenta en un proceso anterior de autoevaluación y coevaluación y se cristaliza en forma de diálogos y conversatorios entre el docente y su alumnado (López-Pastor, 2012). Este espíritu responde a la necesidad de implicación de los estudiantes en el proceso evaluador, planteándose de forma dialogada y compartida, en el que la evaluación se entiende de todos y para el beneficio de todos (Santos Guerra, 2000).

Los beneficios para el aprendizaje son múltiples, tal y como señala Bretones (2006), destacando el desarrollo por parte de los estudiantes de la toma de conciencia sobre la calidad de los trabajos que realiza, presenta y expone o, como consideran Boud y Falchikov (2007) y Bretones (2008), desarrollando competencias interpersonales e instrumentales como trabajar en equipo, optimizando la confianza mutua, las habilidades interpersonales como la empatía y las habilidades comunicativas de 
negociación y argumentación (Quesada et al., 2016; Quesada, Gómez y Cubero, 2015). Para Álvarez (2005) y Hamodi et al. (2015) la evaluación compartida responde acertadamente al desarrollo de un modelo educativo democrático que acoge a todos los afectados por ella y es el diálogo igualitario, defendido por Flecha (1998), el que desactiva los hándicaps socio-culturales y personales que la autoridad docente ha sostenido, impidiendo el diálogo constante, no estimulando sino la repetición, más que el aprendizaje.

La calificación realizada por los estudiantes supone una manera de cerrar el proceso de implicación de estos en la evaluación, pensando básicamente, tal y como se ha venido apuntando hasta ahora, si lo que se pretende es que este tome conciencia de su grado de desarrollo competencial, estableciendo para sí un valor sobre los logros alcanzados. Es aprovechable, en este sentido, la calificación dialogada entre docente y estudiante, que es una consecuencia natural de la evaluación compartida realizada, atendiendo a los criterios de calificación establecidos por el docente con anterioridad (López-Pastor y Pérez-Pueyo, 2017). Esta es la esencia que también promueve Blanco (2010) para la evaluación de competencias en la formación superior, planteando un modelo basado en la calificación dialogada, a partir de los logros alcanzados, en relación a unos estándares de adquisición y desempeño predefinidos en los programas de estudios.

Tanto la calificación dialogada como la autocalificación requieren de tiempo y práctica para su adquisición y uso en un estado de sincera responsabilidad (Sicilia, 2010). La autocalificación requiere de la claridad de los criterios de calificación que, a modo de indicadores de logro competencial, promuevan la autorregulación y con ella la posibilidad de mejorar, controlando así el propio estudiante su proceso de aprendizaje (Luís y Muros, 2018).

Supone una forma de aprender a reconocer los éxitos y los hándicaps, guiando hacia el buen desempeño, aunque necesitando para ello de la creación de un escenario y un clima que facilite en confianza y complicidad la interacción y el intercambio de 
información entre el profesorado y el alumnado, como actores implicados en el proceso de enseñanza y aprendizaje. Algunos inconvenientes, como el desajuste inicial entre la calificación del profesorado y la autocalificación de los estudiantes, que en ocasiones no proviene de procesos de autoevaluación (López-Pastor, 2006), puede generar inicialmente cierta confusión y desconfianza (Panadero-Calderón y Alonso-Tapia, 2013), aunque posteriormente facilitan una mejor toma de conciencia competencial y un mayor logro en su desempeño (Moraza y Antón, 2010).

Varios estudios realizados en la formación del profesorado de EF (MEPEF, CAFyD) confirman la presencia y potencialidad educativa de la negociación de la calificación en situaciones de autocalificación o calificación dialogada para la mejora del compromiso de los estudiantes y su autorregulación sobre lo que requieren aprender para alcanzar los logros preestablecidos (Asún, Fraile y Romero, 2016; Hortigüela, Fernández, Castejón y Pérez-Pueyo, 2017; Luís y Muros, 2018); no obstante, estas iniciativas contrastan con otras en las que la participación e implicación de los estudiantes en la calificación es mínima (Arribas, Manrique y Tabernero, 2016; Cañadas, Santos-Pastor y Castejón, 2017; Martínez-Muñoz, Santos-Pastor y Castejón, 2017), no obstante siguen surgiendo estudios en los que continúan siendo los sistemas de heterocalificación los que prevalecen en opinión de los estudiantes en su formación (Cañadas, Castejón y Santos-Pastor, 2018; Gutiérrez et al., 2013; López-Pastor y Palacios-Picos, 2012).

\subsubsection{Medios, técnicas e instrumentos de evaluación}

Tanto Hamodi et. al (2015) como Rodríguez e Ibarra (2011) realizaron un trabajo de clarificación y clasificación en relación a los medios, técnicas e instrumentos que consideraron imprescindibles para la evaluación. También Brown y Pickford (2013) propusieron una relación de métodos y enfoques de evaluación eficaces para la adquisición y desarrollo de competencias en el ámbito de la educación superior, aunque sin aclarar demasiado y más bien generando cierta confusión. Se apunta el planteamiento de Hamodi et al. (2015) por la claridad en la tipificación (tabla 3.15). 
Tabla 3.15

Medios e instrumentos de evaluación (Hamodi et al. 2015)

\begin{tabular}{|c|c|c|c|}
\hline \multicolumn{4}{|c|}{ Medios } \\
\hline \multicolumn{4}{|c|}{ Escritos } \\
\hline Carpeta o dossier & Informe & Portafolio/electrónico & Proyecto \\
\hline Control (examen) & Ensayo & Prueba objetiva & Monografía \\
\hline Cuaderno de campo & Recensión & Foro virtual & $\begin{array}{l}\text { Test de } \\
\text { diagnóstico }\end{array}$ \\
\hline Diario/reflexivo/clase & Foro virtual & Trabajo escrito & Póster \\
\hline \multicolumn{2}{|c|}{ Estudio de casos } & \multicolumn{2}{|c|}{ Memoria } \\
\hline \multicolumn{4}{|c|}{ Orales } \\
\hline Comunicación & Exposición & Ponencia & Cuestionario oral \\
\hline Discusión grupal & $\begin{array}{l}\text { Cuestionario } \\
\text { oral }\end{array}$ & Pregunta de clase & Presentación oral \\
\hline \multicolumn{2}{|c|}{ Debate/diálogo grupal } & \multicolumn{2}{|c|}{ Mesa redonda } \\
\hline
\end{tabular}

Prácticos

\begin{tabular}{ccc}
\hline Demostración/actuación/representación & Role-playing & Práctica supervisada \\
\hline & Técnicas &
\end{tabular}

\section{No interviniendo el estudiante}

Análisis documental y de producciones (revisión de trabajos personales y grupales)

Observación/directa/de estudiante/del grupo; observación sistemática; análisis de grabación audiovisual

\section{Sí interviniendo el estudiante}

Autoevaluación (mediante la autorreflexión y/o el análisis documental)

Evaluación entre iguales (mediante análisis documental y/o la observación)

Evaluación compartida/colaborativa (mediante una entrevista individual o grupal entre docente y estudiantes)

\begin{tabular}{|c|c|c|c|}
\hline \multicolumn{4}{|c|}{ Instrumentos } \\
\hline Diario del profesor & Escala de estimación & $\begin{array}{c}\text { Ficha de } \\
\text { autoevaluación }\end{array}$ & $\begin{array}{c}\text { Escala de } \\
\text { comprobación }\end{array}$ \\
\hline $\begin{array}{c}\text { Ficha de } \\
\text { observación }\end{array}$ & $\begin{array}{l}\text { Ficha de evaluación } \\
\text { entre iguales }\end{array}$ & $\begin{array}{l}\text { Escala diferencial } \\
\text { semántico }\end{array}$ & $\begin{array}{c}\text { Escala descriptiva o } \\
\text { rúbrica }\end{array}$ \\
\hline $\begin{array}{l}\text { Escala de } \\
\text { estimación }\end{array}$ & Informe de expertos & $\begin{array}{l}\text { Ficha de seguimiento } \\
\text { individual o grupal }\end{array}$ & $\begin{array}{l}\text { Escala verbal o } \\
\text { numérica }\end{array}$ \\
\hline \multicolumn{2}{|c|}{ Informe de autoevaluación } & \multicolumn{2}{|c|}{ Ficha de autoevalución } \\
\hline
\end{tabular}


Los medios para evaluar son las actuaciones y productos que realizan los estudiantes y de los que se vale el docente, como recurso para realizar las oportunas valoraciones al respecto.

Por tanto, son diversas las propuestas que se pueden desarrollar en función de los conocimientos, habilidades y actitudes que se pretenden movilizar (Rodríguez e Ibarra, 2011). Zabalza (2004) considera que los portafolios electrónicos, wikis y blogs, aprovechados como diarios reflexivos, son eficaces para que los estudiantes indaguen, documenten, escriban a partir de los aprendizajes realizados y competencias puestas en marcha a lo largo de las actividades realizadas en clase, facilitando el pensamiento reflexivo, la autocrítica y la autorregulación, tal y como corroboran también diversos estudios al respecto (Belmonte, García y Galián, 2016; Correia, Da Silva y De Castro, 2012; Da Silva y Boruchovitch, 2014; Delgado, Hortigüela, Ausín y Abella, 2018; Garello y Rinaudo, 2013; Santos-Pastor, Castejón y Martínez-Muñoz, 2012).

Para Blanco (2010), la utilización de blogs y wikis creados en abierto por los estudiantes, suponen un forma de abordar el volumen de trabajo tecnológico que asumen. Esto supone una ventana para conocer continuadamente el estado de gestión de las actividades de aprendizaje encomendadas y gestionadas por estos. El docente puede acceder al estado de gestión de las tareas que van desarrollando y colgando en el blog y este se convierte en una plataforma de exposición oral y visual desde el que presentar a los demás las tareas desarrolladas. Dejar comentarios en las entradas del blog es una forma de realizar feedback sobre las tareas realizadas orientando la continuidad del trabajo.

El portafolios es un medio auténtico de evaluación de competencias docentes (Díaz Barriga, 2006; Díaz Barriga y Pérez, 2010). Esta autenticidad radica en las posibilidades de implicación que ofrece al estudiante, pasando por la utilización de la herramienta como una carpeta para acumular producciones a hacer uso de ella como un medio para la reflexión sobre sus ideas y conocimientos y para la autogestión y autorregulación, convirtiéndose en una base para la autoevaluación (Pérez Gómez, 
2012; Shores y Grace, 2004; Villalobos, 2002). Para Alcaraz (2016), la autenticidad radica en la comunicación que se establece entre el docente y el estudiante instituyendo un ambiente de aprendizaje en el que están presentes la negociación, la argumentación, el diálogo y el feedback.

Murillo e Hidalgo (2015), consideran que el uso del portafolios permite una evaluación para el aprendizaje más que del aprendizaje; una evaluación para autogestionar su propio proceso, aprendiendo y evaluándose a la vez y, con ello, aprendiendo a distinguir, opinar, razonar, fundamentar, criticar y decidir sobre lo que sirve y no sirve para aprender. Algunos estudios sobre la utilización del portafolios (Angola y Zambrano, 2016; Bolliger y Shepherd, 2010; Chacón y Chacón-Corzo, 2011; Mira, 2016) muestran resultados de eficacia en tanto optimizaron en alguna medida las capacidades inherentes a esta (comprensión y expresión escrita, compresión y expresión oral y en menor medida la interacción oral), así como la autorreflexión y la autonomía, relacionándose con el desarrollo de competencias por tanto de manera directa (Esteve y Arumí, 2005; Gallego, Cacheiro, Martín y Ángel, 2009)

Por su parte Villardón (2006) reconoce en las simulaciones y resolución de casos, medios eficaces de evaluación para constatar ciertos niveles de logro competencial alcanzado por los estudiantes. Corredor y Romero (2008), Gómez y Richters (2017) y Li (2018) proponen para el desarrollo de la competencia comunicativa (por ejemplo mediante una LE) el uso de exámenes orales, presentaciones o exposiciones, considerándose altamente satisfactorios por su poder de muestra sobre el nivel de desarrollo alcanzado, así como por la oportunidad que ofrecen para el estudiante en la toma de conciencia competencial a partir de las interacciones realizadas, lo que les da una referencia no solo sobre su nivel de comunicación, sino también sobre su capacidad de interrelación con los demás y de regulación emocional facilitadoras de la interacción recíproca para entenderse en este tipo de situaciones (Mayer y Salovey, 1993, 1997). Cabrera y Fariñas (2005) mostraron en su estudio la preferencia de los estudiantes encuestados por el desarrollo de actividades en las que prevaleciera el aprendizaje sensorial (auditivo y visual), encontrándose en formas que incluían la presentación y la exposición oral, percibiendo avances en aspectos 
comunicativos (por ejemplo, para el caso de una LE en la comprensión oral y auditiva). Además se percibieron también otras mejoras relacionadas con la interacción y la vida grupal en las que se compartían los pensamientos y las emociones.

De forma similar, Fraile, Aparicio, Romero y Asún (2019) combinaron medios como los simulacros docentes en el aula de expresión corporal, técnicas como la evaluación entre iguales y la autoevaluación mediante el análisis de grabaciones audiovisuales e instrumentos como las escalas descriptivas de observación (rúbricas) observando su utilidad y eficacia para verificar los avances en el desarrollo competencial de la comunicación no verbal de sus estudiantes desde la práctica, facilitando la autorregulación para su mejora.

Los proyectos de aprendizaje tutelado (PAT) suponen un medio muy eficaz para el desarrollo competencial de los estudiantes, aproximando la realidad académica a la laboral, teniendo estos que participar e implicarse de forma activa, orientados por el profesorado, para resolver un problema o situación real del ámbito profesional en escenarios diversos (Gil Flores, Álvarez Rojo, García Jiménez y Romero Rodríguez, 2004; Mayer, 2004). La autonomía para la realización de las tareas desde la perspectiva del learning by doing (aprender haciendo), habitualmente de forma grupal, en torno a un proyecto real o simulación, activan las competencias de los estudiantes para aplicarlas en situación (López Noguero, 2005). Conectan la teoría y la práctica mediante la realización de TG orientados por el docente y fundamentados en un espíritu de cooperación y colaboración, permitiendo desarrollar la comunicación, la crítica, el liderazgo, la responsabilidad y el trabajo en equipo (Barba, Martínez y Torrego, 2012).

Así se observa en los resultados presentados por Manrique et al. (2010), mostrando su validez para el desarrollo de competencias interpersonales como el trabajo en equipo, las habilidades para las relaciones interpersonales y la comunicación mediante el diálogo y la negociación para tomar decisiones. De la misma manera Martínez-Mínguez et al. (2019) muestran la eficacia de los PAT para el desarrollo competencial de los estudiantes, encontrando en la interacción interpersonal la 
necesidad de comunicación y consenso para tomar decisiones, así como una mayor implicación a medida que obtenían información sobre su proceso de aprendizaje y podían hacer juicios sobre su trabajo, tomando conciencia de lo que están aprendiendo a medida que avanzan (Martínez-Mínguez, 2016).

La generación por parte de los estudiantes de documentos escritos (informes), demostraciones y prácticas supervisadas, discusiones y debates grupales al respecto, suponen una combinación de medios que facilitan la autonomía de los estudiantes, su implicación y responsabilidad, el desarrollo de aprendizajes más profundos gracias al seguimiento y retroinformación recibida, el desarrollo de su capacidad para trabajar en equipo, las habilidades inter e intrapersonales y la toma de conciencia de un mayor dominio de conocimientos y habilidades requeridas para el desarrollo de las actividades y tareas propuestas (Aparicio y Fraile, 2014; Manrique, López-Pastor, Monjas y Real, 2010; Martínez-Mínguez, 2016; Martínez-Mínguez, Moya, Nieva y Cabañete, 2019). Pero son sobre todo los exámenes en diversas modalidades y la realización de trabajos escritos, informes y ensayos los medios más presentes en los sistemas de evaluación aplicados a la FIPEF (Arribas et al., 2016; Gutiérrez-García, Pérez-Pueyo y PérezGutiérrez, 2013; Hamodi et al., 2015; Martínez-Muñoz, Castejón y Santos-Pastor, 2012; Palacios-Picos, López-Pastor y Barba, 2013), aspecto que no es de extrañar siendo el texto escrito el soporte tradicional de presentación de la información en la universidad (Díaz, 1993).

Rodríguez e Ibarra (2011), en relación a las técnicas de evaluación, consideran que son las tres estrategias las que ayudan al docente a obtener la información que requiere para abordar los aspectos a evaluar: observación, entrevistas y análisis documental de las producciones académicas de los estudiantes. Si el docente realiza la evaluación sin la implicación de los estudiantes, en función del medio, oral, escrito o a partir de simulacros y situaciones prácticas, puede hacer uso de técnicas como el análisis documental, la observación o la grabación audiovisual. Si el estudiante participa en el proceso de evaluación, las técnicas que pueden aplicarse son la autoevaluación, mediante la autorreflexión y el análisis documental, la evaluación entre iguales 
(coevaluación) y la evaluación compartida a modo de conversatorios (entrevistas individuales y grupales) entre el profesorado y su alumnado (Hamodi et al., 2015).

Asún et al. (2019), en relación a la experiencia de trabajo en equipo realizada con estudiantes CAFyD, encontraron en la percepción de estos que la coevaluación se desarrolló con ciertas dificultades, aunque finalmente consideraron su efectividad para el desarrollo de la responsabilidad personal y grupal, sin perjuicio de preferir la autoevaluación para evaluar el trabajo grupal realizado.

Al respecto, Jiménez (2006) y Morales (2008) señalaron que la autoevaluación y la coevaluación suponen dos técnicas muy útiles para orientar el reparto de la calificación de cada miembro de los grupos que trabajan juntos, minimizando el riesgo, como apuntan Cuadrado et al. (2012), de caer en un sistema de calificación equitativa para todos por igual que, en ocasiones, beneficia el efecto polizón en los equipos (Kerr y Bruun, 1983).

Los instrumentos de evaluación son "aquellos recursos vinculados a las actividades de evaluación, para establecer en ellos los elementos a valorar, indicando con claridad los niveles de logro de cada uno" (Pérez-Pueyo, López-Pastor, Hortigüela, Gutiérrez, 2017, p.80). Las listas de control, escalas verbales y numéricas, rúbricas o escalas descriptivas, escalas de valoración diferenciada, escalas graduadas, fichas de seguimiento individuales, grupales y de observación son algunas propuestas de instrumentos de evaluación planteadas por Pérez-Pueyo y López-Pastor (2017). En este sentido, su uso está cada vez más presente en la formación competencial del profesorado de EF (Alonso-Cortés et al., 2017; Coral, Esquerda y Benito, 2017; Martínez-Mínguez, 2017; Pérez, 2015; Santos-Pastor y Martínez-Muñoz, 2017) .

Los instrumentos de evaluación han de seleccionarse considerando objetivos, contenidos objeto de evaluación, metodologías, nivel educativo, número de estudiantes, dado que no todos sirven para cualquier circunstancia, sino que es esta la que marca su uso y efectividad (Castejón, Capllonch, González-Fernández y López-Pastor, 2011). 
Además, la evaluación de competencias requiere del uso de diversos instrumentos de evaluación, respondiendo así con ellos al carácter pluridimensional que las constituyen (conocimientos, habilidades y destrezas, actitudes) y que el estudiante, ante las situaciones problema que se le plantean, moviliza estratégicamente. Las competencias se adquieren, desarrollan y demuestran desde la acción con lo que en ocasiones no son directamente observables dada su complejidad, aunque siempre puede ser inferida del desempeño, lo que va requerir de la utilización de varios instrumentos que permitan observar, recoger las suficientes evidencias en cantidad y calidad, como para emitir una valoración sobre el grado de desarrollo competencial de los estudiantes (VillardónGallego, 2006).

\subsubsection{Experiencias de Evaluación Formativa en la Formación del Profesorado de} EF

En diversas experiencias realizadas en la formación del profesorado de EF se han ido combinando, en un sistema de evaluación formativa y compartida, diferentes medios, técnicas e instrumentos.

Así, Santos-Pastor et al. (2017) utilizaron el portafolio y prácticas simuladas supervisadas a niveles macro y diarios de aprendizaje y debates sobre lecturas a nivel micro. También se utilizaron la autoevaluación y la autocalificación, junto con una escala numérica diseñada por los propios estudiantes con la ayuda del profesorado.

Específicamente Fraile et al. (2018) diseñaron un procedimiento metodológico mediante prácticas supervisadas a modo de simulaciones docentes, autoevaluación mediante autoinformes, coevaluación a través de rúbricas de observación, debate y reflexión grupal, así como grabaciones audiovisuales para capturar mediante imágenes y audios las prácticas simuladas realizadas y facilitar la toma de conciencia competencial, conforme diversos indicadores de logro predefinidos. 
Se muestra a continuación el esquema del procedimiento metodológico utilizado (figura 3.11) así como una descripción más detallada sobre el desarrollo de la experiencia.

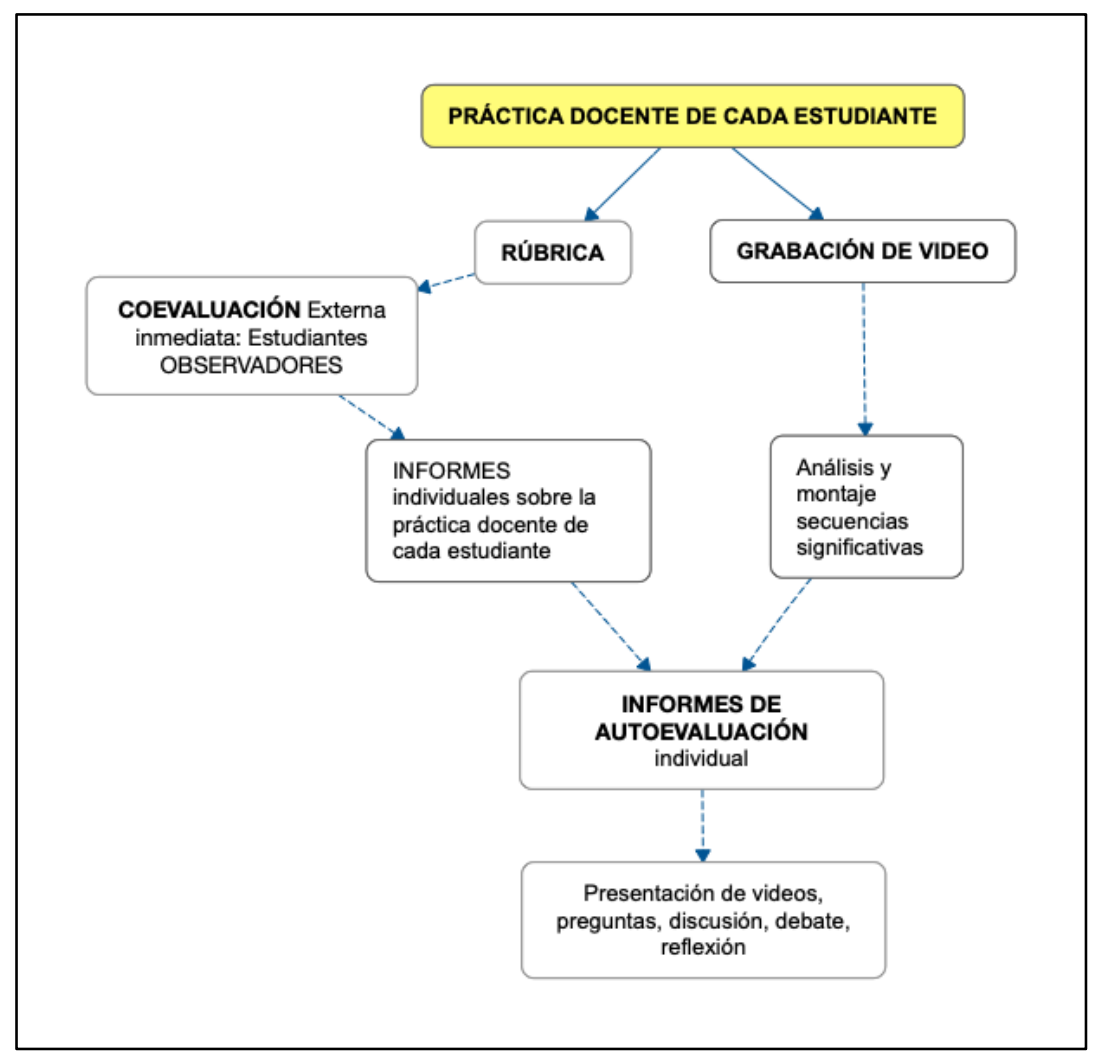

Figura 3. 11. Dispositivo de evaluación formativa en base a simulaciones docentes tuteladas, a partir de Fraile et al. (2018)

El procedimiento se puso en marcha en dos asignaturas relacionadas con los contenidos de Expresión Corporal de las titulaciones de grado MEPEF y CAFyD, de las facultades de Educación (Valladolid) y CAFyD (Huesca). Se estableció una primera fase de revisión de los conocimientos teórico-prácticos mediante el estudio de diversos artículos científicos al respecto, abordando las dimensiones expresivo corporales: espacio-temporal, comunicativa, lúdica, hedonista, introyectiva y cooperativa. Este trabajo supuso la base del conocimiento para desarrollar las propuestas prácticas que fundamentarían las simulaciones docentes. El trabajo de documentación disciplinar realizado se desarrolló metodológicamente en forma cooperativa, potenciando una 
experiencia de trabajo grupal de comunicación, interrelación y discusión entre los miembros de los grupos (Velázquez, Fraile y López-Pastor, 2014).

De la misma manera se buscó fortalecer el pensamiento analítico y sintético durante el trabajo de los contenidos disciplinares, realizando los miembros de los grupos, tal y como indican Fraile, Catalina, de Diego y Aparicio (2018), tareas de selección y procesamiento de la información, resumen y escritura, creando nuevos documentos disciplinares de referencia (informes de contenidos) desde los que fundamentar cada propuesta práctica de actividades a diseñar.

La segunda fase, desarrollada en clave práctica de simulaciones docentes, suponía la adopción de los estudiantes de diversos roles, ocupando el rol de "docentes", “observadores" y "participantes" en las actividades simuladas. En relación al rol "docente" (todos los estudiantes asumen al menos en una ocasión este rol), cada estudiante lo ocupa diseñando su sesión sobre Expresión Corporal y dirigiéndola durante 15 minutos, teniendo como "participantes" a sus propios compañeros. Cada una de estas sesiones es grabada en vídeo para su posterior visionado analítico. Las simulaciones docentes se valoran como herramienta para desarrollar la toma de conciencia competencial, con objeto de vincular el saber teórico y práctico dentro de la complejidad de la formación docente (MECD, 2003).

Los estudiantes asumen también el rol de "observadores" colaborando, ayudados de rúbrica de observación, en el desarrollo de un proceso de coevaluación para con sus compañeros "docentes", tomando notas sobre sus intervenciones en base a diversas competencias de referencia (entre ellas, organización y planificación docente, comunicación verbal y no verbal, habilidades en las relaciones interpersonales, competencia emocional).

Se desarrolla así un proceso de coevaluación entre los propios estudiantes, ofreciendo los "observadores", tras las sesiones prácticas desarrolladas por sus compañeros "docentes", un feedback sobre su actuación. Esta coevaluación, tras la 
intervención de cada estudiante "docente", se materializa en forma de conversatorio entre los implicados (cinco minutos de duración), siendo orientado por los docentes responsables de la materia. Se opta por grabar en audio el conversatorio mantenido a fin de que pueda ser reproducido y contrastado por los estudiantes "docentes" junto con el video de las sesión llevada a cabo.

Se inicia por todos los estudiantes (dado que han ocupado un rol "docente") un proceso de autoevaluación apoyándose en la información recogida mediante las vías audio y vídeo descritas. Este proceso converge en la realización por su parte de un autoinforme personal destacando los éxitos competenciales y también los déficits, mostrando al resto de compañeros en sesión ad hoc, la información recogida en dicho autoinforme y procediendo al visionado de algunas secuencias seleccionadas que ilustren los aspectos remarcados.

Los resultados de la experiencia mostraron avances en la toma de conciencia competencial y desarrollo de competencias como el liderazgo educativo, comprobando la importancia de dinamizar los procesos de aprendizaje y motivar la participación del alumnado; de las misma manera, se avanzó en el desarrollo de la competencia comunicativa prestando especial interés a la comunicación no verbal y al lenguaje corporal como recursos del docente. Finalmente se desarrolló la competencia para la organización y planificación docente.

Con el presente capítulo se ha tratado de conceptualizar y contextualizar el universo competencial en la formación superior, específicamente en el campo de la EF, informando además sobre las dinámicas formativas, procedimientos metodológicos y evaluadores, percepciones, valoraciones, apreciaciones del estudiantado de EF en el contexto nacional, sobre su desarrollo competencial en los estudios MEPEF y CAFyD cursados.

Además se ha mostrado una revisión sobre las dinámicas de evaluación formativa desarrolladas y experimentadas en la FIPEF, evidenciando frecuentemente 
influencias sobre el desarrollo competencial de los estudiantes, atendiendo a los conocimientos disciplinares, pero también al desarrollo de competencias transversales indispensables para la iniciación profesional de los estudiantes.

Por tanto, se ha tratado de establecer un panorama sobre la forma de disposición de la formación superior para la adquisición y desarrollo de las competencias transversales de los estudiantes de EF en el contexto nacional, considerando también su percepción y consideración, a fin de ofrecer un marco teórico y conceptual de contraste para poder abordar el objeto de estudio y las preguntas de investigación que lo completan. Se pretende así conocer finalmente si la disposición de la formación en los estudios MEPEF y CAFyF está ayudando formativamente a la adquisición y desarrollo de las competencias transversales docentes de los estudiantes. 


\section{OBJETIVOS DE LA INVESTIGACIÓN}

La investigación sobre el desarrollo de competencias transversales docentes en la FIPEF, supone conocer efectivamente si la formación prestada ayuda en su adquisición y desarrollo, considerando las dinámicas de las materias que conforman los planes de estudios, pero también las metodologías y los sistemas de evaluación aplicados (Hortigüela et al., 2016).

Este es precisamente el objeto central de preocupación que guía este estudio, teniendo como referentes las propias percepciones y valoraciones de los estudiantes al respecto. Supone indagar qué aspectos de la formación cursada presentes en las materias que conforman los títulos que habilitan para el ejercicio profesional de la EF, ayudan, facilitan, el desarrollo competencial de los estudiantes. Tales aspectos presentes en la formación suponen los planteamientos pedagógicos y didácticos, metodológicos, tareas y actividades de enseñanza y aprendizaje, así como los sistemas de evaluación utilizados para su gestión, que guían a los futuros docentes hacia el qué y el cómo enseñar así como el saber diseñar los programas, actividades y tareas de la enseñanza de la educación física en el contexto escolar y poner en práctica y evaluar los procesos de enseñanza y aprendizaje (Gutiérrez-Díaz, García-López, Pastor-Vicedo, Romo-Pérez, Eirín-Nemiña y Fernández-Bustos, 2017).

Este objeto central de investigación admite, dado su carácter integral, la posibilidad de establecer preguntas de investigación que pudieran guiar de una forma más precisa su abordaje, interrogando sobre el problema que plantea pero urgiendo al abordaje específico de dos de los grupos de competencias transversales de interés, instrumentales e interpersonales. La formulación establecida para las preguntas, admite la posibilidad de ser abordadas desde las metodologías, cuantitativa y cualitativa, dado el carácter mixto de la metodología presente en este estudio. Se presentan a continuación tales preguntas de investigación: 
Pregunta 1. ¿Cuál es la percepción de los estudiantes de EF sobre la ayuda formativa recibida durante su formación para el desarrollo de sus competencias instrumentales desde la perspectiva de género y de la titulación cursada?

Pregunta 2. ¿Cuál es la percepción de los estudiantes de EF sobre la ayuda formativa recibida durante su formación para el desarrollo de sus competencias interpersonales desde la perspectiva de género y de la titulación cursada?

Pregunta 3. ¿Qué relación existe entre el uso de metodologías activas y de evaluación formativa respecto de la percepción de desarrollo de competencias instrumentales e interpersonales que tienen los estudiantes de EF tras su formación?

Pregunta 4. ¿Qué relación existe entre el uso de los instrumentos de evaluación aplicados durante la formación inicial, respecto de la percepción de desarrollo de competencias instrumentales e interpersonales que tienen los estudiantes de EF tras su formación?

Pregunta 5. ¿Qué relación existe entre las formas de calificación utilizadas durante la formación cursada respecto de la percepción de desarrollo de competencias instrumentales e interpersonales que tienen los estudiantes de EF tras su formación?

A partir del objeto central de investigación y de las preguntas descritas se concretan los siguientes objetivos de investigación:

Objetivo 1. Conocer el grado de ayuda formativa recibida a lo largo de la FIPEF, para el desarrollo de las competencias instrumentales.

De este objetivo general subyacen dos específicos: 
1.1.Conocer cómo influye el género a la hora de considerar la ayuda formativa recibida durante la formación, para el desarrollo de las competencias instrumentales.

1.2. Conocer cómo influye el "tipo de estudios de EF" cursados por los estudiantes, a la hora de considerar la ayuda formativa recibida durante su formación para el desarrollo de las competencias instrumentales.

Objetivo 2. Conocer el grado de ayuda formativa recibida a lo largo de la FIPEF, para el desarrollo de las competencias interpersonales.

De este objetivo general subyacen dos específicos:

2.1.Conocer cómo influye el "género" de los estudiantes a la hora de considerar la ayuda formativa recibida a través de las materias cursadas para el desarrollo de las competencias interpersonales.

2.2. Conocer cómo influye el "tipo de estudios de EF" cursados por los estudiantes, a la hora de considerar la ayuda formativa recibida para el desarrollo de las competencias interpersonales.

Objetivo 3. Conocer si existe una relación entre el uso de metodologías activas y la presencia de la evaluación formativa respecto de la percepción de desarrollo de competencias que tienen los estudiantes tras su formación.

Objetivo 4. Conocer si existe una relación entre el uso de los instrumentos de evaluación utilizados respecto de la percepción de desarrollo de competencias que tienen los estudiantes tras su formación.

Objetivo 5. Conocer si existe una relación entre las formas de calificación utilizadas respecto a la percepción de desarrollo de competencias que tienen los estudiantes tras su formación. 


\section{METODOLOGÍA DE LA INVESTIGACIÓN}

En este capítulo se presentan los elementos centrales de la metodología de la investigación. Se estructura en tres secciones: la primera en la que se muestran los referentes teóricos de la investigación, abordando los aspectos característicos del enfoque metodológico mixto; la segunda en la que se da cuenta del planteamiento general de la investigación, aportando información sobre la relación del estudio con otro de mayor calado vinculado a un proyecto de investigación $\mathrm{I}+\mathrm{D}+\mathrm{i}$; y en una tercera en la que se presenta su diseño, describiendo de forma pormenorizada la utilización de los dos métodos que se combinan en el estudio (cuantitativo y cualitativo), dando cuenta de las muestras, los instrumentos de recogida de información, los procedimientos de análisis de los datos y los aspectos de rigor científico.

\subsection{Los referentes teóricos de la metodología de investigación}

Se indican en esta sección los aspectos que justifican la utilización de una metodología mixta de investigación (que combina las perspectivas cuantitativa y cualitativa) para afrontar los objetivos del presente trabajo. Se consideró esencial, para profundizar en el fenómeno objeto de estudio, el uso de diversas técnicas de recogida de información procedentes de los enfoques cuantitativo y cualitativo, pudiendo combinarlas en base a la perspectiva mixta de investigación.

\subsubsection{Enfoque metodológico de la investigación}

Se muestran a continuación las características del enfoque metodológico mixto considerando la naturaleza del objeto de estudio, los fundamentos teóricos de este método, los aspectos que permiten conectar las tradiciones cuantitativa y cualitativa y sus características principales. 


\subsubsection{El objeto de estudio}

En relación al desarrollo de las competencias transversales docentes en la formación del profesorado de EF, se pretende conocer si los esfuerzos formativos realizados ayudan en su adquisición y desarrollo, considerando las dinámicas de las materias que conforman los planes de estudios, pero también las metodologías y sistemas de evaluación aplicados en integrados en la formación. La preocupación por las posiciones del estudiantado sobre su desarrollo competencial, durante la formación inicial cursada, da cuenta de un modelo de investigación que considera su voz como una referencia válida para estudiar la conciencia y el desarrollo competencial de estos, teniendo en cuenta la formación que han recibido. Su conocimiento en detalle pasa por indagar sobre las vivencias, experiencias formativas, pensamientos y reflexiones que permitan comprender de qué forma se han podido ir adquiriendo y desarrollando las competencias transversales objeto de estudio, en virtud de las materias desarrolladas en la formación y los procesos metodológicos y de evaluación experimentados.

\subsubsection{El método mixto de investigación}

En la tradicional dualidad metodológica de la investigación (cuantitativacualitativa), el método mixto surge como una alternativa para aprovechar las ventajas de los dos métodos, articulando sus fortalezas, con vistas a ofrecer una más completa interpretación a cerca del fenómeno de preocupación, en una posición para el investigador más enriquecedora y flexible. Green y Caracelli (1997) valoran, en virtud de la complejidad de los fenómenos sociales, la necesidad de abordarlos a través de diferentes métodos para comprenderla mejor, con lo que la mezcla coherente de ambos enfoques facilitaría el análisis de dicha complejidad.

Se trata de una metodología que orienta la recogida de información y el tratamiento analítico de los datos, combinando las posibilidades de ambos métodos en diversos momentos del proceso de investigación (Creswell y Plano, 2007). El investigador puede mezclar métodos, técnicas, instrumentos, conceptos y lenguaje 
cuantitativo y cualitativo en su estudio de investigación, así como su propia perspectiva en el propio contexto (Greene y Caracelli, 2003; Onwuegbuzie y Johnson, 2006).

Este planteamiento, por tanto, requiere seleccionar los procedimientos en los que se recogen, analizan y mezclan datos cuantitativos y cualitativos en un mismo estudio de investigación (Creswell y Plano, 2007).

A partir de lo expuesto, son tres los aspectos que subyacen y favorecen la aplicación del método: (1) los métodos mixtos conviven con los métodos cuantitativo y cualitativo, siendo altamente útiles en suma; (2) se combinan para aprovechar sus fortalezas y ventajas y optimizar así el esfuerzo investigador y, (3) permiten profundizar más en el fenómeno de estudio y comprenderlo mejor.

Conocer las fortalezas de los métodos cuantitativo y cualitativo a priori, puede ayudar al investigador a tomar posiciones para combinar las posibilidades de ambos. De este modo se maximiza su utilidad y eficacia acorde a los intereses de la investigación, siendo esta la verdadera justificación del uso del método mixto, considerando que el resultado será potencialmente más efectivo que el obtenido desde un único planteamiento metodológico. Se muestran a continuación otras fortalezas (tabla 5.1) de ambos métodos (Johnson y Turner, 2003). 
Tabla 5.1

Fortalezas de los métodos cuantitativo y cualitativo (Jhonson y Turner, 2003)

Fortalezas del método cuantitativo

Es útil para estudiar una muestra amplia de Los datos se categorizan en virtud de sus sujetos.

Aporta cantidad, datos numéricos y Es útil para describir fenómenos complejos y precisión.

Prueba y verifica la construcción de teorías en relación a la ocurrencia de los fenómenos.

Fortalezas del método cuantitativo significados.

estudiar profundamente un número limitado de casos.

Se puede obtener información sobre casos individuales.

Las hipótesis se plantean antes de la Permite describir detalladamente los recogida de datos.

\begin{tabular}{|c|c|}
\hline $\begin{array}{l}\text { La información recogida puede } \\
\text { generalizarse si los datos se fundamentan } \\
\text { en un muestro aleatorio de tamaño } \\
\text { suficiente. }\end{array}$ & $\begin{array}{l}\text { Permite conocer, describir y comprender los } \\
\text { fenómenos que forman parte de las } \\
\text { experiencias personales de las personas. }\end{array}$ \\
\hline
\end{tabular}

Los investigadores pueden desarrollar situaciones que eliminan o minimizan los problemas con las variables, facilitando una mayor credibilidad en la medición de las

Permiten al investigador estudiar las dinámicas de los procesos. relaciones de las causas y efectos.

La recogida de información a partir de La recogida de información se realiza métodos cuantitativos es frecuentemente habitualmente de desde un proceso más rápido. reposado.

Los resultados de la investigación son Los resultados van ligados a la subjetividad e suficientemente independientes del interpretación del investigador. investigador.

\subsubsection{Aspectos característicos del método mixto}

Se abordan a continuación elementos característicos que constituyen la esencia del método mixto: el referente filosófico del que emana este paradigma, los propósitos fundamentales que persigue, las principales ventajas e inconvenientes y su proceso de funcionamiento. 


\subsection{El referente filosófico}

Para Tashakkory y Teddlie (2003) este nuevo paradigma supone el tercer movimiento metodológico y, por tanto, con el mismo estatus que los dos clásicos. Los tres se van desarrollando en un continuum en el ámbito de aplicación de las ciencias sociales. Sus fuentes filosóficas se enraízan en el pragmatismo (Johnson y Onwuegbuzie, 2004; Tashakkori Teddlie, 1998) que:

- Atiende de forma profunda la realidad y la influencia del mundo interior de las personas en la acción, prefiriendo esta antes que la filosofía.

- Reconoce la emergencia del mundo social que incluye su cultura, instituciones, lenguaje y pensamiento.

- Rechaza los dualismos tradicionales y prefiere posiciones moderadas, a fin de resolver problemas mediante elecciones metodológicas.

- Observa el conocimiento como algo a construir fundamentándose en la realidad en la que se vive.

- Plantea la investigación en interacción con el medio como equivalente a la investigación experimental, tratando de resolver los problemas desde la perspectiva con la que se ve el mundo.

- Ofrece a partir de la generación de teorías una información valiosa para la práctica, con lo que la idea de praxis está presente en sus postulados.

- Alcanza verdades temporales, que pueden cambiar desde los resultados de las investigaciones.

- Observa las teorías, perspectivas y, experiencias como caminos útiles, para poder comprender mejor a las personas y a los contextos en los que viven (eclecticismo y pluralismo).

Las controversias y rechazos provocados por fallos, en su lógica a juicio de diversas corrientes filosóficas o, la acusación de incapacidad para producir verdaderos cambios transformadores y respuestas satisfactorias a los problemas de la sociedad, no oscurecen la utilidad del método sino más bien lo contrario. Su pluralismo filosófico admite en su lógica la combinación de distintos métodos para investigar, como la 
inducción (descubrimiento de patrones), la deducción (prueba de teorías) y la abducción (considerar el mejor conjunto de explicaciones para explicar los resultados) (Hernández Sampieri, Fernández y Baptista, 2010), posibilitando ofrecer respuestas a los problemas para resolverlos.

Para Greene (2007), la esencia del pragmatismo y de la perspectiva mixta de investigación radica en su capacidad de convocatoria de distintos modelos mentales en un mismo espacio de investigación, a fin de establecer un diálogo a partir de los enfoques cuantitativo y cualitativo que lo nutren, para redundar en una mejor comprensión del fenómeno de investigación y su abordaje.

\subsection{Propósitos del método mixto}

Atendiendo a Greene (2007), Tashakkori y Teddlie (2008) y Bryman (2008), los objetivos fundamentales del enfoque mixto son las siguientes:

- Triangular (conseguir converger, confirmar, corresponder los métodos cuantitativos y cualitativos, enfatizando el contraste en la información por las dos vías obtenidas).

- Complementar (comprender los resultados de un método sobre la base de resultados del otro).

- Integrar (abordar de forma más completa el fenómeno objeto de investigación utilizando la información cuantitativa y cualitativa).

- Desarrollar (utilizar los resultados desde un método para informar al otro en diversas cuestiones como los procedimientos, la recogida de información o el análisis de los datos).

- Iniciar (encontrar contradicciones y obtener nuevos puntos de vista, pudiendo modificar el planteamiento original de la investigación de un método, con interrogantes y resultados surgentes del otro.

- Expandir (ampliar el límite de investigación haciendo uso de los dos métodos en distintas fases del proceso investigador, pudiendo extender el conocimiento obtenido de uno de los métodos en el otro).

- Compensar (equilibrar las debilidades de un método con las fortalezas del otro). 
- Diversificar perspectivas (obtener distintas miradas, convergentes o divergentes, sobre el fenómeno objeto de investigación).

- Robustecer la credibilidad de los resultados al hacer uso de ambos métodos.

\subsection{Ventajas e inconvenientes del método mixto}

Una de las ventajas generales más importantes que ofrece el método mixto es que permite al investigador responder de forma simultánea a preguntas exploratorias y confirmatorias y, por lo tanto, generar una teoría para responder a su problema de investigación (Teddlie y Tashakkori, 2003). No obstante se muestran a continuación (tabla 5.2) otras ventajas y también inconvenientes de su uso en investigación (Collins, Onwuegbuzie y Sutton, 2006; Creswell, 2005; Hernández Sampieri et al., 2010; Miles y Huberman, 1994; Todd, Nerlich, Clarke y McKeown, 2004).

Tabla 5.2

Ventajas e inconvenientes del método mixto

\section{Ventajas} desde la diversidad de contextos de análisis.

\section{Inconvenientes}

Requiere del esfuerzo para los
investigadores de aprender a desarrollar ambos métodos, comprender y saber cómo hacer su combinación.

Facilita la claridad en el planteamiento del Requiere de mayor tiempo de investigación problema, así como las formas más eficaces y de un uso más complejo de recursos. para estudiarlo.

Permite explorar distintos niveles del Supone para los investigadores atender al problema de estudio. posible conflicto de resultados a partir de los datos cuantitativos y cualitativos analizados.

Permite alcanzar una mayor riqueza interpretativa $o$ mayor poder de entendimiento sobre el problema de investigación (cuantitativa: frecuencia, magnitud, generalización y amplitud; cualitativa: complejidad, profundidad, compresión).

Permite una mejor exploración y explotación de los datos, facilitando al investigador el entrenamiento y el refuerzo de destrezas investigadoras
Dificulta en la práctica el desarrollo de los dos métodos, lo que puede requiere en ocasiones de la ayuda de otros investigadores
Se encuentran resistencias entre los puristas metodológicos que consideran que el trabajo de investigación ha de realizarse solo desde uno de los métodos clásicos. 


\subsection{El proceso metodológico mixto}

Hernández Sampieri y Mendoza (2008) lo consideran como la combinación e integración de los enfoques cuantitativo y cualitativo en las etapas de planteamiento del problema, diseño de investigación, muestreo, recogida y análisis de datos y/o resultados e interpretación.

Se origina con el planteamiento del problema que demanda la integración de las perspectivas cuantitativa y cualitativa de investigación para su estudio (Creswell y Plano, 2007), lo que requiere formular preguntas de investigación en varias posibilidades: a) inicialmente cuantitativas y cualitativas separadas pero seguidas de una mixta; b) una o varias preguntas generales de tipo mixto susceptibles de ser abordadas desde las dos metodologías o que pueda diversificarse en varias preguntas de orden cuantitativo y cualitativo; c) preguntas para cada fase según el investigador observe cómo evoluciona el estudio.

En relación al diseño, se pueden distinguir algunos modelos generales, sin perjuicio de que las investigaciones con métodos mixtos supongan frecuentemente la creación de diseños propios. No obstante en cualquier caso, para su elección conviene responder y reflexionar sobre algunas preguntas relacionadas con (1) el tipo de datos prioritarios en la investigación (si los cuantitativos, los cualitativos o ambos de forma similar), (2) el tipo de recogida de datos que se realizará; al mismo tiempo (simultáneo) o primero un tipo de datos y después el otro (secuencial); (3) la finalidad de la integración de los datos cuantitativos y cualitativos (triangulación, complementación, explicación); (4) la fase del proceso en la que se ha de desarrollar la estrategia de combinación (planteamiento del problema, recogida de datos, análisis, resultados e interpretación) (Hernández Sampieri et al., 2010).

Así mismo es necesario considerar el peso o la primacía que tendrá uno u otro método en el estudio, así como decidir sobre la gestión de los tiempos en referencia, sobre todo, a la recogida y análisis e interpretación de los datos (Tashakkori y Teddlie, 
1998). Para el caso de estatus iguales se sugieren dos modelos generales de aplicación a las investigaciones: concurrente (simultánea) y secuencial (figura 5.1).

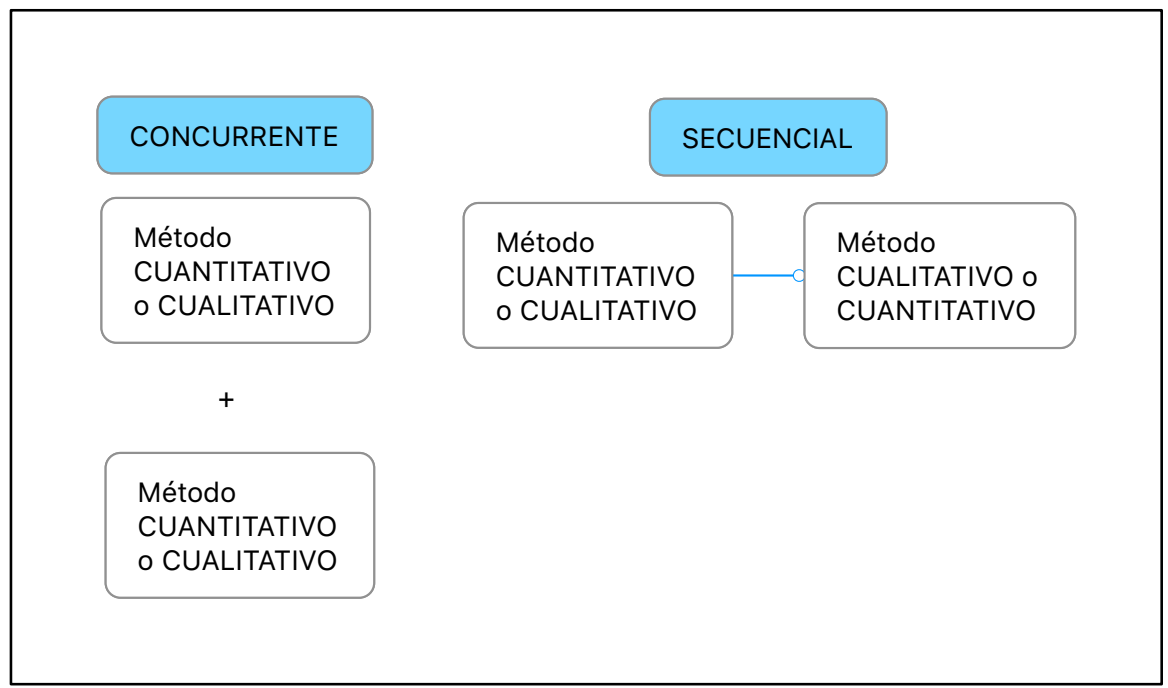

Figura 5. 1. Modelos generales de diseño metodológico mixto para estatus iguales

En el caso de diseños con peso distinto de uno u otro método (figura 5.2) se requiere de la toma de decisiones sobre la prevalencia de uno u otro en el estudio.

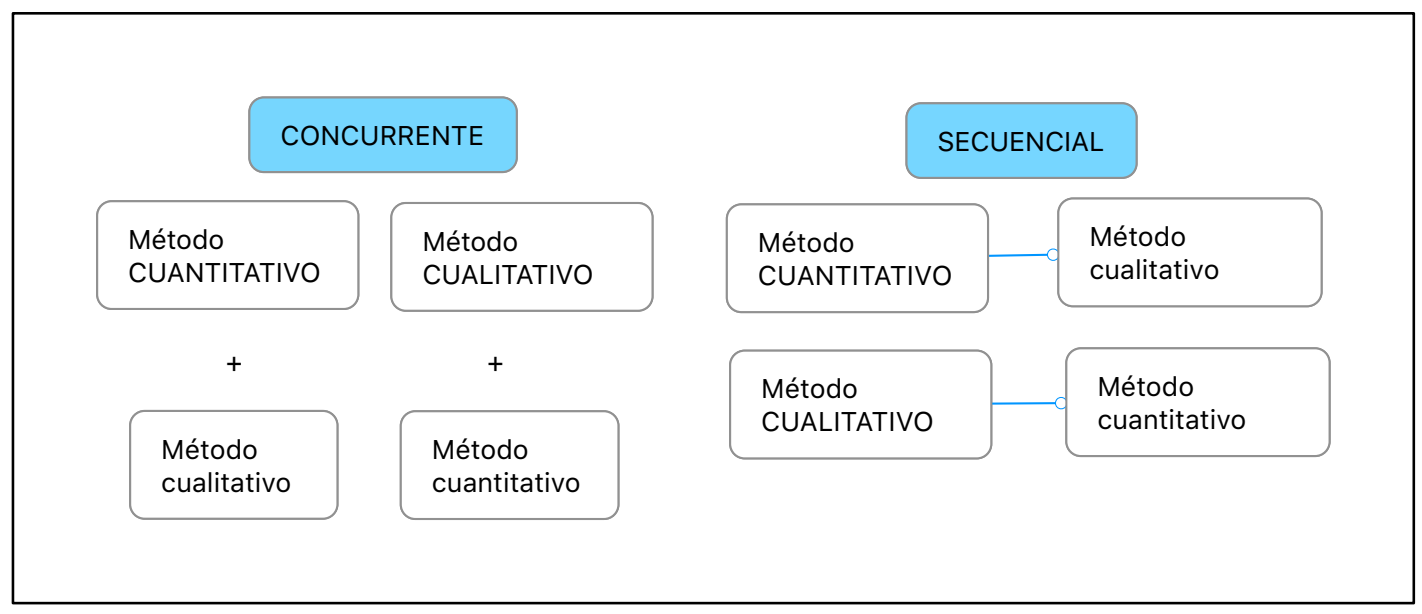

Figura 5. 2. Modelos generales de diseño metodológico mixto para estatus distintos 
De una forma más específica se articulan nuevos diseños a partir de los modelos generales (Creswell y Plano, 2007; Hernández Sampieri y Mendoza, 2008), destacándose los de triangulación, anidado, explicativo y exploratorio.

El diseño de triangulación tiene como finalidad la obtención de datos diferentes pero complementarios sobre el mismo objeto de estudio; los métodos cuantitativo y cualitativo gozan del mismo estatus y se efectúan en un mismo tiempo.

El diseño de anidado o incrustado recoge datos cuantitativos y cualitativos de forma simultánea, pero es uno de los métodos el que guía el proyecto, siendo el menos prioritario de los dos el que se anida dentro del que es guía del estudio.

El diseño explicativo requiere de una fase de análisis de datos cuantitativos seguida de otra de análisis cualitativos, produciéndose la integración en la medida en la que los primeros informan a la recogida de datos cualitativos. Es decir, la segunda fase se construye sobre los resultados de la primera, los resultados de ambas construyen un informe interpretativo del estudio.

Finalmente el diseño exploratorio supone, en esencia, una primera fase de recogida y análisis de datos cualitativos, seguida de una segunda de datos cuantitativos; aunque es posible ejecutarlo de dos formas. Primera opción es la derivativa, en la que la recogida y análisis de datos cuantitativos se construye sobre una base de resultados cualitativos, realizando la combinación en la conexión que se produce entre el momento de análisis de los datos cualitativos y al recogida de datos cuantitativos. Una segunda opción, comparativa, que parte de una fase primera y exploratoria de recogida de datos cualitativos, obteniendo una panorámica general en forma de base de datos sobre el fenómeno objeto de investigación, después, para en una segunda fase recoger y analizar los datos cuantitativos, logrando una segunda base de datos. Los resultados de las dos bases de datos se comparan y se integran en su escritura como reporte del estudio. 
Desde este panorama de diseños se establecerá en adelante el propio para el presente estudio, triangular, elaborado para la presente investigación, desgranando sus aspectos y elementos principales.

\subsection{Planteamiento de la investigación}

La tesis doctoral que se presenta forma parte del proyecto de investigación "Las competencias docentes en la formación inicial del profesorado de Educación Física”. Se trata de un proyecto financiado por el plan estatal de Investigación Científica y Técnica y de Innovación del Plan I+D+i (Ref. EDU2013-42024-R) con una duración de cuatro años (2013-2016). El objeto general de este proyecto supone conocer la percepción que estudiantes, egresados y profesorado tienen sobre el desarrollo competencial en los estudios superiores de EF a partir de la formación dispuesta al respecto, así como la influencia de la evaluación formativa durante el proceso de formación, en 19 facultades MEPEF y de CAFyD del territorio nacional.

Formaron parte activa del proyecto 28 investigadores e investigadoras de la Red Nacional de Evaluación Formativa y Compartida (López-Pastor, Castejón, Sicilia, Navarro y Webb, 2011; Navarro, Santos-Pastor, Buscá, Martínez-Mínguez y MartínezMuñoz, 2010). La Red (https://redevaluacionformativa.wordpress.com) se creó en 2005 por el interés de un grupo de docentes universitarios sobre la evaluación formativa en relación al nuevo EEES y el enfoque competencial de los estudios superiores.

En una fase inicial de la investigación del proyecto I+D+i se desarrolló una revisión bibliográfica sobre las competencias del profesorado de EF, seleccionando las transversales, las específicas y las docentes, consideradas imprescindibles para la FIPEF.

El histórico investigativo de la Red sobre los procesos de evaluación formativa, así como la nueva información bibliográfica recabada en consonancia con el objetivo 
del nuevo proyecto financiado, sirvió para construir el cuestionario de la investigación. El resultante, tras los necesarios ajustes, se sometió a los correspondientes procesos de validez y fiabilidad (aspecto que se explicará más adelante), antes de ser aplicado. Para esta tesis, como parte del contexto, se ha atendido específicamente al grupo de estudiantes. Los datos obtenidos tras la aplicación del cuestionario fueron volcados a una base de datos, analizando los resultados al respecto. La presencia de los datos cuantitativos obtenidos se considera parte importante de la presente investigación, ocupando un lugar en el diseño de investigación que se mostrará a continuación.

\subsection{El diseño de la investigación}

A lo largo de esta sección se ponen de manifiesto los elementos que han servido para el diseño de investigación. Se exponen los métodos, las técnicas e instrumentos de investigación utilizados, junto con la justificación de su selección y uso, así como sus características.

\subsubsection{Diseño de la metodología de investigación}

Hernández Sampieri y Mendoza (2008) y Creswell (2009) sugieren para la presentación de los diseños mixtos la especificación de los métodos, así como la forma de recolección y de análisis de los datos. Sugieren además la presentación del esquema mixto diseñado junto con la explicación de las fases y dinámica de funcioanmiento del mismo, clarificando también la triangulación. A continuación se explica el procedimiento metodológico diseñado y utilizado.

A fin de recoger, analizar e interpretar los datos obtenidos, se optó por un diseño de triangulación concurrente (Creswell y Plano, 2007; Hernández Sampieri y Mendoza, 2008), dado que se consideró el más indicado para confirmar y ratificar resultados y validar, de forma cruzada, los datos cuantitativos y cualitativos, beneficiándonos así de 
las ventajas y las fortalezas de cada método. Se toman como base y guía del estudio los resultados cuantitativos para contrastar con los resultados cualitativos.

Se comenzó por establecer las preguntas de investigación que ayudaran a alcanzar los objetivos previstos a partir de ellas, construyendo preguntas de carácter mixto y sirviéndose de los procedimientos metodológicos cuantitativo y cualitativo para responderlas (Fase 1).

En la Fase 2, se recogieron los datos a partir de las dos perspectivas metodológicas: cuantitativa y cualitativa (se recolectan los datos sobre la percepción y caracterización que hacen los estudiantes en relación a la ayuda formativa recibida para la adquisición y desarrollo de sus competencias transversales, considerando las variables género, tipo de estudios cursados y facultades de procedencia). También la relación del uso de metodologías activas, de evaluación formativa, instrumentos de evaluación y sistemas de calificación aplicados a los estudios cursados en relación a la adquisición y desarrollo de las competencias objeto de estudio.

Se fueron analizando (Fase 3), de forma simultánea, los datos cuantitativos y cualitativos. Desde el punto de vista cuantitativo, se realiza un estudio estadístico descriptivo, comparativo y correlacional. Desde el punto de vista cualitativo, se realiza un análisis de contenidos procedente de la realización de dos GD, cuyos debates fueron registrados y transcritos.

En el momento de la presentación de los resultados y su interpretación (a partir de los objetivos de la investigación), se realizó la integración, comparando y explicando los dos tipos (cuantitativos y cualitativos), incluyendo en la escritura, referencias a las preguntas de investigación, mediante resultados cuantitativos (estadísticos: tablas y gráficos), seguido de resultados cualitativos, presentados en forma de tablas, redes semánticas y segmentos de texto, que pudieran contrastar, interpretar y explicar los hallazgos cuantitativos, tal y como propone Creswell (2009) (Fase 4). Finalmente se 
realizó la discusión a partir de la combinación realizada de los resultados, respondiendo a las preguntas de investigación y estableciendo las conclusiones (Fase 5).

Se muestra en la figura 5.3 el esquema del diseño metodológico aplicado, atendiendo las dos vías metodológicas (cuantitativa y cualitativa) que son la base para el ejercicio de la triangulación de los resultados.

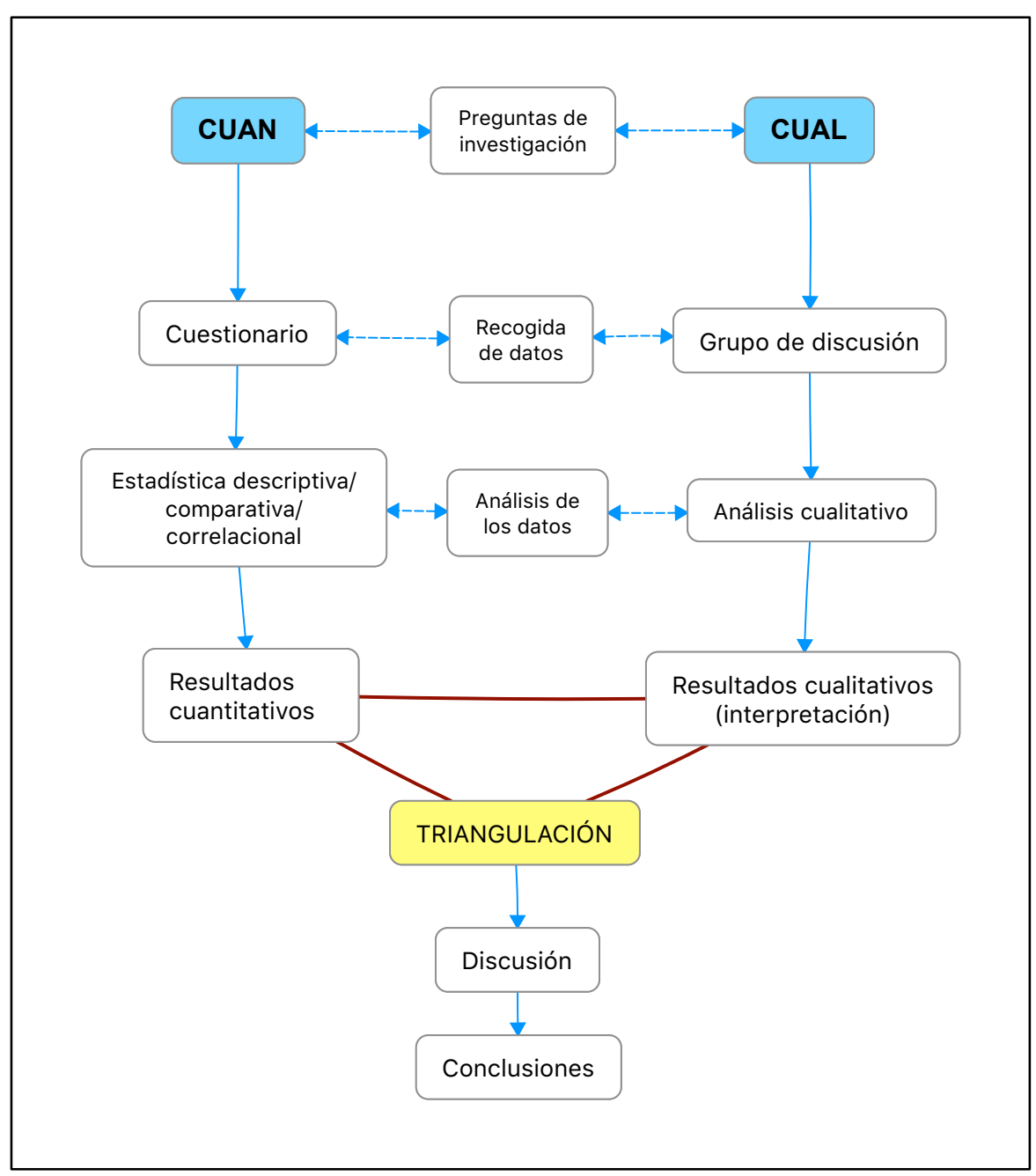

Figura 5. 3. Esquema del diseño de investigación y detalle de la triangulación de resultados 


\subsubsection{Métodos de investigación utilizados}

La combinación de métodos cuantitativo y cualitativo, desde una perspectiva mixta de investigación, permite en este estudio, explorar, analizar, comparar, describir, interpretar y explicar en qué medida y de qué manera la formación recibida ha facilitado la adquisición y desarrollo de las competencias transversales de los estudiantes.

\subsubsection{El método cuantitativo}

En investigación social se inscribe en el paradigma positivista que tiene como finalidad el control de los fenómenos mediante la experimentación, a través de pruebas causa-efecto y siguiendo un riguroso procedimiento para alcanzar estándares de validez y fiabilidad, de cara a que las conclusiones extraídas puedan contribuir a la generación de conocimiento. Desde este modelo se concibe la realidad como algo estable, donde el conocimiento parte de la explicación y la predicción buscando, desde la experimentación, la objetividad de los resultados. Test y análisis estadísticos son habituales instrumentos y técnicas utilizadas con muestras amplias de población. Su tratamiento permite manejar conjuntos de datos numéricos, facilitando su descripción, comparación y correlación (Bisquerra, 2009).

Algunas características que definen el método cuantitativo son (Fraile, 2018): (1) estudia los fenómenos observables susceptibles de medición y control experimental; (2) toma como punto de partida un planteamiento positivista que busca causas de los fenómenos, siendo lo subjetivo descartado de la investigación; (3) el análisis de la realidad se realiza desde un punto de vista objetivo y externo al fenómeno; (4) los estudios realizados se plantean para la comprobación hipotético-deductiva, siendo el resultado final el hecho trascendente de la investigación; (5) los resultados son generalizables. 


\subsection{La muestra}

En relación a la muestra, la selección de los estudiantes participantes en el estudio se realizó mediante un muestro incidental no probabilístico, dado que a pesar de que un muestreo aleatorio hubiera permitido generalizar los resultados, de esta forma se pudo facilitar el acceso de los investigadores al campo. La muestra final es de 1173 estudiantes. Proceden de las titulaciones de los grados de Maestro de Educación Primaria con la mención en EF (MEPEF) (794 estudiantes) y de Ciencias de la Actividad Física y del Deporte (CAFyD) (373 estudiantes), aunque hay 6 que no han aportado información al respecto $(n=1167)$. (Figura 5.4)



Figura 5. 4. Distribución de la muestra en función de la titulación de Educación Física cursada

De la misma manera de los 1173 estudiantes, 24 no emitieron información en relación al género $(n=1149)$, siendo 463 el número de mujeres participantes; igualmente 39 no informaron sobre su edad $(n=1134)$ (Figuras 5.5 y 5.6). 


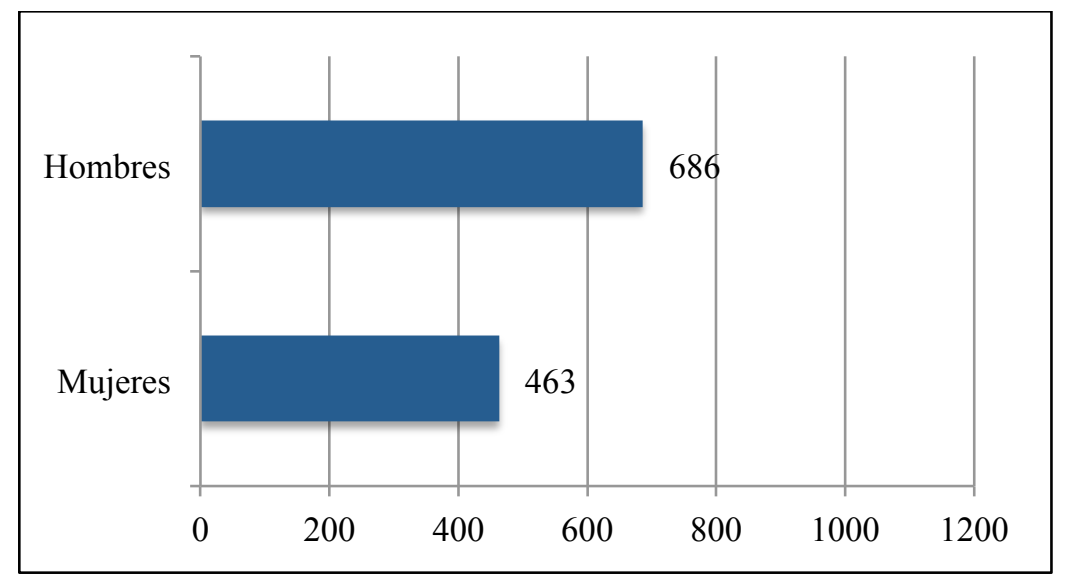

Figura 5. 5. Distribución de la muestra según el género

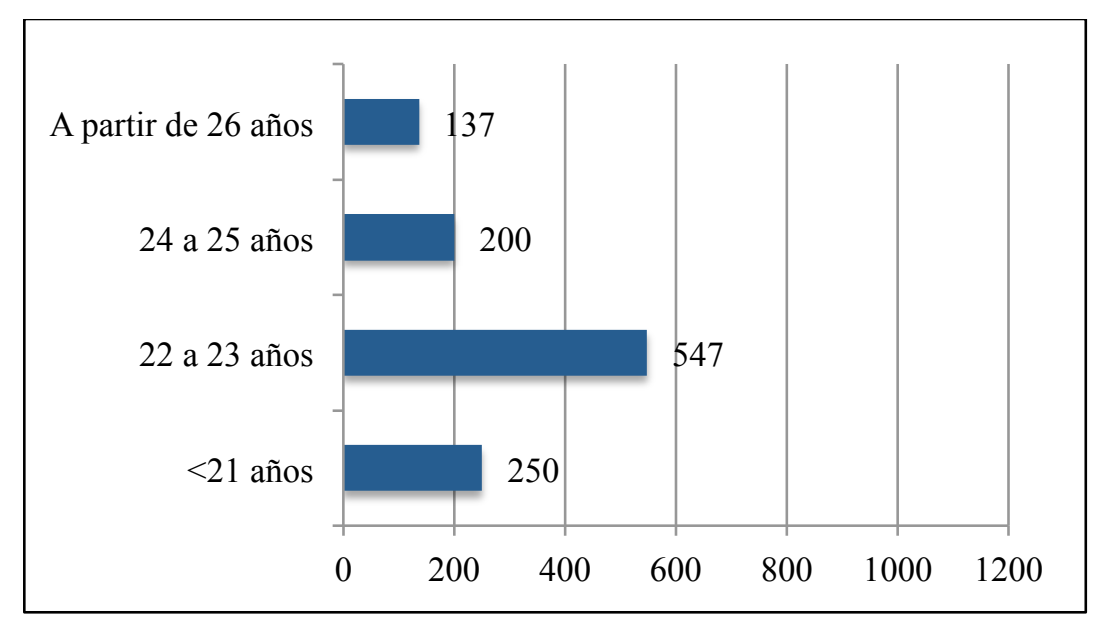

Figura 5. 6. Distribución de la muestra atendiendo a las franjas de edad

En relación a las facultades donde realizaron sus estudios, se pudo averiguar, a partir de las localidades de origen, el tipo de estudios cursados y la procedencia de los investigadores que colaboraron en la gestión del proyecto, las facultades de Educación y de Ciencias de la Actividad Física y del Deporte de los estudiantes, estableciéndose finalmente en 12 las Facultades MEPEF y en 7 las Facultades CAFyD implicadas en el proyecto. A este respecto, se descartaron de los 1173 estudiantes participantes en el estudio, 17 que no informaron sobre su localidad de origen y 6 que no lo hicieron sobre el tipo de estudios cursados $(n=1150)$. 
Las Facultades MEPEF participantes son las siguientes: Albacete (Universidad de Castilla La Mancha), Barcelona (Universidad de Barcelona), Córdoba (Universidad de Córdoba), Granada (Universidad de Granada), Madrid (Universidad Autónoma de Madrid), Murcia (Universidad de Murcia), Santander (Universidad de Cantabria), Segovia (Universidad de Valladolid), Sevilla (Universidad de Sevilla), Tenerife (Universidad de La Laguna), Valencia (Universidad de Valencia) y Valladolid (Universidad de Valladolid).

Por su parte, las Facultades de CAFYD de origen de los participantes son: Huesca (Universidad de Zaragoza), León (Univesidad de Léon), Lleida (Universidad de Lleida), Murcia (Universidad Católica de Murcia), Sevilla (Universidad de Sevilla), Vic (Universidad Vic) y Vitoria (Universidad de País Vasco) (Figuras 5.7 y 5.8).



Figura 5. 7. Distribución de la muestra considerando las facultades de Educación y universidades de procedencia 


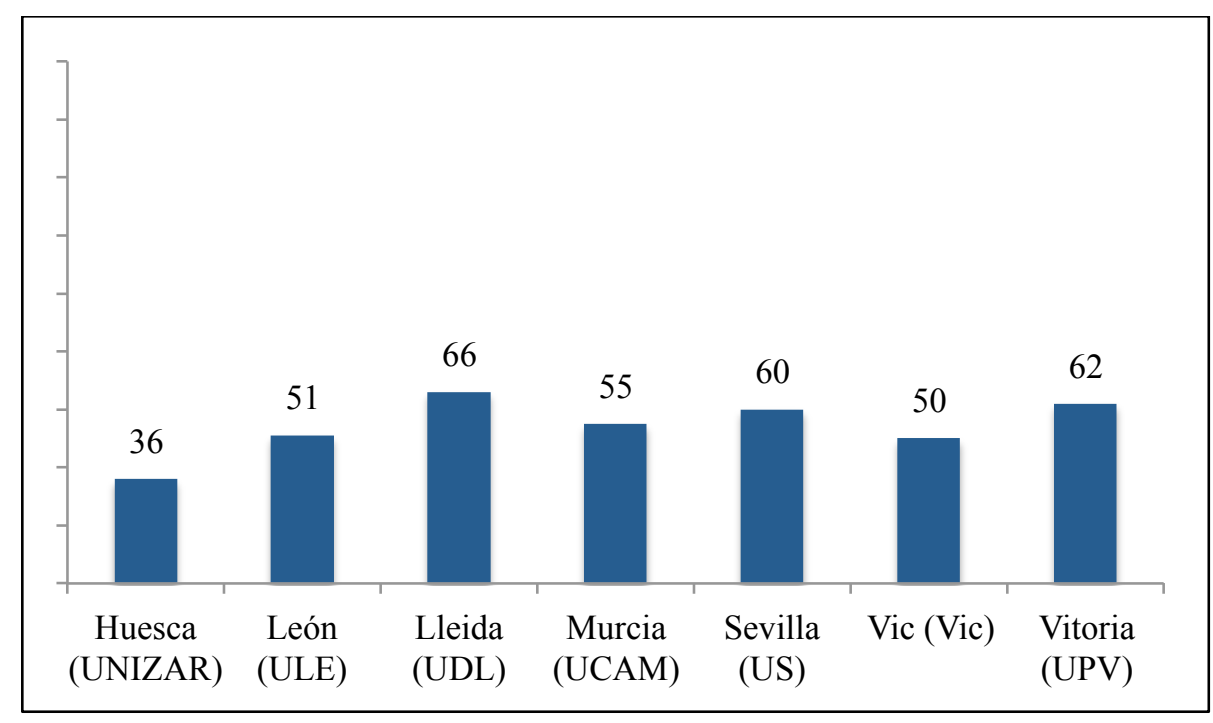

Figura 5. 8. Distribución de la muestra considerando las facultades de Ciencias de la Actividad Física y del Deporte y universidades de procedencia

\subsection{Instrumento de recogida de datos}

Respecto al uso de instrumentos, tal y como se avanzó anteriormente, se aplicó un cuestionario (Anexo 1) para obtener información sobre la percepción del desarrollo competencial a partir de la formación de EF cursada, denominado "Las competencias docentes en la formación del profesorado", diseñado especialmente para el desarrollo del proyecto de investigación del que forma parte la presente tesis doctoral. Los Libros Blancos para los títulos MEPEF y CAFyD (ANECA, 2005a, 2005b) fueron la base sobre la que se construyó el cuestionario para, posteriormente, ser sometido a un proceso de validación, en Palacios-Picos, López-Pastor y Fraile-Aranda (pendiente), sujeto a los siguientes momentos: (1) seleccción de los items a partir de los Libros Blancos establéciendose una versión inicial; (2) revisión por 10 investigadores y académicos expertos en Didáctica de la EF, con amplia trayectoria nacional e internacional, depurando el documento incialmente diseñado y obteniendo otro con 76 items; (3) valoración de la comprensión de los items establecidos realizándose un primer pretest con estudiantes. Para la estimación de las respuestas de cada item se usó una escala tipo Likert (Likert, 1932) de 5 puntos cuyos valores oscilan entre 0 (nada) a 4 (muchísimo), anque las preguntas 8 y 9 se contestan de 0 a 10 . Los 76 items del cuestionario están agrupados en 8 preguntas (tabla 5.3). 
Tabla 5.3

Estructura del cuestionario: preguntas e items

Preguntas

Sentido de la pregunta e items

Se refiere a 36 competencias potencialmente adquiridas durante la Pregunta 1 formación cursada; 20 items referidas a las competencias específicas de EF y 16 a las transversales o genéricas.

\begin{tabular}{ll}
\hline Pregunta 2 & Formada por 10 items sobre las competencias docentes \\
\hline Preguntas 3 y 4 & $\begin{array}{l}\text { Se refiere a la presencia de las metodologías activas y de la evalución } \\
\text { formativa y continua en los estudios cursados y la potencial influencia } \\
\text { sobre el desarrollo competencial de lso estudiantes. }\end{array}$ \\
\hline Pregunta 5 & $\begin{array}{l}\text { Se refiere (14 items) a la frecuencia de utilización de los instrumentos y } \\
\text { procedimientos de evaluación durante la formación inicial. }\end{array}$ \\
\hline Pregunta 6 & $\begin{array}{l}\text { Se estructura mediante 7 items que recogen la evaluación en general, la } \\
\text { posibilidad de ser compartida con el estudiantes y la influencia en su } \\
\text { motivación. }\end{array}$ \\
\hline Pregunta 7 & $\begin{array}{l}\text { Se refiere (5 items) a la gestión de la calificación durante la formación } \\
\text { cursada. }\end{array}$ \\
\hline Pregunta 8 & $\begin{array}{l}\text { Sobre el grado de satisfacción en relación a los estudios cursados y posible } \\
\text { recomendación a terceros. }\end{array}$ \\
\hline $\begin{array}{l}\text { Parte final } \\
\text { (preguntas de } \\
\text { control) }\end{array}$ & $\begin{array}{l}\text { Se recogen datos relacionados con los estudios de EF cursados, localidad, } \\
\text { sexo, edad, vías de acceso a la universidad (las posibles respuestas vienen } \\
\text { ya definidas). }\end{array}$ \\
\hline
\end{tabular}

La vía telemática fue la forma escogida para extender el cuestionario entre los estudiantes, utilizando para ello el sistema de "Formularios de Google". Así, se envió a través de correo electrónico el enlace con el cuestionario, informando además de la forma de proceder y las condiciones de garantía de anonimato y confidencialidad de la información resultante. Los datos del estudio se recogieron durante el curso 2014-2015.

En relación a las preguntas del cuestionario utilizadas para realizar el estudio cuantitativo, se escogieron solamente aquellas que se pensó podían ayudar a responder de forma directa a los objetivos de la presente investigación.

A. Pregunta 1, seleccionando de los 16 items referidos a las competencias transversales, 12 representativas de lo más genuino de estas y que a su vez formaban parte de tres bloques objeto de atención, atendiendo a la tipificación de González y Wagenaar (2003): instrumentales (items P1.25 a P1.29 junto con 
P1.8, referida a la comunicación no verbal y considerada complementaria a la comunicación oral y escrita presente entre ellas (Knapp, 1992); interpersonales (item P1.26 a P.133) y sistémicas (items P1.34, P1.35 y P1.36).

B. Preguntas 3 y 4 (sobre la posible influencia de las metodologías activas y la evaluación formativa y continua para el desarrollo de las competencias genéricas).

C. Pregunta 5 (sobre la de utilización de los instrumentos y procedimientos de evaluación, 14 items).

D. Pregunta 7 (5 items sobre la experiencia de calificación durante la formación cursada).

E. También se utilizaron las preguntas de control en torno a la titulación cursada, localidad y el género, pudiendo obtener a partir de las dos primeras, dos nuevas variables que recogieron las facultades de procedencia (Facultades de Educacion y CAFyD).

\subsection{Análisis estadístico de los datos}

En relación al análisis estadístico, se realizó un estudio descriptivo, comparativo y correlacional haciendo uso del software estadístico SPSS (v.21) para Windows.

Para el tratamiento de los items de las preguntas relacionadas con las competencias transversales, se hallaron nuevas variables, considerando la tipificación realizada en los tres bloques de competencias genéricas objeto de estudio a partir de la agrupación de los items que las conforman, obteniendo los promedios de los tres bloques, instrumentales (MB1), interpersonales (MB2), sistémicas (MB3). Para la variable MB1 (competencias instrumentales) se utilizó la media aritmética de los items presentes en el cuestionario tipificados en este grupo: $\overline{\times} \mathrm{B} 1=(\mathrm{P} 1.8+\mathrm{P} .25+\mathrm{P} 1.26+\mathrm{P} 1.27+\mathrm{P} 1.28+\mathrm{P} 1.29) / 6$. De la misma manera se obtuvo la variable MB2 (competencias interpersonales) a partir de la media aritmética de los ítems considerados para este grupo: $\overline{\times} \mathrm{B} 2=$ $(\mathrm{P} 1.30+\mathrm{P} 1.31+\mathrm{P} 1.32+\mathrm{P} 1.33) / 4$. También se obtuvo la variable MB3 (competencias sistémicas) realizando la media aritmética de los ítems considerados como sistémicos a partir de la literatura científica consultada, $\overline{\mathrm{X}} \mathrm{B} 3=(\mathrm{P} 1.34+\mathrm{P} 1.35+\mathrm{P} 1.36) / 3$. 
No obstante, considerando los resultados obtenidos de promedio para este último bloque y sus ítems, comparativamente se observaron resultados más sustanciales para profundizar sobre ellos en MB1 y MB2, con lo que los relacionados con el bloque 3 finalmente no se abordaron en el informe final de resultados del presente estudio.

Para el análisis exploratorio de los items seleccionados del cuestionario, así como las dos nuevas variables creadas, se realizó un estudio estadístico descriptivo, organizando y presentando los datos haciendo uso de los estadísticos de tendencia central como la media $(\bar{x})$ y de dispersión, desviación típica $(\sigma)$.

Se hizo uso puntual de las tablas de frecuencias sobre todo en aquellos casos en las que las desviaciones de la media eran elevadas, requiriendo el desglose de los datos para su explicación.

En relación a las variables ordinales de la escala, se han tratado como numéricas, atendiendo a O`Brien (1979), Schroeder, Sjoquist y Stephan (1990) y Díaz (2002), citados en Gutiérrez, Pérez, Pérez y Palacios (2011) quienes establecen que una variable ordinal puede tratarse como numérica si presenta cinco o más categorías. En la tabla 5.4 se muestra la escala ordinal de tratamiento de las respuestas del cuestionario. Su uso para el análisis se consideró en función de los siguientes valores asignados.

Tabla 5.4

Valores asignados a las variables nominales del cuestionario (Gutiérrez et al., 2011)

\begin{tabular}{ccc} 
Variable numérica & Variable de escala & $\begin{array}{c}\text { Intervalo de valores asignados a } \\
\text { la variable }\end{array}$ \\
\hline Nada & 0 & $(0-0,5)$ \\
\hline Poco & 1 & $(0,6-1,5)$ \\
\hline Moderadamente & 2 & $(1,6-2,5)$ \\
\hline Mucho & 3 & $(2,6-3,5)$ \\
\hline Muchísimo & 4 & $(3,6-4)$ \\
\hline
\end{tabular}

Seguidamente se desarrolló un estudio comparativo. La realización de la prueba de Kolmogorov-Smirnov permitió comprobar la ausencia de normalidad de las variables 
utilizadas, obligando a seguir una vía analitica no paramétrica y desde ella indagar sobre las diferencias para los items seleccionados, en virtud de las variables factor género titulación cursada y facultades de procedencia. Se utlizaron para ello pruebas como la $U$ de Mann-Whitney y puntualmente Kruskal-Wallis.

Finalmente se realizó un estudio correlacional a fin de averiguar en qué medida las variables sobre métodologías activas, evaluación formativa, instrumentos de evaluación y sistemas de calificación se relacionaban con la adquisición y desarrollo de las competencias transversales objeto de estudio. Para ello se obtuvo el coeficiente de correlación de Spearman, estableciéndose el nivel de significación de $P<0,05$.

En relación a los aspectos éticos de la investigación, el procedimiento investigador seguido en el propio proyecto $\mathrm{I}+\mathrm{D}+\mathrm{i}$ ha asegurado el cumplimiento estricto de sus principios, gestionando el envío del cuestionario de forma telemática a través de correo electrónico, prestando información a los participantes sobre el objetivo de la investigación y las condiciones establecidas de anonimato y confidencialidad $\mathrm{y}$ considerando para la propia gestión del proyecto, las prerrogativas éticas propuestas por American Psychological Association (2010).

También la aprobación y seguimiento del proyecto de tesis por parte del programa de doctorado de adscripción (Investigación Transdisciplinar en Educación) ha garantizado sistemáticamente el cumplimiento de los parámetros del Código de Buenas Prácticas en Investigación de la Universidad de Valladolid, salvaguardando los aspectos éticos del proceder investigador.

\subsection{Rigor cientifico}

Como se ha indicado, el cuestionario es el instrumento de recogida de información cuantitativa utilizado, analizando la fiabilidad de sus preguntas mediante el procedimiento del coeficiente de Alfa de Crombach, destacándose un valor de 0,879. 


\subsubsection{El método cualitativo}

La realidad de la educación supone la interacción compleja de múltiples variables que, en ocasiones, la investigación cuantitativa no es capaz de recoger y por tanto explicar. En base a este hecho, es necesario realizar estudios más específicos que permitan ahondar en las profundidades de los fenómenos educativos a estudiar, a fin de poder ofrecer una mejor interpretación y explicación sobre ellos. Por ello la investigación cualitativa parece adecuada para que el investigador pueda acceder a los detalles de las experiencias formativas ocurridas, las percepciones de las personas, las interacciones, los comportamientos y las reacciones.

Uno de los aspectos característicos de la investigación cualitativa, como indican Denzin y Lincoln (2005), es la localización del investigador como un observador en un lugar, tiempo y circunstancias concretas. Esto confiere, en base a sus experiencias, un carácter flexible, abierto, adaptativo, paciente y sabedor de que los fenómenos son complejos y sus significados no siempre están a la vista, necesitando acercarse a las vidas de las personas, interactuando con ellas, para poner en valor sus palabras y las acciones en las que participan (Strauss y Corbin, 1990).

A partir de Fraile (2018) se considera que investigar desde esta metodología es acompañar la experiencia e interrogarla para poder desvelar sus significados y efectos que siempre son susceptibles de interpretación y abiertos a cambios. Esto supone describir los fenómenos a partir de la acción, haciéndolos compresibles desde la interacción con y entre los participantes.

Desde esta perspectiva, investigar en educación requiere adoptar una mirada subjetiva sobre los procesos de enseñanza-aprendizaje que se desarrollan en un espacio interactivo de vivencias, de generación de conocimientos y experiencias en la acción, tratando de comprender cómo se llevan a cabo, para establecer si fuera necesario, aquellos cambios que permitieran optimizarlos (Elliot, 1990; Stenhouse, 1984). 
Este punto de vista fenomenológico de la investigación supone, para el presente caso, una vía directa de entrada a los escenarios educativos para analizar, comprender y mejorar los procesos formativos de los estudiantes pensando en su desarrollo competencial, estableciendo un diálogo directo con ellos y sus necesidades y establecer en mejor medida, cómo poder atenderlas, pudiendo interactuar con ellos, preguntando y recogiendo evidencias sobre las situaciones formativas que han experimentado (Flick, 2007).

Se toman de Maxwell (1998) los objetivos principales de la investigación cualitativa (tabla 5.5) que sin duda contribuyen a la toma de decisiones sobre la adopción de estrategias metodológicas para abordar el presente estudio.

Tabla 5.5

Principales propósitos de la investigación cualitativa (Maxwell, 1998)

\section{Propósitos de la investigación cualitativa}

\begin{tabular}{ll}
\hline Comprender los & Permite discernir sobre los sucesos, las situaciones y la acción que \\
siginificados & $\begin{array}{l}\text { protagonizan los participantes del estudio, así como de sus } \\
\text { explicaciones al respecto. El interés se centra en el sentido que } \\
\text { tienen los sucesos experimentados para los participantes, } \\
\text { aceptando su punto de vista como parte de la realidad que se } \\
\text { intenta comprender. }\end{array}$ \\
\hline Comprender el contexto & $\begin{array}{l}\text { Supone que el escenario de actuación de los participantes también } \\
\text { cobra relevancia dada su influencia para el desarrollo de las } \\
\text { acciones. Requiere estudiar a un grupo específico y limitado de } \\
\text { participantes, valorando la peculiaridad de sus perspectivas en } \\
\text { situación, para obtener información de primera mano sobre los }\end{array}$ \\
sucesos y las acciones en las que participan. \\
\hline $\begin{array}{l}\text { Comprender los } \\
\text { procesos }\end{array}$ & $\begin{array}{l}\text { Supone dotar de valor a los procesos que originan los sucesos y los } \\
\text { acontecimientos, más allá de las consecuencias surgentes de } \\
\text { dichos procesos. }\end{array}$ \\
\hline $\begin{array}{l}\text { Desarrollar } \\
\text { explicaciones causales }\end{array}$ & $\begin{array}{l}\text { Requiere analizar los datos obtenidos en relación a los sucesos } \\
\text { objeto de investigación, para proponer explicaciones causales para } \\
\text { despues discutirlas. }\end{array}$
\end{tabular}

\subsection{La muestra}

Dado que se pensó en el grupo de discusión (GD) como instrumento para la recogida de información, se consideró una muestra pequeña a fin de poder manejar la 
información resultante, con un límite de entre 5 y 10 participantes, puesto que desde consideraciones de orden cuantitativo, la comunicación en los grupos se relaciona con el número de canales abiertos que aumenta en función del número de participantes. Así, con dos personas se abre un canal de comunicación, con tres se abren tres canales, con cuatro surgen 6 y así de este modo los canales aumentan a medida que aumenta también el número de participantes, buscando un cierto orden, equilibrio participativo en el intercambio comunicativo (Ibáñez, 1998).

En cualquier caso, los estudiantes fueron convocados en un número máximo de 10 para asegurar la viabilidad del desarrollo del grupo de discusión y previniendo ausencias de último momento. La convocatoria se hizo bien vía correo electrónico o, en caso de ser estudiantes con quienes se mantiene una relación directa de docencia y/o tutoría, de forma oral y directa, aunque confirmando la convocatoria formalmente también por la vía del e-mail.

\subsection{Instrumento de recogida de datos}

Como instrumento cualitativo de recogida de información, se utilizó el GD a fin de obtener datos sobre el pensamiento de los estudiantes sobre el proceso formativo que habrían cursado y la relación de este con su percepción de desarrollo competencial, en un momento casi de finalización de sus estudios.

Se realizaron dos GD con estudiantes de EF de los títulos de grado de Maestro de Educación Primaria, mención EF y de CAFyD de las Facultades de Educación y de CAFyD de las Universidad de Valladolid (campus Valladolid y Segovia) y Zaragoza (campus Huesca). Estas dos facultades formaban parte de las participantes en la investigación. La elección de las personas, en función de las variables a tratar, se realizó mediante redes personales pre-existentes entre ambas universidades (Ibáñez, 1998), dado que su profesorado forma parte del equipo investigador del proyecto $\mathrm{I}+\mathrm{D}+\mathrm{i}$ de referencia y de la Red Nacional de Evaluación Formativa y Compartida. 
De este modo, las relaciones entre ambas universidades fueron de máxima fluidez, colaboración e interacción docentes-alumnado.

De acuerdo con Morgan (1998) los GD son valiosos para conocer qué piensan los participantes, pero aún lo son más para descubrir por qué estos piensan como lo hacen. Barbour (2014) considera que los GD planteados en clave de interacción y debate, tienen la capacidad de reflejar los problemas y las preocupaciones de estos. Álvarez-Gayou (2003) considera el GD como una estrategia de interacción comunicativa que privilegia la conversación sobre un tema en un tiempo específico, capturando en ese espacio y ese tiempo la forma de pensar, sentir y vivir sobre un fenómeno de preocupación para los participantes, provocando autoexposiciones fundamentadas en su conocimiento y en sus experiencias.

En consonancia con Wolff, Knodel y Sittitrai (1993), se defiende la idea de utilización del GD después de haber obtenido resultados de encuestas o cuestionarios, para contrastar ambos resultados, corroborarlos, esclarecerlos, transformándolos en hallazgos mediante explicaciones, especialmente, sobre aquellas relaciones y asociaciones que pudieran parecer insólitas y sorprendentes a ojos del investigador, realizando un verdadero ejercicio de triangulación de información.

Se desarrolló un primer GD (GD1), durante el curso 2014-1015, en la Facultad de Educación de la Universidad Autónoma de Madrid, de forma simultánea con la realización de otros GD con egresados y docentes, en el ámbito de los intereses del proyecto de investigación $\mathrm{I}+\mathrm{D}+\mathrm{i}$ de referencia para esta tesis doctoral. Estuvo formado por 8 estudiantes, de los que 4 son mujeres y 4 hombres con edades comprendidas entre 22 y 26 años.

El guion del GD1 (Anexo 2) fue confeccionado por dos de los investigadores participantes en el proyecto $\mathrm{I}+\mathrm{D}+\mathrm{i}$, experimentados en su desarrollo y gestión. La confección del guion pasó por la formulación de ciertas preguntas que orientaran la discusión y el debate, garantizando el abordaje de las dos temáticas centrales 
consideradas imprescindibles y puntos de partida para indagar, siendo lo suficientemente amplias y sugerentes como para incentivar la participación y activar el comienzo del debate (Mena, 2006).

1. ¿Las competencias (genéricas, docentes y específicas) planteadas en la formación inicial del profesorado de Educación Física son las adecuadas?

2. ¿Son coherentes los procedimientos de evaluación para la valoración de las competencias?

A partir de la idea de profundizar en estas dos temáticas centrales, se establecieron otras temáticas secundarias para su tratamiento en caso de no ser las primeras suficientemente desarrolladas. Las preguntas de las temáticas secundarias se plantean como directas (conocen la realidad en primera persona) o indirectas (son sus percepciones sobre el tema), dando preferencia para el caso de los estudiantes, a las más directas.

a) ¿Qué competencias en la formación inicial son las que tienen más valor para los estudiantes?

b) ¿Qué competencias adquieren los estudiantes durante su formación?

c) ¿Qué procedimientos de evaluación predominan en la evaluación de las competencias?

d) ¿Existe coherencia entre las competencias a desarrollar y lo que realmente se evalúa?

e) ¿Cómo la evaluación formativa ha favorecido la adquisición de las competencias en la formación inicial?

f) ¿Qué actividades formativas han ayudado a la adquisición de las competencias docentes durante la formación cursada?

g) ¿Existe una transferencia positiva de las buenas prácticas vividas en la formación cursada a los contextos de práctica docente de Primaria, Secundaria y Bachillerato? 
Los estudiantes fueron dispuestos en sillas formando un círculo, incluyendo en este a los dos dinamizadores de la sesión, evitando así la formación de liderazgos, facilitando que todos se viesen y con ello la interacción de unos con otros (Bergua, 2011).

El encuentro fue dinamizado por uno de los dos investigadores responsables expertos en el diseño del guión de preguntas, informando a los participantes sobre el proceder, la necesidad de respetar las reglas básicas de la discusión (turnos de palabra, intervención de todos, no monopolizar el debate) y del entendimiento (evitando los comentarios hirientes, descalificaciones), justificando además el objetivo de la discusión y la finalidad de los datos recogidos.

También colaboró un segundo investigador, el autor de este trabajo, como secretario apoyando la constitución del GD, anotando la secuencia de las intervenciones, el orden de participación y cuantos aspectos sobresalientes aparecieran durante la discusión y fueran del interés para esta investigación. Tras las presentaciones, explicaciones iniciales y acomodación del grupo que realizó el dinamizador (15 minutos), se comenzaron las intervenciones abordando las preguntas de temática central.

Se observó una participación activa, suscitándose el debate como nota predominante. El tiempo de duración (1 hora y 30 minutos) fue suficiente para ello. Finalmente se agradeció a los participantes la colaboración y la participación desinteresada y se informó de la posibilidad, si así lo requerían, de borrar de la transcripción los comentarios que consideraran. Se realizó una doble grabación de audio de la sesión y la correspondiente transcripción.

Habiendo analizado los datos obtenidos del GD1, en relación a las preguntas de investigación, se observaron informaciones aún débiles, insuficientes y de poca profundidad en algunos aspectos importantes para la investigación en lo referente a las relaciones entre la formación cursada, la evaluación experimentada y la percepción de 
adquisición y desarrollo de algunas competencias de los bloques competenciales objeto de estudio.

Es por ello que, considerando estos déficits, se decidió realizar un segundo GD (GD2) a fin de abordar de forma más específica y profunda tales aspectos. Se desarrolló durante el curso 2016-2017, convocando a 8 estudiantes, aunque fue finalmente conformado por 6 estudiantes, 3 hombres y 3 mujeres con edades comprendidas entre $\operatorname{los} 22$ y 26 años.

El guión del GD2 fue confeccionado a este respecto mediante distintas preguntas (Anexo 3) que permitieran ahondar en las condiciones formativas que presumiblemente hubieran podido ayudar al desarrollo de sus competencias instrumentales e interpersonales.

En un primer momento se presentaron algunos resultados de la información cuantitativa y cualitativa encontrada hasta el momento, para que pudieran ser debatidos y reafirmados en la discusión, para seguidamente poder ahondar en preguntas más específicas que ayudaran a comprender el fenómeno.

a) ¿Qué experiencias o acciones formativas se han realizado en tu formación (en las asignaturas cursadas: actividades, métodos, sistemas de evaluación, tareas,..) y cómo crees que te han ayudado a adquirir y desarrollar tus competencias instrumentales e interpersonales?

b) ¿Cuáles son las dificultades con las que te has encontrado durante la formación que has cursado para adquirir y desarrollar tus competencias instrumentales e interpersonales?

c) ¿En qué crees te resultará útil para tu actividad docente desarrollar tus competencias instrumentales e interpersonales? 
El encuentro se produjo en un aula de la Facultad de Educación de la Universidad de Valladolid. Para desarrollar la sesión de discusión se dispuso a los participantes en círculo, en torno a una mesa y, con grabadoras en el centro. Para comenzar, actuó como dinamizador el autor de esta tesis, mediante una presentación inicial, informando del objetivo de la sesión, la salvaguarda de la información recabada, la importancia de respetar el buen entendimiento (uso de un lenguaje respetuoso, control de los comentarios hirientes, descalificaciones) y el cumplimiento de ciertas reglas básicas (respeto del turno de palabra, intervención de todos, no monopolio). Seguidamente se comenzó con el debate orientando la participación mediante las preguntas establecidas.

Se fue registrando por escrito la secuencia de las intervenciones, el orden de participación y los aspectos que destacaran y guardaran relación con los objetivos de la investigación. A pesar de intervenir puntualmente para aclarar algún aspecto de las preguntas cuando se respondían de forma desviada en relación al objeto de investigación, el estado general del debate fue de alta participación y fluidez, generándose un ambiente de intercambio de pensamientos y experiencias enriquecedor para la investigación. El tiempo final de duración de la sesión fue de 1 hora. Además, a su término, se informó de la posibilidad si así lo requerían los participantes, de poder borrar de la transcripción cuantos comentarios aportados a título personal no quisieran que formaran parte de ella, agradeciendo además la colaboración por la participación. Se realizó una doble grabación y la correspondiente transcripción.

\subsection{Análisis de datos cualitativos}

Se reitera la idea, mediante el uso del GD como instrumento de recogida de información cualitativa, de contrastar la información obtenida con la información cuantitativa, buscando con ello, como se ha venido explicando, contrastar, corroborar y verificar resultados. 
Bajo el paradigma interpretativo se pretende, a partir del análisis de los datos recogidos, estudiar la perspectiva de los estudiantes sobre la formación recibida y si ésta les ayudó a adquirir y desarrollar sus competencias transversales, intentando comprender e interpretar los significados atribuidos al respecto y su propio pensar y sentir (Gibbs, 2012).

Para el desarrollo del proceso de análisis de los datos, se contó con el apoyo del software Atlas.ti (v.8) que permitió el manejo de la información para reducirla y codificarla a fin de ser descrita e interpretada, facilitando así su posterior tratamiento y presentación (Friese, 2011). Siendo el análisis de los datos una tarea artesana de segmentación de texto y coloreado para ayudar a manejar la masa de datos y su comprensión.

Gracias a las nuevas tecnologías se han podido optimizar el procedimiento, continuando con la segmentación textual, aplicando igualmente etiquetas o códigos, pero pudiendo manejar volúmenes importantes de datos, siendo el investigador quien lo hace de forma asistida por ordenador, conformándose una mecánica más ligera de proceder, aunque el esfuerzo analítico e interpretativo sigue recayendo en él (Creswell, 2013). Para Seale (2002) una de las ventajas del uso del ordenador para asistir el proceso analítico de los datos es la concienciación metodológica, dado el control del investigador sobre los registros de información, lo que le permite gestionar mejor las decisiones al respecto durante el propio proceso.

Pero forma parte del inicio del proceso de análisis de los datos, la transformación de las transcripciones de los GD (Anexo 4 y Anexo 5) en documentos primarios. Para ello, se creó, mediante Atlas.ti, un proyecto en donde se ubicaron cuatro documentos primarios, dos registros de audio (grabaciones de los GD) y dos de texto (transcripciones de los audios de los GD). Se consideró que la presencia de los cuatro documentos primarios en el mismo proyecto podría favorecer la mejor comprensión de los temas debatidos, atendiendo no solo a lo que expresan los estudiantes al respecto sino también a cómo lo expresan tanto en la forma textual como en la de audio. 
Para el abordaje analítico de los documentos textuales, se estableció inicialmente una lista de códigos “de protocolo" (Miles, Huberman y Saldaña, 2014), a partir de la literatura técnica y normativa minuciosamente analizada (Dey, 1993; Miles y Huberman, 1994) (perspectiva deductiva). Esto sirvió como base sobre la que iniciar la codificación posterior.

Seguidamente, de forma pormenorizada, se fue segmentando la información y codificando, aplicando a los tramos escogidos (citas), códigos a modo de etiquetas, convirtiendo el flujo de información en una cadena de unidades de menor tamaño, ayudándose para ello de la lista de códigos "de protocolo" creada, pero considerando también la emergencia de otros relacionados, estableciendo por tanto una estrategia combinada de codificación deductiva e inductiva, abierta y surgente de la propia realidad textual (Charmaz, 2006; Strauss y Corbin, 1998).

Se establecieron varios procesos de codificación que se podrían agrupar en torno a dos ciclos (Saldaña, 2009). Un primer ciclo en el que se fueron segmentando los textos mediante tramos de distintas magnitudes, codificando, revisando el proceso, decidiendo en las revisiones sobre el mantenimiento de los segmentos y códigos aplicados, conformando una primera batería. En este momento prevalecen los códigos más de tipo descriptivo, respondiendo a un enfoque elemental de codificación y atendiendo a un deseo investigador de describir en profundidad el fenómeno.

No obstante, también se contemplaron otros enfoques (Miles et al., 2014) con los que poder aplicar códigos de tipo evaluativo (métodos afectivos) sobre juicios de los estudiantes sobre algunos aspectos de la formación cursada, códigos de atributo con los que poder atender a las características de los participantes (género, titulación cursada) y códigos simultáneos (métodos gramaticales), dada la existencia de tramos de texto que sugieren significados múltiples, justificando así la presencia de más de un código para su etiquetado. 
Se vislumbra, sin embargo, como objetivo principal del proceso de codificación, generar categorías, con lo que se atenderá también al proceso de conceptualización y no solo de descripción. La aplicación de la comparación constante entre los grupos es lo que ayuda al análisis a trascender los límites de la mera descripción (Barbour y Kitzinger, 1999). Precisamente en el segundo ciclo de codificación se establecieron meta-códigos, grupos de códigos o categorías (finalmente 13), identificando así los temas surgentes de los GD y de valor para la investigación, reuniendo en ellos un importante material informativo de la codificación de primer ciclo (figura_) que finalmente caracterizaba y dimensionaba a las categorías creadas en virtud de las relaciones mantenidas entre sí.

Las 13 categorías finales resultantes son las siguientes:

1. En relación a la caracterización de la formación recibida para el desarrollo de sus competencias transversales, se obtuvo información sobre las competencias (8): crítica, compromiso ético, comunicativa, conocimiento de informática aplicada al ámbito de la EF, conocimiento de una LE, habilidades en las relaciones interpersonales, organización y planificación y trabajo en equipo.

2. En relación a las metodologías y sistemas de evaluación (2): evaluación formativa y metodologías activas.

3. Finalmente dos categorías sobre los instrumentos de evaluación y los sistemas de calificación y tres categorías más con los códigos de atributo del estudio (3): género, tipo de estudios y universidades de procedencia.

Pero, como se ha mencionado con anterioridad, no todas las categorías creadas finalmente fueron atendidas en la presente investigación. Buscando comparar, contrastar, ratificar y explicar los resultados cualitativos con los cuantitativos, se seleccionaron aquellas categorías competenciales que permitieran por la abundancia y significatividad de sus resultados, realizar tal comparación y contraste. Las categorías seleccionadas sobre las competencias transversales fueron las siguientes: conocimiento de una LE (en correspondencia al ítem 1.28 del cuestionario), conocimiento de informática aplicada al ámbito de la EF (ítem 1.29), trabajo en equipo (ítem 1.30) y habilidades en las relaciones interpersonales (ítem 1.31). 
Además, se incluyeron las categorías: metodologías activas y evaluación formativa (en correspondencia con las preguntas 3 y 4 del cuestionario), instrumentos de evaluación y sistemas de calificación (en consonancia con preguntas 5 y 7 del cuestionario), género y tipo de estudios.

Se observa en la figura 5.9 la categoría conocimiento de una LE y los códigos que conforman su vecindario.

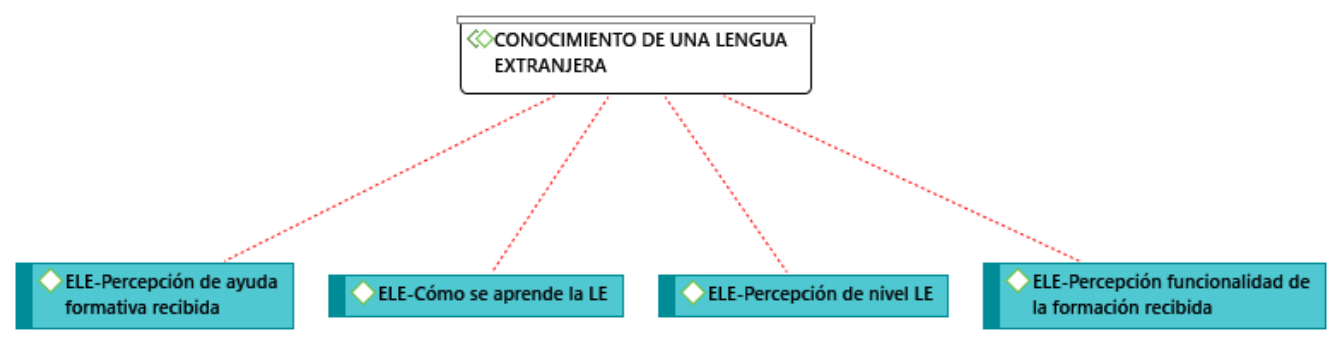

Figura 5. 9. Red de la categoría Conocimiento de una Lengua extranjera y sus códigos

A continuación se muestra la categoría conocimientos de informática aplicada al ámbito de la EF (figura 5.10) y sus códigos.

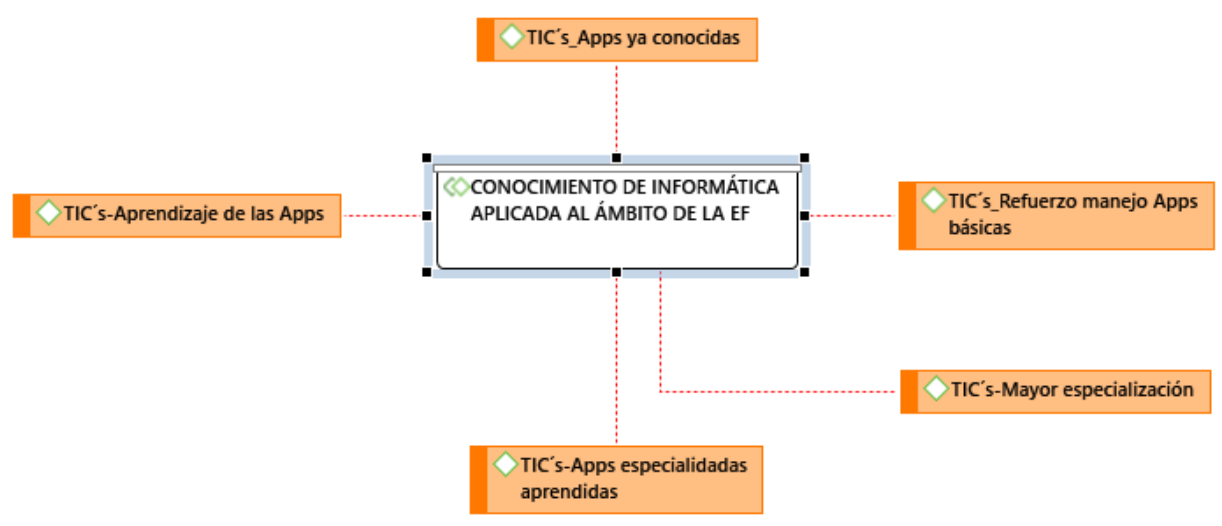

Figura 5. 10. Red de la categoría Conocimientos de informática aplicados al ámbito de la Educación Física y sus códigos 
También en la figura 5.11 se muestra el esquema creado para la categoría trabajo en equipo y su vecindario de códigos.

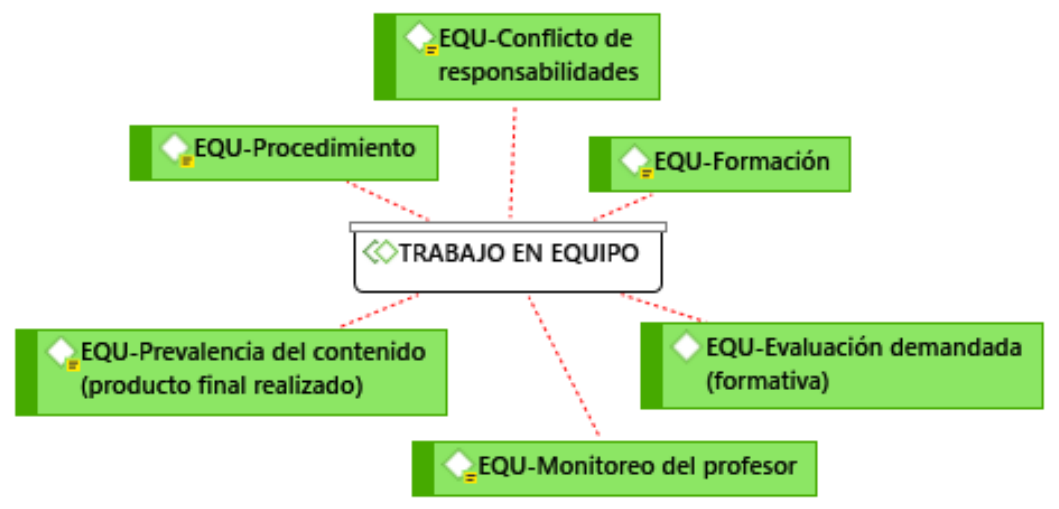

Figura 5. 11. Red de la categoría Trabajo en equipo y sus códigos

Así mismo la figura 5.12 contiene la red de códigos para la categoría habilidades para las relaciones interpersonales.

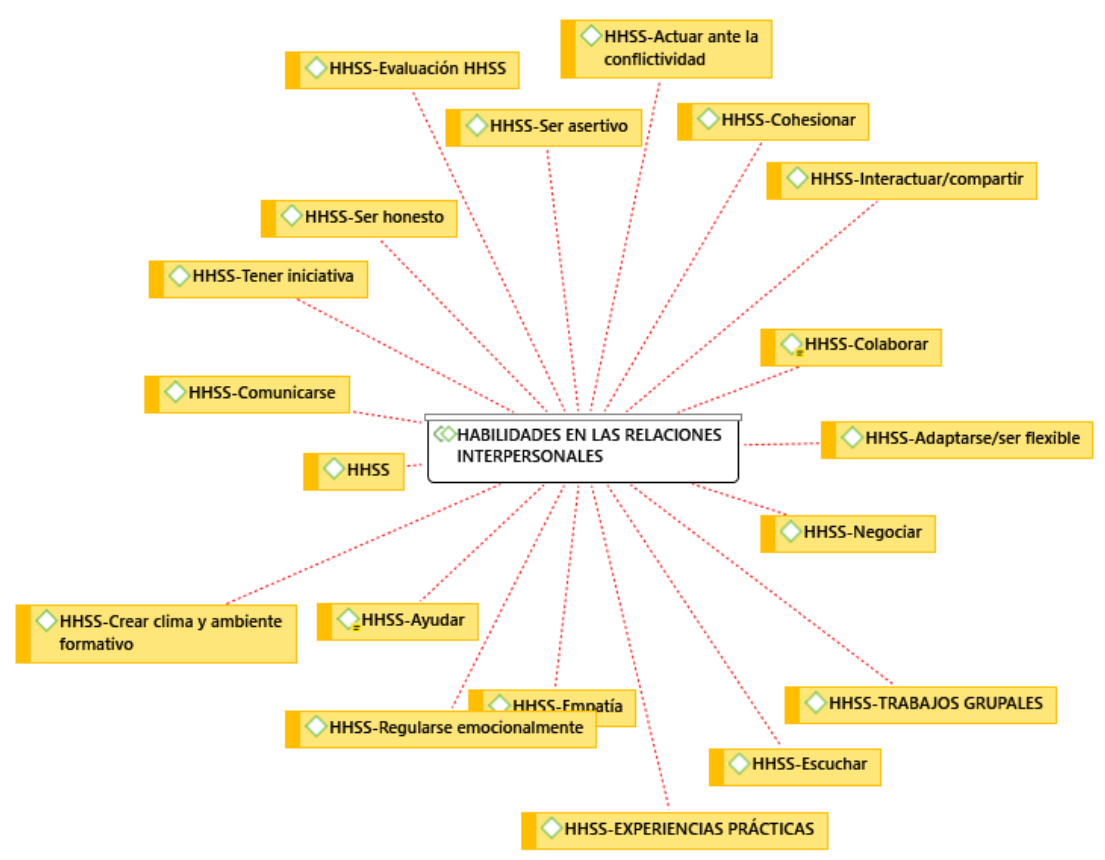

Figura 5. 12. Red de la categoría Habilidades en las relaciones interpersonales y sus códigos 
También se muestra en la figura 5.13 las categorías metodologías activas y evaluación formativa y sus vecindarios de códigos.
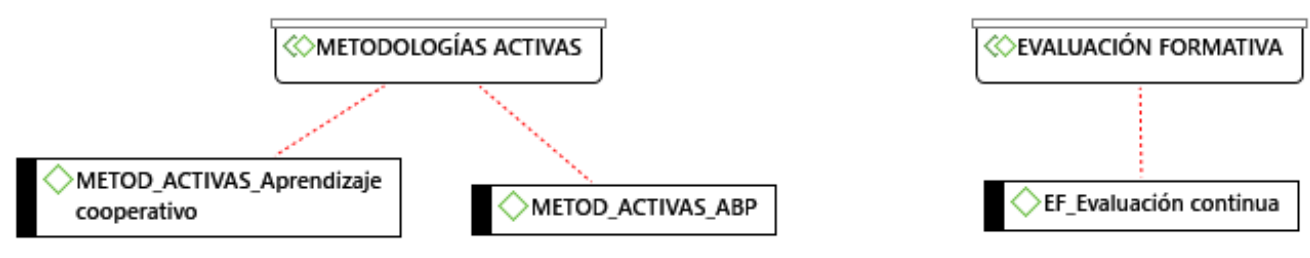

Figura 5. 13. Redes de las categorías Metodologías activas y Evaluación formativa y sus códigos

En la figura 5.14 y 5.15 se pueden apreciar las redes de códigos para las categorías instrumentos de evaluación y formas de calificación.

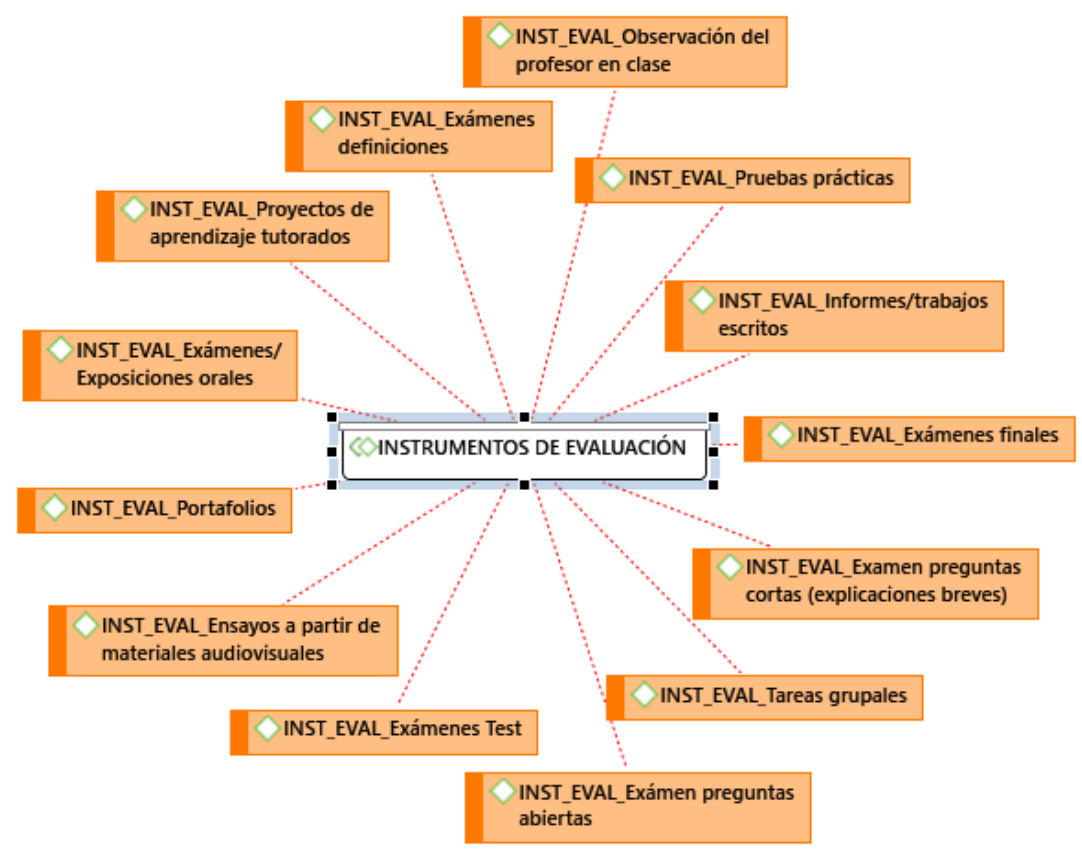

Figura 5. 14. Red de la categoría Instrumentos de evaluación y sus códigos 


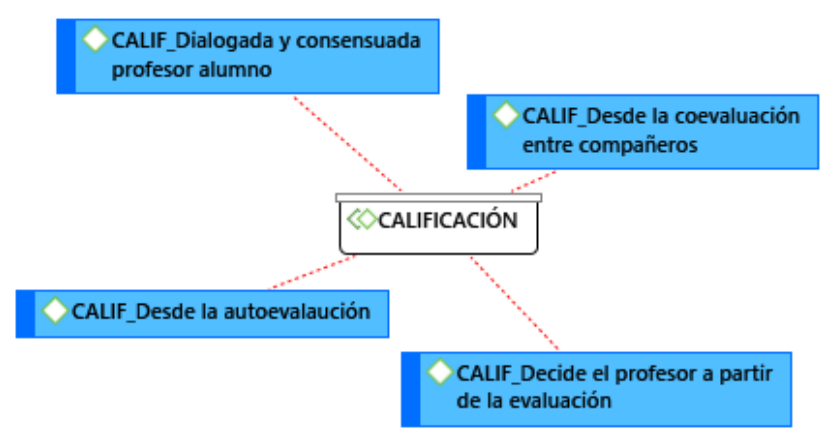

Figura 5. 15. Red de la categoría Formas de calificación y sus códigos

Finalmente en el la figura 5.16 se muestran las redes de las categorías creadas para recoger los códigos de atributo sexo y tipo de estudios.
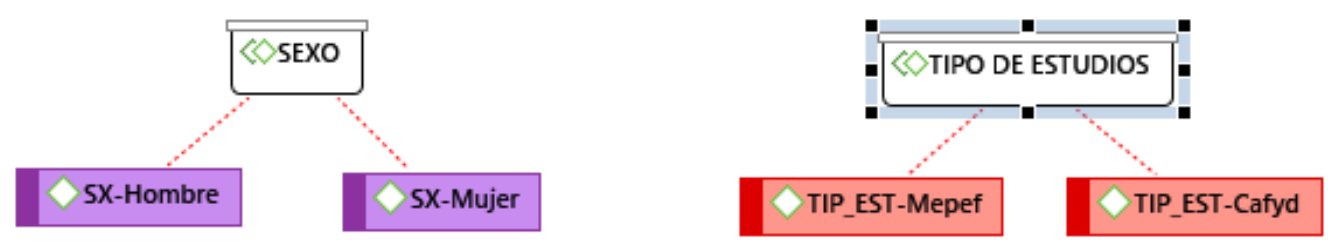

Figura 5. 16. Redes de las categorías Sexo y Tipo de estudios de Educación Física cursados y sus respectivos códigos

El esfuerzo codificador dio como resultado dos tipos de códigos en función de su carga de citas (enraizamiento): códigos con mayor frecuencia de carga y códigos de menor frecuencia. En la figura 5.17 se observa el código ELE-Cómo se aprende una LE, con una frecuencia elevada de citas.

Si se encontraran códigos con un índice bajo de enraizamiento, se valora la posibilidad de fusión con otros que compartieran significado, pudiendo ambos, fusionados, ayudar a explicar el fenómeno de investigación. 


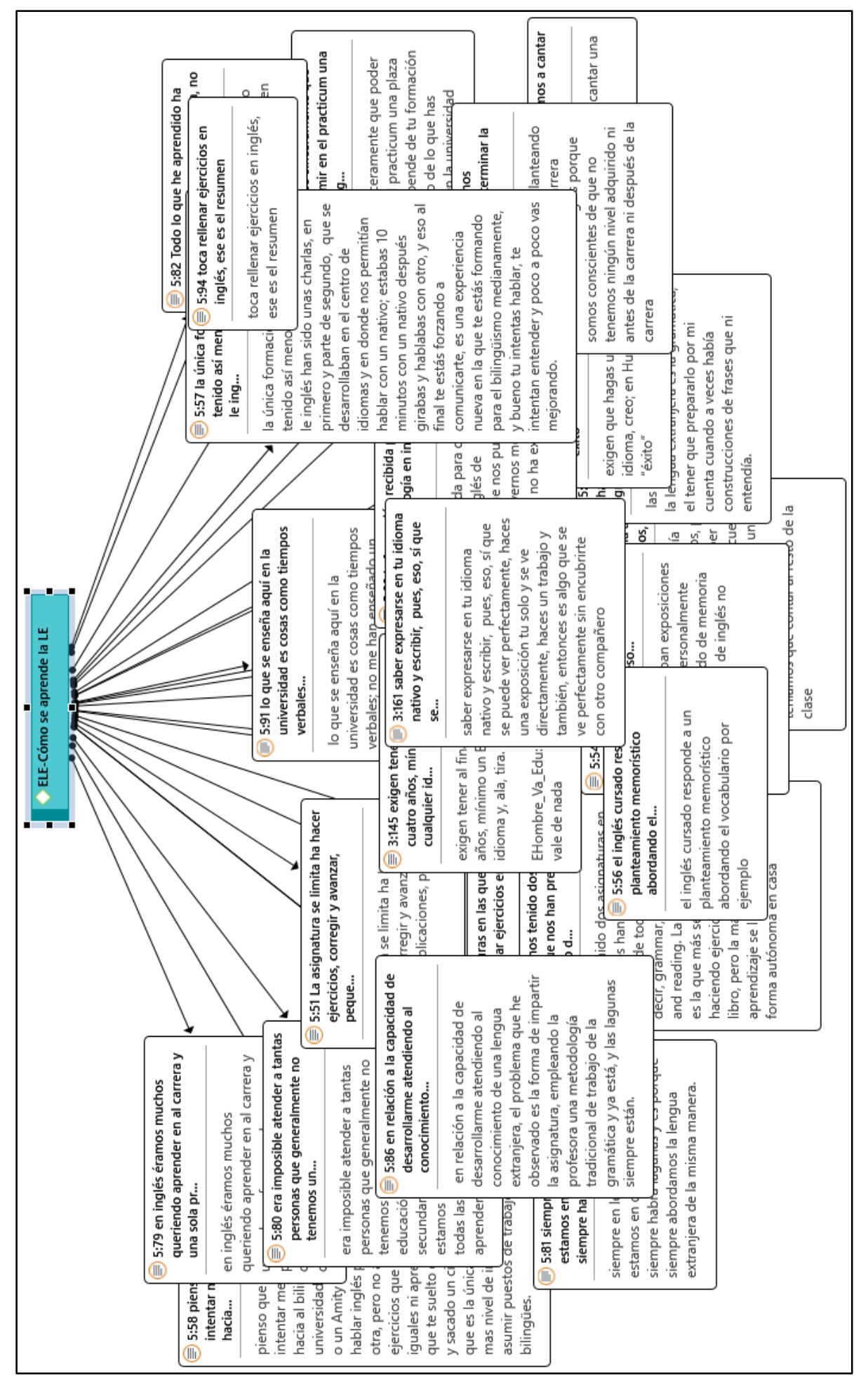

Figura 5. 17. Código con alto índice de fundamentación y su vecindario de citas 
El paso de describir a conceptualizar (Friese, 2014), pasa por realizar operaciones previas que permitan analizar cuidadosamente y dimensionar las relaciones entre los códigos y sus citas, entre código-código y entre las propias citas.

Una de las herramientas más potentes de Atlas.ti para iniciarse en el tratamiento de este proceso es la co-ocurrencia de códigos. Mediante ella podemos establecer si cuando se observa un código, este mantiene también relaciones de cierta significatividad con otros códigos. La tabla resultante (figura 5.18) ofrece evidencias sobre las relaciones de co-ocurrencia entre pares de códigos, pudiendo abordar posteriormente la profundidad de estas relaciones (por ejemplo mediante redes semánticas) y tomando nuevas decisiones al respecto. Para la presente investigación, se utiliza esta herramienta a fin de observar posibles vinculaciones entre los códigos de las categorías que conceptualizan y caracterizan las competencias objeto de estudio y aquellos que describen la presencia de las metodologías activas, sistemas de evaluación formativa, instrumentos de evaluación y estrategias de calificación.

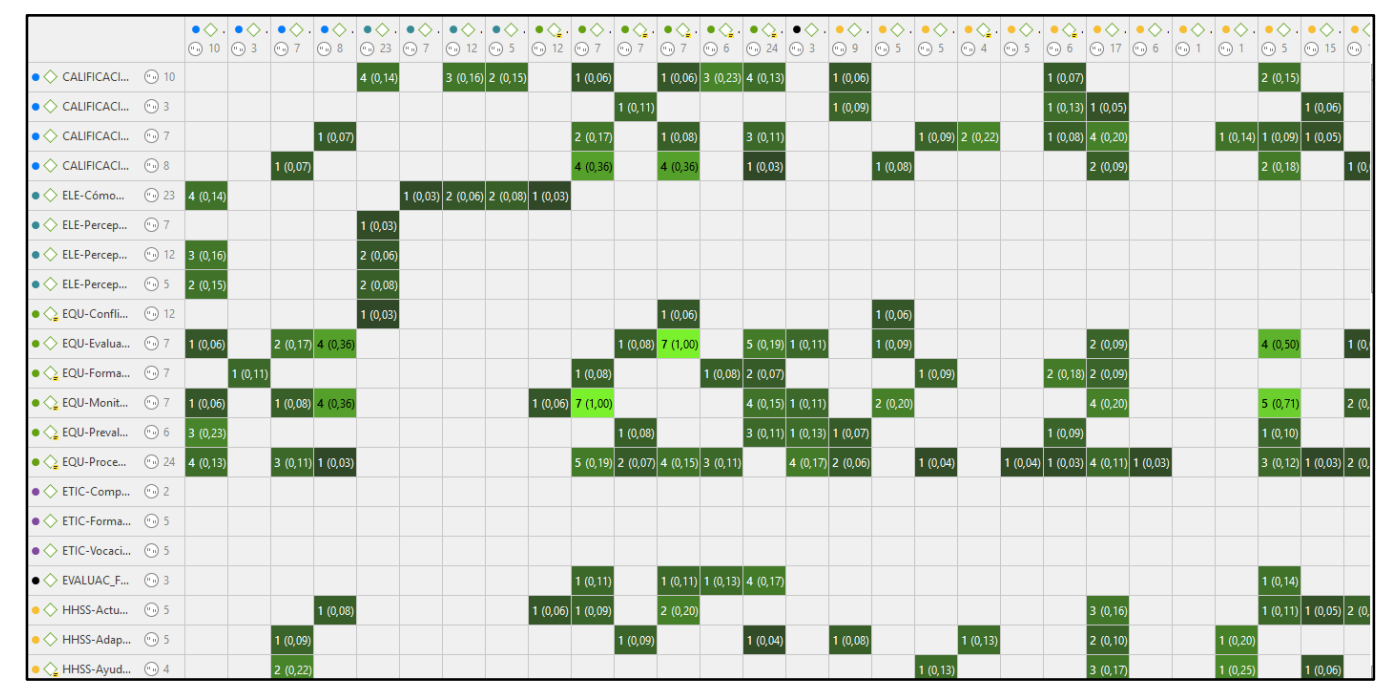

Figura 5. 18. Tabla de coocurrencia de códigos (Software Atlas.ti)

Como se explicaba, es posible explorar más sobre las relaciones entre los códigos y también entre las propias citas, pudiendo ayudarse de redes semánticas para ir desentrañando y reconociendo tales relaciones., De este modo es posible obtener un 
mejor conocimiento del fenómeno objeto de investigación, cita a cita y código a código, a través de sus significados, hasta saturar la red de relaciones tejidas en torno a las categorías del estudio.

El establecimiento de estos vínculos es un componente intrínseco del proceso de análisis de datos por el cual se establece la forma en que los conceptos, los temas y las palabras de los participantes se relacionan entre sí. Estos vínculos tienen un carácter semántico. En la figura 5.19 se muestra gráficamente una de las redes semánticas de citas realizadas vinculando unas a otras mediante operadores semánticos, pudiendo ayudar a esclarecer y entender las dimensiones y características de un código al que se asocian en virtud de sus significados.

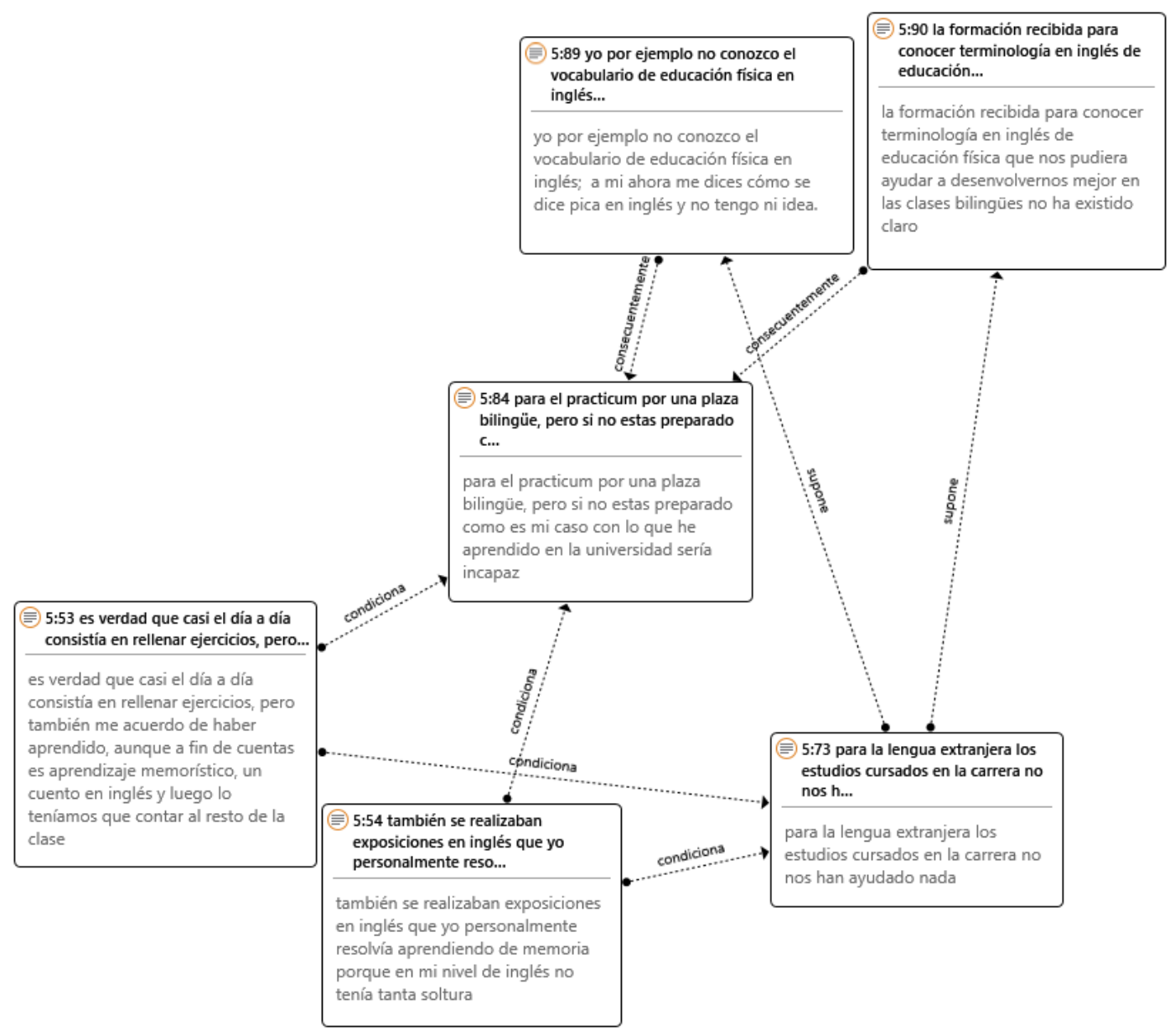

Figura 5. 19. Red semántica de citas (hipervínculos) 
Los análisis pormenorizados de las relaciones entre las citas permiten construir otras redes de mayor complejidad, como las que vinculan los códigos que constituyen una categoría, pudiendo explorar el analista las relaciones entre ellos a fin de comprender los significados y dimensiones que esconden y por ende conocer más sobre las categorías de estudio (figura 5.20).

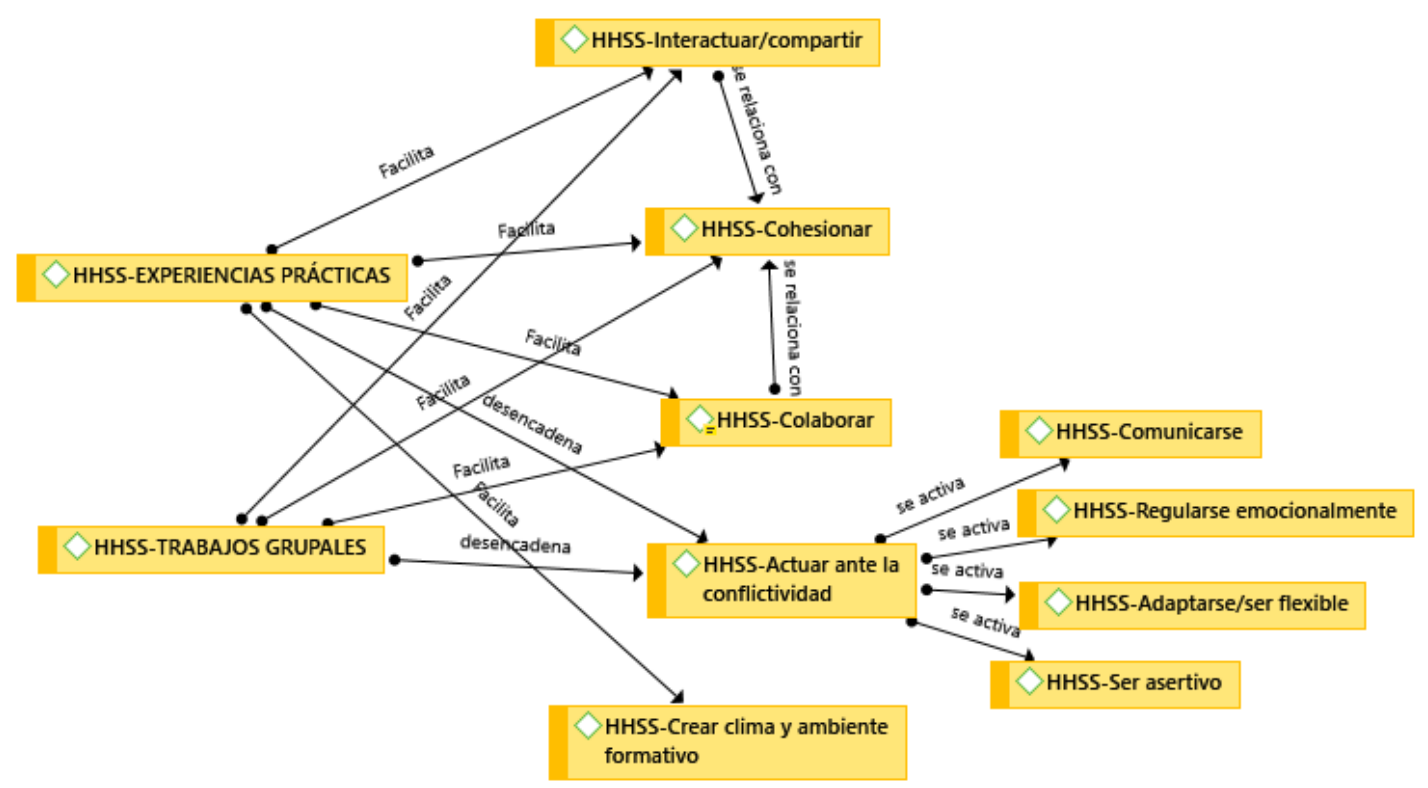

Figura 5. 20. Red semántica de códigos

Finalmente, a lo largo del proceso investigador se fueron creando memos (anotaciones) a modo de narraciones de cierta extensión, capturas de pensamiento y reflexiones durante el tratamiento de los datos, su análisis y las conclusiones que se iban alcanzando durante el proceso analítico. Se ha considerado su creación y utilización, pues han permitido mantener la pista de las ideas que se iban desarrollando, permitiendo su flujo, al ir comparando los conceptos y en base a tales comparaciones ir refinando dichas ideas y transformándolas en palabras, pudiendo finalmente poder comunicarlas (Glaser, 1998).

\subsection{Criterios de rigor en la investigación cualitativa}

Para el caso de la indagación cualitativa, se consideran la credibilidad, la dependencia, la transferibilidad y la confirmabilidad (Guba, 2008) como los aspectos a 
considerar para asegurar el rigor científico. A continuación se describen de qué forma han sido considerados particularmente en el tratamiento de los GD realizados y en el análisis documental consiguiente.

\section{- Credibilidad}

Ha sido el ejercicio de triangulación, el realizado para contrastar y en su caso ratificar, validar o verificar los aspectos que definen el fenómeno de investigación, haciéndolo desde varios frentes, tal y como apunta Denzin en 1978, citado por Flick (2014), Guba (2008) y Janesick (2003). Inicialmente, en el tratamiento inter-métodos del estudio, utilizando intencionalmente aquellos que, como investigador, se consideran en su combinación con más fortalezas y posibilidades para responder a los objetivos de investigación (desde el punto de vista cuantitativo haciendo uso del cuestionario, desde el punto de vista cualitativo, escogiendo el GD para recoger los datos de este orden). En definitiva se ha buscado enfrentar un método con el otro para optimizar las posibilidades de ambos y aportar amplitud y profundidad al análisis.

También se ha desarrollado la triangulación a partir de la recolección de los datos, estudiando el fenómeno en momentos y lugares diferentes y con personas distintas, siendo intencional su selección así como los entornos temporales y locales. En el presente estudio se seleccionaron estudiantes de diferentes grupos, titulados MEPEFCAFyD, en contextos distintos (uno el que envuelve la autogestión del cuestionario y otro el de los GD). De la misma manera se considera la representatividad de voces de los participantes (Tashakkori y Teddlie, 2008) incluyendo en los GD tanto a estudiantes hombres como mujeres en un número representativamente equilibrado.

Se fue reflexionando además sobre el análisis de los diferentes datos y de los resultados surgentes, así como sus interpretaciones procurando en la narrativa del informe conectarlos, sincronizarlos, dotando de coherencia estructural a su presentación, asumiendo las posibilidades de convergencia, complementariedad y divergencia (Kelle y Erzberger, 2004). 
Además se ha realizado la triangulación de investigadores, compartiendo con otros colegas los resultados a medida que se iban obteniendo, a fin de integrar en la investigación, a modo de auditorías, su punto de vista sobre las dudas surgentes. Se admitieron explicaciones y mejoras en torno al fenómeno en estudio contribuyendo a minimizar los sesgos del propio investigador principal, contrastando las diversas miradas sobre los resultados que tratan de explicar el fenómeno de investigación.

Del mismo modo, también se realizó la triangulación de teorías con investigadores de tendencias alternativas y/o críticas en relación al fenómeno objeto de investigación, lideradas por el investigador anfitrión durante la realización de la estancia internacional.

Se desarrolló también una densa y pormenorizada revisión de la literatura científica y normativa sobre el fenómeno de investigación (se consultaron, estudiaron y registraron más de 1100 referencias bibliográficas en diversos idiomas a lo largo de los cuatro años de desarrollo de la presente tesis doctoral, aunque se utilizó finalmente el $70 \%$ de la bibliografía recabada). Desde esta se construyó el marco teórico, apostando con ello por una mayor credibilidad para el trabajo realizado. Como se explicaba, el proceso investigador se ha desarrollado de forma continuada y prolongada en el tiempo (2015-2019), aspecto que favorece también la credibilidad de la investigación en tanto permite al investigador conocer de forma más profunda la realidad objeto de investigación porque está inmerso en ella (Angulo, 1990). Además se compartieron, en algunos momentos del proceso investigador (GD2), hallazgos de la investigación con los participantes implicados (Guba y Lincoln, 1981), favoreciendo y aprovechando la retroalimentación surgente para precisar y clarificar las interpretaciones realizadas como investigador.

\section{- Dependencia}

Una de los elementos que muestran la dependencia en la investigación es el seguimiento de esta (réplica paso a paso) por otros investigadores o auditores que hicieron el seguimiento de la presente tesis (director, codirector, responsables de 
programa de doctorado de adscripción, investigadores nacionales e internacionales con los que se fueron realizando sesiones de seguimiento continuado), compartiendo sistemáticamente a lo largo de la investigación y también en el presente documento los siguientes aspectos:

1. Detallado sobre las perspectiva teórica y el diseño de investigación por el que se apuesta.

2. Explicación sobre la selección de los participantes y los instrumentos de recogida de información en las dos perspectivas metodológicas.

3. Descripción detallada de los procesos de análisis de datos, estadístico y cualitativo (proceso de codificación y categorización, operaciones realizadas) asistiéndose, como en el caso, de un software como Atlas.ti que tecnifique la codificación, genere representaciones gráficas y muestras visuales de relaciones entre conceptos y asista en la recogida sistemática de reflexiones en relación al proceso de investigación mediante memos.

También, tal y como se ha indicado anteriormente, se considera para la dependencia la triangulación de investigadores para contrastar la información y minimizar el impacto del sesgo del investigador único compartiendo el proceso investigador con ellos. En este sentido el chequeo cruzado de la codificación, contrastando con investigadores (colegas) los códigos y las categorías que se fueron creando, ha permitido la presencia en la investigación de una mirada abierta, múltiple y flexible facilitadora de la discusión y el debate para la reflexión.

Finalmente la dependencia está presente también en la selección de los métodos integrados en el mixto, de forma que la complementariedad de ambos favorezca minimizar las debilidades compensándose con las fortalezas del otro; para este caso el cuestionario fue reforzado con la realización del GD para complementarse mutuamente en el mismo estudio. 


\section{-Transferibilidad}

A sabiendas de las dificultades para la generalización de los resultados, ya que no es la finalidad del método mixto utilizado para esta investigación, sí se ha realizado un muestro estructural en el desarrollo de los GD considerando la representatividad de los participantes en virtud de varias agrupaciones (hombres-mujeres, titulaciones MEPEF y CAFyD de referencia). Se consideró necesario la creación de grupos para registrar y valorar sus diferentes discursos en relación al fenómeno de investigación, buscando obtener ideas en cierta profundidad sobre dicho fenómeno y, a partir de ello, quizá poder presentar pautas para otros estudios en relación al mismo fenómeno, así como posibles soluciones alternativas en otros ambientes de formación superior en relación al fenómeno o problema a resolver.

\section{- Confirmabilidad}

Esta puede alcanzarse mediante la triangulación de métodos, de datos, de investigadores y de teorías, aspectos y dinámicas realizadas al respecto ya descritas anteriormente. Guba y Lincoln (1981) establecieron que la confirmabilidad también se puede alcanzar si el investigador deja una ruta clara del proceso investigador realizado. A este respecto se realizaron varias grabaciones de audio de cada uno de los GD así como sus transcripciones correspondientes, pudiendo ser documentos de audio y textuales observables por cualquier investigador. También se han descrito los aspectos que caracterizan la selección de los participantes en el estudio, los lugares en los que se han realizado los trabajos de campo y el papel y rol asumido como investigador en las interacciones con los participantes en el estudio.

Otro de los aspectos favorecedor de la confirmabilidad es el desarrollo de la discusión como capítulo con entidad propia en la presente tesis en donde se contrastan los principales resultados con la literatura científica existente.

Finalmente las numerosas sesiones de tutela con los directores de la tesis, supusieron incentivos para la reflexión sobre las creencias, concepciones, prejuicios, criterios éticos), registrando en forma de grabaciones, las reuniones a fin de escucharlas 
transcurrido un tiempo, pensando sobre su contenido y pudiendo dejar reflejo de ello en el escrito del trabajo.

Se presentan a continuación de forma resumida el tratamiento realizado para la consecución de los criterios de rigor científico (tabla 5.6).

Tabla 5.6

Tratamiento de los criterios de rigor cientifico

Criterios de rigor científico

Acciones presentes en el proceso investigador

$\checkmark$ Triangulación inter métodos del estudio (cuantitativo-cualitativo)

$\checkmark$ Triangulación a partir de la recolección de los datos.

$\checkmark$ Coherencia estructural del informe de resultados (conexión, sincronía, interpretación).

$\checkmark \quad \checkmark$ Triangulación de investigadores.

$\checkmark$ Triangulación de teorías con investigadores de tendencias y líneas alternativas y críticas.

$\checkmark$ Revisión densa y pormenorizada, durante un periodo de cuatro años, de la literatura científica y normativa.

$\checkmark$ Realización de proceso investigador continuado y prolongado en el tiempo (2015-2019).

$\checkmark$ Feedback con participantes en el estudio compartiendo hallazgos (en GD).

$\checkmark$ Seguimiento de la investigación por auditores externos .

$\checkmark$ Triangulación de investigadores para minimizar el impacto del sesgo mediante chequeo cruzado de la codificación y categorización.

$\checkmark$ Selección intencionada de los instrumentos de recogida de información en base a su complementariedad (cuestionario+GD).

$\checkmark$ Salvaguarda de la representatividad de los participantes (muestro
estructural) considerando agrupaciones atendiendo al género y al
tipo de estudios cursados.


$\checkmark$ Triangulación de métodos, datos, investigadores y teorías.

$\checkmark$ Claridad en la ruta del proceso investigador aportando los documentos primarios objeto de análisis.

ن̊

$\checkmark$ Claridad en la descripción de los participantes, escenarios del trabajo de campo y rol del investigador en las interacciones con los participantes.

$\checkmark$ Discusión de los resultados con la literatura científica.

$\checkmark$ Reflexividad en las sesiones informativas con directores de la tesis registrando en forma de grabaciones de audio los conversatorios, dejando impronta del debate interno al respecto en el trabajo. 


\section{RESULTADOS}

En este capítulo se presentan los resultados cuantitativos y cualitativos procedentes del cuestionario y GD de forma integrada. No obstante se comienza presentando los resultados de orden cuantitativo que, siendo la base y guía del estudio, son contrastados y complementados con los obtenidos del análisis del discurso del alumnado participante en los GD (cualitativos).

Dada la naturaleza del método mixto, la integración de los resultados cuantitativos y cualitativos en un mismo capítulo, facilita el ejercicio de la complementariedad y el contraste, además de ayudar a comprender mejor el objeto de investigación. No obstante, tal y como se describió en el capítulo de metodología, se sigue un diseño de triangulación concurrente siendo los resultados cuantitativos los que guían el estudio, de tal forma que los cualitativos complementan y contrastan a los primeros. Se incluyen así en la escritura resultados cuantitativos en forma de estadística seguido de resultados cualitativos utilizando recursos como listas de códigos, redes semánticas y fragmentos de texto que ayudan a contrastar y corroborar los resultados cuantitativos (Creswell, 2009).

Para el estudio estadístico, se ha desarrollado un análisis descriptivo general para todo el alumnado, presentando las variables unidimensionales que suponen la percepción de la formación recibida para el desarrollo de las competencias transversales. Para ello, se toman como medida de centralización la media $(\bar{x})$ y de dispersión la desviación típica $(\sigma)$. En relación a los datos relacionados con la mediana, se ha descartado su presentación ya que las puntuaciones son muy similares a los de la media, incluso, en algunos casos, sus valores son idénticos; por lo tanto, no aportan ningún matiz diferenciador. 
Se han utilizado puntualmente las tablas de frecuencias y sus porcentajes en aquellos casos en los que las desviaciones típicas de la media son elevadas, para así, desglosando los datos, comprender mejor el fenómeno. De la misma manera, se presentan aquellos diagramas de barras para los ítems estudiados que resultan gráficamente aclaratorios, con objeto de extraer los promedios y desviaciones típicas significativos.

Además atendiendo a las variables "género", "tipo de estudios de educación física cursados" y "facultades de procedencia del alumnado encuestado" en relación a las preguntas o ítems sobre la percepción de la ayuda formativa recibida para el desarrollo de las competencias instrumentales e interpersonales objeto de investigación, se ha desarrollado, además del análisis descriptivo, el correspondiente comparativo.

Finalmente se ha realizado un análisis correlacional entre los bloques de preguntas del cuestionario relacionados con las metodologías activas, sistemas de evaluación formativa, instrumentos de evaluación y formas de calificación y los relacionados con las competencias transversales instrumentales e interpersonales objeto de estudio.

Además, se presentan los resultados procedentes de los GD realizados, con el fin de complementar y contrastar los resultados obtenidos a partir del cuestionario aplicado. Este trabajo ha supuesto el estudio del discurso de los estudiantes para, estableciendo un proceso de codificación y categorización, redimensionar la información y comprender mejor los aspectos de desarrollo competencial que son objeto de este estudio. Se ha hecho uso de herramientas específicas y filtros del software Atlas.ti, tales como la herramienta de consulta, la coocurrencia de códigos y las redes semánticas, a fin de relacionar códigos de diversos tipos y obtener información que pudiera contribuir a optimizar la obtenida del análisis cuantitativo a partir del cuestionario aplicado, para comparar y contrastar ambas. 
Se recuerda (ya señalado en el apartado de metodología) que los ítems de la escala ordinal del cuestionario aplicado, se corresponden con los que señalamos en la tabla 6.1. De esta forma, al analizar las medias, se considera la siguiente sistematización en función de los valores asignados.

En relación a las variables ordinales de la escala, se han tratado como numéricas, atendiendo a O`Brien (1979), Schroeder, Sjoquist y Stephan (1990) y Díaz (2002) quienes establecen que una variable ordinal puede tratarse como numérica si presenta cinco o más categorías (Gutiérrez et al., 2011).

Tabla 6.1

Valores asignados a las variables nominales del cuestionario (Gutiérrez et al., 2011)

\begin{tabular}{ccc} 
Variable numérica & Variable de escala & $\begin{array}{c}\text { Intervalo de valores asignados } \\
\text { a la variable }\end{array}$ \\
\hline Nada & 0 & $(0-0,5)$ \\
\hline Poco & 1 & $(0,6-1,5)$ \\
\hline Moderadamente & 2 & $(1,6-2,5)$ \\
\hline Mucho & 3 & $(2,6-3,5)$ \\
\hline Muchísimo & 4 & $(3,6-4)$ \\
\hline
\end{tabular}

Los resultados se presentan en torno a los objetivos de investigación que guían el presente estudio. Responder a cada uno de ellos supone profundizar en torno a la ayuda formativa recibida para la adquisición y desarrollo de los dos tipos de competencias transversales objeto de investigación. Para el bloque de las instrumentales (B1), se ha realizado un estudio descriptivo y comparativo para los ítems de todo el bloque y de forma más pormenorizada en relación a los ítems del cuestionario P1.28, Grado de ayuda formativa recibida para el desarrollo de la competencia para el conocimiento de una lengua extranjera y P1.29. Grado de ayuda formativa recibida para el desarrollo de los conocimientos de informática relativos al ámbito de estudio, dado que son las que han recibido una consideración de mínimo desarrollo por parte de los estudiantes encuestados. Para el bloque de las competencias interpersonales (B2), se ha optado igualmente por un estudio descriptivo y comparativo para todos ítems del bloque y un estudio más específico para los ítems: P1.30. Grado de ayuda formativa 
recibida para el desarrollo de la competencia trabajo en equipo y P1.31. Grado de ayuda formativa recibida para el desarrollo de las habilidades en las relaciones interpersonales, siendo estas dos las mejor consideradas como desarrolladas por los estudiantes a partir de la formación recibida. Se responde en profundidad así en relación a la brecha formativa establecida con respecto a los cuatro ítems en estudio.

\subsection{Conocer el grado de ayuda formativa recibida a lo largo de la formación inicial del profesorado de Educación Física, para el desarrollo de las competencias instrumentales (B1)}

\section{Análisis descriptivo para el bloque B1}

El bloque de competencias instrumentales está conformado por los items (tabla 6.2) del cuestionario titpificadas como tales (P1.8, P1.25, P1.26, P1.27, P1,28 y P1.29).

Tabla 6.2

Ítems del cuestionario que integran B1

\section{B1 (competencias instrumentales)}

1.8.- Grado de ayuda en el desarrollo de la competencia docente: conocer los elementos y fundamentos de la expresión corporal y la comunicación no verbal y su valor formativo y cultural

1.25.- Grado de ayuda en el desarrollo de la competencia docente: capacidad de análisis y síntesis

1.26.- Grado de ayuda en el desarrollo de la competencia docente: capacidad de organización y planificación

\begin{tabular}{l}
\hline $\begin{array}{l}\text { 1.27.- Grado de ayuda en el desarrollo de la competencia docente: } \\
\text { comunicación oral y escrita en lengua nativa }\end{array}$ \\
\hline $\begin{array}{l}\text { 1.28.- Grado de ayuda en el desarrollo de la competencia docente: } \\
\text { conocimiento de una lengua extranjera }\end{array}$ \\
\hline $\begin{array}{l}\text { 1.29.- Grado de ayuda en el desarrollo de la competencia docente: } \\
\text { conocimientos de informática relativos al ámbito de estudio }\end{array}$ \\
\hline
\end{tabular}

Considerando la perspectiva de todo el alumnado encuestado en relación a este bloque 1 de competencias, se obtuvo la variable dependiente que representa las competencias instrumentales y recogía la puntuación de cada sujeto realizando la media 
aritmética de todas las respuestas a los ítems incluidos en el bloque 1 [ $\bar{x}(\mathrm{~B} 1)]$, utilizando los promedios de los items representantes de este bloque $\overline{\mathrm{X}} \mathrm{B} 1=(\mathrm{P} 1.8+\mathrm{P} .25+\mathrm{P} 1.26+\mathrm{P} 1.27+\mathrm{P} 1.28+\mathrm{P} 1.29) / 6$. Acompañan a estos resultados descriptivos de bloque, los correspondientes a cada item que conforman el mismo (tabla $6.3)$.

Tabla 6.3

Descriptivos para B1 y sus items (todos los estudiantes)

\section{PREGUNTAS BLOQUE 1. Competencias Instrumentales}

$[\overline{\times}(\mathrm{MB} 1)=2,08 ; \sigma=, 703]$

\begin{tabular}{llll}
\hline $\begin{array}{l}\text { P1.26.- Grado de ayuda recibida para el desarrollo de la competencia } \\
\text { docente: Capacidad de organización y planificación }\end{array}$ & 1160 & 2,59 &, 844 \\
\hline $\begin{array}{l}\text { P1.8.- Grado de ayuda recibida para el desarrollo de la competencia } \\
\text { docente: Conocer los elementos y fundamentos de la expresión } \\
\text { corporal y la comunicación no verbal y su valor formativo y cultural }\end{array}$ & 1171 & 2,48 &, 938 \\
\hline $\begin{array}{l}\text { P1.27.- Grado de ayuda recibida para el desarrollo de la competencia } \\
\text { docente: Comunicación oral y escrita en lengua nativa }\end{array}$ & 1156 & 2,44 & 1,009 \\
\hline $\begin{array}{l}\text { P1.25.- Grado de ayuda recibida para el desarrollo de la competencia } \\
\text { docente: Capacidad de análisis y síntesis }\end{array}$ & 1161 & 2,36 &, 896 \\
\hline $\begin{array}{l}\text { P1.29.- Grado de ayuda recibida para el desarrollo de la competencia } \\
\text { docente: Conocimientos de informática relativos al ámbito de estudio }\end{array}$ & 1161 & 1,77 & 1,053 \\
\hline $\begin{array}{l}\text { P1.28.- Grado de ayuda recibida para el desarrollo de la competencia } \\
\text { docente: Conocimiento de una lengua extranjera }\end{array}$ & 1154 & 1,23 & 1,11
\end{tabular}

De todos los ítems destacan por su escasa valoración y serán objeto de un análisis más detallado en adelante, los relacionados con la ayuda recibida para el desarrollo de P1.28. Conocimiento de una lengua extranjera (LE) y P1.29. Conocimientos de informática relativos al ámbito de estudio, con promedios ciertamente bajos de valoración y una dispersión considerablemente elevada $(\sigma>1)$.

Así, la competencia relacionada con P1.29 Conocimiento de informática relativos al ámbito de estudio, presenta una desviación típica considerablemente elevada $(\sigma=1,053)$, vinculada a una moderada percepción de la ayuda formativa recibida para su desarrollo $(\bar{x}=1,77)$, considerando esta puntuación bastante escasa. 
Los datos cualitativos analizados revelan ciertos códigos que permiten entender y describir la relevancia de su significado. Se presentan a continuación de forma ordenada, junto con su valor de enraizamiento en los discursos analizados (tabla 6.4).

Tabla 6.4

Relación de códigos que explican el significado de la formación cursada y su contribución para el desarrollo de P1.29

\begin{tabular}{lc}
\multicolumn{1}{c}{ Código } & Enraizamiento \\
\hline Apps ya conocidas & 15 \\
Apps especializadas aprendidas & 14 \\
\hline Demanda de mayor especialización & 10 \\
\hline Aprendizaje de las Apps & 5 \\
\hline Refuerzo manejo Apps básicas & 3 \\
\hline
\end{tabular}

Los códigos que explican P1.29 revelan la caracterización de la formación recibida y la contribución a su funcionamiento. Destacan los códigos Apps ya conocidas (15 evidencias); Apps especializadas aprendidas (14 evidencias); demanda de mayor especialización (10 evidencias); aprendizaje de las Apps (5 evidencias) y refuerzo manejo Apps básicas (3). La información recabada al respecto se diversifica por tanto en 5 códigos y 47 evidencias que caracterizan a P1.29.

Es especialmente acusada la apreciación de poca ayuda recibida en la formación cursada para el desarrollo de P1.28 Conocimiento de una LE ( $\bar{x}=1,23)$, junto con una importante elevada puntuación de desviación típica obtenida comparativamente en todas las competencias del bloque $(\sigma=1,11)$. Esta dispersión se observa en las respuestas del alumnado (figura 6.1), apreciándose una diversificación de éstas, especialmente en relación a ninguna ayuda recibida $(32,7 \%)$ y poca ayuda recibida $(28,6 \%)$; también en relación a una percepción de moderada ayuda recibida $(24,2 \%)$ y en menor medida, refiriéndose a mucha ayuda recibida $(11,9 \%)$ y muchísima ayuda recibida $(2,7 \%)$. 


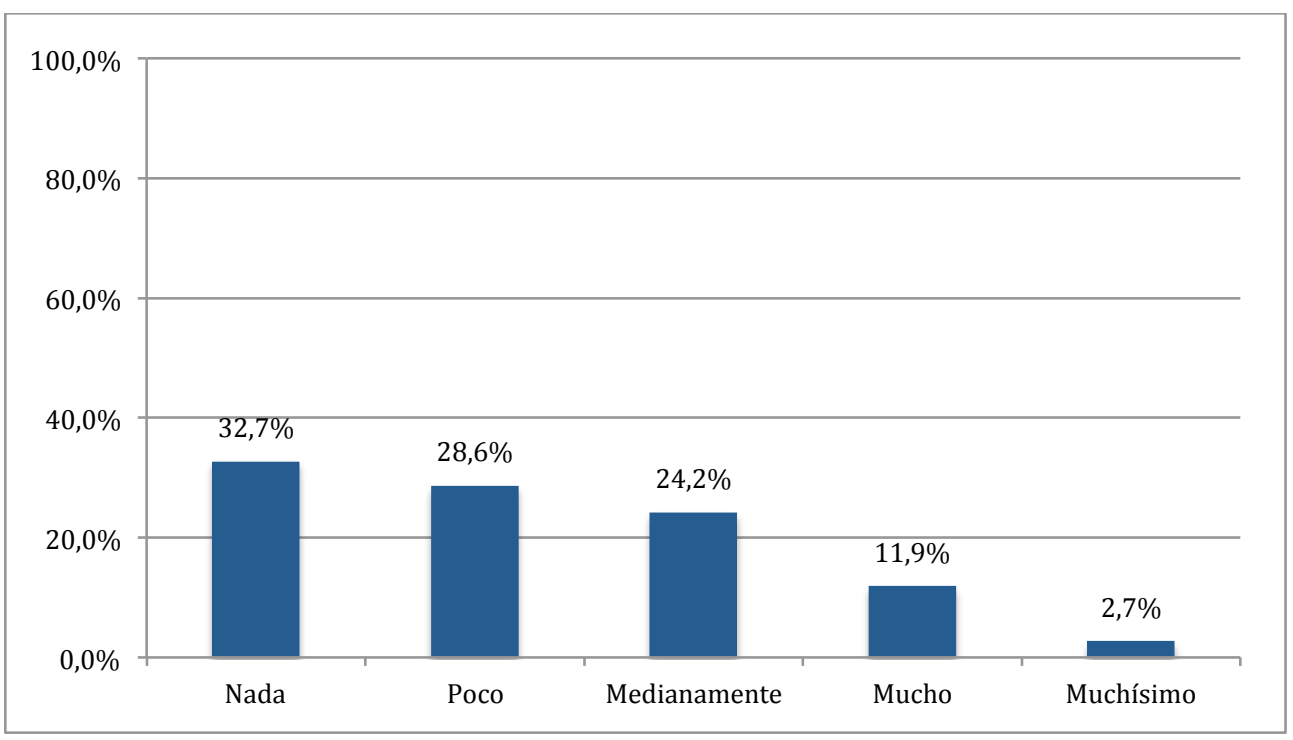

Figura 6. 1. Frecuencias en las respuestas en relación a P1.28

Los datos cualitativos analizados respecto de P1.28, se recogen en 6 códigos y 47 evidencias que esconden la riqueza de significados. Se presentan a continuación dichos códigos de forma ordenada, junto con su valor de enraizamiento en los discursos analizados (tabla 6.5).

Tabla 6.5

Relación de códigos que explican el significado de la formación cursada y su contribución para el desarrollo de P1.28

\begin{tabular}{lc}
\multicolumn{1}{c}{ Código } & Enraizamiento \\
\hline Cómo se aprende LE & 23 \\
\hline Percepción de nivel LE & 12 \\
\hline Percepción de ayuda formativa recibida & 7 \\
\hline Percepción de funcionalidad de la formación recibida & 5 \\
\hline
\end{tabular}

Los códigos aplicados describen significados en relación a la percepción de la ayuda formativa para el desarrollo de P1.28, en los siguientes términos: cómo se aprende LE (23 evidencias); percepción de nivel LE (12 evidencias); percepción de ayuda formativa recibida (7 evidencias); percepción de utilidad de la formación recibida (5 evidencias). 
Se presenta a continuación el estudio de las competencias de tipo instrumental atendiendo a la variable factor "género".

\subsubsection{Conocer cómo influye el "género" a la hora de considerar la ayuda formativa recibida durante la formación, para el desarrollo de las competencias instrumentales.}

\section{Análisis descriptivo y comparativo atendiendo al "género"}

En relación al género, hombre y mujer, se presentan a continuación en la tabla 6.6, los estadísticos descriptivos para MB1 (competencias instrumentales).

Tabla 6.6

Valores de la variable MB1 en relación a la variable factor "género"

\begin{tabular}{ccccc} 
Género & $\mathbf{N}$ & $\overline{\times}(\mathbf{M B} 1)$ & $\boldsymbol{\sigma}$ & Error típico \\
\hline Hombre & 685 & 2,09 &, 715 & 0,27 \\
\hline Mujer & 461 & 2,06 &, 694 & 0,32
\end{tabular}

Tanto para los estudiantes hombres como para las mujeres, las materias cursadas han ayudado medianamente al desarrollo del conjunto de las competetencias instrumentales a lo largo de su formación, aunque son los hombres en los que se observa un promedio mínimamente mayor $(\bar{x}=2,09)$ comparativamente; para las mujeres, se aprecia una valoración media al respecto sensiblemente inferior $(\bar{x}=2,06)$, aunque es en ellas donde se aprecia un grado de desacuerdo en las respuestas menos elevado $(\sigma=0,694)$. En la figura 6.2 , se observa esta sensible diferencia y su relación con el promedio general percibido por todos los estudiantes con respecto al bloque 1 $[\overline{\times}(\mathrm{B} 1)=2,08]$ : 


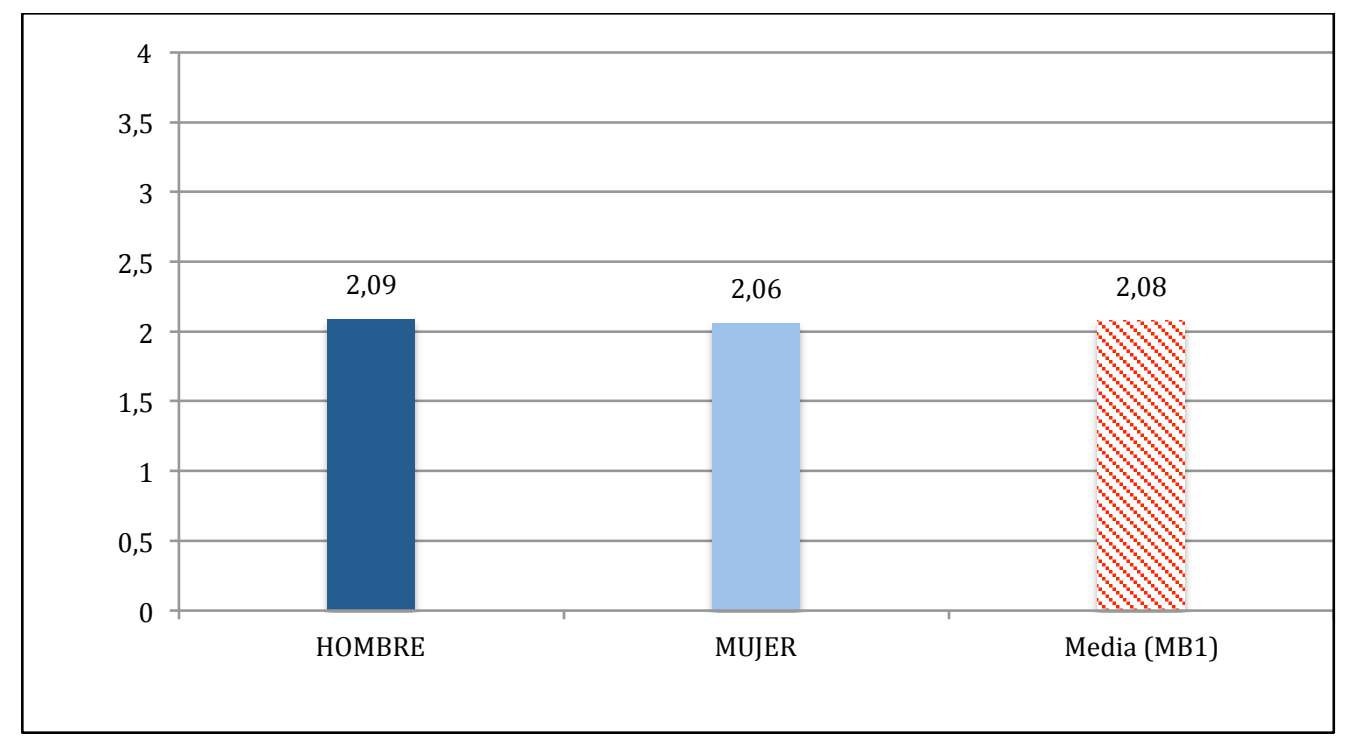

Figura 6. 2. Percepción media de los estudiantes hombres y mujeres en relación al grado de ayuda formativa recibida para el desarrollo de MB1

Para conocer la diferencia entre hombres y mujeres en relación a los promedios obtenidos en este sentido para MB1, se aplicó la prueba $U$ de Mann-Whitney con objeto de verificar si las diferencias de medias eran estadísticamente signficativas. Como se aprecia, la prueba muestra un nivel de significación de $0,495(0,495>0,05)$, lo que refuerza la hipótesis nula, es decir reconocer que no existen diferencias estadísticamente significativas entre el grado de ayuda formativa recibida para el desarrollo de MB1, respecto del género (tabla 6.7 ).

Tabla 6.7

Diferencias en la percepción de los estudiantes hombres y mujeres en relación a MBI

\begin{tabular}{lccc} 
& Hombres & Mujeres \\
\hline MB1. Competencias Instrumentales & $\bar{x}$ & $\bar{x}$ & $P$ \\
& 2,09 & 2,06 & 0,495 \\
\hline
\end{tabular}

Específicamente en relación a las dos competencias con menos promedio obtenido integradas en B1 y objeto de estudio, P1.28 y P1.29, se presentan a continuación sus correspondientes estadísticos descriptivos (tabla 6.8) atendiendo al género. 
Tabla 6.8

Valores de promedio obtenidos para P1.29 y P1.28 en relación a la variable factor "género"

\begin{tabular}{llllll} 
& Género & $\mathbf{N}$ & $\bar{x}$ & $\boldsymbol{\sigma}$ & $\begin{array}{l}\text { Error } \\
\text { típico }\end{array}$ \\
\hline $\begin{array}{l}\text { 1.29.- Grado de ayuda en el desarrollo } \\
\text { de la competencia docente: }\end{array}$ & Hombre & 685 & 1,82 & 1,064 & 0,041 \\
$\begin{array}{l}\text { conocimientos de informática relativos } \\
\text { al ámbito de estudio }\end{array}$ & Mujer & 459 & 1,68 & 1,036 & 0,048 \\
\hline $\begin{array}{l}\text { 1.28.- Grado de ayuda en el desarrollo } \\
\text { de la competencia docente: } \\
\text { conocimientos de una lengua extranjera }\end{array}$ & Hombre & 680 & 1,21 & 1,126 & 0,043 \\
\hline
\end{tabular}

Se establece a continuación, ordenadamente y de forma gráfica (figura 6.3), los promedios obtenidos para los dos ítems seleccionados de B1, considerando el "género".

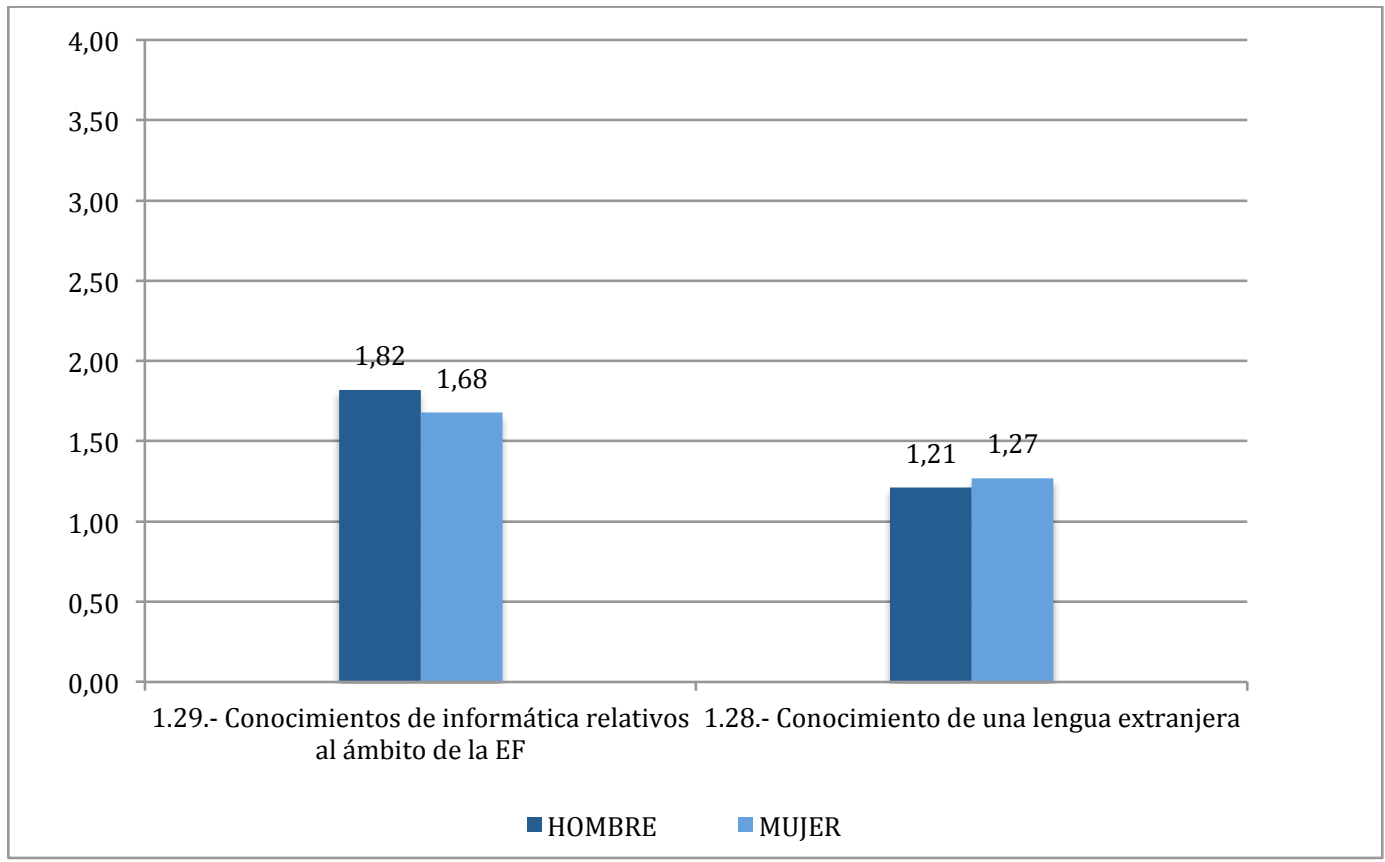

Figura 6. 3. Representación gráfica de las medias de tendencia central de P1.29 y P1.28, integradas en B1, considerando la variable factor "género" 
Se observa específicamente para P1.29 Conocimientos de informática relativos al ámbito de estudio, que la valoración sobre la ayuda formativa recibida es considerada en ambos grupos como moderada-baja, siendo la percepción de los hombres $(\bar{x}=1,82)$ sensiblemente mayor que la de las mujeres $(\bar{x}=1,68)$.

Igualmente el análisis de la desviación típica en ambos grupos revela una muy elevada dispersión en las respuestas ( $\sigma=1,064$ para los hombres y $\sigma=1,033$ en el caso de las mujeres).

A fin de establecer si el género resultaba estadísticamente significativo en relación a la percepción de la ayuda recibida para el desarrollo de P1.29, se aplicó nuevamente la prueba $U$ de Mann-Witney (tabla 6.9). El resultado obtenido evidencia la existencia de una diferencia estadísticamente significativa al respecto $(0,042<0,05)$. Estos valores permiten validar la hipótesis alterna y la diferencia estadísticamente significativa, a partir de la diferencia de género, permitiendo estimar que, reconociendo las diferencias entre las medias de ambos grupos, es la de los hombres la que está diferencialmente por encima de las mujeres; por lo tanto, la variable género masculino influye en la percepción del grado de ayuda formativa recibida para el desarrollo de P1.29.

Tabla 6.9

Diferencias en la percepción de los estudiantes hombres y mujeres sobre P1.29

Hombres Mujeres

\begin{tabular}{lccc}
\hline $\begin{array}{l}\text { 1.29.- Grado de ayuda en el desarrollo de la } \\
\text { competencia docente: conocimientos de informática } \\
\text { relativos al ámbito de estudio }\end{array}$ & $\overline{\times}$ & $\overline{\times}$ & $P$ \\
\hline
\end{tabular}

Este aspecto se ve reforzado, desde el estudio cualitativo, con una mayor presencia de códigos explicativos de los datos procedentes de los GD realizados para el caso de los estudiantes hombres. Se presenta a continuación la comparativa de presencia de códigos en los hombres y en las mujeres, a fin de apreciar mejor la diferencia (tabla $6.10)$ 
Tabla 6.10

Estudio comparativo entre estudiantes hombres y mujeres sobre los códigos que explican el funcionamiento de la formación recibida para el desarrollo de P1.29

\begin{tabular}{lclc}
\multicolumn{1}{c}{ Hombres } & \multicolumn{2}{c}{ Mujeres } \\
\hline \multicolumn{1}{c}{ Código } & Enraizamiento & \multicolumn{1}{c}{ Código } & Enraizamiento \\
\hline $\begin{array}{l}\text { Demanda de mayor } \\
\text { especialización }\end{array}$ & 10 & $\begin{array}{l}\text { Apps especializadas } \\
\text { aprendidas }\end{array}$ & 5 \\
$\begin{array}{l}\text { App especializadas } \\
\text { aprendidas }\end{array}$ & 8 & $\begin{array}{l}\text { Apps ya conocidas } \\
\text { Refuerzo manejo Apps } \\
\text { básicas }\end{array}$ & 1 \\
App ya conocidas & 8 & & 1 \\
$\begin{array}{l}\text { Aprendizaje de las Apps } \\
\text { Refuerzo manejo Apps } \\
\text { básicas }\end{array}$ & 4 & & \\
\hline
\end{tabular}

Se aprecia para el grupo de hombres una presencia de todos los códigos establecidos para el análisis del fenómeno; sin embargo, en las mujeres se observa la presencia de tres de los cinco dispuestos y menor número de evidencias. Para conocer mejor el significado de cada uno de los códigos en el contexto de cada grupo, se presenta una comparativa de redes semánticas a fin de interpretar y explicar la ayuda formativa recibida para el desarrollo de P1.29; para ello, se indagó sobre las relaciones entre los códigos, entre las citas y entre ambos.

Para el caso de las estudiantes mujeres (figura 6.4), a partir de la red semántica resultante del estudio relacional de citas y códigos, se muestra que la formación cursada dispone una serie de conocimientos de informática básicos y App ya conocidas que se repiten durante el proceso formativo; trabajar su contenido sirve en todo caso para reforzar su manejo.

Grupo Mujeres (5:35)

En la asignatura de TICs lo que hicimos fue repetir lo que sabíamos de antes. 
Grupo Mujeres (5:36)

En la asignatura de matemáticas sí que hemos realizado alguna práctica con el programa Excel aunque no relacionada con su aplicación a nuestro ámbito de la EF.

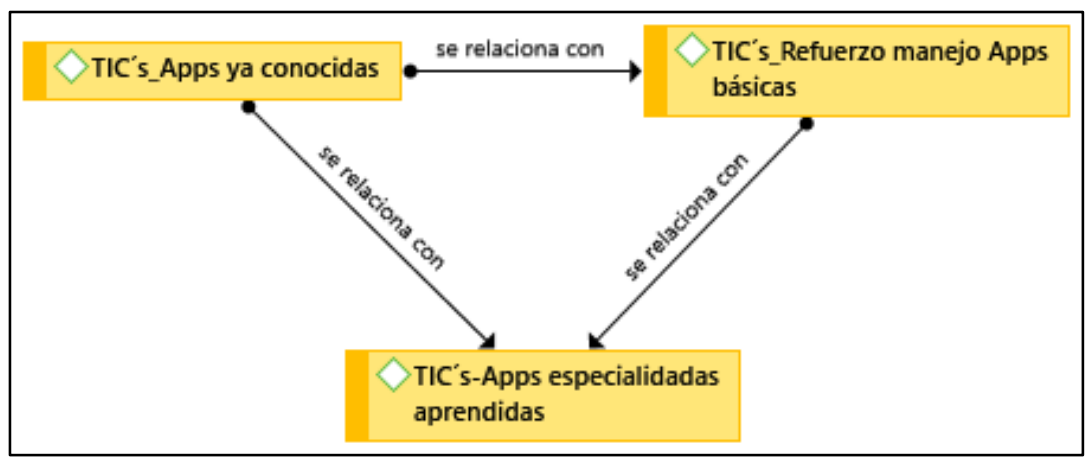

Figura 6. 4. Red semántica del grupo de mujeres que explica las experiencias formativas relacionadas con la adquisición y desarrollo de P.129

No obstante en la formación recibida se reconoce haber aprendido el manejo de algunas Apps especializadas, pero sin relacionarse directamente con la aplicación al ámbito de la EF, aunque susceptibles de ser aplicadas a este mismo (creación de webquest, cazatesoros).

\section{Grupo Mujeres (5:37)}

En la signatura TICs aprendimos a crear una página web propia de una materia, por ejemplo yo la hice sobre ciencias sociales y pienso que sí se podría llevar a cabo una página web para trabajar los contenidos de EF.

Para el grupo de estudiantes hombres, se observa mayor presencia de códigos en su discurso, junto con un número mayor de evidencias argumentativas que los caracterizan y dimensionan (figura 6.5). 




Figura 6. 5. Red semántica del grupo de hombres que explica las experiencias formativas relacionadas con la adquisición y desarrollo de P1.29

Se considera inicialmente que durante la formación cursada no se ha enseñado nada nuevo o, en el mejor de los casos, la formación tecnológica recibida ya se conocía. Se insiste en la idea de que ya se partía de un conocimiento tecnológico general, que supera las alternativas formativas enseñadas. Por tanto, lo más básico al respecto parece que ya se poseía.

Grupo Hombres (5:66)

No nos han enseñado nada nuevo a lo largo de toda la carrera.

Grupo Hombres (3:132)

En el manejo y control de las TIC's casi se tienen que poner los alumnos a dar clase a los profesores.

Este aspecto se relaciona con una percepción de la formación recibida cuyo fin, en todo caso, es reforzar los conocimientos tecnológicos que ya se disponen (refuerzo manejo Apps básicas), fundamentalmente instrumentales y básicos (creadores de presentaciones visuales, programas de edición de audio). 
Grupo Hombres (5:63)

En cuanto al uso de aplicaciones que sirvan para el día a día [...] el resto, son refuerzos de power point, refuerzos en el manejo del audacity para poner música en el aula.

No obstante, esta realidad también convive con el reconocimiento de haber aprendido el uso de algunas Apps especializadas (geocaching, wikiloc) no específicamente educativas aunque aplicables a la docencia en general y, en cierta medida, a la EF en particular.

Grupo Hombres (5:32)

Algunas aplicaciones que pueden ser utilizadas para trabajar con niños en educación física escolar como es el caso de las aprendidas en la asignatura de educación física en el medio natural: geocaching, wikiloc.

Grupo Hombres (5:70)

Para la educación física si tu llevas una programación sobre senderismo o de orientación sí las puedes utilizar, pero aun siendo aplicables a la enseñanza no son creadas específicamente para la educación, ya que pueden ir destinadas a cualquier otro ámbito.

Las herramientas aprendidas durante la formación se reconocen que lo fueron mediante un sistema de descubrimiento y exploración libre. Además se observa en el Practicum y en la figura del tutor del centro, que se hace un uso educativo diario de las herramientas tecnológicas, siendo este espacio también utilizado para el descubrimiento, uso, manejo, observación y comprobación de sus posibilidades pedagógicas. 
Grupo Hombres (5:65)

Es un aprendizaje algo basado en el descubrimiento, ya que se nos da una serie de pinceladas y después con el profesor vas manejando e investigando sus posibilidades, aplicándolo en las actividades en el medio natural o creando algo nuevo desde ellas.

Grupo Hombres (5:34)

Yo el contacto que he tenido fue en el Practicum 1 donde una profesora usaba una aplicación en donde se registraban y analizaban notas en relación a la evolución del alumno...por ejemplo si ha subido tantos puntos o ha bajado tantos otros en tal o cual momento; también contabilizada las faltas de asistencia... era realmente buena la aplicación... eso para un análisis de datos sobre el alumnado puede servirte muy bien.

El grupo de estudiantes hombres, en relación a la formación cursada, demandan aprender Apps más especializadas en el ámbito educativo (ya que lo que se conoce tecnológicamente es demasiado básico). Son consideradas como necesarias, pudiendo poder seleccionar aquellas que mejor les permita motivar y hacer más atractivos los contenidos a su futuro alumnado; conociéndolas demandan su uso y aplicabilidad.

\footnotetext{
Grupo Hombres (3:13)

Considero que sería necesario enseñarnos herramientas docentes, ya que habrá programas y ciertas cosas que desconozcamos.
}

\section{Grupo Hombres (3:15)}

Yo creo que en esa competencia en lo que nos deberían formar, como habéis dicho, no es en cómo utilizarlas, nosotros sabemos y los que vienen por detrás más todavía, sino en cómo enseñarnos el filtro a la hora de buscar recursos que a los alumnos se les haga atractivos por el tema de las TIC's, pero que sean de calidad. 
La competencia P1.28. Conocimiento de una $\mathbf{L E}$ es la que recibe una valoración media más baja de las competencias instrumentales. Es mínimo y común para hombres y mujeres el reconocimiento sobre la ayuda recibida para su desarrollo, siendo en las mujeres algo superior la valoración al respecto que en los hombres $(\bar{x}=1,27$ y $\bar{x}=1,21)$. En ambos grupos se observa una elevada dispersión en las respuestas, apreciable en valores de desviación típica excesivamente elevados y que oscilan entre 1,091 y 1,126 .

Se aplicó la prueba $U$ de Mann-Whitney a fin de conocer la posible existencia de diferencias estadísticamente significativas entre los grupos para P1.28 (tabla 6.11). El resultado obtenido permite afianzar la hipótesis nula y reconocer que no existen diferencias estadísticamente significativas para esta variable en relación al género; siendo las diferencias que se aprecian, en todo caso, no relacionadas con este factor $(0,234>0,05)$.

Tabla 6. 11

Diferencias en la percepción de los estudiantes hombres y mujeres sobre P1.28

\begin{tabular}{lccc} 
& Hombres & Mujeres & \\
\hline $\begin{array}{l}\text { 1.28.- Grado de ayuda en el desarrollo de la } \\
\text { competencia docente: conocimiento de una lengua } \\
\text { extranjera }\end{array}$ & $\bar{x}$ & $\overline{\times}$ & $P$ \\
\hline
\end{tabular}

La ausencia de diferencias significativas también se aprecia tras analizar los datos cualitativos procedentes de los GD; no obstante se observan matices que si bien no hacen diferir sustancialmente su percepción, sí lo matizan en mayor detalle caracterizando particularmente dicha percepción en ambos grupos (tabla 6.12). 
Tabla 6.12

Estudio comparativo entre estudiantes hombres y mujeres sobre los códigos que explican el funcionamiento de la formación recibida para el desarrollo de P1.28

\begin{tabular}{lclc}
\multicolumn{1}{c}{ Hombres } & \multicolumn{2}{c}{ Mujeres } \\
\hline \multicolumn{1}{c}{ Código } & Enraizamiento & \multicolumn{1}{c}{ Código } & Enraizamiento \\
\hline Cómo se aprende LE & 11 & Cómo se aprende LE & 12 \\
$\begin{array}{l}\text { Percepción de nivel LE } \\
\begin{array}{l}\text { Percepción de ayuda } \\
\text { formativa recibida }\end{array}\end{array}$ & 9 & $\begin{array}{l}\text { Percepción de nivel LE } \\
\text { Percepción de ayuda }\end{array}$ & 3 \\
$\begin{array}{l}\text { Percepción de } \\
\text { funcionalidad de la } \\
\text { formación recibida }\end{array}$ & 5 & $\begin{array}{l}\text { formativa recibida } \\
\text { funcepción de } \\
\text { formación recibida }\end{array}$ & 3 \\
\hline
\end{tabular}

Se aprecia para los dos grupos una presencia similar de los códigos que explican la formación recibida para $\mathrm{P} 1.28$; tan solo los códigos cómo se aprende LE y percepción de nivel $L E$ muestran algunas diferencias en cuanto a su enraizamiento. Como apuntábamos anteriormente, el significado de las evidencias encontradas para ambos grupos muestra una idea similar al respecto; pero el estudio de las evidencias que dimensionan y caracterizan a ciertos códigos ofrece un significado en más detalle que es necesario reconocer.

Para el caso del grupo de estudiantes mujeres, como se observa en la red semántica (figura 6.6), la forma de aprender una $L E$, parte de un modelo repetido en todas las etapas educativas cursadas, en clave de repaso, dirigido hacia la enseñanza de aspectos fundamentalmente gramaticales, desde un procedimiento autónomo de aprendizaje, aunque no exento de vacíos y lagunas.

Grupo Mujeres (5:81)

Siempre en lengua extranjera estamos en clave de repaso y siempre habrá lagunas, y es porque abordamos la lengua extranjera de la misma manera. 
Grupo Mujeres (5:52)

Hemos tenido dos asignaturas en las que nos han preparado y evaluado de todas las partes, es decir, grammar, listening, writing and reading. La parte de gramática es la que más se prepara en clase haciendo ejercicios a través de un libro, pero la mayoría del aprendizaje se lleva a cabo de forma autónoma en casa.

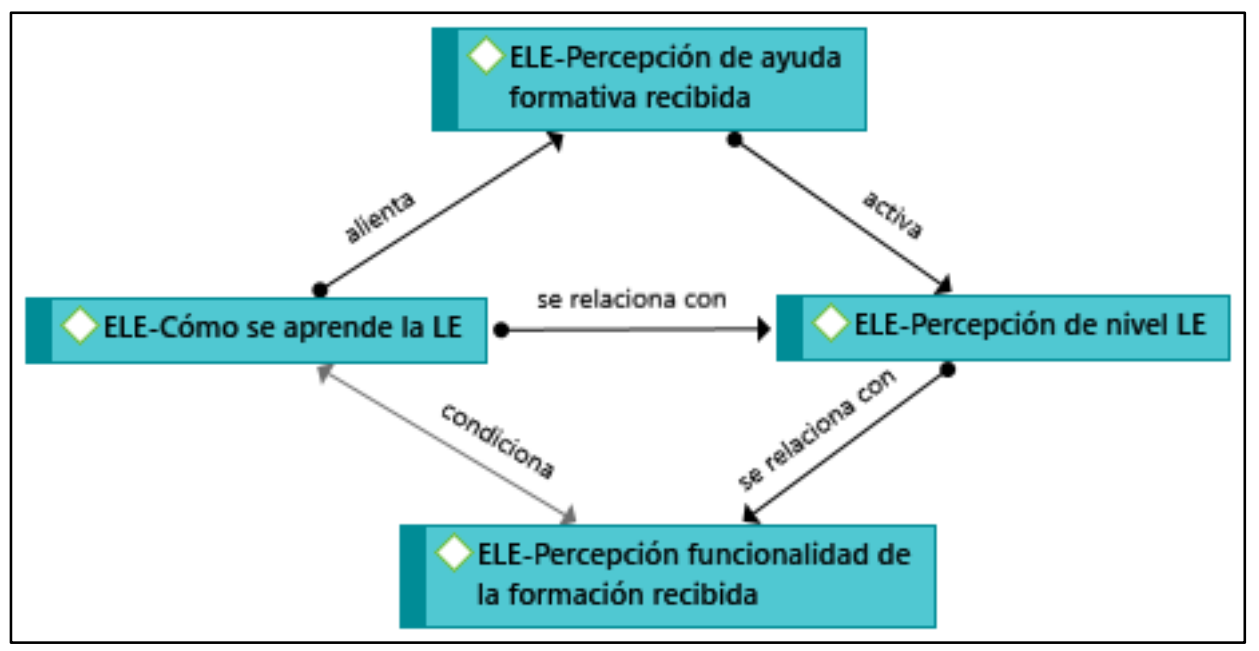

Figura 6. 6. Red semántica del grupo de mujeres que explica las experiencias formativas relacionadas con la adquisición y desarrollo de P1.28

Este modelo formativo para aprender una LE alienta, dadas las dificultades encontradas, una percepción de poca ayuda formativa recibida. Esto activa una percepción y apreciación de nivel bajo de dominio de la competencia; así, al viajar a un país extranjero reconocen un nivel inferior al que necesitan para comunicarse en ese contexto.

Grupo Mujeres (5:74)

Yo le daría una valoración de poco a la ayuda formativa para desarrollar la lengua extranjera en la carrera.

Grupo Mujeres (3:46)

Pero es como en cualquier lado, aquí tu te sacas el $\mathrm{C} 1$ y yo por ejemplo me saqué hace unos años el B2 [...] un nivel medio de ingles [...]; y me lo saco y lo domino bien y, fui para Inglaterra un mes, y volví diciendo no tengo ni idea. 
La percepción de bajo nivel competencial para el dominio de una LE, condicionado por las carencias formativas arrastradas de etapas educativas anteriores, finalmente se relaciona con una idea de funcionalidad más relacionada con la necesidad de obtener una titulación y conocer lo básico, que la de aprender a comunicarse en cualquier situación.

Grupo Mujeres (3:140)

Una cosa es la teoría y luego un examen con un señor que te pregunta $[\ldots]$, y otra cosa es tener un nivel; pero ya como que, da igual, o sea, lo que te exigen es tener el título y que tengas cierta desenvoltura en el idioma.

Para el grupo de estudiantes hombres (figura 6.7), de la misma manera, se describe un modelo formativo para la enseñanza de LE fundamentado esencialmente en la gramática y perpetuando dificultades y barreras constantemente; no obstante se buscan alternativas formativas, extra-académicas, para interactuar, forzar la competencia comunicativa y mejorar.

Grupo Hombres (5:86)

En relación a la capacidad de desarrollarme atendiendo al conocimiento de una lengua extranjera, el problema que he observado es la forma de impartir la asignatura, empleando la profesora una metodología tradicional de trabajo de la gramática y ya está, y las lagunas siempre están.

Grupo Hombres (5:57)

La única formación que hemos tenido menos memorística sobre el inglés han sido charlas, en primero y parte de segundo, en el centro de idiomas y en donde nos permitían hablar con un nativo; estabas 10 minutos con un nativo después girabas y hablabas con otro, y eso al final te estás forzando a comunicarte, es una experiencia nueva en la que te estás formando para el bilingüismo medianamente, donde tu intentas hablar, te intentan entender y poco a poco vas mejorando. 


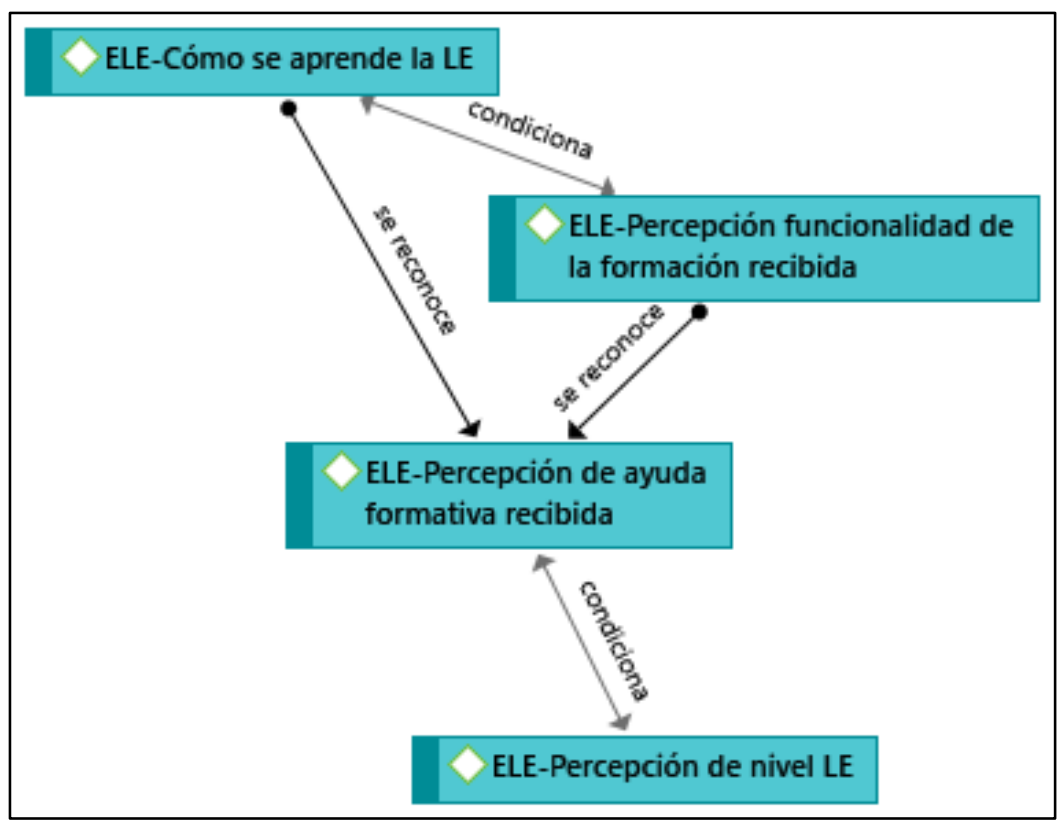

Figura 6. 7. Red semántica del grupo de hombres que explican las experiencias formativas relacionadas con la adquisición y desarrollo de P1.28

La forma de aprender una LE experimentada hasta el momento condiciona una percepción de ausencia de funcionalidad del modelo formativo, considerando que éste no ayuda a alcanzar un mejor nivel de comunicación $y$, que va a requerir consecuentemente a futuro, un sobresfuerzo personal.

Grupo Hombres (3:76)

Eso sirve de bastante poco. Si el día de mañana, yo acabo, y lo que me estás exigiendo (es) un B2, si partes de un B1 prepárate bien.

En virtud de las dificultades acumuladas y presentes en el modelo de aprendizaje experimentado, se reconoce por tanto una mínima ayuda formativa recibida para adquirir una LE, hasta el punto de condicionar su percepción de nivel, considerándose por ejemplo muy limitados, para entender el contenido de una película en versión original (inglés) o comunicarse y dialogar con alguien haciendo uso de una LE. 
Grupo Hombres (5:50)

Personalmente aún repitiendo varias veces la asignatura, de esta en la Universidad no me han enseñado nada.

Grupo Hombres (3:83)

No aprendes a hablar inglés porque aprender a hablar inglés es mucho más profundo, es por ejemplo ver una película, saber lo que te están hablando, poder tener una charla con alguien en inglés y yo personalmente no estoy en disposición de ello.

Se presentan a continuación a partir de la variable "tipo de estudios de EF" cursados, la formación recibida para el desarrollo de las competencias instrumentales objeto de estudio.

\subsubsection{Conocer cómo influye el "tipo de estudios de Educación Física" cursados a la hora de considerar la ayuda formativa recibida durante la formación para el desarrollo de las competencias instrumentales.}

\section{Análisis descriptivo y comparativo atendiendo al "tipo de estudios de EF" cursados.}

Se consideran para el "tipo de estudios de EF" cursados por los estudiantes, los dos títulos desde los que se accede a la profesión docente para el área. Así contamos con dos titulaciones universitarias: Grado Universitario de Maestro de Educación Primaria con la mención en Educación Física (MEPEF) y Grado Universitario en Ciencias de la Actividad Física y del Deporte (CAFyD).

Los estadísticos descriptivos para MB1 a partir de la variable independiente “tipo de estudios de EF" cursados, se presentan a continuación en la tabla 6.13. 
Tabla 6.13

Valores de la variable MBI en relación a la variable factor "tipo de estudios de EF" cursados

\begin{tabular}{ccccc} 
Estudios de EF cursados & $\mathbf{N}$ & $(\overline{\times} \mathbf{B 1})$ & $\boldsymbol{\sigma}$ & Error típico \\
\hline MEPEF & 781 & 2,12 &, 712 & 0,25 \\
\hline CAFyD & 371 & 1,99 &, 681 & 0,35
\end{tabular}

Para los estudiantes procedentes de ambos grados universitarios, las materias cursadas han ayudado medianamente a lo largo de su formación al desarrollo del conjunto de las competencias instrumentales; aunque son los procedentes del grado MEPEF, en los que se observa un promedio mayor $(\bar{x}=2,12)$. Por otro lado, para los estudiantes procedentes del grado CAFyD, se aprecia una valoración media inferior $(\bar{x}=1,99)$, aunque es en esta titulación donde hay un mayor grado de acuerdo en las respuestas $(\sigma=0,681)$. Esta diferencia se observa de forma gráfica en la figura 6.8.

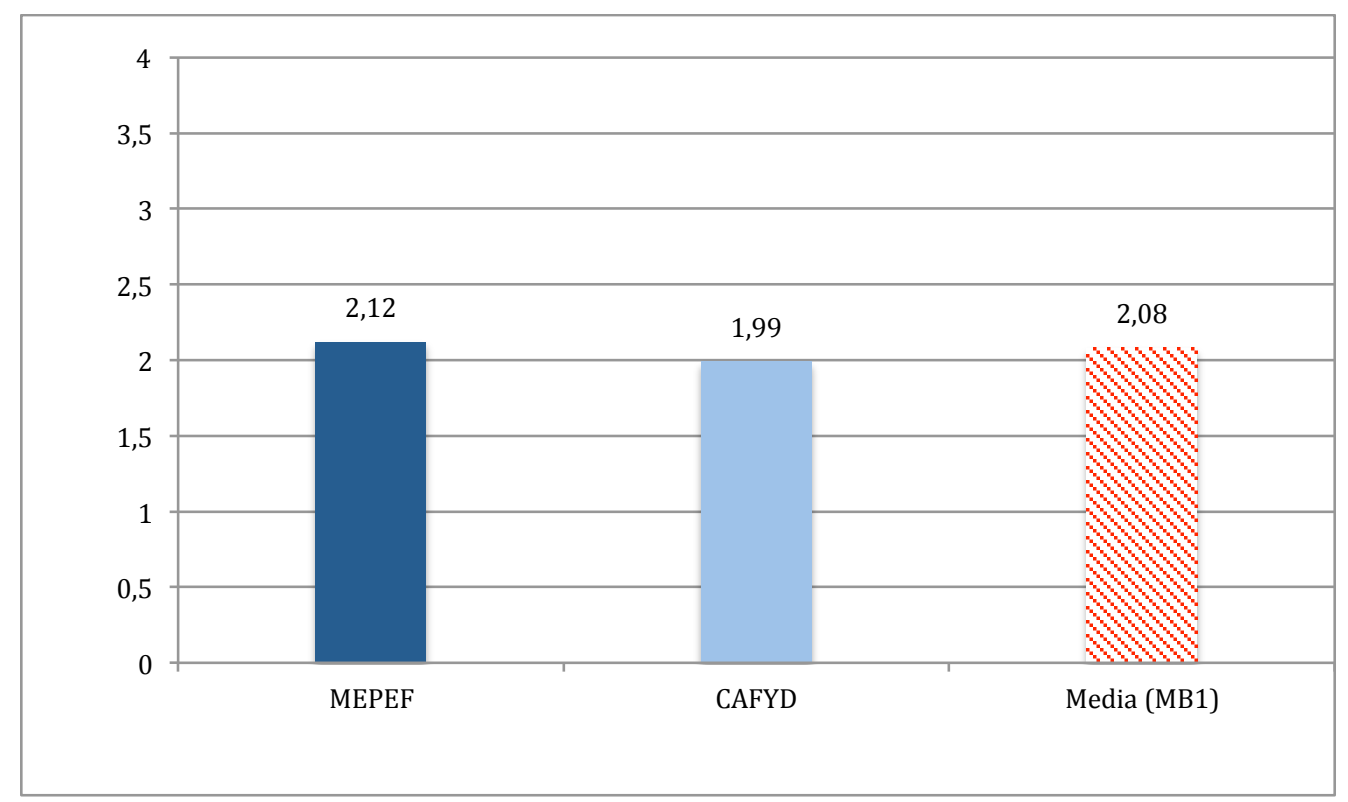

Figura 6. 8. Percepción media de los estudiantes de los grupos MEPEF y CAFyD en relación al grado de ayuda formativa recibida para el desarrollo de MB1 
Se aplicó la prueba $U$ de Mann-Whitney para verificar si las diferencias entre el tipo de estudios de EF cursados en relación a los promedios obtenidos para MB1 son o no estadísticamente significativas (tabla 6.14).

Tabla 6.14

Diferencias en la percepción de los estudiantes MEPEF y CAFyD en relación a MBI

MEPEF CAFyD

MB1. Competencias Instrumentales

$\overline{\mathrm{x}} \quad \overline{\mathrm{x}} \quad P$

$2,12 \quad 1,99 \quad 0,004$

Según se recoge anteriormente, la prueba muestra un nivel de significación de $0,004(0,004<0,05)$, lo que indica que ha de ser aceptada la hipótesis alterna; es decir, reconocer que sí se encuentran diferencias estadísticamente significativas entre el grado de ayuda formativa recibida para el desarrollo de MB1, en relación al tipo de estudios cursados, en favor de los estudiantes MEPEF, quienes presentan una valoración media superior $(\bar{x}=2,12)$ a la de los estudiantes CAFyD $(\bar{x}=1,99)$. Por tanto, en la percepción de los estudiantes, la ayuda recibida a partir de las materias cursadas en el grado MEPEF, fue mayor que la recibida en el grado CAFyD, aunque reconociendo en ambos grupos como "medianamente" el grado de ayuda recibida para el desarrollo de MB1.

De la misma manera, en este caso atendiendo a la titulación cursada, se presentan a continuación los correspondientes estadísticos descriptivos de las dos competencias seleccionadas de B1 en relación a la perpceción sobre la ayuda formativa recibida para su desarrollo (tabla 6.15): P1.29 conocimientos de informática relativos al ámbito de estudio y P1.28 conocimiento de una LE. 
Tabla 6.15

Valores de promedio obtenidos para P1.29 y P1.28 en relación a la variable factor "tipo de estudios de EF" cursados

\begin{tabular}{|c|c|c|c|c|c|}
\hline & Titulación & $\mathbf{N}$ & $\bar{x}$ & $\boldsymbol{\sigma}$ & Error típico \\
\hline $\begin{array}{l}\text { 1.29.- Grado de ayuda en el desarrollo } \\
\text { de la competencia docente: }\end{array}$ & MEPEF & 783 & 1,80 & 1,097 & 0,039 \\
\hline $\begin{array}{l}\text { conocimientos de informática relativos } \\
\text { al ámbito de estudio }\end{array}$ & CAFyD & 372 & 1,71 & ,956 & 0,05 \\
\hline $\begin{array}{l}\text { 1.28.- Grado de ayuda en el desarrollo } \\
\text { de la competencia docente: }\end{array}$ & MEPEF & 777 & 1,38 & 1,126 & 0,04 \\
\hline $\begin{array}{l}\text { conocimientos de una lengua } \\
\text { extranjera }\end{array}$ & CAFyD & 371 & 0,93 & 1,009 & 0,052 \\
\hline
\end{tabular}

Se establece a continuación ordenadamente (de mayores a menores valoraciones) y de forma gráfica (figura 6.9), los promedios obtenidos para cada una de las preguntas que conforman B1, considerando el Tipo de estudios de Educación Física cursados.

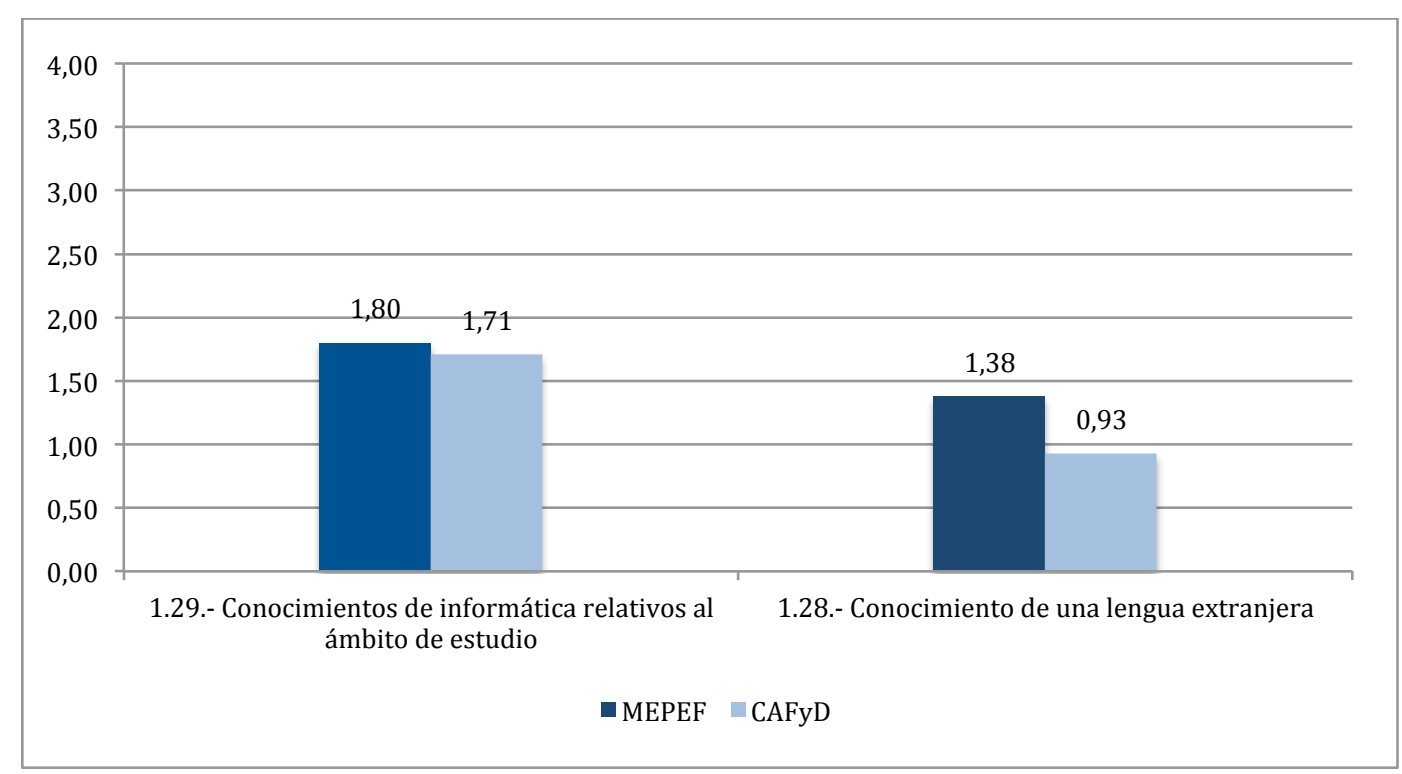

Figura 6. 9. Representación gráfica de las medias de tendencia central de P1.29 y P1.28, integradas en B1, considerando la variable factor "tipo de estudios de EF" cursados

Como se aprecia, los estudiantes del grupo MEPEF obtienen valoraciones de promedio superiores a los estudiantes CAFyD en relación a la ayuda formativa recibida para el desarrollo de $\mathrm{P} 1.29$ conocimientos de informática relativos al ámbito de 
estudio a partir de las materias cursadas $(\bar{x}=1,80$ de los primeros frente a $\bar{x}=1,71$ en los segundos), aunque el grado de ayuda recibida en ambos casos es considerada como moderada; además para los primeros (MEPEF) el desacuerdo en las respuestas es significativamente elevado expresado en un valor de $\sigma=1,097$.

A fin de establecer si el hecho de cursar una $\mathrm{u}$ otra titulación resultaba estadísticamente significativo en relación a la percepción de la ayuda formativa recibida para el desarrollo de P1.29, se aplicó la prueba $U$ de Mann-Witney cuyo resultado $(0,135>0,05)$ afianza la hipótesis nula $\mathrm{y}$, por tanto, no se evidencian diferencias estadísticamente significativas entre las medias obtenidas, a partir de las dos titulaciones de EF cursadas (tabla 6.16).

Tabla 6.16

Diferencias en la percepción de los estudiantes MEPEF y CAFyD sobre P1.29

MEPEF CAFyD

\begin{tabular}{lccc}
\hline $\begin{array}{l}\text { 1.29.- Grado de ayuda en el desarrollo de la } \\
\text { competencia docente: conocimientos de informática } \\
\text { relativos al ámbito de estudio }\end{array}$ & $\bar{x}$ & $\bar{x}$ & $P$ \\
\hline
\end{tabular}

Específicamente, a fin de conocer la percepción de los estudiantes en relación a su procedencia formativa (facultades MEPEF y facultades CAFyD), se muestran a continuación los resultados de promedio, destacándose a priori, para el caso de las facultades MEPEF, que ninguna de las analizadas muestra valores de $\bar{x}>3 \mathrm{y}$, sin embargo, sí puntuaciones considerablemente bajas en una gran parte de los casos (tabla $6.17)$. 
Tabla 6.17

Valores de promedio obtenidos para P1.29 en relación a la variable factor "facultades $M E P E F^{\prime \prime}$

\begin{tabular}{llcccc}
\multicolumn{1}{c}{ Competencia } & \multicolumn{1}{c}{$\begin{array}{c}\text { Facultad de } \\
\text { Educación }\end{array}$} & N & $\overline{\times}$ & $\boldsymbol{\sigma}$ & $\begin{array}{c}\text { Error } \\
\text { típico }\end{array}$ \\
\hline & Valencia (UV) & 76 & 2,43 & 0,984 & 0,113 \\
& Tenerife (ULL) & 34 & 2,32 & 1,093 & 0,187 \\
& Valladolid (UVa) & 44 & 2,27 & 1,086 & 0,164 \\
& Granada (UGR) & 92 & 2,21 & 1,043 & 0,109 \\
P1.29.- Grado de ayuda en el & Murcia (UMU) & 67 & 1,91 & 0,981 & 0,120 \\
desarrollo de la competencia & Córdoba (UCO) & 20 & 1,90 & 1,021 & 0,228 \\
docente: conocimientos de & Segovia (UVa) & 28 & 1,89 & 1,050 & 0,202 \\
informática relativos al & Albacete (UCLM) & 102 & 1,68 & 0,966 & 0,096 \\
ámbito de estudio & Santander (UniCan) & 64 & 1,56 & 1,207 & 0,151 \\
& Sevilla (US) & 159 & 1,39 & 0,974 & 0,077 \\
& Barcelona (UB) & 30 & 1,33 & 0,994 & 0,182 \\
& Madrid (UAM) & 45 & 1,05 & 1,160 & 0,175 \\
\hline
\end{tabular}

A continuación (figura 6.10), se presenta gráfica y ordenadadamente (mayor a menor valoración) los promedios obtenidos para P1.29, a partir de las facultades MEPEF de procedencia de los estudiantes encuestados. 


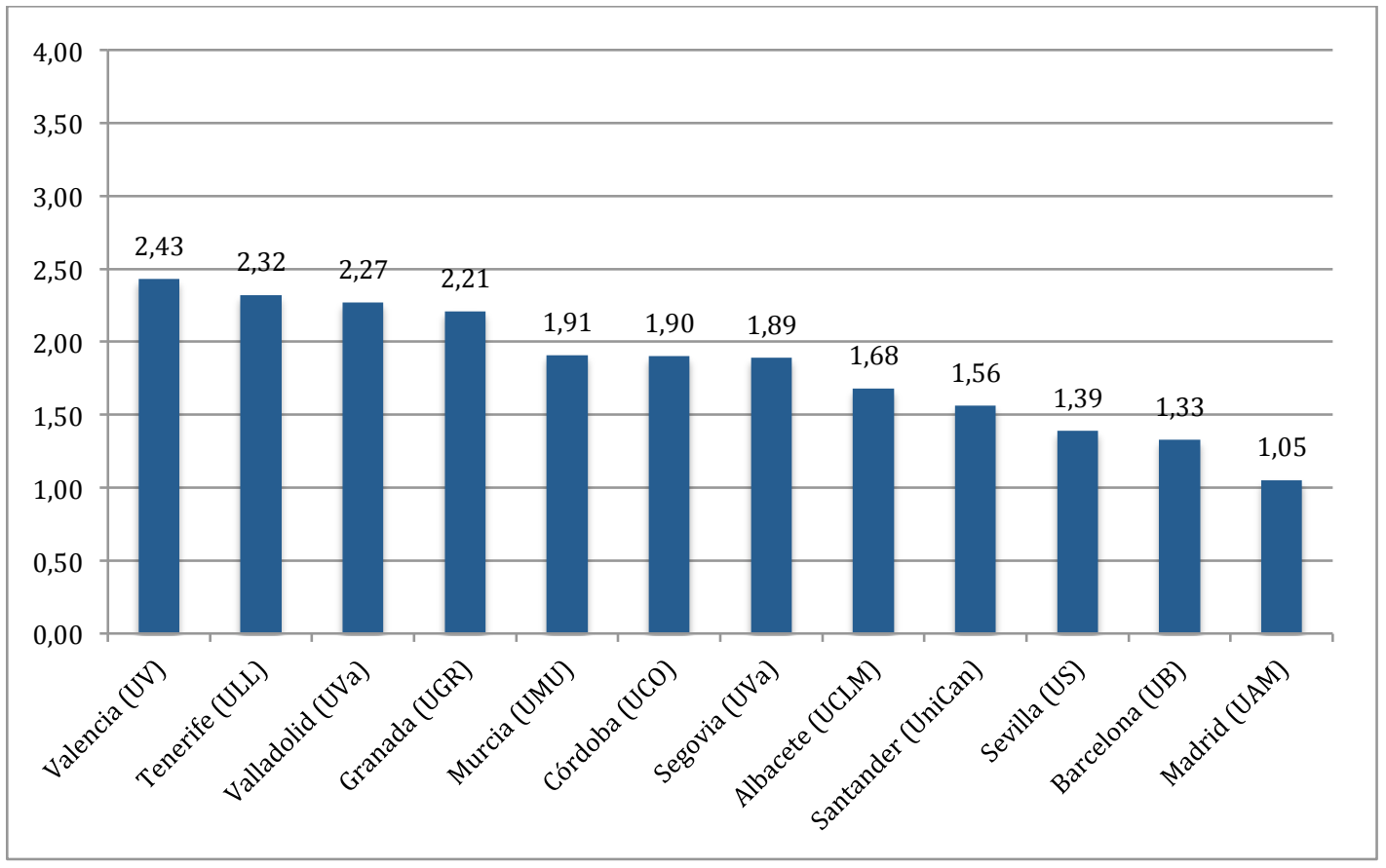

Figura 6. 10. Representación gráfica de los valores de promedio obtenidos para P1.29 en relación a la variable factor "facultades MEPEF"

Como se adelantaba, un aspecto a destacar a partir de los promedios obtenidos y compartido por todas las facultades MEPEF estudiadas, es la pobre percepción del grado de ayuda recibida por parte de los estudiantes encuestados para el desarrollo de P1.29; no obstante, de los promedios obtenidos, el más elevado se observa para la facultad MEPEF de la Universidad de Valencia $(\bar{x}=2,43)$, y el más bajo para la de la Universidad Autónoma de Madrid $(\bar{x}=1,05)$. Para la primera, se aprecia un moderado grado de ayuda formativa recibida para el desarrollo de P1.29, mientras que para la segunda se aprecia una consideración de poca la ayuda formativa recibida; para este caso además, se obtiene el más alto valor de desviación típica $(1,160)$. 
A continuación se muestra el resultado de la prueba Kruskal-Wallis, a fin de conocer la influencia de la variable facultades MEPEF sobre P1.29, y si existe una igual afección de las distintas facultades analizadas en relación a dicha pegunta. Los resultados se observan en la siguiente tabla 6.18 .

Tabla 6.18

Prueba Kruskal-Wallis para P1.29 y variable factor "facultades MEPEF"

P1.29. Grado de ayuda formativa recibida para el desarrollo de conocimientos de informática aplicada al ámbito de la EF

\begin{tabular}{lr}
\hline Chi-cuadrado & 109.931 \\
Gl & 15 \\
Sig.asintót. &, 000 \\
\hline
\end{tabular}

La prueba muestra un valor de $0,000($ Sig. $<0,05)$, lo que indica el rechazo de la hipótesis nula y que, por tanto, sí influye el factor aplicado a la variable P1.29. Por ello, dado que el resultado de Kruskal-Wallis nos permite aceptar la hipótesis alterna, se realiza un análisis post hoc, a fin de comprobar qué pares de facultades de educación difieren entre sí, a través de la prueba HSD Tukey (tabla 6.19), ya que el estadístico de la prueba de homogeneidad de varianzas (Sig. Levène $=0,055>0,05)$ permite asumir varianzas iguales.

Tabla 6.19

Resultados del análisis post hoc entre P1.29 y la variable factor "facultades MEPEF" (comparadas de dos en dos)

\begin{tabular}{clc}
$\begin{array}{c}\text { (I) Facultad de } \\
\text { Educación }\end{array}$ & $\begin{array}{c}\text { (J) Facultad de } \\
\text { Educación }\end{array}$ & $\begin{array}{c}\text { HSD Tukey } \\
\text { Sig. }\end{array}$ \\
\hline Valencia (UVa) & Albacete (UCLM) & 0,000 \\
& Santander (UniCan) & 0,000 \\
& Sevilla (US) & 0,000 \\
& Barcelona (UB) & 0,000 \\
& Madrid (UAM) & 0,000 \\
\hline Tenerife (ULL) & Santander (UniCan) & 0,041 \\
& Sevilla (US) & 0,000 \\
& Barcelona (UB) & 0,012 \\
& Madrid (UAM) & 0,000
\end{tabular}




\begin{tabular}{cll}
\hline Valladolid (UVa) & Santander (UniCan) & 0,036 \\
& Sevilla (US) & 0,000 \\
& Barcelona (UB) & 0,011 \\
& Madrid (UAM) & 0,000 \\
\hline Granada (UGR) & Albacete (UCLM) & 0,029 \\
& Santander (UniCan) & 0,012 \\
& Sevilla (US) & 0,000 \\
& Barcelona (UB) & 0,006 \\
& Madrid (UAM) & 0,000 \\
\hline Murcia (UMU) & Sevilla (US) & 0,042 \\
& Madrid (UAM) & 0,002 \\
\hline
\end{tabular}

La diferencia es significativa al nivel de .05 .

Se aprecian diferencias estadísticamente significativas para cuatro facultades MEPEF que obtuvieron las cuatro puntuaciones más altas: (1) entre la Facultad de Educación de Valencia (puntuación más alta obtenida) y las Facultades de Albacete (Sig. HSD Tukey =0,000), Santander (Sig. HSD Tukey =0,000), Sevilla (Sig. HSD Tukey $=0,000)$, Barcelona (Sig. HSD Tukey =0,000) y Madrid (Sig. HSD Tukey = 0,000). (2) Entre la Facultad de Educación de Tenerife (segunda puntuación más alta obtenida) y las de Santander (Sig. HSD Tukey =0,041), Sevilla (Sig. HSD Tukey = 0,000), Barcelona (Sig. HSD Tukey =0,012) y Madrid (Sig. HSD Tukey =0,000). (3) Entre la Facultad de Educación de Valladolid (tercera puntuación más alta alcanzada) y las de Santander (Sig. HSD Tukey =0,036), Sevilla (Sig. HSD Tukey = 0,000), Barcelona (Sig. HSD Tukey =0,011) y Madrid (Sig. HSD Tukey =0,000). (4) Entre la Facultad de Educación de Granada (4 ${ }^{a}$ puntuación más alta alcanzada) y las de Albacete (Sig. HSD Tukey =0,029), Santander (Sig. HSD Tukey =0,012), Sevilla (Sig. HSD Tukey $=0,000)$, Barcelona (Sig. HSD Tukey =0,006) y Madrid (Sig. HSD Tukey = 0,000). (5) Entre la Facultad de Educación de Murcia y las de Sevilla (Sig. HSD Tukey $=0,042)$ y Madrid (Sig. HSD Tukey $=0,002)$.

Para el caso de las facultades CAFyD, los resultados de promedio (tabla 6.20), se destacan en general valoraciones considerablemente bajas que revelan un moderado grado de ayuda formativa recibida en la formación cursada para su desarrollo. 
Tabla 6.20

Valores de promedio obtenidos para P1.29 en relación a la variable factor "facultades $C A F y D^{\prime \prime}$

\begin{tabular}{llcccc}
\multicolumn{1}{c}{ Competencia } & \multicolumn{1}{c}{ Facultad CAFyD } & N & $\bar{x}$ & $\boldsymbol{\sigma}$ & $\begin{array}{c}\text { Error } \\
\text { típico }\end{array}$ \\
\hline & Murcia (UCAM) & 55 & 2,13 & 0,963 & 0,130 \\
& Huesca (UNIZAR) & 35 & 1,83 & 1,071 & 0,181 \\
$\begin{array}{l}\text { P1.29.- Grado de ayuda } \\
\text { en el desarrollo de la }\end{array}$ & Vic (VIC) & 48 & 1,81 & 0,891 & 0,129 \\
competencia docente: & Sevilla (UPO) & 59 & 1,76 & 0,916 & 0,119 \\
$\begin{array}{l}\text { conocimientos de } \\
\text { informática relativos al }\end{array}$ & Vitoria-Gasteiz (UPV) & 58 & 1,72 & 0,894 & 0,117 \\
ámbito de estudio & Lleida (UDL) & 65 & 1,68 & 0,886 & 0,110 \\
& León (ULE) & 51 & 1,04 & 0,824 & 0,115 \\
\hline
\end{tabular}

Se muestra a continuación de forma gráfica el ranking obtenido (figura 6.11), apreciando comparativamente las bajas valoraciones alcanzadas (entre 2,13 y 1,04 ) en relación a la ayuda formativa recibida para el desarrollo de P1.29.

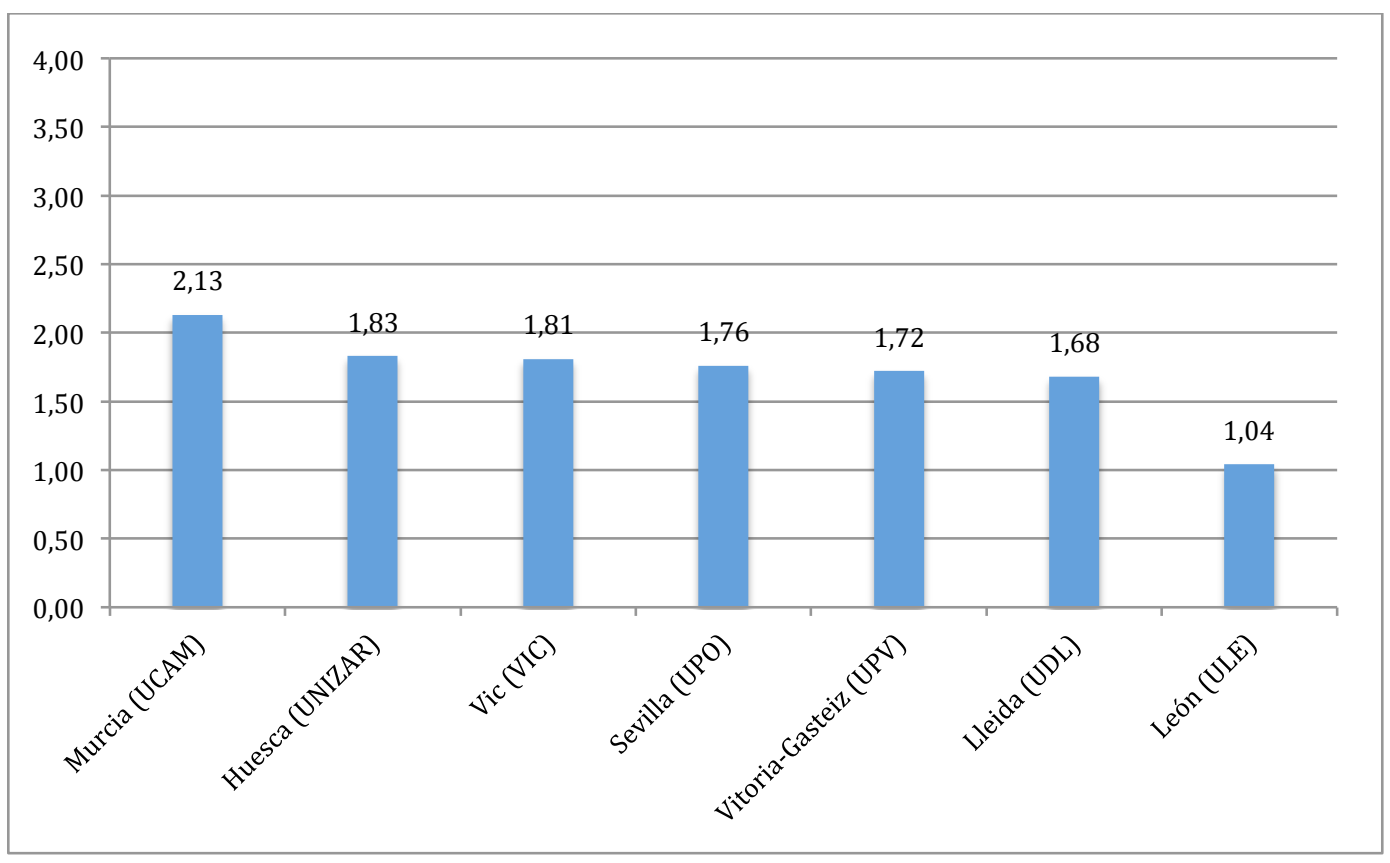

Figura 6. 11. Representación gráfica de los valores de promedio obtenidos para P1.29 en relación a la variable factor "facultades CAFyD" 
En virtud de las puntuaciones de promedio obtenidas, tal y como se adelantaba, la ayuda formativa recibida para el desarrollo de P1.29, es considerada por sus estudiantes en casi todas las facultades analizadas como moderada. Este es el caso de las facultades CAFyD de Murcia ( $\bar{\chi}=2,13)$ (puntuación más alta), Huesca $(\bar{x}=1,83)$, Vic $(\bar{x}=1,81)$, Sevilla $(\bar{x}=1,76)$, Vitoria-Gasteiz $(\bar{x}=1,72)$ y Lleida $(\bar{x}=1,68)$. Tan solo para el caso de la facultad CAFyD de León se obtiene un promedio de 1,04, lo que supone desde la percepción de sus estudiantes, una consideración de poca ayuda formativa recibida a través de las asignaturas cursadas. En relación a los valores de desviación típica, se aprecia bastante dispersión en las respuestas para el caso de Huesca, con un valor de $\sigma=1,071$; para el resto de las facultades, se obtienen valores de desviación típica aceptables, inferiores a 1.

A fin de conocer la influencia de la variable facultades CAFyD sobre P1.29, y si existe igual afección de las distintas facultades analizadas en relación a dicha pegunta, se aplica la prueba Kruskal-Wallis (cuyo resultado se muestra en la tabla 6.21).

Tabla 6.21

Prueba Kruskal-Wallis para P1.29 y variable factor "facultades CAFyD"

P1.29. Grado de ayuda formativa recibida para el desarrollo de conocimientos de informática relativos al ámbito de estudio

\begin{tabular}{lr}
\hline Chi-cuadrado & 37,061 \\
Gl & 7 \\
Sig.asintót. &, 000 \\
\hline
\end{tabular}

Se puede apreciar que la prueba arroja un nivel de significación de 0,000 (Sig. $<0,05)$, rechazando la hipótesis nula y aceptando la influencia de la variable factor aplicada a la variable estudiada P1.29 y la propia variable P1.29. Por tanto, dado que el resultado de Kruskal-Wallis nos lleva a aceptar la hipótesis alterna, se realiza un análisis post hoc para comprobar qué pares de facultades CAFyD difieren significativamente entre sí; la prueba de contraste aplicada es HSD Tukey (tabla 6.22) tras reconocer la igualdad de varianzas gracias al estadístico de Levène (Sig.=0,249). 
Tabla 6.22

Resultados del análisis post hoc entre P1.29 y la variable factor "facultades CAFyD" (comparadas de dos en dos)

(I) Facultad CAFyD

(J) Facultad CAFyD

HSD Tukey Sig.

\begin{tabular}{rll}
\hline Murcia (UCAM) & León (ULE) & 0,000 \\
\hline Huesca (UNIZAR) & León (ULE) & 0,003 \\
\hline Vic (VIC) & León (ULE) & 0,001 \\
\hline Sevilla (UPO) & León (ULE) & 0,001 \\
\hline Vitoria-Gasteiz (UPV) & León (ULE) & 0,003 \\
\hline Lleida (UDL) & León (ULE) & 0,005 \\
\hline León (ULE) & Murcia (UCAM) & 0,000 \\
& Huesca (UNIZAR) & 0,003 \\
& Vic (VIC) & 0,001 \\
& Sevilla (UPO) & 0,001 \\
& Vitoria-Gasteiz (UPV) & 0,003 \\
& Lleida (UDL) & 0,005 \\
\hline
\end{tabular}

La diferencia es significativa al nivel de .05 .

Se observa que las diferencias significativas se encuentran entre la Facultad CAFyD de León (promedio más bajo obtenido) con respecto a las de Murcia (Sig. HSD Tukey $=0,000)$, Huesca $($ Sig. HSD Tukey =0,003), Vic (Sig. HSD Tukey =0,001), Sevilla (Sig. HSD Tukey =0,001), Vitoria-Gasteiz (Sig. HSD Tukey =0,003), y Lleida (Sig. HSD Tukey =0,005).

Los datos cualitativos evidencian una mayor presencia de códigos explicativos sobre la ayuda formativa recibida en los estudios cursados para el grupo de estudiantes de MEPEF más que para el grupo de CAFyD (tabla 6.23). Aunque en esencia se transmite una misma idea, a partir de las materias y asignaturas cursadas, que la formación recibida se fundamenta en Apps ya conocidas y en consecuencia se demanda una mayor especialización. 
Tabla 6.23

Estudio comparativo entre estudiantes MEPEF y CAFyD sobre los códigos que explican el funcionamiento de la formación recibida para el desarrollo de P1.29

MEPEF

CAFyD

\begin{tabular}{lccc}
\hline \multicolumn{1}{c}{ Código } & Enraizamiento & Código & Enraizamiento \\
\hline App especializadas aprendidas & 14 & $\begin{array}{l}\text { Apps ya conocidas } \\
\text { Demanda de mayor } \\
\text { especialización }\end{array}$ & 1 \\
App ya conocidas & 14 & & \\
$\begin{array}{l}\text { Demanda de mayor } \\
\text { especialización }\end{array}$ & 9 & & \\
Aprendizaje de Apps & 5 & & \\
Refuerzo manejo Apps básica & 3 & & \\
\hline
\end{tabular}

Para el grupo de estudiantes de CAFyD (figura 6.12), se observan dos menciones explicativas en relación a su percepción sobre la ayuda recibida para el desarrollo de su competencia informática aplicada al ámbito de la EF (P1.29). Esta explicación se relaciona con el conocimiento de partida de las Apps básicas que se manejan en la formación recibida y que se considera todos ya saben; consecuentemente, se demanda una formación tecnológica más especializada y de mayor complicación.

Grupo CAFyD (3:137)

Porque lo básico en verdad es lo que tu dices, todo el mundo sabe.

Grupo CAFyD (3:113)

Acaso sería que fuera más específico y en todas, y en todas, ese mismo, ese campo es que fuera de algo más complicado (especializado) por así decirlo. 


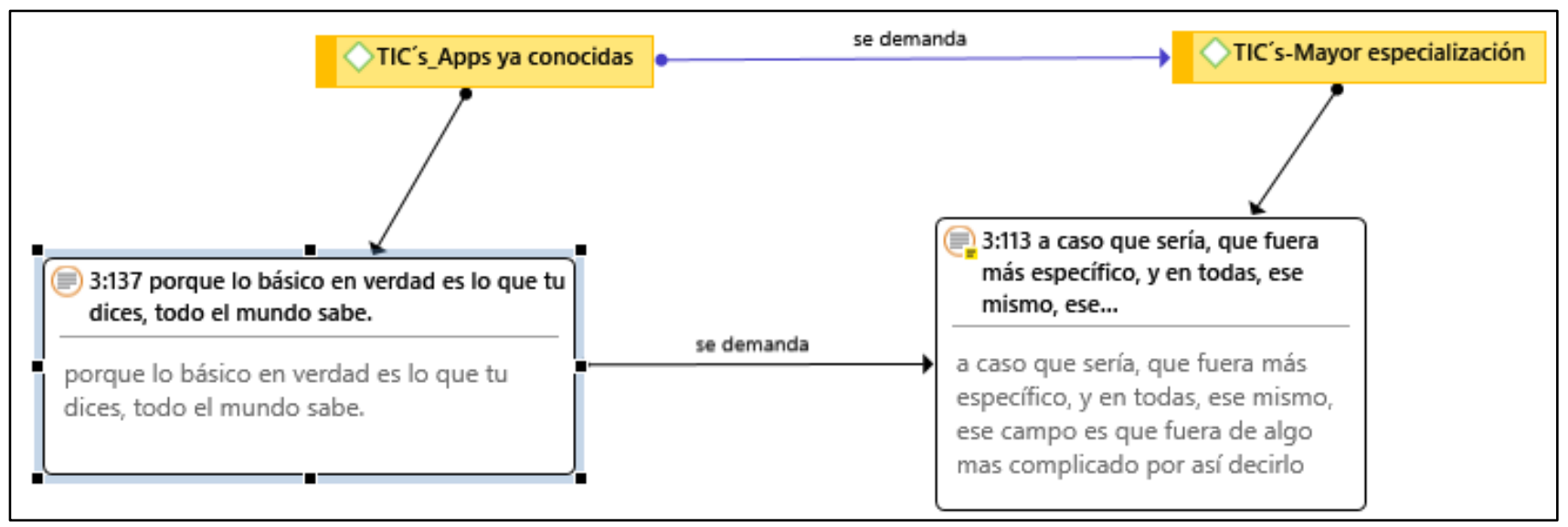

Figura 6. 12. Red semántica del grupo de estudiantes CAFyD que explica las experiencias formativas relacionadas con la adquisición y desarrollo de P1.29

Por su parte, el grupo de estudiantes MEPEF (figura 6.13) destaca igualmente que P1.29, es una de las competencias que más se conocen de partida y que por tanto requiere de menos tratamiento formativo. Por tanto, se reafirma la idea de manejo del conocimiento tanto de los estudiantes de EF que se forman actualmente, pero más aún de aquellos que lo harán en el futuro. En todo caso, se considera importante para su puesta en práctica pero ya aprendida y manejada suficientemente. Las herramientas que más se usan ya se conocen porque se vienen utilizando comúnmente.

\section{Grupo MEPEF (3:135)}

El tema de las TIC's yo creo que ahora los que venimos por detrás ya controlamos bastante, cada vez más.

\section{Grupo MEPEF (3:331)}

Considero que es una de las (competencias) que menos (hemos desarrollado) a lo mejor; yo la considero muy importante para su aplicación, pero quizás no tanto en la formación nuestra, porque creo que ya la llevamos implícita muchas veces. 


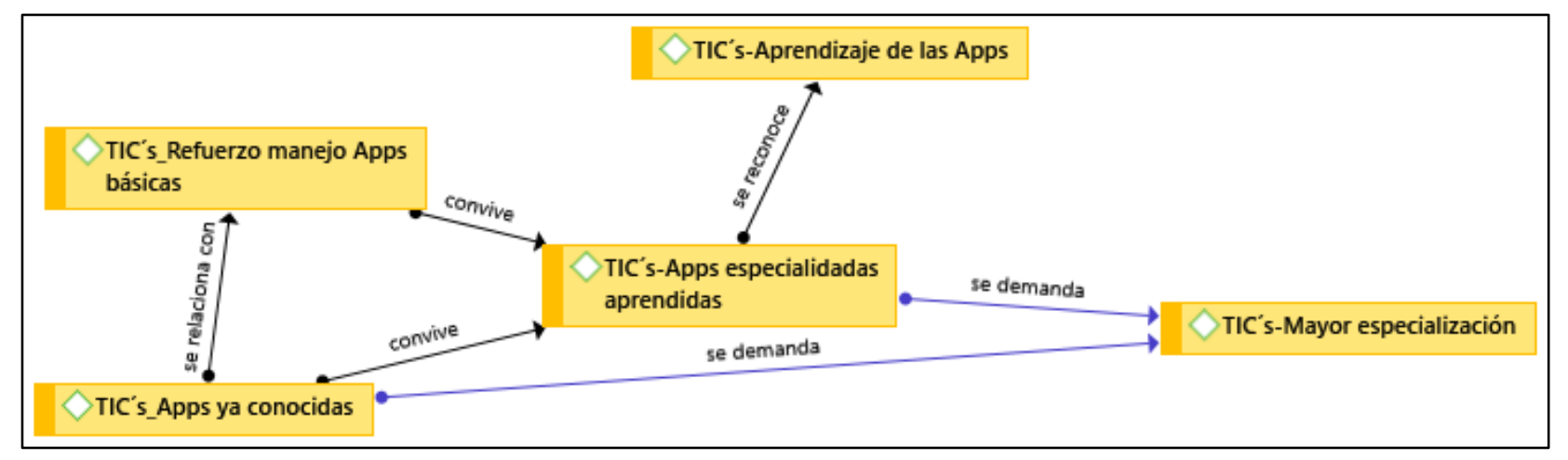

Figura 6. 13. Red semántica del grupo de estudiantes MEPEF que explica las experiencias formativas relacionadas con la adquisición y desarrollo de P1.29

No obstante se convive con la percepción de haber recibido cierta formación relacionada con el manejo de herramientas especializadas aplicables al sector educativo pero no específicas para el desarrollo de la disciplina (EF). Así se consideran aprendidas aplicaciones para ayudar a funciones docente como el control del aula, la participación, el refuerzo de los aprendizajes, la evaluación, así como el manejo de entornos virtuales.

\section{Grupo MEPEF (5:64)}

Nos han enseñado otras formas de trabajar con los niños en clase con aplicaciones como kahoot y el plickers.

\section{Grupo MEPEF (5:39)}

Nos enseñaron algo a utilizar cómo se puede hacer un cuestionario en moodle, cómo lanzar preguntas en moodle, cómo gestionar grupos.

En menor medida se valora el aprendizaje de aplicaciones especializadas para el ámbito de la EF en relación a la práctica de actividades físicas en el medio natural, aunque se reconoce que no tienen un carácter marcadamente educativo, simplemente sirven al fin previsto (herramientas de realidad aumentada en torno a la geolocalización como geocahing, wikiloc; uso de códigos $Q R$ ). 
Grupo MEPEF (5:59)

Educación física en el medio natural es la asignatura donde más se han trabajado con aplicaciones tecnológicas aplicadas al campo: con geocaching o wikiloc y códigos QR para realizar localizaciones, pero tampoco las veo; tú puedes apropiarte de ellas pero propiamente para educación yo tampoco las veo.

Además la fórmula del aprendizaje por descubrimiento es la que parece se lleva a cabo para el desarrollo de la formación tecnológica.

\section{Grupo MEPEF (5:67)}

Al principio se aborda un poco a modo de aprendizaje por descubrimiento; aquí tienes esto se entra así.

Finalmente se demanda una mayor especialización y novedad en la formación tecnológica a recibir, fundamentalmente, en clave didáctica para facilitar la práctica de aula.

\section{Grupo MEPEF (3:17)}

Yo considero que por ejemplo no se debería centrar en el primer año [...] las TIC's de manera general $[\ldots]$ pero yo creo que ese paso se le pueden saltar y directamente ir a como aplicarlas de forma educativa.

\section{Grupo MEPEF (3:13)}

Considero que será necesario a lo mejor enseñarles herramientas docentes, sabes, porque habrá programas y ciertas cosas que desconozcamos.

Esto supone por ejemplo aprender el manejo de aplicaciones que faciliten el aprendizaje de los contenidos disciplinares como herramientas de uso especializado para el desarrollo de los contenidos de EF y de otras disciplinas. 
Grupo MEPEF (3:18)

Dentro de cada mención, aplicadas a la EF, bueno pues vamos a ver qué tipo de TIC's tenemos al alcance para poder trabajar con los niños, los de música pues igual, los de conocimiento del medio, como sea; otras como inglés [...] pues que todos tengan un poco conocimiento de las TIC's pero más orientado hacia lo suyo.

Para P1.28. Conocimiento de una lengua extranjera, se percibe por parte de los estudiantes de MEPEF un grado de ayuda formativa recibida mayor $(\bar{x}=1,38)$ que el percibido por los estudiantes $\mathrm{CAFyD}(\overline{\times}=0,93)$, aunque estas percepciones representan una estimación de poca ayuda recibida para el desarrollo de esta competencia. Además para los estudiantes del grupo MEPEF, se obtiene un valor de $\sigma=1,126$ que lleva a pensar en un desacuerdo muy elevado en las respuestas.

A fin de esclarecer la existencia de diferencias estadísticamente significativas en relación a la percepción sobre la ayuda formativa recibida para el desarrollo de P1.28, se aplicó la prueba $U$ de Mann-Witney, cuyo resultado $(0,000<0,05)$ afianza la hipótesis alterna y por tanto muestra diferencias estadísticamente significativas entre las medias obtenidas a partir de las dos titulaciones de EF cursadas (tabla 6.24).

Tabla 6.24

Diferencias en la percepción de los estudiantes MEPEF y CAFyD sobre P1.28

MEPEF CAFyD

1.28.- Grado de ayuda en el desarrollo de la competencia docente: Conocimiento de una lengua extranjera

1,38

$0,93 \quad 0,000$

Considerando la procedencia de los estudiantes encuestados en relación a las facultades MEPEF en donde se cursaron estudios, se muestran las siguientes valoraciones medias a partir de la variable factor mencionada, facultades MEPEF (tabla $6.25)$. 
Tabla 6.25

Valores de promedio obtenidos para P1.28 en relación a la variable factor "facultades $M E P E F^{\prime \prime}$

\begin{tabular}{lccccc}
\multicolumn{1}{c}{ Competencia } & $\begin{array}{c}\text { Facultad de } \\
\text { Educación }\end{array}$ & $\mathbf{N}$ & $\overline{\times}$ & $\boldsymbol{\sigma}$ & $\begin{array}{c}\text { Error } \\
\text { típico }\end{array}$ \\
\hline & Albacete (UCLM) & 102 & 1,88 & 0,941 & 0,094 \\
& Tenerife (ULL) & 34 & 1,85 & 0,744 & 0,128 \\
& Granada (UGR) & 92 & 1,71 & 1,163 & 0,121 \\
& Segovia (UVa) & 28 & 1,70 & 0,823 & 1,158 \\
& Santander (UniCan) & 64 & 1,65 & 1,272 & 0,160 \\
P1.28.- Grado de ayuda en el & Murcia (UMU) & 67 & 1,61 & 0,953 & 0,116 \\
desarrollo de la competencia \\
docente: conocimiento de una \\
lengua extranjera & Valencia (UV) & 76 & 1,51 & 1,230 & 0,143 \\
& Valladolid (UVa) & 44 & 1,25 & 1,102 & 0,166 \\
& Córdoba (UCO) & 20 & 1,15 & 1,137 & 0,254 \\
& Barcelona (UB) & 30 & 1,03 & 0,890 & 0,162 \\
& Madrid (UAM) & 45 & 0,79 & 0,914 & 0,139 \\
& Sevilla (US) & 159 & 0,72 & 1,024 & 0,081 \\
\hline
\end{tabular}

Se presenta seguidamente, de forma gráfica (figura 6.14) y ordenadadamente (mayor a menor valoración), los promedios obtenidos para P1.28, a partir de las facultades MEPEF de procedencia de los estudiantes encuestados. 


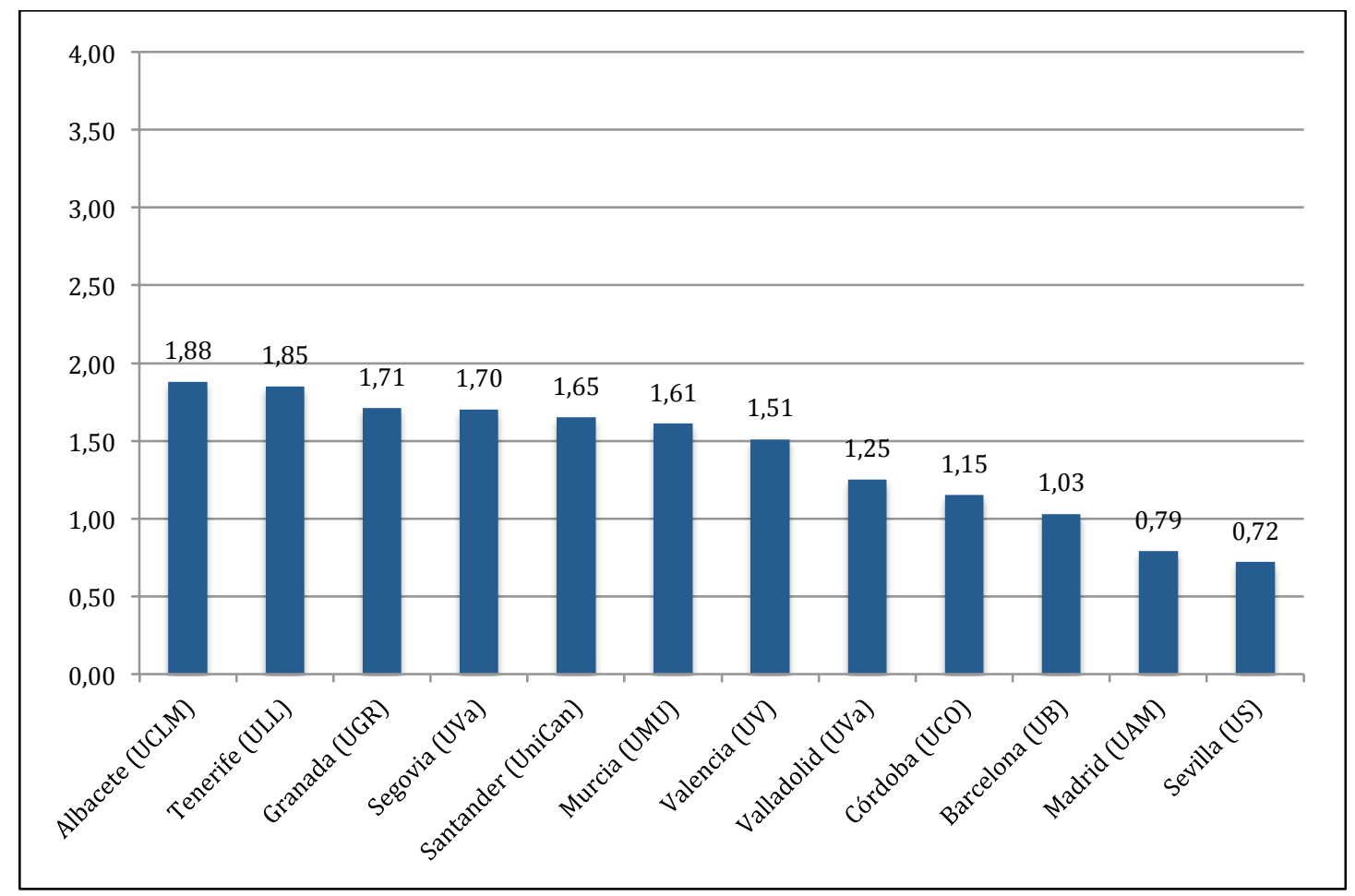

Figura 6. 14. Representación gráfica de los valores de promedio obtenidos para P1.28 en relación a la variable factor "facultades MEPEF"

Como se puede apreciar, P1.28 presenta puntuaciones de valoración muy bajas de no ser lograda más que "moderadamente" y "poca" la ayuda formativa recibida para su desarrollo. En esta consideración, las facultades MEPEF que obtienen las puntuaciones más altas (grado moderado) son las de Albacete $(\bar{x}=1,88)$, Tenerife $(\bar{x}=1,85)$, Granada $(\bar{x}=1,71)$, Segovia $(\bar{x}=1,70)$, Santander $(\bar{x}=1,65$ con un valor de $\sigma=1,272$, que muestra un significativo desacuerdo en las respuestas) y Murcia $(\bar{x}=1,61)$; por el contrario, quienes obtienen en las puntuaciones más bajas aún (poco grado de ayuda formativa recibida), son para los casos de las facultades de educación de las Universidades Autónoma de Madrid $(\bar{x}=0,79)$ y de Sevilla $(\bar{x}=0,72)$, esta última con un valor de desviación típica considerablemente elevada de 1,024.

A continuación se muestra el resultado de la prueba de Kruskal-Wallis aplicada, a fin de conocer la influencia de la variable facultades MEPEF sobre P1.28 y si existe la misma afección entre las distintas facultades analizadas en relación a dicha pegunta. Los resultados se observan en la siguiente tabla 6.26. 
Tabla 6.26

Prueba Kruskal-Wallis para P1.28 y variable factor "facultades MEPEF"

P1.28. Grado de ayuda formativa recibida para el desarrollo del conocimiento de una $L E$

Chi-cuadrado 128,426

G1

Sig.asintót.

, 000

El valor que arroja la prueba es de $0,000($ Sig. $<0,05)$, con lo que se rechaza la hipótesis nula y, por tanto, se reconoce que el factor aplicado a la variable estudiada P1.28 sí que la afecta. Por ello, dado que el resultado de Kruskal-Wallis nos lleva a aceptar la hipótesis alterna, se realiza un análisis post hoc para comprobar en qué pares de Facultades de MEPEF existen tales diferencias estadísticamente significativas;. Se aplica la prueba Games-Howell (tabla 6.27), ya que a partir del resultado obtenido de la prueba de homogeneidad de varianzas (Sig. Levéne $=0,000<0,005$ ) no se asumen varianzas iguales.

Tabla 6.27

Resultados del análisis post hoc entre P1.28 y la variable factor "facultades MEPEF" (comparadas de dos en dos)

(I) Facultad de Educación

(J) Facultad de Educación

Games-Howell Sig.

\begin{tabular}{cll}
\hline Albacete (UCLM) & Barcelona (UB) & 0,003 \\
& Madrid (UAM) & 0,000 \\
& Sevilla (US) & 0,000 \\
\hline Tenerife (ULL) & Barcelona (UB) & 0,017 \\
& Madrid (UAM) & 0,000 \\
& Sevilla (US) & 0,000 \\
\hline Granada (UGR) & Madrid (UAM) & 0,000 \\
& Sevilla (US) & 0,000 \\
\hline Segovia (UVa) & Madrid (UAM) & 0,005 \\
& Sevilla (US) & 0,000 \\
\hline Santander (UniCan) & Madrid (UAM) & 0,009 \\
& Sevilla (US) & 0,000 \\
\hline Murcia (UMU) & Madrid (UAM) & 0,002 \\
& Sevilla (US) & 0,000 \\
\hline
\end{tabular}




\begin{tabular}{lll}
\hline Valencia (UV) & Madrid (UAM) & 0,036 \\
& Sevilla (US) & 0,000 \\
\hline
\end{tabular}

La diferencia es significativa al nivel de .05 .

Los resultados obtenidos dan cuenta de diferencias significativas entre las facultades MEPEF que se sitúan en el ranking con las puntuaciones más altas y más bajas alcanzadas (Universidad de Barcelona) y fundamentalmente (Autónoma de Madrid y Universidad de Sevilla). Por tanto aparecen diferencias entre (1) la Facultad de Educación de Albacete (puntuación más alta obtenida) y las de Barcelona (Sig. Games-Howell = 0,003), Madrid (Sig. Games-Howell =0,000) y Sevilla (Sig. GamesHowell = 0,000). (2) Entre la Facultad de Educación de Tenerife (segunda mejor puntuación) y las de Barcelona (Sig. Games-Howell =0,017), Madrid (Sig. GamesHowell $=0,000)$ y Sevilla (Sig. Games-Howell =0,000). (3) Entre la Facultad de Educación de Granada (tercera valoración más alta obtenida) y las de Madrid (Sig. Games-Howell =0,000) y Sevilla (Sig. Games-Howell=0,000). (4) Entre la Facultad de Educación de Segovia y las de Madrid (Sig. Games-Howell=0,005) y Sevilla (Sig. Games-Howell = 0,000). (5) Entre la Facultad de Educación de Santander y las de Madrid (Sig. Games-Howell=0,009) y Sevilla (Sig. Games-Howell=0,000). (6) Entre la Facultad de Educación de Murcia y las de Madrid (Sig. Games-Howell=0,002) y Sevilla (Sig. Games-Howell=0,000). (7) Entre la Facultad de Educación de Valencia y las de Madrid (Sig. Games-Howell=0,036) y Sevilla (Sig. Games-Howell=0,000).

Considerando la procedencia de los estudiantes encuestados en relación a las facultades CAFyD en donde se cursaron estudios, se muestran las siguientes valoraciones medias a partir de la variable factor mencionada. Las bajas puntuaciones alcanzadas dan cuenta de que la ayuda formativa percibida para el desarrollo de esta competencia, a partir de la variable factor aplicada es muy baja (promedios obtenidos entre 1,73 y 0,22 ) (tabla 6.28).

Estas valoraciones atendiendo a las facultades CAFyD objeto de estudio, dan cuenta de la poca ayuda formativa recibida para el desarrollo de P1,28, salvo el caso de 
la Universidad Vic $(\bar{x}=1,73)$, que recibe la mayor valoración de sus estudiantes, aunque en clave de ayuda moderada.

Tabla 6.28

Valores de promedio obtenidos para P1.28 en relación a la variable factor "facultades $C A F y D^{\prime \prime}$

\begin{tabular}{|c|c|c|c|c|c|}
\hline Competencia & Facultad CAFyD & $\mathbf{N}$ & $\bar{x}$ & $\sigma$ & Error típico \\
\hline \multirow{7}{*}{$\begin{array}{l}\text { P1.28.- Grado de ayuda } \\
\text { en el desarrollo de la } \\
\text { competencia docente: } \\
\text { conocimiento de una } \\
\text { lengua extranjera }\end{array}$} & Vic (VIC) & 48 & 1,73 & 0,792 & 0,114 \\
\hline & Huesca (UNIZAR) & 34 & 1,26 & 1,358 & 0,230 \\
\hline & Murcia (UCAM) & 55 & 1,00 & 1,064 & 0,145 \\
\hline & Lleida (UDL) & 65 & 0,91 & 0,931 & 0,115 \\
\hline & Vitoria-Gasteiz (UPV) & 58 & 0,79 & 0,951 & 0,125 \\
\hline & Sevilla (UPO) & 59 & 0,78 & 0,892 & 0,116 \\
\hline & León (ULE) & 51 & 0,22 & 0,415 & 0,058 \\
\hline
\end{tabular}

En la figura 6.15 se muestra el gráfico del ranking generado. Se puede observar (ordenadamente de mayor a menor valoración) lo significativo de las bajas puntuaciones alcanzadas para cada una de las facultades CAFyD analizadas.

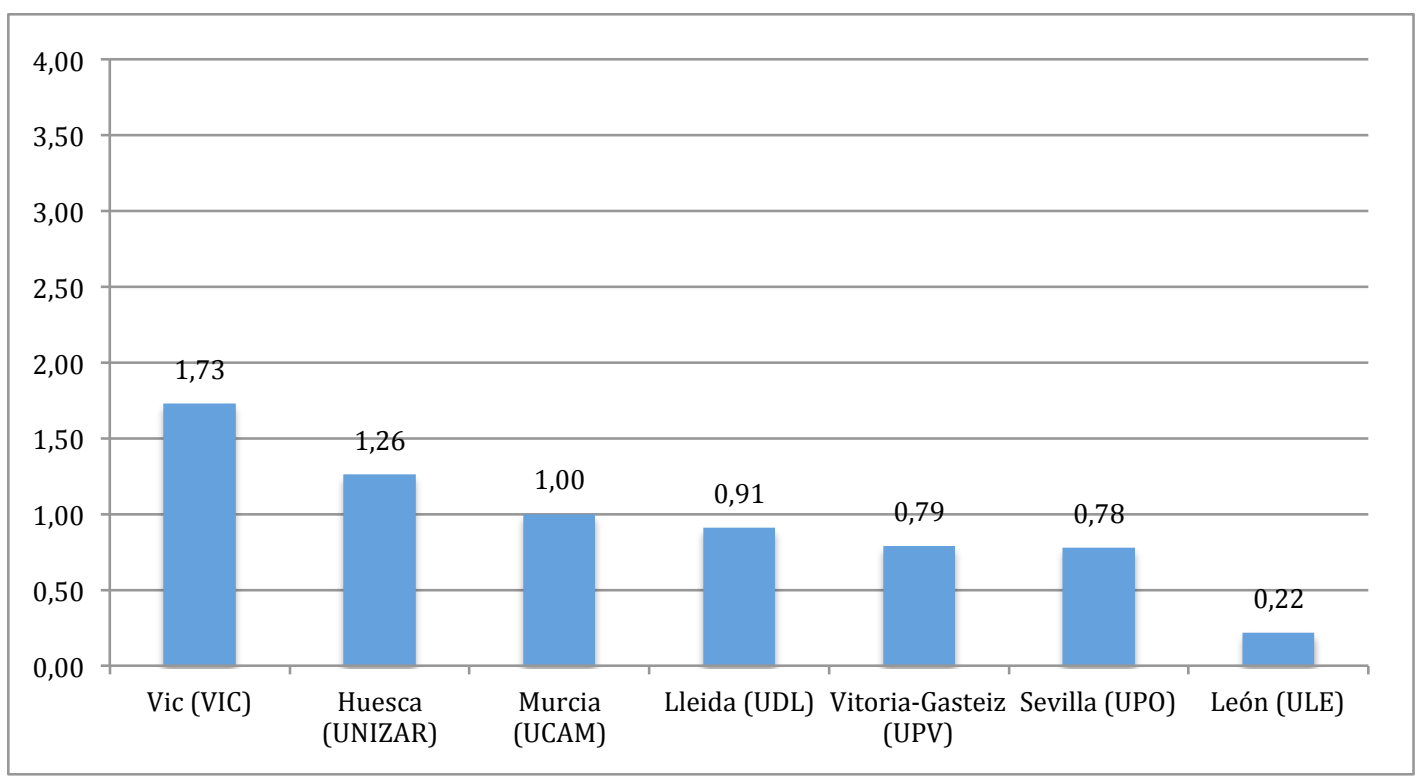

Figura 6. 15. Representación gráfica de los valores de promedio obtenidos para P1.28 en relación a la variable factor "facultades CAFyD" 
Como se anunciaba, cabe destacar que la puntuación más alta se obtiene para el caso de la facultad CAFyD de Vic $(\bar{x}=1,73)$; no obstante tal valoración se traduce en una percepción por parte de sus estudiantes, de un grado moderado de ayuda formativa recibida para el desarrollo de P1.28. Igualmente son significativos los casos de las facultades CAFyD de Huesca, Murcia, Lleida, Vitoria-Gasteiz y Sevilla, con promedios muy bajos que oscilan entre 1,26 y 0,78 y que dan cuenta de una percepción por parte de los estudiantes de poca ayuda formativa recibida a través de las materias cursadas. Finalmente es especialmente significativo el caso de la facultad CAFyD de León $(\bar{x}=0,22)$, para la que se recoge una consideración de ninguna ayuda formativa recibida para el desarrollo de P1.28. En relación a los valores de desviación típica obtenidos, tan solo los casos de Huesca y Murcia $(\sigma=1,358$ y $\sigma=1,064)$, dan cuenta de la considerable dispersión en las respuestas.

Con objeto de conocer la influencia de la variable facultades CAFyD sobre P1.28 y si existe la misma afección de las distintas facultades analizadas en relación a dicha pegunta, se aplica la prueba Kruskal-Wallis (cuyo resultado se muestra en la tabla $6.29)$.

Tabla 6.29

Prueba Kruskal-Wallis para P1.28 y variable factor "facultades CAFyD"

P1.28. Grado de ayuda formativa recibida para el desarrollo del conocimiento de una $L E$

\begin{tabular}{lr}
\hline Chi-cuadrado & 67,584 \\
Gl & 7 \\
Sig.asintót. &, 000 \\
\hline
\end{tabular}

La prueba muestra un nivel de significación de 0,000 (Sig.<0,05), rechazando la hipótesis nula y aceptando la influencia de la variable factor aplicada a la variable estudiada P1.28 y la propia variable P1.28. Por tanto, dado que el resultado KruskalWallis nos lleva a aceptar la hipótesis alterna, se realiza un análisis post hoc para comprobar qué pares de facultades CAFyD difieren significativamente entre sí; se opta por la prueba de constraste Games-Howell (tabla 6.30) tras reconocer la heterogeneidad de varianzas a partir del estadístico de Levène obtenido (Sig. $=0,000)$. 
Tabla 6.30

Resultados del análisis post hoc entre P1.28 y la variable factor "facultades CAFyD" (comparadas de dos en dos)

(I) Facultad CAFyD

(J) Facultad CAFyD Games-Howell Sig.

\begin{tabular}{cll}
\hline Vic (VIC) & Murcia (UCAM) & 0,004 \\
& Lleida (UDL) & 0,000 \\
& Vitoria-Gasteiz (UPV) & 0,000 \\
& Sevilla (UPO) & 0,000 \\
& León (ULE) & 0,000 \\
\hline Huesca (UNIZAR) & León (ULE) & 0,002 \\
\hline Murcia (UCAM) & Vic (VIC) & 0,004 \\
& León (ULE) & 0,000 \\
\hline Lleida (UDL) & Vic (VIC) & 0,000 \\
& León (ULE) & 0,000 \\
\hline Vitoria-Gasteiz (UPV) & Vic (VIC) & 0,000 \\
& León (ULE) & 0,002 \\
\hline Sevilla (UPO) & Vic (VIC) & 0,000 \\
& León (ULE) & 0,001 \\
\hline León (ULE) & Vic (VIC) & 0,000 \\
& Huesca (UNIZAR) & 0,002 \\
& Murcia (UCAM) & 0,000 \\
& Lleida (UDL) & 0,000 \\
& Vitoria-Gasteiz (UPV) & 0,002 \\
& Sevilla (UPO) & 0,001 \\
\hline (U) &
\end{tabular}

La diferencia es significativa al nivel de .05 .

Como se puede observar las diferencias se encuentran en dos facultades CAFyD; (1) Entre la facultad de Vic (mejor puntuación) y las de Murcia (Sig. Games-Howell= 0,004), Lleida (Sig. Games-Howell = 0,000), Vitoria-Gasteiz (Sig. Games-Howell = 0,000), Sevilla (Sig. Games-Howell=0,000), y León (Sig. Games-Howell=0,000). (2) $\mathrm{Y}$ entre la facultad CAFyD de León (última en el ranking de puntuaciones obtenido) y todas las demás: Vic (Sig. Games-Howell =0,000), Huesca (Sig. Games-Howell = 0,002), Murcia (Sig. Games-Howell =0,000), Lleida (Sig. Games-Howell =0,000), Vitoria-Gasteiz (Sig Games-Howell=0,002), y Sevilla (Sig. Games-Howell=0,001). 
Conociendo las diferencias entre grupos de estudios, los datos cualitativos evidencian un mayor peso de códigos que caracterizan y dimensionan la formación recibida en relación al desarrollo de P1.28 (tabla 6.31) en el caso de los estudiantes de MEPEF que en el grupo de CAFyD.

Tabla 6.31

Estudio comparativo entre estudiantes MEPEF y CAFyD sobre los códigos que explican el funcionamiento de la formación recibida para el desarrollo de P1.28

\begin{tabular}{lclc}
\multicolumn{1}{c}{ MEPEF } & \multicolumn{2}{c}{ CAFyD } \\
\hline \multicolumn{1}{c}{ Código } & Enraizamiento & \multicolumn{1}{c}{ Código } & Enraizamiento \\
\hline Cómo se aprende LE & 18 & $\begin{array}{l}\text { Cómo se aprende LE } \\
\text { Percepción de } \\
\text { funcionalidad de la } \\
\text { formación recibida }\end{array}$ & 5 \\
Percepción de nivel LE & 9 & Percepción de nivel LE & 3 \\
$\begin{array}{l}\text { Percepción de ayuda } \\
\text { formativa recibida }\end{array}$ & 7 & & 5 \\
\hline
\end{tabular}

En relación al grupo de estudiantes MEPEF (figura 6.16), describen una forma de aprender que parece planteada en la formación y resuelta por su parte desde la memorización, reconociendo falta de soltura para comunicarse en otro idioma, hasta el punto de no considerarse capacitados para, por ejemplo, ocupar un puesto docente bilingüe durante el Practicum.

Grupo MEPEF (5:53)

Es verdad que casi el día a día consistía en rellenar ejercicios, pero también me acuerdo de haber aprendido, aunque a fin de cuentas es aprendizaje memorístico, un cuento en inglés y luego contarlo al resto de la clase.

\section{Grupo MEPEF (5:54)}

También se realizaban exposiciones en inglés que yo personalmente resolvía aprendiendo de memoria, porque en mi nivel de inglés no tenía tanta soltura. 
Yo creo sinceramente que poder asumir en el practicum una plaza bilingüe depende más de tu formación anterior que de lo que has aprendido en la universidad.



Figura 6. 16. Red semántica del grupo de estudiantes MEPEF que explica las experiencias formativas relacionadas con la adquisición y desarrollo de P1.28

Es por ello que la percepción de ayuda formativa recibida se reconoce como mínima, lo que supone particularmente, por ejemplo, que dicha ayuda no tenga relación con la mención en EF, haciendo consecuentemente más difícil la posibilidad de desenvolverse en puestos docentes bilingües a la hora de cursar las prácticas formativas, reforzando el nivel bajo para manejar una LE que se considera se tiene de base.

\section{Grupo MEPEF (5:73)}

Para la lengua extranjera los estudios cursados en la carrera no nos han ayudado nada.

\section{Grupo MEPEF (5:90)}

La formación recibida para conocer terminología en inglés de educación física que nos pudiera ayudar a desenvolvernos mejor en las clases bilingües no ha existido. 
Grupo MEPEF (5:84)

Para el Prácticum por una plaza bilingüe, pero si no estás preparado como es mi caso con lo que he aprendido en la universidad sería incapaz.

Prevén a futuro como alternativa formativa complementaria, aprender una LE en contextos de inmersión lingüística confiando en que les ayude a mejorar su nivel con esperanzas de poder incorporarse con el tiempo y tras la experiencia de inmersión, al ejercicio docente en centros bilingües.

\section{Grupo MEPEF (5:58)}

Pienso que la única forma de intentar mejorar el idioma y tender hacia al bilingüismo desde la universidad es yendo a un Erasmus o un Amity en el que te pones a hablar inglés porque no te queda otra; [...] creo que es la única forma de salir con más nivel de inglés de la facultad y asumir puestos de trabajo bilingües.

Para el grupo de los estudiantes CAFyD (figura 6.17), la formación para el aprendizaje de una LE tiene un carácter obligatorio, debiendo obtener un determinado nivel al final de los estudios cursados, aunque finalmente no le encuentran funcionalidad ni valor, posiblemente por la no certificación del nivel alcanzado y superado en la universidad. Se define el modelo formativo experimentado como similar al de etapas formativas anteriores, repitiendo la dinámica de aprendizaje y no consiguiendo anclar una base sólida de partida sobre la que construir otros aprendizajes. Además se reconocen dificultades para la atención a tantas personas durante el aprendizaje de la LE en la universidad, afectando a la posibilidad de mejorar surgiendo una idea de no aprender nada.

Grupo CAFyD (3:145)

Exigen tener al final de los cuatro años, mínimo un B1 en cualquier idioma y, hala, tira $[\ldots]$ pero luego no vale de nada. 
Grupo CAFyD (5:80)

Era imposible atender a tantas personas que generalmente no tenemos una base obtenida ni en educación primaria ni en secundaria, y claro, siempre estamos haciendo lo mismo en todas las etapas, pero no aprendemos nada.

Grupo CAFyD (5:79)

En inglés éramos muchos queriendo aprender en la carrera y una sola profesora y, claro, no podía atender individualmente a cada persona que estábamos en clase.

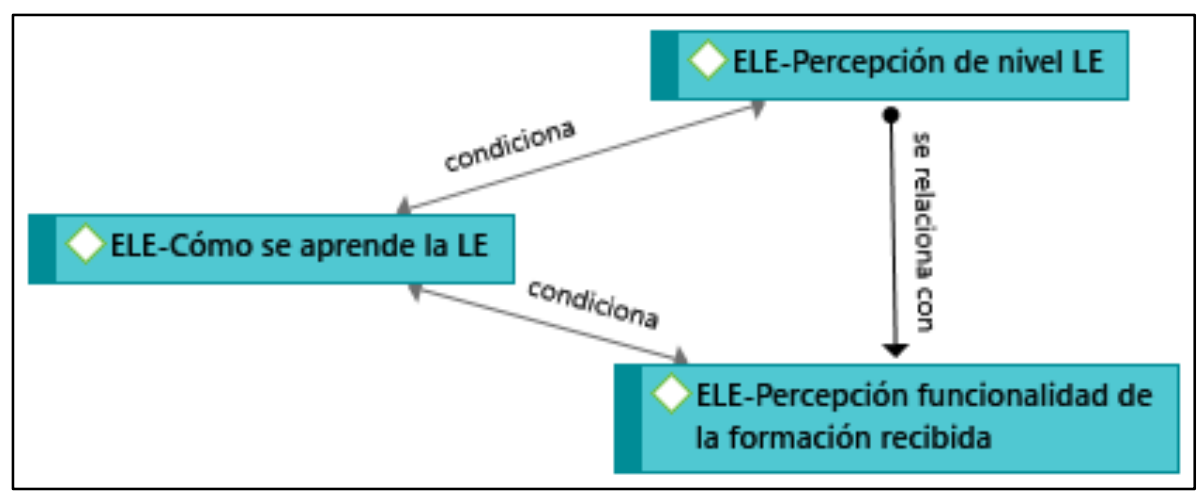

Figura 6. 17. Red semántica del grupo de estudiantes CAFyD que explica las experiencias formativas relacionadas con la adquisición y desarrollo de P1.28

Paralelamente, las experiencias cursadas en la formación superior condicionan la percepción de nivel alcanzado, considerando que es la LE la competencia con mayores taras y deficiencias formativas; siendo conscientes de que si se lograra la certificación de un nivel determinado, no significa que dicho nivel sea comunicativamente efectivo. Por tanto se desconfía del nivel que se pueda certificar con respecto al nivel de comunicación efectivo alcanzado.

Grupo CAFyD (3:141; 3:142)

Al preguntarles por la competencia que consideran tienen más deficitaria: “[...] el tema del idioma”; "[...] en la universidad yo creo que el caso del idioma. 
Grupo CAFyD (3:144)

En cuanto que conoces un poco lo que es un B2 fuera, te dices, no te confundas: tienes un B1 con un poquito de B2, aunque ese curso lo llamen B2 [...] Ese es el nombre que le ponen algunos con lo cual ya es un problema ponerles nombres.

\subsection{Conocer el grado de ayuda formativa recibida a lo largo de la formación inicial del profesorado de Educación Física, para el desarrollo de las competencias interpersonales (B2)}

\section{Análisis descriptivo para el bloque B2}

El bloque de competencias instrumentales está conformado por los items del cuestionario titpificadas como tales (P1.30, P1.31, P1.32, P1.33) (tabla 6.32).

Tabla 6.32

Items del cuestionario que integran B2

\section{B2 (competencias interpersonales)}

P1.30.- Grado de ayuda en el desarrollo de la competencia docente: trabajo en equipo

1.31.- Grado de ayuda en el desarrollo de la competencia docente: habilidades en las relaciones interpersonales

1.32.- Grado de ayuda en el desarrollo de la competencia docente: razonamiento crítico

1.33.- Grado de ayuda en el desarrollo de la competencia docente: compromiso ético.

Considerando la perspectiva de todo el alumnado encuestado en relación a este bloque 2 de competencias, se obtuvo la variable dependiente que representa las competencias instrumentales, y recogía la puntuación de cada sujeto realizando la media aritmética de todas las respuestas a los ítems incluidos en el bloque 2 [ $\overline{\times}(\mathrm{B} 2)]$ utilizando los promedios de los items representantes de este bloque $\overline{\times} \mathrm{B} 2=(\mathrm{P} 1.30+\mathrm{P} .31+\mathrm{P} 1.32+\mathrm{P} 1.33) / 4$. Acompañan a estos resultados descriptivos de bloque, los correspondientes a cada item que conforman el mismo (tabla 6.33). 
Tabla 6.33

Descriptivos para B2 y sus items (todos los estudiantes)

PREGUNTAS BLOQUE 2. Competencias Interpersonales

$[\bar{x}(\mathrm{MB} 2)=2,80 ; \sigma=, 677]$

P1.30.- Grado de ayuda en el desarrollo de la competencia docente:

trabajo en equipo

$1163 \quad 3,23 \quad, 813$

P1.31.- Grado de ayuda en el desarrollo de la competencia docente:

habilidades en las relaciones interpersonales

$\begin{array}{lll}1160 & 2,79 \quad, 893\end{array}$

P1.32.- Grado de ayuda en el desarrollo de la competencia docente:

razonamiento crítico

$1162 \quad 2,65 \quad, 884$

P1.33.- Grado de ayuda en el desarrollo de la competencia docente:

compromiso ético

$1159 \quad 2,52 \quad, 960$

Se observa que fundamentalmente son dos las competencias interpersonales que reciben una mayor valoración, en relación a la ayuda recibida para su desarrollo a lo largo de las materias cursadas: P1.30, trabajo en equipo y P1.31, habilidades en las relaciones interpersonales, cuyos promedios alcanzados evidencian un grado de mucha ayuda formativa recibida

Así, particularmente, se aprecia que para los estudiantes las materias cursadas a lo largo de su formación inicial han ayudado mucho al desarrollo de P1.30, trabajo en equipo $(\bar{x}=3,23)$, con una desviación típica de 0,813 , obteniendo la mayor puntuación de todas las competencias analizadas. Se observa una polarización de la frecuencia de respuesta (figura 6.18) en torno a valoraciones de muchísimo $(43,2 \%)$ y mucho $(40,2 \%)$, siendo menores las valoraciones de moderadamente $(13,6 \%)$, poco $(2,5 \%) \mathrm{y}$ nada $(0,5 \%)$, lo que evidencia un acuerdo en las respuestas, expresando las múltiples ayudas recibidas para el desarrollo de esta competencia $\mathrm{y}$, por tanto, una clara percepción de la presencia del trabajo en equipo en la formación cursada. 


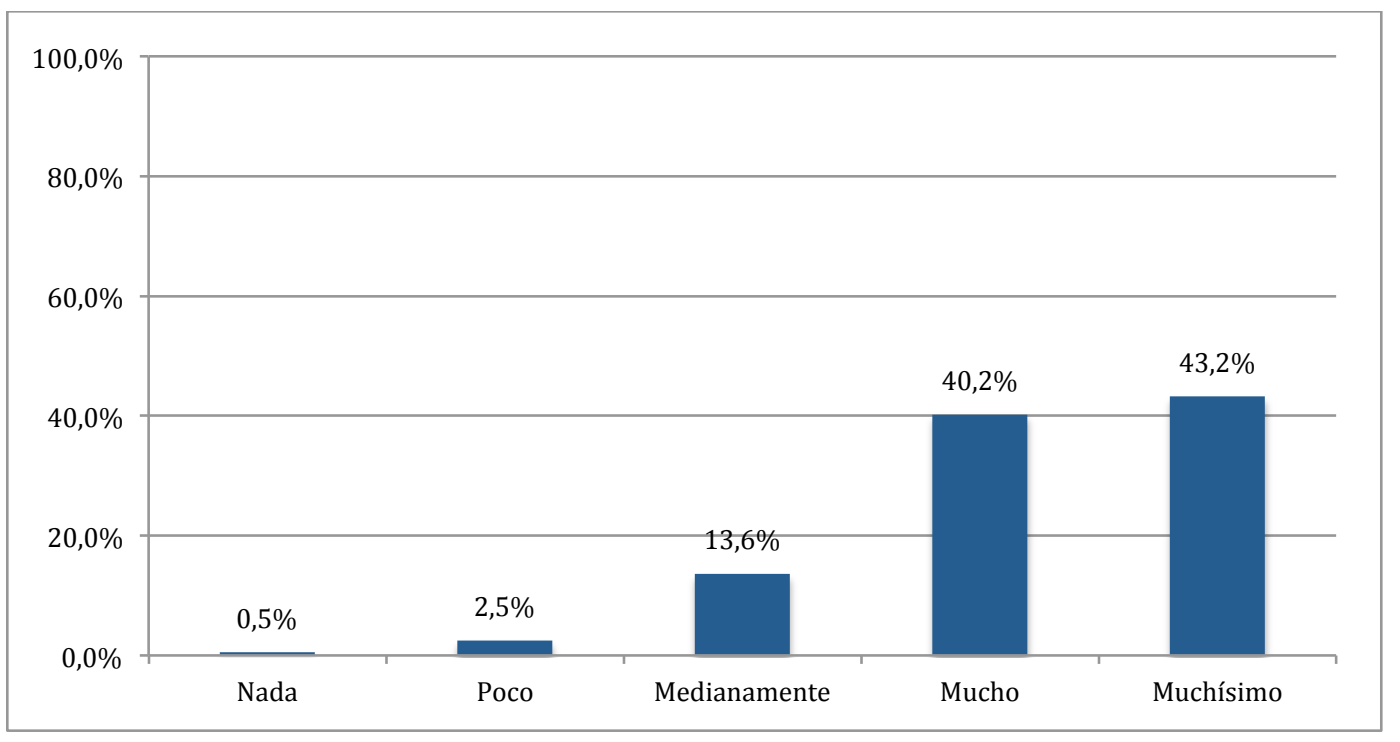

Figura 6. 18. Frecuencias en las respuestas en relación a P1.30

A partir del análisis de los datos cualitativos realizado, se encontraron en el discurso de los estudiantes 6 códigos que explican el funcionamiento interno de las experiencias formativas vivenciadas y su asociación con la adquisición de la competencia P1.30, explicados con 62 evidencias. A continuación, se presentan de forma ordenada tales códigos junto con su enraizamiento (tabla 6.34).

Tabla 6.34

Relación de códigos que explican el significado de la formación cursada en relación al desarrollo de P1.30

\section{Código Enraizamiento}

\begin{tabular}{ll}
\hline Procedimiento & 24 \\
\hline Conflicto de responsabilidades & 12 \\
\hline Formación & 7 \\
\hline Monitoreo del profesor & 7 \\
\hline Prevalencia del contenido & 6 \\
\hline Evaluación demandada & 6 \\
\hline
\end{tabular}

Los códigos caracterizan las experiencias formativas de trabajo en equipo realizadas en la formación recibida así como su dinámica de funcionamiento, destacando por el mayor numero de evidencias, los códigos procedimiento (24 
evidencias), que revelan aspectos sobre cómo se abordan las tareas encomendadas a los grupos; conflicto de responsabilidades (12 evidencias); formación (7 evidencias); monitoreo (seguimiento) del profesor durante el proceso (7 evidencias); prevalencia del contenido formativo frente al proceso de trabajo en equipo (6 evidencias) y evaluación demandada (6 evidencias).

En relación a la consideración de la ayuda formativa recibida para el desarrollo de P1.31. Habilidades en las relaciones interpersonales, se observa una estimación de $\bar{x}=2,79$, valorando los estudiantes encuestados en mucha la ayuda formativa recibida en sus estudios de EF. Además el valor de desviación típica de 0,893 , evidencia un cierto acuerdo de respuesta que se observa en la agrupación de estas en torno a muchísimo y mucho $(66,6 \%)$, frente, en menor medida, a moderadamente $(26,6 \%)$ y poco o nada $(6,8 \%)$ (figura 6.19).

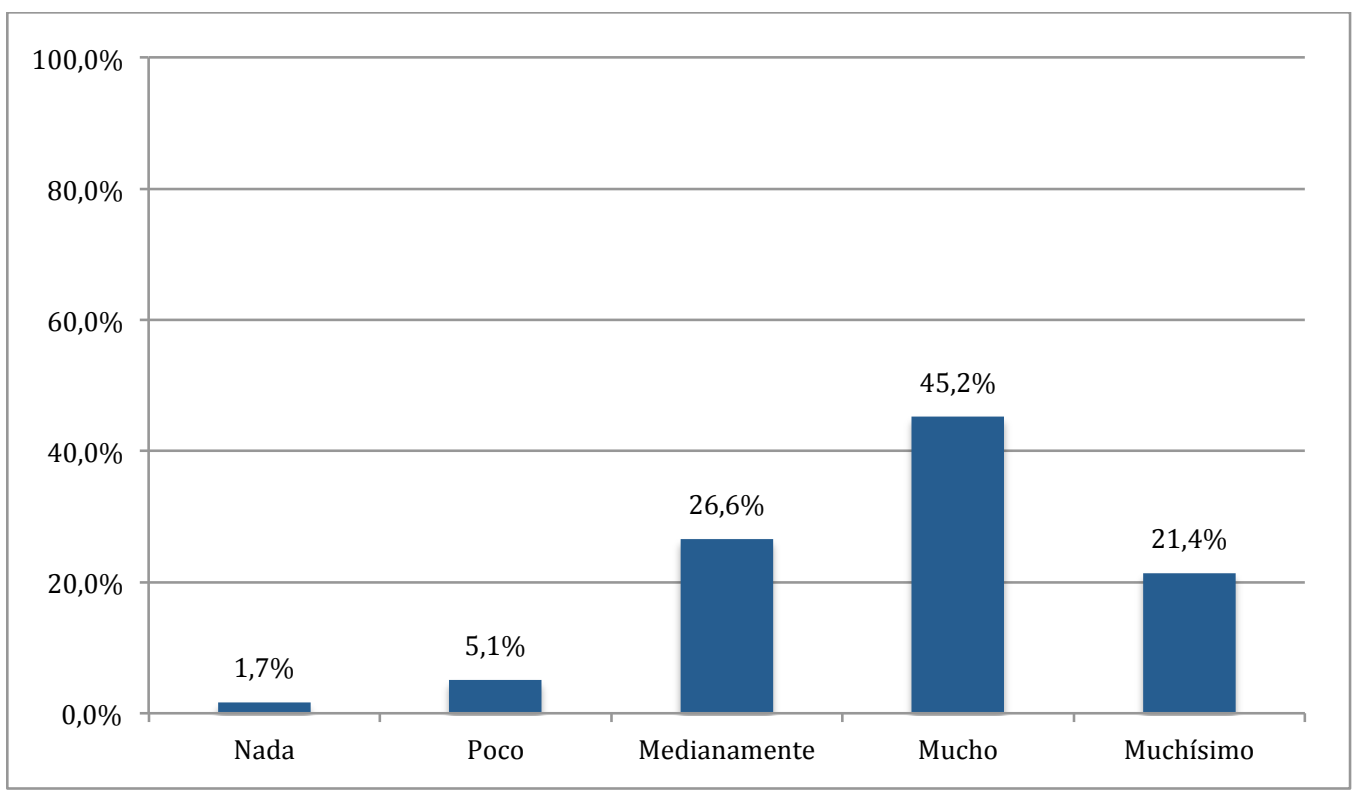

Figura 6. 19. Frecuencias en las respuestas en relación a P1.31

En el análisis de los datos cualitativos, se encontraron en el discurso de los estudiantes 14 códigos con 78 evidencias que revelan la presencia y manejo de ciertas habilidades para gestionar las relaciones interpersonales y que se relacionan con varias materias y experiencias formativas cursadas. 
A partir de ahí, se observa cómo las dinámicas de funcionamiento de tales experiencias ayudaron en la adquisición, manejo y desarrollo de P1.31. Se presentan a continuación de forma ordenada tales códigos junto con su enraizamiento (tabla 6.35).

Tabla 6.35

Relación de códigos que explican el significado de la formación cursada en relación al desarrollo de P1.31

\begin{tabular}{lc}
\multicolumn{1}{c}{ Código } & Enraizamiento \\
\hline Interactuar/compartir & 18 \\
\hline Comunicarse & 16 \\
\hline Colaborar & 6 \\
\hline Crear clima y ambiente formativo & 6 \\
\hline Actuar ante la conflictividad & 5 \\
\hline Adaptarse/ser flexible & 5 \\
\hline Cohesionar & 5 \\
\hline Negociar & 4 \\
\hline Ser asertivo & 4 \\
\hline Ayudar & 3 \\
\hline Regularse emocionalmente & 2 \\
\hline Tener iniciativa & 2 \\
\hline Escuchar & 1 \\
\hline Ser honesto & 1 \\
\hline
\end{tabular}

Los códigos obtenidos se ordenan a partir de su enraizamiento: interactuar/compartir (18 evidencias), comunicarse, (16 evidencias), colaborar (6 evidencias), crear clima y ambiente formativo (6 evidencias), actuar ante la conflictividad, adaptarse/ser flexible y cohesionar (5 evidencias respectivamente), negociar y ser asertivo (4 evidencias respectivamente), ayudar (3 evidencias), regularse emocionalmente, tener iniciativa (ambas 2 evidencias), escuchar y ser honesto (una evidencia respectivamente).

Se presenta a continuación el estudio de las competencias de tipo interpersonal atendiendo a la variable "género". 


\subsubsection{Conocer cómo influye el "género" de los estudiantes a la hora de considerar la ayuda formativa recibida a través de las materias cursadas para el desarrollo de las competencias interpersonales.}

\section{Análisis descriptivo y comparativo atendiendo al "género"}

Atendiendo a la variable género, los estadísticos descriptivos para MB2 se presentan a continuación en la tabla 6.36 :

Tabla 6.36

Valores de la variable MB2 en relación a la variable factor "género"

\begin{tabular}{lcccc}
\multicolumn{1}{c}{ Género } & $\mathbf{N}$ & $\overline{\times}(\mathbf{M B 2})$ & $\boldsymbol{\sigma}$ & Error típico \\
\hline Mujer & 461 & 2,83 &, 696 & 0,032 \\
Hombre & 685 & 2,78 &, 666 & 0,025 \\
\hline
\end{tabular}

Se observa que tanto los estudiantes hombres como las mujeres perciben que las materias cursadas les han ayudado mucho en el desarrollo de sus competetencias interpersonales a lo largo de su formación. Aunque son las mujeres las que obtienen una puntuación mas alta $(\bar{x}=2,83)$. Por otra parte entre los hombres se estima una valoración media sensiblemente inferior $(\bar{x}=2,78)$. En ambos casos, se observa un desacuerdo en las respuestas expresado en valores que oscilan entre $\sigma=0,666$ y $\sigma=0,696$.

Este contraste se aprecia en la figura 6.20, en donde de forma gráfica se indica además, cómo la valoración de promedio de las estudiantes mujeres está por encima de la media general de estudiantes para este bloque de competencias $[\overline{\times}(\mathrm{B} 2)=2,80]$. 


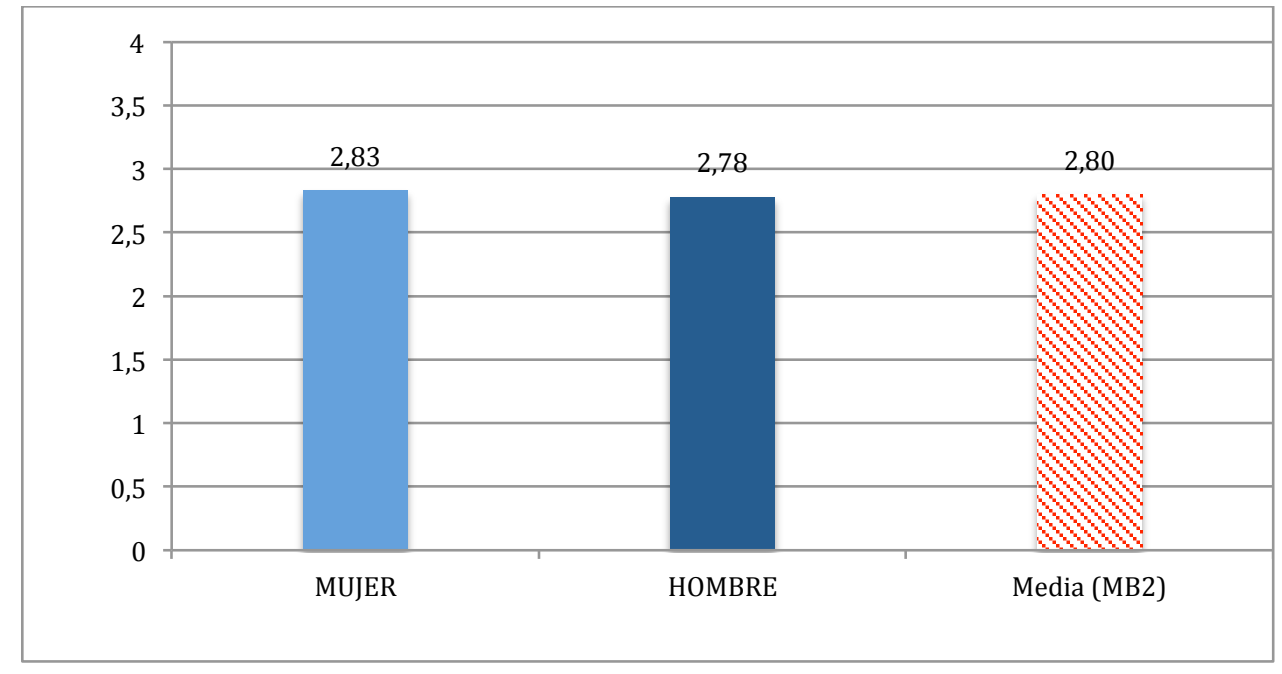

Figura 6. 20. Percepción media de los estudiantes hombres y mujeres en relación al grado de ayuda formativa recibida para el desarrollo de MB2

El análisis de la diferencia de medias teniendo en cuenta el factor "género", se realiza aplicando la prueba $U$ de Mann-Whitney a fin de valorar si las diferencias de medias son o no estadísticamente signficativas en relación a los promedios obtenidos para MB2 (tabla 6.37).

Tabla 6.37

Diferencias en la percepción de los estudiantes hombres y mujeres en relación a MB2

\begin{tabular}{lccc} 
& Hombres & Mujeres \\
\hline MB2. Competencias Interpersonales & $\bar{x}$ & $\bar{x}$ & $P$ \\
& 2,83 & 2,78 & 0,254 \\
\hline
\end{tabular}

Como se aprecia, la prueba muestra un nivel de significación de 0,254 $(0,254>0,05)$, lo que indica que se consolida la hipótesis nula. Sin embargo, no se reconoce una diferencia estadísticamente significativa entre el grado de ayuda formativa recibida para el desarrollo del bloque de competencias interpersonales, respecto del género. Por lo tanto, la diferencia de medias en relación a MB2 es nula.

Las dos competencias destacadas en B2 por la alta puntuación obtenida, P1.30 y P1.31 se estudian a partir de la variable independiente "género" (tabla 6.38). 
Tabla 6.38

Valores de promedio obtenidos para P1.30 y P1.31 en relación a la variable factor "género"

\begin{tabular}{llllll} 
& Género & $\mathbf{N}$ & $\overline{\times}$ & $\boldsymbol{\sigma}$ & $\begin{array}{l}\text { Error } \\
\text { típico }\end{array}$ \\
\hline $\begin{array}{l}\text { 1.30.- Grado de ayuda en el desarrollo } \\
\text { de la competencia docente: trabajo en } \\
\text { equipo }\end{array}$ & Hombre & 685 & 3,16 &, 852 & 0,033 \\
\hline $\begin{array}{l}\text { 1.31.- Grado de ayuda en el desarrollo } \\
\begin{array}{l}\text { de la competencia docente: habilidades } \\
\text { en las relaciones interpersonales }\end{array}\end{array}$ & Hombre & 461 & 3,33 &, 746 & 0,035 \\
\hline
\end{tabular}

Se establece a continuación ordenadamente (de mayores a menores valoraciones) y de forma gráfica los promedios obtenidos para las dos comeptencias, P1.30 y P1.31 integradas en B2 considerando el género de los estudiantes (figura 6.21).

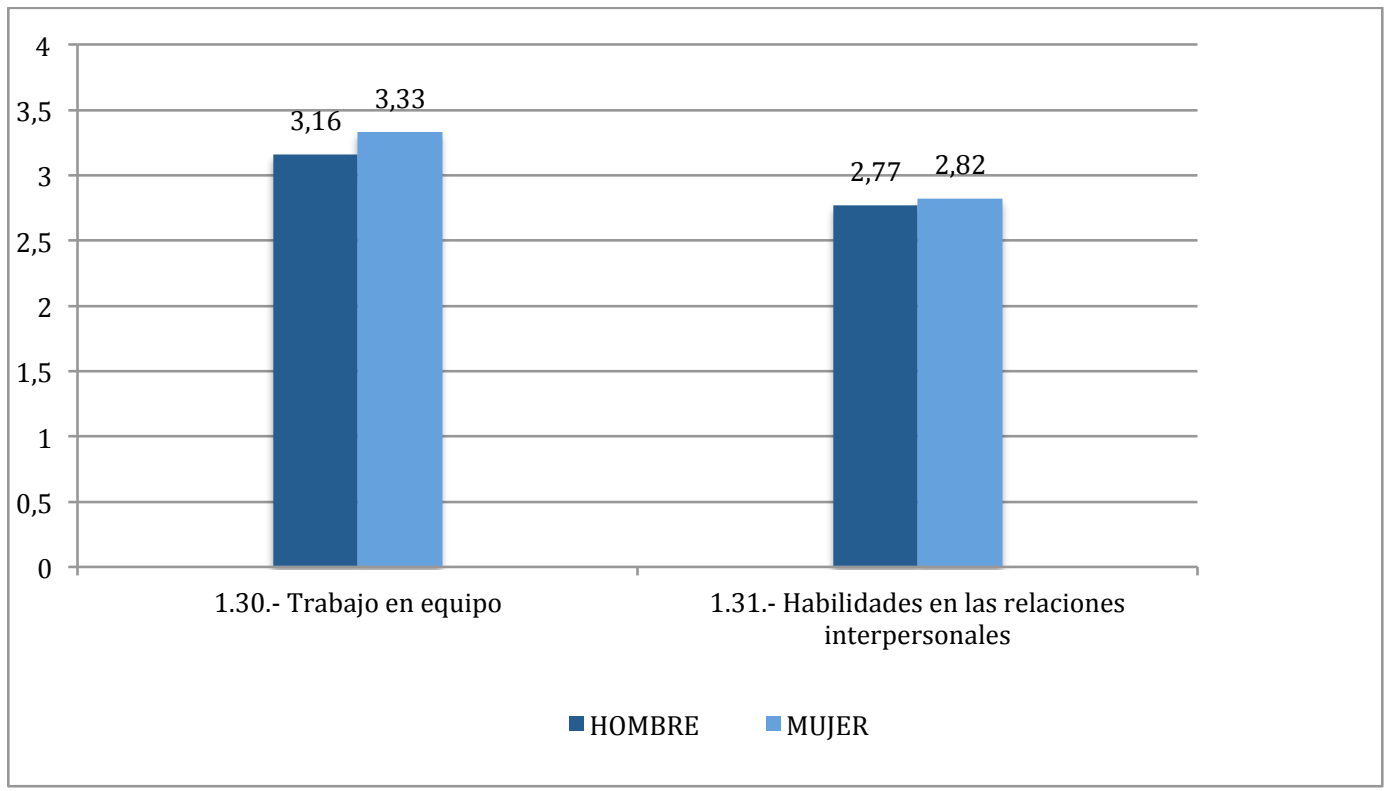

Figura 6. 21. Representación gráfica de las medidas de tendencia central de P1.30 y P1.31 considerando la variable factor "género"

Se aprecia a partir de los resultados obtenidos una percepción de ayuda recibida para su desarrollo mayor en las mujeres que en los hombres. 
En este sentido para P1.30, trabajo en equipo, ambos grupos consideran que es mucha la ayuda recibida en los estudios cursados para su desarrollo. Pero son las mujeres las que manifiestan un mayor grado $(\bar{x}=3,33)$ que los hombres $(\bar{x}=3,16)$. Además, se destaca que la dispersión en las respuestas es para el caso de las mujeres menor que para el de los hombres, reconociéndose por tanto y comparativamente, un mayor acuerdo en torno a la media en las primeras que en los segundos $(\sigma=0,746 \mathrm{y}$ $\sigma=0,853)$.

La prueba $U$ de Mann-Whitney ayuda a conocer la posible existencia de diferencias estadísticamente significativas entre los grupos para P1.30 (tabla 6.39), arrojando un resultado que apunta hacia la existencia de una diferencia estadísticamente siginificativa en función del género $(0,001<0,05)$. Esto pone en evidencia que el género sí influye y afecta de forma estadisticamente significativa a la valoración de promedio, sobre la consideración de ayuda formativa recibida en los estudios cursados para su desarrollo. Por tanto, se reconoce una mayor diferencia en este caso por parte de las mujeres frente a los hombres $(\bar{x}=3,33$ frente $\bar{x}=3,16)$.

Tabla 6.39

Diferencias en la percepción de los estudiantes hombres y mujeres sobre P1.30

\begin{tabular}{lccc} 
& Hombres & Mujeres \\
\hline $\begin{array}{l}\text { 1.30.- Grado de ayuda en el desarrollo de la } \\
\text { competencia docente: Trabajo en equipo }\end{array}$ & $\overline{\times}$ & $\overline{\times}$ & $P$ \\
\hline
\end{tabular}

Atendiendo a las experiencias formativas descritas en los GD y sus características presentes en la formación recibida para el desarrollo de P1.30, los códigos que explican el fenómeno están presentes en similar sentido en el discurso de las mujeres y en el de los hombres (tabla 6.40). 
Tabla 6.40

Estudio comparativo entre estudiantes hombres y mujeres sobre los códigos que explican el funcionamiento de la formación recibida en relación al desarrollo de P1.30

\begin{tabular}{|c|c|c|c|}
\hline \multicolumn{2}{|c|}{ Hombres } & \multicolumn{2}{|c|}{ Mujeres } \\
\hline Código & Enraizamiento & Código & Enraizamiento \\
\hline Procedimiento & 16 & Procedimiento & 8 \\
\hline $\begin{array}{l}\text { Conflicto de } \\
\text { responsabilidades }\end{array}$ & 6 & $\begin{array}{l}\text { Conflicto de } \\
\text { responsabilidades }\end{array}$ & 6 \\
\hline Formación & 4 & Formación & 3 \\
\hline Monitoreo del profesor & 5 & Monitoreo del profesor & 2 \\
\hline $\begin{array}{l}\text { Prevalencia del } \\
\text { contenido }\end{array}$ & 5 & Evaluación demandada & 2 \\
\hline Evaluación demandada & 4 & Prevalencia del contenido & 1 \\
\hline
\end{tabular}

A continuación se presenta el estudio comparativo entre hombres y mujeres a partir del análisis de las relaciones entre códigos y entre sus evidencias, mediante redes semánticas, a fin de interpretar y conocer mejor la vivencia de la dinámica interna de las experiencias formativas descritas relacionadas con la adquisición y desarrollo de P1.30 según los grupos.

Para el caso de las estudiantes mujeres, se observa e interpreta a la luz de la red semántica creada (véase figura 6.22), que el funcionamiento de las experiencias formativas de práctica de trabajo grupal, parte del código formación, que para ellas surge en la propia cadencia por trabajar juntas, repartiendo las cargas de trabajo, para finalmente conformar un todo, producto académico, que se prepara para la entrega. No obstante se observa cómo la comunicación, el diálogo, se percibe como la base para supervisar la participación en el proceso. Se advierte que ante las posibles dificultades por la inacción de algunos miembros, se opta con cierta antelación, por animar a los compañeros a centrarse, a retomar su tarea, monitorizando así los resultados en los tiempos estimados. 
Grupo Mujeres (5:46)

[...] sería quedar, repartir los epígrafes, luego buscabas la información cada uno en su casa, habríamos un drive común, íbamos pegando los epígrafes del trabajo y cada uno cuando pudiera iba pegando la información que había encontrado, y luego ya el resto si nos daba tiempo lo leíamos y ponías un día límite, después otro maquetaba e imprimía y ya está el proceso.

Grupo Mujeres (3:29)

Viene alguien a tu grupo de trabajo y trabaja con nosotros, y si ves que a las dos semanas no ha hecho nada, le dices, oye, venga, no de malas, sino se que no se, es como, no me fastidies [...].

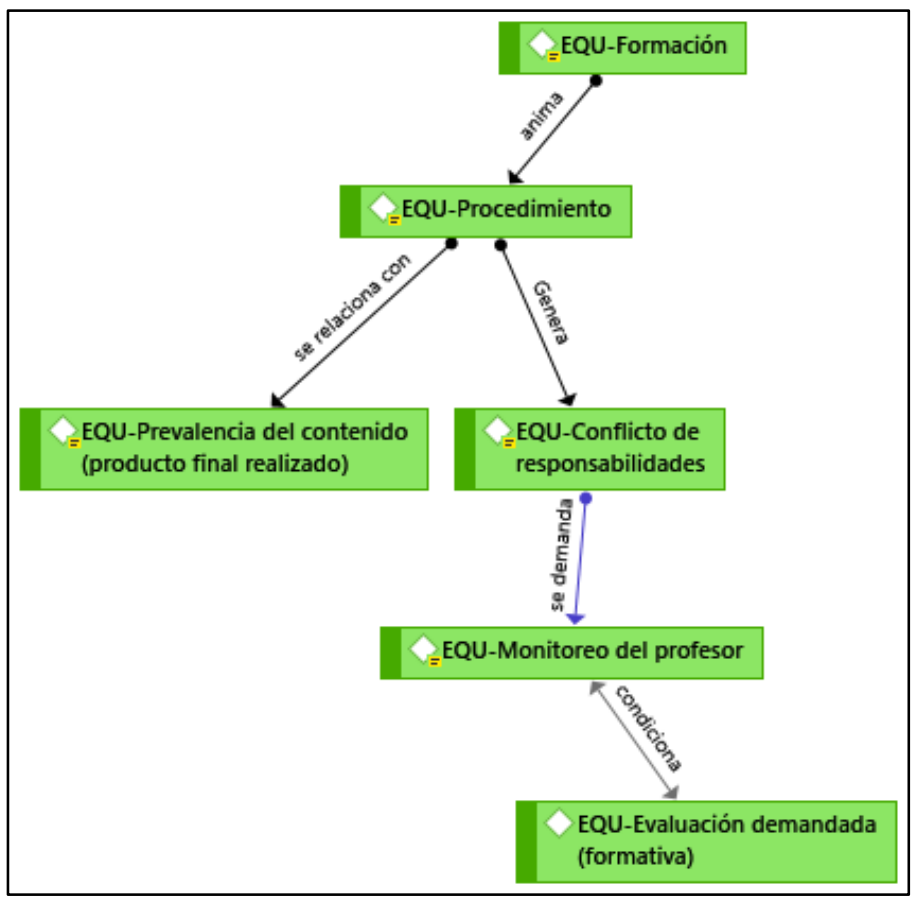

Figura 6. 22. Red semántica del grupo de estudiantes mujeres que explica las experiencias formativas relacionadas con la adquisición y desarrollo de P1.30

Este procedimiento de trabajo grupal se relaciona en gran medida con la prevalencia del contenido a desarrollar y no tanto con el proceso de trabajo grupal puesto en marcha. 
Grupo Mujeres (3:42)

Ese yo creo que es el problema, que a través del trabajo en grupo quieren evaluar una serie de contenidos, entonces, al final, el trabajo en grupo no lo están teniendo en cuenta, desde mi punto de vista.

Además el procedimiento de trabajo grupal desarrollado genera una serie de conflictos de responsabilidad entre los miembros del grupo, debido a las diferencias de posturas e intereses. Discrepancias que no se saben gestionar también por la ausencia de compromiso asumido por algunos miembros de los grupos, trasgrediendo la confianza y el respeto que de partida se requiere para afrontar las tareas grupales.

\footnotetext{
Grupo Mujeres (5:121)

El método que adoptamos para abordar el trabajo nos ha generado conflictos personales entre algunos miembros de los grupos al no saber gestionar las discrepancias o tener intereses diferentes.
}

\section{Grupo Mujeres (5:129)}

Si te toca gente que realmente no asume el compromiso o no le importa los estudios que cursa en la carrera, entonces ocurren muchos conflictos y de algo que es totalmente académico pasa a ser algo personal; entonces los trabajos en grupo están muy bien con determinadas personas pero con la misma confianza y respeto, porque cuando se adolece de esto, entonces no hay más que conflictos.

Finalmente estos aspectos justifican la demanda de un modelo de evaluación, que ayude a conseguir que todos los miembros del grupo conozcan el trabajo de los otros y no solo el que cada uno genera, mostrándose la urgencia de valorar cómo todos han participado en el proceso para la consecución del objetivo grupal; paralelamente se demanda una mayor implicación docente en la evaluación del proceso, observando y valorando diversas capacidades presentes en el proceso como la comunicación y la disposición al acuerdo. 
Grupo Mujeres (3:36)

Y claro hay que demostrar de alguna manera que todos saben de todas las partes del trabajo.

Grupo Mujeres (3:37)

El profesor debe estar evaluando ese trabajo en grupo, cómo habla cada persona, quien quiere ponerse de acuerdo, quien quiere solucionarlo, quien no,

Para el caso de los estudiantes hombres, la red semántica creada (figura 6.23) para interpretar y comprender el significado atribuido a los códigos que explican las experiencias formativas cursadas y que consideran se relacionan con la adquisición y desarrollo de P1.30, toma como punto de partida, al igual que el caso de las estudiantes mujeres, el código formación. Este se entiende autodidacta y sin intermediación de los formadores o de la propia formación cursada. Además explica una forma de proceder en la práctica, que se relaciona básicamente por la distribución de tareas y contenidos, conformando un concepto de trabajo grupal y un proceder vinculados entre si; trabajar en grupo es el procedimiento para hacerlo y el procedimiento conforma el concepto de trabajar en grupo.

Grupo Hombres (3:32)

A trabajar en grupo nadie te enseña, tú formas un grupo y con los miembros estableces tus normas de trabajo; es simple, quedamos hoy y tú te encargas de esto, de esto y de esto, y siempre va a haber gente que tire más, es normal, dotes de líder; otro que acepte todo, otro que se lleve bien. 


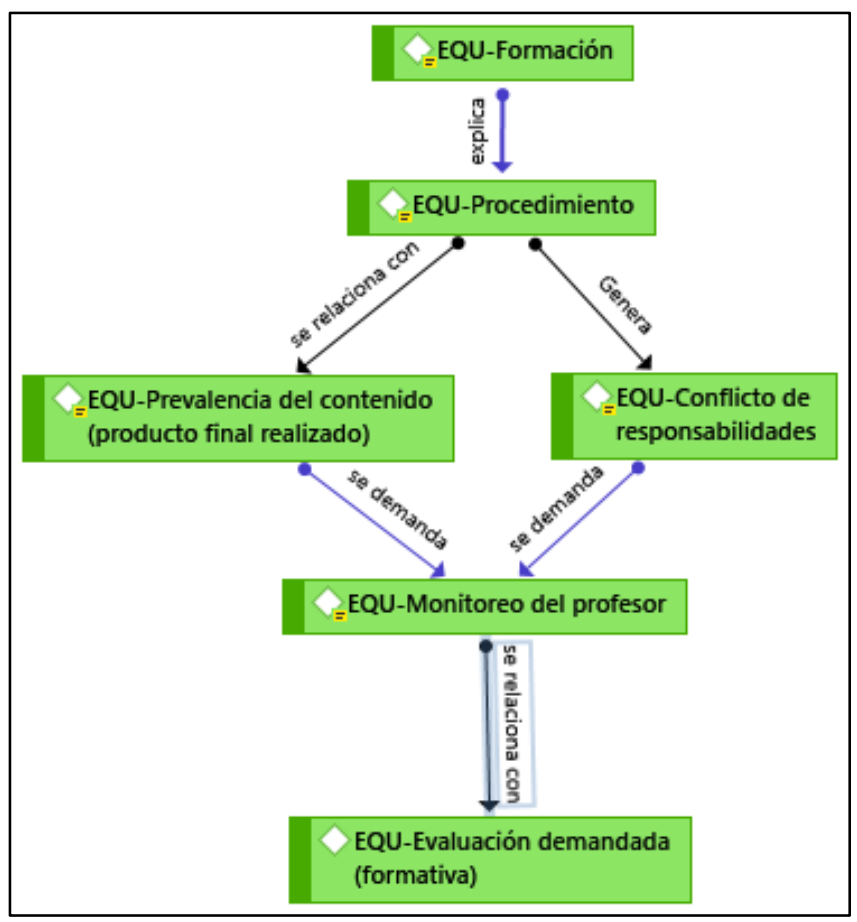

Figura 6. 23. Red semántica del grupo de estudiantes hombres que explica las experiencias formativas relacionadas con la adquisición y desarrollo de P1.30

Esta forma de proceder se relaciona más con la prevalencia del contenido que con el propio proceso de trabajo grupal establecido, alineándose con un modelo de evaluación que se centra finalmente en la producción final del trabajo grupal realizado.

Grupo Hombres (3:38)

Yo creo que el profesor no sabe de nuestro proceso porque no lo ve y aunque trabajamos en grupo, cooperamos, hablamos, todo es trabajo en equipo, pero al final él lo que quiere es el documento.

Grupo Hombres (3:33)

Al final en estas evaluaciones, para mí siempre son injustas, porque hay gente que se lleva más nota de la que se puede merecer y hay gente que se puede llevar menos también. 
También consideran que el proceso que autogestionan en la práctica genera conflictos de responsabilidades e intereses, a la hora de asumir la intensidad de las cargas de trabajo en relación a otros miembros del grupo; de forma, que se producen dos velocidades de trabajo no compartiendo las mismas expectativas de éxito. Además ocurre, ante este divorcio de intereses y el conflicto en las relaciones interpersonales que surge, un encubrimiento de la problemática, que genera frustración y condiciona la validez del trabajo grupal realizado.

Grupo Hombres (5:119)

Cuando trabajas con alguien quieres obtener una buena calificación, pero es posible encontrar personas que integran los grupos que se conforman con una calificación suficiente para aprobar y superar la materia y en eso tenemos un problema, porque al final sale por algún lado, porque yo no me voy a conformar con un siete cuando el otro se quiere conformar con un cinco.

Grupo Hombres (3:24)

Es muy sangrante muchas veces el tapar también a los compañeros; bueno, no has hecho tal, no vas a decirlo; al final el profesor no sabe que este no ha hecho esto o que no ha ido a las reuniones de grupo.

Por su parte, tanto la vivencia de los conflictos interpersonales como del propio modelo de evaluación centrado en la producción final realizada y no en el proceso, hace que se demande un perfil docente que optimice el seguimiento de dicho proceso (monitoreo del profesor). Por ello, por ejemplo, se sugiere el registro para cada uno de los miembros de los grupos, de aspectos del proceso de trabajo grupal realizado, que garantice un proceso evaluador formativo compartido con ellos, dialogado y más justo (evaluación demandada). 
Grupo Hombres (3:43)

[...] porque yo en el trabajo en grupo no te he visto colaborar, no te he visto cooperar, no te he visto implicado en el grupo, entonces creo que no es justo que tú tengas las misma nota que tu compañero que sí le he visto preocupado, que ha venido a las tutorías cuando las habéis pedido, que le he visto más implicado que tú [...] y hablarlo y ver si es verdad o es mentira.

En relación a P1.31, habilidades en las relaciones interpersonales, también se aprecia en hombres y mujeres una percepción de mucha ayuda formativa recibida a lo largo de la formación cursada para su desarrollo, observándose de nuevo una estimación mayor en el caso de las mujeres $(\bar{x}=2,82)$ que en el caso de los hombres $(\bar{x}=2,77)$. Además se considera que la dispersión en las respuestas es de nuevo sensiblemente menor en el caso de las mujeres, con una desviación típica inferior a la de los hombres $(\sigma=0,888$ frente a $\sigma=0,896)$.

La prueba $U$ de Mann-Whitney ayuda a conocer la posible existencia de diferencias estadísticamente significativas entre los grupos. Desde el resultado obtenido se apunta hacia la inexistencia de diferencia estadísticamente siginificativa en función del género para P1.31 (P. 0,458>0,05), verificando la hipótesis nula (tabla 6.41).

Tabla 6.41

Diferencias en la percepción de los estudiantes hombres y mujeres sobre P1.31

\begin{tabular}{lccc} 
& Hombres & Mujeres & \\
\hline $\begin{array}{l}\text { 1.31.- Grado de ayuda en el desarrollo de la } \\
\text { competencia docente: habilidades en las } \\
\text { relaciones interpersonales }\end{array}$ & $\bar{x}$ & $\overline{\times}$ & $P$ \\
\hline
\end{tabular}

En relación a la descripción de las habilidades interpersonales presentes en las experiencias formativas cursadas y sus dinámicas de funcionamiento, que consideran les han ayudado a desarrollar P1.31, los códigos que explican el fenómeno parecen estar presentes de forma similar tanto en los discursos de las estudiantes mujeres como en el de los estudiantes hombres (tabla 6.42). 
Tabla 6.42

Estudio comparativo entre estudiantes hombres y mujeres sobre los códigos que explican el funcionamiento de la formación recibida en relación al desarrollo de P1.31

Hombres

Mujeres

\begin{tabular}{lclc}
\hline \multicolumn{1}{c}{ Código } & Enraizamiento & \multicolumn{1}{c}{ Código } & Enraizamiento \\
\hline Comunicarse & 11 & Interactuar/compartir & 10 \\
Interactuar/compartir & 8 & Comunicarse & 5 \\
Colaborar & 4 & Adaptarse/ser flexible & 5 \\
Negociar & 4 & $\begin{array}{l}\text { Crear clima y } \\
\text { ambiente formativo }\end{array}$ & 4 \\
Actuar ante la & 3 & Cohesionar & 3 \\
conflictividad & & Actuación ante la & \\
Ayudar & 3 & conflictividad & 2 \\
Crear clima y ambiente & 2 & $\begin{array}{l}\text { Regularse } \\
\text { emocionalmente }\end{array}$ & 2 \\
formativo & & Ser asertivo & 2 \\
Cohesionar & 2 & Colaborar & 2 \\
Tener iniciativa & 2 & & \\
Ser asertivo & 2 & & \\
Escuchar & 1 & & \\
Ser honesto & 1 & & \\
\hline
\end{tabular}

La red semántica que se estableció para comprender la percepción del grupo de estudiantes mujeres (figura 6.24), toma como puntos de partida las situaciones de aprendizaje, trabajos en grupo, experiencias prácticas, simulaciones docentes en las materias específicas de la titulación cursada, como por ejemplo, expresión corporal, reconociéndolas como facilitadoras de la interacción y la socialización, la colaboración y el aumento de la cohesión grupal.

Grupo mujeres (5:2)

Mediante los trabajos en grupo, las exposiciones que hemos hecho en la que nuestros compañeros eran nuestros alumnos y otras situaciones, han generado un aumento en nuestras relaciones interpersonales y generalmente en el compañerismo. 
Grupo mujeres (5:11)

En asignaturas como expresión corporal, que fue una de las primeras, pues yo creo que ahí experimenté las relaciones de colaboración con todos mis compañeros, porque no es fácil proviniendo de diferentes grupos, no conoces a muchos compañeros, y descubres a personas que pensabas conocías y descubres en mayor profundidad.

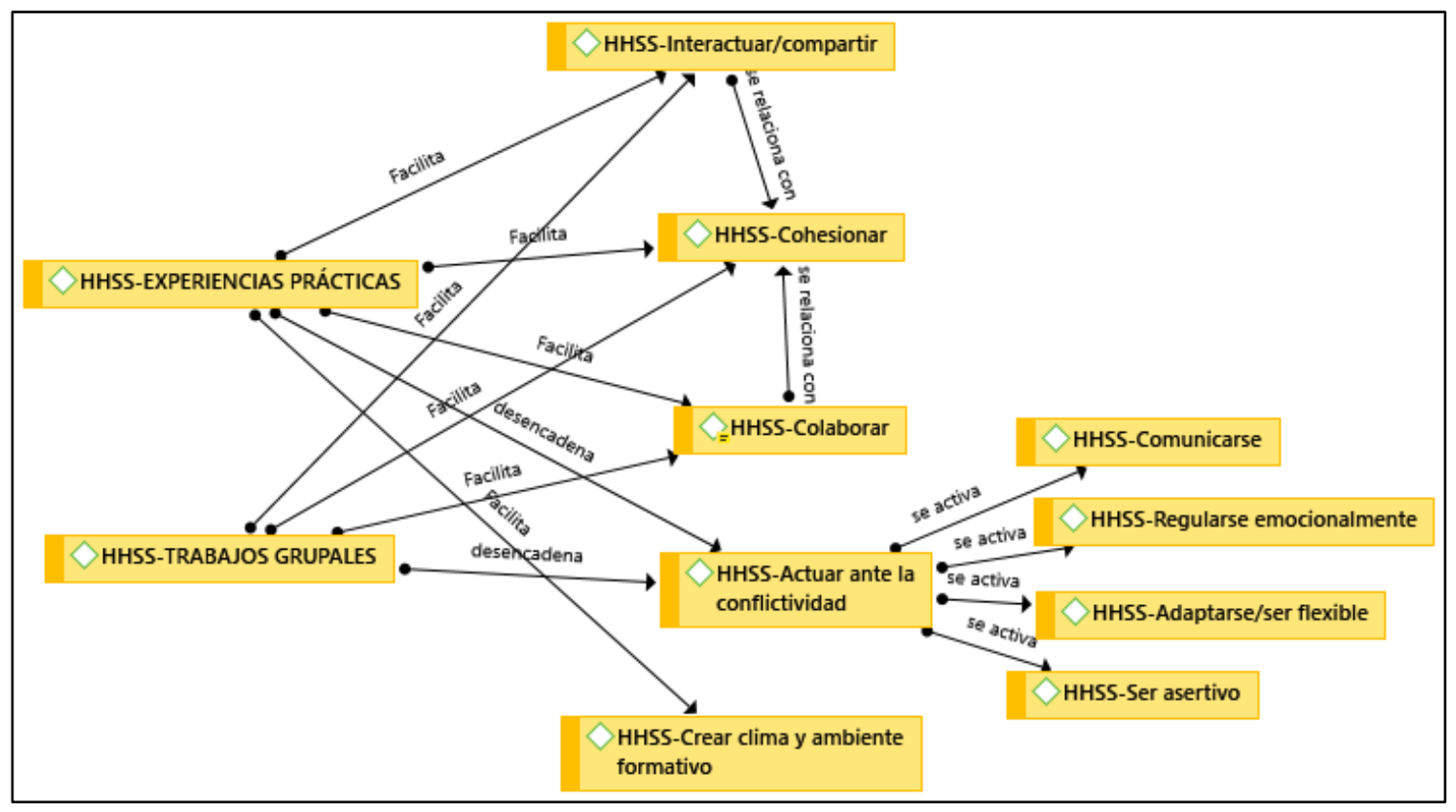

Figura 6. 24. Red semántica del grupo de estudiantes mujeres que explica las experiencias formativas relacionadas con la adquisición y desarrollo de P1.31

Así mismo, las experiencias formativas cursadas parece desencadenan ciertas situaciones de conflictividad por la interacción que generan, abordándolas comunicativamente de una forma más defensiva en los comienzos del proceso socializador. Posteriormente activan una estrategia para enfrentarse al conflicto más flexible y adaptativa a las situaciones, reflexiva, regulando la emocionalidad, optando por un modelo de comunicación y diálogo más en calma y asertivo. 
Grupo mujeres (5:19)

$[\ldots]$ en los trabajos grupales $[\ldots]$ cuando veo que van a venir las cosas (conflictos) suelo ponerme a la defensiva y me quejo; no obstante este curso he intentado ofrecer más oportunidades pensando que he de ver las cosas de una forma distinta, no tan inflexible, intentando decir las cosas, la verdad, con mas tranquilidad, de forma más abierta y mas reflexiva.

También, algunas experiencias prácticas relacionadas con las exposiciones orales de trabajos, son especialmente valoradas cuando el docente aporta a los estudiantes un feedback reforzador, en aquellas habilidades interpersonales que durante la exposición resultaron exitosas, ayudando a tomar conciencia sobre su existencia y aplicación y correspondiendo en la generación de un clima de aula más positivo y formativo.

Grupo mujeres (5:43)

Las exposiciones en público que teníamos que hacer, en vez de darnos los datos negativos y fallos nos decían también los aspectos positivos que habíamos realizado y que no nos dábamos cuenta de ellos, creándonos un ambiente de seguridad, ya que al habernos planteado los aspectos positivos sobre nuestras habilidades sociales mostradas en las exposiciones en público, nos hacía pensar en no ser tan malos como quizá pensáramos.

Para el caso de los estudiantes hombres, la red semántica creada (figura 6.25) también parte de la importancia para su formación, de algunas experiencias prácticas realizadas y de trabajos grupales abordados, en las materias específicas de EF, que por su especial naturaleza, se reconoce, han facilitado el manejo de habilidades en las relaciones interpersonales, como la capacidad de interactuar y compartir, así como desarrollar un clima y un ambiente formativo de cohesión grupal. Tal es el caso de la realización de proyectos de AFMN en donde se fortalece la convivencia extra aula. 
Grupo hombres (5:12)

Es la propia naturaleza de la educación física, porque al final no es estar en un aula sentado muchas veces, es estar moviéndote con un compañero, es al final como un equipo; tú al final el aula lo ves como un equipo donde estamos todos juntos y al final no importa tanto la nota final; es el tema de la acampada y las actividades que te obligan a salir.

\section{Grupo hombres (5:13)}

Son actividades dinámicas y activas y al fin de al cabo son actividades (acampadas, actividades físicas en la naturaleza) que generan divertimento y unión y hace que te relaciones más a tus compañeros.

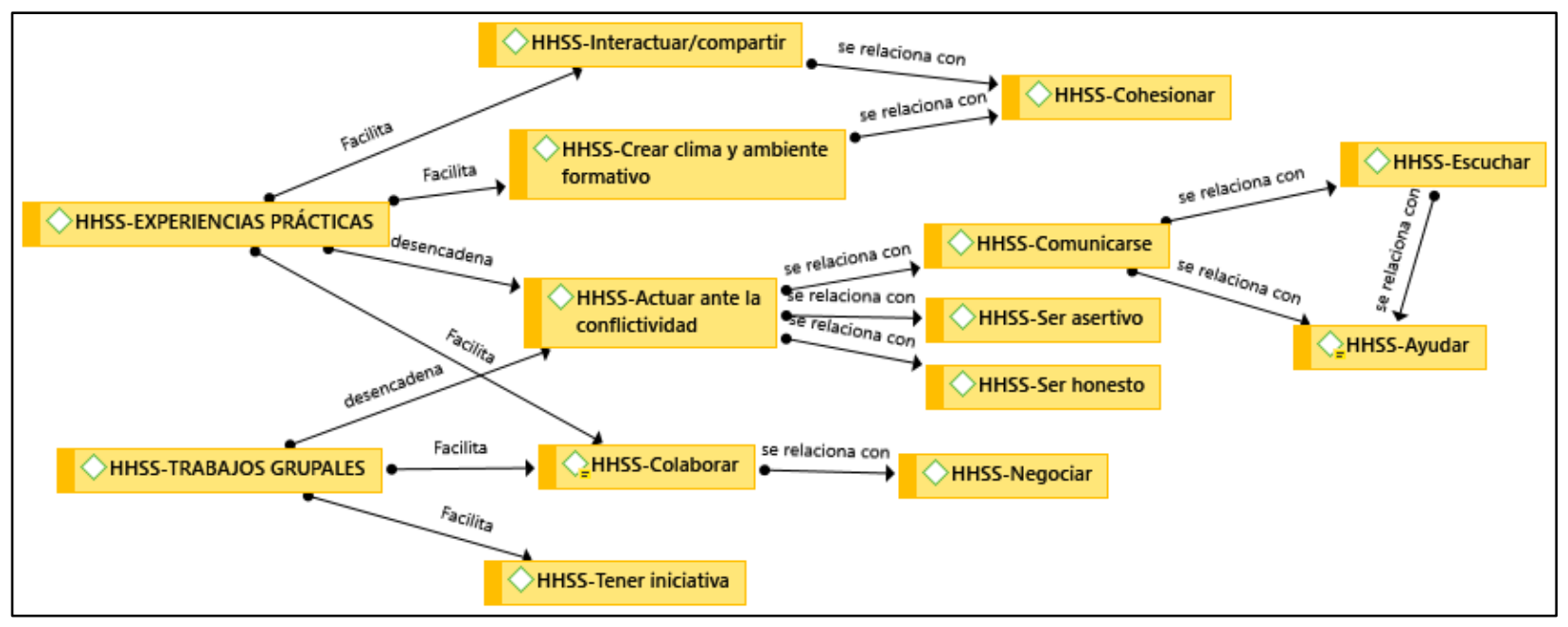

Figura 6. 25. Red semántica del grupo de estudiantes hombres que explica las experiencias formativas relacionadas con la adquisición y desarrollo de P1.31

De la misma manera, las experiencias descritas desencadenan situaciones de conflictividad interpersonal, roces, discrepancias y dificultades para gestionarlo que han permitido activar y manejar algunas habilidades prosociales para afrontarlo, como la asertividad, la comunicación y la escucha, para honestamente reconociendo los errores para ayudar a mejorar. 
Grupo hombres (3:64)

Cuando me dices lo que he fallado, es que yo inmediatamente, después de haber pasado sea lo que sea, es que lo acepto porque si es que tienes razón, he fallado un poco en esto, y sé que lo podría haber hecho mucho mejor.

Grupo hombres (5:18)

Yo por ejemplo, he mejorado en la asertividad; durante la elaboración de trabajos grupales acabamos peleados con algún compañero, y este año hemos intentado no repetir eso; $[\ldots]$ y pienso que eso es una evolución que estamos teniendo, ya que cuando empezamos los estudios permites todo, permites echarte el trabajo encima, pero llega un momento en el que aprendes a decir hasta aquí.

Además parece que las experiencias formativas de TG también han facilitado el desarrollo de habilidades interpersonales, como la capacidad de colaborar y negociar, necesitando para ello dialogar y llegar a acuerdos para trabajar grupalmente y atender responsablemente a las tareas y con ellas al objetivo común.

\footnotetext{
Grupo hombres (5:44)

Hemos trabajado mucho la capacidad de trabajar en equipo mediante diferentes trabajos grupales. Es una de las partes positivas que he visto en la carrera. Podría decir que en todas las asignaturas hemos tenido que hacerlo y me parece un avance, ya que nos hace convivir, trabajar con diferentes compañeros, debatir, hablar las cosas y llegar a un acuerdo.
}

De la misma manera, las experiencias formativas descritas han facilitado el despertar de la iniciativa personal para romper el hielo, aportar ideas y proponer caminos para que los grupos de trabajo comiencen a funcionar. 
Grupo hombres (5:42)

Yo he aprendido a tener iniciativa, es decir, si no arranca nadie, ya arranco yo, y lo que hago es intentar dar el primer paso muchas veces y eso lo he aprendido en la facultad porque yo antes no me mostraba tan lanzado; pero ya llega un punto en el que si tengo que trabajar soy yo el primero que dice lo que creo que tenemos que hacer, esto sí me lo han proporcionado las experiencias que he tenido en la facultad.

Se presenta a continuación el estudio de las competencias de tipo interpersonal atendiendo a la variable "tipo de estudios de EF" cursados.

\subsubsection{Conocer cómo influye el "tipo de estudios de Educación Física" cursados por los estudiantes, a la hora de considerar la ayuda formativa recibida para el desarrollo de las competencias interpersonales.}

\section{Análisis descriptivo y comparativo atendiendo al "tipo de estudios de EF" cursados.}

Los estadísticos descriptivos para MB2 (competencias interpersonales) a partir de la variable independiente "Tipo de estudios de EF" cursados se presentan a continuación en la tabla 6.43 .

Tabla 6.43

Valores de la variable MB2 en relación a la variable factor "tipo de estudios de EF" cursados

\begin{tabular}{lcccc} 
Estudios de EF cursados & $\mathbf{N}$ & $\overline{\times}(\mathbf{M B} 2)$ & $\boldsymbol{\sigma}$ & Error típico \\
\hline MEPEF & 794 & 2,85 &, 670 & 0,024 \\
\hline CAFyD & 373 & 2,69 &, 681 & 0,035 \\
\hline
\end{tabular}


Para los estudiantes procedentes de ambos títulos de grado, las dinámicas foramtivas de las materias cursadas han ayudado mucho al desarrollo de las competetencias interpersonales a lo largo de su formación, aunque son los procedentes del título de MEPEF en los que se observa un promedio sensiblemente mas elevado $(\bar{x}=2,85)$; por su parte en los estudiantes procedentes del título CAFyD se aprecia una valoración media al respecto algo inferior $(\bar{x}=2,69)$. Para ambas titulaciones se aprecia un aceptable acuerdo de respuesta, representado en valores relativamente bajos de desviación típica $(0,670$ y 0,681 respectivamente). La representación gráfica de la diferencias entre los grupos se observa en la figura 6.26.

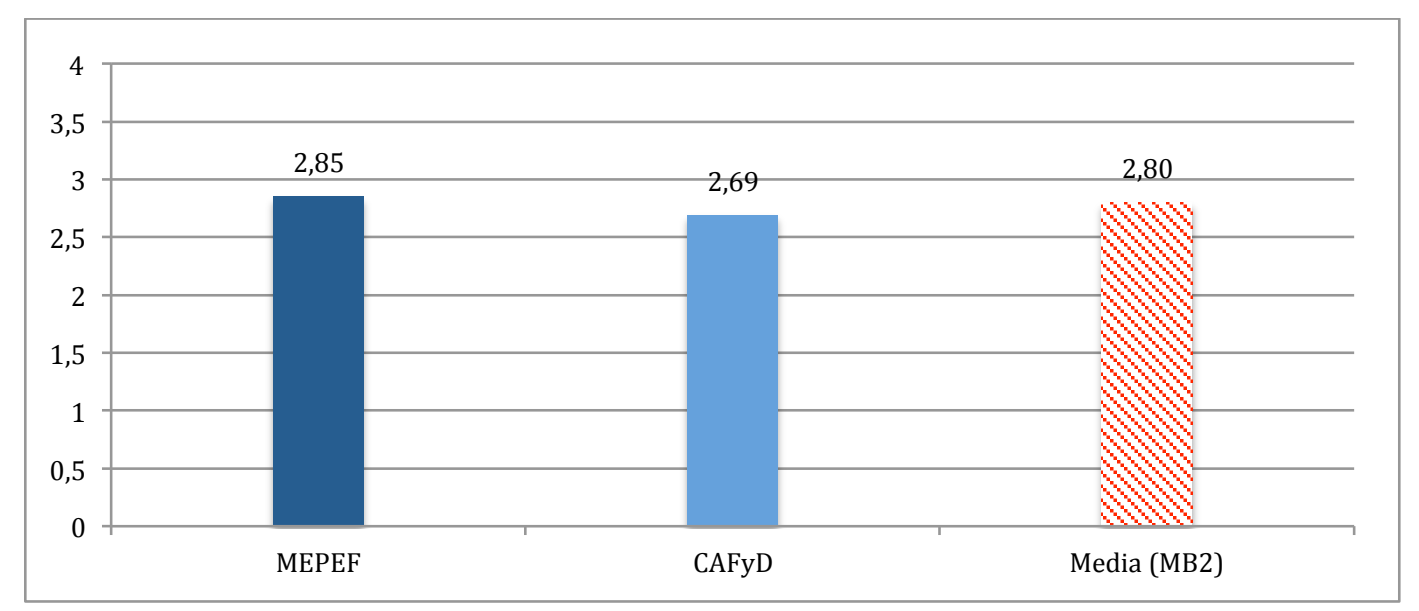

Figura 6. 26. Percepción media de los estudiantes de los grupos MEPEF y CAFyD en relación al grado de ayuda formativa recibida para el desarrollo de MB2

Para analizar la diferencia de medias a partir del "tipo de estudios de Educación Física" cursados, se aplicó una prueba U de Mann-Whitney, con objeto de valorar si las diferencias de medias a partir de los dos tipos de estudios cursados son o no estadísticamente signficativas en relación a MB2 (tabla 6.44).

Tabla 6.44

Diferencias en la percepción de los estudiantes hombres y mujeres en relación a MB2

\begin{tabular}{lccc} 
& MEPEF & CAFyD & \\
\hline MB2. Competencias Interpersonales & $\overline{\times}$ & $\overline{\times}$ & $P$ \\
& 2,85 & 2,69 & 0,000 \\
\hline
\end{tabular}


La prueba arroja un nivel de significación de 0,000 ( $\mathrm{p}<0,05)$, lo que indica que se rechaza la hipótesis nula y se reconoce una diferencia estadísticamente significativa entre el grado de ayuda recibida para el desarrollo del bloque de competencias interpersonales, respecto de los estudios de Educación Física cursados, apreciándose en favor de los estudiantes MEPEF una mayor percepción de ayuda formativa recibida $(\bar{x}=2,85)$, que para los de la titulación CAFyD $(\bar{x}=2,69)$.

En relación a P1.30 y P1.31 integradas en B2, se presentan a continuación sus correspondientes estadísticos descriptivos (tabla 6.45), atendiendo a la variable factor objeto de estudio.

Tabla 6.45

Valores de promedio obtenidos para P1.30 y P1.31 en relación a la variable factor "tipo de estudios de EF" cursados

\begin{tabular}{llcccc} 
& Titulación & $\mathbf{N}$ & $\overline{\times}$ & $\boldsymbol{\sigma}$ & $\begin{array}{l}\text { Error } \\
\text { típico }\end{array}$ \\
\hline $\begin{array}{l}\text { 1.30.- Grado de ayuda en el desarrollo } \\
\text { de la competencia docente: trabajo en } \\
\text { equipo }\end{array}$ & MEPEF & 785 & 3,29 &, 776 & 0,028 \\
\hline $\begin{array}{l}\text { 1.31.- Grado de ayuda en el desarrollo } \\
\text { de la competencia docente: habilidades } \\
\text { en las relaciones interpersonales }\end{array}$ & MEPEF & 783 & 2,88 &, 884 & 0,032 \\
\hline
\end{tabular}

Se establece a continuación ordenadamente (de mayores a menores valoraciones) y de forma gráfica los promedios obtenidos para cada una de las preguntas que conforman B2, considerando el tipo de estudios de EF cursados (Figura $6.27)$. 


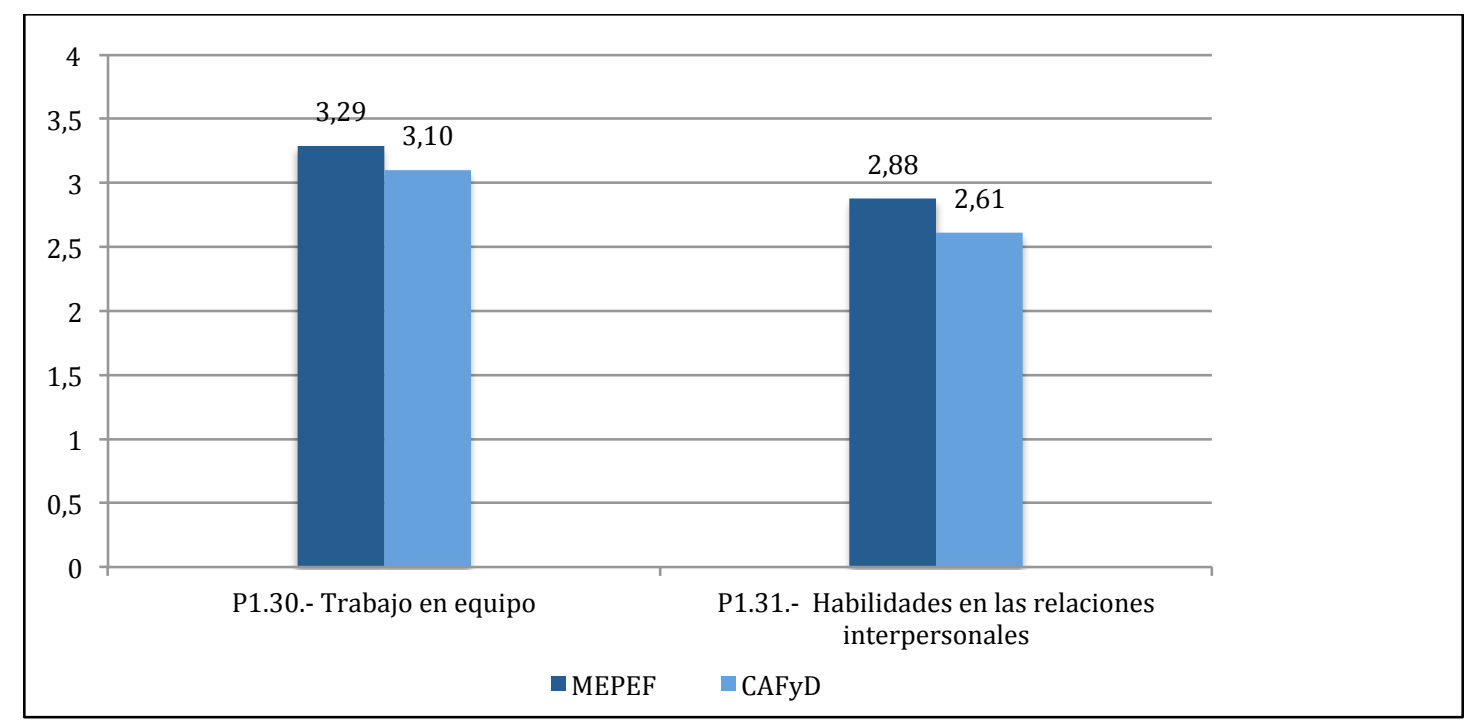

Figura 6. 27. Representación gráfica de las medidas de tendencia central de P1.30 y P1.31 considerando la variable factor "tipo de estudios de EF" cursados

Se aprecia cómo la percepción sobre la ayuda formativa recibida para el desarrollo de cada item agrupado en torno a B2, recibe una mayor valoración en el grupo de los estudiantes MEPEF que en el de CAFyD.

Atendiendo al análisis de cada uno de los items y sus valores de promedio, en la pregunta P1.30, ayuda formativa recibida para el desarrollo del trabajo en equipo, es donde se aprecia un mayor grado de ayuda formativa recibida, percibiendo tanto los estudiantes MEPEF como los CAFyD, que fue mucha la ayuda recibida para el desarrollo de la competencia mencionada, pero con una valoración superior en los primeros $(\bar{x}=3,29)$ que en los segundos $(\bar{x}=3,10)$. Esta elevada percepción, desde ambas titulaciones, es la más alta de todas las competencias transversales analizadas, al igual que la más elevada del bloque B2. De la misma manera se aprecia un aceptable desacuerdo en las respuestas en ambos grupos, aunque significativamente mejor en los estudiantes MEPEF $(\sigma=0,776)$, lo que manifiesta un acuerdo de respuesta aceptable si se vincula a la alta ayuda formativa recibida para el desarrollo de esta competencia. 
Se aplicó (tabla 6.46) la prueba $U$ de Mann-Whitney a fin de establecer si el hecho de cursar una $\mathrm{u}$ otra titulación resultaba estadísticamente significativo, en relación a la percepción de la ayuda recibida para el desarrollo de (P1.30) Trabajo en equipo, confirmándose la existencia de diferencias estadísticamente significativas entre los grupos $(0,000<0,05)$.

Tabla 6.46

Diferencias en la percepción de los estudiantes MEPEF y CAFyD sobre P1.30

\begin{tabular}{lccc} 
& MEPEF & CAFyD & \\
\hline 1.30.- Grado de ayuda en el desarrollo de la & $\bar{x}$ & $\bar{x}$ & $P$ \\
competencia docente: Trabajo en equipo & 3,29 & 3,10 & 0,000
\end{tabular}

Esta diferencia de percepciones también se observa si se atiende a las facultades de procedencia en la que los estudiantes cursan sus estudios. Se puede observar cómo la percepción de ayuda formativa recibida para el desarrollo de P1.30 es mayor en las facultades MEPEF que en las facultades CAFyD.

Para el caso de las primeras (tabla 6.47) es especialmente relevante el caso de la Facultad de Educación de Segovia (UVa), que muestra la más alta puntuación $(\bar{x}=3,57)$. En el extremo se encuentra la facultad MEPEF de Santander $(\bar{x}=3,11)$ en donde, a pesar de ser la úñtima del ranking, sigue mostrando por parte de sus estudiantes haber recibida mucha ayuda formativa para el desarrollo de la competencia para el trabajo en equipo. 
Tabla 6.47

Valores de promedio obtenidos para P1.30 en relación a la variable factor "facultades $M E P E F^{\prime \prime}$

\begin{tabular}{lccccc}
\multicolumn{1}{c}{ Competencia } & $\begin{array}{c}\text { Facultad de } \\
\text { Educación }\end{array}$ & $\mathbf{N}$ & $\bar{x}$ & $\boldsymbol{\sigma}$ & $\begin{array}{c}\text { Error } \\
\text { típico }\end{array}$ \\
\hline & Segovia (UVa) & 28 & 3,57 & 0,690 & 0,130 \\
& Valladolid (UVa) & 44 & 3,55 & 0,548 & 0,083 \\
& Barcelona (UB) & 30 & 3,53 & 0,507 & 0,093 \\
& Tenerife (ULL) & 34 & 3,47 & 0,563 & 0,097 \\
& Madrid (UAM) & 45 & 3,40 & 0,780 & 0,116 \\
$\begin{array}{l}\text { P1.30.- Grado de ayuda } \\
\text { recibida para el desarrollo de } \\
\text { la competencia docente: }\end{array}$ & Córdoba (UCO) & 20 & 3,35 & 0,988 & 0,221 \\
Trabajo en equipo & Albacete (UCLM) & 102 & 3,30 & 0,768 & 0,076 \\
& Valencia (UV) & 76 & 3,26 & 0,755 & 0,087 \\
& Granada (UGR) & 92 & 3,24 & 0,747 & 0,078 \\
& Sevilla (US) & 159 & 3,20 & 0,825 & 0,065 \\
& Murcia (UMU) & 67 & 3,15 & 0,783 & 0,096 \\
& Santander (UniCan) & 64 & 3,11 & 0,911 & 0,114 \\
\hline
\end{tabular}

Se establece a continuación de forma gráfica y ordenadadamente (mayor a menor valoración) (figura 6.28), los promedios obtenidos para P1.30, en relación a las facultades MEPEF de procedencia. 


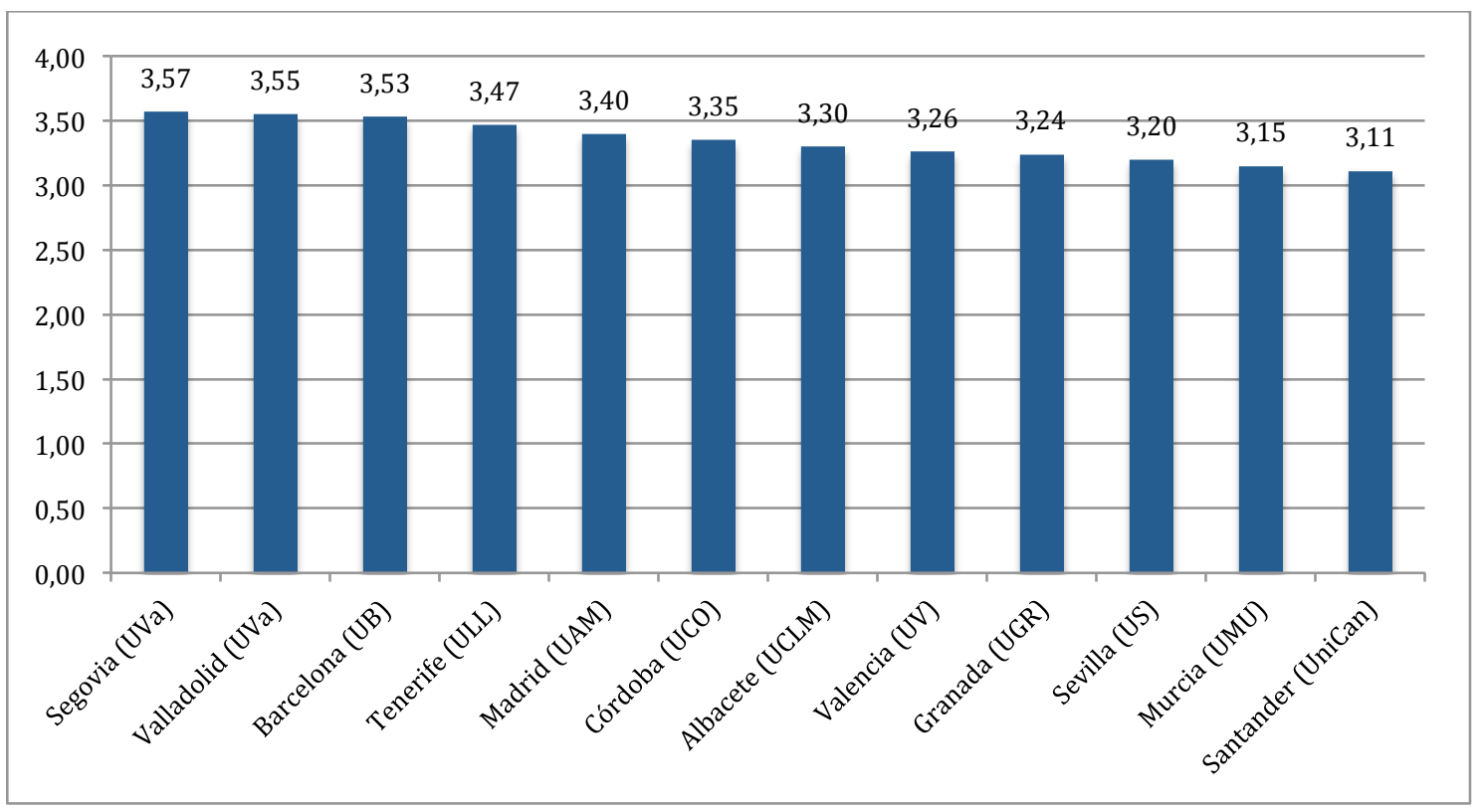

Figura 6. 28. Representación gráfica de los valores de promedio obtenidos para P1.30 en relación a la variable factor "facultades MEPEF"

Como se puede observar en las puntuaciones de promedio obtenidas para cada facultad, en todas $(\bar{x}>3)$, se observa una percepción por parte de los estudiantes encuestados de mucha ayuda recibida para el desarrollo de P1.30. Son especialmente relevantes los casos de las facultades de educación de Segovia y Valladolid (UVa) que muestran las puntuaciones más altas $(\bar{x}=3,57$ y $\bar{x}=3,55$ respectivamente). También para la Facultad de Educación de la Universidad de Barcelona se observa una puntuación considerablemente elevada $(\bar{x}=3,50)$. Las tres obtienen valores de desviación típica aceptables $(\sigma<1)$. A pesar de las elevadas valoraciones se observa que la facultad con la puntuación más baja es la de Santander $(\bar{x}=3,11)$, pero aún así se reconoce también en relación a ella, que para sus estudiantes, es mucha la ayuda formativa recibida para el desarrollo de P1.30. Para esta facultad se obtiene el valor de desviación típica más alto de todas, 0,911, que acercándose a la unidad, muestra una evidente dispersión en las respuestas.

Se muestra a continuación el resultado obtenido (tabla 6.48) a partir de la aplicación de la prueba Kruskal-Wallis, a fin de conocer la influencia de la variable facultades MEPEF sobre P1.30 y si existe igual modo de afección de las distintas facultades analizadas en relación a dicha pegunta. 
Tabla 6.48

Prueba Kruskal-Wallis para P1.30 y variable factor "facultades MEPEF"

P1.30. Grado de ayuda formativa recibida para el desarrollo del trabajo en equipo

\begin{tabular}{lr}
\hline Chi-cuadrado & 31,191 \\
Gl & 15 \\
Sig.asintót. &, 008 \\
\hline
\end{tabular}

La prueba arroja un nivel de significación de 0,008 (Sig.<0,05). Esto indica que ha de ser rechazada la hipótesis nula y por tanto aceptar que sí existe influencia del factor aplicado a la variable P1.30 bajo estudio y la propia variable P1.30. Por ello, dado que el resultado de la prueba nos lleva a aceptar la hipótesis alterna, se realiza un análisis post hoc mediante la prueba de Games-Howell, para comprobar qué pares de facultades MEPEF difieren significativamente entre sí, no asumiendo varianzas iguales dado el resultado de la prueba de homogeneidad de las varianzas realizadas (Sig. Levène $=0,019<0,05$ ). Los resultados obtenidos (tabla 6.49) establecen los pares en los que se aprecian diferencias estadísticamente significativas.

Tabla 6.49

Resultados del análisis post hoc entre P1.30 y la variable factor "facultades MEPEF" (comparadas de dos en dos)

(I) Facultad de Educación

\begin{tabular}{clc}
\hline Segovia (Uva) & Granada (UGR) & 0,045 \\
& Santander (UniCan) & 0,008 \\
& Sevilla (US) & 0,019 \\
& Murcia (UMU) & 0,015 \\
\hline Valladolid (Uva) & Granada (UGR) & 0,030 \\
& Santander (UniCan) & 0,004 \\
& Sevilla (US) & 0,009 \\
& Murcia (UMU) & 0,008 \\
\hline Barcelona (UB) & Santander (UniCan) & 0,013 \\
& Sevilla (S) & 0,030 \\
& Murcia (UMU) & 0,023 \\
\hline Tenerife (ULL) & Santander (UniCan) & 0,027 \\
& Murcia (UMU) & 0,047
\end{tabular}

La diferencia es significativa al nivel de .05 . 
Los resultados apuntan hacia diferencias significativas en cuatro de las facultades analizadas con respecto al resto. (1) Entre la Facultad de Educación de Segovia (mejor puntuación obtenida) y las facultades de Granada (Sig. Games-Howell $=$ 0,045), Santander (Sig. Games-Howell =0,008), Sevilla (Sig. Games-Howell =0,019) y Murcia (Sig. Games-Howell =0,015). (2) Entre la Facultad de Educación de Valladolid (segunda peor puntuación alcanzada) y las Facultades de Granada (Sig. Games-Howell $=0,030)$, Santander (Sig. Games-Howell = 0,004), Sevilla (Sig. Games-Howell =0,009) y Murcia (Sig. Games-Howell = 0,008). (3) Entre la Facultad de Educación de la Universidad de Barcelona (tercera con mejor puntuación) y las Facultades de Santander (Sig. Games-Howell =0,013), Sevilla (Sig. Games-Howell =0,020) y Murcia (Sig. $D M S=0,023)$. Y (4) Entre la Facultad de Educación de la Universidad de Tenerife (cuarta con mejor puntuación obtenida) y las Facultades de educación de Santander (Sig. Games-Howell = 0,027) y Murcia (Sig. Games-Howell = 0,047).

Atendiendo a las facultades CAFyD, para la pregunta P1.30, se obtienen también puntuaciones de promedio muy elevadas, siendo la Facultad CAFyD de Vic la que obtiene la puntuación más alta $(\bar{x}=3,40)$ y la Facultad CAFyD de León la que obtiene la más baja $(\bar{x}=2,65)$ (tabla 6.50$)$. 
Tabla 6.50

Variables de promedio obtenidos para P1.30 en relación a la variable factor "facultades CAFyD"

\begin{tabular}{llcccc}
\multicolumn{1}{c}{ Competencia } & \multicolumn{1}{c}{ Facultad CAFyD } & N & $\bar{x}$ & $\boldsymbol{\sigma}$ & Error típico \\
\hline & Vic (VIC) & 48 & 3,40 & 0,676 & 0,098 \\
& Murcia (UCAM) & 55 & 3,25 & 0,886 & 0,120 \\
P1.30.- Grado de ayuda en & Lleida (UDL) & 65 & 3,18 & 0,967 & 0,120 \\
el desarrollo de la & Huesca (UNIZAR) & 35 & 3,17 & 0,707 & 0,119 \\
competencia docente: & Sevilla (UPO) & 59 & 3,05 & 0,860 & 0,112 \\
Trabajo en equipo & Vitoria-Gasteiz (UPV) & 58 & 3,02 & 0,827 & 0,109 \\
& León (ULE) & 51 & 2,65 & 0,934 & 0,131 \\
\hline
\end{tabular}

En la figura 6.29 se presenta ordenádamente (mayor a menor valoración) tales promedios obtenidos para $\mathrm{P} 1.30$.

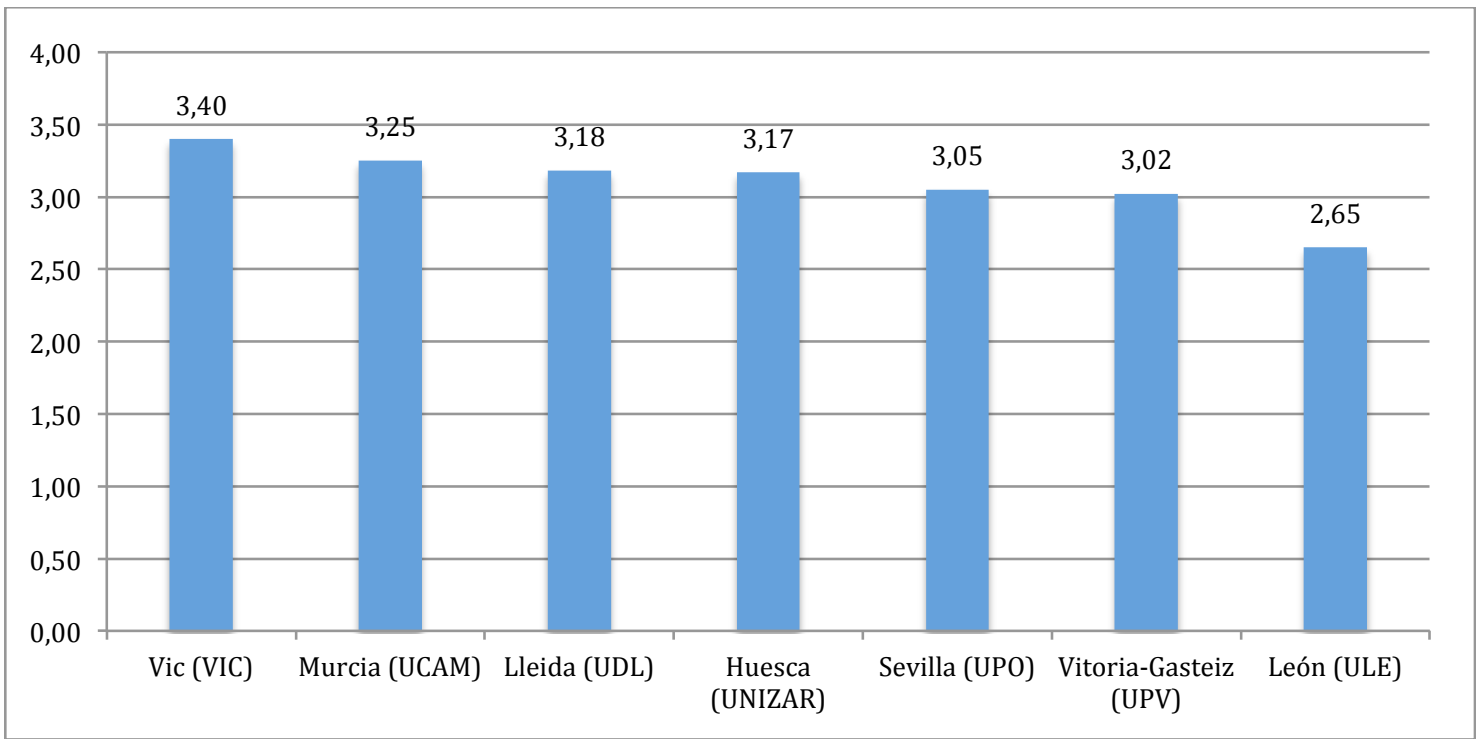

Figura 6. 29. Representación gráfica de los valores de promedio obtenidos para P1.30 en relación a la variable factor "facultades CAFyD"

Se observan puntuaciones muy elevadas para seis de las facultades CAFyD analizadas (valoraciones de promedio que oscilan entre 3,40 y 3,02 ) lo que da cuenta de una consideración, por parte de sus estudiantes, de mucha ayuda formativa recibida para el desarrollo de P1.30, a través de las asignaturas cursadas. La Facultad CAFyD de 
León, obtiene una puntuación de $\bar{x}=2,65$, que aún siendo la más baja, muestra igualmente que la ayuda formativa recibida para el desarrollo de esta competencia, a juicio de sus estudiantes, es de mucha. La dispersión más alta en las respuestas se observa en los casos de las Facultades de Lleida $(\sigma=0,967)$ y León $(\sigma=0,934)$.

Se aplica la prueba Kruskal-Wallis (tabla 6.51) para conocer la influencia de la variable facultades CAFyD sobre P1.30 y con ello conocer si existe una misma afección de las distintas facultades CAFyD analizadas en relación a la dicha pregunta.

Tabla 6.51

Prueba Kruskal-Wallis para P1.30 y variable factor "facultades CAFyD"

P1.30. Grado de ayuda formativa recibida para el desarrollo de conocimientos de informática aplicada al ámbito de la EF

\begin{tabular}{lr}
\hline Chi-cuadrado & 26,540 \\
Gl & 7 \\
Sig.asintót. &, 000 \\
\hline
\end{tabular}

Como se puede apreciar, la prueba muestra un nivel de significación de 0,000 (Sig. $<0,05)$, lo que permite rechazar la hipótesis nula y aceptar la influencia de la variable factor aplicada a la variable estudiada P1.30 y la propia variable P1.30. Por tanto, dado que el resultado de la prueba nos lleva a aceptar la hipótesis alterna, se realiza un análisis post hoc para comprobar qué pares de facultades CAFyD difieren significativamente entre sí. La prueba de contraste aplicada es HSD Tukey (tabla 6.52) tras reconocer la igualdad de varianzas, gracias al estadístico de Levène obtenido $($ Sig. $=0,136)$. 
Tabla 6.52

Resultados del análisis post hoc entre P1.30 y la variable factor "facultades CAFyD" (comparadas de dos en dos)

$\begin{array}{lll}\text { (I) Facultad CAFyD } & \text { (J) Facultad CAFyD HSD Tukey Sig. }\end{array}$

\begin{tabular}{rll}
\hline Vic (VIC) & León (ULE) & 0,000 \\
\hline Murcia (UCAM) & León (ULE) & 0,007 \\
\hline Lleida (UDL) & León (ULE) & 0,019 \\
\hline León (ULE) & Vic (VIC) & 0,000 \\
& Murcia (UCAM) & 0,007 \\
& Lleida (UDL) & 0,019
\end{tabular}

La diferencia es significativa al nivel de .05 .

Las diferencias que se aprecian se encuentran entre la Facultad CAFyD de León (puntuación más baja obtenida) con respecto a las Facultades de Vic (Sig. HSD Tukey= 0,000), Murcia (Sig. HSD Tukey =0,007) y Lleida (Sig. HSD Tukey = 0,019), ostentando éstas las tres mejores puntuaciones alcanzadas.

La caracterización de las experiencias formativas descritas sobre el desarrollo de P1.30, se detalla en el estudio cualitativo realizado mediante la codificación aplicada al discurso de los estudiantes CAFyD y MEPEF. Se observa por lo general igual presencia de códigos que caracterizan el fenómeno para los dos grupos, aunque una menor frecuencia de evidencias explicativas para el caso del grupo de los estudiantes CAFyD (tabla 6.53). 
Tabla 6.53

Estudio comparativo entre los estudiantes MEPEF y CAFyD sobre los códigos que explican el funcionamiento de la formación recibida para el desarrollo de P1.30

MEPEF

CAFyD

\begin{tabular}{lclc}
\hline \multicolumn{1}{c}{ Código } & Enraizamiento & \multicolumn{1}{c}{ Código } & Enraizamiento \\
\hline Procedimiento & 17 & Procedimiento & 6 \\
Conflicto de & 6 & $\begin{array}{l}\text { Conflicto de } \\
\text { responsabilidades }\end{array}$ & 6 \\
responsabilidades & 6 & Formación & 4 \\
Monitoreo del profesor & 5 & Evaluación demanda & 2 \\
Prevalencia del contenido & 4 & Monitoreo del profesor & 1 \\
Evaluación demandada & 3 & Prevalencia del contenido & 1 \\
Formación & & & \\
\hline
\end{tabular}

Pero más allá del peso de los códigos en virtud de su enraizamiento en cada grupo, el estudio de las relaciones entre las citas (hipervínculos), a través de las redes semánticas, permite establecer un orden interpretativo de los datos a partir de sus características y dimensiones. A continuación, se presentan las redes semánticas en relación a los códigos presentes en los discursos de cada uno de los grupos, comenzando por el grupo de estudiantes CAFyD (figura 6.30). 


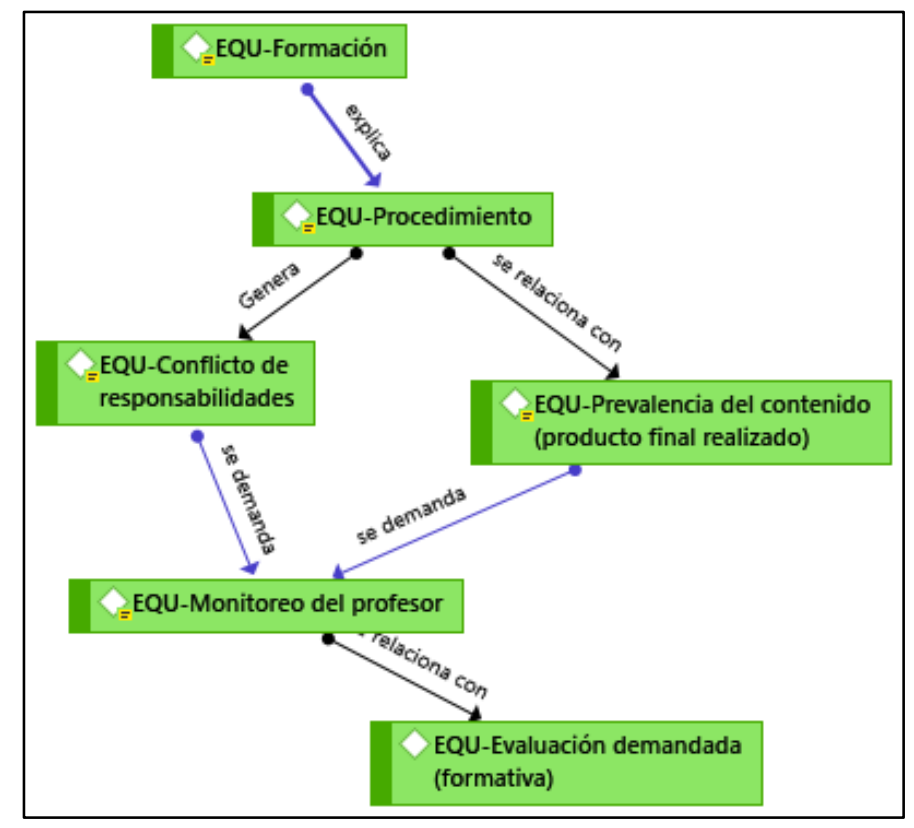

Figura 6. 30. Red semántica del grupo de estudiantes CAFyD que explica las experiencias formativas relacionadas con la adquisición y desarrollo de P1.30

Este grupo de estudiantes no considera haber recibido un modelo formativo de referencia para aprender a trabajar grupalmente (formación). Es la propia tradición y la cadencia de trabajar en grupo como metodología establecida, lo que ha impulsado y desarrollado un modelo auto-formativo con el que enfrentarse, desde la perspectiva del trabajo grupal, a dichas tareas.

\section{Grupo CAFyD (3:28)}

En general los alumnos aprenden a trabajar en equipo porque después de cuatro años haciendo trabajos grupales ya conoces a tus compañeros, has visto muchas cosas, has reconocido si te has equivocado alguna vez o deberías haberlo reconocido desde mi punto de vista.

La inexistencia de un modelo formativo explica un procedimiento básico, común, para el abordaje de la tarea encomendada, repartiendo para ello las cargas de trabajo. En el caso de los estudiantes CAFyD se reconoce que el sistema supone un reparto de tareas y de cargas de trabajo que se asume, aunque valorando que el trabajo así realizado no es realmente grupal. 
Grupo CAFyD (3:25)

Nosotros ahora que estamos en cuarto, estamos haciendo trabajos y no los estamos sabiendo hacer en grupo porque no, porque coge uno y se pone en grupo a hacerlo todo y al que le cae otro, y entonces [...], el trabajo concreto está siendo de todo menos grupal.

Grupo CAFyD (3:21)

Los trabajos lo que suele pasar siempre es que tú haces esta parte, tú esta y tú esta y luego que haya una presentación cualquiera con preguntas de cualquier cosa relacionada con tu propio trabajo.

Este procedimiento de trabajo grupal se relaciona con una preferencia, dentro del modelo de evaluación aplicado, por el contenido más que por el proceso realizado, de forma que la gestión de las tareas cumplidas por cada miembro del grupo culminan con la unión de todas ellas, conformando una producción final que es la que es solicitada por el docente para validar la superación de la materia cursada. Se reconoce que el contenido a desarrollar prevalece por encima del procedimiento puesto en marcha.

\section{Grupo CAFyD (3:40)}

Se llega una semana antes y ya se nos come el tiempo, tú haces esto, tú esto y tú esto; y verdaderamente no hay trabajo de grupo porque así va muy separado; unos hacen una cosa, otros otra y otros otra, y ha cogido uno y lo ha juntado todo, en vez de cuántas veces ha quedado el grupo para debatir, para decir vamos a hacer esto.

De la misma manera, dicho procedimiento parece genera ciertos conflictos en las relaciones interpersonales entre los miembros del grupo, relacionadas con las diferencias en las aportaciones de algunos miembros con respecto a las de otros. Este hecho, describen, queda encubierto y oculto finalmente por la propia cadencia del proceso y de presentación general de resultados, desencadenando a la larga cierta conflictividad. 
Grupo CAFyD (3:79)

Se puede ver perfectamente, haces una exposición tú solo y se ve directamente, haces un trabajo solo y también, entonces es algo que se ve perfectamente sin escudarte en otro compañero; hay cosas que son más individuales; pero lo del trabajo en equipo es una tapadera tras otra; y ese es el problema.

Se demanda consecuentemente un perfil docente que asuma tareas de supervisión y monitoreo sobre el proceso de trabajo grupal, participando activamente en el control y la gestión del proceso. Este papel más activo del docente, piensan, ayuda a integrar en el proceso de aprendizaje un modelo de evaluación más formativo para los estudiantes que ayude a la reflexión sobre el desarrollo del proceso de trabajo grupal realizado.

\section{Grupo CAFyD (3:22)}

Sería muy buena idea si, por ejemplo, tienes que hacer un trabajo y te han puesto esa fecha para dentro de un mes, dos meses; que el profesor cada semana recogiera un diario en el cual diga lo que este grupo esta semana ha hecho, esto y esto, y este componente y este se han dedicado a efectuar sobre esto y esto sobre esto, y bueno al final el profesor se está dando cuenta de quién está trabajando, y los del propio grupo también se están dando cuenta de quién está trabajando, y quién está colaborando; y yo creo que sería una manera buena de poder tener un control sobre eso.

Para el caso de los estudiantes MEPEF (Figura 6.31), se aprecia un modelo similar de trabajo grupal experimentado durante su formación al del grupo CAFyD. 


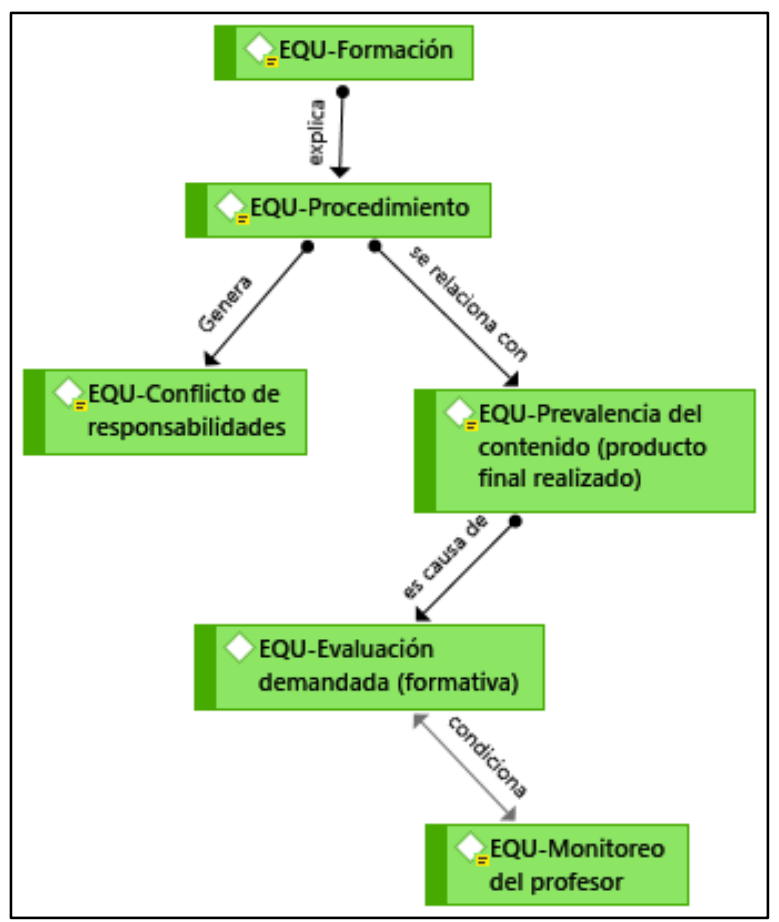

Figura 6. 31. Red semántica del grupo de estudiantes MEPEF que explica las experiencias formativas relacionadas con la adquisición y desarrollo de P1.30

La formación para aprender a trabajar en equipo es autogenerada y simple. Se fundamenta en la iniciativa para establecer unas normas de trabajo con las que fundar un grupo de trabajo y desarrollar conjuntamente una tarea común.

\section{Grupo MEPEF (3:107)}

A trabajar en grupo nadie te enseña, tú formas un grupo y con los miembros que forman ese grupo, estableces ya tus normas de trabajo.

La ausencia de formación recibida explica un procedimiento para desarrollar ese trabajo grupal, que consiste en un corta y pega a distancia, utilizando en este caso para ello la herramienta google drive, sin necesidad de la presencialidad para la realización el trabajo grupal. 
Grupo MEPEF (5:114)

Habríamos un drive común; íbamos pegando los epígrafes del trabajo y cada uno cuando pudiera, iba pegando la información que había encontrado, y luego, ya el resto, si nos daba tiempo lo leíamos y poníamos un día límite; después entre que se maquetaba e imprimía ya estaba el proceso.

Esta forma de proceder en el trabajo grupal genera ciertos conflictos de responsabilidades que se relacionan con la vivencia de situaciones de irresponsabilidad de algunos miembros de los grupos al participar en la vida grupal. Se describe la responsabilidad efectiva no asumida por algunos miembros de grupos de trabajo, lo que genera en otros miembros enfado, frustración y un sentimiento de derrota que condiciona el concepto de trabajo grupal y las propias relaciones interpersonales.

\begin{abstract}
Grupo MEPEF (3:20)
Si ya partes de que tienes en un grupo una persona irresponsable, por mucho trabajo en grupo o en equipo que quieras hacer es imposible.
\end{abstract}

\title{
Grupo MEPEF (3:41)
}

Entonces qué es trabajo en grupo, ¿ser un pringado?, ¿trabajar el doble que los demás?; es ser un pringado, es que es eso. Y sino, yo no lo veo de otra manera. A mi es una de las cosas que más me ha molestado en la carrera; el tema del trabajo en grupo, cuando trabajas con gente trabajadora, da gusto, es genial, perfecto. Pero cuando ya tienes setas, te los comes con patatas.

Además, el procedimiento de trabajo grupal que se realiza se relaciona íntimamente con la prevalencia del contenido a desarrollar y generar como fin del trabajo a realizar, que se integra en un modelo de evaluación proyectada por el docente más centrada en los resultados. De este aspecto emana la demanda de un modelo de evaluación más formativa y compartida, lo que condiciona la adopción por el docente de un rol que monitorice, guíe, supervise, medie, negocie y se interese también por el proceso y por las personas dentro del mismo (monitoreo del docente). 
Grupo MEPEF (3:34)

Yo considero que no se evalúa el trabajo en grupo, se evalúa el resultado del trabajo en grupo.

Grupo MEPEF (3:35)

Yo creo se debería, lo que decía también antes, que se consensue la nota, que se preocupe el profesor, que esté más cerca; [...] cómo os habéis organizado, qué habéis hecho, habéis quedado, y por qué no lo habéis hecho así, y por qué lo habéis decidido realizar así, y por qué, yo que sé, no sé, preguntar al grupo, al alumno.

También se aprecia una percepción de mucha ayuda formativa recibida para el desarrollo de P1.31, habilidades en las relaciones interpersonales, siendo nuevamente el valor de promedio obtenido para los estudiantes MEPEF, de $\bar{x}=2,88$, mayor que para los procedentes de CAFyD $(\bar{x}=2,61)$. Las estimaciones para la desviación típica son casi idénticas en ambos grupos $(\sigma=0,884$ y $\sigma=0,885)$.

Aplicada la prueba $U$ de Mann-Whitney (tabla 6.54) a fin de establecer si cursar una u otra titulación resultaba estadísticamente significativo en relación a la percepción de la ayuda formativa recibida para el desarrollo de (P1.31) las habilidades para las relaciones interpersonales, se confirmó que sí existen diferencias estadísticamente significativas entre los grupos $(0,000<0,05)$.

Tabla 6.54

Diferencias en la percepción de los estudiantes MEPEF y CAFyD sobre P1.31

\begin{tabular}{lccc} 
& MEPEF & CAFyD & \\
\hline $\begin{array}{l}\text { 1.31.- Grado de ayuda en el desarrollo de la } \\
\text { competencia docente: habilidades en las } \\
\text { relaciones interpersonales }\end{array}$ & $\overline{\mathrm{x}}$ & $\overline{\mathrm{x}}$ & $P$ \\
\hline
\end{tabular}

Esta diferencia es perceptible igualmente atendiendo a las facultades en las que los estudiantes cursan sus estudios (tabla 6.55). Así para los estudiantes MEPEF, a partir del ranking de facultades de educación, se observa cómo la de la Universidad de 
Córdoba es la que muestra la valoración más elevada $(\bar{x}=3,50)$, considerando sus estudiantes que allí se recibió mucha ayuda formativa para el desarrollo de P1.31. En el otro extremo se encuentra la facultad de educación de la Universidad de Sevilla con una valoración moderada sobre la ayuda formativa recibida $(\bar{x}=2,56)$

Tabla 6.55

Valores de promedio obtenidos para P1.31 en relación a la variable factor "facultades $M E P E F^{\prime \prime}$

\begin{tabular}{|c|c|c|c|c|c|}
\hline Competencia & $\begin{array}{l}\text { Facultad de } \\
\text { Educación }\end{array}$ & $\mathbf{N}$ & $\bar{x}$ & $\sigma$ & $\begin{array}{l}\text { Error } \\
\text { típico }\end{array}$ \\
\hline \multirow{12}{*}{$\begin{array}{l}\text { P1.31.- Grado de ayuda recibida } \\
\text { para el desarrollo de la } \\
\text { competencia } \\
\text { Habilidades en las relaciones } \\
\text { interpersonales }\end{array}$} & Córdoba (UCO) & 20 & 3,50 & 0,688 & 0,154 \\
\hline & Valladolid (UVa) & 44 & 3,27 & 0,624 & 0,094 \\
\hline & Segovia (UVa) & 28 & 3,25 & 0,701 & 0,132 \\
\hline & Barcelona (UB) & 30 & 3,17 & 0,648 & 0,118 \\
\hline & Granada (UGR) & 92 & 3,11 & 0,777 & 0,081 \\
\hline & Tenerife (ULL) & 34 & 3,00 & 0,888 & 0,152 \\
\hline & Murcia (UMU) & 66 & 2,92 & 0,829 & 0,102 \\
\hline & Santander (UniCan) & 64 & 2,81 & 1,125 & 0,141 \\
\hline & Madrid (UAM) & 45 & 2,80 & 0,815 & 0,121 \\
\hline & Albacete (UCLM) & 102 & 2,79 & 0,860 & 0,085 \\
\hline & Valencia (UV) & 76 & 2,78 & 0,947 & 0,109 \\
\hline & Sevilla (US) & 158 & 2,56 & 0,885 & 0,070 \\
\hline
\end{tabular}

Se establece a continuación de forma gráfica y ordenada (mayor a menor valoración), los promedios obtenidos para P1.31 en relación a las facultades MEPEF de procedencia (figura 6.32). 


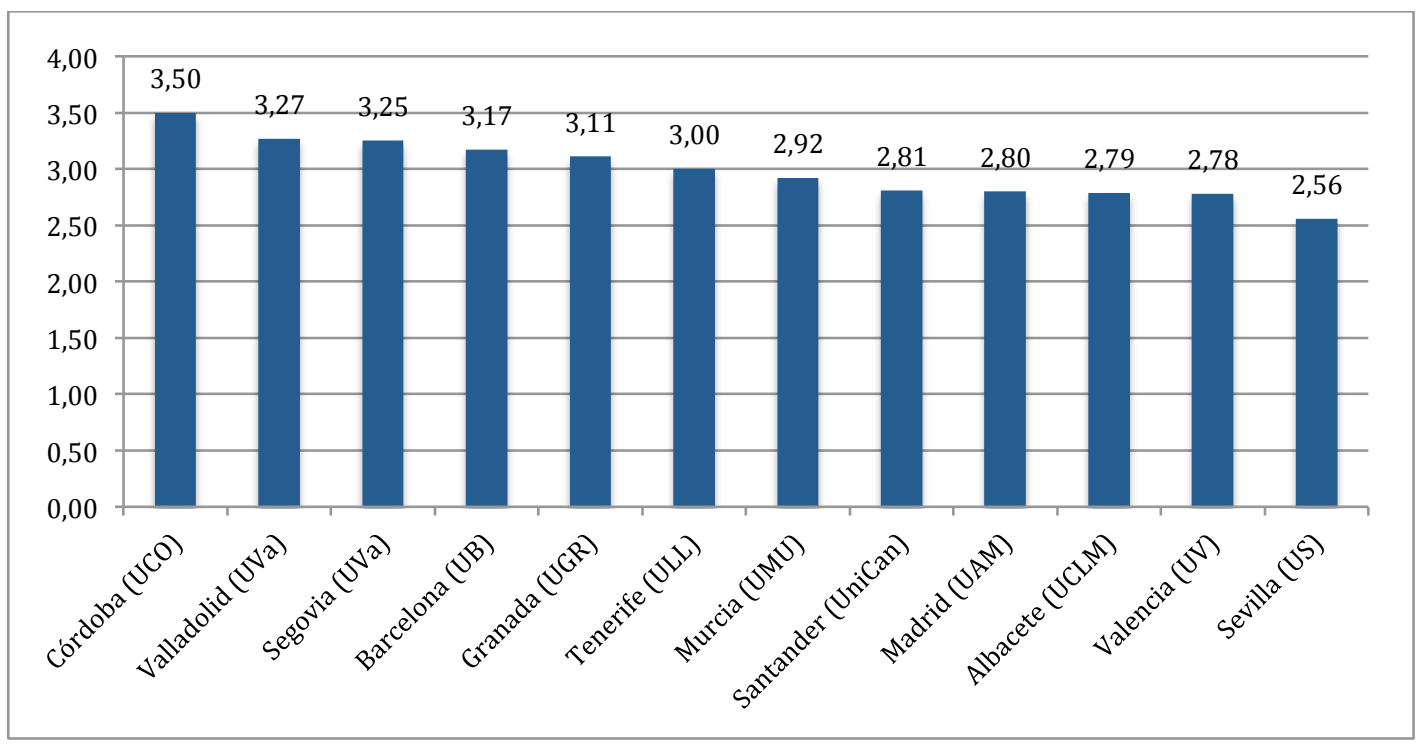

Figura 6. 32. Representación gráfica de los valores de promedio obtenidos para P1.31 en relación a la variable factor "facultades MEPEF"

Efectivamente, se observa que todos los estudiantes de las facultades revisadas valoran la ayuda formativa recibida para el desarrollo de P1.31 como considerable, salvo para el caso de la facultad de educación de la Universidad de Sevilla $(\bar{x}=2,56)$, cuyos estudiantes la valoran como moderada. Dentro del grupo de las facultades que obtienen puntuaciones elevadas $(\bar{x}>3)$, además del caso de Córdoba $(\bar{x}=3,50)$, son destacables de nuevo los casos de las facultades de educación de Valladolid y Segovia (Universidad de Valladolid) que obtienen puntuaciones elevadas y similares entre sí $(\bar{x}=3,27$ y $\bar{x}=3,25$ respectivamente), siendo consideradas por sus estudiantes como muy facilitadoras de ayuda formativa y encaminadas al desarrollo de las habilidades en las relaciones interpersonales para el ejercicio docente.

Se presenta el resultado obtenido a partir de la aplicación de la prueba KruskalWallis, a fin de conocer la influencia de la variable facultades MEPEF sobre P1.31 y si existe idéntica afección de las distintas facultades analizadas, en relación a dicha pegunta. Los resultados se observan en la tabla 6.56 . 
Tabla 6.56

Prueba Kruskal-Wallis para P1.31 y variable factor "facultades MEPEF"

P1.31 Grado de ayuda formativa recibida para el desarrollo de las habilidades en las relaciones interpersonales

Chi-cuadrado $\quad 63,972$

Gl 15

$\begin{array}{ll}\text { Sig.asintót. } & , 000\end{array}$

La prueba muestra un nivel de significación de 0,000 (Sig.<0,05). Esto supone rechazar necesariamente la hipótesis nula y, por tanto, aceptar que sí existe influencia del factor aplicado a la variable P1.31 bajo estudio y la propia variable P1.31. Por ello, dado que el resultado de Kruskal-Wallis nos ha llevado a aceptar la hipótesis alterna, se realiza un análisis post hoc, comprobando qué pares de facultades MEPEF difieren entre sí. También se aplica la prueba de Games-Howell (tabla 6.57), tras no asumir, a partir de la prueba de homogeneidad de varianzas, que estas son iguales (Sig. Lèvene = $0,001<0,05)$.

Tabla 6.57

Resultados del análisis post hoc entre P1.31 y la variable factor "facultades MEPEF" (comparadas de dos en dos)

(I) Facultad de Educación

(J) Facultad de Educación

Games-Howell Sig.

\begin{tabular}{rll}
\hline Córdoba (UCO) & Albacete (UCLM) & 0,024 \\
& Valencia (UV) & 0,001 \\
& Sevilla (US) & 0,031 \\
\hline Valladolid (UVa) & Albacete (UCLM) & 0,022 \\
\hline Segovia (UVa) & Sevilla (US) & 0,003 \\
\hline Barcelona (UB) & Sevilla (US) & 0,005 \\
\hline Granada (UGR) & Sevilla (US) & 0,000 \\
\hline Albacete (UCLM) & Córdoba (UCO) & 0,024 \\
& Valladolid (UVa) & 0,022 \\
\hline Valencia (UV) & Córdoba (UCO) & 0,031 \\
\hline Sevilla (US) & Córdoba (UCO) & 0,001 \\
& Valladolid (UVa) & 0,000 \\
& Segovia (UVa) & 0,003 \\
& Barcelona (UB) & 0,005
\end{tabular}


La diferencia es significativa al nivel de .05 .

Los resultados verifican que existen diferencias significativas entre (1) la facultad de educación de Albacete (tercera puntuación más baja obtenida) y las facultades de Córdoba (Sig. Games-Howell = 0,024) y Valladolid (Sig. Games-Howell $=0,022$ ), ambas con las dos mejores puntuaciones. (2) Entre la facultad de educación de Valencia (segunda puntuación más baja) y la de Córdoba (Sig. Games-Howell =0,031). (3) Entre la facultad de educación de Sevilla (valoración más baja obtenida) y las de Córdoba (Sig. Games-Howell = 0,001), Valladolid (Sig. Games-Howell = 0,000), Segovia (Sig. Games-Howell =0,003), Barcelona (Sig. Games-Howell =0,005) y Granada (Sig. Games-Howell=0,000).

Atendiendo a las facultades de Ciencias de la Actividad Física y del Deporte se muestran los siguientes promedios, siendo el caso de la Facultad CAFyD de la Universidad Católica de Murcia donde se obtiene la puntuación más alta $(\bar{\chi}=2,93)$ y la Facultad CAFyD de la Universidad de León, donde se obtiene el promedio más bajo $(\bar{x}=2,18)$ valorando sus estudiantes como moderada la ayuda formativa recibida para el desarrollo de P1.31 (tabla 6.58).

Tabla 6. 58 Valores de promedio obtenidos para P1.31 en relación a la variable factor "facultades CAFyD"

\begin{tabular}{llllll}
\multicolumn{1}{c}{ Competencia } & \multicolumn{1}{c}{ Facultad CAFyD } & $\mathbf{N}$ & $\bar{x}$ & $\boldsymbol{\sigma}$ & $\begin{array}{c}\text { Error } \\
\text { típico }\end{array}$ \\
\hline & Murcia (UCAM) & 54 & 2,93 & 0,866 & 0,118 \\
& Vic (VIC) & 48 & 2,90 & 0,831 & 0,120 \\
P1.31.- Grado de ayuda en el & Huesca (UNIZAR) & 35 & 2,77 & 0,808 & 0,136 \\
$\begin{array}{l}\text { desarrollo de la competencia } \\
\text { docente: habilidades en las }\end{array}$ & Sevilla (UPO) & 59 & 2,66 & 0,801 & 0,104 \\
relaciones interpersonales & Lleida (UDL) & 65 & 2,62 & 0,913 & 0,113 \\
& Vitoria-Gasteiz (UPV) & 58 & 2,33 & 0,803 & 0,105 \\
& León (ULE) & 51 & 2,18 & 0,932 & 0,130 \\
\hline
\end{tabular}


En la figura 6.33 se presenta ordenadamente (mayor a menor valoración) tales promedios obtenidos para P1.31, considerando las facultades CAFyD de procedencia de sus estudiantes y encabezando con la mejor valoración sobre la ayuda formativa recibida para su desarrollo, como se ha anunciado, la facultad CAFyD de Murcia.

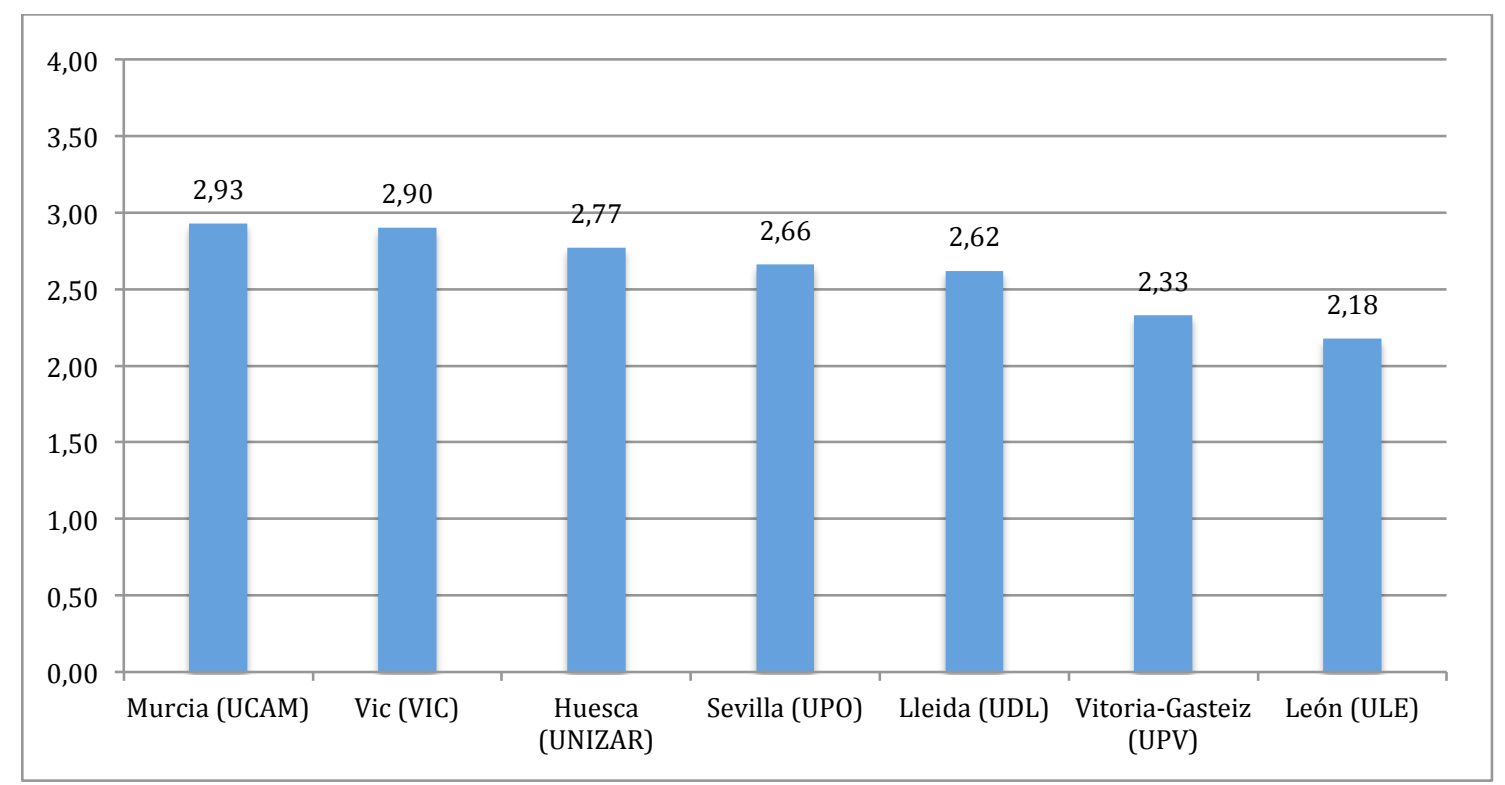

Figura 6. 33. Representación gráfica de los valores de promedio obtenidos para P1.31 en relación a la variable factor "facultades CAFyD"

A pesar de que para ninguna de las facultades CAFyD analizadas se obtienen puntuaciones de $\bar{x}>3$, cinco de las siete obtienen valoraciones que evidencian una percepción de mucha ayuda formativa recibida para el desarrollo de P1.31, a través de las asignaturas cursadas en su formación. Este es el caso de las facultades CAFyD de Murcia $(\bar{x}=2,93)$, Vic $(\bar{x}=2,90)$, Huesca $(\bar{x}=2,77)$, Sevilla $(\bar{x}=2,66)$ y Lleida $(\bar{x}=2,62)$. Las facultades de Vitoria-Gasteiz $(\bar{x}=2,33)$ y León $(\bar{x}=2,18)$ alcanzan las puntuaciones más bajas, evidenciando una percepción de sus estudiantes de una moderada ayuda formativa recibida para el desarrollo de esta competencia. El desacuerdo en las respuestas es ciertamente aceptable para la mayoría de los casos, ya que oscilan los valores de desviación típica obtenidos entre 0,801 y 0,866 , salvo para los casos de Lleida $(\sigma=0,913)$ y León $(\sigma=0,932)$, en donde se intuye cierto desacuerdo, aunque en ningún caso considerable. 
Se aplica la prueba Kruskal-Wallis (tabla 6.59), a fin de conocer si existe influencia de la variable facultades CAFyD sobre P1.31 y, con ello, saber si existe igual afección de las distintas facultades CAFyD analizadas en relación a la dicha pregunta.

Tabla 6.59

Prueba Kruskal-Wallis para P1.31 y variable factor "facultades CAFyD"

P1.31 Grado de ayuda formativa recibida para el desarrollo de las habilidades en las relaciones interpersonales

\begin{tabular}{lr}
\hline Chi-cuadrado & 36,628 \\
Gl & 7 \\
Sig.asintót. &, 000
\end{tabular}

La prueba muestra un nivel de significación de $0,000(\mathrm{Sig} .<0,05)$, rechazando con ello la hipótesis nula y aceptando la influencia de la variable factor aplicada a la variable estudiada P1.31 y la propia variable P1.31. Dado que el resultado de KruskalWallis lleva a aceptar la hipótesis alterna, se realiza un análisis post hoc para comprobar qué pares de facultades CAFyD difieren significativamente entre sí. La prueba de contraste aplicada es HSD Tukey (tabla 6.60), tras reconocer la igualdad de varianzas, mediante el estadístico de Levène $(\mathrm{Sig} .=0,688)$.

Tabla 6.60

Resultados del análisis post hoc entre P1.31 y la variable factor "facultades CAFyD" (comparadas de dos en dos)

\begin{tabular}{rlc} 
(I) Facultad CAFyD & (J) Facultad CAFyD & HSD Tukey Sig. \\
\hline Murcia (UCAM) & Vitoria-Gasteiz (UPV) & 0,006 \\
& León (ULE) & 0,000 \\
\hline Vic (VIC) & Vitoria-Gasteiz (UPV) & 0,016 \\
& León (ULE) & 0,001 \\
\hline Huesca (UNIZAR) & León (ULE) & 0,035 \\
\hline Vitoria-Gasteiz (UPV) & Murcia (UCAM) & 0,006 \\
& Vic (VIC) & 0,016 \\
\hline León (ULE) & Murcia (UCAM) & 0,000 \\
& Vic (VIC) & 0,001 \\
& Huesca (UNIZAR) & 0,035
\end{tabular}

La diferencia es significativa al nivel de .05 . 
Se aprecian diferencias significativas entre (1) la facultad CAFyD de VitoriaGasteiz (segunda puntuación más baja obtenida) y las facultades de Murcia (Sig. HSD Tukey $=0,006)$ y Vic (Sig. HSD Tukey =0,016). (2) Entre la facultad CAFyD de Léon (puntuación más baja alcanzada) y las facultades de Murcia (Sig. HSD Tukey =0,000), Vic (Sig. HSD Tukey =0,001) y Huesca (Sig. HSD Tukey =0,035).

Regresando al discurso de los estudiantes considerando las titulaciones cursadas y en relación al desarrollo de P1.31, en el grupo de los estudiantes CAFyD se observa una menor presencia de códigos (6) que explican la ayuda formativa recibida para el desarrollo de P1.31, frente al grupo de los estudiantes MEPEF (12 códigos) (tabla 6.61). Estos últimos describen de una forma más completa las habilidades interpersonales que reconocen han manejado durante su formación.

Tabla 6.61

Estudio comparativo entre estudiantes MEPEF y CAFyD sobre los códigos que explican el funcionamiento de la formación recibida para el desarrollo de P1.31

MEPEF

CAFyD

\begin{tabular}{lclc}
\hline \multicolumn{1}{c}{ Código } & Enraizamiento & \multicolumn{1}{c}{ Código } & Enraizamiento \\
\hline Interactuar/compartir & 18 & Adaptarse/ser flexible & 3 \\
Comunicarse & 16 & Colaborar & 1 \\
$\begin{array}{l}\text { Crear clima y ambiente } \\
\text { formativo }\end{array}$ & 6 & Ser honesto & 1 \\
Colaborar & 5 & Negociar & 1 \\
Actuar ante la & 5 & Ayudar & 1 \\
conflictividad & 5 & & \\
Cohesionar & 4 & & \\
Ser asertivo & 3 & & \\
Negociar & 2 & & \\
Adaptarse/ser flexible & 2 & & \\
Ayudar & 2 & & \\
Regularse emocionalmente & 2 & & \\
Tener iniciativa & & & \\
\hline
\end{tabular}


El estudio de las evidencias y las relaciones entre los códigos permite establecer redes semánticas para poder reconocer, apreciar e interpretar mejor la percepción y valoración de los estudiantes en relación a la ayuda formativa recibida para desarrollar $\mathrm{P} 1.31$. A continuación se presenta la red semántica en relación a los códigos presentes en el discurso de los estudiantes procedentes de la titulación CAFyD (figura 6.34).

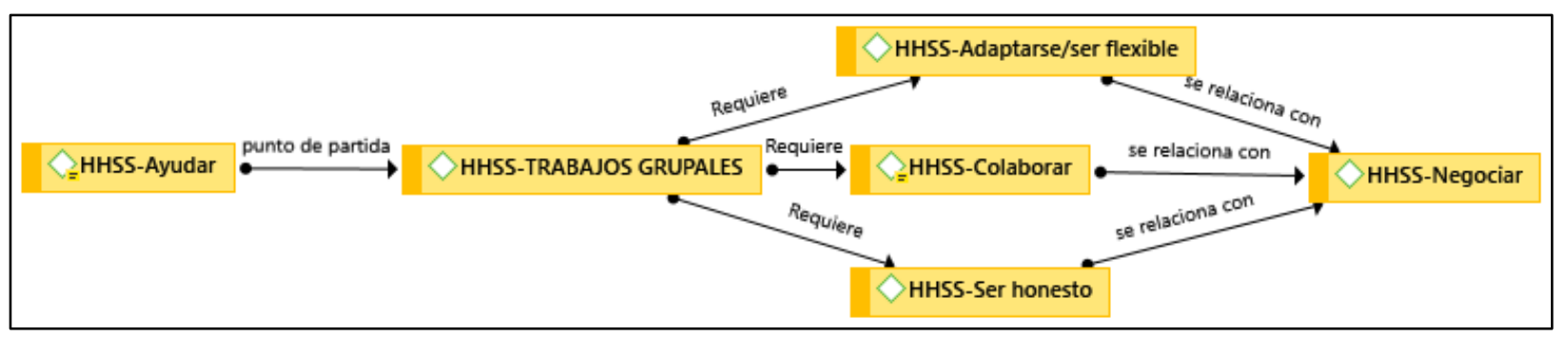

Figura 6. 34. Red semántica del grupo de estudiantes CAFyD que explora las experiencias formativas relacionadas con la adquisición y desarrollo de P1.31

Inicialmente consideran que a lo largo de los estudios cursados sí les han insistido en la necesidad de ayudarse mutuamente, con lo que se entiende que la ayuda mutua, como habilidad prosocial, está presente en su ideario de interacción de partida.

$$
\text { Grupo CAFyD (3:65) }
$$

Yo creo que por lo general sí que nos incentivan bastante en algunas clases a ayudarnos unos a otros, porque si no, perderíamos todos.

Así mismo, trabajar grupalmente se reconoce como la experiencia práctica en la que, para resolver las tareas y compromisos e interactuar unos con otros, han necesitado colaborar, ser flexibles y adaptativos, honestos, para alcanzar acuerdos (negociar).

\section{Grupo CAFyD (3:28)}

En general los alumnos aprenden a trabajar en equipo porque después de cuatro años haciendo trabajos grupales ya conoces a tus compañeros, has visto muchas cosas, has reconocido si te has equivocado alguna vez, te has autoevaluado o deberías haberlo hecho desde mi punto de vista. 
Grupo CAFyD (3:30)

Al final aprendes a obrar en grupo y a prendes a ponerte de acuerdo.

Para el caso de los estudiantes MEPEF, se aprecia mayor complejidad en la descripción de las habilidades interpersonales manejadas en las experiencias formativas y materias cursadas a lo largo de su formación. Esta complejidad (Figura 6.35) se hace presente en un mayor número de códigos presentes en su discurso y en la complejidad de relaciones entre ellos.



Figura 6. 35.Red semántica del grupo de estudiantes MEPEF que explica las experiencias formativas relacionadas con la adquisición y desarrollo de P1.31

Se reconoce que para abordar las experiencias formativas prácticas de especialización en EF, especialmente en materias como AFMN, mediante trabajos grupales y colaborativos, han necesitado del manejo de habilidades comunicativas (comunicación), dialogando, negociando, para resolver asuntos pendientes, adaptándose y flexibilizando las posiciones, y tomando la iniciativa, a fin de conseguir interactuar y colaborar de mejor forma. 
Grupo MEPEP (5:116)

Tienes que llegar a mucho entendimiento, muchas conversaciones, mucho diálogo; es que es en definitiva entenderse, porque es fundamental.

\section{Grupo MEPEF (5.5)}

La mención de educación física facilita el retomar conversaciones que se quedaron paradas durante el primer o segundo año, socializarte con los demás porque las actividades que realizamos como el senderismo, las rutas en BTT, la orientación, requieren de la colaboración, del diálogo hablando unos con otros, y pasando las actividades juntos.

\section{Grupo MEPEF (5:41)}

Hablamos de habilidades aprendidas para relacionarnos en grupos nuevos de trabajo como tener iniciativa.

También las experiencias prácticas formativas de especialización en la disciplina, de carácter expresivo corporal, reconocen, han favorecido el desarrollo de un clima y ambiente formativo positivo, seguro, de cohesión grupal y de equipo, en el que las relaciones personales se optimizan, en mayor medida que en el resto de materias cursadas, cuyo planteamiento didáctico, más convencional, no facilita tanto este aspecto.

\section{Grupo MEPEF (5.21)}

En las actividades de expresión corporal si que es verdad que hay un cambio de la primera a la última sesión, porque es cierto que al principio conoces a algunos pocos compañeros con los que habitualmente más te relacionas, y después vas participando en las actividades, te vas relacionando y dices, me siento segura, me siento cómoda, aunque te salga fatal, pero en el fondo te sientes seguro. 
Grupo MEPEF (5.9)

En expresión corporal en donde el contacto físico, la experimentación con el contacto táctil, une a las personas y se forma un clima un ambiente de clase que no se consigue con los planteamientos didácticos de otras materias cursadas, o en otras menciones.

De la misma manera, se reconoce que la forma de afrontar los trabajos grupales encomendados ha generado conflictos y diferencias interpersonales entre los miembros de los grupos, angustiándose inicialmente por no saber abordar ni resolver tales diferencias y discrepancias, pero aprendiendo a ser asertivo.

\footnotetext{
Grupo MEPEF (5.45)

Reconozco que el método que adoptamos para abordar el trabajo grupal, nos ha generado conflictos personales entre algunos miembros de los grupos al no saber gestionar las discrepancias o tener intereses diferentes.
}

Grupo MEPEF (3:121).

Eso es lo que nos agobia a todos al principio, el no saber reaccionar cuando tenemos un problema.

Grupo MEPEF (5:133).

[...] cuando empezamos los estudios permites todo, permites echarte el trabajo encima, pero llega un momento en el que aprendes a decir hasta aquí.

También la participación en las experiencias prácticas realizadas, así como en los grupos de trabajo para abordar las tareas encomendadas, ha facilitado el desarrollo de experiencias de ayuda mutua a partir del reconocimiento de los errores cometidos, para contribuir a la mejora y a la transformación. 
Grupo MEPEF (5:118).

[...] por ejemplo tu vas a exponer algo, y algo que los maestros vamos a tener que hacer es valorar y según lo que expongas, pues eso, evaluar la intervención de los compañeros; cuando alguien va a exponer un trabajo, se te da la oportunidad de valorar, de decir, ver lo que has fallado, pero claro [...] honestamente, soy tu compañero, te voy a ayudar, no te voy a decir cosas malas [...] de forma crítica te digo esto y me parecería que esto lo tendrías que cambiar.

También se reconoce que las experiencias prácticas expresivo corporales han facilitado la toma de conciencia y la regulación emocional, consiguiendo transformar un estilo de interacción a priori brusco con los demás mejorándolo.

\section{Grupo MEPEF (5:16)}

A lo mejor yo me relaciono con los demás de forma brusca y cortante y me he dado cuenta de que mis gestos o mis palabras muestran ese tipo de relación con los demás, y participando en las actividades de expresión corporal en las que el cuerpo también hace relaciones he conseguido ser más consciente y mejorar.

A modo de síntesis, se constata a partir del estudio realizado la brecha entre la ayuda formativa recibida para el desarrollo de competencias instrumentales (B1), con respecto a la prestada para el desarrollo de competencias interpersonales (B2). Se observa así un mayor grado de ayuda recibida para las segundas y por tanto una mayor percepción de desarrollo competencial al respecto.

Dentro de B1 se halló que los estudiantes consideran haber recibido menos y peores ayudas formativas especialmente para el desarrollo de las competencias conocimiento de una LE y conocimientos de informática relativos al ámbito de la EF, que para el desarrollo de otras competencias como la organización y planificación, la comunicación verbal y no verbal y análisis y síntesis, cuyos valores dan cuenta de percepciones aceptablemente moderadas. 
Atendiendo al género, son los hombres los que perciben en mejor medida que las mujeres la ayuda formativa recibida para el desarrollo de sus competencias instrumentales, aunque en cualquier caso es para ambos una ayuda formativa moderada y no se aprecian diferencias significativas entre ambos grupos al respecto. Para el caso de la competencia P1.29 conocimientos de informática relativos al ámbito de estudio, las percepciones de hombres y mujeres son bajas, siendo la valoración de los hombres sensiblemente mayor, existiendo diferencias significativas entre ambos grupos.

La competencia P1.28 conocimiento de una LE es la que recibe valoraciones más bajas en relación a la ayuda que les ha sido prestada en la formación superior cursada. Se considera así una muy poca ayuda formativa recibida desde las materias cursadas al respecto y por tanto una muy poca consideración de desarrollo competencial. No obstante son las mujeres las que realizan una valoración sensiblemente superior a la de los hombres, aunque no se aprecian diferencias significativas entre ambos grupos.

Atendiendo al tipo de estudios de EF cursados, el grupo MEPEF valora en mejor medida la ayuda formativa recibida para el desarrollo del bloque de competencias instrumentales (B1). Específicamente para el caso de la competencia P1.29 conocimientos de informática relativos al ámbito de la EF, las valoraciones de ambos grupos son ciertamente bajas, evidenciando una escasa ayuda formativa recibida para su desarrollo a través de las materias cursadas, no obstante se aprecia una percepción sensiblemente mayor para los estudiantes del grupo MEPEF aunque sin diferencias significativas con respecto al grupo CAFyD. Atendiendo a las facultades de procedencia de ambos grupos, para el caso MEPEF son la facultades de educación de las universidades de Valencia, Tenerife y Valladolid las mejor situadas en cuanto a la formación prestada al respecto. Para el caso de las facultades CAFyD son las facultades de las universidades de Murcia (UCAM) y Huesca las que obtienen mejores valoraciones en cuanto a la prestación de las ayudas formativas al respecto. 
Para el caso de P1.28 conocimiento de una LE, las valoraciones de ambos grupos son muy bajas (especialmente en el caso de los estudiantes del grupo CAFyD), mostrando así una idea de la mínima ayuda formativa recibida para su desarrollo, afectando en ambos grupos a su consideración de mínimo nivel competencial alcanzado. Atendiendo a las facultades de procedencia de ambos grupos, para el caso MEPEF son la facultades de educación de las universidades de Castilla la Mancha (Albacete), La Laguna (Tenerife) y Granada las mejor situadas en cuanto a la formación prestada al respecto. En las cinco últimas se encuentran Valladolid, Córdoba, Barcelona (UB), Madrid (UAM) y Sevilla. Para el caso de las facultades CAFyD, las de Vic y Huesca obtienen mejores puntuaciones sobre la ayuda formativa que prestan. En el extremo se encuentra la facultad CAFyD de León con una muy baja percepción de sus estudiantes en cuanto a la ayuda recibida para desarrollar esta competencia en las materias cursadas.

Dentro del bloque de las competencias interpersonales (B2) se encontró que las que mejor valoración reciben en relación a la ayuda formativa recibida para su desarrollo son las competencias P1.30 trabajo en equipo y P1.31 habilidades para las relaciones interpersonales (ambas en un grado de mucha ayuda formativa recibida). No obstante otras competencias interpersonales como el razonamiento crítico y el compromiso ético obtienen valoraciones de mucha y moderada ayuda formativa recibida.

Atendiendo al género, son las mujeres las que perciben en mayor medida que los hombres la ayuda formativa recibida para el desarrollo de B2, aunque no se consideran diferencias significativas entre ambos grupos. Para el caso de la competencia P1.30 trabajo en equipo, ambos grupos consideran haber recibido mucha ayuda formativa para su desarrollo, aunque las mujeres en mayor medida. No obstante se aprecia en ambos grupos un contraste entre los valores estadísticos (mucha ayuda formativa recibida) y los resultados cualitativos que dan cuenta de una mínima formación recibida para abordar las dinámicas de trabajo grupal experimentadas y con ello, la imposibilidad de aprender verdaderamente a trabajar en equipo. 
En relación a la competencia P1.31 habilidades para las relaciones interpersonales, hombres y mujeres consideran haber recibido mucha ayuda formativa a través de las dinámicas de las materias cursadas para su desarrollo, siendo la percepción de las mujeres al respecto mayor que la de los hombres. En ambos casos se considera por tanto muy desarrollada a partir de la formación prestada.

Considerando el tipo de estudios de EF cursados, ambos grupos consideran haber recibido mucha ayuda formativa para el desarrollo de B2, aunque en mayor medida el grupo de estudiantes MEPEF. Esta misma valoración se obtiene para el caso de la competencia para P1.30 trabajo en equipo, siendo los estudiantes MEPEF los que aprecian en mayor medida la ayuda formativa recibida para su desarrollo. En cualquier caso se aprecia un contraste en cuanto a los benevolentes resultados estadísticos obtenidos y la descrita escasa formación recibida para gestionar las experiencias de trabajo grupal, redundando en una verdadera ausencia de formación para aprender a trabajar en equipo a partir de tales experiencias. Atendiendo a las facultades de procedencia de los estudiantes, las de educación que mejores valoraciones obtienen en cuanto a la ayuda que prestan para el desarrollo de P1.30 son las de Segovia y Valladolid (UVa). Para el caso de las facultades CAFyD obtienen mejores valoraciones las de Vic y Murcia (UCAM).

Para el caso de P1.31, estudiantes MEPEF y CAFyD consideran haber recibido mucha ayuda formativa para su desarrollo, aunque la percepción del grupo MEPEF al respecto es mayor, encontrándose diferencias significativas entre ambos grupos. Estos consideran haber desarrollado habilidades interpersonales a través de las dinámicas pedagógicas de algunas materias cursadas como comunicarse, negociar, adaptarse y ser flexible, ser asertivo en situaciones de conflicto, ayudar, contribuir a la cohesión grupal y regularse emocionalmente. Las facultades de educación de Córdoba y Valladolid obtienen valoraciones mayores sobre la ayuda prestada para el desarrollo P1.31. Para el caso de las facultades CAFyD obtienen mejores valoraciones las de Murcia (UCAM) y Vic. 


\subsection{Conocer si existe una relación entre el uso de metodologías activas y la presencia de la evaluación formativa respecto de la percepción de desarrollo de competencias que tienen los estudiantes tras su formación.}

A fin de conocer las posibles relaciones entre el uso de las metodologías activas y sistemas de evaluación formativa y la percepción de ayuda formativa recibida para la adquisición de competencias transversales (instrumentales e interpersonales) durante las asignaturas cursadas, se aplicó el coeficiente de correlación de Spearman (tabla 6.62).

Tabla 6.62

Relación entre el uso de metodologías activas y utilización de evaluación formativa y la percepción de ayuda formativa recibida para el desarrollo de las competencias instrumentales e interpersonales

Métodos y evaluación

Instrumentales Interpersonales

La utilización de metodologías activas en las asignaturas cursadas en tus estudios te han ayudado a adquirir competencias transversales

$0,291 * *$

$412 * *$

La utilización de la evaluación formativa y continua en las asignaturas cursadas en la carrera te han ayudado a adquirir competencias transversales

$0,346^{* *} \quad 0,449 * *$

$* \mathrm{P}<0,05 * * \mathrm{P}<0,001$

En las correlaciones obtenidas (no muy notables), se observa que sí existe una relación directa entre el uso de metodologías activas durante las asignaturas cursadas en la formación. Para el caso de la relación con las competencias instrumentales, se observa una correlación débil $(\mathrm{r}<0.300)$, pero para el caso de la adquisición de las competencias interpersonales, se aprecia una correlación mayor $(\mathrm{r}=0,412 ; \mathrm{P}<0,001)$ que cobra sentido para este tipo de competencias, que requieren de una importante participación e implicación de los estudiantes durante el proceso de su adquisición y desarrollo.

De la misma manera, se obtuvo un coeficiente de correlación poco notable entre la percepción de utilidad de la evaluación formativa y su valoración como ayuda formativa para la adquisición de competencias transversales durante la formación cursada, no obstante sí existe una relación directa entre ambas $(r>0,400 ; \mathrm{P}<0,001)$. Se 
observa cómo para las competencias interpersonales la correlación con el uso de la evaluación formativa es mayor $(\mathrm{r}=0,449 ; \mathrm{P}<0,001)$ que para las instrumentales $(\mathrm{r}=0,346 ; \mathrm{P}<0,001)$. Posiblemente unas correlaciones poco notables se relacionen con la dificultad de evaluar de forma puntual este tipo de competencias que, por lo general, su adquisición y desarrollo se muestra en la acción y de forma procesual cuando el alumnado se desempeña durante la ejecución. No obstante, parece que sobre todo para las competencias de carácter interpersonal, el uso de un sistema de evaluación formativa sí podría jugar un papel relevante en la evaluación de la adquisición y su desarrollo.

Para las cuatro competencias transversales objeto de revisión en el presente trabajo, grado de ayuda recibida para el desarrollo de P1.28 conocimiento de una lengua extranjera, P1.29 conocimientos de informática relativos al ámbito de estudio, P1.30 trabajo en equipo, P1.31 habilidades en las relaciones interpersonales, se buscó igualmente el grado de correlación mediante el coeficiente de Spearman, sobre la utilización de metodologías activas y modelos de evaluación formativa en las asignaturas cursadas (tabla 6.63). 
Tabla 6.63

Relación entre el uso de metodologías activas y utilización de evaluación formativa y la percepción de ayuda formativa recibida para el desarrollo de P1.28, P1.29, P1.30 y $P 1.31$

P1.28. grado de ayuda recibida

para el

conocimiento de

una LE
P1.29, grado de ayuda recibida

para el conocimiento

de informática

relativos al

ámbito de

estudio
P1.30, grado de ayuda recibida para el desarrollo del trabajo en equipo
P1.31, grado de ayuda recibida para el desarrollo de las habilidades

en las relaciones interpersonales

La utilización de metodologías activas en las asignaturas cursadas en tus estudios te han $0,115^{* *}$ $0,192 * *$ $0,267 * *$ $0,337^{* *}$ ayudado a adquirir competencias transversales

La utilización de la evaluación formativa y continua en las asignaturas cursadas en la $0,152 * *$ $0,254 * *$ $0,267 * *$ $0,397^{* *}$ carrera te han ayudado a adquirir competencias transversales

$* \mathrm{P}<0,05 * * \mathrm{P}<0,001$

Como se puede apreciar, se observan relaciones directas aunque débiles $(\mathrm{r}<0,300)$ entre el uso de metodologías activas y modelos de evaluación formativa y la percepción de ayuda formativa recibida para desarrollar sus competencias P1.28, P1.29 y P1.30. Algo más directa y positiva se aprecia la correlación obtenida para el caso de $\mathrm{P} 1.31(\mathrm{r}=0,337 ; \mathrm{P}<0,001)$. Se puede considerar que el desarrollo de las habilidades interpersonales requiere del uso de estrategias metodológicas activas así como de modelos de evaluación compartida y formativa, en la medida en que es necesaria la participación e implicación activa y consciente del alumnado, debiendo aplicar en situaciones reales de interacción tales habilidades, para relacionarse entre si, emprender proyectos y tareas compartidas y solucionar problemas. 
Los resultados procedentes del análisis de los datos cualitativos revelan, de forma similar, una mayor relación directa entre las metodologías activas aplicadas en su formación a lo largo de las asignaturas cursadas, así como de modelos de evaluación formativa y continua y la percepción como ayudas para desarrollar P1.30. Tales metodologías se relacionan con la participación en proyectos de trabajo, en donde se debe colaborar para atender todos los aspectos que permiten desarrollar un proyecto de interés para todos, que en el caso que describen, en relación al desarrollo de materias como AFMN, requieren responsabilizarse de gestionar no solo los aspectos didácticos de preparación de las actividades físicas en la naturaleza, sin también atender a los ámbitos preparatorios, administrativos, económicos y de previsión y adquisición de recursos de forma colaborada.

Se formaban grupos, cada grupo se encargaba de organizar una actividad compartida, claro, es que es evaluación formativa y continua; tú tienes que llamar al autobús y contratar al autobús, llamar al albergue, no sé qué, al final lo estás haciendo tú, estás aprendiendo haciendo, que es de lo que se trata (3:150).

De la misma manera se observan varias coocurrencias entre métodos activos relacionados con la participación en grupos de trabajo, colaborando y cooperando entre sí y la activación, para ello, de diversas habilidades interpersonales (P1.31) como la interacción, la colaboración, la comunicación y la negociación para llegar a acuerdos.

Al trabajar en equipo las relaciones interpersonales están integradas, pero al hacer los grupos aleatoriamente, es cuando más las podemos trabajar [...] esta competencia sobre todo la hemos trabajado en la mención en la asignatura de medio natural y le convivir juntos y en expresión corporal a la hora de estar interactuando entre nosotros constantemente $(5: 1)$.

En síntesis, se observa por tanto la presencia de metodologías activas en la formación cursada y sobre todo su uso parece se relaciona con el desarrollo de 
competencias más de tipo interpersonal. Se entienden las metodologías activas como aquellas que favorecen la implicación y la participación de los estudiantes, con lo que cobra sentido que sean las competencias interpersonales las que se desarrollen en mayor medida. Particularmente para el caso de P1.31 habilidades para las relaciones interpersonales es evidente la relación entre el uso de metodologías activas y su desarrollo. Habilidades como la comunicación, la ayuda mutua, la asertividad, la negociación, la interacción se activan en la medida en que están presentes en las dinámicas formativas de las materias (en este caso en clave metodológica). Los planteamientos de aprendizaje basados en proyectos y en dinámicas de trabajos grupales en materias y actividades relacionadas con las AFMN activan y desarrollan estas habilidades sociales.

La utilización de evaluación formativa durante la formación cursada revela una mayor relación de esta con respecto al desarrollo de competencias interpersonales más que instrumentales. Específicamente su uso parece nuevamente correlacionar en mayor medida con P1.31.

\subsection{Conocer si existe una relación entre el uso de los instrumentos de evaluación utilizados respecto de la percepción de desarrollo de competencias que tienen los estudiantes tras su formación.}

Respecto de las correlaciones existentes entre los instrumentos de evaluación utilizados durante las asignaturas cursadas y la percepción de ayuda formativa recibida para el desarrollo de las dos competencias instrumentales objeto de estudio, para P1.28, conocimiento de una LE, se aprecia que los instrumentos de evaluación que se relacionan de una forma más notable con la percepción de desarrollo competencial al respecto, son el uso de exámenes orales $(\mathrm{r}=0,320 ; \mathrm{P}<0,001)$, el uso de portafolios $(\mathrm{r}=0,268 ; \mathrm{P}<0,001)$ y la observación del profesor en clase $(\mathrm{r}=0,247 ; \mathrm{P}<0,001)$. En correlación negativa se observan el uso del examen tipo test y la generación de informes y trabajos escritos. 
Este tipo de instrumentos permiten valorar de una forma más intensa y profunda la adquisición, dominio y uso de las destrezas lingüísticas en situaciones interactivas y dialógicas, creando significados para comunicarse, condiciones esenciales para la adquisición y desarrollo de una LE. Contrariamente, fórmulas más tradicionales como el examen tipo test o la creación de informes y trabajos escritos no responden a las expectativas de adquisición de P1.28 (tabla 6.64).

Tabla 6.64

Relación entre los instrumentos de evaluación y la percepción de ayuda formativa recibida para el desarrollo de P1.28

\section{Instrumentos de evaluación}

Exámenes orales

Portafolios

Observación del profesor en clase (fichas de observación)

Ensayos a partir de textos escritos o materiales audiovisuales

Exámenes escritos dejando disponer de documentos

Proyectos de aprendizaje tutorados

El control de la participación en el aula (en grupos y debates)

Examen de preguntas cerradas (definiciones)

Examen de preguntas abiertas

Pruebas prácticas de carácter físico (ejercicios físicos, situaciones de juego,...)

Cuadernos de campo (o fichas de sesiones prácticas)

Examen de preguntas cortas (explicaciones breves)

Examen tipo test

Informes y trabajos escritos

\section{P1.28. Grado de ayuda} recibida para el conocimiento de una $\mathrm{LE}$

$* \mathrm{P}<0,05 * * \mathrm{P}<0,001$

Cualitativamente, a partir de la exploración de coocurrencia de códigos (tabla 6.65), se obtuvieron correlaciones muy similares a las descritas anteriormente, especialmente entre tres instrumentos de evaluación. 
Tabla 6.65

Coocurrencia de códigos sobre los instrumentos de evaluación y la percepción de ayuda formativa recibida para el desarrollo de P1.28

P1.28. Grado de ayuda recibida para el conocimiento de una

strumentos de evaluación

LE

Evidencias

Coeficiente de correlación

\begin{tabular}{lcc}
\hline $\begin{array}{l}\text { Exámenes/Exposiciones } \\
\text { orales }\end{array}$ & 4 & 0,14 \\
$\begin{array}{l}\text { Informes/trabajos } \\
\text { escritos }\end{array}$ & 1 & 0,03 \\
\hline
\end{tabular}

Como se aprecia, se hace alusión a dos instrumentos de evaluación empleados durante la formación recibida como son el examen oral o exposición en clase que evidencia la soltura conversacional y los trabajos escritos (mínimamente) que muestran la capacidad para escribir en el idioma extranjero.

Asignaturas en las que al final te toca rellenar ejercicios en inglés, ese es el resumen $(5: 49)$

[...] eso sí que se puede ver perfectamente, haces una exposición tú solo y se ve directamente, haces un trabajo y también, entonces es algo que se ve perfectamente $(3: 161)$.

Se muestran a continuación (tabla 6.66) los resultados obtenidos en relación a las correlaciones de Spearman encontradas entre los instrumentos de evaluación utilizados en las materias cursadas y la adquisición de P1.29, conocimientos de informática aplicada al ámbito de estudio. 
Tabla 6.66

Relación entre los instrumentos de evaluación y la percepción de ayuda formativa recibida para el desarrollo de P1.29

\section{P1.29 Grado de ayuda recibida para el conocimiento de informática aplicados al ámbito de estudio}

Instrumentos de evaluación

\begin{tabular}{lc}
\hline Exámenes orales & $0,272^{* *}$ \\
$\begin{array}{l}\text { Ensayos a partir de textos escritos o materiales } \\
\text { audiovisuales }\end{array}$ & $0,252^{* *}$ \\
Proyectos de aprendizaje tutorados & $0,234^{* *}$ \\
Exámenes escritos dejando disponer de documentos & $0,224^{* *}$ \\
Observación del profesor en clase (fichas de observación) & $0,219^{* *}$ \\
$\begin{array}{l}\text { El control de la participación en el aula (en grupos y } \\
\text { debates) }\end{array}$ & $0,186^{* *}$ \\
Portafolios & $0,174^{* *}$ \\
Cuadernos de campo (o fichas de sesiones prácticas) & $0,172^{* *}$ \\
Examen de preguntas cerradas (definiciones) & $0,164^{* *}$ \\
Examen de preguntas abiertas & $0,157^{* *}$ \\
Pruebas prácticas de carácter físico (ejercicios físicos, \\
situaciones de juego,...)
\end{tabular}
$* \overline{\mathrm{P}<0,05 * * \mathrm{P}<0,001}$

Para P1.29 parece que la utilización de instrumentos como los exámenes orales $(\mathrm{r}=0,272 ; \mathrm{P}<0,001)$, el uso de ensayos a partir de textos escritos o materiales audiovisuales $(\mathrm{r}=0,252 ; \mathrm{P}<0,001)$ o los proyectos de aprendizaje tutorados $(\mathrm{r}=0,234$; $\mathrm{P}<0,001)$ correlacionan positiva y directamente con la percepción de ayuda formativa recibida para su adquisición. Contrariamente el uso de exámenes tipo test parece no favorece tal adquisición. Considerando que no hay un solo nivel de desarrollo en el manejo de las TIC, sino que existen diversos niveles que van reclutando diversas capacidades, toman sentido modelos de evaluación en donde la comunicación está presente, y que permiten descubrir la adquisición y el grado de desarrollo que alcanza el estudiante. 
De forma muy relacionada, los resultados de orden cualitativo permiten apreciar ciertas correlaciones (tabla 6.67) entre, específicamente, la utilización de un instrumento de evaluación como es el control de la participación en el aula mediante el desarrollo de trabajos grupales y debates y su valoración como ayuda para desarrollar P1.29.

Tabla 6.67

Coocurrencia de códigos sobre los instrumentos de evaluación y la percepción de ayuda formativa recibida para el desarrollo de P1.29

\begin{tabular}{lcc}
\multicolumn{1}{c}{$\begin{array}{c}\text { Instrumentos de } \\
\text { evaluación }\end{array}$} & $\begin{array}{c}\text { P1.29. Grado de ayuda recibida para el conocimiento de } \\
\text { informática aplicado al ámbito de la EF }\end{array}$ \\
\cline { 2 - 3 } & Evidencias & Coeficiente de correlación (CC) \\
\hline $\begin{array}{c}\text { Control de la participación } \\
\text { en el aula (TG y debates) }\end{array}$ & 2 & 0,12 \\
\hline
\end{tabular}

Se enseña la utilización de una herramienta tecnológica y se evalúa su uso en la realización de trabajos, cuyo resultado (un producto audiovisual, una página web, un blog, wiki) es finalmente valorado.

Hemos tenido una asignatura orientada específicamente a las nuevas tecnologías y a través de ella hemos conocido un poco más este mundo, teniendo que hacer trabajos sobre wikis, blogs y vídeos $(5: 31)$.

Esa asignatura de TICs fue en primero y me acuerdo que realizamos un vídeo sobre una vivencia de nuestra vida $(5: 93)$.

En relación a las dos competencias interpersonales objeto de análisis del presente trabajo, se presentan a continuación los resultados de la correlación de Spearman aplicado, a fin de establecer como correlaciona la percepción de ayuda formativa recibida para su adquisición con respecto a los instrumentos de evaluación utilizados en la formación inicial de los estudiantes a partir de las asignaturas cursadas. 
Para P1.30, la ayuda formativa recibida se relaciona positivamente, aunque no de forma notable, con la realización de informes y trabajos escritos $(\mathrm{r}=0,218 ; \mathrm{P}<0,001)$ y también con el control de la participación en el aula mediante tareas en grupo y debates $(\mathrm{r}=0,216 ; \mathrm{P}<0,001)$. Es lógico pensar que los instrumentos que facilitan la participación y la interacción en el aula (control de la participación en el aula mediante la realización de los trabajos grupales) así como la realización de informes y trabajos escritos, permiten observar las capacidades que se aúnan para ese trabajo, siendo esa tarea grupal la forma de apreciar sus capacidades y habilidades al respecto (tabla 6.68). Igualmente se observa una relación directa, si bien débil, respecto al uso de las pruebas prácticas de carácter físico, por ejemplo las situaciones de juego, como forma de favorecer formativamente la adquisición y desarrollo de P1.30, especialmente cuando exige de la colaboración y la cooperación entre equipos para alcanzar juntos un objetivo común.

Tabla 6.68

Relación entre los instrumentos de evaluación y la percepción de ayuda formativa recibida para el desarrollo de $P 1.30$

P1.30 Grado de

Instrumentos de evaluación ayuda recibida para el desarrollo del trabajo en equipo

\begin{tabular}{lc}
\hline Informes y trabajos escritos & $0,218^{* *}$ \\
El control de la participación en el aula (tareas en grupos y debates) & $0,216^{* *}$ \\
Ensayos a partir de textos escritos o materiales audiovisuales & $0,194^{* *}$ \\
Portafolios & $0,185^{* *}$ \\
Proyectos de aprendizaje tutorados & $0,178^{* *}$ \\
Cuadernos de campo (o fichas de sesiones prácticas) & $0,150^{* *}$ \\
Pruebas prácticas de carácter físico (ejercicios físicos, situaciones & $0,108^{* *}$ \\
de juego,...) & $0,098^{* *}$ \\
Examen de preguntas abiertas & $0,088^{* *}$ \\
Examen de preguntas cortas (explicaciones breves) & $0,079^{* *}$ \\
Observación del profesor en clase (fichas de observación) & $0,071^{* *}$ \\
Examen de preguntas cerradas (definiciones) & 0,045 \\
Exámenes escritos dejando disponer de documentos & 0,031 \\
Examen tipo test & 0,009 \\
Exámenes orales &
\end{tabular}

$* \mathrm{P}<0,05 * * \mathrm{P}<0,001$ 
La información cualitativa obtenida a partir de la herramienta coocurrencia de códigos (tabla 6.69), revela de forma similar correlaciones positivas y directas, si bien no demasiado notables, entre instrumentos como el control de la participación en clase mediante el desarrollo de tareas en grupo $(\mathrm{CC}=0,21)$, la realización de informes y trabajos escritos $(\mathrm{CC}=0,13)$ y la observación del profesor en clase $(\mathrm{CC}=0,16)$.

\begin{abstract}
Yo también lo que he estado viendo en las clases, se juntan los grupos y trabajan, y el profesor observa, y cuando entregan el resultado final, él que ha observado pone una nota, y si ha estado bien, unos han estado trabajando más y otros han estado trabajando menos, tú tienes tal nota y tú tienes cual otra (3:173).
\end{abstract}

En la asignatura de expresión corporal, cuando teníamos que hacer los informes semanales de contenidos por cada tema trabajado, todos asumíamos un rol, no me acuerdo muy bien [...] entonces cada uno se encargaba pues de un poco de que el trabajo saliera adelante y cada uno cumplía sus cometidos (5:24).

Tabla 6.69

Coocurrencia de códigos sobre los instrumentos de evaluación y la percepción de ayuda formativa recibida para el desarrollo de P1.30

\begin{tabular}{ccc}
$\begin{array}{c}\text { Instrumentos de } \\
\text { evaluación }\end{array}$ & $\begin{array}{c}\text { P1.30. Grado de ayuda recibida para desarrollo del } \\
\text { trabajo en equipo }\end{array}$ \\
\cline { 2 - 3 } & Evidencias & Coeficiente de correlación (CC)
\end{tabular}

El control de la participación en el aula (tareas en grupos y debates)

Informes/trabajos escritos

7

0,21

Observación del profesor en clase

4,13
4
0,16

Finalmente se observan, en relación a la percepción de desarrollo de P1.31, habilidades en las relaciones interpersonales, correlaciones directas respecto a los instrumentos de evaluación utilizados en las materias cursadas como son los proyectos de aprendizaje tutelado $(\mathrm{r}=0,257 ; \mathrm{P}<0,001)$ y el control de la participación en el aula mediante tareas grupales y debates $(\mathrm{r}=0,232 ; \mathrm{P}<0,001)$. También existe una correlación directa, aunque débil $(\mathrm{r}=0,160 ; \mathrm{P}<0,001)$, en relación al uso de pruebas de carácter 
físico como la participación en situaciones de juego y el desarrollo de las habilidades para las relaciones interpersonales, pues en situaciones de interacción y comunicación social es en donde se requiere de la práctica de estas habilidades para regular estos procesos, entenderse, trabajar en equipo, resolver problemas y conflictos llegar a acuerdos y negociar (tabla 6.70).

Tabla 6.70

Relación entre los instrumentos de evaluación y la percepción de ayuda formativa recibida para el desarrollo de $P 1.31$

Instrumentos de evaluación

P1.31 Grado de ayuda recibida para el desarrollo

las habilidades en las relaciones interpersonales

Proyectos de aprendizaje tutorados

$0,257 * *$

El control de la participación en el aula (en grupos y

debates)

$0,232 * *$

Ensayos a partir de textos escritos o materiales audiovisuales

$0,228 * *$

Portafolios

$0,226^{* *}$

Cuadernos de campo (o fichas de sesiones prácticas)

$0,214^{* *}$

Observación del profesor en clase (fichas de observación)

$0,191^{* *}$

Pruebas prácticas de carácter físico (ejercicios físicos,

situaciones de juego,...)

$0,160 * *$

Examen de preguntas cortas (explicaciones breves)

$0,154 * *$

Exámenes orales

$0,152 * *$

Examen de preguntas abiertas

$0,143^{* *}$

Informes y trabajos escritos

$0,124 * *$

Examen de preguntas cerradas (definiciones)

$0,118^{* *}$

Exámenes escritos dejando disponer de documentos

$0,099 * *$

Examen tipo test

$0,008 * *$

$* \mathrm{P}<0,05 * * \mathrm{P}<0,001$

De forma pormenorizada la observación de coocurrencia de códigos, a partir de los datos cualitativos, permitió observar dentro de los instrumentos de evaluación analizados, cuáles podrían tener una relación más estrecha y de qué forma, en cuanto apoyo formativo, con respecto al desarrollo de algunas de las habilidades para las 
relaciones interpersonales (P1.31) descritas por los participantes. Las correlaciones si bien son directas no pueden ser consideradas como notables.

Así, se puede observar desde los resultados cualitativos (tabla 6.71) cómo instrumentos de evaluación como las exposiciones orales se consideran una ayuda formativa para el desarrollo de la capacidad de interactuar y compartir $(\mathrm{CC}=0,15) \mathrm{y}$ también en menor medida, de adaptación y flexibilidad a nuevas formas de participación $(\mathrm{CC}=0,13)$. De forma similar el control de la participación en clase mediante la realización de tareas grupales coocurre con la capacidad de interactuar y compartir $(\mathrm{CC}=0,10)$ pero no con adaptarse y ser flexible.

Mis primeras exposiciones fueron un caos, casi traumáticas en primero de carrera, pero creo que las experiencias de exponer en público me han ayudado a relajarme, a relacionarme mejor con personas que a priori no conocía de nada $(5: 102)$.

Mediante los trabajos en grupo, las exposiciones que hemos hecho en la que nuestros compañeros eran nuestros alumnos y otras situaciones, han generado un aumento en nuestras relaciones interpersonales y generalmente en el compañerismo (5:2).

Hemos desarrollado diferentes tipos de exposiciones orales y cambiado los grupos de trabajo regularmente. De esta manera teníamos que adaptarnos a la forma de trabajar de otras personas, a otras maneras de pensar (5:128) 
Tabla 6.71

Coocurrencia de códigos sobre los instrumentos de evaluación y la percepción de ayuda formativa para el desarrollo de P1.31

P1.31. Grado de ayuda recibida para el desarrollo las habilidades en las relaciones interpersonales

Instrumentos de evaluación

\begin{tabular}{cccc}
\hline \multicolumn{2}{c}{ Interactuar } & \multicolumn{2}{c}{ Adaptarse/ser flexible } \\
\hline Evidencias & $\begin{array}{c}\text { Coeficiente de } \\
\text { correlación (CC) }\end{array}$ & Evidencias & $\begin{array}{c}\text { Coeficiente de } \\
\text { correlación (CC) }\end{array}$
\end{tabular}

\begin{tabular}{|c|c|c|c|c|}
\hline Exposiciones orales & 4 & 0,15 & 2 & 0,07 \\
\hline $\begin{array}{l}\text { El control de la } \\
\text { participación en el aula } \\
\begin{array}{l}\text { (tareas en grupos } \\
\text { debates) }\end{array}\end{array}$ & 3 & 0,10 & & \\
\hline
\end{tabular}

En resumen, los instrumentos de evaluación que mejor correlacionan con las competencias de tipo instrumental son los exámenes orales, el uso del portafolios y la propia observación del docente en clase. Cobran sentido si se piensa en P1.28 conocimiento de una LE, que requiere del desarrollo de procesos de interacción y comunicación haciendo uso de la LE, con lo que exámenes orales, presentaciones y exposiciones son fórmulas muy útiles que contribuyen a su desarrollo.

Para el caso de P1.29, conocimientos de informática relativos al ámbito de especialización, son nuevamente los exámenes orales, los ensayos a partir de textos escritos o materiales audiovisuales y los proyectos de aprendizaje tutorado, los instrumentos que parece mejor favorecen su desarrollo, dado que activan la comunicación y el diálogo con el docente o entre el propio estudiantado. Este es el caso además del control de la participación en el aula a través de trabajos grupales y debates, que parece también se relaciona con la adquisición y desarrollo de esta competencia.

Para el caso de competencias interpersonales como P1.30 trabajo en equipo, la realización de informes y trabajos escritos junto con el control de la participación en el aula mediante el desarrollo de trabajos grupales y debates, facilitan la participación y la implicación de los estudiantes, activando las habilidades que implican colaborar y cooperar y con ello aprender a trabajar juntos, en equipo. 
Para el caso de P1.31 habilidades para las relaciones interpersonales, los proyectos de aprendizaje tutorado, el control de la participación en el aula mediante la realización de trabajos grupales así como la utilización de exposiciones orales, suponen instrumentos de evaluación para aprender a interactuar con los demás y compartir, así como aprender a flexibilizar posiciones y ser adaptativo, capacidades necesarias para el desarrollo de relaciones sociales y de la convivencia.

\subsection{Conocer si existe una relación entre las formas de calificación utilizadas respecto a la percepción de desarrollo de competencias que tienen los estudiantes tras su formación.}

Respecto a las relaciones entre las formas de calificación y la formación recibida para el desarrollo de la competencia instrumental P1.28 conocimiento de una LE (tabla 6.72), se observan correlaciones débiles pero directas para todas las formas de calificación participativas, especialmente para la calificación a partir de la coevaluación entre compañeros $(\mathrm{r}=0,268 ; \mathrm{P}<0,001)$. Este hecho, se explica con cierta lógica, en la medida en que una mayor interacción mediante el uso de situaciones interactivas y dialógicas facilita en la práctica, la toma de conciencia sobre los errores cometidos y un mejor anclaje por tanto de los aprendizajes.

Tabla 6.72

Relación entre la forma de calificar y la percepción de ayuda formativa recibida para desarrollar P1.28

P1.28. Grado de ayuda

Forma de calificación

recibida para el

conocimiento de una

LE

\begin{tabular}{lc}
\hline $\begin{array}{l}\text { Se califica a partir de la coevaluación, entre compañeros } \\
\text { (parcial o totalmente) }\end{array}$ & $0,268^{* *}$ \\
$\begin{array}{l}\text { El alumnado se autocalifica (parcial o totalmente) } \\
\text { Se califica a partir de la autoevaluación (total o parcialmente) }\end{array}$ & $0,245^{* *}$ \\
$\begin{array}{l}\text { Se califica de forma dialogada y consensuada, entre } \\
\text { profesorado y alumnado (parcial o totalmente) }\end{array}$ & $0,230^{* *}$ \\
La calificación la decide el profesor a partir de la evaluación & 0,14 \\
\hline
\end{tabular}

$* \mathrm{P}<0,05 * * \mathrm{P}<0,001$ 
El análisis de los datos cualitativos a partir del estudio de coocurrencia de códigos revela que la forma de calificación experimentada por el alumnado en relación a P1.28 no es participada y es, por tanto, el docente quien decide la calificación a partir de la evaluación realizada $(\mathrm{CC}=0,33)$, reclamando estos otra forma de calificación distinta a la procedente de la heteroevaluación mediante examen (tabla 6.73).

Se aprende de otra manera y no haciendo ejercicios que los haces todos iguales, ni aprendiendo de memoria; te suelto el rollo en el examen y ya he aprobado sacando un cinco $(3: 132)$.

Tabla 6.73

Coocurrencia de códigos sobre la forma de calificación y la percepción de ayuda recibida formativa para desarrollar $P 1.28$

P1.28. Grado de ayuda recibida para el conocimiento

Formas de calificación de una $L E$

\begin{tabular}{lcc}
\cline { 2 - 3 } & Evidencias & Coeficiente de correlación (CC) \\
\hline $\begin{array}{l}\text { Decidida por el profesor a } \\
\text { partir de la evaluación }\end{array}$ & 3 & 0,33 \\
\hline
\end{tabular}

Para P1.29, conocimientos de informática aplicada al ámbito de estudio, se observa en relación a las formas de calificación dispuestas en las asignaturas cursadas, correlaciones directas pero débiles en todas las formas participativas (tabla 6.74), destacándose aquellas a partir de la coevaluación entre compañeros $(\mathrm{r}=0,272 ; \mathrm{P}<0,001)$ y a partir de la autoevaluación $(\mathrm{r}=0,236 ; \mathrm{P}<0,001)$. Formas que permiten por ejemplo el intercambio de información con los demás, beneficiando la exploración, aprendizaje y aplicación de los recursos y dispositivos digitales aprendidos. 
Tabla 6.74

Relación entre la forma de calificar y la percepción de ayuda formativa recibida para desarrollar P1.29

P1.29. Grado de ayuda recibida para el

Forma de calificación conocimiento

informática aplicada al ámbito de la EF

Se califica a partir de la coevaluación, entre compañeros (parcial o totalmente)

$0,272 * *$

$0,236^{* *}$

$0,225 * *$

El alumnado se autocalifica (parcial o totalmente)

$0,206^{* *}$ y alumnado (parcial o totalmente)

La calificación la decide el profesor a partir de la evaluación

0,04

$* \mathrm{P}<0,05 * * \mathrm{P}<0,001$

El estudio cualitativo revela que se trata de un modelo de calificación dialogada con el profesorado la forma que se utiliza habitualmente para el desarrollo de P1.29 (tabla 6.75).

Tabla 6.75

Coocurrencia de códigos sobre la forma de calificar y la percepción de ayuda formativa recibida para desarrollar P1.29

P1.29. Grado de ayuda recibida para el conocimientos

Formas de calificación de informática aplicada al ámbito de la $\mathbf{E F}$

\begin{tabular}{lcc}
\cline { 2 - 3 } & Evidencias & Coeficiente de correlación (IC) \\
\hline Dialogada con el profesor & 3 & 0,18
\end{tabular}

En algunos casos como el aprendizaje y manejo de Apps aplicadas a materias como AFMN, parece que es el profesorado quien enseña sobre el terreno, permite la práctica y el manejo de estas en la propia acción y valora su uso y aplicación en diálogo y comunicación con el alumnado. 
Hemos tenido la suerte de tener un profesor de educación física en el medio natural que investigaba el tema de las TIC's, nos enseñaba cantidad de programas y herramientas que aplicábamos con su ayuda en las actividades en la naturaleza $(3: 139)$.

Se presentan a continuación los resultados de la correlación de Spearman que dan cuenta de las relaciones entre las formas de calificación aplicadas a las asignaturas cursadas en cuanto apoyos formativos útiles para el desarrollo de las competencias interpersonales P1.30, trabajo en equipo y P1.31, habilidades en las relaciones interpersonales.

Para el caso del desarrollo de P1.30 (tabla 6.76), las correlaciones encontradas en relación a las formas de calificación aplicadas en su formación no dan cuenta de correlaciones aceptables. Todas son muy débiles $(r<1)$ aunque directas y positivas. Trabajar en equipo supone la inmersión activa en procesos grupales para alcanzar objetivos comunes mediante la realización de diversas tareas. Para ello, se activan diversas capacidades que evolucionan en la medida en que cambia también el propio equipo. Adquiere sentido que el desarrollo de esta competencia parta de ejercicios de autoevaluación y de autocalificación sobre la participación de uno mismo en situación, pues se requiere de la responsabilidad personal para el entendimiento y participación en los procesos interactivos que subyacen en el trabajo en equipo. 
Tabla 6.76

Relación entre la forma de calificar y la percepción de ayuda formativa recibida para desarrollar P1.30

P1.30. Grado de ayuda

Forma de calificación

recibida para el

desarrollo del trabajo

en equipo

Se califica a partir de la autoevaluación (total o parcialmente)

$0,084^{* *}$

El alumnado se autocalifica (parcial o totalmente)

$0,075 *$

Se califica a partir de la coevaluación, entre compañeros (parcial o totalmente)

$0,074^{*}$

La calificación la decide el profesor a partir de la evaluación

$0,070^{*}$

Se califica de forma dialogada y consensuada, entre profesorado y alumnado (parcial o totalmente)

0,011

$* \mathrm{P}<0,05 * * \mathrm{P}<0,001$

No obstante, a partir del análisis de coocurrencia de códigos realizado (tabla 6.77) se verifica también que las formas de calificación centradas en el docente a partir de la evaluación de productos elaborados, es relacionada con el desarrollo de P1.30 aunque de forma parcial, no atendiendo al proceso de trabajo grupal realizado, considerando esto ciertamente problemático.

Ese yo creo que es el problema, que a través del trabajo en grupo quieren evaluar otra serie de contenidos, otra serie de competencias, entonces, al final, el trabajo en grupo no lo están teniendo en cuenta, desde mi punto de vista (3:42).

Tabla 6.77

Coocurrencia de códigos sobre la forma de calificar y la percepción de ayuda formativa recibida para desarrollar P1.30

P1.30. Grado de ayuda recibida para el desarrollo del trabajo en equipo

Formas de calificación

Evidencias $\quad$ Coeficiente de correlación (CC)

Decidida por el profesor a partir de la evaluación

4

3 compañeros 
Otra de las formas de calificación que se reconoce como apoyo formativo para el desarrollo de P1.30 es la realizada a partir de la coevaluación entre compañeros, aunque no exenta de dificultades por cuestiones de falta de honestidad y responsabilidad personal.

En expresión corporal por ejemplo, teníamos fichas en las que teníamos que reflejar las reuniones que habíamos ido, quien había faltado, quien no, y la gente no es honesta (3:156).

Finalmente la tabla 6.78, muestra los resultados de las relaciones entre las formas de calificación presentes en su formación y su percepción como ayuda formativa para desarrollar P1.31, habilidades en las relaciones interpersonales. Se observan unas correlaciones que, si bien son positivas y directas en las formas participativas de calificación, su puntuación es débil $(\mathrm{r}<200)$. Se aprecia una relación negativa en cuanto a la calificación decidida por el profesor a partir de la evaluación.

Las fórmulas se acercan más bien hacia ejercicios de autocalificación y calificación a partir de la coevaluación y la autoevaluación dado el territorio socioemocional en el que se manejan. 
Tabla 6.78

Relación entre las formas de calificar y la percepción de ayuda formativa recibida para desarrollar P1.31

P1.31. Grado de ayuda recibida para

Forma de calificación el desarrollo de las habilidades en las relaciones interpersonales

El alumnado se autocalifica (parcial o totalmente) $0,181^{* *}$

Se califica a partir de la coevaluación, entre compañeros (parcial o totalmente)

$0,159 * *$

Se califica a partir de la autoevaluación (total o parcialmente)

$0,158 * *$

Se califica de forma dialogada y consensuada, entre profesorado y alumnado (parcial o totalmente)

$0,143^{* *}$

La calificación la decide el profesor a partir de la evaluación

$-0,010$

$* \mathrm{P}<0,05 * * \mathrm{P}<0,001$

Las correlaciones reveladas en el estudio cualitativo evidencian que la calificación a partir de la coevaluación entre compañeros parece correlacionar (aunque no de forma notable) con una consideración de ayuda formativa para desarrollar sus habilidades interpersonales, especialmente en lo referente a sus capacidades adaptativa $\mathrm{y}$ de ayuda (tabla 6.79), que facilitan el reconocimiento del error para mejorar. No obstante se reconocen verdaderas dificultades y resistencias para aprovechar las oportunidades de intercambio de información de unos para con otros a fin de desarrollar esas mejoras.

[...] en TAFAD conseguíamos un clima de clase, además desde un principio siempre nos evaluábamos y nos decíamos los fallos y no había ningún problema; sin embargo, en la universidad, en alguna ocasión ha pasado, y como dijeras algo malo, “eh!, por qué has dicho eso!", cuando en realidad estás haciendo una crítica para que la otra persona mejore (3:63). 
Tabla 6.79

Coocurrencia de códigos sobre las formas de calificación y la percepción de ayuda formativa recibida para desarrollar P1.31 y sus capacidades de adaptarse y ayudarse

P1.31. Grado de ayuda recibida para el desarrollo las habilidades en las relaciones interpersonales

Formas de

\begin{tabular}{|c|c|c|c|}
\hline \multicolumn{2}{|c|}{ Adaptarse } & & udarse \\
\hline Evidencias & $\begin{array}{c}\text { Coeficiente de } \\
\text { correlación }(\mathrm{CC})\end{array}$ & Evidencias & $\begin{array}{l}\text { Coeficiente de } \\
\text { correlación }(\mathrm{CC})\end{array}$ \\
\hline
\end{tabular}

Desde la

$1 \quad 0,08$

2

0,22

compañeros

También parece que la calificación a partir de la autoevaluación correlaciona directa (aunque débilmente) con la consideración de ayuda recibida para desarrollar habilidades como la comunicación y la colaboración, ayudando también a tomar conciencia para cambiar y mejorar (tabla 6.80).

Tabla 6.80

Coocurrencia de códigos sobre las formas de calificación y la percepción de ayuda formativa recibida para desarrollar P1.31 y sus capacidades de comunicar y colaborar

P1.31. Grado de ayuda recibida para el desarrollo las habilidades en las relaciones interpersonales

\begin{tabular}{lcccc} 
Formas de & \multicolumn{2}{c}{ Comunicar } & \multicolumn{2}{c}{ Colaborar } \\
\cline { 2 - 5 } & Evidencias & $\begin{array}{c}\text { Coeficiente de } \\
\text { correlación (CC) }\end{array}$ & Evidencias & $\begin{array}{c}\text { Coeficiente de } \\
\text { correlación (CC) }\end{array}$ \\
\cline { 2 - 5 } & 1 & 0,08 & 2 & 0,22 \\
\hline partir de la & & & &
\end{tabular}

Pienso que he mejorado mucho mi comunicación no verbal a la hora de expresarme; es verdad que no te das cuenta hasta que no te ves y en las grabaciones de video que se hicieron sobre nuestra práctica docente en expresión corporal, yo me vi y recuerdo las dos exposiciones con sorpresa sobre mi forma de expresarme que tengo, valorándome positivamente por la evolución (5:17). 
Finalmente parece que la calificación dialogada con el profesor favorece el desarrollo de la capacidad de pedir ayuda para resolver los conflictos grupales (tabla 6.81), realizar el seguimiento de las tareas que responsablemente se han asumido en el grupo de trabajo, activándose mediante la comunicación y el diálogo, otras habilidades como la de negociación, permitiendo justificar y argumentar cada uno las actuaciones realizadas.

\begin{abstract}
Yo he tenido este problema, no nos ponemos de acuerdo entre nosotros, no conseguimos solucionarlo y queremos trabajar por separado. Ahí, ese profesor a quien se le está contando llama a todas las partes implicadas para decir, bueno, qué ha pasado aquí; (...) es buen ejemplo para enseñar a un maestro, intentar mediar y si no se puede solucionar, pues no se soluciona, pero ahí el profesor está hablando con los integrantes, evaluando con ellos el trabajo grupal, quien quiere ponerse de acuerdo y buscar soluciones, quien no $(3: 1)$.
\end{abstract}

Tabla 6.81

Coocurrencia de códigos sobre la forma de calificar y la percepción de ayuda formativa recibida para desarrollar P1.31 en sus capacidades de negociar y pedir ayuda

P1.31. Grado de ayuda recibida para el desarrollo las habilidades en las relaciones interpersonales

Formas de

\begin{tabular}{|c|c|c|c|}
\hline \multicolumn{2}{|c|}{ Negociar } & & ir ayuda \\
\hline Evidencias & $\begin{array}{l}\text { Coeficiente de } \\
\text { correlación }(\mathrm{CC})\end{array}$ & Evidencias & $\begin{array}{l}\text { Coeficiente de } \\
\text { correlación (CC) }\end{array}$ \\
\hline
\end{tabular}

Dialogada y

consensuada

2

0,20

1

0,11

profesor alumno

En resumen, sobre las formas de calificación, se observa para el caso de P1.28, conocimiento de una LE, que formas de calificación participadas, como la calificación a partir de la coevaluación entre compañeros, aunque débilmente, sí se considera una ayuda formativa para su desarrollo. No obstante esta preferencia contrasta con la información cualitativa obtenida en donde se revela también una funcionalidad parcial de la calificación decidida por el profesor a partir de la evaluación de las tareas encomendadas. 
En relación a P1.29, conocimientos de informática aplicados al ámbito de estudio, son las formas de calificación a partir de la coevaluación entre compañeros y a partir de la autoevaluación, las que se consideran en cierta medida que ayudan en su desarrollo. También el estudio cualitativo revela la fórmula de calificación dialogada con el docente. En definitiva todas estrategias de calificación participadas.

En el caso de las competencias interpersonales, para P1.30, trabajo en equipo, las fórmulas de calificación a partir de la autoevaluación y de la autocalificación activan aspectos de responsabilidad individual que favorecen su adquisición y desarrollo. No obstante los resultados cualitativos revelan que existe una realidad evaluadora en la que es el docente quien decide la calificación a partir de la evaluación de los resultados de las tareas (grupales) encomendadas (aunque no de los procesos, aspecto que como se ha visto anteriormente, se reclama) o también la aplicada a partir de experiencias de coevaluación entre compañeros.

Finalmente, para el caso de P1.31 son formas de calificación que se consideran apoyo formativo para su adquisición y desarrollo, la autocalificación, la calificación a partir de la coevaluación y la autoevaluación. Así la calificación a partir de la coevaluación entre compañeros y de la autoevaluación se relaciona con el desarrollo de habilidades interpersonales como la adaptación y la prestación de ayuda, junto con la comunicación y la colaboración. Finalmente, también se aprecia una relación entre la calificación dialogada y consensuada con el docente y el desarrollo de capacidades como pedir ayuda ante situaciones desfavorables, dialogar y negociar, comunicando, argumentando y justificando. 


\section{DISCUSIÓN}

Se discuten en este capítulo, orientado a través de las preguntas de investigación, los aspectos más esclarecedores sobre la ayuda formativa recibida durante la FIPEF para el desarrollo de las competencias instrumentales e interpersonales de los estudiantes. Así mismo sobre el uso de las metodologías activas y la evaluación formativa, instrumentos de evolución y sistemas de calificación y su relación con el desarrollo de las mencionadas competencias.

\section{1 ¿Cuál es la percepción de los estudiantes de Educación Física sobre la ayuda formativa recibida durante su formación para el desarrollo de sus competencias instrumentales (B1), desde la perspectiva de género y de la titulación cursada?}

A partir de los resultados obtenidos, se ha observado una importante diferencia en la percepción de los estudiantes sobre el desarrollo de sus competencias instrumentales, menos desarrolladas en función de la formación recibida, especialmente para el caso del conocimiento de una lengua extranjera y el conocimiento de informática aplicado al ámbito de estudio (la EF), frente a otras frecuentemente más desarrolladas como algunas interpersonales como el trabajo en equipo y las habilidades para las relaciones interpersonales. Estas estimaciones coinciden con otras similares en las que se evidencia esta brecha entre las competencias de tipo instrumental frente a las de tipo interpersonal (Álvarez, Iglesias y García, 2008; Conchado y Carot, 2013; Gutiérrez, Hortigüela, Peral y Pérez-Pueyo, 2018; Martínez, Martín-González, GarcíaPeñalvo y Cruz-Benito, 2018). Esta brecha, ya estaba presente en los estudios de Gallardo (2006) en el que el $87 \%$ de los estudiantes encuestados valoraban no haber desarrollado nada la competencia para la LE, sin embargo alrededor del $80 \%$ reconocían haber desarrollado entre bastante y mucho la competencia para trabajar en equipo. De la misma manera, se encuentran semejanzas en este sentido con los resultados de los trabajos de Marín-Díaz, Latorre-Medina y Blanco-Encomienda (2010), Pazo-Haro y Tejada-Mora (2012) Romero, Castejón, López-Pastor y Fraile (2017) y Martínez y González (2019) en los que es frecuente que estos dos grupos de competencias y las 
cuatro mencionadas contenidas en ellas, muestren posiciones tan antagónicas mostradas en las valoraciones de los estudiantes.

En relación a la competencia conocimiento de una lengua extranjera se observa la debilidad de su adquisición tras los estudios cursados, permaneciendo esta competencia entre el ranking de las analizadas en la posición más deficitaria, valorando los estudiantes una pobreza formativa recibida para su desarrollo, aspecto igualmente presente en los estudios de Clemente y Escribá (2013), Gallardo (2006), Jiménez et al. (2007), Mir (2007), Mora (2003) y Muñoz-Cantero et al. (2014). De acuerdo con De la Maya y Luego (2015) y Jóver et al. (2016) un probable relación con la escasa carga de créditos destinada para su formación en el cómputo total de sus estudios, está reduciendo tanto el desarrollo del conocimiento de la LE como lo relacionado con la formación didáctica, no cualificando suficientemente a los docentes especialistas en otras disciplinas distintas a la LE.

En relación al género, los resultados del estudio realizado muestran la inexistencia de diferencias significativas entre hombres y mujeres, no obstante se aprecia en la percepción de estas últimas una valoración sobre la formación recibida al respecto, que aun siendo muy baja, es mayor que la del grupo de los hombres. En relación a cómo aprenden la LE en su formación, ambos grupos coinciden en una misma percepción sobre el tipo de actividades desarrolladas para hacerlo, más bien del tipo no comunicativas (Harmer, 2007), en donde el trabajo autónomo y la gramática tienen mayor peso. La necesidad del trabajo de aspectos gramaticales, escritura, ejercicios de repetición y autocorrección, traducción, uso del diccionario, se considera esencial para la adquisición de una LE tal y como apuntan Eslami-Rasekh y Valizadeh (2004) y González et al. (2015), siendo necesario diseñar y desarrollar en el aula actividades del tipo comunicativo, prácticas, significativas para los estudiantes y suficientemente motivantes y aplicables a contextos reales, como así indican Dörnyei (2003), Harmer (2007) y el MCEL (2001). Parece haber, a partir de los resultados obtenidos, una mayor tendencia hacia la inclusión en la formación del profesorado de EF de un modelo formativo de corte más tradicional (Brown, 2007), muy similar a los dispuestos en etapas formativas anteriores, arrastrando quizás por ello déficits 
formativos que parece no se resuelven, más bien todo lo contrario, se cronifican (Jiménez, 2004; Madrid, 2002).

En relación a dimensiones como la compresión y expresión oral, los hombres reconocen déficits en su adquisición y manejo y acuden, como alternativa para reforzar la debilidad formativa, a otras actividades extra académicas, en donde aseguran la presencia de actividades interactivas de comunicación. Este aspecto, recurrente para ambos sexos en el trabajo de Cortina (2011), también muestra déficits para la comprensión y expresión oral en opinión de ambos grupos encuestados. La forma de afrontar la formación se realiza esencialmente mediante estrategias de memorización y compensación (Oxford, 1990, 1993) especialmente entre los hombres. Se observan coincidencias en este sentido con los resultados de García y Jiménez (2015), en donde los estudiantes hombres aplicaban estrategias más bien del tipo metacognitivas y sobre todo de compensación del tipo social, buscando ayudas para enmendar su déficit de conocimientos o pidiendo ayuda al docente para solventar sus problemas.

A partir de las dificultades encontradas durante la formación cursada, ambos grupos consideran no haber recibido la ayuda necesitada para superar los estándares previstos, valorando la poca funcionalidad del modelo formativo recibido $\mathrm{y}$ considerando en parte por ello, poseer un nivel bajo de competencia adquirida, especialmente en la comprensión y expresión oral. Este aspecto es coincidente con los resultados de Cantón et al. (2013) y Jiménez (2004), cuyos estudiantes mostraban también niveles bajos de dominio competencial sobre el esperado, lo que como en la situación de estudio, les dificulta para desenvolverse y comunicarse por ejemplo en contextos internacionales de interacción.

En relación a la titulación cursada, los resultados obtenidos revelan para ambos grupos, una deficiente ayuda formativa recibida para el desarrollo de la LE, pero mostrándose además, que la valoración más baja al respecto se da en el caso de la titulación CAFyD. En cualquier caso, sí se observa una diferencia estadísticamente significativa entre ambos grupos, lo que nos hace pensar en la influencia de la titulación 
en la ayuda prestada para el desarrollo de esta competencia. Desde las titulaciones, sobre la forma de aprender una LE los estudiantes MEPEF revelan que es fundamentalmente la memorización la estrategia que aplican para aprender a partir de actividades (fundamentalmente) no comunicativas, dispuestas en las materias cursadas; no obstante, se reconoce haber participado en otro tipo de actividades interactivas, como las exposiciones orales, pero que afrontan igualmente desde la memorización, dada la falta de soltura que reconocen sufren para la expresión oral en la LE. Este aspecto es contrario al mostrado por García y Jiménez (2015), en el que los estudiantes MEPEF encuestados no hacían uso en tanta medida de la memorización y sí de estrategias metacognitivas y de compensación, hecho también presente en los resultados de los trabajos de Clark y Trafford (1995), Griffiths (2003) y Lee y Oxford (2008), en los que la memorización es una estrategia usada pero de forma compensada con otras cognitivas. En nuestro caso parece que el uso de la memorización para superar los obstáculos formativos en relación al conocimiento de una LE, así como las dificultades en la expresión y comunicación oral, redundan en un grado de autoconocimiento de insuficiente nivel alcanzado, en contraste con el exigido y esperado por las estancias académicas y profesionales, aspecto recogido igualmente en Gómez et al. (2014), Jiménez (2004) y Madrid (2002).

Los estudiantes CAFyD reconocen un déficit formativo tras cursar las asignaturas dispuestas para el conocimiento y uso de una LE, en consonancia con los resultados de los trabajos de Romero et al. (2017) y ANECA (2005b). Consideran que aprenden en la universidad de la misma forma que lo hicieron en etapas educativas pasadas, arrastrando dificultades que no hacen base en su formación. No obstante, consideran que si bien podrían alcanzar y certificar el nivel exigido conforme el MCEL, continúan sin conseguir adquirir ni desarrollar las habilidades comunicativas propias de dicho nivel (Gómez et al., 2014). Este hecho lleva consigo cierta percepción de no funcionalidad de la formación recibida en relación al esfuerzo realizado y conforme al modelo pedagógico recibido, de ahí que se desprenda cierto halo de desmotivación y de fracaso en su participación durante el proceso de aprendizaje, aspectos también presentes en los trabajos de Cortina (2011) y Saravia y Bernaus (2008). 
Finalmente, los estudiantes MEPEF parecen conscientes de la necesidad de resolver sus debilidades comunicativas al respecto, asumiendo la urgencia de participar en experiencias formativas de inmersión lingüística en otros países, sabedores de la necesidad de adquirir estos dominios como la base necesaria para su inserción laboral en centros educativos bilingües, tal y como consideran Cuervo et al. (2013). En la actualidad, existe una creciente presencia de centros bilingües en el mapa educativo nacional y, ya forma parte de la función docente, conocer y aplicar diversas estrategias didácticas para la enseñanza integrada de los contenidos propios del área de EF, mediante el uso de una LE (Nunan y Lam, 1998).

A partir de los resultados obtenidos, para la competencia conocimientos de Informática aplicada al ámbito de la $E F$, se observa que continúa siendo una de las menos desarrolladas en la formación inicial del profesorado de EF, aspecto que coincide con las percepciones generales que se encontraron para los estudiantes de formación del profesorado en Raposo-Rivas et al.(2006), Romero et al. (2017) y Sarceda-Gorgoso y Rodicio-García (2018). Contrariamente, para los estudiantes encuestados por San Nicolás et al. (2012), se percibía una mayor percepción de conocimientos adquiridos y dominio de su competencia digital a partir de los estudios cursados.

Los déficits encontrados contrastan, sin embargo, con las cada vez más emergentes experiencias en las que el profesorado de EF en ejercicio hace uso de las herramientas TIC especializadas aplicadas a la EF y a la actividad física (Arévalo, 2016; Castellano y Casamichana, 2014; Dorado y Gewerc, 2017; Edison et al., 2013; López, 2018; Pérez y Pérez, 2013; Quintero et al., 2018). Esto muestra una gran importancia de la aplicación didáctica de recursos tecnológicos a la gestión del área y que favorablemente parece se va adquiriendo en la formación continua que el profesorado realiza durante su vida profesional (Prat et al., 2014), acortando así paulatinamente la brecha digital y potenciando la aplicación de la tecnología a la realidad del aula de EF. 
Atendiendo al género, a pesar de las diferencias encontradas, ambos grupos reconocen en mayor medida que la formación cursada tiene fundamentalmente un carácter instrumental, básicamente de uso de dispositivos, recursos digitales y equipos informáticos convencionales y programas para el procesamiento de la información, que ya se conocen pero que en la formación cursada se insiste en su tratamiento; este aspecto está presente también en los trabajos de Almerich (2005), Cabero y Llorente (2006) y Gisbert et al. (2011) con estudiantes y profesores de EF, en donde tanto hombres como mujeres presentan un nivel de usuario normal en el uso de procesadores de texto, sistema operativo y hojas de cálculo a partir de la formación recibida. Se muestra en ellos, además, como en el caso en estudio, una insistencia en las materias cursadas sobre los recursos básicos TIC que los estudiantes parece ya portan al acceder a la universidad, demandando estos, al respecto, la apertura de otros espacios formativos para incorporar las herramientas aprendidas o resolver las dudas sobre su manejo y potencialidad de aplicación.

También hombres y mujeres reconocen haber recibido cierta formación tecnológica especializada, de potencial uso educativo, como la referida a la creación de contenidos digitales (webquest) o al manejo de herramientas de geolocalización relacionadas con las AFMN experimentadas durante su formación, valorando ambos, en alguna medida, sus posibilidades para utilizar y desarrollar particularmente en la EF escolar. Los estudiantes hombres encuestados reconocen que, aun habiendo recibido cierta formación tecnológica especializada, demandan un mayor esfuerzo desde la formación superior para enseñar el manejo de herramientas y App para incorporar específicamente al contexto docente, justificando su demanda en los posibles beneficios para los aprendizajes de su futuro alumnado. Este aspecto también está presente en el pensamiento de los estudiantes hombres encuestados por Cózar et al. (2014) y Gabarda et al. (2017), quienes, aún sabiendo manejar herramientas tecnológicas especializadas, reconocen necesitar de una mayor capacitación tecnológica como docentes en formación.

Contrariamente García et al. (2012) y Gutiérrez et al. (2010), en su trabajos con estudiantes de EF, encontraron que tanto mujeres como hombres, habiendo aprendido el 
uso de herramientas tecnológicas de creación de contenidos o de creación de podcast, App especializadas o programas educativos, consideraban una escasa aplicación de estas a la práctica docente o, como en el caso de Gabarda et al. (2017), no se sentían suficientemente preparados para crear contenidos digitales.

En relación a los escenarios formativos, en el presente estudio, los estudiantes hombres perciben que el Practicum es un lugar de descubrimiento, observación y comprobación de la potencialidad educativa de las herramientas tecnológicas aprendidas. Este aspecto es recogido también por Sarceda-Gorgoso y Rodicio-García (2018), encontrando sus estudiantes que las prácticas formativas en los centros escolares suponen un potencial escenario de adquisición y desarrollo de competencias tecnológicas y en la interacción con el tutor, otra fuente más de aprendizaje en situación de realidad.

En cuanto a las titulaciones, los dos grupos muestran valoraciones muy bajas sobre la formación recibida para el desarrollo de su competencia tecnológica, aunque no en clave de diferencias significativas entre ambas. No sucede lo mismo en los resultados del estudio de Romero et al. (2017), quienes sí encontraron diferencias estadísticamente significativas, obteniendo para el caso de los estudiantes MEPEF una puntuación sensiblemente superior. Los estudiantes CAFyD reconocieron la necesidad de recibir una formación tecnológica más allá del uso instrumental de los dispositivos tecnológicos, considerando que esta debería tener un sentido más especializado, percepción coincidente con la de los estudiantes del mencionado estudio y expresando la necesidad de ser formados en la utilización específica de las posibilidades TIC, más que en el mero aprendizaje de conocimientos informáticos, que por otro lado también se reconoce e insta desde el Libro Blanco del título en CAFyD (ANECA, 2005b).

Los estudiantes MEPEF consideran que los conocimientos tecnológicos básicos atendidos en la universidad ya se poseen, percepción coincidente con las conclusiones presentes en el trabajo de Pino y Soto (2010), y que dan cuenta de la necesidad de actualización constante de dicha formación, para satisfacer las necesidades específicas 
derivadas de la función docente, aspecto también presente en el Libro Blanco del título MEPEF (ANECA, 2005a), cuando se insta a la formación tecnológica para ser potencialmente aplicada a las actividades de enseñanza y aprendizaje en el aula de primaria. Además, a pesar de considerar cierta formación tecnológica recibida aplicable a las funciones docentes en el aula, no la reciben específicamente para la gestión didáctica del área de EF. Encuentran en ello un hándicap dado que además su plan de estudios evidencia una escasa formación teórico-práctica específica al respecto (Balanskat et al., 2006), hecho que no favorece el desarrollo de su competencia tecnológica tal y como apunta Zabalza (2011).

En cualquier caso, parece que para la formación del profesorado de EF se demanda un planteamiento de desarrollo tecnológico que atienda a dimensiones más allá del uso instrumental de las herramientas, valorando su potencial para optimizar otras dimensiones que permitan expresarse, comunicar, producir creativamente, así como difundir información, haciendo uso de variados dispositivos y App, con diferentes lenguajes y formas, que mejor contribuyan a optimizar la docencia del área tal y como muestran también Adell y Castañeda (2012), Arévalo (2016) y Gewerc et al. (2011).

Esta situación, siguiendo a Vilcazan et al. (2017), parece que se relaciona con la propia naturaleza del nacimiento de las herramientas tecnológicas, entornos virtuales de aprendizaje, herramientas y App para la gestión educativa de los conocimientos, pensadas más para el desarrollo de aprendizajes cognitivos que para los físico-motrices característicos del área. Esto requiere de un esfuerzo adaptativo por parte de los docentes para buscar la aplicación de tales herramientas a los contenidos prácticos de EF. Aún así, esto parece va cambiando por ejemplo en el aula de EF en educación primaria y secundaria al introducir el videojuego y los exergames en el tratamiento de los contenidos de EF tal y como muestran los trabajos de Edison et al. (2013) y Dorado y Gewerc (2017). Es por ello que las herramientas tecnológicas específicas aprendidas en la formación superior no son observadas por los estudiantes de EF en magisterio como útiles para la especialización del área, al no encontrar la aplicabilidad directa para el tratamiento de lo corporal en los contextos escolares (Pino y Soto, 2010) y como en el presente estudio, teniendo sentido demandarlas. 


\section{2 ¿Cuál es la percepción de los estudiantes de Educación Física sobre la ayuda formativa recibida durante su formación para el desarrollo de sus competencias interpersonales (B2), desde la perspectiva de género y de la titulación cursada?}

Como en el caso en estudio, son diversos los trabajos que muestran un desarrollo formativo superior de competencias interpersonales al del resto de competencias, especialmente en lo referente a las dos competencias de referencia, trabajo en equipo y habilidades en las relaciones interpersonales (Alonso, 2008; Carot et al., 2011; Pérez, 2007; Romero et al., 2011; Hamodi et al., 2018).

Para el caso del trabajo en equipo, se muestra su importancia en la formación cursada, reconociendo los estudiantes participantes en el estudio una muy elevada percepción de su desarrollo. Se evidencia, por tanto, y extensiblemente en el colectivo docente universitario la importancia que otorgan a esta competencia (Perrenoud, 2013), materializándola en forma de experiencias de trabajo grupal (TG), para abordar las disciplinas conducentes a la consecución de ambos títulos de grado. Este aspecto coincide con la importancia mostrada por el profesorado universitario respecto del trabajo en equipo y presente en los Libros Blancos de los títulos MEPEF y CAFyD (ANECA, 2005a, 2005b), así como con las propuestas para la renovación de las metodologías educativas en la universidad desde el Ministerio de Educación (MEC, 2006), en las que se insta hacia un cambio metodológico en el que el alumnado sea más protagonista de su aprendizaje, lo haga en entornos colaborativos de formación y recibieran una formación más próxima a la realidad laboral de inserción, en donde la competencia para el trabajo en equipo es insistentemente muy apreciada para el desarrollo profesional (Barriopedro et al., 2016; Bartual y Turmo, 2016).

Esta consideración de elevada ayuda formativa recibida para su desarrollo, es coincidente con los resultados de varios estudios que revelan igualmente la alta satisfacción de los estudiantes al respecto, como los de Clemente y Escribá (2013), Escolano-Pérez et al. (2012), Fuentes-Abeledo et al. (2008), González et al. (2010), Pazo-Haro y Tejada-Mora (2012), Rodríguez et al. (2018), Romero et al. (2011). Ellos, 
los estudiantes, perciben haber recibido una importante capacitación, vinculándose esta a las experiencias prácticas de TG desarrolladas durante su formación. Aunque Gutiérrez et al. (2013) y Conchado y Carot (2013), instan a la diferenciación entre el TG y el verdadero trabajo en equipo como competencia, pues es posible que los estudiantes asimilen ambos conceptos a partir de la experiencias desarrolladas, pensando que la realización de unas lleva directamente al dominio de la competencia, y eso no es del todo cierto, además de no acercarse a la realidad laboral, como también revelan los estudios de Barraycoa y Lasaga (2009).

En relación a las diferencias observadas en virtud del género, en nuestro caso en favor del grupo de estudiantes mujeres, algunos estudios ya establecieron tendencias similares (Rodríguez et al., 2018; Romero al., 2011) revelando una consideración de desarrollo del trabajo en equipo mayor en la percepción de las mujeres, aunque, como describe Jackson (2014), no conviene generalizar, pues otras experiencias en otros grupos de pertenencia en nuevos contextos y circunstancias podrían mostrar tendencias distintas.

Hombres y mujeres coinciden en la percepción de la formación de los grupos de trabajo para abordar las tareas de TG de forma autodidacta, autónoma, planteando como dinámica de funcionamiento el reparto de las tareas y estableciendo plazos de entrega individuales, para realizar el montaje final de la producción académica a entregar y ser evaluada. Con este procedimiento de "corta y pega" ambos centran su preocupación básica en la elaboración y entrega del producto final, en un escenario formativo que mira básicamente al contenido del conocimiento (Barraycoa y Lasaga, 2010). Pero también se revela al menos la presencia de ciertos aspectos como los de búsqueda de información y de distribución de cargas entre los miembros del equipo que, tal y como establece Huber (1991), forman parte, entre otros, del proceso de aprendizaje para responder activamente al abordaje de las tareas encomendadas y con ello iniciarse en el aprendizaje de trabajar en equipo. 
Pero este modelo experimentado, por si solo y para el caso que nos ocupa, parece no asistir por completo al aprendizaje del trabajo en equipo, dado que el procedimiento que siguen hombres y mujeres no favorece más que una organización del trabajo de carácter mecanicista en lugar de orgánica, ya que finalmente los grupos no trabajarían conjuntamente más que para entregar un producto final a evaluar, sumando las partes trabajadas en un todo, tal y como también encontraron Moreno et al. (2007) y Conchado y Carot (2013). No obstante, diferencialmente, las mujeres promueven en sus grupos de trabajo un modelo de interdependencia más recíproca, preocupado por el seguimiento de la tarea y por los resultados parciales obtenidos, en donde para ellas la comunicación asertiva es esencial (Romero et al., 2011; Savoie y Bruner, 2000). Este aspecto, para León et al. (2014), es un predictor fundamental de la interdependencia y de la autoevaluación grupal (Johnson y Johnson, 1999), facilitando la activación de procesos de intercambio de información, recurriendo al feedback tal y como apuntan Asún, Aparicio, Romero y Fraile (pendiente), como la forma de orientar la supervisión sobre el rendimiento, facilitando la coordinación, minimizando los conflictos, compartiendo las limitaciones, comunicándose y resolviendo anticipadamente los problemas (Del Canto et al., 2009) y transfiriendo todo ese saber y saber hacer aprendido, al resultado obtenido, para nutrir así la experiencia de equipo (Álvarez et al., 2013; Garvín, 1993).

En relación a la gestión de los conflictos grupales, parece existir, para las estudiantes participantes en nuestro estudio, una preocupación por la gestión del compromiso, la responsabilidad y la confianza mutua que afecta a las relaciones interpersonales (Poblete y García, 2004; Pujolás, 2009). Sin embargo, para el caso de los hombres, la preocupación por el conflicto se adentra más en la diferencia de expectativas e intereses (interdependencia negativa de objetivos y tareas), encubriendo en ocasiones la discrepancia ocasionada, impidiendo con ello la posibilidad de compartir un mismo modelo mental y desarrollándose con el tiempo un efecto polizón (Kerr y Brum, 1983; Salas et al., 2005; Slavin, 2014). Esto les genera frustración tras la experiencia en virtud de la descompensación de cargas de trabajo asumidas, aspectos, también presentes en los resultados de los estudios de Livingstone y Lynch (2002). 
En este sentido, se entiende la importancia para hombres y mujeres de un modelo de evaluación centrado en el proceso de la experiencia de TG realizado, para verificar y hacer constar otros aspectos presentes en dicho proceso. Este hecho se relaciona con la importancia que ambos conceden a la supervisión por parte del docente, entendiendo su rol como el de responsable de organización que fija el mandato colectivo, disponiendo y estructurando los recursos y dinamizando las actividades grupales dispuestas para sus estudiantes (Rousseau et al., 2006), supervisando y dinamizando para ayudar a los grupos (Fraile, 2008; Livingstone y Lynch, 2002), asegurando la comunicación interpersonal, la confianza intragrupal y la responsabilidad personal y grupal (Salas et al., 2005).

Desde la perspectiva de la titulación, en ambos grupos, MEPEF y CAFyD, independientemente de la percepción elevada de desarrollo, se constata una ausencia de formación y orientación inicial para el desarrollo exitoso del TG en los estudios cursados. El papel organizador de la formación y los formadores para enseñar a trabajar en equipo es esencial, hasta el punto de marcar los objetivos tal cual lo harían las propias instituciones en el mundo laboral, disponiendo e instruyendo a los equipos y a sus miembros hacia la consecución de tales objetivos (Savoie y Méndes, 1993). La formación competencial recibida condiciona la acción y, por tanto, ser competente para desenvolverse profesional, cultural y socialmente en diversos contextos, requiere de una formación académica de partida (Zagalaz, 2007), que enseñe habilidades complejas que permitan la adaptación posterior de estas, con cierto éxito, a situaciones y entornos variables (Perrenoud, 2008). De no ser así, como es el presente caso, el escenario formativo sigue siendo tradicional, basado en los conocimientos y poco útil, por lo lejos que está de generar cierta transferencia fuera del entorno formativo, tal y como apunta Bolívar (2008).

En relación a la conflictividad experimentada en los procesos de TG realizados para los estudiantes CAFyD, se revela la presencia de cierto efecto polizón que genera una descompensación de las cargas de trabajo asumidas y que la propia cadencia del proceso de trabajo grupal oculta. Este efecto es resultante de la falta de coordinación con el grupo de trabajo. Como en el estudio de París et al. (2016), surgen diferencias en 
relación a la percepción que unos miembros del grupo tienen sobre otros en torno a lo que cada uno aporta para afrontar las cargas de trabajo. Estas diferencias de cargas y aportaciones al grupo de sus miembros generan con el tiempo falta de cohesión, desunión y barreras en las relaciones interpersonales de unos con otros y en definitiva conflictividad (Torrelles et al., 2011).

Por su parte, los estudiantes procedentes de los estudios MEPEF consideran que es la irresponsabilidad mostrada como disposición de algunos componentes para con sus grupos de trabajo, la causante de los conflictos que se generan, siendo el efecto, a medio plazo, de frustración y de pérdida de sentido del estilo de TG experimentado (Burdett, 2007; McConnell, 2005). En los trabajos de Fidalgo-Blanco et al. (2013), se evidencian de la misma manera el conflicto y el desequilibrio que se produce en la gestión de las tareas realizadas por los estudiantes, debido a la falta de seguimiento de las responsabilidades asumidas por cada componente y por ende del propio desarrollo del trabajo. Este hecho contrasta con estudios similares (Pazo-Haro y Tejada-Mora, 2012; Romero y Salicetti, 2009) en donde se obtienen valoraciones positivas sobre el esfuerzo cooperativo desarrollado, siendo la responsabilidad aplicada a las experiencias realizadas lo que facilitó la resolución de los problemas que surgieron, así como la mejora de la interdependencia positiva sobre los objetivos entre los integrantes de los grupos de trabajo, minimizando así los problemas (Johnson et al., 1999).

Es por ello entendible que también se demande para el docente una mayor atención al proceso y no solo al resultado, a fin de ayudarles a orientar su proceso de aprendizaje. Este aspecto, también presente en el trabajo de Gutiérrez-García et al. (2013), revela la escasa presencia de forma general en las dinámicas de TG realizados, de comentarios sobre los resultados por parte del docente, de retroalimentaciones en situación, mostrándose la cara de un modelo de evaluación en donde el contenido abordado y el resultado de la tarea encargada, aún tiene un peso mayor que el del propio proceso. Se insiste por ello en la necesidad de que el docente asuma, tal y como proponen Álvarez (2011), Asún et al. (2019) y Tardif (2006), realmente un rol de orientador, guía y acompañante sobre el trabajo del estudiante durante el proceso, estableciendo una mayor interacción con los estudiantes. 
Sobre las habilidades en las relaciones interpersonales tal y como se ha descrito, los resultados obtenidos evidencian bastante ayuda formativa recibida a lo largo de la formación cursada, aspecto coincidente con los resultados de estudios similares en el contexto español (Alonso, 2008; ANECA, 2007; Carot et al., 2011; Freire et al., 2013). Este aspecto se podría relacionar con la importancia que formativamente en su momento dieron los académicos, empleadores y graduados tras ser consultados en el proyecto Tuning y estudios posteriores, definiendo las competencias a desarrollar en la formación superior (Capell et al., 2006; González y Wagenaar, 2003). Entre ellas, ocuparon una posición destacada las habilidades para las relaciones interpersonales. De la misma manera, en los libros blancos para los títulos de MEPEF y CAFyF (ANECA, 2005a, 2005b), se valoran como imprescindibles las habilidades para las relaciones interpersonales de cara al ejercicio profesional futuro.

No obstante, los datos obtenidos contrastan con ciertos déficits formativos si se compara la adquisición y desarrollo de estas competencias con otras de otra índole. Así, las competencias sociales, personales y de regulación emocional, aun siendo desarrolladas y manejadas en entornos de aprendizaje de formación del profesorado, ocupan ciertamente posiciones inferiores en los ránquines y valoraciones, siendo las de carácter específico técnico-metodológicas las que ocupan posiciones superiores (Barceló y Ruiz-Corbella, 2015; Bartual y Turmo, 2016; Clemente y Escribá, 2013; Corominas, 2001). Esta realidad hace necesario su reconsideración en la formación del profesorado para proyectar a la realidad educativa, docentes social y emocionalmente competentes, que sepan manejar las relaciones alumnado-familias-profesorado, sintonizando con las señales socio afectivas que muestran los demás (Armengol et al., 2011; Mayer y Salovey, 1997).

En relación al género, los resultados encontrados no mostraron diferencias significativas entre hombres y mujeres en la percepción de la formación recibida para su desarrollo, aunque encontramos matices que tal y, como plantean Alcalá et al (2006) y Caballero (2204), merece la pena subrayar. Aunque tanto hombres como mujeres consideraron haber desarrollado, durante las experiencias prácticas realizadas en su formación, las habilidades de interactuar, socializar y colaborar. Para el caso de las 
mujeres durante los TG y experiencias de simulaciones docentes realizadas, la interacción presentó un mayor carácter adaptativo y de expresión emocional abierta, aspecto presente de forma similar en los estudios de Denis et al. (2005), Gartzia et al. (2012), Olaz (2012), Romero et al. (2011). Para el caso de los hombres, los estudiantes reconocen avances en la interacción y cohesión grupal a partir de las experiencias prácticas situadas en las AFMN experimentadas lo que facilitaba la convivencia, aspectos esenciales para crear y fortalecer el sentido de equipo (Ros, 2006; Torrelles et al ., 2014).

Sobre las situaciones de conflictividad experimentadas y presentes en las relaciones sociales que surgen de las experiencias prácticas de TG realizadas, hombres y mujeres afrontaron, de igual forma, los problemas y tensiones mediante la comunicación asertiva, la escucha y el diálogo, tal y como observó también Rodríguez Mena (2003). Pero, para el caso de las mujeres se mostraba una mayor capacidad de regulación emocional, como también apreciaron Molero et al. (2010), que las predisponen, en mejor medida, para reflexionar sobre los sentimientos experimentados, reparando la emocionalidad inicialmente negativa, para moderarla y proyectarla hacia otra más positiva (Mayer y Salovey, 1997), flexibilizando las posiciones y apostando por actuaciones de mayor tacto, sensibilidad y calma, como muestran también los estudios de Chan et al. (2011) y Toussaint y Webb (2005). Estos aspectos, desarrollados por hombres y mujeres durante su formación, son especialmente valorados como imprescindibles en el perfil del buen docente, en opinión de los estudiantes universitarios encuestados por González et al. (2008), Valdemoros-San Emeterio y Lucas-Molina (2014). De la misma manera, y en relación a la capacidad de escucha, Bisquerra (2005) considera que es una de las habilidades fundamentales para el manejo de las relaciones interpersonales docente-alumnado, para el desarrollo del trabajo colaborativo y para el desarrollo de relaciones prosociales y de establecimiento de climas de trabajo eficaces y satisfactorios para los grupos.

Por otro lado, la toma de iniciativa, presente entre las habilidades desarrolladas por el grupo de hombres, puede entenderse quizá, siguiendo a Hermann y Betz (2004) y Mosse (1995), como parte del arquetipo social masculino preocupado por mostrarse 
socialmente mediante la exaltación de clásicos valores de valentía y atrevimiento para alcanzar las metas y cumplir objetivos previstos.

Respecto a las diferencias en cuanto a la titulación cursada, los resultados obtenidos muestran que los estudiantes CAFyD han recibido menos ayudas formativas en forma de experiencias que los estudiantes MEPEF, aspecto también expresado en el estudio de Hamodi et al. (2018), en el que los primeros parece que habían desarrollado más las competencias específicas mientras que los para los eran las personales. Estos últimos valoran haber sido formados desde las experiencias prácticas de AFMN (identifican que dichas experiencias prácticas requieren de la colaboración y suponen por ejemplo la organización de rutas BTT, senderistas y carreras de orientación) utilizando sus habilidades comunicativas, de forma receptiva y expresiva. Esencialmente para negociar en situaciones de interacción, dialogar, interactuar con los demás y mantener un perfil comunicador asertivo, siendo capaces de emitir su mensaje de forma compresible y directa, tomando la iniciativa, respetando las opiniones de los demás aún en situaciones problemáticas, de tensión y conflicto o de dificultades para el entendimiento. Estos aspectos son coincidentes con algunos resultados de los trabajos de Abarca y Sala (2002), Danielson (2011), Fernández-Batanero (2011, 2013), Fraile (2013), Gallego y Rodríguez (2014), Imbernón (2007), Mérida (2012), Mireya y Filella (2016) y Ruíz Omeñaca (2008) que consideran más allá de la función instrumental de la comunicación de transmisión de la información, otras funciones a manejar en situaciones de interacción en el contexto educativo como la negociación, la colaboración, la gestión de los conflictos de aula, la mediación, la adaptabilidad y flexibilidad ante los desafíos, para facilitar la convivencia y el buen clima de aula.

A este respecto, los resultados también revelan que su participación en las prácticas o simulaciones docentes, realizados en materias como expresión corporal, fueron capaces de contribuir a la creación de un ambiente de aula de cierta seguridad y comodidad y en donde se afianzó la unión y la cohesión grupal. En este sentido, en las prácticas grupales expresivo-corporales se desarrollan numerosas experiencias de contacto corporal y fortalecimiento de la cooperación que, tal y como apuntan Learreta, et al. (2005) y Ruano (2013), despiertan y activan la dimensión prosocial de las 
habilidades interpersonales como la prestación de ayuda, comportamiento presente en los resultados obtenidos, y sin duda beneficioso para los demás y facilitador de las buenas relaciones de convivencia (Gimpel y Merrell, 1998; Merrell, 2002). Por su parte, este tipo de habilidades desarrolladas, tal y como sostienen Blázquez (2016) y Valdemoros-San Emeterio y Lucas-Molina (2014), han de ser experimentadas de forma práctica en situaciones próximas a la realidad docente, para facilitar la transferencia como competencia docente al ejercicio profesional de la $\mathrm{EF}$, donde se requiere saber crear ambientes de aula que permitan la socialización, la convivencia, la interacción cercana y afectiva con el alumnado, como requisitos necesariamente presentes para posibilitar la prestación de la ayuda formativa para garantizar mayor éxito en los aprendizajes.

Además, los resultados revelan la presencia de comportamientos de regulación y control emocional que, a priori para la gestión de las relaciones interpersonales, se muestran de forma tosca, pero en virtud de las experiencias participadas y de la reflexividad, se intentan regular y controlar conscientemente durante las interacciones en el aula. Este aspecto, recogido por Camacho y Padrón (2006) González et al. (2010), Sánchez y Boronat (2014), está suficientemente presente en la percepción de los estudiantes MEPEF, en cuanto la capacidad que les habilita para analizar y ser más reflexivos sobre el propio comportamiento emocional, para favorecer un mejor clima de convivencia.

En la práctica de la inteligencia emocional, los dominios de conciencia de uno mismo y autogestión emocional favorecen el afrontamiento de las propias vivencias emocionales, así como el desarrollo de la conciencia social y el manejo de las relaciones de interacción con los demás, favoreciendo la autoeficacia de la expresión de las emociones en las relaciones sociales (Goleman, 1998; Goleman et al., 2002; PérezEscoda et al., 2013; Saarni, 1998). Además, poner en práctica la reflexión y el debate en los ambientes formativos supone entrenar la capacidad de conciencia y regulación emocional que, de forma directa, favorecen la responsabilidad personal y grupal y habilidades prosociales como ayudar, sentir por el otro, colaborar y cooperar y 
comprometerse (Caprara Steca, 2005; Caprara et al., 2005; Catalano et al., 2004; Hay y Cook, 2007; Penne et al., 1995; Warneken y Tomasello, 2009).

Por su parte, los estudiantes CAFyD, aunque dando menos muestras sobre el desarrollo y manejo de las habilidades para las relaciones interpersonales, sí revelan algunas desarrolladas como la capacidad de ayudar a los demás, que se incentiva y activa desde los planteamientos didácticos de las acciones formativas en las que participan y por tanto está presente como ideario de partida durante su formación, lo que, siguiendo a Salas et al. (2005) y Marks et al. (2000), aproxima a los estudiantes durante su participación en los TG, hacia el comportamiento de respaldo, favorecedor de la prestación de apoyos y de la colaboración. Algunas estudios al respecto con estudiantes CAFyD mencionan también, a partir de las experiencias realizadas en materias de especialización, ciertos avances competenciales socio-emocionales evidenciados en formas de ayuda prestada, colaboración, adaptación, que redundaban en una mejor interacción (Alonso et al, 2013; Rodríguez et al., 2013; Rueda y López, 2013).

También Boned et al. (2006) mostraron cómo para el desarrollo de los ámbitos profesionales objeto de formación (organización y gestión, AFMN, actividad física y salud) los estudiantes CAFyD percibían la necesidad de poner en práctica de forma prioritaria habilidades para afrontar las relaciones sociales, de regulación emocional, de negociación para la gestión de las crisis; habilidades interpersonales también advertidas en las experiencias realizadas por Dyson y Grineski (2001) y Eldar, (2008), junto con el reconocimiento de las limitaciones y la adopción de un comportamiento adaptativo como activadores de la colaboración. 


\section{3 ¿Qué relación existe entre el uso de metodologías activas y de evaluación}

formativa respecto de la percepción de desarrollo de competencias instrumentales e interpersonales (B1/B2) que tienen los estudiantes de Educación Física tras su formación?

\section{a) En relación a las metodologías activas}

En nuestro estudio se ha comprobado que la valoración que hacen los estudiantes encuestados en relación al uso de metodologías activas para el desarrollo de sus competencias transversales es, para el caso de las del tipo instrumentales (B1), mínima en la formación cursada. Esto no es así para el caso del bloque de las competencias interpersonales (B2), donde se observa una correlación mayor al respecto, coincidiendo con los resultados del Informe Reflex (ANECA, 2007), aunque en cualquier caso, no podríamos valorar como notables. Estos resultados contrastan con la valoración positiva y de idoneidad de los métodos activos para el desarrollo de competencias en todas las esferas formativas incluida la universitaria, constatadas desde el Proyecto Tuning (González y Wagenaar, 2003) y proyectadas desde por el Ministerio de Educación (MEC, 2006). En este se muestra que la necesidad de renovación de las metodologías en la universidad, considerando que es el estudiante el elemento nuclear del proceso de enseñanza y aprendizaje y que su implicación y participación, ha de considerarse siempre presente en el planteamiento de las metodologías y sistemas de evaluación aplicadas por el profesorado en el aula. Esta idoneidad fue corroborada también en los estudios de Hortigüela et al. (2015) y Hortigüela et al. (2016) en los que los autores mostraron cómo la utilización de metodologías activas, abiertas y participativas, favorecían un mayor desarrollo competencial en los estudiantes de EF participantes en sus investigaciones.

Efectivamente, se observa una débil presencia de la utilización en la formación del profesorado de EF de métodos activos para el desarrollo de su competencia conocimientos de Informática aplicada al ámbito de la EF. En el mismo sentido, el estudio de Morales et al., 2015, evidenció también, en opinión de los estudiantes encuestados, una escasa presencia en su formación de métodos activos para el desarrollo de su competencia tecnológica, por lo que estos instaban al cambio de las metodologías 
tradicionales por otras más activas y participativas, reclamando en ellas un mayor protagonismo y responsabilidad en el aprendizaje tecnológico para que este sea más efectivo. Como establece Zabalza (2011), el déficit metodológico para el desarrollo de esta competencia en parte puede explicarse por el uso habitual aún en la universidad de la magistralidad como metodología pedagógica generalizada, con la que la transmisión de la información sigue primando más que la interacción. Otra posible causa, como considera Laurillard (2002), se relaciona con la falta de práctica tecnológica del profesorado universitario quien, no habiendo sido formado tecnológicamente, es lento en su desarrollo tecnológico y aplicabilidad a las materias que imparte. Es posible además que la velocidad de los cambios tecnológicos no favorezcan el aprendizaje suficientemente rápido como para responder a las demandas socioeducativas en su entorno académico (Mishra y Koehler, 2006). Estos aspectos pueden explicar el común de los perfiles académicos que en el uso tecnológico no actúan para sus estudiantes como guías, orientadores, investigadores y tutores virtuales (Goodyear at al., 2010), aspecto esencial para desarrollar el nuevo espíritu competencial de Bolonia para la formación superior.

A partir de los resultados obtenidos, frente a la débil presencia de metodologías activas para el desarrollo de la competencia tecnológica de nuestro estudio, diversos autores (Adell y Castañeda, 2012; Arévalo, 2016; Ferrés y Piscitelli, 2012; Gewerc et al., 2011; Llorente, 2008; McKeachie y Svinicki, 2006; Pessoa et al., 2015) destacan la necesidad de utilización de modelos formativos activos, dialógicos, creativos, lúdicos, participativos, facilitadores de la expresión, la comunicación, la generación de producciones creativas, la difusión y la publicación, siendo los estudiantes agentes activos y protagonistas, que aprenden a utilizar con sentido intencionalmente didáctico, la tecnología durante su formación, pudiendo transferir más fácilmente lo aprendido y practicado al mundo laboral (Carrasco et al., 2012). En este sentido, Robledo et al. (2015) mostraron el especial potencial del aprendizaje basado en problemas (ABp) y del método de casos para resolverlos; métodos situados y participativos que favorecen la implicación de los estudiantes, aplicando estos los cocimientos y habilidades tecnológicas aprendidas, para afrontar conjuntamente los retos (Perrenoud, 2012). También en este mismo sentido se posicionan los trabajos de Aristizábal y Cruz (2018), 
Barrett (2005), Barrows (1986) y Sagástegui (2004) que consideran la idoneidad y la potencialidad del ABp para, entre otras, la adquisición y desarrollo de la competencia tecnológica.

De forma similar, se observa que las relaciones entre la percepción de desarrollo de la competencia conocimiento de una lengua extranjera y los métodos activos son débiles en razón a los datos obtenidos de nuestro estudio, con lo que es razonable pensar que tampoco se hace énfasis en estos durante la formación inicial. Este resultado es similar al procedente del informe Reflex (ANECA, 2017) en el que, como en el presente caso, tampoco se observa un excesivo énfasis en la puesta en marcha de metodologías activas para el desarrollo de la competencia para el conocimiento de una LE. El resultado obtenido es coherente con la percepción de nuestros estudiantes cuando identifican la metodología experimentada para el conocimiento de una LE como tradicional, en la que parece que el estudio de los contenidos de la LE es preferente. Paradójicamente el análisis de las guías docentes de las materias previstas para la ELE en los planes formativos de los títulos que nos atañen, muestran una previsión hacia el uso de metodologías activas, cooperativas, colaborativas en las que se anticipa una gran implicación del estudiante en su realización.

Diversos estudios en escenarios de formación del profesorado muestran resultados, contrariamente a los obtenidos el que nos ocupa, positivos en la utilización de metodologías integradas para el desarrollo de la competencia para el conocimiento de una LE (Dalton-Puffer, 2011; Doiz et al., 2013; Lagabaster y Ruiz de Zarobe, 2010; Lasagabaster, 2012). También los trabajos de Hernando et al. (2015) y Hortigüela et al. (2016) dan cuenta de la potencialidad de los métodos integrados mediante AICLE/ICLHE en el ámbito formativo universitario de la EF. Incluso Coral (2018), en relación a la formación del profesorado de EF, expresaba las ventajas de la hibridación de procedimientos metodológicos activos y participativos en un contexto de métodos integrados AICLE/ICLHE para la enseñanza plurilingüe, considerando que la comunicación es más eficiente si se arbitran diferentes metodologías participativas de forma conjunta, tal es el caso de AICLE/ICLHE y aprendizaje cooperativo. Estos resultados están en consonancia con la preferencia de esta metodología por la Comisión 
Europea (1995) para la ELE en todas las etapas educativas, a fin de superar el mero estudio de los contenidos del idioma para alcanzar otras dimensiones de desarrollo como la expresión y la comunicación, así como su uso vehicular para enseñar los contenidos de otras materias, sin duda aspectos impulsores del plurilingüismo.

Como se exponía al principio, los resultados obtenidos evidencian una correlación algo mayor entre la aplicación de métodos activos durante la formación cursada y la precepción de desarrollo de las competencias interpersonales (B2). Para este bloque, se observa que la relación entre estos métodos activos aplicados en la formación y el desarrollo de la competencia trabajo en equipo, a pesar de no ser del todo notable (correlación débil), es mayor con respecto a las valoraciones sobre las dos competencias instrumentales anteriormente citadas, hecho que se observa también ANECA (2007).

La presencia de métodos activos, identificados por los estudiantes encuestados, se relaciona con lo que han identificado como método de trabajo grupal (TG). No obstante, a pesar del reconocimiento generalizado como generador de aprendizajes conducentes al desarrollo del trabajo en equipo como competencia (Barfield, 2003; Escolano-Pérez et al., 2012; Johson y Johnson, 2006; McDonnel, 2005; Molina et al., 2010), en nuestro caso, paradójicamente, adolece su desarrollo de los aspectos técnicos que favorecen verdaderamente el aprendizaje para trabajar en equipo (Salas et al., 2005), pues como se ha visto la dinámica en la que se forma esta competencia se reduce a un "corta y pega" (Barraycoa y Lasaga, 2010), generando más bien conflictos interpersonales alrededor del método aplicado (Burdett, 2007; Del Canto, 2009) que éxitos en el desarrollo de la competencia.

La percepción elevada de los estudiantes sobre la presencia del trabajo en equipo en las materias cursadas contrasta sorprendentemente con la tónica general de funcionamiento del TG, como método prioritario reconocido como utilizado a lo largo de la formación pero sin atender aspectos esenciales para su desarrollo (más allá de la gestión de las tareas de aprendizaje encargadas) como aprender a gestionar las 
diferencias en las expectativas, intereses, objetivos y capacidades individuales aportadas por los miembros de los grupos. Tampoco a superar las diferencias sobre las cargas repartidas para la ejecución de las tareas, a equilibrar las funciones y roles desempeñados y a abordar las dificultades para realizar el seguimiento mutuo de las tareas y la responsabilidad individual y grupal (autoevaluación grupal). De la misma manera tampoco a resolver los problemas de comunicación intragrupal, a controlar el efecto polizón y las crisis de disgregación grupal, frustración y pérdida de sentido del método y los problemas en las relaciones interpersonales consecuencia de la conflictividad al respecto generada.

Tales situaciones desatendidas y fuente de conflicto, ya fueron identificadas, como acabamos de resumir y en el mismo sentido, en diversas investigaciones y experiencias (Aguilera, 2018; Del Canto et al., 2009; Fraile, 2008; Fraile et al, 2009; Gámez y Torres, 2012; Jhen y Mannix, 2001; Kerr y Brum, 1983; McConell, 2015; Putman, 1997; Sheingold et al.,1984), siendo una muestra de su presencia e irrupción frecuentemente en la vida de los grupos de trabajo, afectando a la validez del método y reduciéndolo a un mero reparto de tareas para conformar un producto final a entregar (Conchado y Carot, 2013).

Esto está lejos de la pretensión de enseñar a trabajar en equipo, aprendiendo a comunicarse, compartiendo solidariamente conocimientos, habilidades y actitudes para la realización de las tareas encomendadas, abrazando los intereses grupales por encima de los individuales (Moreno et al, 2007) y mostrando interdependencias con respecto a los flujos de trabajo realizados, metas y resultados, asumiendo roles y responsabilidades (Hackman y Wageman, 2005; Hollenbeck et al., 1995; Salas et al., 1992); aspectos que impiden acercarse a la idea real competencial eficaz del trabajo en equipo, para su mejor transferencia a la vida personal y profesional futura (Poblete y Villa, 2004).

Es por ello que se considera el aprendizaje cooperativo (AC) como una cierta evolución del TG (Barriopedro et al., 2016) en cuanto método que mejor atiende y controla técnicamente el aprendizaje de la competencia. El AC asegura la gestión 
formativa de aquellos aspectos que han de estar necesariamente presentes en las experiencias de TG y que facilitan los aprendizajes para el desarrollo de esta (interdependencia positiva, comportamiento de respaldo y apoyo mutuo o interacción promotora, gestión de las habilidades en las relaciones interpersonales, seguimiento mutuo de las tareas, autoevaluación o procesamiento grupal), articulando comunicación y confianza y asegurando además que todos los miembros de los grupos aprenden mientras realizan las tareas (Johnson y Johnson, 1999; Salas et al., 2005; Velázquez, 2013; Velázquez et al., 2014).

En relación a la presencia de métodos activos y la percepción de adquisición de la competencia habilidades para las relaciones interpersonales, se observa un mejor valor de correlación, que aunque no podríamos considerar como notable, sí es ciertamente alentador comparativamente con los valores encontrados para las competencias anteriormente mencionadas.

Se podría entender el elevado promedio de percepción de ayuda recibida para su desarrollo, considerando también a la luz de los resultados obtenidos, la influencia del TG como procedimiento metodológico participativo y de implicación de los estudiantes. Este parece estar presente en la gestión didáctica de algunas materias específicas del área (expresión corporal y AFMN) mostrándose como estrategia para garantizar la participación e implicación de los estudiantes, construyendo el aprendizaje en escenarios y situaciones de interacción, intercambio de ideas y conocimientos mediante el uso de grupos de trabajo para la consecución de tareas (Barfield, 2003; Johnson y Johnson, 2006; McConnell, 2005).

En nuestro caso se observa que las experiencias de TG realizadas parece que activaron la puesta en acción de habilidades para afrontar los conflictos grupales derivados de los roces por el desarrollo conjunto de las tareas, tales como la comunicación, el diálogo y la escucha, así como la expresión y regulación emocional. Beneficios para la formación socioemocional de los futuros docentes que ya relacionaban Chickering y Gamson (1991) con el desarrollo de este tipo de 
metodologías en los procesos formativos. En el mismo sentido algunas investigaciones (Gómez, 2008; Parra y Domínguez, 2009; Prouty et al., 2007 y Santos y Martínez, 2011) mostraron cómo el desarrollo de métodos de índole colaborativa ayudan a expresarse emocionalmente, adaptándose y acomodándose en lo que a la regulación de las emociones se refiere, en las circunstancias de afrontamiento de estas.

Por otra parte, las actividades especializadas (AFMN) en las que se aplicó el TG, desarrolladas en entornos reales (extra aula: organización y desarrollo de rutas de BTT y senderismo, carreras de orientación, acampada) y de simulación de prácticas docentes, así como los TG prácticos realizados en experiencias de expresión corporal, parece que ayudaron al desarrollo de un estilo de comunicación más asertivo, dialogante y negociador, contribuyendo a una mejor convivencia mediante la creación de ambientes más cómodos, seguros y facilitadores de la cooperación y la cohesión grupal; despertando habilidades prosociales como la prestación de ayuda facilitadora de las buenas relaciones de convivencia. Algunas experiencias didácticas puestas en marcha al respecto mostraron beneficios similares alcanzados por los estudiantes tras su participación en ellas (Baena-Extremera y Granero-Gallegos, 2008; Caballero, 2012; Granero-Gallegos et al., 2005).

\section{b) En relación a la evaluación formativa}

Respecto a la presencia de los sistemas de evaluación formativa y su relación con la promoción de las competencias instrumentales e interpersonales objeto de estudio, nuestros resultados muestran en general correlaciones poco notables, aunque las puntuaciones son más elevadas en las segundas que en las primeras. En este mismo sentido se muestran los resultados de Cañadas (2018) y Gallardo-Fuentes et al., (2018). Este último, especialmente en lo que se refiere a la competencia tecnológica, para la que se aprecia una influencia débil de la evaluación formativa. Este hecho se entiende si, como hemos constatado a partir de los resultados obtenidos, es débil también la presencia de metodologías activas en su formación, identificándose aún en mayor medida los sistemas metodológicos tradicionales y magistrales como procedimientos muy presentes en la formación universitaria, tal y como considera Zabalza (2001) y tal y 
como hemos observado en el análisis de las guías docentes de las materias específicas para el desarrollo de la competencia tecnológica en la formación del profesorado de EF.

Para el caso del conocimiento de una lengua extranjera, la presencia de la evaluación formativa en su desarrollo es igualmente débil. Este hecho también se constata en las guías docentes tras cuyo análisis, como ya hemos apuntado, se observa mayor presencia de instrumentos de evaluación no participativos, lo que nos hace pensar en una separación entre enseñanza y evaluación, más característico de un modelo de enseñanza tradicional, dado que la evaluación formativa integra ambas dentro del mismo proceso (López-Pastor, 2012). De acuerdo con Bonson y Benito (2005) y Dochy et al. (2002) la enseñanza tradicional de la LE, separa la enseñanza de la evaluación y sus pretensiones se acercan más a las de acreditación y certificación, como parece se apunta en el estudio realizado. Es por ello que, siguiendo a Coral (2018), es necesario la aplicación de métodos abiertos, integrados, holísticos para la ELE y contemplando con estos la utilización de otros activos que faciliten la interacción y la comunicación entre los estudiantes, para redundar finalmente en la mejora de sus competencias lingüísticas (Doiz et al., 2013; Hernando et al., 2015; Hortigüela et al., 2016). Se requiere por tanto superar las prácticas de evaluación tradicional para abrazar un sistema de evaluación formativa y compartida, si lo que se persigue es el desarrollo competencial de los estudiantes (Barraza, 2007).

Otros trabajos (Atienza et al., 2016; Fraile et al., 2018; Hortigüela et al., 2015; Martínez-Mínguez, 2016) muestran sin embargo, como en nuestro caso, cierta conexión entre los sistemas de evaluación formativa aplicada y el desarrollo de competencias interpersonales, como el trabajo en equipo y las habilidades para las relaciones interpersonales, especialmente si existen situaciones de aprendizaje en donde aparecen procesos de colaboración, interacción y comunicación (Brown y Glasner, 2003; Brown y Pikcford, 2013; Zabalza, 2011). Situaciones que, como contempla Villardón (2006), activan la implicación y la participación de los estudiantes durante el proceso de enseñanza y aprendizaje, promoviéndose competencias de este tipo (Hall y Burke, 2003; Kaftan et al., 2006; Sluijsmans et al.,1998). Esto da cuenta de la conexión entre la aplicación de métodos activos y sistemas de evaluación participativa para el mejor 
desarrollo competencial en la formación superior, siendo clave para ello la implicación de los estudiantes a fin de mejorar en beneficio de su propio proceso de aprendizaje (Arribas et al., 2010; Buscá et al., 2012).

\section{4 ¿Qué relación existe entre el uso de los instrumentos de evaluación aplicados durante la formación inicial respecto de la percepción de desarrollo de competencias instrumentales e interpersonales que tienen los estudiantes de} Educación Física tras su formación?

Para el desarrollo del conocimiento de una lengua extranjera, los resultados obtenidos muestran relaciones débiles en general con respecto a todos los instrumentos habituales de evaluación, siendo los exámenes orales los que parecen considerarse mas formativos y presentes para su desarrollo, junto con el uso de portafolios y la observación del profesor en clase ayudado de fichas de observación. Estos aparecen coherentemente previstos en el estudio realizado de las guías decentes de las asignaturas competentes en la ELE en los planes formativos que nos ocupan.

La política lingüística del MCEL (2001) considera como preferentes los exámenes orales, en forma de conversaciones y debates informales, fichas/escalas de observación del docente en clase y umbrales y plataformas del tipo portafolios para hacer acopio de información sobre los aprendizajes alcanzados por los estudiantes. Los trabajos de Corredor y Romero (2008), Gómez y Richters (2017) y Li (2018) muestran también la fortaleza de las exposiciones y exámenes orales para desarrollar la competencia comunicativa usando una LE, facilitando además la toma de conciencia sobre el nivel de desarrollo en situación que, junto con la interacción con el docente u otros estudiantes en clave de feedback, benefician en su desarrollo.

Como en el caso que ocupa, también son diversos los estudios que muestran la influencia de los portafolios como instrumentos eficaces para el desarrollo de esta competencia (Angola y Zambrano, 2016; Bolliger y Shepherd, 2010; Chacón y Chacón- 
Corzo, 2011; Mira, 2016), pero también como un instrumento de evaluación auténtica, dado que permiten no solo recoger y recopilar los resultados de las tareas realizadas, sino activar también las capacidades de reflexión, autogestión y autorregulación, sentando las bases en el estudiante para desarrollar procesos de autoevaluación competencial (Díaz Barriga, 2006; Díaz Barriga y Pérez, 2010; Pérez Gómez, 2012; Shores y Grace, 2004; Villalobos, 2002). Además, los resultados muestran, al igual que lo hace Coral et al. (2017) y Pérez (2015), la utilidad de las escalas y fichas de observación destinadas al profesor para evaluar el dominio lingüístico de los estudiantes, a fin de evidenciar su grado de adquisición y desarrollo en las tareas a realizar junto con sus dificultades, ayudando a disminuir la brecha teórico-práctica en situación.

Los instrumentos de evaluación que parece se consideran de mayor ayuda para el desarrollo de los conocimientos de informática aplicados al ámbito de estudio son los exámenes orales aunque también la realización de ensayos escritos a partir de materiales audiovisuales. Estos últimos están presentes en la FIPEF tal como muestran los trabajos de Gutiérrez-García et al. (2013), Martínez-Muñoz et al. (2012), Palacios et al. (2013), siendo entendible dado que el texto escrito ha sido y continúa siendo finalmente el soporte tradicional de presentación de la información en la universidad (Díaz, 1993).

El uso de exámenes orales en forma de exposiciones y presentaciones supone una forma de mostrar y explicar ante los demás los trabajos tecnológicos realizados. Zabalza (2014) y Blanco (2010) proponen el uso de blogs de acceso abierto y wikis para ir desarrollando las tareas de evaluación de los aprendizajes, mostrando y pudiendo exponer de forma continuada a los demás el estado de su situación, justificando lo realizado. La posibilidad de dejar el docente comentarios en las entradas del blog supone una forma de feedback informativo sobre su estado, orientando la continuidad del trabajo y optimizando su desarrollo competencial. Es posible de esta forma hacer el seguimiento y valorar los aprendizajes competenciales realizados, tanto en la dimensión instrumental (utilización de los recursos digitales), como intelectual, comunicativa y ética de la competencia tecnológica (Area et al., 2012; Ferrari, 2013; Krumsvik, 2008; Llorente, 2008). 
También, aunque desde resultados débiles, el control de la participación en el aula mediante la realización de trabajos (sobre la creación y uso de blogs, wikis y materiales audiovisuales) está en consonancia con el ejercicio profesional en la actualidad, en el que se utilizan estos recursos para crear nuevos escenarios pedagógicos para comunicar, interactuar, cooperar, crear e innovar mediante la aplicación de estos y otros dispositivos tal y como muestran las experiencias de Arévalo (2016), Caballero et al. (2016), Castro-Lemus y Gómez (2016), Monguillot et al. (2014), Pérez y Pérez (2013), Quintero et al. $(2016,2018)$. Este planteamiento, muy próximo a la realidad profesional, ptimiza la dimensión didáctico-metodológica de la competencia tecnológica, aprendiendo desde la práctica y haciendo prevalecer la utilidad de los recursos utilizados (Arévalo, 2007), apareciendo de manera tácita en los parámetros formativos a los que instan Carreiro da Costa (2006) y Quintana (2000).

En relación a la competencias trabajo en equipo, parece que los instrumentos más relacionados con su adquisición y desarrollo son la realización de informes y trabajos escritos y la participación en el aula mediante la realización de tareas en grupo, teniendo sentido su combinación en la medida en la que este último genera una respuesta colaborativa ante un problema a resolver. Asún et al. (2017) y Hamodi et al. (2018), en estudios similares al nuestro, muestran una importante presencia tanto de trabajos escritos como instrumentos de evaluación en la formación del profesorado de $\mathrm{EF}$, así como de otros que requieren del feedback y de la interacción con el docente, lo que da cuenta de una cierta evolución positiva hacia esta tendencia participativa en la formación nacional en el sector, tal y como sostienen Romero et al. (2017).

Pensamos por ello que la utilización de forma combinada de instrumentos que favorecen la interacción con el docente y entre el propio estudiantado resultan eficaces para desarrollar procesos de evaluación formativa, como muestran Fraile et al. (2019) y Santos-Pastor et al. (2017). Así, estrategias de combinación de medios, técnicas e instrumentos de evaluación que movilizan la interacción y la implicación de los estudiantes en el proceso de aprendizaje (trabajos prácticos supervisados como las simulaciones docentes, diarios de aprendizaje, uso de rúbricas e instrumentos de observación), resultan efectivas si pensamos en la naturaleza multidimensional de las 
competencias, pudiendo con ello obtener diversas muestras sobre la movilización de recursos personales para la consecución de las tareas en escenarios diversos, lo que hace más factible una verdadera evaluación competencial de los estudiantes (Cano et al, 2014; Lleixá et al., 2008; Tejada, 2005). Coincidimos además con Villardón (2006) en la importancia de proponer situaciones prácticas como las simulaciones mencionadas o la resolución de casos prácticos, en tanto suponen interesantes prácticas de aula que permiten constatar durante la realización de tareas, los niveles de logro competencial alcanzados en clave de colaboración e interacción.

Para la segunda competencia, habilidades en las relaciones interpersonales, son los proyectos de aprendizaje tutorados (PAT) y el control de la participación en el aula mediante la realización de tareas grupales los instrumentos mejor alineados con su desarrollo. La presencia y pertinencia del PAT está presente en las experiencias de Manrique et al. (2010), Martínez-Mínguez (2016), Martínez-Mínguez et al. (2019) en los que se muestra la activación de determinadas habilidades en las relaciones interpersonales como la comunicación, la responsabilidad individual y grupal, así como la toma de decisiones en consenso. La realización de actividades en escenarios diversos aplicando los aprendizajes a la práctica mediante el know how junto con el asesoramiento docente, ayuda al despertar competencial sobre todo en aspectos interrelacionales, al afrontar los retos desde una perspectiva colaborativa (Gil Flores et al., 2004; Mayer, 200). Paralelamente, parece que la utilización de estos instrumentos convive con otros como las exposiciones orales que, entendidas como presentaciones y exposiciones de las tareas grupales realizadas, dan cuenta de las habilidades de interacción con los demás, especialmente en clave de gestión de la comunicación y de interrelación, tal y como apuntan Corredor y Romero (2008), Gómez y Ritchers (2017) y Li (2018), observando además las posibilidades que ofrecen también para la regulación emocional, en beneficio de la interacción y el entendimiento en este tipo de situaciones (Mayer y Salovey, 1993, 1997). 


\section{5 ¿Qué relación existe entre las formas de calificación utilizadas durante la formación cursada respecto de la percepción de desarrollo de competencias instrumentales e interpersonales que tienen los estudiantes de Educación Física tras su formación?}

Para las cuatro competencias objeto de estudio, parece existir, de forma común a partir de los resultados obtenidos, una mayor presencia de la calificación participada a partir de la coevaluación y autoevaluación desarrollada entre los estudiantes y/o entre estos con el docente. Esto sugiere la existencia de una tendencia (aunque débil) hacia procesos de evaluación dialogados entre estudiantes y docentes. Esta tendencia está también presente en diversos estudios en los que la coevaluación y la autoevaluación se emplean como técnicas de evaluación formativa en la formación del profesorado, iniciando desde ellas un trabajo de conciencia competencial a partir de los errores que cometidos de forma dialogada y compartida, son susceptibles de ser abordados en situación para mejorar (Moraza y Antón, 2010), lo que facilita su desarrollo competencial (Gómez y Quesada, 2017; López-Pastor et al., 2016; Moreno et al., 2019).

De la misma manera, algunos estudios recientes (Asún et al., 2016; Hortigüela et al., 2017; Luís y Muros, 2018) muestran una tendencia hacia modelos de calificación negociada o de autocalificación, al menos de forma parcial. No obstante, se observa en nuestro estudio cierta presencia también de la heterocalificación a partir de la evaluación realizada por el docente, en este caso en relación al conocimiento de una LE y al trabajo en equipo. Esta representación de la heterocalificación también está presente en los trabajos de Cañadas et al. (2018), Gutiérrez et al. (2013) y López-Pastor y Palacios-Picos (2012).

Tal vez esta ambivalencia se relacione, como apuntan Buscá et al. (2012), Martínez-Muñoz et al. (2012) y Ruiz-Gallardo et al. (2013), con la alta consideración de coherencia formativa que tiene el profesorado cuando plasma en las guías docentes de las materias que imparte modelos metodológicos alternativos y formas de evaluación, aunque finalmente aplica instrumentos de evaluación más restrictivos y de fácil 
calificación como son los exámenes. De la misma manera, es posible para el caso del trabajo en equipo, según apuntan Barraycoa y Lasaga (2010), que los planteamientos de TG establecidos, tal cual hemos observado, no acompañen del todo el aspecto formativo procedimental de la tarea que se realiza, específicamente cuando se desatiende al proceso, no interactuando ni retroalimentando con información en tiempo real y, sin embargo atendiendo más al producto final realizado, redundando en una evaluación y calificación con cierto peso en aras a dicho producto académico resultante.

Puede que la presencia de exámenes y de la heterocalificación consiguiente contribuya a una menor percepción de desarrollo competencial por parte de los estudiantes. Tal y como plantean Hamodi et al. (2018), los medios e instrumentos más cercanos a la evaluación formativa y que impliquen interacción con los estudiantes ayudan a desarrollar ciertas competencias, más que los tradicionales (exámenes en cualquiera de sus formas). 


\section{CONCLUSIONES}

Se recogen en este capítulo las conclusiones principales a las que se han llegado tras el desarrollo de la investigación. Para ello se tomarán como referencia los objetivos del trabajo.

Objetivo 1. Conocer el grado de ayuda formativa recibida a lo largo de la FIPEF, para el desarrollo de sus competencias instrumentales.

Se considera de forma general que la formación recibida por los estudiantes de Educación Física no ha ayudado al desarrollo de sus competencias instrumentales en lo referente al conocimiento de una lengua extranjera e informática aplicada al ámbito de especialización, dos de las competencias de este tipo menos desarrolladas tradicionalmente durante los estudios de formación del profesorado. Se confirma por tanto la continuidad en el déficit formativo en su adquisición y desarrollo. El resto de competencias instrumentales recibieron valoraciones moderadas sobre su desarrollo.

Objetivo 1.1 Conocer cómo influye el género a la hora de considerar la ayuda recibida durante su formación, para el desarrollo de sus competencias instrumentales.

En relación al desarrollo de los conocimientos de informática relativos al ámbito de especialización, tanto las mujeres como los hombres valoran de forma moderadabaja la formación recibida para su adquisición y desarrollo, siendo los hombres quienes realizan una valoración al respecto algo mejor. Ambos establecen que los conocimientos tecnológicos ya se poseen en el comienzo de los estudios y que por tanto, en el mejor de los casos son reforzados durante la formación. Se demanda además el aprendizaje de herramientas tecnológicas mas específicas que respondan a las necesidades docentes reales en el ejercicio de la profesión, observado su uso durante los procesos de Practicum pero no presentes durante la formación cursada. 
Sobre la competencia para el conocimiento de una lengua extranjera, las valoraciones de hombres y mujeres, sin apenas diferencias, evidencian un importante déficit formativo que no ayuda a su adquisición y desarrollo. La formación recibida de tipo tradicional toma como referentes los aspectos gramaticales de la lengua extranjera, considerando ambos grupos ser una forma de aprender similar a la experimentada en etapas anteriores, reconociendo que los déficits arrastrados de ellas se muestran sin resolver en la formación en la universidad.

Objetivo 1.2 Conocer cómo influye el "tipo de estudios de EF" cursados por los estudiantes, a la hora de considerar la ayuda recibida durante su formación para el desarrollo de sus competencias instrumentales.

En relación a los estudios cursados de Educación Física, los estudiantes MEPEF muestran una valoración en relación al desarrollo general de sus competencias instrumentales mayor que la de los estudiantes CAFyD. En relación a los conocimientos de informática relativos al ámbito de estudio, los estudiantes MEPEF obtienen una puntuación superior a los estudiantes CAFyD, aunque ambos muestran a partir de la formación cursada en su titulación un deficitario desarrollo. Los estudiantes procedentes de las facultades MEPEF de Valencia, Tenerife y Valladolid obtienen puntuaciones moderadas, los estudiantes MEPEF de Barcelona y Madrid sin embargo muestran percepciones bajas de ayuda formativa recibida para el desarrollo de esta competencia. Son los estudiantes CAFyD de las facultades de Murcia los que perciben una mayor apoyo formativo para su desarrollo tecnológico; no así en León, con resultados muy bajos al respecto. Desde la perspectiva de ambas titulaciones los estudiantes muestran que los conocimientos informáticos ya se poseen cobrando sentido la demanda de mayor especialización en la formación a cursar para responder a la realidad de uso de la tecnología en el contexto docente.

Para el caso del conocimiento de una lengua extranjera, la ayuda formativa recibida es en ambos casos valorada como muy deficitaria por ambos grupos de estudiantes, siendo los procedentes CAFyD los que muestran valoraciones más bajas al respecto. Atendiendo a las facultades, los centros de formación de maestros que mas apoyo formativo prestan son Albacete y Tenerife; por el contrario las peores 
valoraciones recaen en las facultades de Madrid y Sevilla. En el caso de las facultades CAFyD, todas son valoradas de forma muy deficitaria siendo la de Sevilla y León las peor valoradas.

Para los estudiantes MEPEF la dinámica formativa cursada a través de las materias de especialización revela como fórmula habitual la memorización no encontrando en ella el recurso que necesitan para comunicarse e interactuar en el idioma, no pudiendo afrontar así los desafíos de las prácticas formativas en centros bilingües ni su transferencia al mundo profesional. Por ello consideran en mínimo la ayuda formativa recibida para el desarrollo de la lengua extranjera en los estudios cursados, debiendo buscar apoyo formativo externo para alcanzar otras cotas de nivel al respecto. Los estudiantes CAFyD a partir de la formación recibida no encuentran funcionalidad ni valor en las dinámicas de las materias cursadas al respecto, valorando finalmente que la ayuda recibida fue muy escasa no cumpliendo sus expectativas.

Objetivo 2. Conocer el grado de ayuda formativa recibida a lo largo de la FIPEF, para el desarrollo de sus competencias interpersonales.

De forma general la valoración que se obtiene sobre la ayuda formativa recibida para el desarrollo de competencias interpersonales, es muy elevada. Se acusa en este sentido la diferencia con respecto a las instrumentales ya vistas. Es especialmente relevante el caso de la intensa formación recibida de competencias como el trabajo en equipo y las habilidades en las relaciones interpersonales obteniendo puntuaciones que dan cuenta de su desarrollo. No obstante las valoraciones del resto de competencias interpersonales son también muy elevadas.

Objetivo 2.1. Conocer cómo influye el "género" de los estudiantes a la hora de considerar la ayuda formativa recibida a través de las materias cursadas para el desarrollo de las competencias interpersonales.

En relación al género, ambos grupos de estudiantes muestran puntuaciones elevadas en relación a la ayuda formativa recibida para desarrollar las competencias interpersonales. Específicamente en relación al trabajo en equipo, el grupo de mujeres 
muestra mayor valoración sobre la formación cursada al respecto, no obstante, paradójicamente, ambos grupos, hombres y mujeres, consideran que la formación cursada es inexistente más allá de las practicas de trabajo grupal realizadas que como procedimiento metodológico habitual puesto en práctica. Este aspecto contrasta en gran medida con las valoraciones estadísticas. Ambos grupos aprenden a trabajar en equipo de forma autodidacta, sin seguimiento del proceso iniciado por parte del docente, más allá del mero planteamiento del trabajo grupal como sistema de canalización del tratamiento de los contenidos disciplinares.. Pero no es el proceso lo que se atiende y es este la fuente de aprendizajes competenciales para desarrollar el trabajo en equipo como competencia. Los conflictos interrelacionales surgentes durante el proceso no son tratados formativamente, afectando al sentido y funcionalidad del procedimiento metodológico aplicado y por ende al sentido conflictivo del hecho de trabajar en equipo. Se demanda por ello un mayor seguimiento del proceso por parte del docente que ayude a canalizar las dificultades y a optimizar los esfuerzos de trabajo grupal realizados, mediante otra forma de evaluar.

En relación a la competencia habilidades en las relaciones interpersonales, ambos grupos muestran una valoración de mucha ayuda formativa recibida para su desarrollo, especialmente elevada para el caso de las mujeres. Ambos grupos, de una forma similar, reconocen que la forma de desarrollar esta competencia viene de la mano de las experiencias prácticas y trabajos grupales realizados a lo largo de la formación para abordar los contenidos disciplinares de las materias. Se establece que desde esta forma de participación e implicación se afrontan retos que permiten desarrollar habilidades interactivas, comunicativas, de resolución de conflictos y problemas, colaborativas que redundan en capacidades como la negociación, la asertividad, la honestidad, el desarrollo de la cohesión grupal, la regulación emocional para facilitar la convivencia y la contribución hacia la creación conjunta de ambientes formativos y climas positivos de aula.

Objetivo 2.2. Conocer cómo influye el "tipo de estudios de Educación Física" cursados por los estudiantes, a la hora de considerar la ayuda formativa recibida para el desarrollo de sus competencias interpersonales. 
Nuevamente los estudiantes MEPEF muestran una percepción más alta que los CAFyD en relación a la ayuda formativa recibida para el desarrollo de sus competencias interpersonales. Específicamente para el desarrollo del trabajo en equipo los primeros obtienen puntuaciones más elevadas aunque ambos consideran haber recibido mucha ayuda formativa recibida para su adquisición y desarrollo. En relación a las facultades de educación de procedencia de los estudiantes MEPEF son los casos de Segovia y Valladolid para las que se muestran mayores valores de apoyo formativo prestado. En el caso de las facultades CAFyD son especialmente relevantes las aportaciones de las facultades de Vic y Murcia (UCAM). Atendiendo a la forma de aprender a trabajar en equipo se muestra un déficit formativo al respecto lo que explica para ambos grupos de estudiantes la necesidad de proceder en la práctica de forma autodidacta, por la propia tradición procedimental de actuación que se estila en sus contextos formativos. Se considera que se presta mayor atención al contenido disciplinar y al producto final resultante de su tratamiento y no tanto al proceso, que pasa por momentos de conflicto interpersonal y crisis de equipo que no se ayuda a responder operativamente. Se demanda por ello mayor atención del docente hacia el proceso mediante un sistema de evaluación que lo atienda, lo oriente y lo optimice en aras al desarrollo de la competencia.

Sobre el desarrollo de la competencia habilidades en las relaciones interpersonales, nuevamente las valoraciones de los estudiantes MEPEF muestran mayores apoyos formativos para su desarrollo. Son significativos los casos de las facultades de educación de Córdoba, Valladolid y Segovia, que muestran valores muy altos de apoyo formativo prestado al respecto. En el caso de las facultades CAFyD, las de Murcia (UCAM) Vic y Huesca dan cuenta del mucho apoyo prestado para el desarrollo de las habilidades interpersonales hacia su alumnado.

Los estudiantes MEPEF y CAFyD muestran de forma similar que las dinámicas de trabajo grupal, requieren del despliegue de habilidades interpersonales como la adaptación y la flexibilidad, la colaboración y la honestidad, requiriendo de la comunicación y la negociación para llegar a acuerdos de grupo. 
Objetivo 3. Conocer si existe una relación entre el uso de metodologías activas y de evaluación formativa respecto de la percepción de desarrollo de competencias que tienen los estudiantes tras su formación.

En relación a las metodologías activas experimentadas por los estudiantes durante su formación se encuentra que favorecen el desarrollo de las competencias instrumentales, pero en mayor medida el desarrollo de sus competencias interpersonales, pues se reconoce la importancia para ello de la participación e implicación de los estudiantes en el proceso de enseñanza y aprendizaje. Específicamente en relación a las competencias conocimiento de una lengua extranjera e informática relativa al ámbito de la Educación Física, se apreciaron relaciones existentes pero débiles. En el caso del trabajo en equipo y las habilidades en las relaciones interpersonales, se aprecian relaciones mayores. Metodologías como el trabajo grupal mediante proyectos facilita el desarrollo de las competencias para gestionar los conocimientos, herramientas y relaciones interpersonales y grupales.

Con respecto a la evaluación formativa se aprecia que se relaciona más con el desarrollo de competencias interpersonales, pues trabajar en equipo y desarrollar las habilidades de interrelación con los demás es susceptible de optimizar desde sistemas de evaluación que consideren por ejemplo la coevaluación como estrategias para ello.

Objetivo 4. Conocer si existe una relación entre el uso de los instrumentos de evaluación respecto de la percepción de desarrollo de competencias que tienen los estudiantes tras su formación.

En relación al conocimiento de una lengua extranjera, son los exámenes y exposiciones orales fundamentalmente los instrumentos de evaluación que se relacionan mejor con su desarrollo. Adquiere sentido si esta competencia pretende optimizar los procesos de comunicación interpersonal. Se acompaña este instrumento con otros como los trabajos escritos para dar cuenta de los conocimientos gramaticales adquiridos. En relación al conocimiento de informática relativa al ámbito de la Educación Física, son aquellos que implican participación, implicación e interacción entre los estudiantes los que favorecen su desarrollo. Al igual que para el desarrollo de las competencias 
interpersonales, trabajo en equipo y habilidades en las relaciones interpersonales, para las que ayuda el control de la participación en el aula mediante la realización de trabajos grupales, la realización de informes y trabajos escritos y las exposiciones orales.

Objetivo 5. Conocer si existe una relación entre las formas de calificación utilizadas durante la formación inicial respecto a la percepción de desarrollo de competencias que tienen los estudiantes tras su formación

El estudio de las formas de calificación revela que facilitan el desarrollo del conocimiento de una lengua extranjera aquellas participadas por el estudiantado, aunque estos reconocen que la habitual es la decidida por el profesorado a partir del proceso de evaluación de los contenidos disciplinares desarrollados. Para el caso de los conocimientos de informática en el ámbito de especialización, se muestra la presencia de la forma dialogada de calificación con el profesorado, por ejemplo en el caso del uso de App utilizadas en actividades físicas en la naturaleza en donde el diálogo con el docentes sobre sus uso, da pie a establecer un sistema de evaluación sobre su manejo basado en el diálogo, la interacción y la implicación de los estudiantes.

Para el trabajo en equipo, se aprecia la presencia de sistemas de calificación a partir autoevaluación, la autocalificación desde la coevaluación entre compañeros, pero también la evaluación decidida por el profesorado a partir de la preferencia por la valoración de los productos académicos resultantes de los trabajos grupales, que como se ha explicado atiende más al contenido disciplinar que a los procesos de trabajo en equipo generados a través del método de trabajo grupal aplicado. Finalmente en relación al desarrollo de sus habilidades para las relaciones interpersonales, son los sistemas de calificación participados los que prevalecen como ayudas formativas en la formación recibida por los estudiantes, principalmente provenientes de las relaciones de coevaluación establecidas entre compañeros

Atendidos los objetivos el estudio, se puede establecer en relación al objeto general de la investigación, que la contribución de la FIPEF al desarrollo de las 
competencias objeto de estudio se relaciona en gran medida con las dinámicas de desarrollo de los contenidos disciplinares, asumiendo que desde la implicación de los estudiantes en su aprendizaje se aumenta la percepción de desarrollo competencial en estos. La participación de estos en las dinámicas de funcionamiento de las materias a cursar siendo protagonistas de ellas, mediante la utilización de métodos activos y estrategias de evaluación formativa, facilita la toma de conciencia competencial, la reflexividad al respecto, la mejora desde la propia acción y el acceso a otros grados de desarrollo competencial, dotando a la formación a cursar de un carácter profesionalizador. 


\section{DEBILIDADES Y FORTALEZAS DEL ESTUDIO}

En relación al cuestionario, dado que la presente tesis forma parte de un proyecto de investigación $\mathrm{I}+\mathrm{D}+\mathrm{i}$, de gran calado y amplitud, quizá sea causa de las limitaciones relacionadas con las preguntas y sus items que, para el caso de las competencias genéricas, se considera no han recogido suficientemente otras presentes en los Libros Blancos y de importante presencia en el contexto profesional docente como el liderazgo, el reconocimiento de la diversidad y la multiculturalidad o la toma de decisiones y la resolución de problemas.

También se encuentran algunas carencias sobre competencias consideradas como transversales y presentes en otros bloques de preguntas, enunciadas con mínimos matices en su formulación, pudiendo ser respondidas en un mismo sentido (por ejemplo el item 1.30, trabajar en equipo, y el item 2.5, trabajar en quipo con otros docentes). De la misma manera para el caso de la pregunta 4 sobre metodologías activas, quizá hubiera tenido mayor valor ahondar en su tipología contemplando algunos procedimientos metodológicos de impacto en la actualidad, como por ejemplo el aprendizaje cooperativo, el aprendizaje servicio o los métodos integrados para la enseñanza de las lenguas, a fín de valorar su presencia y la posible infuencia para la adquisición y desarrollo de las competencias en estudio.

En relación a la recogida de información cualitativa, se considera necesario recopilar una información más pormenorizada quizá mediante entrevistas en profundidad a estudiantes de cuarto curso de grado, para abordar directamente y de forma extensa su percepción sobre el desarrollo formativo de las competencias objeto de estudio. Se ha observado que los grupos de discusión en ocasiones dejan pasar aspectos relevantes para la investigación que por la naturaleza del debate no son abordados en profundidad y quizá, pudieran encontrarse ahí, muchas más respuestas para comprender el desarrollo de las competencias en la formación superior. 
No obstante entre las fortalezas de la metodología empleada, el haber integrado dos métodos, cuantitativo y cualitativo, en un tercero que auna lo mejor de cada uno, ha permitido comprender y explicar la forma en la que se aborda la FIPEF en relación al desarrollo de las comeptencias en estudio. La información cuantitativa recabada ha podido ser mejor entendida, interpretada y explicada, encontrando gracias a la información cualitativa obtenida, respuestas a las paradojas y las contradicciones encontradas cuando se contrastaban ambas informaciones.

También entre las fortalezas se encuentra el ejercicio realizado de profundización en cada competencia seleccionada y estudiada, tanto en relación con las dinámicas formativas que ayudan en su construcción, como en el uso de las metodologías y de la evaluación como integrantes de la FIPEF para desarrollarlas. El estudio específico de cada competencia atendiendo los aspectos estructurales mencionados de dicha formación, dan cuenta sobre qué se atiende en ella, de qué forma se presenta a los estudiantes y cómo se evalúa, obteniendo información sobre si estas contribuciones favorecen el desarrollo o no de las competencias de los estudiantes y en qué grado o medida.

De la misma manera el haber atendido a los dos grupos de estudiantes y a las facultades de origen de estos, permite mapear el estado de la cuestión de forma localizada, sirviendo para las instituciones universitarias de referencia para conocer de qué forma contribuyen en las titulaciones que imparten al desarrollo de las competencias que están marcadas en los planes de estudios. 


\section{LINEAS DE INVESTIGACIÓN FUTURAS}

El estudio a cerca de cómo los estudiantes adquieren y desarrollan sus competencias transversales, requiere conocer en mayor profundidad cómo se desarrollan los procesos de evaluación durante la formación que cursan. Una de las lecturas que se pueden hacer alrededor del estudio realizado es la relacionada con la evaluación de competencias transversales, pues como se ha encontrado en el estudio, se sabe que el espíritu de participación e implicación del estudiantado favorece la toma de conciencia y su despertar competencial, pero quizá sea necesario profundizar en la evaluación, qué hacer y cómo hacer, para consecuentemente favorecer su desarrollo.

Puede ser objeto de investigación la realización de estudios prolongados en el tiempo en relación a la forma en la que se evalúan competencias de difícil valoración como el trabajo en equipo, la creatividad, el liderazgo o el aprendizaje autónomo, que por su consideración de proceso y por estar atravesadas por otras competencias que las constituyen, caracterizan y dimensionan, resultan difíciles de ser evaluadas, no ofreciendo respuestas claras sobre el grado de adquisición y desarrollo a los estudiantes.

Sería interesante también realizar estudios de campo en las prácticas formativas de la FIPEF de cara a conocer en situación, la propia acción docente, de qué forma resuelven los estudiantes de EF los problemas reales que se encuentran en los centros educativos de destino, estableciendo dispositivos de registro de información para recoger los éxitos y limitaciones competenciales de forma que pudieran ser atendidos pormenorizadamente, optimizando el valor del Practicum más allá del planteamiento de base de este, por el que se acude a los centros a experimentar en lo nuclear de la función docente como es la impartición. Se considera que generar procesos de reflexión competencial durante los periodos de Practicum, puede ayudar a establecer una mayor relación entre la formación inicial cursada y el ejercicio profesional futuro, acortando la brecha entre universidad y escuela. 


\section{REFERENCIAS BIBLIOGRÁFICAS}

Abarca, M., y Sala, J. (2002). Las competencias emocionales de los futuros profesores/as. Revista Electrónica Interuniversitaria de Formación del Profesorado, 5(3), 1-4.

Achtenhagen, F., y Grubb, N. W. (2001). Vocational and ocupational education: Pedagogical complexity, institutional diversity. In V. Richardson (Ed.), Handbook of Research on Teaching (pp. 604-639). Washington: AERA.

Adams-Becker, S., Cummins, M., Davis, A., Freeman, A., Hall-Giesinger, C., y Ananthanarayanan, V. (2017). NMC Horizon Report: 2017 Higher Education Edition. Austin, TX: The New Media Consortium.

Adell, J., y Castañeda, L. (2012). Tecnologías emergentes, ¿pedagogías emergentes?. En J. Hernádez, M. Pennesi, D. Sobrino, y A. Vázquez (Eds.), Tendencias emergentes en educación con Tic (pp. 13-32). Barcelona: Asociación Espiral, Educación y Tecnología.

Aguerrondo, I. (2009). Conocimiento complejo y competencias educativas. IBE/UNESCO Working Papers on Curriculum Issues(8), 1-11.

Aguilera, A. (2018). ¿Cómo valoran los estudiantes de magisterio la docencia que reciben? Revista Fuentes, 20(1), 57-76.

Aitken, J. (1993). National vocational qualifications: A review. Electrotecnology, 1922.

Alarcón, G., y Guirao, C. (2014). El enfoque de las capacidades y las competencias transversales en el EEES. Historia y Comunicación Social, 18.

Alcalá, V., Camacho, M., Giner, D., Giner, J., e Ibáñez, E. (2006). Afectos y género. Psicothema, 18(1), 143-148.

Alcaraz, N. (2016). La evaluación a través de portafolios: ¿una ocasión para el aprendizaje? Revista Iberoamericana de Evaluación Educativa, 9(1), 31-46.

Allan, J., Clarke, K., y Jopling, M. (2009). Effective teaching in higher education: perceptions of first year undergraduate students. International Journal of Teaching and Learning in Higher Education(21), 362-372. 
Almerich, G., Suárez, J., Orellana, N., Belloch, C., Bo, R., y Gastaldo, I. (2005). Diferencias en los conocimientos de los recursos tecnológicos en profesores a partir del género, edad y tipo de centro. Revista Electrónica de Investigación y Evaluación Educativa, 11(2), 127-146.

Almirall, L., y Besora, V. (2015). "Sense limits" (sin límites). Un proyecto colaborativo interdisciplinar. Tándem. Didáctica de la Educación Física(50), 71-77.

Alonso, J. I., Gea, G., y Yuste, J. L. (2013). Formación emocional y juego en futuros docentes de Educación física. Revista interuniversitaria de formación del profesorado, 16(1), 97-108.

Alonso, L. E., Fernández, C. J., y Nyssen, J. M. (2009). El debate sobre las competencias. Una investigación cualitativa en torno a la educación superior y el mercado de trabajo en España. Madrid: ANECA.

Alonso, P. (2008). La formación en competencias del profesorado de Magisterio en la especialidad de Educación Física. Educar(42), 63-77.

Alonso-Cortés, M. D., Díez-Fernández, A., Pérez-Pueyo, A., Domínguez, R., González, I., y Gutiérrez, C. (2017). La evaluación de competencias y subcompetencias a través de procesos de evaluación formativa con portafolio y rúbricas en el Máster de formación del profesorado. En V. López-Pastor y A. Pérez-Pueyo (Eds.), Evaluación formativa y compartida en educación: experiencias de éxito en todas las etapas educativas (pp. 386-401). León: Universidad de León.

Álvarez, E., Iglesias, M. T., y García, M. S. (2008). Desarrollo de competencias en el Prácticum de Magisterio. Aula Abierta, 36(1-2), 65-78.

Álvarez, J. M. (2005). Evaluar para conocer, calificar para excluir. Madrid: Morata.

Álvarez, M., Asensio, I., y García, J. (2013). Deporte y competencias genéricas en la universidad: diseño y validación del "competest". Revista complutense de educación, 24(1), 141-163.

Álvarez, M. M. (2011). Perfil del docente en el enfoque basado en competencias. Revista Electrónica Educare, XV(1), 99-107.

Álvarez-Gayou, J. L. (2003). Cómo hacer investigación cualitativa. Fundamentos y metodología. México, DF: Paidós. 
American Psychological Association (2010). Publication manual of the American Psychological Association. Washington

Amoros, A. J., y Horn, T. S. (2000). Intrinsic motivation: relationships with collegiate athletes' gender, scholarship status, and perceptions of their coaches' behavior. Journal of Sport and Exercise Psychology(22), 63-84.

Anderson, N. (2008). Learning Strategies. Handbook of Research in second language teaching and learning. Hinkel Seatle University. NY: Routledge.

André, A., Louvet, B., y Deneuve, P. (2013). Cooperative group, risk- taking and inclusion of pupils with learning disabilities in physical education. British Educational Research Journal, 39(4), 677-693.

ANECA. (2005a). Libro Blanco. Título de Grado en Magisterio. Madrid: Agencia Nacional de la Evaluación de la Calidad y la Acreditación.

ANECA. (2005b). Libro Blanco. Título de Grado en Ciencias de la Actividad Física y el Deporte. Madrid: Agencia Nacional de Evaluación de la Calidad y la Acreditación.

ANECA. (2007). El profesional flexible en la sociedad del conocimiento. Madrid: Agencia Nacional de la Evaluación de la Calidad y la Acreditación.

Angola, J., y Zambrano, G. (2016). El portafolio de valoración como estragegia de evaluación en la producción escrita del inglés. Acción Pedagógica(25), 48-59.

Anguita, R. (1997). Algunas claves de la historia de la Formación del Profesorado en España para comprender el presente. Revista interuniversitaria de formación del profesorado(30), 97-109.

Angulo, J. F. (1990). Etnografía y currículum. In J. B. Martínez (Ed.), Hacia un enfoque interpretativo de la enseñanza (pp. 85-110): Universidad de Granada.

Angulo Rasco, J. F. (2008). La voluntad de distracción: las competencias en la universidad. In J. Gimeno Sacristán (Ed.), Educar por competencias: ¿qué hay de nuevo?. Madrid: Morata.

Antunes, I., Serpa, S., y Carita, I. (1998). Liderazgo y satisfacción en la educaicón física. Revista de Psicología del Deporte, 8(1), 147-162. 
Aparicio, J. L., y Fraile, A. (2014). Las competencias interpersonales en la formación del profesorado de educación física a través de un programa de expresión corporal. International Journal for 21st Century Education, 10, 21-34. http://goo.gl/9ndWF5) (2017-03- 22.

Aparicio, J. L., Fraile, A., y Velasco, S. (2017). El uso del vídeo para el análisis competencial de la práctica docente en la formación del profesorado de educación física. En A. P. Costa, P. Alexandre, S. Oliveira, \& R. Arellano (Eds.), Investigação Qualitativa na Educação (Vol. 1, pp. 230-235). Aveiro: Ludomedia.

Aramendi, P., Bujan, K., Garín, C., y Vega, A. (2014). Estudio de caso y aprendizaje cooperativo. Profesorado. Revista de Currículum y Formación del Profesorado, $18(1), 413-429$.

Aranda, M., Puentes, R., y Antequera, J. M. (2008). Competencias profesionales desde el punto de vista de los empleadores, ex alumnos y alumnos de la Universidad de Jaén Universidad, Sociedad y Mercados Globales (pp. 437-451): Asociación Española de Dirección y Economía de la Empresa (AEDEM).

Area, M. (2004). De la biblioteca al Centro de Recursos para el Aprendizaje e Investigación. Madrid: Dirección General de Universidades. Ministerio de Educación y Ciencia.

Area, M., Gutiérrez, A., y Vidal, F. (2012). Alfabetización digital y competencias informacionales. Barcelona: Fundación Telefónica.

Arévalo, M. (2007). La tecnología al servicio de la actividad física y el deporte. Tándem. Didáctica de la Educación Física(25), 6-12.

Arévalo, M. (2016). De la tecnología a la Educación Física. Tándem. Didáctica de la Educación Física(53), 7-11.

Argote, L., Gruenfeld, D., y Naquin, C. (2001). Group learning in organizations. In M. E. Turner (Ed.), Groups at work: Advances in Theory and research. Mahwah: Lawrence Erlbaum. 
Arias, M., Torres, T., y Yáñez, J. C. (2014). El desarrollo de competencias digitales en la educación superior. Historia y Comunicación Social, 19, 355-366. doi:http://dx.doi.org/10.5209/rev_HICS.2014.v19.44963.

Aristizábal, P., y Cruz, E. (2018). Desarrollo de la competencia digital en la formación inicial del profesorado de educación infantil. Píxel-Bit. Revista de Medios y Educación(52), 97-110.

Armengol, C., Castro, D., Jariot, M., Massot, M., y Sala, J. (2011). El practicum en el Espacio Europeo de Educación Superior (EEES): mapa de competencias del profesional de la educación. Revista de Educación(354), 71-98.

Armour, K. (2014). Pedagogical cases in physical education and youth sport. Oxford: Routledge.

Aronson, E., Blaney, N., Stephan, C., Sikes, J., y Snapp, M. (1978). The jigsaw classroom. Beverly Hills, CA: SAGE.

Arribas, H., Blas, D., Cabanas, V., De las Heras, A., Flórez, E., y Talegón, J. (2008). Una puerta (entre) abierta: oportunidades educativas en el medio natural. Ágora para la EF y el Deporte(7-8), 7-34.

Arribas, J. M., Manrique, J. C., y Tabernero, B. (2016). Instrumentos de evaluación utilizados en la formación inicial del profesorado y su coherencia para el desarrollo de competencias profesionales en los estudiantes: visión del alumnado, egresados y profesorado. Revista Complutense de Educación, 27(1), 237-255. doi:10.5209/rev_RCED.2016.v27.n1.45724.

Ashouri, A. F., y Fotovatnia, Z. (2010). The effect of individual differences on learners' translation belief in EFL learning. English Language Teaching, 3(4), 228-236.

Askew, S., y Lodge, C. (2000). Gifts, ping-pong and loops: Linking feedback and learning. IE S. Askew (Ed.), Feedback for learning (pp. 1-17). London: Routledge.

Asún, S., Fraile, A., y Romero, M. R. (2016). Cooperación interuniversitaria de profesorado para diseñar y optimizar una evalución entre iguales y su calificación. Comunicación presentada en las 1ras. Jornadas de Buenas Prácticas en Evaluación Formativa en Docencia Universitaria, Léon. 
Asún, S., Rapún, M., y Romero, M. R. (2019). Percepciones de estudiantes universitarios sobre una evañuación formativa en el trabajo en equipo. Revista Iberoamerica de Evalaución Educativa, 12(1), 175-192.

Asún, S., Aparicio, J. L., Romero, M. R. y Fraile, A. (pendiente). Problemas en la gestión del feedback en la formación del profesorado de Educaión Física. Retos: Nuevas tendencias en Educación Física, Deporte y Recreación.

Atienza, R., y Gómez-Gonzalvo, F. (2016). El edublog. Una herramienta para la adquisición de la competencia del tratamiento de la información y competencia digital desde la educación física. Revista Española de Educación Física y Deportes(402), 27-45.

Atienza, R., Valencia-Peris, A., Martos-García, D., López-Pastor, V., y Devís-Devís, J. (2016). La percepción del alumnado universitario de educación física sobre la evaluación formativa: ventajas, dificultades y satisfacción. Movimento, 22(4), 1033-1047.

Aubrun, S., y Orifiamma, R. (1990). Les competences de 3ème dimension. París: Conservatoire des Arts et Metiers.

Baena-Extremera, A., y Granero-Gallegos, A. (2008). Las actividades físicas en la naturaleza en el currículum actual: contribución a la educación para la ciudadanía y los derechos humanos. Retos: Nuevas tendencias en Educación Física, Deporte y Recreación(14), 48-53.

Balanskat, A., Blamire, R., y Kefala, S. (2006). The ICT Impact Report: A review of studies of ICT impact on schools in Europe, European Schoolnet. Luxembourg: European Comission.

Ballester, R., y Gil, M. D. (2002). Habilidades sociales. Madrid: Síntesis.

Bandow, D. (2001). Time to create sound teamwork. The Journal for Quality and Participation(24), 41-47.

Bar-On, R. (2000). Emotional and social intelligence: Insights from the Emotional Quotient Inventory (EQ-i). En R. Bar-On y J. Parker (Eds.), The handbook of emotional intelligence: theory, development, assessment, and application at 
home, school, and in the workplace (pp. 363-387). San Francisco, CA: JosseyBass Inc.

Barahona, J. (2012). La enseñanza de la Educación Física implementada con TIC. Educación Física y Deporte, 31(2), 1047-1056.

Barba, J., Martínez, S., y Torrego, L. (2012). El proyecto de aprendizaje cooperativo: una experiencia en el grado de maestra de Educación Infantil. REDU : Revista de Docencia Universitaria, 10(1), 123-144.

Barbour, R. (2014). Los grupos de discusión en la investigación cualitativa. Madrid: Narcea.

Barbour, R., y Kitzinger, J. (1999). Developing Focus Group Research: Politics, Theory and Practice. London: Sage.

Barceló, M. L., y Ruiz-Corbella, M. (2015). Las competencias profesionales del maestro de educación primaria desde la perspectiva del maestro tutor del centro de prácticas. Revista Fuentes(17), 17-39.

Barfield, R. (2003). Students perceptions of and satisfaction with group grades and the group experience in the college classroom. Assessment \& Education in Higher Education, 28(4), 355-364.

Barnett, R. (2001). Los límites de la competencia. El conocimiento, la educación superior y la sociedad. Barcelona: Gedisa.

Barraycoa, J., y Lasaga, O. (2009). Competencias e inserción laboral: un análisis de la empleabilidad en los recién licenciados en Ade y Economía. Madrid: CEU Ediciones.

Barraycoa, J., y Lasaga, O. (2010). La competencia de trabajo en equipo: más allá del corta y pega. Vivat Academia(11), 1-5.

Barrett, T. (2005). Understanding problem-based learning. En T. Barrett, I. MacLabharainm, y H. Fallon (Eds.), Handbook of enquiry and problem-based learning (pp. 13-25). Galway: CELT.

Barrientos, E., y López-Pastor, V. (2017). Evaluación orientada al aprendizaje en educación superior: últimas tendencias. Infancia, Educación y Aprendizaje, 3(2), $582-587$. 
Barrionuevo, E. F. (2011). El valor del realismo en las tareas de educación física bilingüe. Revista Digital Educativa Wadi-red, 1(1), 27-32.

Barriopedro, M. I., López de Subijana, C., Gómez, M. A., y Rivero, A. (2016). La coevaluación como estrategia para mejorar la dinámica del trabajo en grupo: una experiencia en Ciencias del Deporte. Revista complutense de educación, 27(2), $571-584$

Barrows, H. S. (1986). A taxonomy of problem-based learning methods. Medical Education, 20(6), 481-486.

Bartual, M. T., y Turmo, J. (2016). Educación Superior y competencias para el empleo. El punto de vista de los empresarios. Revista complutense de educación, 27(3), 1211-1228.

Basso-Aranguiz, M., Bravo-Molina, M., Castro-Riquelme, A., y Moraga-Contreras, C. (2018). Propuesta de modelo tecnológico para Flipped Classroom (T-Flic) en educación superior. Revista Electrónica Educare, 22(2), 1-17.

Becerril, R., y Bores, N. (2015). Posibilidades educativas e intergeneracionales de la orientación deportiva: investigando desde la práctica en el medio natural. EBM. Revista de Ciencias del Deporte, 11, 27-28.

Belmonte, M. L., García, M. P., y Galián, B. (2016). Blogfolio. Aprendiendo a través de la evaluación. Revista Electrónica Interuniversitaria de Formación del Profesorado, 19(3), 25-33.

Beneitone, P., Esquetini, C., González, J., Marty Maletá, M., Siufi, G., y Wagenaar, R. (2007). Reflexiones y perspectivas de la Educación Superior en América Latina. Informe Final Proyecto Tuning América Latina: 2004-2007. Bilbao: Universidad de Deusto.

Benítez, O. (2007). Las tareas comunicativas en el aprendizaje de lenguas extranjeras: una alternativa para el desarrollo de habilidades comunicativas. Revista Iberoamericana de Educación, 42(5), 1-10.

Bergmann, J., y Sams, A. (2012). Flip your classroom. Reach every student in every class every day. U.S.A.: International Society for technology in education. 
Bergua, J. A. (2011). Estilos de investigación social. Técnicas, epistemología, algo de anarquía y una pizca de sociosofía. Zaragoza: Prensas Universitarias de Zaragoza.

Bernard, M. (1980). El cuerpo. Buenos Aires: Paidós.

Berraza, A. (2007). La formación docente bajo una conceptualización comprehensiva y un enfoque por competencias. Estudios Pedagógicos, 33(2), 131-153.

Bisquerra, R. (2005). La educación emocional en la formación del profesorado. Revista interuniversitaria de formación del profesorado(54), 95-114.

Bisquerra, R. (2009). Métodología de la investigación educativa. Madrid: La Muralla.

Bisquerra, R. (2003). Educación emocional y competencias básicas para la vida. Revista de investigación educativa, 21(1), 7-43.

Bisquerra, R., \& Pérez-Escoda, N. (2007). Las competencias emocionales. Educación $X X 1(10), 61-82$.

Blanco, A. (2010). Desarrollo y evaluación de competencias en Educación Superior. Madrid: Narcea.

Blasco, J. E., Mengual, S., y Roig, R. (2011). Competencias tecnológicas en el espacio europeo de educación superior. Propuesta de formación del maestro especialista en educación física. Revista de currículum y formación del profesorado, 11(2), $2-16$

Blázquez, D. (2016). Competencias docentes para ser mejor profesor de Educación Física. La gestión didáctica de la clase. Barcelona: Inde.

Bolívar, A. (2008). El discurso de las competencias en España: educación básica y educación superior. REDU : Revista de Docencia Universitaria, 2(3), 1-23.

Bolliger, D., y Shepherd, C. (2010). Student perception of ePortfolio integration in online courses. Distance Education, 31(3), 294-314.

Boned, C., Rodríguez, G., Mayorga, J., y Merino, A. (2006). Competencias profesionales del licenciado en ciencias de la actividad física y el deporte. European Journal of Human Movement(15), 1-23. 
Bonsón, M., y Benito, Á. (2005). Evaluación y aprendizaje. En Á. Benito y A. Cruz (Eds.), Nuevas claves para la docencia universitaria en el Espacio Europeo de Educación Superior. Madrid: Narcea.

Borrell, F. (1998). Como trabajar en equipo. Barcelona: Gestion 2000.

Boston, C. (2002). The concept of formative assessment: ERIC Digest.

Boud, D., y Falchikov, N. (2007). Rethinking Assessment in Higher Education. Learning for the long term. London: Routledge.

Boud, D., y Molloy, E. (2013). Rethinking models of feedback for learning: the challenge of design. Assessment and Evaluation in Higher Education, 38(6), 698-712.

Bovill, C., y Bulley, C. J. (2011). A model of active student participation in curriculum design: Exploring desirability and possibility. En C. Rust (Ed.), Improving student learning global theories and local practices: Institutional, disciplinary and cultural variations (pp. 176-188). Oxford: The Oxford Centre for Staff and Educational Development.

Bretones, A. (2006). La participación del alumnado en la evaluación de sus aprendizajes. Kikiriki, 65, 6-15.

Bretones, A. (2008). Participación del alumnado de educación superior en su evaluación. Revista de educación(347), 181-202.

Bricall, J. M. (2000). Informe Universidad 2000. Conferencia de Rectores de las Universidades Españolas (CRUE). Retrieved from https://www.oei.es/historico/oeivirt/bricall.htm

Brinton, D. M., Snow, M. A., y Wesche, M. B. (1989). Content-based second language instruction. Boston: Heinle and Heinle.

Brown, H. (2007). Principles of language learning and teaching. White Plains, NY: Pearson Education.

Brown, H. D. (1994). Principles of foreign language learning and teaching. Englewood Cliffs, New Jersey: Prentice-Hall.

Brown, S., y Glasner, A. (2003). Evaluar en la universidad. Problemas y nuevos enfoques. Madrid: Narcea. 
Brown, S., y Pickford, R. (2013). Evaluación de habilidades y competencias. Madrid: Narcea.

Bryman, A. (2008). Why do research. Integrate / Combine / Mesh / Blend / Mix / Merge / Fuse. Quantitative an Qualitative research? In M. M. Bergman (Ed.), Advances in Mixed Methods Research (pp. 87-100). London: SAGE.

Bullock, D. (2004). Moving from theory to practice: an examination of the factors that preservice teachers encounter as they attempt to gain experience teaching with technology during field placement experiences. Journal of Technology and Teacher Education, 12(2), 211-237.

Bunk, G. (1994). La transmisión de las competencias en la formación y perfeccionamiento profesionales de la RFA. Revista Europea de Formación Profesional(1), 8-14.

Burbules, N. (2012). El aprendizaje ubicuo y el futuro de la enseñanza. Encounters on education(13), 3-14.

Burdett, J. (2007). Degrees of separation balancing intervention and independence in group work assignments. The Australian Educational Researcher, 34(1), 55-71.

Burms, R. W., \& Klingstedt, J. L. (1981). Competency Based Education. An Introduction. Englewood Cliffs: Educational Technology Publications.

Buscà, F., y Capllonch, M. (2008). De las competencias básicas a las competencias profesionales transversales. Aportaciones desde el ámbito de la educación física. Tándem: Didáctica de la educación física(26), 34-51.

Buscá, F., Rivera, E., y Trigueros, C. (2012). La credibilitat dels sistemes d'avaluació formativa en la formació inicial del professorat d' educació física. Temps d'Educació(43), 167-184.

Caballero, A. (2004). Cómo enfocar la educación emocional dentro del aula desde la perspectiva de género. Paper presented at the Conferencia Internacional Orientación, Inclusión Social y desarrollo de la carrera, La Coruña.

Caballero, P. (2012). Potencial educativo de las actividades físicas en el medio natural: Actividades de colaboración simple. EmasF. Revista digital de Educación Física, 19(99-14). 
Caballero, P., Domínguez, G., y Arjona, J. A. (2016). Senderismo 2.0. Tándem. Didáctica de la Educación Física(53), 19-25.

Cabero, J., Castaño, C., Cebreiro, B., Gisbert, M., Martínez, F., Morales, J. A., . . . Salinas, J. (2003). Las nuevas tecnologías en la actividad universitaria. Pixel-Bit. Revista de Medios y Educación(20), 81-100.

Cabero, J., y Llorente, M. C. (2006). Capacidades tecnológicas de las TIC por los estudiantes. Enseñanza(24), 159-175.

Cabrera, J. S., y Fariñas, G. (2005). El estudio de los estilos de aprendizaje desde una perspectiva vigoskiana: una aproximación conceptual. Revista Iberoamericana de Educación(37), 1-9.

Camacho, H., y Padrón, M. (2006). Malestar docente y formación inicial del profesorado: percepciones del alumnado. Revista interuniversitaria de formación del profesorado, 20(2), 209-230.

Cannon-Bowers, J. A., Tannenbaum, S. I., Salas, E., y Volpe, C. E. (1995). Defining competencies and establishing team training requirements. En A. Guzzo y E. Salas (Eds.), Team effectiveness and decision making in organizations. San Francisco (CA): Jossey-Bass.

Cano, E. (2005). Cómo mejorar las competencias de los docentes. Guía para la autoevaluación y el desarrollo de las competencias del profesorado. Barcelona: Graó.

Cano, E., Portillo, M. C., y Puigdellívol, I. (2014). Evaluación de competencias en los entornos de practicum de los estudios de magisterio mediante el uso de blogs. Tendencias pedagógicas(23), 9-28.

Cantón, I., Cañón, R., y Arias, A. R. (2013). La formación universitaria de los maestros de Educación Primaria. Revista interuniversitaria de formación del profesorado(76), 45-63.

Cañadas, L. (2018). La evaluación formativa en la adquisición de competencias docentes en la formación inicial del profesorado de Educación Física. (Tesis Doctoral), Universidad Autónoma de Madrid. 
Cañadas, L., Castejón, J., y Santos-Pastor, M. L. (2018). Relación entre la participación del alumnado en la evaluación y la calificación en la formación inicial del profesorado de educación física. Cultura, Ciencia y Deporte, 13, 291-308.

Cañadas, L., Santos-Pastor, M. L., y Castejón, F. J. (2017). Diferencias en las formas de calificación empleadas por el profesorado universitario. Infancia, Educación y Aprendizaje, 3(2), 600-605. doi:10.22370/ieya.2017.3.2.787

Cañadas, L., Santos-Pastor, M. L., y Castejón, F. J. (2019). Percepción de egresados y profesorado sobre la implicación del alumnado en la evaluación y la calificación en Educación Superior. Revista Iberoamericana de Evaluación Educativa, 12(1), 193-209. doi:10.15366/riee2019.12.1.011

Caprara, G. V., y Steca, P. (2005). Affective and social self-regulatory efficacy beliefs as determinants of positive thinking and happiness. European Psychologist, 10(4), 275-286.

Caprara, G. V., Steca, P., Zelli, A., y Capanna, C. (2005). A new scale for measuring adults' prosocialness. European Journal of Psychological Assessment, 21(2), 77-89.

Carless, D. (2016). Feedback as dialogue. Encyclopedia of educational philosophy and theory. Hong Kong: University of Hong Kong, .

Carneiro, R., Toscano, J. C., y Díaz, T. (2009). La integración de las TIC en instituciones educativas. Los desafios de las TIC para el cambio educativo. Madrid: Organización de Estados Iberoamericanos.

Carot, J. M., Conchado, A., Mora, J. G., y Vila, L. (2011). La opinión de los graduados europeos sobre la universidad cinco años después de haber finalizado sus estudios. Papers, 94(4), 1245-1261.

Carr, W., y Kemmis, S. (1988). Teoría crítica de la enseñanza. La investigación-acción en la formación del profesorado. Barcelona: Martínez Roca.

Carrasco, M., Abraldes, A., y Gómez, M. (2012). Utilización de las TIC como recurso metodológico. Propuesta de una WebQuest como aplicación práctica en Actividad Física y Deporte. Actividad fisica y deporte: ciencia y profesión(16), 13-20. 
Carreiro da Costa, F. (2006). La enseñanza de la Educación Física ante la implantación del Espacio Europeo de Educación Superior. Educación Física y Deporte, 25(2), $29-43$.

Carreras, J., y Perrenoud, P. (2005). El debate sobre las competencias en la enseñanza universitaria. Barcelona: ICE Universidad de Barcelona.

Casey, A., Goodyear, V., y Armour, K. (2016). Digital technologies and learning in physical education: pedagogical cases. London: Routledge.

Casey, A., Goodyear, V., y Armour, K. (2017). Rethinking the relationship between pedagogy, technology and learning in healt and physical education. Sport, Education and Society, 22(2), 288-304.

Castejón, J., Capllonch, M., González-Fernández, N., y López-Pastor, V. (2011). Técnicas e instrumentos de evaluación. En V. López-Pastor (Ed.), Evaluación formativa y compartida en educación superior Propuestas, técnicas, instrumentos y experiencias (pp. 65-93). Madrid: Narcea.

Castejón, J. L., Cantero, M. P., y Pérez, N. (2008). Differences in the socio-emotional competency profile in university students from different disciplinary areas. Electronic Journal of Research in Educational Psychology, 6(15), 339-362.

Castellano, J., y Casamichana, D. (2014). Deporte con dispositivos de posicionamiento global (GPS): Aplicaciones y limitaciones. Revista de psicología del deporte, 23(2), 355-364.

Castro-Lemus, N., y Gómez, J. (2016). Incorporating QR codes in Physical Education in Secondary. Retos: Nuevas tendencias en Educación Física, Deporte y Recreación(29), 114-119.

Catalano, R. F., Berglund, M. L., Ryan, J. A., Lonczak, H. S., y Hawkins, D. (2004). Positive youth development in the United States: Research findings on evaluations of positive youth development programs. The Annals of the American Academy of Political and Social Science, 591(1), 98-124.

Cebrián de la Serna, M. (2003). Enseñanza virtual para la innovación universitaria. Madrid: Narcea. 
Cerqueiro, F. (2013). Actividades lúdicas de repaso y su función motivadora en lenguas para fines específicos. Encuentros(22), 38-52.

Chacón, C., y Chacón-Corzo, M. (2011). El uso del portafolio en la enseñanza de Lenguas Extranjeras. Acción Pedagógica(20), 32-41.

Chamot, A. U., y O'Malley, J. M. (1994). The CALLA handbook: Implementing the Cognitive Academic Language Learning Approach. Reading, MA: AddisonWesley Publishing Co.

Chan, M., Rogers, K., Parisotto, K., y Biesanz, J. (2011). Forming first impressions: The role of gender and normative accuracy in personality perception. Journal of Research in Personality, 45(1), 117-120.

Chaplin, C. (Writer). (1936). Modern Times. In U. Artits (Producer). USA.

Charmaz, K. (2006). Constructing grounded theory: a practical guide through qualitative analysis. Thousand, OAK: SAGE.

Chen, G., Donahue, L. M., y Klimoski, R. J. (2004). Training undergraduates to work in organizational teams. Academy of Management Learning and Education, 3(1), $27-40$.

Chickering, A. W., y Gamson, Z. F. (1991). Applying the seven principles for good practice in undergraduate education. New Directions for Teaching and Learning(47), 34-67.

Chomsky, N. (1986). Knowledge of language: its nature, origin and use. New York: Praeger.

Clancy, M. E., y Hruska, B. L. (2005). Developing Language Objetives for English Learners in Physical Education. Journal of Physical Education, Recreation and Dance, 76(4), 30-35.

Clark, A., y Trafford, J. (1995). Boys into modern languages: an investigation of the discrepancy in attitudes and performance between boys and girls in modern languages. Gender and Education(7), 315-325.

Clemente, J. S., y Escribá, C. (2013). Análisis de la percepción de las competencias genéricas en la universidad. Revista de educación(362), 535-561. 
Clety, H. (2009). Dynamiques des représentations et efficacité dans les systèmes "Equipe de Travail". Université Charles-de-Gaulle Lille 3, Lille. Retrieved from https://tel.archives-ouvertes.fr/file/index/docid/463338/filename/HenryCLETY2009.pdf

Collins, K., Onwuegbuzie, A., y Sutton, I. (2006). A model incorporating the rationale and purpose for conducting mixed methods research in special education and beyond. Learning disabilities: a contemporary journal, 4(1), 67-100.

Conchado, A., y Carot, J. M. (2013). Puntos fuertes y débiles en la formación por competencias según los graduados universitarios españoles. Revista de Docencia Universitaria, 11(1), 429-446.

Conde, C., y Almagro, B. (2013). Estrategias para desarrollar la inteligencia emocional y la motivación en el alumnado de Educación Física. E-motion. Revista de Educación, MOtricidad e Investigación(1), 212-220.

Contreras, J. (2010). Ser y saber en la formación didáctica del profesorado: una visión personal. Revista interuniversitaria de formación del profesorado, 68(24,2), 6181.

Contreras, O. (1992). Orígenes y evolución de la Formación Inicial del Profesorado en Educación Física. Revista interuniversitaria de formación del profesorado(15), 73-86.

Coral, J. (2010). L'aprenentatge de l'anglès a través de l'educació física: el programa 'Mou-te i aprèn'. Temps d'educació(39), 149-170.

Coral, J. (2018). Adaptaciones metodológicas de la didáctica de la educación física en los grados universitarios en inglés. El aprendizaje integrado de contenidos y lengua inglesa y la competencia discursiva. En C. Escobar y L. Arnau (Eds.), Los retos de la internacionalización de los grados universitarios en el contexto del Espacio Euriopeo de Educación Superior (pp. 165-186). Madrid: Síntesis.

Coral, J., Esquerda, G., y Benito, J. (2017). Design and validation of a tool to evaluate Physical Education and Language integrated learning tasks. Didacticae(2), 4358. 
Corominas, E. (2001). Competencias genéricas en la formación universitaria. Revista de educación(325), 299-322.

Corominas, E., Tesouro, M., Capell, D., Teixidó, J., Pèlach y Busóm, J., y Cortada, R. (2006). Percepciones del profesorado ante la incorporación de las competencias genéricas en la formación universitaria. Revista de educación(341), 301-336.

Corrales Wade, K. (2009). Construyendo un segundo idioma: el constructivismo y la enseñanza del L2. Zona próxima: revista del Instituto de Estudios Superiores en Educación, 10(156-167).

Corredor, J., y Romero, A. (2008). Planeación, organización y expresión de un tipo de discurso oral: la exposición. Consideraciones, sugerencias y recomendaciones. Cuadernos de Lingüistica Hispánica(12), 57-76.

Correia, S., Da Silva, L., y De Castro, R. M. (2012). Abordagens à aprendizagem, autorregulação e motivação: convergência no desempenho acadêmico excelente. Revista Brasileira de Orientação Profissional, 13(2), 153-162.

Cortina, B. (2011). La expresión oral en lengua inglesa de los futuros maestros: un reto para el ESpacio Europeo de Educación Superior. Porta Linguarum: revista internacional de didáctica de las lenguas extranjeras(16), 155-177.

Creswell, J. (2005). Educational research: planning, conducting and evaluating quantitative and qualitative research. Upper Saddle River, NJ: Pearson.

Creswell, J. (2009). Research design: qualitative and mixed methods approaches. London: SAGE.

Creswell, J. (2013). Qualitative inquiry and research design: choosing among five approaches. London: SAGE.

Creswell, J., y Plano, V. (2007). Designing and conducting Mixed Methods Research. California: Sage Publications, Inc.

Cózar, R., Hernández, J. L., Hernández, J. A., de Moya, M. V., y Guerrero, Ó. (2002). El tratamiento de la competencia digital en el grado de maestro en educación primaria de la facultad de Albacete. Comunicación presentada en las XXII Jornadas Universitarias de Tecnología Educativa, Toledo. 
Cózar, R., y Roblizo, M. J. (2014). La competencia digital en la formación de los futuros maestros: percepciones de los alumnos de los Grados de Maestro de la Facultad de Educación de Albacete. Revista Latinoamericana de Tecnología Educativa, 13(2), 119-133.

Cuadrado, C., Fernández-López, F., Fernández-López, M., Fernández-Pacheco, C., González, D., y Lifante, I. (2012). Técnicas de trabajo en equipo para estudiantes universitarios. Comunicación presentada en las X Jornadas de redes de investigación en docencia universitaria, Alicante.

Cuervo, A. M., Alonso, R. M., y Sabadell, M. (2013). Reflexiones en torno a la lengua francesa en Castilla y León: secciones bilingües y formación de los profesores de disciplinas no lingüísticas (DNL). Revista de Docencia Universitaria, 11(1), 365-388.

Da Silva, J. A., y Boruchovitch, E. (2014). Self-regulated learning in students of pedagogy. Revista Paideia, 24(59), 323-330. doi:10.1590/198243272459201406

Dalton-Puffer, C. (2011). Content-and-language integrated learning: from practice to principles. Annual Review of Applied Linguistics(31), 182-204.

Danielson, C. (2011). Competencias docentes: desarrollo, apoyo y evaluación. Santiago de Chile: CINDE y Diálogo Iberoamericano.

Darnis, F., y Lafont, L. (2013). Cooperative learning and dyadic interactions: two modes of knowledge construction in socio- constructivist settings for team-sport teaching. Physical Education and Sport Pedagogy, 20(5), 459-473.

De la Maya, G., y Luengo, R. (2015). Teacher training programs and development of plurilingual competence. In D. Marsh, M. L. Pérez Cañado, \& J. Ráez Padilla (Eds.), CLIL in action: voices from the classroom (pp. 114-129). Newcastle upon Tyne: Cambridge Scholars Publishing.

De la Orden Hoz, A. (2011). El problema de las competencias en la educación general. . Bordón, 63(1), 47-61.

De Miguel, M. (2005a). Cambio de paradigma metodológico en la Educación Superior. Exigencias que conlleva. Cuadernos de Integración Europea(2), 16-27. 
De Miguel, M. (2005b). Modalidades de enseñanza centradas en el desarrollo de competencias. Orientaciones para promover el cambio metodológico en el Espacio Europeo de Educación Superior. Oviedo: Universidad de Oviedo.

De Miguel, M., Alfaro, I. J., Apodaca, P., Arias, J. M., García, E., y Pérez, A. (2005). Adaptación de los planes de estudio al proceso de convergencia europea. Oviedo: Ediciones de la Universidad de Oviedo.

De Rueda, B., y López, C. (2013). Música y programa de danza creativa como herramienta expresión de emociones. Retos: Nuevas tendencias en Educación Física, Deporte y Recreación(24), 141-148.

De Vargas, E. (2006). La situación de enseñanza y aprendizaje como sistema de actividad: el alumno, el espacio de interacción y el profesor. Revista Iberoamericana de Educación, 39(4), 1-10.

Del Canto, P., Gallego, I., López, J. M., Mora, J., Reyes, A., Rodríguez, E., . . V Valero, M. (2009). Conflictos en el trabajo en grupo: cuatro casos habituales. Revista de Formación e Innovación Educativa Universitaria, 2(4), 344-359.

Del Castillo, H., Herrero, D., García, A. B., Checa, M., y Monjelat, N. (2012). Desarrollo de competencias a través de los videojuegos deportivos: alfabetización digital e identidad. Revista de Educación a Distancia(33), 2-22.

Delgado, A. (2006). Evaluación de competencias en el Espacio Europeo de Educación Superior. Barcelona: JM Bosch Editor.

Delgado, A., y Oliver, R. (2009). Interacción entre evaluación contínua y autoevalución formativa: la potenciación del aprendizaje autónomo. Revista de Docencia Universitaria(4), 1-13.

Delgado, V., Hortigüela, D., Ausín, V., y Abella, V. (2018). El Blog como instrumento de mejora para la autorregulación del aprendizaje del estudiante universitario. Estudios Pedagógicos, 44(2), 171-184.

Deller, S., y Price, C. (2007). Teaching Other Subjects Through English. Oxford: Oxford University Press.

Delors, J. (1996). La educación encierra un tesoro. Informe a la UNESCO de la Comisión Internacional sobre Educación para el Siglo XXI. Madrid: Santillana. 
Denis, M., Hamarta, E., y Ari, R. (2005). An investigation of social skills and loneliness levels of university students with respect to their attachment styles in a sample of turkish students. Social Behavior and Personality, 33(1), 19-32.

Denton, D. (2014). Using screen capture feedback to improve academic performance. Tench trends. Linking Research and Practice to Improve Learning, 58(6), 51-56.

Denzin, N., \& Lincoln, Y. (2005). The Sage Handbook of Qualitative Research. Thousand Oaks: SAGE.

DeSeCo. (2005). The definition ans selection of key competencies. Executive summary.

Devís, J. (1996). Educación Física, deporte y currículum. Investigación y desarrollo curricular. Madrid: Apendizaje visor.

Devos, N. (2012). Content and language integrated learning in physical education: Evidence for language and content scaffolding during peer interaction. En P. Lennon (Ed.), Learning autonomy in the english classroom: empirical studies and Ideas for teachers. Francfort: Peter Lang.

Dey, I. (1993). Qualitative data analysis: A user-friendly guide for social scientists. London: Routledge.

Díaz Barahona, J. (2012). La enseñanza de la Educación Física implementada con TIC. Revista Educación física y deporte, 31(2), 1047-1056.

Díaz Barriga, F. (2006). Enseñanza situada: vínculo entre la escuela y la vida. México D.F.: McGraw-Hill.

Díaz Barriga, F., y Pérez, M. (2010). El portafolio docente a escrutinio: sus posibilidades y restricciones en la formación y evaluación del profesorado. Observar(4), 6-27.

Díaz del Cueto, M. (2013). Cómo se forma el profesorado de Educación Física. Las competencias en los planes de formación. Tándem. Didáctica de la Educación Física(43), 28-38.

Díaz, M. (1993). Evaluación participativa en la universidad: una aventura formativa. Revista de Enseñanza Universitaria(6), 111-121.

Díaz-Granados, D., y Salas, E. (2008). Temas emergentes y conclusiones en la investigación a cerca de los equipos y el trabajo de equipo. Persona, 11(11-32). 
Díez Gutiérrez, E. J. (2008). El modelo neoliberal de convergencia europea en la formación superior. Tándem: Didáctica de la educación física(26), 7-18.

Díez Gutiérrez, E. J. (2009). El capitalismo académico: la reforma universitaria en el contexto de la globalización. Revista iberoamerica de Educación, 50(1), 1-9.

Díez-Gutiérrez, E. J. (2015). La construcción educativa del nuevo sujeto neoliberal. Cuadernos de Pedagogía, 454, 76-81.

Díez-Gutiérrez, E. J. (2018). Universidad e investigación para el bien común: la función social de la universidad. Aula Abierta, 47(4), 395-402.

Dochy, F., Segers, M., y Dierick, S. (2002). Nuevas vías de aprendizaje y enseñanza y sus consecuencias: una era de evaluación. Revista de Docencia Universitaria, 2(2), 13-30.

Doiz, A., Lasagabaster, D., y Sierra, J. (2013). English-medium instruction at universities: Global challenges. Multilingual matters. Toronto: Global challenges.

Doman, E. (2014). Insight into EFL Teaching and Issues in Asia. London: Cambridge Scholars.

Dorado, S., y Gewerc, A. (2017). El profesorado español en la creación de materiales didácticos: los videojuegos educativos. Digital Education Rewiew(31), 176-195.

Dörnyei, Z. (2003). Attitudes, orientations, and motivations in language learning: Advances in theory, research, and applications. Oxford: Blackwell.

Driskell, J. E., y Salas, E. (1992). Collective behavior and team performance. Human Factors, 34(3), 277-288.

Dyson, B. (2001). Cooperative Learning in an elementary Physical Education program. Journal of Teaching in Physical Education, 20(3), 264-281.

Dyson, B., y Grineski, S. (2001). Using cooperative learning structures to achieve quality physical education. Journal of Physical Education, Recreation and Dance, 72(2), 28-31.

Edison, J., Felipe, J., y Giraldo, J. C. (2013). Exergames: una herramienta tecnológica para la actividad física. Revista Médica de Risaralda, 19(2), 126-130. 
ELC/ENLU, 2006. Declaración de Nancy. Universidades multilingües para una Europa multilingüe abierta al mundo. Berlín: Consejo Europeo para las Lenguas

Eldar, E. (2008). Educating through the Physical-behavioural interpretation. Physical Education and Sport Pedagogy, 13(2), 215-229.

Elliott, J. (2005). La investigación-acción en educación. Madrid: Morata.

Eraut, M. (1994). Developing Professional Knowledge and Competence. Londres: The Palmer Press.

Escolano, A. (2010). Discurso ideológico, modernización técnica y pedagógica crítica durante el Franquismo. Historia de la Educación, 8, 7-26.

Escolano-Pérez, E., Tomás-Aragonés, L., y Herrero-Nivela, M. L. (2012). Percepción del alumnado universitario sobre su primera experiencia de aprendizaje colaborativo. Comunicación presentada en el V Congreso Mundial de Estilos de Aprendizaje, Santander, 27, 28 y 29 de junio de 2012.

Eslami-Rasekh, Z., y Valizadeh, K. (2004). Classroom activities viewed from different perspectives: Learners' voice vs. teachers' voice. TESL EJ, 8(3), 1-13.

Esteve, O., y Arumí, M. (2005). La evalución por competencias y el portafolio del estudiante: dos expereincias en asignaturas de Lengua Alemana $y$ de Interpretación Simultánea. Comunicación presentada en el II Congreso Internacional AIETI 2005. Formación, invesigación y profesión, Madrid.

Esteve Zaragoza, J. M. (2006). La profesión docente en Europa: perfil, tendencias y problemática. La formación inicial. Revista de educación(340), 19-86.

Eurydice (2002). Las competencias clave. Un concepto en expansión dentro de la educación general obligatoria. Bruselas: Eurydice.

Eurydice (2004). The taching profession in Europe: Profile, trends and concerns. Report IV: Keeping teaching attractive for the 21st century. Brusels: Eurydice.

Extremera, N., y Fernández Berrocal, P. (2004). Inteligencia emocional, calidad de las relaciones interpersonales y empatía en estudiantes universitarios. Clínica y Salud, 15(2), 117-137.

Feria-Madueño, A., Grimaldi-Puyana, M., Sánchez-Oliver, A. J., y Alcaraz-Rodríguez, V. (2017). Aprendizaje cooperativo y su percepción en futuros docentes de 
Educación Física. Trances. Revista de Transmisión del Conocimiento y de la Salud(9), 189-198.

Fernández, A. (2014). Receptive vocabulary knowledge and motivation in CLIL and EFL. Revista de lingüística y lenguas aplicadas, 9(1), 23-32. doi:http://dx.doi.org/10.4995/rlyla.2014.2077

Fernández Batanero, J. M. (2012). Capacidades y comepetencias docentes para la inclusión del alumnado en la educación superior. Revista de Educación Superior, $X L I(2)(162), 9-24$.

Fernández Batanero, J. M. (2013). Competencias docentes y educación inclusiva. Revista electrónica de investigación educativa, 15(2), 82-99.

Fernández Berrueco, R., y Sánchez-Tarazaga, L. (2014). Competencias docentes en secundaria. Análisis de perfiles de profesorado. Revista Electrónica de Investigación y Evaluación Educativa, 20(1-20).

Fernández, F., Hinojo, F. J., y Aznar, I. (2002). Las actitudes de los docentes hacia la formación en tecnologías de la información y comunicación (TIC) aplicadas a la educación. Contextos educativos: Revista de Educación(5), 253-270.

Fernández March, A. (2006). Metodologías activas para la formación de competencias. Educatio siglo XXI(24), 35-56.

Fernández-Balboa, J. M. (2006). ¿Evaluación? No gracias, calificación. Cuadernos de pedagogía(243), 92-97.

Fernández-Berrocal, P., Extremera, N., y Palomera, R. (2008). Emotional Intelligence as a crucial mental ability on educational context. En A. Valle y J. C. Núñez (Eds.), Handbook of Instructional Resources and their applications in the classroom (pp. 67-88). New York: Nova.

Fernández-Río, J. (2014). Another step in models-based practice: hybridizing cooperative learning and teaching for personal and social responsibility. The Journal of Physical Education, Recreation and Dance, 85(7), 3-5.

Fernández-Río, J., Calderón, A., Hortigüela, D., Pérez-Pueyo, Á., y Aznar, M. (2016). Modelos pedagógicos en educación física: consideraciones teórico prácticas. Revista Española de Educación Física y Deportes(413), 55-75. 
Fernández-Río, J., y Méndez-Jiménez, A. (2016). El aprendizaje cooperativo: modelo pedagógico para Educación Física. Retos: Nuevas tendencias en Educación Física, Deporte y Recreación(29), 201-206.

Fernández-Río, J., y Velázquez, C. (2005). Desafios físico cooperativos. Retos sin competición para las clases de Educación Física. Sevilla: Wanceulen.

Ferrari, A. (2013). DIGCOM: A Framework for Developing and Understanding Digital Competence in Europe: European Comisión. Joint Research Centre. Institute for Prospective Technological Studies.

Ferreres, C. (2016). Uso, conocimiento y actitudes hacia las TIC. Tándem. Didáctica de la Educación Física(53), 43-48.

Ferrés, J., y Piscitelli, A. (2012). La competencia mediática: propuesta articulada de $\begin{array}{llll}\text { dimensiones } & \text { e }\end{array}$ doi:http://doi.org/10.3916/C38-2012-02-08.

Fidalgo-Blanco, Á., Lerís, D., Sein-Echaluce, M. L., y García-Peñalvo, F. J. (2013). Indicadores para el seguimiento y evaluación de la competencia de trabajo en equipo a través del método CTMTC. Comunicación presentada en el II Congreso Internacional sobre Aprendizaje, Innovación y Competitividad (CINAIC 2013), Madrid.

Flecha, R. (1998). Compartiendo palabras. Barcelona: Paidós.

Flick, U. (2007). Introducción a la investigación cualitativa. Sage: London.

Flick, U. (2014). La gestión de la calidad en investigación cualitativa. Madrid:

Flores Aguilar, G., Prat Grau, M., y Soler Prat, S. (2014). La voz del profesorado de educación física sobre su formación académica ante la realidad multicultural: análisis de la situación y propuestas de mejora. Revista electrónica de investigación educativa, 17(2), 183-199.

Florido, C., Jiménez, J. L., y Santana, I. (2008). Obstáculos en el camino hacia Bolonia: efectos de la implantación del Espacio Europeo de la Educación Superior (EEES) sobre los resultados académicos. Revista de educación(354), 629-656.

Fraile, A. (2004a). El profesor de Educación Física como investigador de su práctica. Tandem. Didáctica de la Educación Física(15), 37-49. 
Fraile, A. (2004b). Modelos y tradiciones en la formación del profesorado de Educación Física. In A. Fraile (Ed.), Didáctica de la Educación Física: una perspectiva crítica y transversal. Madrid: Biblioteca Nueva.

Fraile, A. (2004c). Un cambio democrático en las aulas universitarias: una experiencia en la formación del profesorado de educación física. Contextos educativos: Revista de Educación(6-7), 213-234.

Fraile, A. (2006a). El sistema universitario como modelo posible para la educación superior latinoamericana. Revista electrónica de investigación educativa, 8(1), $1-15$.

Fraile, A. (2006b). Cambios en el aula universitaria ante los retos europeos. Tándem. Didáctica de la Educación Física(20), 57-72.

Fraile, A. (2008). El aprendizaje cooperativo como metodología para el desarrollo de los ECTS: una experiencia de formación del profesorado de educación física. Fuentes: Revista de la Facultad de Ciencias de la Educación(8), 22-35.

Fraile, A. (2010). La autoevaluación: una estrategia docente para el cambio de valores educativos en el aula. Ser Corporal(3), 6-18.

Fraile, A. (2009). El Espacio Europeo de Enseñanza Superior: un controvertido camino para la formación y el cambio educativo del profesorado universitario. Revista Universidades, 40, 3-17.

Fraile, A. (2013). El coaching como estrategia pedagógica para la mejora del autoconocimiento de los educadores deportivos. E-motion. Revista de Educación, Motricidad e Investigación(1), 1-13.

Fraile, A. (2018). Investigar y enseñar en Educación Física. Hacia un proceso democratizador. Armenia: Kinesis.

Fraile, A., y Aparicio, J. L. (2015). La expresión corporal y el desarrollo de las competencias transversales en la formación del profesorado. Tándem. Didáctica de la Educación Física(47), 1-8.

Fraile, A., Aparicio, J. L., Asún, S., y Romero, M. R. (2018). La evaluación formativa de las competencias genéricas en la formación del profesorado de educación física. Estudios Pedagógicos, 44(2), 39-53. 
Fraile, A., Aparicio, J. L., Romero, M. R., y Asún, S. (2019). Evaluación de la conducta kinésica de los estudiantes universitarios de educación física. Revista Iberoamericana de Evaluación Educativa, 12(1), 103-120.

Fraile, A., Catalina, J., De Diego, R., y Aparicio, J. L. (2018). Las capacidades cognitivas en la evalaución de la formación inicial del profesorado de Eduación Física. Sportis, Scientific Technical Journal of School Sport, Physical Education and Psychomotricity, 4(1), 77-94.

Freeman, D., y Freeman, Y. (1995). Whatever happened to sheltered English? CABE Newsletter, 18(2), 12-13.

Freire, M. J., Teijeiro, M., y Pais, C. (2011). Políticas educativas y empleabilidad:¿ cuáles son las competencias más influyentes? Education Policy Analysis Archives/Archivos Analíticos de Políticas Educativas(19), 1-24.

Freire, M. J., Teijeiro, M. M., y Pais, C. (2013). La adecuación entre las competencias adquiridas por los graduados y las requeridas por los empresarios. Revista de educación(362), 13-41.

Freire, P. (1978). La pedagogía del oprimido. Madrid: Siglo XXI.

Freire, P. (1986). La eduación como práctica de la libertad. Madrid: Siglo XXI.

Freire, P. (1990). La naturaleza política de la educación. Barcelona: Paidós.

Freire, P. (1998). Pedagogy of freedom. Ethics, democracy and civic courage. Oxford: Rowman \& Littlefield Publishers, Inc.

Friese, S. (2011). Using ATLAS.ti for analyzing the financial crisis data. Forum. Qualitative social research, 12(1), 1-24.

Friese, S. (2014). Qualitative data analysis with ATLAS. ti. London: Sage.

Fuentes-Abeledo, E., González-Sanmamed, M., y Raposo-Rivas, M. (2008). Desarrollar competencias en la formación inciial de maestros: valoraciones, retos $\mathrm{y}$ propuestas. Innovación Educativa(18), 45-68.

Gabarda, V., Rodríguez, A., y Moreno, M. D. (2017). La competencia digital en estudiantes de magisterio. Análisis competencial y percepción personal del futuro maestro. Educatio Siglo XXI, 35(2), 253., 35(2), 253-274. 
Gairín, J., Muñoz, J. L., Galán, A. B., Sanahuja, J., y Fernández, M. (2004). Acciones tutoriales para la Universidad. Paper presented at the III Simposium Iberoamericano de Docencia Universitaria, Bilbao.

Galarza, G. (2004). Hacia la construcción del espacio latinoamericano de la Educación Superior. Riobamba, Ecuador: Universidad Estatal de Bolívar.

Gallardo, M. A. (2006). Evaluación de las competencias profesionales para la inserción laboral de los maestros de Educación Física. Revista Electrónica de Investigación Psicoeducativa, 4(9), 469-492.

Gallardo-Fuentes, F., López-Pastor, V., y Carter-Tuhillier, B. (2018). Efectos de la aplicación de un sistema de evaluación formativa en la autopercepción de competencias adquiridas en la formación inicial del profesorado. Estudios Pedagógicos, 44(2), 55-77.

Gallego, D., Cacheiro, M. L., Martín, A. M., y Ángel, W. (2009). El eportfolio como estrategia de enseñanza y aprendizaje. Revista Electrónica de Tecnología Educativa(30), 1-12.

Gallego, J. L., y Rodríguez, A. (2014). Percepción del alumnado universitario de Educación Física sobre su competencia comunicativa. Movimento: Revista da Escola de Educação Física, 20(2), 425-444.

Gallego, V., Muñoz, J. A., Arribas, H., y Rubia, B. (2016). Aprendizaje ubicuo: un proceso formativo en educación física en el medio natural. Revista Latinoamericana de Tecnología Educativa, 15(1), 59-73.

Gámez , M. J., \& Torres, C. (2012). Las técnicas de grupo como estrategia metodológica en la adquisición de la competencia de trabajo en equipo de los alumnos universitarios. Journal for Educators, Teachers and Trainers, 4(14-25).

Gámez-Montalvo, M. J., y Torres-Martín, C. (2012). Las técnicas de grupo como estrategia metodológica en la adquisición de la competencia de trabajo en equipo de los alumnos universitarios. Journal for Educators, Teachers and Trainers, 4, 14-25. 
García, A. J. (2016). Las habilidades sociales en contextos profesionales. En A. J. García (Ed.), Competencias sociales en las relaciones interpersonales y grupales (pp. 21-35). Madrid: Pirámide.

García Carretero, M. (1990). Amorós en España. Gimnasio de Segovia. Comunicación presentada en el Seminario Francisco Amorós. Su obra entre dos culturas, Madrid.

García, E. (2010). Competencias éticas del profesor y calidad de la educación. Revista Electrónica Interuniversitaria de Formación del Profesorado, 13(4), 29-41.

García, I., Gros, B., y Escofet, A. (2012). La influencia del género en la cultura digital del estudiantado universitaria. Athenea Digital, 12(3), 95-114.

García, M., Cabanillas, G., Morán, V., y Olaz, F. (2014). Diferencias de género en habilidades sociales en estudiantes universitarios de Argentina. Anuario electrónico de estudios en Comunicación Social" Disertaciones", 7(2), 114-135.

García, M. M., y Jiménez, A. (2015). Estrategias utilizadas por estudiantes universitarios en el aprendizaje de la lengua extranjera según el género y nivel de competencia. Docencia e Investigación, 25(1), 29-58.

García-Ruso, H. (2003). Aportaciones al conocimiento del profesor de Educaión Física, desde el análisis de la investigación. XXI Congreso Nacional de Educaicón Física. Tenerife. Universidad de la Laguna.

García Ruso, H. (2004). La investigación del conocimiento práctico del profesor de Educación Física. Tándem, Didáctica de la Educación Física, 15, 50-57.

García-Valcárcel, A., Basilotta, V., y López, C. (2014). Las TIC en el aprendizaje colaborativo en el aula de primaria y secundaria. Comunicar(42), 65-74. doi:http://dx.doi.org/10.3916/C42-2014-06.

García-Valcárcel, A., y Martín del Pozo, M. (2016). Análisis de las competencias digitales de los graduados en titulaciones de maestro. Revista Latinoamericana de Tecnología Educativa, 15(2), 155-168. doi:10.17398/1695-288X.15.2.155.

Garello, M. V., y Rinaudo, M. C. (2013). Autorregulación del aprendizaje, feedback y transferencia de conocimiento: investigación de diseño con estudiantes universitarios. . Revista Electrónica de Investigación Educativa, 15(2), 131-147. 
Gartzia, L., Aritzeta, A., Balluerka, N., y Barbera, E. (2012). Inteligencia emocional y género: más allá de las diferencias sexuales. Anales De Psicología, 28(2), 567575.

Garvin, D. A. (1993). Building a learning organization. Harvard Business Review., 71(4), 78-91.

Gauthier, C. (2006). La política sobre formación inicial de docentes en Québec. Revista de educación(340), 165-185.

Gessa, A. (2011). La coevaluación como metodología complementaria de la evaluación del aprendizaje. Análisis y reflexión en las aulas universitarias. Revista de educación(354), 749-764.

Gewerc, A., Montero, L., Pernas, E., y Alonso, A. (2011). Competencia digital y planes de estudio universitarios. En busca del eslabón perdido. Revista de Universidad y Sociadad de Conocimiento, 2(8), 14-30.

Gibbs, G. (2006). Assessment frames student learning. In C. Bryan \& K. Clegg (Eds.), Innovative assessment in higher education New York: Routledge.

Gibbs, G., y Simpson, C. (2004). Conditions under which assessment supports students'learning. Learning and Teaching in Higher Education(1), 3-31.

Gibbs, G. (2012). El análisis de datos cualitativos en Investigación Cualitativa. Madrid: Narcea.

Giddens, A. (1998). The third way. Cambridge: Polity.

Giddens, A. (2001). The global third way debate. Camdbrige: Polity Press.

Giddens, A. (2004). The third way and its critics. Cambridge: Polity Press.

Gil Flores, J., Álvarez Rojo, V., García Jiménez, E., \& Romero Rodríguez, S. (2004). La enseñanza universitaria. Planificación y desarrollo de la docencia. Madrid: EOS.

Gil Madrona, P. (1999). Recorrido histórico de los modelos de formación inicial en España del profesorado de Educación Física en Educación Primaria. En Actas del VII Congreso Nacional de Teoría de la Educación. Cambio educativo: presente y futuro. Tarragona. 
Gimeno Sacristán, J. (1992). La evaluación en la enseñanza. En J. Gimeno Sacristán y A. Pérez Gómez (Eds.), Comprender y transformar la enseñanza (pp. 334-394). Madrid: Morata.

Gimeno Sacristán, J. (2005). La educación que aún es posible: ensayos acerca de la cultura para la educación. Madrid: Morata.

Gimeno Sacristán, J. (2008). Educar por competencias, ¿qué hay de nuevo?. Madrid: Morata.

Gimpel, G. A., y Merrell, K. W. (1998). On the nature and value of social skills. En G. A. Gimpel y K. W. Merrell (Eds.), Social skills of childrens and adolescents: conceptualization, assessment, treatment (pp. 1-28). Mahwah, NJ: Lawrence Elrbaum Associates.

Giroux, H. A. (1983). Critical theory and educational practice. Victoria: Deakin University.

Giroux, H. A. (1990). Los profesores como intelectuales. Hacia una pedagogía crítica del parendizaje. Barcelona: Paidós.

Gisbert, M., Espuny, C., y González, J. (2011). INCOTIC. Una herramienta para la @utoevaluación diagnóstica de la competencia digital en la universidad. Revista de currículum y formación del profesorado, 15(1), 75-90.

Glaser, B. (1998). Doing grounded theory. Issues and discussions. Mill Valley, CA: Sociology Press.

Goleman, D. (1998). La inteligencia emocional. Barcelona: Kairós.

Goleman, D. (2006). Inteligencia Social. La nueva ciencia de las relaciones humanas. Barcelona: Kairós.

Goleman, D. (2012). La inteligencia social. Barcelona: Kairós.

Goleman, D., Boyatzis, R., y McKee, A. (2002). El líder resonante crea más. El poder de la inteligencia emocional. Barcelona: Plaza y Janés.

Gómez, A., Solaz, J. J., y Sanjosé, V. (2014). Competencia en lengua inglesa de estudiantes universitarios españoles en el contexto del EEES: nivel de dominio lingüístico, estrategias metacognitivas y hábitos lectores. Revista de educación(363), 154-183. 
Gómez, C., y Richters, M. (2017). Presentaciones orales en IFE (inglés para fines específicos): un estudio de casos en ingeniería mecánica. Infancia, Educación y Aprendizaje, 3(2), 448-453. doi:https://doi.org/10.22370/ieya.2017.3.2.763

Gómez, M. Á., y Quesada, V. (2017). Coevaluación o evaluación compartida en el contexto universitario: la percepción del alumnado de primer curso. Revista Iberoamericana de Evaluación Educativa, 10(2), 9-30. doi:https://doi.org/10.15366/riee2017.10.2.001

Gómez, V. (2008). Juegos y actividades de reto y aventura en el contexto escolar. Wanceulen E.F. Digital(4), 1-12.

Gonczi, A. (1997). Future directions for vocational education in Australian Secondary Schools. Australian and New Zeland Vocational Educational Research(5), 77108.

González, A. (2005). La didáctica de la pragmática en el proceso enseñanza-aprendizaje de lenguas segundas y extranjeras: algunas consideraciones. Lenguaje $y$ $\operatorname{textos}(23), 127-137$.

González Cabarcos, A. X., y Mundina Gómez, J. J. (2014). Actividades física y deportivas en el medio natural. Enseñando mediante proyectos en el ámbito universitario. Revista Española de Educaicón Física y Deportes(405), 97-104.

Gonzalez, J., y Wagenaar, R. (2003). Tuning Educational Structures in Europe. Bilbao: Universidad de Deusto.

González, M., Pesquero, E., Sánchez, M., Fernández, P., de Juanas, Á., y Martín, R. (2010). Las competencias de los maestros de primaria: percepción de los estudiantes en prácticas. Investigación en la Escuela(72), 71-83.

Gonzalez Maura, V., y Gonzalez Tirado, R. M. (2008). Competencias genéricas y formación profesional: un análisis desde la docencia universitaria. Revista iberoamericana de educación,(47), 185-209.

González, P. F., Castillo, L. M., Quiñónez, A. L., Caberera, P. A., y Ochoa, C. A. (2018). Percepciones sobre la influencia de las actividades no comunicativas en la motivación para el aprendizaje de una lengua extranjera. Revista complutense de educación, 29(1), 165-180. 
González, P. F., Ochoa, C. A., Cabrera, P. A., Castillo, L. M., Quiñónez, A. L., Solano, L. M., . . . Arias, M. (2015). EFL Teaching in the Amazon Region of Ecuador: A Focus on Activities and Resources for Teaching Listening and Speaking Skills. English Language Teaching, 8(8), 94-103. doi:doi:10.5539/elt.v8n8p94.

Goodyear, P., Salmon, G., Spector, J. M., Steeples, C., y Tickner, S. (2001). Competences for online teaching: A special report. Educational Technology Research and Development, 49(1), 65-72.

Goodyear, V., Casey, A., y Kirk, D. (2014). Hiding behind the camera: social learning within the cooperative learning model to engage girls in physical education. Sport, Education \& Society, 19(6), 712-734.

Goudas, M., y Magotsiou, E. (2009). The effects of a cooperative Physical Education program on students`social skills. Journal of Applied Sport Psychology, 21(3), 356-364.

Granero-Gallegos, A., Ruíz Juan, F., y García Montes, E. (2005). El camino de santiago, una actividad física de rerecreación y formación para los jóvenes. Retos: Nuevas tendencias en Educación Física, Deporte y Recreación(7), 7-13.

Greene, J. (2007). MIxed methods in Social Inquiry. San Francisco: Jossey-Bass.

Greene, J., y Caracelli, V. (1997). Advances in mixed-method evaluation: the challenges and benefits of integrating diverse paradigms. San Francisco: Jossey-Bass.

Greene, J., y Caracelli, V. (2003). Making paradigm sense of mixed methods practice. En A. Tashakkori y C. Teddlie (Eds.), Handbook of mixed methods in social and behavioral research (pp. 91-110). London: SAGE.

Green, J., y Oxford, R. (1995). A closer look at learning strategies, L2 proficiency and gender. TESOL Quarterly(29), 261-297.

Griffiths, C. (2003). Patterns of language learning strategy use. System(31), 367-383.

Guba, E. (2008). Criterios de credibilidad en la investigación naturalista. En J. Gimeno Sacristán y A. Pérez Gómez (Eds.), La enseñanza: su teoría y su práctica (pp. 148-165). Madrid: Akal. 
Guba, E., y Lincoln, Y. (1981). Effective evaluation: improving the usefulness of evaluation results through responsive and naturalistic approaches. San Francisco: Jossey-Bass.

Gullickson, A. R. (2007). The joint committe on standars for educactional evaluation. Bilbao: Mensajero.

Gutiérrez, A., Palacios, A., y Torrego, L. (2010). La formación de los futuros maestros y la integración de las TIC en la eduación: anatomía de un desencuentro. Revista de Educación(352), 215-231.

Gutiérrez, C., Hortigüela, D., Peral, Z., y Pérez-Pueyo, Á. (2018). Percepciones de los alumnos del grado en Maestro en Educación Primaria con mención en Educación Física sobre la adquisición de competencias. Estudios Pedagógicos, 44(2), 223-229.

Gutiérrez, C., Pérez, A., y Pérez, M. (2013). Percepciones de profesores, alumnos y egresados sobre los sistemas de evaluación en estudios universitarios de formación del profesorado de Educación Física. Ágora para la Educación Física y el Deporte, 15(2), 130-151.

Gutiérrez, C., Pérez, Á., Pérez, M., y Palacios, A. (2011). Percepciones de profesores y alumnos sobre la enseñanza, evaluación y desarrollo de competencias en estudios universitarios de formación de profesorado. Cultura y Educación, 23(4), 499-514.

Gutiérrez-Díaz, D., García-López, L.M., Pastor-Vicedo, J.C., Romo- Pérez, V., EirínNemiña, R. \& Fernández-Bustos, G. (2017). Per- cepción del profesorado sobre la contribución, dificultades e im- portancia de la Educación Física en el enfoque por competencias. Retos. Nuevas Tendencias en Educación Física, Deporte y Recrea- ción, 31, 34-39.

Hackman, J. R., y Wageman, R. (2005). A theory of team coaching. Academy of Management Review(30), 269-287.

Hall, K., y Burke, W. (2003). Making formative assessment work: Effective practice in the primary classroom. Maidenhead, UK: McGraw-Hill Education. 
Hamodi, C. (2016). Terminología básica sobre evaluación del aprendizaje. Propuestas prácticas útiles para docentes Ediciones de la Universidad de Valladolid.

Hamodi, C., López-Pastor, V., y López-Pastor, A. T. (2015). Médios, técnicas e instrumentos de evaluación formativa y compartida del aprendizaje en educación superior. Perfiles Educativos, 37(147), 146-161.

Hamodi, C., Moreno-Murcia, J. A., y Barba, R. (2018). Medios de evaluación y desarrollo de competencias en educación superior en estudiantes de Educación Física. Estudios Pedagógicos, 44(2), 241-257.

Hanna, G. S., y Dettmer, P. A. (2004). Assessment for effective teaching: using contextadaptative planning. Boston, MA: Pearson.

Harmer, J. (2007). How to teach English. Harlow: Pearson Education Limited.

Hay, D. F., y Cook, K. V. (2007). The transformation of prosocial behavior from infancy to childhood. In C. A. Brownell \& K. C.B. (Eds.), Socioemotional development in the toddler years: transitions and transformations (pp. 100-131). New York: The Guilford Press.

Hellison, D. (1985). Goals and strategies for physical education. Champaign, IL: Human Kinetics.

Hellison, D. (1995). Teaching responsibility through physical activity. Champaign, IL: Human Kinetics.

Hernández, E., y Sánchez, I. (2012). Implementación de una estrategia de aprendizaje cooperativo en primer curso de Ciencias del Deporte. Revista Iberoamericana de Educación(60), 1-6.

Hernández Sampieri, R., Fernández, C., y Baptista, P. (2010). Metodología de la investigación. Mexico D.F: McGraw-Hill.

Hernández Sampieri, R., y Mendoza, C. (2008). El matrimonio cuantitativo cualitativo: el paradigma mixto. Comunicación presentada en el $6^{\circ}$ Congreso de Investigación en Sexología, Universidad Juárez Autónoma de Tabasco, México.

Herrington, J., y Herrington, A. (1998). Evaluación auténtica y multimedia ¿de qué manera los estudiantes responden a un modelo de evaluación auténtica?. Higher Education Research and Development, 17(3), 305-322. 
Higgins, R., Hartley, P., y Skelton, A. (2002). The conscientious consumer: reconsidering the role of assessment feed-back in student learning. Studies in Higher Education, 27(1), 53-64.

Hollenbeck, J. R., Ilgen, D., Sego, D., Hedlund, J., Major, D., y Phillips, J. (1995). Multilevel theory of team decision-making: decision performance in teams incorporating distributed expertise. Journal of Applied Psychology(80), 292-316.

Hong-Nam, K., y Leavell, A. (2006). Language learning strategy use of ESL students in an intensive english context. System(34), 339-415.

Hortigüela, D., Fernández, J., Castejón, F. J., y Pérez-Pueyo, A. (2017). Formative assessment, work regulation, organization, egagement, trecking and attendance in Spanish Universities. Revista Electrónica Interuniversitaria de Formación del Profesorado, 20(3), 49-63.

Hortigüela, D., Hernando, A., y Pérez-Pueyo, Á. (2016). ¿Qué estrategias metodológicas utiliza el profesor de Educación Física en el aula?. En I. Amor, J. L. Luengo-Almena, y M. Martínez (Eds.), Educación intercultural: metodología de aprendizaje en contextos bilingües (pp. 103-106). Granada: Atrio.

Hortigüela, D., Pérez-Pueyo, Á., y Fernández-Río, J. (2016). Influencia de las experiencias vivenciadas por el alumnado en el desempeño de futuras competencias docentes. Contextos Educativos(19), 25-41. doi:10.18172/con.2742.

Hortigüela, D., Pérez-Pueyo, A., y Abella, V. (2015). ¿De qué manera se implica el alumnado en el aprendizaje?. Análisis de su percepción en procesos de evaluación formativa. Revista de Investigación en Educaicón(13), 88-104.

Hortigüela, D., Pérez-Pueyo, Á., y López-Pastor, V. (2015). Implicación y regulación del trabajo del alumnado en los sistemas de evaluación formativa en educación superior. Revista Electrónica de Investigación y Evaluación Educativa, 21(1), 115.

Houston, W. R. (1974). Exploring Competency Based Education. Berkeley: McCutchan Publishing Corporation. 
Huber, G. P. (1991). Organizacional learning. The contributing processes and the literatures. Organization Science(2), 88-115.

Ibáñez, J. (1998). Cómo se realiza una investigación mediante grupos de discusión. En M. García, J. Ibáñez, y F. Alvira (Eds.), El análisis de la realidad social: métodos ytécnicas de investigación (pp. 569-581). Madrid: Alianza Universidad.

Imbernón, F. (1994). La formación y el desarrollo profesional del profesorado. Hacia una nueva cultura profesional. Barcelona: Graó.

Imbernón, F. (2007). La formación permanente del profesorado: nuevas ideas para formar en la innovación y el cambio. Barcelona: Graó.

Janesick, V. (2003). The choreography of qualitative research design. Minuets, improvisations and cristallization. En N. Denzin e Y. Lincoln (Eds.), Strategies of qualitative inquiry (pp. 46-79). California: SAGE.

Jares, X. R. (2006). Pedagogía de la convivencia. Barcelona: Graó.

Jhen, K. A., y Mannix, E. A. (2001). The dynamic nature of conflict: A longitudinal study of intragroup conflict and group performance. Academy of Management Journal(44), 238-251.

Jiménez, A., Holgado, M. A., y Pérez, S. (2007). Una selección de actividades docences para el desarollo de competencias profesionales. Salamanca: Servicio de Publicaciones. Universidad Pontificia de Salamanca.

Jiménez, G. (2006). Obtención de notas individuales a paartir de una nota de grupo mediante evaluación cooperativa. Revista Iberoamericana de Educación, 38(5), $1-15$.

Jiménez, M. A. (2004). La competencia lingüistica de los alumnos de la titulación Maestro Especialidad de Lengua Extranjera (Inglés). Estudio de casos. (Tesis Doctoral), Universidad de Granada.

Johnson, D., y Johnson, R. (1994). Learning together and alone: Cooperation, competition and individualization Needham Heights: Allyn and Bacon.

Johnson, D., y Johnson, R. (1999). Aprender juntos y solos. Aprendizaje cooperativo, competitivo e individualista. Buenos Aires: Aique. 
Johnson, D., y Johnson, R. (2006). Joining together: group theory and group skills. Boston: Pearson.

Johnson, D., Johnson, R., y Holubec, E. (1999). El aprendizaje cooperativo en el aula. Buenos Aires: paidós.

Johnson, B., y Onwuegbuzie, A. (2004). Mixed methods research: A research paradigm whose time has come. Educational Research, 33(7), 14-26.

Johnson, B., y Turner, L. (2003). Data collection strategies in mixed methods research. En A. Tashakkori y C. Teddlie (Eds.), Handbook of mixed methods in social and behavioral research. London: SAGE.

Jonnaert, P., Barrette, J., Masciotra, D., y Yaya, M. (2008). La competencia como organizadora de los programas de formación: hacia un desempeño competente. Profesorado: Revista de curriculum y formación del profesorado, 12(3), 1-32.

Jóver, G., Fleta, T., y González, R. (2016). La formación inicial de los maestros de educación primaria en el contexto de la enseñanza bilingüe en lengua extranjera. Bordón. Revista de Pedagogía, 68(2), 121-135.

Juez, A., Julián, J. A. y Fraile, A. (2009). Estrategias de aprendizaje cooperativo mediante un proyecto de acción grupal: análisis de una experiencia universitaria de educación física. Tándem(31), 82-92.

Kaftan, J. M., Buck, G. A., y Haack, A. (2006). Using formative assessments to individualize instruction and promote learning. Middle school journal, 37(4), 44-49.

Kagan, S. (2000). L'apprendimento cooperativo: l'approccio strutturale. Roma: Edizioni Lavoro.

Kelle, U., y Erzberger, C. (2004). Quantitative and qualitative methods: no confrontation. En U. Flick, E. Von Kardorff, e I. Steinke (Eds.), A companion to qualitative research. London: SAGE.

Kelly, J. (2002). Entrenamiento de las Habilidades Sociales. Bilbao: Descleé de Brower.

Kelly, K. (2005). How Technology evolves: TED Conference. 
Keppell, M., Au, E., Ma, A., y Chan, C. (2006). Learning and learning-oriented assessment in technology-enhanced environments. Assessment and Evaluation in Higher Education, 31(4), 453-463.

Kerr, N. L., y Bruun, S. E. (1983). Dispensability of member effort and group motivation losses: free-rider effects. Journal of Personality and Social Psychology, 44(1), 78-94.

Knapp, M. L. (1992). La comunicación no verbal. El cuerpo y el entorno. Barcelona: Paidós.

Koka, A., y Hein, V. (2005). The effect of perceived teacher feed-back on intrinsic motivation in physical education. International Journal of Sport Psychology, 36(2), 91-106.

Kong, S. C. (2015). An experience of a three year study on the development of critical thinking skills in flipped secondary classrooms with pedagogical and technological support. Computers \& Education, 89(16-31). doi:http://doi.org/10.1016/j.compedu.2015.08.017

Kozlowski, S., e Ilgen, D. (2006). Enhancing the effectiveness of work groups and teams. Psychological Science in the Public Interest, 7(3), 77-124.

Krashen, S. D., y Terrell, T. (2000). The natural approach: language acquisition in the classroom. Essex: Pearson Education.

Krumsvik, R. J. (2008). Situated learning and teachers' digital competence. Education and Information Technologies, 13(13), 279.

Kudláček, M., y Klavina, A. (2010). Adapted Physical Education in School. En M. Kudláček, N. Morgulec-Adamowicz, y J. Verellen (Eds.), European Standards in Adapted Physical Activity. Olomouc: Palacky University Olomuc.

Langlade, A., y Langlade, N. R. (1983). Teoría eneral de la gimnasia. Buenos Aires: Stadium.

Larrosa, J. (1996). La experiencia de la lectura: estudios sobre literatura y formación. Barcelona: Laertes.

Larsen-Freeman, D. (2000). Techniques and principles in language teaching. New York: University Press. 
Lasagabaster, D. (2012). El papel del inglés en el fomento del multilingüismo en la universidad. Elia. Estudios de lingüística inglesa aplicada(12), 13-44.

Lasagabaster, D., y Ruiz de Zarobe, Y. (2010). CLIL in Spain: implementation, results and teaching training. Newcastle: Cambridge Scholars Publishing.

Laurillard, D. (2002). Rethinking university teaching, a conversational framework for the effective use of learning technologies. London: Routledge Falmer.

Laval, C. (2004). La escuela no es una empresa. El ataque neoliberal a la enseñanza pública. Barcelona: Paidós.

Lavega, P., Ticó, J., Salas, C., Sáez de Ocáriz, U., Lasierra, G., Torrents, C., y Vives, M. (2012). Educar competencias en el grado de Ciencias de la Actividad Física $y$ del Deporte en el INEFC, Universidad de Lleida. Experiencia mediante un trabajo cooperativo. Comunicación presentada en el Congrés Internacional de Docència Universitària i Innovació (CIDUI), Barcelona.

Le Boterf, G. (1996). De la competénce a la navigation profesionelle. París: Les Editions d’Organisations.

Le Boterf, G. (2001). Ingeniería de competencias. Barcelona: Ediciones Gestión 2000.

Leach, D. J., Wall, T. D., Rogelberg, S. G., y Jackson, P. R. (2005). Team autonomy, performance and member job strain: Uncovering the teamwork KSA link. Applied Psychology: An International Review, 54(1), 1-24.

Learreta, B. (2005). Formación inicial del profesorado de educación física a través del aprendizaje cooperativo. Revista Electrónica Interuniversitaria de Formación del Profesorado, 8(1), 1-4.

Learreta, B., Sierra, M. Á., y Ruano, K. (2005). Los contenidos de la expresión corporal. Barcelona: INDE.

Lee, K., y Oxford, R. (2008). Understanding EFL learners strategy use and strategy awareness. Asian EFL Journal, 10(1), 7-32.

León, B. (2009). Salud mental en las aulas. Revista de Estudios de Juventud(84), 66-83.

León, B., Felipe, E., Iglesias, D., y Marugán, M. (2014). Determinantes en la eficacia del aprendizaje cooperativo. Una experiencia en el EEES. Revista de investigación educativa, 32(2), 411-424. 
León, B., Medina, S., Cantero, F. J., y Gil, F. (1998). Entrenamiento en habilidades sociales para los profesionales de la salud. En J. M. León y C. Jiménez (Eds.), Psicología de la salud. Sevilla: SAV.

Levine, J. M., Resnick, L. B., y Higgins, E. T. (1993). Social foundations of cognition. Annual Review of Psychology(44), 485-612.

Li, X. (2018). Enseñanza de presentaciones en inglés como tarea situada en el aula de inglés como lengua extranjera: un estudio cuasi-experimental de los efectos de la autorreflexión asistida por video. Revista Signos. Estudio ed Lingüística, 51(98), $359-381$.

Likert, R. (1932). A technique for the measurement of attitudes. Archives of Psychology(140), 5-55.

Livingstone, D., y Lynch, K. (2002). Reflections on group project work and studentcentred learning. Journal of Geography in Higher Education, 26(2), 213-215.

Lizaso, I., y Reizábal, L. (2016). Evaluación e intervención en habilidades sociales. In A. J. García (Ed.), Comptecias sociales en las relaciones interperosnales y grupales (pp. 37-66). Madrid: Pirámide.

Lleixà, T., Robert, M., y Batalla, A. (2008). La evaluación de competencias en la formación del profesorado de educación física: el caso del Blaagaard Seminarium de Copenhague. Fuentes: Revista de la Facultad de Ciencias de la Educación(8), 116-124.

Llorente, M. C. (2008). Aspectos fundamentales de la formación del profesorado en TIC. Pixel-Bit. Revista de Medios y Educación(31), 121-130.

López Fernández, I. (2002). Evolución histórica de la formación inicial del profesorado de educación física en España. Fuentes, 4, 164-184.

López Noguero, F. (2005). Metodología participativa en la enseñanza universitaria. Madrid: Narcea.

López, S. (2018). Nuevas metodologías educativas para combatir la inactividad física. La tecnología al servicio de la educación. International Journal of Developmental and Educational Psychology, 2(1), 55-60. 
López-Pastor, V. (2004). Evaluación, califiación, credencialismo y formación inicial del profesorado: efectos y patologías generadas en la enseñanza. Revista interuniversitaria de formación del profesorado, 18(3), 221-232.

López-Pastor, V. (2006). El papel de la evaluación formativa en el proceso de convergencia hacia el EEES. Análisis del estado de la cuestión y presentación de un sistema de intervención. Revista interuniversitaria de formación del profesorado, 20(3), 93-119.

López-Pastor, V. (2012). Evaluación formativa y compartida en la universidad: clarificacion de conceptos y propuetas de intervención desde la Red Interuniversitaria de Evaluacuón Formativa. Psychology, Society \& Education, $4(1), 117-130$.

López-Pastor, V., Castejón, J., Sicilia, A., Navarro, V., y Webb, G. (2011). The process of creating a cross-university network for formative and shared assessment in higher education and its potential applications. Innovations in Education and Teaching International, 48(1), 79-90.

López-Pastor, V., y Palacios-Picos, A. (2012). Percepción de los futuros docentes sobre los sistemas de evaluación de sus aprendizajes. TESI, 13(3), 317-341.

López-Pastor, V., y Pérez-Pueyo, A. (2017). Evaluación formativa y compartida en educación: experiencias de éxito en todas las etapas educativas. Léon: Universidad de León.

López-Pastor, V., y Pérez-Pueyo, Á. (2017). Introducción a la creación y uso de escalas descriptivas y rúbricas. En V. López-Pastor y Á. Pérez-Pueyo (Eds.), Evaluación formativa y compartida en educación: experiencias de éxito en todas las etapas educativas. León: Universidad de León.

López-Pastor, V., Pérez-Pueyo, A., Barba, J., y Lorente-Catalán, E. (2016). Percepción del alumnado sobre la utilización de una escala graduada para la autoevalución y coevaluación de trabajos escritos en la formación del profeosrado de Educación Física (FIPEF). Cultura, Ciencia y Deporte, 11(31), 37-50.

López-Pastor, V. M., Monjas, R., y Pérez-Brunicardi, D. (2003). Buscando alternativas a la forma de entender y practicar la educación física escolar. Barcelona: Inde. 
Luís, J. C., y Muros, B. (2018). La autocalificación como instrumento de aprendizaje en una asignatura universitaria inversa. Estudios Pedagógicos, 44(2), 79-91.

Madrid, D. (1999). La investigación de los factores motivacionales en el aula de idiomas. Granada: Grupo Editorial Universitario.

Madrid, M., y Madrid, D. (2014). La formación inicial del profesorado para la educación bilingüe. Granada: Universidad de Granada.

Maldonado, M. (2008). Aprendizaje basado en proyectos colaborativos. Una experiencia en educación superior. Laurus, 14(28), 158-180.

Manrique, J. C., López-Pastor, V., Monjas, R., y Real, F. (2010). El potencial de los proyectos de aprendizaje tutorado y los sistemas de evalaución formativa en la mejora de la autonomía del alumnado. Una experiencia interdisciplinar en la formación inicial del profesorado. Revista Española de Educación Física y Deportes(14), 39-57.

Marín-Díaz, V., Latorre-Medina, M. J., y Blanco-Encomienda, F. J. (2010). Las competencias profesionales de la Titulación de Magisterio vistas desde la óptica del alumno receptor. Estudio del caso de Educación Primaria. Estudios sobre educación, 19, 219-235.

Marks, M. A., Mathieu, J. E., y Zaccaro, S. J. (2000). A temporally based framework and taxonomy of team processes. Academy of Management Review(26), 356376.

Maroto Sánchez, A. (2007). El uso de las nuevas tecnologías en el profesorado universitario. Pixel-Bit. Revista de Medios y Educación(30), 61-72.

Martín, E. (2009). Profesorado competente para formar alumnado competente: el reto del cambio docente. In J. I. Pozo \& M. P. Echeverría (Eds.), Psicología del aprendizaje universitario: la formación en competencias (pp. 199-215). Madrid: Morata.

Martín, X., y Puig, J. M. (2007). Las siete competencias básicas para educar en valores. . Barcelona: Graó. 
Martínez Bonafé, J. (2004). La Formación del Profesorado y el discurso de las competencias. Revista interuniversitaria de formación del profesorado(51), 127144.

Martínez Bonafé, J. (2013). Las reformas en la formación inicial del profesorado. ¿Pero cuáles son los buenos saberes de las buenas maestras?. Revista interuniversitaria de formación del profesorado(78), 89-102.

Martínez, F. (2002). TIC y globalización. En M. V. Aguiar, J. Farray, y J. A. Brito (Eds.), Cultura y educación en la sociedad de la información. La Coruña: Netbiblo.

Martínez, J. B. (2010). El curriculum como espacio de participación. La democracia escolar ¿es posible?. En J. Gimeno (Ed.), Saberes e incertidumbres sobre el curriculum (pp. 162-179). Madrid: Morata.

Martínez, P., y González, N. (2019). El dominio de competencias transversales en Educación Superior en diferentes contextos formativos. Educação y Pesquisa, $45,1-23$.

Martínez Rodríguez, J. B. (2008). La ciudadanía se convierte en competencia: avances y retrocesos. En J. Gimeno Sacristán (Ed.), Educar por competencias, ¿qué hay de nuevo? Madrid: Morata.

Martínez-Mínguez, L. (2016). Proyectos de Aprendizaje Tutorados y autoevaluación de competencias profesionales en la formación inicial del profesorado. Retos: Nuevas tendencias en Educación Física, Deporte y Recreación(29), 242-250.

Martínez-Mínguez, L. (2017). Coevaluación y heteroevaluación a través de una escala de puntuación en la formación inicial del profesorado. En V. López-Pastor y A. Pérez-Pueyo (Eds.), Evaluación formativa y compartida en educación: experiencias de éxito en todas las etapas educativas (pp. 422-432). León: Universidad de León.

Martínez-Mínguez, L., Moya, L., Nieva, C., y Cabañete, D. (2019). Percepciones de estudiantes y docentes: evaluación formativa en proyectos de aprendizaje tutorados. Revista Iberoamericana de Evaluación Educativa, 12(1), 59-84. 
Martínez-Moreno, A., Morales-Baños, V., e Ibáñez-Pérez, R. (2016). Calidad del liderazgo en la formación inicial. Sport TK: Revista Euroamericana de Ciencias del Deporte, 5, 103-105.

Martínez-Muñoz, L. F., Santos-Pastor, M. L., y Castejón, F. J. (2017). Percepciones de alumnado y profesorado en Educación Superior sobre evaluación en formación inicial en educación física. Retos: Nuevas tendencias en Educación Física, Deporte y Recreación(32), 76-81.

Martínez-Muñoz, L. F., Castejón, F. J., y Santos-Pastor, M. L. (2012). Diferentes percepciones sobre evaluación formativa entre profesorado y alumnado en formación inicial en Educación Física. Revista Electrónica Interuniversitaria de Formación del Profesorado, 15(4), 57-67.

Mas, O. (2011). El profesor universitario: sus competencias y formación. Revista de currículum y formación del profesorado, 15(3), 195-211.

Mas, O., París, G., y Torrelles, C. (2016). El trabajo en equipo: dominio competencial en diferentes grados de la Uiversitat Autónoma de Barcelona y de la Universitat de Lleida. UT. Revista de Ciències de l'Educació(1), 55-66. doi:DOI: http://dx.doi.org/10.17345/ute.2016.1.978.

Maulini, C., Fraile, A., y Cano, R. (2015). Competencias y formación universitaria del educador deportivo en Italia. Estudios Pedagógicos, 41(1), 167-182. doi:http://dx.doi.org/10.4067/S0718-07052015000100010.

Maxwell, J. (1998). Designing a qualitative study. En L. Birckman y D. Rog (Eds.), Handbook of applied social research methods (pp. 69-100). Thousand, OAK: SAGE.

Mayer, J. D., y Salovey, P. (1993). The intelligence of emotional intelligence. Intelligence(17), 433-442.

Mayer, J. D., y Salovey, P. (1997). What is emotional intelligence?. En P. Salovey y D. Sluyter (Eds.), Emotional Development and Emotional Intelligence: Implications for Educators. New York: Basic Books.

Mayer, V. (2004). Project Oriented Learning (POL) as a communication tool of Environmental Sciences in the community of Sohanguve. A case study. 
Comunicación presentada en la Internatinal Conference on Sustainability of Water Resources. Murdoch University, Western Australia

Mayordomo Pérez, A. (2003). La transisicón a la democracia: educación y desarrollo político. Historia de la Educación(21), 19-47.

McClelland, D. C. (1973). Testing for competence rather than for intelligence. In A. Alberici \& P. Serreri (Eds.), Competencias y formación en la edad adultas. El balance de competencia. Barcelona: Laertes.

McClough, A. C., y Rogelberg, S. G. (2003). Selection in teams: An exploration of the teamwork knowledge, skills and ability test. International Journal of Selection and Assessment, 11(1), 56-66.

McConnell, D. (2005). Networked e-learning groups. Studies in Higher Education, $30(1), 25-42$.

McDonald, R., Boud, D., Francis, J., y Gonzci, A. (2000). Nuevas perspectivas sobre evaluación. Boletín Cinterfor(149), 41-72.

McGuire, B., Parker, L., y Cooper, W. (2001). Physical Education and Language: do actions speak louder than words?. Physical Education \& Sport Pedagogy, 6(2), 101-116.

McKeachie, W., y Svinicki, M. (2006). McKeachie's teaching tips. College teaching series. Boston: Houghton Mifflin.

McLaren, P. (1995). Pedagogía crítica y cultura depredadora: politicas de oposición a la era postmoderna. Barcelona: Paidós.

McVee, M. B., Bailey, N. M., y Shanahan, L. E. (2008). Teachers and teacher educators learning from new literacies and new technologies. Teaching Education, 19(3), 197-210.

MEC (1976). Orden de 29 de noviembre de 1976 por la que se establecen nuevos contenidos en las orientaciones pedagógicas del área social en la segunda etapa de la Educación General Básica. . BOE(290), 24093-24094.

MEC (1977). Orden de 30 de junio de 1977 por la que se prorroga la Orden de 29 de noviembre de 1976, que estableció nuevos contenidos en las orientaciones 
pedagógicas del área social en la segunda etapa de la Educación General Básica. BOE(180), 16898-16899.

MEC (1979). Informe sobre el programa de cosntrucciones escolares. Servicio de Publicaciones del Ministerio de Educación y Ciencia.

Mérida, R. (2012). La controvertida aplicación de las competencias en la formación docente universitaria. REDU : Revista de Docencia Universitaria, 11(1), 185212.

Merrell, K. W. (2002). Preschool and kindergarten. Behavior scales. Austin, TX: ProEd.

Miles, M., y Huberman, M. (1994). An expanded sourcebook qualitative data analysis. London: SAGE.

Miles, M., Huberman, M., y Saldaña, J. (2014). Qualitative Data Analysis: A Methods Sourcebook. London: SAGE Publications.

Mir, A. (2007). Las competencias transversales en la Universidad Pompeu Fabra. La visión de los docentes y estudiantes de segundo ciclo. Revista de Docencia Universitaria(1), 1-16.

Mira, M. J. (2016). Portfolio Eurpeo de las Lenguas Electrónico: una experiencia de innovación en la Escuela Oficial de Idiomas. Revista Electrónica de Tecnología Educativa(55), 1-26.

Mireya, P., y Filella, G. (2016). Importancia de la educación emocional en la formación inicial del profesorado. Intercambio/Échange(1), 212-219. doi:10.21001/ie.2016.1.17

Mishra, P., y Koehler, M. (2006). Technological pedagogical content knowledge: a framework for teacher knowledge. Teachers College Record,, 108(6), 10171054.

MIT (2016). Diez tecnologías emergentes en 2016. Retrieved from https://www.technologyreview.es/s/5583/mit-technology-review-presenta-las10-tecnologias-emergentes-de-2016 
Molero, D., Ortega, F., y Moreno, M. R. (2010). Diferencias en la adquisición de competencias emocionales en función del género. Revista Electrónica de Investigación y Docencia(3), 165-172.

Molero, J. J. (2011). De la educación física hacia la educación física bilingüe: un análisis desde el punto de vista metodológico. EmásF(10), 7-16.

Molina, P., Valencia-Peris, A., y Gómez-Gonzalvo, F. (2016). Innovación docente en educación superuor: edublogs, evaluación formativa y aprendizaje colaborativo. Revista de currículum y formación del profesorado, 20(2), 432-449.

Monedero Moya, J. J. (1999). Uso y evaluación de materiales educativos durante el desarrollo del curriculum:¿ qué hacen los profesores?,¿ qué pueden hacer? PixelBit. Revista de Medios y Educación(12), 55-64.

Monereo, C. (2001). La enseñanza estratégica para la autonomía. In C. Monereo (Ed.), Ser estratégico y autónomo aprendiendo. Unidades de enseñanza estratégica para la ESO (pp. 11-27). Barcelona: Graó.

Monereo, C., y Pozo, J. I. (2003). La Universidad ante la nueva cultura educativa. Madrid: Síntesis.

Monguillot, M. (2015). Diseño de situaciones de aprendizaje mediadas por TIC en Educación Física. Revista Iberoamericana de Educación, 68(2), 63-82.

Monguillot, M., González, C., Guitert, M., y Zurita, C. (2014). Mobile learning: una experiencia colaborativa mediante códigos QR. RUSC: Revista de Universidady Sociedad del Conocimiento, 11(1), 175-191.

Monjas, R., Ponce, A., y Gea, J. M. (2015). La transmisioón de valores a través del deporte. Deporte escolar y deporte federado: relaciones, puentes y posibles transferencias. Retos: Nuevas tendencias en Educación Física, Deporte y Recreación(28), 276-284.

Mora, J. G. (2003). Competencias y empleo de los jóvenes graduados universitarios. Revista de educación(330), 157-170.

Morales, C. (2001). La incorporación de la tecnología en las escuelas y la actitud que manifiestan los maestros de educación básica en la ciudad de México. In C. 
Ávila, G. Knezek, \& R. Christensen (Eds.), El punto de vista de los usuarios de las nuevas tecnologías en educación: estudio de diversos países. México: ILCE.

Morales, M., Trujillo, J. M., y Raso, F. (2015). Percepciones a cerca de la integración de las TIC en el proceso de enseñanza-aprendizaje de la universidad. Píxel-Bit. Revista de Medios y 103-117. doi:http://dx.doi.org/10.12795/pixelbit.2015.i46.07

Morales, P. (2008). Estrategias para evaluar y calificar el producto del equipo: cómo diferenciar las calificaciones individuales. In I. Prieto (Ed.), La enseñanza centrada en el aprendizaje: estrategias útiles para el profesorado (pp. 151-169). Barcelona: Octaedro.

Moraza, J. I., y Antón, A. (2010). La evaluación compartida: estudio comparativo entre la autoevaluación y autocalificaicón del alumnado y la evaluación y califiación del profesor. International Journal of Developmental and Educational Psychology, 3(1), 97-104.

Moreno, J. A., Candela, A., y Bañuelos, P. (2019). Evaluaciones formativas en el aula: análisis discursivo de la actividad de retroalimentación en la práctica supervisada de psicólogos educativos en formación. Revista Iberoamericana de Evaluación Educativa, 12(1), 121-137.

Moreno, M., Quesada, C., y P., P. (2010). El "grupo de trabajo" como método innovador de formación del profesorado para potenciar la transferencia del aprendizaje. Revista Española de Pedagogía(246), 281-295.

Moreno, S., Bajo, M., Moya, M., Maldonado, A., y Tudela, P. (2007). Las competencias en el nuevo paradigma educativo para Europa. Granada: Universidad de Granada.

Moreno-Murcia, J. A., Huéscar, E., Peco, N., Alarcón, E., \& Cervelló, E. (2013). Relación del feedback y las barreras de comunicación del docente con la motivación intrínseca de estudiantes adolescentes de educación física. Anales de Psicología, 29(19), 267-273.

Morgan, D. (1998). The Focus Group Guidebook (Focus Group Kit, Vol. 1). Thousand, OAK: SAGE. 
Muñoz, C. (2007). CLIL: some thoughts on its psycholinguistic principles. RESLA, Revista Española de Lingüística Aplicada, 20.

Muñoz-Cantero, J., Rebollo, N., y Espiñeira, E. M. (2014). Percepción de competencias en el EEES: análisis en el grado de educaicón primaria. Revista Electrónica Interuniversitaria de Formación del Profesorado, 17(3), 123-139.

Murillo, F. J., e Hidalgo, N. (2015). Dime cómo evalúas y te diré qué sociedad construyes. Revista Iberoamericana de Evaluación Educativa, 8(1), 6-9.

Murillo, S., y Mena, L. (2006). Detectives y camaleones. El grupo de discusión: una propuesta para la investigación cualitativa. Madrid: Talasa.

Navarro, V., Santos-Pastor, M. L., Buscá, F., Martínez-Mínguez, L., y Martínez-Muñoz, L. F. (2010). La experiencia de la red universitaria española de evaluación formativa y compartida: proceso y abordaje. Revista Iberoamericana de Educación, 52(7), 1-13.

Nicol, D., y McFarlane-Dick, D. (2006). Formative assessment and self-regulated learning: a model and seven principles of good feedback practice. Studies in Higher Education, 31(2), 199-218. doi:10.1080/03075070600572090

Nicol, D., y Milligan, C. (2006). Rethinking technology-supported assessment practices in relation to the seven principles of good feedback practice. En C. Bryan y K. Clegg (Eds.), Innovative Assessment in Higher Education (pp. 64-77). New York: Routledge.

Nunan, D., y Lam, A. (1998). Teacher education for multilingual contexts: models and Issus. En J. Cenoz y F. Genessee (Eds.), Beyond Bilingualism, Multilinguallism and multilingual educacion (pp. 117-140). Clevedon: Multilingual Matters.

OECD (2001). Definition and selection of competencies: Theorical and conceptual foundation. París: OECD.

OECD (2005). The definition and selection of keycompetencies: Executive summary. París: Organitation for Economic Cooperation and Development.

OIE (2015). Informe OIE sobre jóvenes y mercado laboral: el camino del aula a la empresa. Madrid: Observatorio de Innovación en el Empleo. 
Olaz, F. (2012). Escala de Autoeficacia Social para Universitarios (EAS-U). Estudios Psicométricos y Bases Conceptuales. España: Editorial Académica Española.

Orden ECI/3857/2007, de 27 de diciembre, por el que se establecen los requisitos para la verificación de los títulos universitarios oficiales que habiliten para el ejercicio de la profesión de Maestro en Educación Primaria. BOE 312 de 29 de diciembre de 2007. BOE-A-2007-22449, 53747-53750.

Ortega, J. A. (1999). Las tecnologías y medios de comunicación en el desarrollo del currículo. Granada: Universidad de Granada. Asociación para el desarrollo de la comunidad educativa en España.

Ortega, J. A., y Fuentes, J. (2003). La sociedad del conocimiento y la tecnofobia del colectivo docente: implicación desde la formación del profesorado. Comunicación y Pedagogía(189), 63-68.

Ortega Navas, M. C. (2010). Competencias emergentes del docente ante las demandas del Espacio Europeo de Educación Superior. Revista Española de Educación Comparada(16), 305-327.

Onwuegbuzie, A., y Johnson, R. (2006). The validity issue in Mixed Research. Research in the schools. Mid-South Educational Research Association, 13(1), $48-63$.

Oxford, R. (1990). Language learning strategies: what every teacher should know. New York: Newbury House.

Oxford, R. (1993). Language learning strategies in a nutshell: update and ESL suggestions. TESOL Journal, 2(2), 18-22.

Palacios, A., y López-Pastor, V. (2013). Haz lo que yo digo pero no lo que yo hago: sistemas de evaluación del alumnado en la formación inicial del profesorado. Revista de educación(361), 279-305. doi:10.4438/1988-592X-RE-2011-361-143

Palacios, A., López-Pastor, V., y Barba, J. (2013). Tipologías de profesorado universitario en función de la evaluación aplicada en los futuros docentes. Estudios sobre Educación(24), 173-195. 
Palacios, A., López-Pastor y Fraile, A. (pendiente). Cuestionario sobre percepción de competencias docentes de educación física. Revista Internacional de Medicina y Ciencias de la Actividad Física y el Deporte.

Palomero, P. (2009). Desarrollo de la competencia social y emocional del profesorado: una aproximación desde la psicología humanista. Revista Electrónica Interuniversitaria de Formación del Profesorado, 12(2), 145-153.

Panadero-Calderón, E., y Alonso-Tapia, J. (2013). Revisión sobre autoevalaución educativa: evidencia empírica de su implementación a través de la autocalificación, sin criterios de evaluación, rúbricas y guiones. Revista de Investigación en Educaicón, 11(2), 172-197.

París, G., Torrelles, C., y Mas, O. (2016). La evaluación de la competencia "trabajo en equipo" de los estudiantes universitarios. Revista d'Innovació Docent Universitària(8), 86-97.

Parra, M., Caballero, P., y Domínguez, G. (2009). Estrategias metodológicas para las actividades recreativas en el medio natural. En M. E. García (Ed.), Dinámicas y estrategias de recreación (pp. 199-260). Barcelona: Graó.

Pascual, C. (1991). Orígenes y evolución de la formación inicial del profesorado de Educación Física En Actas del VIII Congreso Nacional de Educación Física de Escuelas de Magisterio. Cuenca.

Pascual, C. (2000). La pedagogía crítica: una cuestión ética. In O. Contreras (Ed.), La formación inicial y permanente del profesorado de Educación Física (pp. 7393). Ciudad Real: Servicio de Publicaciones de la Universidad de Castilla-La Mancha.

Pastor Pradillo, J. L. (1997). El espacio profesional de la Educación Física en España: génesis y formación (1883-1961). Alcalá de Henares: Servicio de Publicaciones de la Universidad de Alcalá.

Pastor Pradillo, J. L. (2000). Definición y desarrollo del espacio profesional de la Educación Física en España (1961-1990). Madrid: Universidad de Alcalá.

Pastor Pradillo, J. L. (2002). Aproximación histórica a la evolución de la Educación Física en España (1883-1990). Historia de la Educación(21), 119-214. 
Pastor Pradillo, J. L. (2004a). La evolución histórica de la docencia de la Educación Física: ¿un proceso inacabado?. Tandem. Didáctica de la Educación Física(15), 96-109.

Pastor Pradillo, J. L. (2004b). ¿Quo vadis gimnástica? Aproximación histórica a la evolución de una profesión. Revista Española de Educación Física y Deportes(1), 15-38.

Pastor Pradillo, J. L. (2007). Fundamentación epistemológica e identidad de la Educación Física. Profesorado: Revista de curriculum y formación del profesorado, 11(2).

Pavón, V. (2001). Un estudio sobre la influencia del componente afectivo actitud en la competencia de aprendices adultos de inglés. En C. Muñoz (Ed.), Trabajos en lingüística aplicada. Barcelona: Aesla.

Pazo-Haro, C. I., \& Tejada-Mora, J. (2012). Las competencias profesionales en Educación Física. Retos: Nuevas tendencias en Educación Física, Deporte y Recreación(22), 5-8.

Peiró, C., y Julián, J. A (2015). Los modelos pedagógicos en educación física. Un enfoque más allá de los contenidos curriculares. Tándem. Didáctica de la Educación Física(50), 9-15.

Penner, L., Fritzsche, B., Craiger, J., y Freifeld, T. (1995). Measuring the prosocial personality. En J. Butcher y C. Spielberger (Eds.), Advances in personality assessment (Vol. 10). Hillsdale, NJ: Erlbaum.

Pérez Cañado, M. L. (2012). CLIL research in Europe: past, present and future. International Journal of Biligual Education and Bilingualis, 15(23), 315-341.

Pérez Cañado, M. L. (2015). Training teachers for plurilingual education: a spanish case study. En D. Marsh, M. L. Pérez Cañado, y J. Ráez Padilla (Eds.), CLIL in action: voices from the classroom (pp. 165-187). Newcastle upon Tyne: Cambridge Scholars Publishing.

Pérez Gómez, A. (1992). Las funciones sociales de la escuela. De la reproducción a la recosntrucción crítica del conocimiento y la experiencia. En J. Gimeno Sacristán 
y A. Pérez Gómez (Eds.), Comprender y transformar la enseñanza (pp. 17-33). Madrid: Morata.

Pérez Gómez, A. (2010). Aprender a educar. Nuevos desafíos para la formación de docentes. Revista interuniversitaria de formación del profesorado, 68(24,2), 3760.

Pérez Gómez, Á. (2012). Educarse en la era digital. Madrid: Morata.

Pérez, M. L. (2015). Evaluating CLIL programmes: instrument design and validation. Pulso(39), 79-112.

Pérez, M. M., y Pérez, R. (2013). Propuesta de unidad didactica sobre geocaching. EmasF. Revista digital de Educación Física, 19(173-179).

Pérez, P. (2007). Competencias adquiridas por los futuros docentes desde la formación inicial. Revista de educación(347), 343-367.

Pérez-Escoda, N., Filella, G., Soldevila, A., \& Fondevila, A. (2013). Evaluación de un programa de educación emocional para profesorado de primaria. Educación $X X 1,16(1), 233-254$. doi:10.5944/educxx1.16.1.725

Pérez-Pueyo, A., Tabernero, B., López, V., Ureña, N., Ruiz, E., Caplloch, M., . . . Castejón, F. J. (2008). Evaluación formativa y compartida en la docencia universitaria y el Espacio Europeo de Educación Superior: cuestiones clave para su puesta en práctica. Revista de educación(347), 435-451.

Perrenoud, P. (2000). Du curriculum aux pratiques: question d'adhésion, d'énergie ou de compétence?. Revista tecnológica educativa, 14(3), 503-523.

Perrenoud, P. (2008). Construir las competencias, ¿es darle la espalda a los saberes? Revista de Docencia Universitaria(11), 1-8.

Perrenoud, P. (2012). Cuando la escuela pretende preparar para para la vida: ¿desarrollar competencias o enseñar otros saberes?. Barcelona: Graó.

Perrenoud, P. (2013). Aprender a trabajar en equipo es desarrollar más de una competencia. Revista de curriculum y formación del profesorado, 17(3), 133149. 
Pertegal-Felices, M. L., Castejón Costa, J. L., y Martínez, M. A. (2011). Competencias socioemocionales en el desarrollo profesional del maestro. Educación XX1, 14(2), 237-260.

Pesquero, E., Sánchez, M., González, M., Martín, R., Guardia, S., Cervelló, J., . . . Varela, P. (2008). Las competencias profesionales de los maestros de Primaria. Revista Española de Pedagogía, 66(241), 447-466.

Pessoa, T., Hernández, M. J., y Muñoz, J. M. (2015). Aprendizaje informal, alfabetización mediática e inclusión social. Profesorado. Revista de Currículum y Formación del Profesorado, 19(2), 75-91.

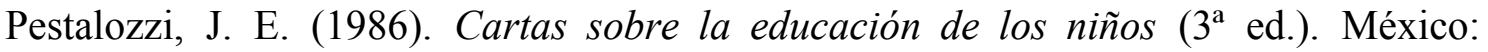
Porrúa.

Pieron, M. (1999). Para una enseñanza eficaz de las actividades físico-deportivas. Barcelona: INDE.

Pino, M., y Soto, J. (2010). Identificación del dominio de competencias digitales en el alumnado del Grado de Magisterio. Teoría de la Educación: Educación y Cultura en la Sociedad de la Información, 11(3), 336-362.

Poblete, M., y García, A. (2004). Análisis y evaluación del trabajo en equipo en alumnado universitario: propuesta de un modelo de evaluación de desarrollo del equipo. En Universidad de Deusto (Ed.), Pedagogía universitaria, hacia un espacio de aprendizaje compartido (Vol. 1, pp. 727-750). Bilbao.

Pol, A. P., Moreno, J. J. M., y Oliver, M. P. (2009). Las competencias genéricas en la educación superior. Estudio comparativo entre la opinión de empleadores y académicos. Psicothema, 21(3), 433-438.

Popescu, E. (2012). Project-based learning with eMUSE. An experience report. In E. Popescu (Ed.), Advances in web-based learning (pp. 41-50). Romania: Springer.

Prat, Q., y Camerino, O. (2012). Las tecnologías del aprendizaje y el conocimiento (TAC) en la educación física. La WebQuest como recurso didáctico. Apunts. Educación física y deportes(109), 44-53. doi:10.5672/apunts.20140983.es.(2012/3).109.04 
Prat, Q., Camerino, O., y Coiduras, J. (2014). Introducción de las TIC en educación física. Estudio descriptivo sobre la situación actual. Apunts. Educación física y deportes, 113(3), 37-44.

Prendes, M. P., Castañeda, L., y Gutiérrez, I. (2010). Competencias para el uso de TIC de los futuros maestros. (Spanish). ICT Competences of Future Teachers. (English), 18(35), 175-182. doi:10.3916/C35-2010-03-11

Prendes, M. P., Castañeda, L., y Gutiérrez, I. (2010). Competencias para el uso de TIC de los futuros maestros. Comunicar, 35(18), 175-182.

Prouty, D., Panicucci, J., y Collinson, R. (2007). Adventure education. Theory and applications. Champaign, IL: Human Kinetics.

Pujolás, P. (2009). La calidad en los equipos de aprendizaje cooperativo. Algunas consideraciones para el cálculo del grado de cooperatividad. Revista de Educación(349), 225-239.

Putnam, J. (1997). Cooperatve learning in diverse classrooms. Upper Saddle RIver, N.J: Prentice-Hall.

Quennerstedt, M., Gibbs, B., Almqvist, J., Nilsson, J., y Winther, H. (2016). Beatrice: Dance video games as a resource for teaching dance. En A. Casey, V. Goodyear y K. Armour (Eds.), Digital technologies and learning in physical education: pedagogical cases (pp. 69-85). London: Routldge.

Quesada, V., García, E., y Gómez, M. A. (2016). Student participation in assessment processes: A way forward. En E. Cano y G. Ion (Eds.), Innovative practices for higher education assessment and measurement (pp. 228-249). Hershey, PE: IGI Global.

Quesada, V., Gómez, M. A., y Cubero, J. (2015). La evaluación colaborativa en Educación Superior. Descripción de una experiencia con alumnos de primer curso. Comunicación presentada en el V Congreso Internacional UNIVEST'15, Los retos de mejorar la evaluación, Girona.

Quintana, J. (2000). Competencias en tecnologías de la información del profesorado de educación infantil y primaria. Revista Interunivesitaria de Tecnología Educativa(0), 166-174. 
Quintero, L., Jiménez, F., y Area, M. (2016). Las e-actividades. Aplicaciones y recursos web. Tándem. Didáctica de la Educación Física(53), 12-18.

Quintero, L., Jiménez, F., y Area, M. (2018). Claves para la integración y el uso didáctico de los dispositivos móviles en las clases de Educación Física. Acción Motriz(20), 17-26.

Ramos, F. (2009a). Una propuesta de AICLE para el trabajo con textos en segundos idiomas. Porta Linguarum(12), 169-182.

Ramos, F. (2009b). Why do we do this?. Reflections of a two-way immersion school principal on the roles of parents, teachers, and her own, in the program. Estudios de Lingüística(23), 225-240.

Ramos, F., y Ruiz Omeñaca, J. (2010). La educación física en centros bilingües. Sevilla: Wanceulen.

Ramos, F., y Ruiz-Omeñaca, J. (2011). La educación física en centros bilingües de primaria inglés-español: de las singularidades propias del área a la elaboración de prpuestas didácticas prácticas con AIBLE. Revista Española de Lingüística Aplicada(24), 153-170.

Ramos, N., Fernandez-Berrocal, P., y Extremera, N. (2007). Perceived emotional intelligence facilitates cognitive-emotional processes of adaptation to an acute stressor. Cognition and Emotion, 21(4), 758-772.

Raposo-Rivas, M. (2004). ¿Es necesaria la formación técnica y didáctica sobre tecnologías de la información y la comunicación?. Argumentos del profesorado de la Universidad de Vigo. Pixel-Bit. Revista de Medios y Educación(24), 43-58.

Raposo-Rivas, M., Fuentes, E., y González, M. (2006). Desarrollo de competencias tecnológicas en la formación inicial de maestros. Revista Latinoamericana de Tecnología Educativa, 5(2), 525-537.

Real Decreto 1393/2007, de 29 de octubre, por el que se establece la ordenación de las enseñanzas universitarias oficiales. BOE 260 de 30 de octubre de 2007. BOE-A2007-18770, 44037-44048. 
Real Decreto 49/2004, de 19 de enero, sobre homologación de planes de estudios y títulos de carácter oficial y validez en todo el territorio nacional. BOE 19, de 22 de enero de 2004. BOE-A-2004-1303.

Real Decreto 55/2005 de 21 de enero, por el que se establece la estructura de las enseñanzas universitarias y se regulan los estudios universitarios oficiales de Grado. BOE 21 de 25 enero 2005, 2842-2846.

Real Decreto 1027/2011, de 15 de julio, por el que se establece el Marco Español de Cualificaciones para la Educación Superior. BOE 185 de 3 de agosto de 2011. BOE-A-2011-13317.

Real Decreto 1044/2003 de 1 de agosto, por el que se establece el procedimiento para la expedición por las universidades del Suplemento Europeo al Título. BOE 218, de 11 de septiembre de 2003. BOE-A-2003-17310.

Real Decreto 1125/2003, de 5 de septiembre, por el que se establece el sistema europeo de créditos y el sistema de calificaciones en las titulaciones universitarias de carácter oficial y validez en todo el territorio nacional. BOE 224, de 18 de septiembre de 2003. BOE-A-2003-17643.

Repetto, E., Beltrán, S., Garay-Gordovil, A., y Pena, M. (2006). Validación del "inventario de competencias socioemocionales-importancia y presencia"(ICS-I; ICS-P) en estudiantes de ciclos formativos y de universidad. Revista Española de Orientación y Psicopedagogía, 17(2), 213-223.

Resolución de 18 de septiembre de 2018, de la Secretaría General de Universidades, por la que se publica el Acuerdo del Consejo de Universidades de 17 de septiembre de 2018, por el que se establecen recomendaciones para la propuesta por las universidades de memorias de verificación del título oficial de Grado en Ciencias de la Actividad Física y del Deporte. BOE 228 de 20 de septiembre de 208. BOE-A-2018-12774.

Resta, P., y Semenov, A. (2004). Las tecnologías de la información y la comunicación en la formación docente. París: UNESCO.

Ribes, M. D. (2011). Habilidades sociales y dinamización de grupos. Sevilla: MAD. 
Richards, J. C., y Rodgers, T. S. (2014). Approaches and methods in language teaching. Cambridge: University Press.

Rico, R., Sánchez-Manzanares, M., Gil, F., Alcover, C. M., y Tabernero, C. (2011). Procesos de coordinación en equipos de trabajo. Papeles del Psicólogo, 32(1), $59-68$.

Riesco Gonzalez, M. (2008). El enfoque por competencias en el EEES y sus implicaciones en la enseñanza y el aprendizaje. Tendencias pedagógicas(13), 79-105.

Ritzer, G. (2007). Los tentáculos de la McDonaldización. Madrid: Editorial Popular.

Roblizo, M., y Cózar, R. (2015). Uso y competencias en TIC en los futuros maestros de educación infantil y primaria: hacia una alfabetización tecnológica real para docentes. Pixel-Bit. Revista de Medios y Educación(47), 23-39.

Rodriguez, A., y Vieira, M. J. (2009). La formación en competencias en la universidad: un estudio empírico sobre su tipología. Revista de investigación educativa, $27(1), 27-47$.

Rodríguez, G., y Ibarra, M. S. (2011). e-Evaluación orientada al e-aprendizaje estratégico en educación superior. Madrid: Narcea.

Rodríguez, G., Ibarra, M. S., y Cubero, J. (2018). Competencias básicas relacionadas con la evaluación. Un estudio sobre la percepción de los estudiantes universitarios. Educación XX1, 21(1), 181-208. doi:10.5944/educXX1.14457.

Rodríguez Jiménez, R. M., Del Mar Caja López, M., Gracia Parra, P., Velasco Quintana, P. J., y Terrón López, M. J. (2013). Inteligencia Emocional y Comunicación: la conciencia corporal como recurso. Red de Docencia Universitaria, 11(1), 213-241.

Rodríguez Martínez, C., y Díez Gutiérrez, E. J. (2014). Conocimiento y competencias básicas en la formación inicial de maestras y maestros. Profesorado. Revista de currículum y formación del profesorado, 18(1), 383-396.

Rodríguez Mena, J. A. (2003). Una mirada desde la perspectiva de género de nuestros/as universitarios/as. Revista Investigación en la Escuela(50), 47-55. 
Roig, R., y Pascual, A. M. (2012). Las competencias digitales de los futuros docentes. Un análisis con estudiantes de Magisterio de Educación Infantil de la Universidad de Alicante. @tic. Revista d'innovació educativa(9), 53-60.

Romero, M., Gisbert, M., y Carrera, X. (2009). Centro virtual de recursos de tecnología educativa: Una herramienta para la formación inicial de maestros en TIC. RUSC: Universities and Knowledge Society Journal, 6(2), 1-14.

Romero, M. R., Asún, S., y Chivite, M. T. (2016). La autoevaluación en expresión corporal en formación inicial del profesorado de educación física: un ejemplo de buena práctica. Retos. Nuevas Tendencias en Educación Física, Deporte y Recreación, 29(1), 236-241.

Romero, M. R., Castejón, F. J., López-Pastor, V., y Fraile, A. (2017). Evaluación formativa, competencias comunicativas y TIC en la formación del profesorado. Comunicar, 25(52), 73-82.

Romero-Cerezo, C. (2004). Argumentos sobre la formación inicial de los docentes en educación física. Profesorado, revista de currículum y formación del profesorado, 8(1), 1-18.

Romero-Cerezo, C., Zagalaz-Sánchez, M. L., Romero-Rodríguez, M. N., y MartínezLópez, E. J. (2011). Las competencias profesionales de los Maestros en Educación Física expresadas por los estudiantes. Retos: Nuevas tendencias en Educación Física, Deporte y Recreación(19), 62-68.

Romero-Martín, M. R., Gelpi, P., Mateu, M., y Lavega, P. (2017). Influencia de las prácticas motrices sobre el estado emocional de estudiantes universitarios. Revista Internacional de Medicina y Ciencias de la Actividad Fisica y del Deporte, 17(67), 449-466.

Ros, J. A. (2006). Análisis de roles de trabajo en equipo: un enfoque centrado en comportamientos. (Tesis Doctoral), Universidad Autonoma de Barcelona, Barcelona.

Rosales, J. J., Caparrós, B., Molina, I., \& Alonso, S. (2013). Habilidades sociales. Madrid: McGraw-Hill.

Rousseau, J. (2007). Emilio, o De la Educación (1 ${ }^{\mathrm{a}}$ ed.). Madrid: Alianza. 
Rousseau, V., Aubé, C., y Savoie, A. (2006). Le fonctionnement interne des équipes de travail: Conception et mesure. Canadian Journal of Behavioural Science / Revue canadienne des sciences du comportement, 38(2), 120-135.

Ruano, K. (2013). El despertar de las emociones. Un trabajo corporal. Multiárea. Revista de Didáctica(6), 311-354.

Ruiz, G., y Cabrera, D. (2004). Los valores del deporte. Revista de educación(335), 919.

Ruíz Omeñaca, J. (2008). Educación Física, valores éticos y resolución de conflictos: reflexiones y propuestas de acciópn. En A. Fraile (Ed.), La resolución de conflcitos en y a través de la Educación Física (pp. 65-115). Barcelona: Graó.

Ruiz-Gallardo, J. R., Ruiz, E., y Ureña, N. (2013). La evalución en la formación inicial del profesorado: qué queremos hacer y qué perciben los alumnos. Cultura, Ciencia y Deporte, 8(22), 17-29.

Russ-Eft, D., Preskill, H., y Sleezer, C. (1997). Team learning and performance. En D. Russ-Eft, H. Preskill, y C. Sleezer (Eds.), Human Resource Development. Research and Implications. Thousand Oaks, CA: Sage.

Saarni, C. (1998). Emotional competence: How emotions and relationships become integrated. En R. A. Thompson (Ed.), Nebraska symposium on motivation (Vol. 36, pp. 115-182). Lincoln: University of Nebraska Press.

Saarni, C. (2000). Emotional Competence. A Developmental Perspective. En R. Baron \& J. Parker (Eds.), The Handbook of Emotional Intelligence. Theory, Development, Assessment, and Application at Home, School, and in the Workplac (pp. 68-91). San Francisco, CA: Jossey- Bass.

Sadler, D. R. (1989). Formative assesment and the design instructional systems. Instructional Science(18), 119-144.

Sagástegui, D. (2004). Una apuesta por la cultura: el aprendizaje situado. Revista Electrónica Sinéctica(24), 30-39.

Sáiz, M. I., y Gómez, G. R. (2011). Aprendizaje autónomo y trabajo en equipo: reflexiones desde la competencia percibida por los estudiantes universitarios 
Revista Electrónica Interuniversitaria de Formación del Profesorado, 14(2), 7385.

Salas, E., Burke, C. S., y Cannon-Bowers, J. A. (2000). Teamwork: emerging principles. International Journal of Management Reviews, 2(4), 339-356.

Salas, E., y Cannon-Bowers, J. A. (2001). The science of training: A decade of progress. Annual Review of Psychology, 52(471-499).

Salas, E., Dickinson, T., Converse, S., y Tannenbaum, S. (1992). Toward an understanding of team performance and training. En R. W. Swezey y E. Salas (Eds.), Teams: Their training and performance. Norwood, NJ: Ablex.

Salas, E., Sims, D. E., y Burke, C. S. (2005). Is there a" big five" in teamwork?. Small Group Research, 36(5), 555-599.

Saldaña, J. (2009). The Coding Manual for Qualitative Researchers. Thousand Oaks, CA: Sage.

Salovey, P., Stroud, L. R., Woolery, A., y Epel, E. S. (2002). Perceived emotional intelligence, stress reactivity, and symptom reports. Further explorations using the trait meta-mood scale. Psychology and Health, 17(5), 611-627.

San Nicolás, M. B., Fariña., E., y Area, M. (2012). Competencias digitales del profesorado y alumnado en el desarrollo de la docencia virtual. Revista de Historia de la Educación Latinoamericana, 14(9), 227-245.

Sánchez, A., López, M., y Fernández, M. V. (2010). Análisis de las competencias genéricas en los títulos de grado del EEES en las universidades españolas. REDU: Revista de Docencia Universitaria, 8(1), 35-73.

Sanchez, B., y Boronat, J. (2014). Coaching educativo: modelo para el desarrollo de competencias intra e interpersonales. Educación XX1, 17(1), 221-242.

Sánchez Bañuelos, F. (1984). Didáctica de la educación física y el deporte. Madrid: Gymnos.

Sancho Saiz, J., Barandiarán Landín, M. C., Apodaca Urquijo, P. M., Lobato Fraile, C. S., San José Álvarez, M. J., y Zubimendi Herranz, J. L. (2009). La formación de trabajo en equipo del alumnado universitario con el aprendizaje cooperativo. 
Comunicación presentada en la IX Jornada sobre Aprendizaje Cooperativo. Almería.

Santos Guerra, M. A. (2000). La escuela que aprende. Madrid: Morata.

Santos Guerra, M. A. (2003). Una flecha en la diana: la evaluación como aprendizaje. Madrid: Narcea.

Santos, M. L., y Martínez, F. (2011). Aprendizaje integrado de las actividades en el medio natural desde las competencias en la ESO. Tándem, Didáctica de la Educación Física(36), 53-60.

Santos-Pastor, M. L., Castejón, F. J., \& Martínez-Muñoz, L. F. (2012). La innovación docente en evaluación formativa y metodología participativa: un proyecto compartido a raíz de la implantación de los nuevos grados. Psychology, Society \& Education, 4(1), 73-86.

Santos-Pastor, M. L., y Mártinez-Muñoz, L. F. (2017). El pacto en el aprendizaje desde la negociación de la rúbrica de evaluación. En V. López-Pastor y Á. PérezPueyo (Eds.), Evaluación formativa y compartida en educación: experiencias de éxito en todas las etapas educativas (pp. 402-413). León: Universidad de León.

Santos-Rego, M. A., Lorenzo-Moledo, M. M., y Priegue Caamaño, D. (2009). Aprendizaje cooperativo: práctica pedagógica para el desarrollo escolar y cultural. Magis. Revista Internacional de investigación en Educación, 1(2), 289303.

Saravia, E., y Bernaus, M. (2008). Motivación y actitudes para el aprendizaje de lenguas de dos colectivos de estudiantes universitarios: futuros maestros de lenguas extranjeras y futuros enfermeros y fisioterapeutas. Porta Linguarum(10), 163184.

Sarceda-Gorgoso, C., y Rodicio-García, M. L. (2018). Escenarios formativos y competencias profesionales en la formación inicial del profesorado. Revista Complutense de Educación, 29(147-163).

Sargent, J. y Casey, A. (2019). Flipped learning, pedagogy and digital technology. Establishing consistent practice to optimise lesson time. European Physical Education Review, doi.org/10.1177/1356336X19826603. 
Savoie, A., y Brunet, L. (2000). Les équipes de travail: champ d'intervention privilégié pour les psychologues. In J. L. Bernaud \& C. Lemonie (Eds.), Traité de psychologie du travail et des organitations (pp. 171-202). Paris: Dunod.

Savoie, A., y Mendès, H. (1993). L'efficacité des équipes de travail : une prédiction initialement multidimensionnelle. En P. Goguelin (Ed.), Psychologie du travail et des organisations. París: EAP.

Schön, D. C. (1983). The reflectives practitioner. How proffesionals think in action. London: Temple Smith.

Schön, D. C. (1987). Educating the reflective practitioner: Toward a new design for teaching and learning in the professions. San Francisco: Jossey-Bass.

Schutte, N. S., Malouff, J., Bobik, C., Coston, T., Greeson, C., Jedlicka, C., y Wendorf, G. (2001). Emotional intelligence and interpersonal relations. Journal of Social Psychology(141), 523-536.

Seale, C. (2002). Quality issues in qualitative inquiry. Qualitative Social Work, 1(1), 97-110.

Sheingold, K., Hawkins, J., y Char, C. (1984). I'm the thinkist, you'rethe typist: the interaction of technology and the social life classrooms. Journal of Social Issues, 40(3), 49-61.

Shores, E. F., y Grace, C. (2004). El portafolios paso a paso: infantil y primaria. Barcelona: Graó.

Sicilia, A. (2010). Libertad, autonomía y libertad en el proceso de autoevaluación y autocalificación. IE A. Sicilia (Ed.), La evaluación y calificación en la Universidad: relatos autobiográficos durante la búsqueda de alternativas (pp. 1-14). Barcelona: Hipatia.

Silva, I., y López-Pastor, V. (2015). ¿Cómo vive el alumnado la evaluación en formación inicial del profesorado? @tic.revista d’innovació educativa(14), 90100.

Slavin, R. E. (2014). Cooperative Learning and Academic Achievement: Why Does Groupwork Work?. Anales de Psicología, 30(3), 785-791. 
Sluijsmans, D., Dochy, F., y Moerkerke, G. (1998). Creating a learning environment by using self-peer-and coassessment. Learning Environments Research, 1(3), 293319.

Sonlleva, M., Martínez, S., y Monjas, R. (2018). Los procesos de evaluación y sus consecuencias. Anñalisis de la experiencia del profesorado de Educación Física. Estudios Pedagógicos, 44(2), 329-351.

Soriano Maldonado, A., y Delgado Noguera, M. A. (2011). Buenas prácticas profesionales en la enseñanza de la educación física. Formación inicial y actualización. Un estudio exploratorio. Revista Motricidad Humana, 12(1), 815.

Sosa, M. J., y Palau, R. F. (2018). Flipped Classroom para adquirir la competencia digital docente: una experiencia didáctica en la educación superior. Píxel-Bit. Revista de Medios y Educación(52), 37-54.

Spiller, D. (2009). Assessment: Feedback to promote student learning. Hamilton, NZ: University of Waikato.

Stenhouse, L. (1984). Investigación y desarrollo del currículum. Madrid: Morata.

Stevens, M., y Campion, M. (1994). The knowledge, skill and ability. Requirements for teamwork: implications for human resources management. Journal of Management(2), 503-530.

Strauss, A., y Corbin, J. (1990). Basics of qualitative research: Grounded Theory Procedures and Techniques. London: SAGE.

Strauss, A., y Corbin, J. (1998). Basics of qualitative research. Techniques and procedures for developing grounded theory. London: Sage.

Suárez, M. L. (2005). Aprendizaje integrado de contenidos y lengua extranjera (AICLE): una de las claves para la convergencia europea. Madrid: Universidad Europea de Madrid.

Sundstrom, E., Demeuse, K. P., y Futrell, D. (1999). Work Teams: Applications and effectiveness. American Psychologist(45), 120-123.

Tardif, J. (2006). L' évaluation des compétences. Documenter le parcours de développement. Montreal: Chenelière Éducation. 
Tashakkori, A., y Teddlie, C. (1998). Mixed methodology: Combining qualitative and quantitative approaches. Thousand Oaks, CA: Sage.

Tashakkori, A., y Teddlie, C. (2003). The handbook of mixed methods in social and behavorial research. California: Sage Publication, Inc.

Tashakkori, A., y Teddlie, C. (2008). Quality of inferences in Mixed Methods Research: Calling for an integrative framework. En M.Bergman (Ed.), Advances in Mixed Methods Research: Theories and Applications (pp. 101-119). California: Sage Publication, Inc.

Teddlie, C., y Tashakkori, A. (2003). Major issues and controversies in the use of a mixed methods in the social and behavorial sciences. En C. Teddlie y A. Tashakkori (Eds.), Handbook of mixed methods in social an behavorial research (pp. 3-49). London: SAGE.

Tejada, J. (2005). El trabajo por competencias en el prácticum: cómo organizarlo y cómo evaluarlo. Revista electrónica de investigación educativa, 7(2), 1-31.

Tejada, J. (2009). Competencias Docentes. Profesorado. Revista de currículum y formación del profesorado, 13(2), 1-15.

Tejada, J., y Navio, A. (2004). Las competencias profesionales (documento mimeografíado): Universidad Autónoma de Barcelona, Departamento de Pedagogía Aplicada.

Tejada, J., y Navío, A. (2005). El desarrollo y la gestión de competencias profesionales. Una mirada desde la formación. Revista Iberoamericana de Educación, 37(2), 115.

Tello, J., y Aguaded, I. (2009). Desarrollo profesional docente ante los nuevos retos de las tecnologías de la información y la comunicación en los centros educativos. Pixel-Bit. Revista de Medios y Educación(34), 31-47.

Tena, M. (2010). Aprendizaje de la Competencia Creatividad e Innovación en el marco de una titulación adaptada al Espacio Europeo de Educación Superior. Formación Universitaria, 3(2), 11-20. doi:10.4067/S0718-50062010000200003. 
Teo, T., Chai, C. S., Hung, D., y Lee, C. B. (2008). Beliefs about teaching and uses of technology among pre-service teachers. Asia-Pacific Journal of Teacher Education, 36(2), 163-174.

Tinning, R. (1992). Educación Física: la escuela y sus profesores: Universidad de Valencia.

Tobón, S. (2005). Formación basada en competencias. Pensamiento complejo, diseño curricular y didactica. Bogotá: ECOE Ediciones.

Tobón, S. (2007). El enfoque complejo de las competencias y el diseño curricular por ciclos propedéuticos. Acción Pedagógica, 16, 14-28.

Todd, Z., Nerlich, B., Clarke, D., y McKeown, S. (2004). Mixing methods in psychology: the integration of qualitative and quantitative methods in theory and practice. New York: Psychology press.

Toledo, I., Rubio, F., y Hermosín, M. (2012). Creencias, rendimiento académico y actitudes de alumnos universitarios principiantes en un programa plurilingüe. Porta Linguarum(18), 213-229.

Torrado, J., y Arce, C. (2015). Liderazgo entre iguales en equipos deportivos: elaboración de un instrumento de medida. Revista de Psicología del Deporte, 24(1), 185-190.

Torrelles, C., Coiduras, J., Isus, S., Carrera, F. X., París, G., y Cela, J. M. (2011). Competencia de trabajo en equipo: definición y categorización. Profesorado, Revista de currículum y formación del profesorado, 15(3), 329-344.

Torrelles, C., Coiduras Rodríguez, J., Carrera Farran, X., e Isus, S. (2014). Du changement dans l'évaluaction du travail d'équipe: validation de l'outil RUTE. Les Dossiers de Sciences de l'Éducation(31), 101-116.

Toussaint, L., y Webb, J. (2005). Gender differences in the relationship between empathy and forgiveness. The Journal of Social Psychology, 145(6), 673-685.

Turón, J., Santiago, R., y Díez, A. (2014). The flipped classroom: cómo convertir la escuela en un espacio de aprendizaje. Universidad de La Rioja: Grupo Océano.

Unión Europea (1995). Libro Blanco. Enseñar y aprender. Hacia una sociedad del conocimiento. Bruselas: Unión Europea. 
Unión Europea (2001). Common European Framework for Languages: learning, teaching, assessment. Strasbourg: Council for Cultural Cooperation Education Committee.

Unión Europea (2006). Competencias Clave para el aprendizaje permanente. Un marco europeo. (2006/962/CE).

Unesco (1998). La Educación Superior en el siglo XXI. Conferencia Mundial sobre Educación Superior. La Educación Superior en el siglo XXI: visión y acción. París.

Unesco (2009). Conferencia Mundial sobre la Educación Superior: La nueva dinámica de la educación superior y la investigación para el cambio social y el desarrollo. París.

Usabiaga-Arruabarrena, O., y Valencia-Peris, A. (2014). Propuesta de innovación educativa para el futuro profesorado de Educación Física a través de una blogosfera. Revista Española de Educación Física y Deportes,(406), 85-92.

Valdemoros-San Emeterio, M. A., y Lucas-Molina, B. (2014). Competencias que configuran el perfil del docente de primaria. Aula Abierta, 42(1), 53-60.

Vallejo, M., y Molina, J. (2011). Análisis de las metodologías activas en el grado de maestro en educación infantil: la perspectiva del alumnado. Revista electrónica interuniversitaria de formación del profesorado, 36(14), 207-217.

Vallerand, R., \& Rousseau, F. (2001). Intrinsic and extrinsic motivation in sport and exercise. En A. Ginger, H. A. Hansemblas, y C. M. Jasselle (Eds.), Hansbook of Sport Psychology (pp. 389-437). New York: Jhon Wiley \& Sons Inc.

Van Manen, M. (2003). Investigación educativa y experiencia vivida. Barcelona: Idea Books.

Velázquez Buendía, R. (2013). El discurso de la formación basada en competencias y el profesorado de educación física eficaz. Tándem: Didáctica de la educación fisica(43), 7-16.

Velázquez, C. (2013). La pedagogía de la cooperación en educación fisica. Armenia: Kínesis. 
Velázquez, C. (2015). Aprendizaje cooperativo en Educación Física: estado de la cuestión y propuesta de intervención. Retos: Nuevas tendencias en Educación Física, Deporte y Recreación(28), 234-239.

Velázquez, C., Fraile, A., y López-Pastor, V. (2014). Aprendizaje cooperativo en Educación Física. Movimento: Revista da Escola de Educação Física, 20(1), 239-259.

Vernetta, M. (2013). El aprendizaje cooperativo en educación superior. Una experiencia en la adquisición de habilidades gimnásticas. Cultura y Educación, 25(1), 3-16.

Vez, J. M. (2006). Aprendizaje de idiomas en los centros de lenguas de las universidades españolas. Análisis del estado actual y propuestas de aplicación general para la convergencia en el EEES. Madrid: Ministerio de Educación y Ciencia.

Vigarello, G. (2005). Ejercitarse y jugar. En A. Corbin, J. J. Courtine, y G. Vigarello (Eds.), Historia del cuerpo: del Renacimiento a la Ilustración (Vol. 1, pp. 229292). Madrid: Taurus.

Vilcazan, E., Contreras, M. A., y Villalba, K. (2017). Tecnología de la información y comunicación en Educación Física: aproximaciones a la formación docente. En J. Sánchez (Ed.), Nuevas ideas en informática educativa (pp. 600-605). Santiago de Chile: Universidad de Chile.

Viles, E., Jaca, C., Campos, J., Serrano, N., y Santos, J. (2012). Evaluación de la competencia de trabajo en equipo en los grados de ingeniería. Dirección y Organización(46), 67-75.

Villa, A., y Poblete, M. (2007). Aprendizaje basado en competencias: una propuesta para la evaluación de las competencias genéricas: Bilbao: Mensajero.

Villa, A., y Poblete, M. (2011). SEBSCO, una experiencia alternativa para evaluar competencias. Aula Abierta, 39(3), 15-30.

Villa Sánchez, A., y Villa Leicea, O. (2007). El aprendizaje basado en competencias y el desarrollo de la dimensión social en las universidades. Educar, 40(15-48).

Villalobos, J. (2002). Portafolios y reflexión: instrumentos de evaluación en una clase de escritura. Educere, 5(16), 390-396. 
Villardón-Gallego, L. (2006). Evaluación del aprendizaje para promover el desarrollo de competencias. Educatio siglo XXI(24), 57-76.

Villardón-Gallego, L. (2015). Competencias genéricas en educación superior. Madrid: Narcea.

Wanner, T., y Palmer, E. (2015). Personalising learning: exploring student and teacher perceptions about flexible learning and assessment in a flipped university course. Computers \& Education(88), 354-369.

Warneken, F., y Tomasello, M. (2009). The roots of human altruism. British Journal of Psychology, 1000(3), 455-471. doi:10.1348/000712608X379061

Weaver, S., Rosen, M., Salas, E., Baum, K., y King, H. (2010). Integrating the science of team training: guielines for continuing education. Journal of Continuing Education in the Health Professions, 30(4), 208-220.

Webber, S. S. (2002). Leadership and trust facilitating cross-functional team success. The Journal of Management Development, 21(3), 201-204.

Wegner, D. M., Erber, R., y Raymond, P. (1991). Transactive memory in close relationships. Journal of Personality and Social Psychology, 61(6), 923-929.

Weinberg, R. S., y Gould, D. (1996). Fundamentos de psicología del deporte y del ejercicio fisico. Barcelona: Arial.

Wharton, G. (2000). Language learning strategy use of bilingual foreign language learners in Singapore. Language Learning(50), 203- 243.

William, D., y Leahy, S. (2015). Embedding formative assessment: practical techniques for K-12 classrooms. West Palm Beach, FL: Learning Sciences International.

William, D., y Thompson, M. (2007). Integrating assessment with inistruction: What will it take to make it work? In C. A. Dwyer (Ed.), The future of assessment: Shaping teaching and learning (pp. 53-82). Mahwah, NJ: Lawrence Erlbaum Associates.

Wolff, B., Knodel, J., y Sittitrai, W. (1993). Focus groups and surveys as complementary research methods : a case exemple. En D. Morgan (Ed.), Successful focus group: advancing the state of the art (pp. 89-104). Newbury, CA: SAGE. 
Yániz, C. (2007). Competencias en la universidad. De la utopía a la pragmatopia. DIDAC(49), 4-9.

Yániz, C. (2008). Las competencias en el currículo universitario: implicaciones para diseñar el aprendizaje y para la formación del profesorado. Revista de Docencia Universitaria, 6(1), 1-14.

Zabalza, M. A. (2004). Diarios de clase : un instrumento de investigación y desarrollo profesional. Madrid: Narcea.

Zabalza, M. A. (2011). Competencias docentes del profesorado universitario: calidady desarrollo profesional. Madrid: Narcea.

Zabalza, M. A. (2012). Las competencias en la formación del profesorado: de la teoría a las propuestas prácticas. Tendencias pedagógicas(20), 5-32.

Zabalza, M. A., y Zabalza Cerdeiriña, M. A. (2011). Los profesores y profesoras como personas. En M. A. Zabalza Beraza y M. A. Zabalza Cerdeiriña (Eds.), Profesores y profesión docente. Entre el "ser"y el ëstar'(pp. 48). Madrid: Narcea.

Zagalaz, M. L. (2007). Apuntes para el cambio educativo. In P. Palou, F. Ponseti, A. Borrás, \& J. Vidal (Eds.), Educación Física en el Siglo XXI. Nuevas perspectivas. Nuevos retos (pp. 223-234). Palma de Mallorca: Universitat de les Illes Balears.

Zainuddin, Z., y Halili, S. (2016). Flipped classroom research and trends from different fields of study. International Review of research in Open and Distributed Learning, 17(3), 313-340. doi:https://doi.org/10.19173/irrodl.v17i3.2274

Zempoalteca, B., Barragán, J. F., González, J., y Guzmán, T. (2017). Formación en TIC y competencia digital en la docencia en instituciones públicas de educación superior. Apertura, 9(1), 80-96.

Zorrilla, P. P. (2002). L'Escuela Central de Profesores de Gimnástica (1887-1892). Apunts. Educación Física y Deportes(69), 6-16. 
ANEXOS

\section{Anexo 1. Cuestionario de competencias docentes de los estudiantes}

Proyecto de Investigación:
Las competencias docentes en la formación inicial del profesorado
de Educación Física
Estudiantes

1.- Teniendo en cuenta todas las asignaturas cursadas en la carrera, ¿en qué grado crees que te han ayudado a desarrollar las siguientes competencias docentes?

1.1.- Diseñar, aplicar y analizar intervenciones didácticas en la asignatura de Educación Física \begin{tabular}{cc|c|c|c|c|} 
nada & poco & medianamente & mucho & muchisimo \\
\cline { 2 - 5 } & 0 & 1 & 2 & 3 & 4 \\
\hline
\end{tabular}

1.2.- Elaborar y poner en práctica programas de Educación Física que faciliten la inclusión efectiva de los alumnos con necesidades educativas especiales

1.3.- Diseñar, desarrollar y evaluar los procesos de enseñanza-aprendizaje relativos a la actividad física y el deporte con atención a las características individuales y contextuales de las personas.

1.4.- Conocer y promover las diferentes manifestaciones motrices que forman parte de tu cultura tradicional

1.5.- Conocer el desarrollo psicomotor y su maduración evolutiva

1.6.- Conocer las capacidades físicas y los factores que determinan su evolución y saber aplicar sus fundamentos técnicos especíicos

1.7.- Conocer los fundamentos biológicos y fisiológicos del cuerpo humano en relación con la actividad física

1.8.- Conocer los elementos y fundamentos de la expresión corporal y la comunicación no verbal y su valor formativo y cultural

1.9.- Conocer los fundamentos básicos de la iniciación deportiva escolar y diseñar tareas específicas para utilizarlos en el ámbito de la enseñanza

1.10.- Disponer de estrategias de aplicación de los elementos de salud sobre la higiene y alimentación en la práctica educativa

1.11.- Disponer estrategias de enseñanza que promuevan la adquisición de hábitos de actividad física regular

1.12.- Saber utilizar el juego como recurso didáctico y como contenido de enseñanza

1.13.- Saber aplicar los fundamentos (técnicas) de las actividades físicas en el medio naturaL

1.14.- Saber utilizar instrumentos de evaluación en la asignatura de Educación Física

1.15.- Promover actividades complementarias relacionadas con la actividad física y el deporte dentro y fuera del recinto educativo

1.16.- Dar respuesta a la diversidad en las prácticas de Educación Física

1.17.- Tener capacidad de reflexión sobre el proceso de enseñanza/aprendizaje, los diferentes tipos organizativos y las distintas metodologías dentro de las clases de Educación Física

1.18.- Conocer y comprender los procesos evolutivos corporales y motrices

1.19.- Diseñar, modificar y/o adaptar al contexto educativo situaciones motrices orientadas al desarrollo y perfeccionamiento de las habilidades motrices

1.20.- Diseñar, desarrollar y evaluar procesos de enseñanza-aprendizaje relativos a competencia motriz, con atención a las características individuales y contextuales de las personas 
1.- Teniendo en cuenta todas las asignaturas cursadas en la carrera, ¿en qué grado crees que te han ayudado a desarrollar las siguientes competencias docentes? (continuación)

1.21.-Analizar y comunicar, de manera crítica y fundamentada, el valor de la actividad física $\quad$ nada $\quad$ poco $\quad$ medianamente mucho muchisimo y el deporte y sus posibilidades de contribuir al desarrollo y bienestar de las personas.

1.22.- Identificar y prevenir los riesgos que se derivan para la salud de la práctica de actividades físicas inadecuadas

1.23.- Conocer características de la organización de los centros educativos

1.24.- Elaborar propuestas de cambio de la realidad educativa

1.25.- Capacidad de análisis y síntesis

1.26.- Capacidad de organización y planificación

1.27.- Comunicación oral y escrita en lengua nativa

1.28.- Conocimiento de una lengua extranjera

1.29.- Conocimientos de informática relativos al ámbito de estudio

1.30.- Trabajo en equipo

1.31.- Habilidades en las relaciones interpersonales

1.32.- Razonamiento crítico

1.33.- Compromiso ético

1.34.-Aprendizaje autónomo

1.35.-Adaptación a situaciones nuevas

1.36.- Creatividad

\begin{tabular}{|c|c|c|c|c|}
\hline & & & & \\
\hline 0 & 1 & 2 & 3 & 4 \\
\hline 0 & 1 & 2 & 3 & 4 \\
\hline 0 & 1 & 2 & 3 & 4 \\
\hline 0 & 1 & 2 & 3 & 4 \\
\hline 0 & 1 & 2 & 3 & 4 \\
\hline 0 & 1 & 2 & 3 & 4 \\
\hline 0 & 1 & 2 & 3 & 4 \\
\hline 0 & 1 & 2 & 3 & 4 \\
\hline 0 & 1 & 2 & 3 & 4 \\
\hline 0 & 1 & 2 & 3 & 4 \\
\hline 0 & 1 & 2 & 3 & 4 \\
\hline 0 & 1 & 2 & 3 & 4 \\
\hline 0 & 1 & 2 & 3 & 4 \\
\hline 0 & 1 & 2 & 3 & 4 \\
\hline 0 & 1 & 2 & 3 & 4 \\
\hline 0 & 1 & 2 & 3 & 4 \\
\hline
\end{tabular}

2.- Teniendo en cuenta todas las asignaturas cursadas en la carrera, ¿en qué grado crees que te han ayudado a desarrollar las siguientes competencias docentes? (continuación)

2.1- Organizar y animar situaciones de aprendizaje

2.2- Gestionar la progresión de los aprendizajes

2.3- Elaborar y poner en práctica estrategias de atención a la diversidad

2.4- Implicar al alumnado en su aprendizaje y en la vida del centro

2.5- Trabajar en equipo con otros docentes

2.6- Participar en la gestión del Centro

2.7- Informar e implicar a las familias

2.8-Utilizar las tecnologías de la información y la comunicación

2.9-Afrontar los deberes y los dilemas éticos de la profesión

2.10- Organizar la propia formación continua

\begin{tabular}{|l|c|c|c|c|}
\multicolumn{1}{l|}{ nada } & poco & medianamente & mucho & muchísimo \\
\hline 0 & 1 & 2 & 3 & 4 \\
\hline 0 & & & & \\
\hline 0 & 1 & 2 & 3 & 4 \\
\hline 0 & 1 & 2 & 3 & 4 \\
\hline & & & & \\
\hline 0 & 1 & 2 & 3 & 4 \\
\hline 0 & & & & \\
\hline & 1 & 2 & 3 & 4 \\
\hline 0 & 1 & 2 & 3 & 4 \\
\hline 0 & 1 & 2 & 3 & 4 \\
\hline & & & & \\
\hline 0 & 1 & 2 & 3 & 4 \\
\hline & & & & \\
\hline 0 & 1 & 2 & 3 & 4 \\
\hline
\end{tabular}


3- Cuando han utilizado metodologías activas en las asignaturas de tu carrera ¿consideras que te han ayudado a adquirir competencias docentes?

4- Cuando han utilizado la evaluación formativa y continua en las asignaturas de tu carrera ¿consideras que te han ayudado a adquirir competencias docentes?

nada poco medianamente mucho muchísimo \begin{tabular}{l|l|l|l|l|l}
0 & 1 & 2 & 3 & 4
\end{tabular} nada poco medianamente $\quad$ mucho muchísim \begin{tabular}{|l|c|c|c|c|}
\hline 0 & 1 & 2 & 3 & 4 \\
\hline
\end{tabular}

5. ¿Con cuánta frecuencia tus profesores han utilizado los siguientes instrumentos y procedimientos de evaluación en las asignaturas que has cursado?

5.1.- Observación del profesor en clase (fichas de observación)

5.2.- El control de la participación en el aula (en grupos y debates)

5.3.- Examen tipo test.

5.4.- Examen de preguntas abiertas

5.5.- Examen de preguntas cortas (explicaciones breves)

5.6.- Examen de preguntas cerradas (definiciones)

5.7.- Exámenes escritos dejando disponer de documentos

5.8.- Exámenes orales

5.9.- Pruebas prácticas de carácter físico (ejercicios físicos, situaciones de juego,...)

5.10.-Portafolios

5.11.- Cuadernos de campo (o fichas de sesiones prácticas)

5.12.- Informes o trabajos escritos

5.13.- Ensayos a partir de textos escritos o materiales audiovisuales

5.14.- Poyectos de aprendizaje tutorados

\begin{tabular}{|c|c|c|c|c|}
\hline $\begin{array}{l}\text { muy poco o } \\
\text { nada }\end{array}$ & $\begin{array}{l}\text { pocas } \\
\text { veces }\end{array}$ & $\begin{array}{l}\text { alguna } \\
\text { vez }\end{array}$ & bastante & mucho \\
\hline 0 & 1 & 2 & 3 & 4 \\
\hline 0 & 1 & 2 & 3 & 4 \\
\hline 0 & 1 & 2 & 3 & 4 \\
\hline 0 & 1 & 2 & 3 & 4 \\
\hline 0 & 1 & 2 & 3 & 4 \\
\hline & & & & \\
\hline 0 & & & & \\
\hline 0 & 1 & 2 & 3 & 4 \\
\hline & & & & \\
\hline 0 & 1 & 2 & 3 & 4 \\
\hline 0 & 1 & 2 & 3 & 4 \\
\hline 0 & 1 & 2 & 3 & 4 \\
\hline 0 & 1 & 2 & 3 & 4 \\
\hline 0 & 1 & 2 & 3 & 4 \\
\hline 0 & 1 & 2 & 3 & 4 \\
\hline
\end{tabular}

\section{6. ¿Cuál es tu grado de acuerdo con los siguientes enunciados?}

6.1.- La interacción entre profesores y estudiantes favorece el proceso de evaluación

6.2.- La realización de las pruebas de evaluación se anunciaron con suficiente tiempo de antelación

6.3.- Las pruebas de evaluación parten de un acuerdo con el alumnado.

6.4.- La recogida de información para la evaluación nos genera tensión y nerviosismo

6.5.- La recogida de información para la evaluación fomenta la motivación para el aprendizaje

6.6.- La evaluación positiva repercute en la autoestima del/a estudiante

6.7.- El conocimiento previo del sistema de evaluación favorece nuestro proceso de aprendizaje del/a estudiante

\begin{tabular}{|c|c|c|c|c|}
\hline $\begin{array}{l}\text { nada de } \\
\text { acuerdo }\end{array}$ & $\begin{array}{l}\text { poco de } \\
\text { acuerdo }\end{array}$ & $\begin{array}{c}\text { ni acuerdo } \\
n i \\
\text { desacuerdo }\end{array}$ & de acuerdo & $\begin{array}{l}\text { muy de } \\
\text { acuerdo }\end{array}$ \\
\hline 0 & 1 & 2 & 3 & 4 \\
\hline 0 & 1 & 2 & 3 & 4 \\
\hline 0 & 1 & 2 & 3 & 4 \\
\hline 0 & 1 & 2 & 3 & 4 \\
\hline 0 & 1 & 2 & 3 & 4 \\
\hline 0 & 1 & 2 & 3 & 4 \\
\hline 0 & 1 & 2 & 3 & 4 \\
\hline
\end{tabular}


7.¿Cuál es tu grado de acuerdo con las siguientes afirmaciones, en relación a cómo se ha establecido la calificación de las asignaturas que has cursado?

7.1.- La calificación la decide el profesor a partir de la evaluación

7.2.- El alumnado se autocalifica (parcial o totalmente)

7.3.- Se califica de forma dialogada y consensuada, entre profesorado y alumnado (parcial o totalmente)

7.4.- Se califica a partir de la autoevaluación (parcial o totalmente)

7.5.- Se califica a partir de la coevaluación, entre compañeros (parcial o totalmente)

8.- Cuál es su grado de satisfacción general con tu carrera (0, mínima satisfacción; 10, máxima satisfacción)

9.- Si me pidieran que recomendara a un amigo mi carrera yo le diría que lo hiciera sin pensarlo (grado de acuerdo de 0, nada de acuerdo; 10 , totalmente de acuerdo)

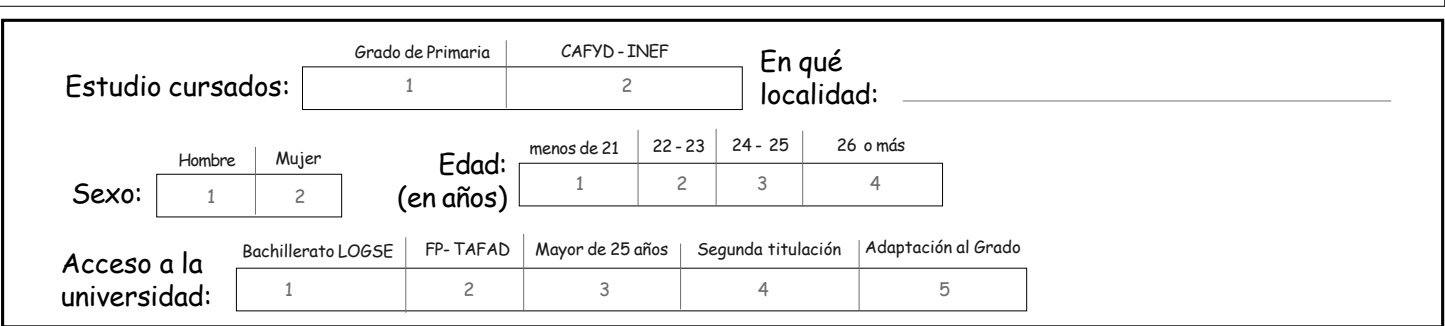




\section{Anexo 2. Guión realizado para el desarrollo del Grupo de Discusión 1}

E. $R$

Pautas para la organización y realización de los grupos de discusión

C. T

Proyecto: "Las competencias docentes en la formación inicial del profesorado de educación física"

\section{Planteamiento de la pregunta base y cuestiones a tener en cuenta}

\section{Tema central:}

Las dos temáticas que entendemos deben presidir el punto de partida del Grupo de Discusión serían las siguientes:

- ¿Las competencias (transversales, docentes y específicas) planteadas en la formación inicial del profesorado de Educación Física son las adecuadas?

- ¿Son coherentes los procedimientos de evaluación utilizadas para la valoración de las competencias?

\section{Temáticas secundarias:}

1. ¿Qué competencias en la FIPEF son las que tienen más valor para los estudiantes, docentes y egresados?

2. ¿Cuáles son las competencias que adquieren los estudiantes de la FIPEF en su tiempo de formación y dentro de las primeras experiencias profesionales?

3. ¿Qué procedimientos de evaluación son las predominantes en la evaluación de las competencias en la FIPEF?

4. ¿Existe coherencia entre las competencias que se intentan desarrollar en la FIPEF y lo que realmente se evalúa?

5. ¿La evaluación formativa favorece la adquisición de las competencias en la FIPEF?

6. ¿Cuáles serían las actividades formativas que más ayudarían a la adquisición de las competencias docentes en la FIPEF?

7. ¿Existe una transferencia positiva de las buenas prácticas vividas en la FIPEF a los contextos de práctica docente de Primaria, Secundaria y Bachillerato?

\section{Observaciones a tener en cuenta:}

Las temáticas secundarias deben plantearse si vemos que nos abordadas de forma natural desde las preguntas de la temática central.

Las preguntas de las temáticas secundarias son directas (conocen la realidad en primera persona) o indirectas (son sus percepciones sobre el tema) dependiendo del grupo de discusión. Por lo tanto, debemos incidir más en las directas. Ver la tabla 


\begin{tabular}{|l|l|l|l|}
\hline & Grupo Docentes & Grupo Estudiantes & Grupo Egresados \\
\hline Preguntas Directas & 1 y 3 & $1,2,3,4,5$ y 6 & $1,2,4,5,6$ y 7 \\
\hline Preguntas Indirectas & $2,4,5,6$ y 7 & 7 & \\
\hline
\end{tabular}




\section{Anexo 3. Guión realizado para el desarrollo del Grupo de Discusión 2}

Pautas para la organización y realización de un segundo grupo de J.L.A discusión con estudiantes de EF: "Las competencias transversales docentes en la formación del profesorado de educación física"

\section{PLANTEAMIENTO DEL GRUPO DE DISCUSIÓN 2}

\section{Presentación de resultados para valoración y debate grupal}

Se presentan los resultados sobre la valoración del grado de ayuda formativa recibida durante los estudios cursados de Educación Física (MEPEF_CAFyD), a partir de una muestra de 1.200 estudiantes de EF de Universidades españolas. La pregunta que orienta las respuestas es la siguiente:

Teniendo en cuenta todas las materias cursadas en la carrera:

¿en qué grado crees que te han ayudado a desarrollar las siguientes competencias docentes: Instrumentales, Interpersonales?

Dados los resultados descriptivos obtenidos, se opta prioritariamente por considerar las competencias contenidas en los bloques instrumentales e interpersonales

Se insista a una nueva valoración y debate sobre la ayuda formativa recibida para el desarrollo de tales competencias, teniendo en cuenta las percepciones de los compañeros estudiantes MEPEF y CAFyD que realizaron el cuestionario y cuyos resultados se comparten con el grupo y considerando también su propia percepción al respecto.

VALORA EL GRADO DE ACUERDO

\begin{tabular}{c}
\hline Nada (0) \\
\hline Poco (1) \\
\hline Medianamente (2) \\
\hline Muchósimo (4) \\
\hline
\end{tabular}

\begin{tabular}{|l|c|}
\hline PREGUNTAS BLOQUE 1. Competencias Instrumentales & X \\
{$[\overline{\times}(\mathrm{MB} 1)=2,08 ; \sigma=, 703]$} & $\mathrm{VG}$ \\
\hline $\begin{array}{l}\text { P1.26.- Grado de ayuda recibida para el desarrollo de la competencia docente: Capacidad } \\
\text { de organización y planificación }\end{array}$ & 2,59 \\
\end{tabular}




\begin{tabular}{|l|l|l|}
\hline $\begin{array}{l}\text { P1.8.- Grado de ayuda recibida para el desarrollo de la competencia docente: Conocer los } \\
\text { elementos y fundamentos de la expresión corporal y la comunicación no verbal y su } \\
\text { valor formativo y cultural }\end{array}$ & 2,48 & \\
\hline $\begin{array}{l}\text { P1.27.- Grado de ayuda recibida para el desarrollo de la competencia docente: } \\
\text { Comunicación oral y escrita en lengua nativa }\end{array}$ & 2,44 \\
\hline $\begin{array}{l}\text { P1.25.- Grado de ayuda recibida para el desarrollo de la competencia docente: Capacidad } \\
\text { de análisis y síntesis }\end{array}$ & 2,36 & \\
\hline $\begin{array}{l}\text { P1.29.- Grado de ayuda recibida para el desarrollo de la competencia docente: } \\
\text { Conocimientos de informática relativos al ámbito de estudio }\end{array}$ & 1,77 \\
\hline $\begin{array}{l}\text { P1.28.- Grado de ayuda recibida para el desarrollo de la competencia docente: } \\
\text { Conocimiento de una lengua extranjera }\end{array}$ & 1,23 \\
\hline
\end{tabular}

\begin{tabular}{|l|c|c|}
\hline PREGUNTAS BLOQUE 2. Competencias Interpersonales & $\overline{\times}$ \\
{$\left[\begin{array}{l}\bar{x}(\mathrm{MB} 2)=2,80 ; \sigma=, 677] \\
\end{array}\right.$} & 3,23 & \\
\hline P1.30.- Grado de ayuda en el desarrollo de la competencia docente: Trabajo en equipo & 2,79 \\
\hline $\begin{array}{l}\text { P1.31.- Grado de ayuda en el desarrollo de la competencia docente: Habilidades en las } \\
\text { relaciones interpersonales }\end{array}$ & \\
\hline P1.32.- Grado de ayuda en el desarrollo de la competencia docente: Razonamiento crítico & 2,65 & \\
\hline P1.33.- Grado de ayuda en el desarrollo de la competencia docente: Compromiso ético & 2,52 & \\
\hline
\end{tabular}

\section{Planteamiento de las preguntas y cuestiones a considerar}

Específicamente para profundizar más sobre la ayuda formativa recibida a partir de las materias cursadas en los estudios para el desarrollo de sus competencias instrumentales e interpersonales, se plantean tres preguntas para ahondar y debatir al respecto. Se aborda cada pregunta atendiendo una a una las competencias que forman parte de cada bloque.

a) ¿Qué experiencias o acciones formativas se han realizado en tu formación (en las asignaturas cursadas: actividades, métodos, sistemas de evaluación, tareas,..) y cómo crees que te han ayudado a adquirir y desarrollar tus competencias instrumentales e interpersonales?

b) ¿Cuáles son las dificultades con las que te has encontrado durante la formación que has cursado para adquirir y desarrollar tus competencias instrumentales e interpersonales? 
c) ¿En qué crees te resultará útil para tu actividad docente desarrollar tus competencias instrumentales e interpersonales? 
Anexo 4. Transcripción del GD 1

TRANSCRIPCIÓN GRUPO DE DISCUSIÓN 1 (Noviembre 2016)

DINAMIZADORA DEL GRUPO (CT): Lo primero que vamos a hacer es, voy a presentarme yo, y también a JL. Yo soy CT y voy a moderar el grupo de discusión que vamos a realizar; JL viene de la Universidad de Valladolid y me va a ayudar a hacer las labores para que después la transcripción no tenga problemas, y que cuando hablamos de grupo las cosa se nos complica un poquito. Os pediremos al final que completéis una hoja con algunos datos para saber de qué universidad sois, qué estudios habéis realizado, todas estas cosas, y en esta hoja poned como especialmente el teléfono, por si cualquier cosa de dieta o lo que sea hay que resolverlo con vosotros y os podamos localizar fácil. Entonces, aunque ya algunos me imagino que algunos os habéis medio presentado, eh, vais diciendo el nombre y de qué universidad venís y así va apuntando el orden:

CT: Lo básico ya lo tenemos; mirad, os explico como funciona un grupo de discusión, no se si ya alguno habéis participado anteriormente en alguna experiencia similar; vamos a plantear un tema encima de la mesa, y queremos saber vuestra opinión para que libremente, vosotros vayáis hablando sobre esa temática; lo único que os vamos a pedir es que mientras uno habla, eh.., aunque queramos intervenir, pues esperamos a que acabe ese compañero esa compañera y después intervenimos nosotros, no se trata de ir haciendo intervenciones por turnos sino generar un diálogo, un debate en torno al tema que os vamos a plantear. La duración suele estar en torno a la hora y cuarto mas - menos, eh; para el trabajo que se está desarrollando en el proyecto de investigación, eh, aunque os hayamos pedido todos los nombres, todo va a ser anónimo, ahora os hemos pedido el nombre para el manejo de aquí sea mucho mas sencillo, pero luego en la investigación se va a mantener el anonimato en todo momento con lo cual sentiros superlibres para poder hablar o decir lo que pensáis; esto, la idea es que, ayude también a la mejora de, de vuestra formación; claro, a vosotros ya os pilla poco, pero para los que vienen por detrás, si se puede mejorar esa formación, que ayude y que complemente.

Bueno pues, os comento un poco; mirad, que vamos a ver un tema que se que os encanta, son el tema de las competencias, verdad que si?, bueno, pues son las competencias; un poco, cómo las están trabajando con vosotros, cómo vosotros estáis aprendiendo, que tipo de competencias pensáis que son las que mas se está incidiendo, ah, cómo se están evaluando esas competencias, tanto competencias generales, transversales y específicas, eh.., de vuestros estudios. Ese sería un poco, la idea; eh, que empezarais a hablar los, y si yo veo que hay que reconducir un poco el tema o preguntar algo concreto pues intervendré, la idea es que yo intervenga lo menos posible y que vosotros seáis los que generéis el discurso sobre esas competencias; entonces, yo plantearía la 
pregunta de: ¿las competencias planteadas en la formación inicial del profesorado de educación física, son las adecuadas?, y el que quiera que abra el debate.

A: A mi por ejemplo [...] me parece, vamos, es que, que duda cabe, eso gestionar aprendizajes, adaptar, llevar los equipos del aula, no se si habría que añadir alguna mas o modificar alguna, luego aquí el problema estaría el tema de cómo se evalúa os si se van a poder re...,

L: Yo también creo que son adecuadas, yo las he leído antes de venir, y creo que son las competencias que tiene que tener un profesor de educación física, bueno en mi caso, solo he cursado dos asignaturas, porque tres las tenía convalidadas, y considero que tanto, vamos, en las dos asignaturas que he cursado, creo que se trabajan todas esas competencias, y se trabaja mucho, el nivel, también, el trabajo autónomo y de investigación del propio alumno, el trabajo en quipo, el que tu mismo preparares las clases, respetar al compañero, es un poco, básicamente, lo que es ser un buen profesor, y yo considero que si que lo hemos hecho.

A: Bueno, en lo que respecta a nuestra universidad, en nuestro caso que hacemos INEF es que teóricamente sí que son adecuadas pero llevadas a cabo para que nosotros podamos aprender cómo conseguir esta atmósfera que tenemos en el aula y tal, no, faltan herramientas, nosotros no tenemos... bueno claro.., di que no tendría que estar allí, pero no tenemos tantas clases para conseguir esas competencias ni manera, vamos, la teoría esta bien pero la práctica falla.

G: Yo coincido también; que el límite, la limitación principal para conseguirlo es el tiempo, aunque es hablar con algún profesor.., porque nosotros antes teníamos en vez de esta asignatura, dábamos lo mismo que esta asignatura pero fraccionado, dábamos educación física y salud, y otra parte era educación física, estaba mucho mas fraccionado, tenían más tiempo para verlo, aprendían más despacio, se quedaba yo creo que mejor que ahora, todo más concentrado, en un tiempo más reducido, y que, mucho más difícil.

S: Yo coincido con él porque en nuestra facultad sí hay ciertas asignaturas que, problemas de asignaturas, que dan mucho temario pero en verdad no están centrándose en ninguno, en ninguno concreto, lo que pasa es que tocas un poco de cada campo pero no estás siendo un experto por así decirlo de un campo concreto; yo creo que es un gran problema.

CT: Animaos; se centra más el trabajo en competencias, en contenidos, está equilibrado..

A: Yo creo desde mi punto de vista que se centra más en contenidos y a lo largo de esos trabajos individuales, grupales y demás, el Plan Bolonia es que es un fantasma... 
$\mathrm{S}$ : Si, yo coincido contigo, es todo mucho contenido y luego esos contenidos.., toda una cosa que te aprendes de memoria, se te olvida a los cinco minutos y no sabes trasladarlo a la vida real, entonces, no te vas a quedar con la de teorías en una clase con niños, entonces competencias en cuanto en un momento práctico, yo creo que ahí tiramos cada uno de instinto de a ver cómo podemos sobrevivir en ese momento.

So: Porque con lo que estás diciendo, lo de las prácticas, por las pruebas hechas en clase con compañeros, es como que no lo acabas de vivir bien, porque es hacerlo a tus compañeros, que siempre estás charlando, donde, jvenga!, danos una clase para que, que luego me toca hacerlo a mi, pero no [...] de verdad, sabes...

S: En una de nuestras asignaturas si que nos encargaba, que teníamos que analizar la intervención de un entrenador, y entonces pues vas analizando, cómo se, como se comporta, como no se va a comportar, si te responde, eso a mi me parece suficiente, por que lo ves directamente, yo creo que debería haber más asignaturas para poder ver este tipo por ejemplo, de observar una realidad; porque lo que dices tú, es que en clase, vale que es que hacer el esfuerzo de intentar enseñarles a tus compañeros lo que tu sabes, pero no, no es real.

L: Yo creo que, perdona, influye ahí un poco también la, lo abiertos o no que sean los centros, que quizás los centros deberían ser más cercanos a las universidades, oye pues llevar esto a la práctica aquí en el centro, vamos a ver, aunque haya profesores supervisando, o se haga un seguimiento o antes [...] y el profesor que hay allí observando, pero que se pueda, que sea más aplicable, porque es que si no, lo que has dicho tú, tu lo llevas a cabo con tus compañeros, pero no es lo mismo, porque ni la edad es la misma por mucho que un adulto quiera, nunca va atener las reacciones que tiene un niño, y al final ni a ti te sirve, ni al compañero le sirve, es que..., no sirve, porque una persona con 18 o 20 años no va a reaccionar como un niño de 12 , entonces, reaccionan como pueden intentando ayudarte hasta el punto de que en el próximo día me toca a mi, o venga, para que no te pongan mala nota, o...

A: Yo también estoy de acuerdo con tener más actividades de eso, de casos reales en vez de casos hipotéticos, o que hagas en la universidad,.. donde te enfrentas a un niño, nueve niños, y el puede ponerse como maestro y puedes plantearle una actividad individual o grupal, la llevas, la vas modificando esto por esto, este mira a lo mejor se ha torcido la muñeca, esto hay que modificarlo, el clima de este grupo no era el esperado, si hay que hacer algo para engancharles, y es ahí donde te salen las competencias; pero, bueno, a lo que íbamos un poco, que quien te las enseña, esas competencia, es como que te sale de, algo fallamos en el oral.., y lo que decía allí la compañera, también a mi modo de ver, faltan herramientas y recursos.

A: Hipotéticamente está todo bastante bien, pero a la hora de la verdad..., ahí está..

L: La aplicabilidad es muy relativa; teoría bien, porque teoría..., tienes toda la que quieras e incluso más, pero luego, a la hora de aplicarlo, ahí ya, los centros no te dejan, o si tienes acceso a un centro, no puedes en cincuenta minutos, hasta qué punto puedes comprobar lo aplicable o no que son las competencias; es que es muy complicado, por eso los centros ..., a fin de al cabo, los que hoy estamos aquí, 
mañana vamos a ser los profesores de esos niños, entonces cuanto más estemos con ellos, mejor podremos nosotros ver como vamos a funcionar, qué debemos de cambiar, o qué haríamos, ....cambiar un poco todo.

AL: Si además es el principio del currículo, no?, se aprende de todo. Que está bien adecuar saber durante la clase que sepan, no minimices el tiempo de una clase, que no minimices recursos, espacios mejores, todo eso, que es a lo que hay que tender, ¿no?.

Ma: Hasta que punto puedes aplicar si con cada reforma que hay en la ley te están quitando más horas, es que esa es otra..., es otra. Yo tengo 2 horas, 3 como mucho horas de educación Física en una clase entre que llegas, se cambian, salen, empezamos, al final es que tienes 30 minutos para dar clase, $30-40$ minutos ... es que es muy reducido, muy complicado.

\section{A: ¿Pero son competencias de formación del profesorado?}

CT: Si estamos hablando de competencias, las generales, eh..., comunes a nuestros compañeros, trabajo en equipo, competencias transversales, perdón, eh, si, pero que las, eh ... las transversales, serían trabajo en equipo y demás, eh, las competencias específicas ya de educación física y las competencias docentes, pues, las que está comentando el compañero, cómo gestionar recursos, cómo gestionar..., estamos hablando de todas las competencias en general.

AL: yo por ejemplo, aquí hay una que es conocer e identificar las diferentes formas de organización social del grupo ...

G: Para qué es estar en una clase con niños...

S: Yo en general la visión que tengo, creo que, vamos, yo tengo una visión un poco más positiva, creo que los recursos están bien, para el cumplimiento del prácticum y de cara a lo que pienso sobre las competencias de los docentes, creo que son como un poco dispersas, yo me imagino que este año, cuando yo acabe cuarto, me imagino leyéndome las competencias y preguntándome ¿yo he conseguido esto? y claro no se hasta que punto puedo conseguir un si o un no rotundo. Creo que la mayoría, serán pues la mayoría de los casos si, o a veces no, o este creo que cojeo un poco pero de cara a los recursos y eso, yo en general estoy contenta, creo que se ofrecen bastantes oportunidades para poder hacer prácticas con niños, tanto en el prácticum como fuera. A lo mejor quizás hablo un poco más concretamente de mi universidad y en mi ámbito que es lo que conozco; las competencias sí las veo como dispersas, muy generales, algunas concretas pero no se hasta qué grado puedo decir eso.

A: Yo creo que también a la hora de decir las competencias, también, influye mucho la forma de valorar de cada centro, de cada asignatura, porque yo creo que hay demasiados exámenes finales en los que realmente tampoco estás plasmando lo que has aprendido en la asignatura, al final tampoco se tiene en cuenta el proceso de aprendizaje que has tenido, yo creo que en el ámbito de la docencia si tu no has 
tenido un buen profesor tampoco vas a adquirir las competencias bastante más adecuadas para poder transmitirlo todo, yo creo que también sería, más, eh, eso, prestar más atención a la forma de evaluación de las asignaturas.

S: Yo creo que ahora eso está cambiando cada vez más, veo cambios en la evaluación de los profesores, veo otra forma de mirar a los alumnos, de tenerlo en cuenta, y sobre todo creo que ahora cada vez más nos tienen más en cuenta, nos hacen mucho hincapié en la reflexión, la reflexión, parece que tiene que ver con todas las competencias, yo creo y con todo.

G: Yo pienso que con respecto a lo que ha dicho mi compañera de las evaluaciones en muchas asignaturas deberían ser más, eh, pruebas como prácticas que tendrían que estar muy abiertas para el examen y así cuidar bien mucha teoría pero al fin y al cabo si tu tienes que tratar con alumnos, por que la enseñanza trata de eso, yo creo que sería mucho mejor que el examen fuera orientado a una práctica o a una clase real ya sea de niños o de lo que sea porque, si te vas poniendo un examen, pero en verdad tu, eres capaz de poner en práctica lo que estás aprendiendo con gente real, porque todo el mundo sabe poquitas cosas pero luego, yo creo que en este aspecto tendría que ser más aprender un acción de examen que aprender haciendo, de práctica de lo que te han enseñado con gente de clase real.

Ma: Personalmente en nuestro caso las asignaturas que hemos cursado las dos han sido evaluación continua, evaluación de la práctica y no hemos tenido examen, en este sentido, creo que es la siguiente pregunta, creo que la estrategia de evaluación es la correcta para conseguir estas competencias, por lo menos en el caso de magisterio en Valladolid, bueno de educación.

A: Eh, en este caso..., son preguntas de, es que tampoco no se muy bien como explicarlo, pero, Educación física en el medio natural tienes que hablar de esta actividad, que tienes una alumna que tiene este problema y que, pues, esto así me parece bien, no sale, que al final, pues mira dime una pregunta, sinceramente, hablo de la esterilla, en fin, no se.., en psicología o algo de esto, exámenes muy.. peculiares y de más y que si no lo ves, ahora mismo no se te decir nada, y de organización escolar, pues.. antes de hacer el prácticum, preguntar, cuándo estás en el centro, lugares, dices ah, pues yo de la a, para que es una a, pues la a se hace esto, esto y con esto se hace tal, y con esto se realiza lo otro, y es que cuando me he enterado, cuando me he dado cuenta de la mayoría de las cosas de la carrera

S: Si bueno, que será, bueno, será así, nosotros no tenemos tantas prácticas como en magisterio, eh, sobre todo con niños, claro, nosotros podemos elegir hacer prácticas en cualquier tipo de, en un gimnasio en fin yo lo voy a hacer en un club deportivo, entonces yo en mi caso si he podido dar clase a niños en un club de atletismo, tal, y sí que veía, que, pues estos detalles de teorías y autores, todo esto, no me servían para nada, pero, no, pues algunas cosas que sí se iban haciendo por allí, para poder aplicarlas en el aula y tal, era de lo que más me acordaba, lo que más iba avanzando, y poco a poco pues, esto funciona, lo único una pena que son solo como cuatro 
pinceladas de esto, y siete mil autores que no se ni citarlos, entonces allí está, digo yo...

\section{CT: ¿vuestros docentes os explican qué competencias trabajáis en cada materia?}

Me: En la mía, ¿en cada asignatura?

A: Hay docentes que te lo explican y docentes que no, que no las explican.

CT: ¿y vosotros creéis que como estudiantes, el estudiante de INEF o Magisterio tiene conciencia de la importancia de las competencias?

TODOS LOS ESTUDIANTES (unanimidad): NO

\section{CT: ¿Qué habría que hacer?}

S: Demostrarles que sí que son importantes y yo creo que te das cuenta de la importancia, pues eso, en un caso de vida real que te plantas delante de niños y dices, venga, a ver qué sabes hacer, en realidad sique,..., pues tendrá que..., todo esto que me están intentando enseñar.

A: O, disfrazarlo por decirlo así, un poco más atractivo, pues bueno nuestros alumnos son lo que son por nosotros para tus profesores de universidad, que si a nosotros nos decís estas son las competencias, le digo, a, vale, gracias. Es que lo lees y no me interesa, se te hace pesado, y al final, lo tienes que, pasa igual aquí o un alumno según como des la clase, va a pasar de ti y no se va enterar de nada. Quieras o no, un poco lo de que no siempre tiene la razón, hacerlo más atractivo y hacerlo de otra manea y si de verdad es importante pues...

L: Que muchas veces parece que los primeros que le quitan importancia a la guía docente a las competencias son los profesores ¿que día te enseñan la guía docente?, el primer día que está la cumple dentro de la guía de que primer día que no vas a hacer nada; esta es la guía docente, muy bien, no te la vuelven a mencionar nunca, una vez cuando alguien tiene algún problema o algo, no, en la guía docente está así, si no te la has leído es tu problema; ¿qué me aporta a mi la guía docente?, dame algo que tenga que ir a la guía docente a verlo, que me pueda interesar, que pueda servirme para la formación, para la asignatura, para la vida, pero si me la nombras el primer día y un día porque tengo un problema con la nota de mi examen o con cualquier cosa, no, la guía docente, y no si quiera te dice vamos a sentarnos y vamos a ver la guía docente, yo te explico donde está, lo que yo quería de acuerdo a las competencias y porqué tienes esto porque no has alcanzado esta competencia, por lo que sea, pero ni siquiera, la guía docente, ahí está...; es que no vale la guía docente, según me la das ahí la dejo, al lado..; házmela atractiva para que yo pueda recurrir a ella y la tenga más en cuenta; yo creo que es un problema también que ... 
A: Estaría bien, sería explicarla el primer día y luego ver si fueran coherentes con ellos mismos, en plan mientras van pasando las clases ir relacionándolo con lo explicado el primer día.

S: Hay muchas veces que una asignatura que ves la guía docente y dices, qué pedazo de asignatura y luego llegas y no se parece en nada, entonces, eso...

A: Que se tenga también un poco en cuenta lo que se dice en una asignatura hasta el final, no solo el primer día, si se va a hacer un trabajo individual, grupal, es eso, que si quieres que vayamos a, venga y utilizad el espacio, conseguir esas cosas, no que no que solo sea el primer día, no se como explicarme...

G: Que se recurra a ella, que sea un recurso, no, como el moodle un poco, que al final encuentra un montón de cosas porque también,... la programación docente sea un recursos, pues que recurras a él, por eso es un recurso, porque se recurre a él, y yo creo que la tienen ahí en un modo legal, por si tienes que reclamar algo, pero no para aplicarla mucho.

G ...y para ver los porcentajes del examen que al final luego cuando te la enseñan, te dicen, porcentaje y porcentaje del examen, presencial, no se qué, no se qué, no se cual; semipresencial, no se cuantos; no presencial, tal; cierras y ya está, y te olvidas de ella.

Ma: Respecto a lo que decías si somos conscientes creo que has preguntado de la importancia de las competencias, yo creo que en $\mathrm{mi}$ caso, eh, cuando hice el prácticum en tercero, cuando realmente eres consciente de qué tipo de competencias has adquirido, de lo que te falta por adquirir y en qué dirección tienes que trabajar, porque ahí es cuando ves tus carencias y tus virtudes.

CT: Las distintas formaciones que estáis cada uno de vosotros se trabajarían por igual todas las competencias es decir, las transversales, las docentes, 0 las generales o se centra más en las específicas, como lo veis.

A: Yo, en nuestro caso en nuestra carrera tal y como está hecha tocamos muchas cosas y no profundizamos en nada. Entonces, como que no te da tiempo a ver bien las competencias específicas, no da tiempo; estás haciendo, bádminton y mil cosas a la vez, y escalada, y por eso mismo, yo creo que, por eso mismo, no somos conscientes de la importancia porque casi no lo vemos, es más aprender el contenido, aprender medidas de seguridad, pero muy por encima, todo en este sentido.

S: Yo creo que en cuanto a específicas casi no lo vemos. Muy general, tienes un grupo ya sea de niños que van a hacer escalada, niños que van a hacer futbol, niños que van a hacer tenis.. 
Ma: Hay veces que en vez de mejor picar de muchas cosas de saber poco o de muchas cosas, es como menos cosas pero bien explicadas.

A: O por lo menos que te den la opción; con el INEF tal y como estaba planteado antes, tu tenias 2 o 3 años de formación general y luego te especializabas en dos o tres deportes, entonces allí si que te da tiempo de ver cómo puedes manejarte en un determinado deporte, porque no es lo mismo dar una clase de escalada que dar una clase de atletismo, no tienes que aprender las mismas cosas, ...o de bailes, entonces claro, que como que te desarrollas en esos ámbitos de manera diferente y así te da la oportunidad de hacerlo; tal y como está ahora muy poco.

G: Te sirve más para conocer otros deportes más que para profundizar en uno solo, que uno solo más que con unos cuantos que sería lo suyo, sería bueno poder salir de ahí que no, mira, yo soy capaz de transmitir mucha información y buenos consejos sobre cómo hacer práctica para este deporte, cosa que en nuestro caso yo creo que muchas veces falta a estas alturas si que algún deporte más general pero en otras lo que ha dicho mi compañera, tocas un poco de baloncesto, un poco de futbol, un poco de balonmano, pero es que en verdad luego, una vez ahí, si vale me lo he pasado bien, tal, ves un poco las normas pero yo en verdad no estoy capacitado para ponerme a dirigir un equipo, ni hacer estiramientos; aprendes lo básico, lo básico que es nada en verdad.

A: Yo creo que liando un poco por ahí ... se centra mucho mas en conocer que en transmitir; es como..., así, conozco eso, el deporte futbol, baloncesto, conozco un montón de deportes, pero luego a la hora de, es que no se transmitirlo, como le enseño yo a un niño a jugar al futbol, yo creo que habría que centrarse más fuera

S: Es como que es una aprendizaje muy pasivo, como que te lo tragas todo pero no aprendes nada sobre transmitirlo.

A: Te dan muchas cosas, esto, esto, esto y esto, y luego a la hora de transmitir es ahora un poco más a la ligera, lo que te salga, a ver si va un profesor que va ...pues... y si no.. pues

G: Tiene que ver un poco, muchas veces la mentalidad que se trata de transmitir, es que el juego el deporte es, estas allí para pasártelo bien, no para aprender o para saber cómo tengo que desarrollar esta competencia o como, qué tengo que hacer para poder el día de mañana ser entrenador de un equipo, o muchas veces te lo venden para que te lo pases bien, para que participes, para que tal, pero no se centran en lo que verdaderamente importa, que es el tema de las competencias, los conocimientos, cómo tu vas a poder el día de mañana desarrollar esa competencia, trabajar; yo creo que ahí hay un problema.

Ma: Yo creo que lo que es este caso no tiene nada que ver el grado en educación primaria con lo que estáis estudiando vosotros, porque vosotros, después tenéis que hacer un master, no?, para poder dar clase. 
A: Nosotros, tal y como está, creo que no podremos trabajar, efectivamente, de prácticamente nada, no podemos dar clase en un instituto porque necesitamos un master en educación, no podemos ser entrenadores ni por los clubs ni por las federaciones, y creo que nos quedan los trabajillos esos de, de poca importancia; a ver, ¿son importantes los trabajos?, a ver, todos los trabajos tiene importancia, pero no me queda cuerpo a mi para estar dos horas semanales cobrando, pues, nada.

Ma: Es decir, yo creo que desde el punto de vista que tenemos nosotros es muy diferente del que podamos tener los que hemos cursado la carrera de grado, al menos de primaria (risas).

No, yo, a ver, yo personalmente, a lo mejor es que he tenido suerte. Considero que sí que me han aportado las herramientas necesarias para, por lo menos, para presentarme ya a una clase; luego otra cosa es que con la experiencia lógicamente, vas adquiriendo las competencias, las vas afianzando, o pero mínimo yo considero que sí me las han aportado, no solo ya enfocando a deportes o tal, si no un poco lo que es educación física, que se trata de educar al cuerpo que no solo es deportes, emociones, es expresión corporal es, yo que se, respeto por la naturaleza, en general, yo creo que desde la educación física se puede enseñar tanto, que yo considero que sí me lo han transmitido, a parte que yo iba con muchas ganas, considero que sí me lo han transmitido, a parte que yo iba con muchas ganas, pero yo considero que me lo han transmitido.

S: Yo también, yo creo que esto es cierto, que un poquito de cada cosa creo que beneficia; sí es verdad que si profundizas pues mejor, pero creo que como tenemos muchas veces tanta carga de trabajos y cosas que estamos agobiados y nos pensamos que cuando acabemos vamos a ser mas expertos de lo que somos y luego nos damos cuenta cuando acabamos que no sabemos nada, entonces yo creo que ahí es donde deberían empezar la especialización de cada uno cuando acabas la carrera, sí vemos unas bases de competencias y unos recursos como ha dicho el compañero.

Ma: Nosotros no tenemos que convertir a los alumnos en atletas ni en jugadores de futbol profesionales ni nada de esto, nosotros tenemos que enseñarles, educar un poco valores que transmite la educación física, o eso considero yo; si un alumno, un niño que es muy bueno en futbol, pues fuera de la educación tendrá esas vías, o en atletismo, o en escalada, o en lo que quiera, pero nosotros lo que tenemos que, tener son unas bases para por lo menos poder llevar un grupo y poder transmitir ciertas cosas. No considero que tengamos que ser expertos en un deporte en concreto o en dos o en tres.

S: Claro, yo creo que nosotros igual tendríamos que diferenciar un poco entre, bueno, no podemos trabajar de eso, pero dar clase en un instituto o en un colegio, que claro ahí no necesitas ser un experto en balonmano, baloncesto o lo que sea, porque necesitas bastante de todo para poder hacer las clases variadas, tal. Pero luego también existe el ámbito de trabajar, pues, como entrenadora de judo, claro y ahí ya sí que necesitas ser un experto, entonces me da la sensación, que ni, tendríamos las, tenemos mínimo, yo creo mínimo ya, pero ni tendríamos las competencias docentes como para enfrentarnos a un grupo de 30 niños todos los días, ni las competencias de (para ser entrenador), eh, si, un estado medio, una cosa difusa que no se sabe bien qué es. 
G: Pero yo creo que volvemos a lo que ha dicho la compañera que cuando acabas es cuando tienes claro voy a tirar por aquí, voy a tirar por allí, y ahí es cuando empiezas a saber a especializarte

Me: Yo creo que, tanto agobio, tanto trabajo que llevas durante toda la carrera, cuando vas a acabar piensas que vas a controlar tal y luego la decepción, te decepcionas de que, pues no sabes tanto como creías a lo mejor, o no has comunicado o tienes la sensación de no haber profundizado nada, pero en general yo creo que por ejemplo nosotros los maestros en educación hemos profundizado bastante al acabar.

S: Yo creo que nosotros es que nuestra carrera esta un poco difusa yo creo que no están establecidos los objetivos ni nada; así como vosotros en magisterio tenéis claro que para el tema de... tenéis que adquirir las competencias docentes necesarias para luego dar clase, pero nosotros por ejemplo en INEF, en cambio nosotros teóricamente no tenemos que tocar ningún tema relacionado con competencias docentes, porque es más para deportes, que eso se ve en el master, y entonces teóricamente no tiene que hacerse, pero nuestro INEF está enfocado principalmente a la docencia entonces eh...no se...no lo veo lógico...

Ma: ..a lo mejor una rama de INEF que fuera ya enfocada a ser profesor, otra rama...

A: Eso sería la utopía...

A: ... o a lo mejor una universidad se especializa en una cosa, otra en otra, para no tener que desplazarte a otro sitio, pero por lo menos tienes la oferta, y así no tienes que hacer luego un master y pagar y...

S: Yo por ejemplo estuve el año pasado de Erasmus en Francia y ahí sí que lo hacen, son tres años, el primer año es común para todos, tocas un poco de todo, te haces una idea y luego los otros dos ya eliges una rama entre docencia, entrenamiento, gestión o salud; y ese es un camino, pero yo creo que aquí es que el nuestro está de una manera que no se sabe muy bien para qué, porque si se supone que para adquirir competencias docentes está el master y que no se debe tocar, luego la idea de que las asignaturas están enfocadas de forma que de ahí pases a dar clase

AL: $Y$ oficialmente esas competencias no están valoradas, por que por ejemplo otros años de la carrera sales con el título de, el título, pero por ejemplo no es como un TAFAD que a lo mejor, que además te dan ya el curso de socorrista y de no se qué, aquí es que no te dan nada.

S: Pero no sirve de nada ... 
$\mathrm{CT}$ : Pero a qué competencias le daríais más valor en vuestra formación, cuales serían las mas importantes para vosotros?, tu crees que necesitarías para ser un buen docente o para ser un buen graduado.

Me: Conocer bien al grupo

G: Saber tener un buen control del grupo, de x numero, para nuestro caso sería lo mas importante.

Me: Saber enseñar

S: Ya no un control del grupo no en plan militar, si no un control de que no se desmadren.

AL: A mi por ejemplo y por experiencia lo digo, expresar las ideas, a la hora de explicar, comunicar, el tono de voz y demás, el tema de controlar a la hora de explicar un poco y se te va cuatro palabras por las ramas, no lo entienden, preguntas, no les queda claro, y sale mal, pierdes tiempo, y se te come y se te puede ir la clase ahí en nada, de la praxis es mejor un poco como explicar y cómo decir y... esa chispa de, claro si, dudas, está muy bien, pum pum rápido, les tienes enganchados... para mi sería una de las más importantes.

Me: Por que claro nosotros las experiencias que hacemos en la universidad con nuestros compañeros les sueltas un sermón de cuatro horas explicando cómo se juega al pilla-pilla y te dicen vale, bien, lo he entendido, pero un niño va a estar ahí dormido y...

So:_Edu: A mi me hace mucha gracia eso de que tu como maestro encima te dicen, no, haz como si fueras niño, pero es muy difícil hablar a un grupo de adultos como si fueran niños cuando ellos te están contestando como si fueran adultos, es como si hablas en inglés y te contestan en español. A mi me parece algo así muy parecido.

A: A mi por experiencia, yo creo que es la más importante; el año pasado a mi me vino genial, estuve de Erasmus, hice prácticas y a la hora de explicar, la barrera del idioma, ...y al final menos es mucho más.

Ma: Yo creo que también estoy un poco de acuerdo porque por mucho conocimientos que tengas por muy preparada que tengas la clase, eh, los tiempos, todo, a ver todo importa y todo cuenta, pero saber explicar y saber cómo transmitir esas cosas a los alumnos, hablar cosas claras, concisas, según la edad, saber cómo tienes que tratar según la edad a cada alumno, me parece que es muy importante porque si tienes problemas y no saber luego, o te lías explicando como decía él, los alumnos no entienden lo que tienen qué hacer, se arma barullo y fuera clase; o sea ya se te ha ido. Entonces el tener la capacidad de explicarte bien, de ser claro, conciso, de utilizar un vocabulario adecuado a la edad, me parece bastante, bastante importante. 
AL: $Y$ eso también y eso en la universidad te lo van a decir en cuanto vamos a hacer esto, esto y esto pero luego al fin y al cabo donde lo aprendes y donde lo adquieres, o sea a la hora de, andar eso de decir, llego tarde, este niño se me ha roto la muñeca que hago, o paro, o estoy fuera pero no me duele, y tener esa chispa del momento, cambio todo, me quedo esto, saco...

\section{S: Capacidad de adaptación}

AL: Exacto, y es que al final es, hay que sacar como profesor de uno alto, bueno por decirlo así, el que mejor, a parte el que más, situación, más chispa, más todo tenga, que consiga cambiar esto en seguida, es improvisar también.

Ma: Y luego yo también creo que es muy importante lo de tener en cuenta el alumnado que tienes, o sea, conocerles, saber si tienes algún alumno con algún problema, otros alumnos que les cuesta mas, tal y saber adaptar un poco todo a esas circunstancias. Para mi, yo considero que eso también es muy importante para que no se sientan frustrados, sobre todo los niños.

G: Yo pienso que también sería muy importante que enseñaran un motivo a cada grupo, porque al fin y al cabo tu tienes los niños, que vale, tu eres el profesor de educación física, y si no consigues motivarlos, hacer que se lo pasen bien, que aprendan, haciendo la práctica deportiva, lo que sea, van a estar de mala gana. Yo creo importante que incidieran en aprender a motivar al alumnado para que se diviertan.

AL: Ahí estoy de acuerdo, es lo que decía antes de que son esos los recursos y las herramientas que faltan, que si estos nos dieran en la universidad., pero es lo que falta un poco, es una actividad, un juego dentro de la universidad sabes que va a funcionar, porque va a funcionar, estás en clase y al final es que, si lo tuviera que hacer al día siguiente te lo haría, pero a la hora, te viene con ganas de no y lo tienes que hacer si o si; pero un niño es eso, le falta, cómo le motivas [...]

Ma: Si porque además, a lo mejor lo que motiva a cinco niños a otros cinco los desmotiva, es que eso es complicado,

S: Eso es conocer al grupo también

$\mathrm{CT}$ : Y habría alguna competencia que vosotros dijerais bueno pues a lo mejor de las mas generales o de las mas transversales se empeñan e esta y esta no hace falta porque ya la controlamos, ya la dominamos, no tiene sentido

Ma: A lo mejor el tema de las TIC's yo creo que ahora la gente que viene por debajo ya nosotros controlamos bastante, cada vez más, entonces considero que, a ver, será necesario a lo mejor enseñarles herramientas docentes, sabes, porque, habrá 
programas, habrá ciertas cosas que desconozcamos, pero el manejo y el control de las TIC's casi se tiene que poner los alumnos a dar clase a los profesores; considero que es una de las que menos a lo mejor, yo la considero muy importante para su aplicación, pero a lo mejor no tanto en la formación nuestra, porque creo que ya la llevamos implícita muchas veces.

G: Si eso a caso que sería, que fuera más específico, y en todas, ese mismo, ese campo es que fuera de algo mas complicado por así decirlo, porque lo básico en verdad es lo que tu dices, todo el mundo sabe.

AL: Al final algo, que es lo que tu dices, luego dentro de la asignatura de TIC's por ejemplo, pero, eh, puestos algo que te lo que te decía, yo se mucho pero el siguiente va a saber más, el siguiente va a saber un poco más, el siguiente muchísimo más. Yo me he llegado al colegio haciendo prácticas y yo me he quedado con la boca abierta al ver a los niños de sexto programar..., niño y te manda meter unos códigos, y ellos no no solo hay que sumar esto y esto y tal, y yo eso no tengo ni idea; si el día de mañana me toca explicar..., nuestra pizarra digital yo personalmente, ¿quien la ha utilizado?, no me ha dado tiempo ni hasta la hora de poder abrir un trabajo, no te lo hace bien, y bueno, yo solo ya a parte [...].

L: Yo creo que en esa competencia, en lo que nos deberían formar, como habéis dicho, no es en el tema de utilizarlas, y nosotros sabemos; y los que vienen por detrás más todavía, sino en el tema de enseñarnos el filtro a la hora de buscar recursos que a los alumnos se les haga atractivos por el tema de las TIC's, pero que sean de calidad; porque a lo mejor tu ves un recursos que a ti te parece buenísimo, le llevas al aula y no es tan bueno como pueda parecer, ¿porqué?, porque tu lo estás viendo desde la perspectiva de adulto, pero encontrar recursos para niños, en nuestro caso, que sean atractivos, a parte del simple hecho de usar la pizarra electrónica y demás, creo que es importante por el que debería de tirar las TIC's, en la formación de los docentes por lo menos

Ma: Y ver como aplicarlas porque a lo mejor yo puedo conocer google maps y yo se que lo puedo llevar al aula, y es un monstruo de tecnología para llevar google maps o wiki docs. o puedes hacer rutas en este caso de educación física, claro, nosotros hemos tenido la suerte de tener un profesor de educación física en el medio natural que investigaba el tema de las TIC's y nos enseñaba cantidad de programas y herramientas, pero geniales, geniales; o sea, yo considero que por ejemplo no se debería centrar en el primer año, se da por lo menos en nuestra carrera se dan las TIC's, que se dan de manera general, y es un poco para enseñártelas, pero yo creo que ese paso se le pueden saltar y directamente ir a como aplicarlas de forma educativa.

L: O dentro de, por lo menos, dentro de cada mención, aplicadas a, a la educación física, bueno pues vamos a ver qué tipo de TIC's tenéis al alcance para poder trabajar con los niños, los de música pues igual, los de conocimiento del medio, como sea; otras como inglés, general, inglés, la generalista, pues que todos tengan un poco conocimiento de las TIC's pero mas orientado hacia lo suyo. 
$\mathrm{CT}$ : Ha salido un poquito antes, al inicio, pero me gustaría que hablarais sobre la coherencia que hay entre el trabajo que se hace de competencias y la evaluación.

AL: Yo estoy en la misma situación que Ma, que al haber cursado TAFAD teníamos varias asignaturas convalidadas $\mathrm{y}$, no se, pero me he encontrado el caso, vas a hacer baloncesto por ejemplo y el objetivo cual sería, saber cómo enseñar baloncesto, y luego te están valorando si metes un tiro libre o no, ..

Ma: Si, eso nos pasaba en TAFAD. O sea era lamentable.

A: $Y$ algo pasa un poco parecido en la universidad, no de tal calibre, pero cantoso

\section{CT: ¿Coincidís los demás?}

Todos: Si; si;

S: Y ten en cuenta donde utiliza la asignatura el profesor ..., depende del profesor

Ma: Es que depende totalmente del profesor

AL: Pero la primera evaluación, también condiciona mucho el estudio, la estrategia de estudio que tu te hagas, por que si sabes que en un examen te van a, depende de lo que te pongan, pues te lo aprendes más tipo lorito y me lo quito de encima, o más intentas no se, aprendértelo bien e integrarlo, eso es, integrar los conceptos que aprendes es lo que hace falta, que igual es una metodología muy fragmentada, en plan de esto te aprendes esto pan, pan, pan, que falta que nos hagan un poco...

S: Y luego, bueno eso también, hay algo que a mi me gustó, por ejemplo las teóricas, nosotras, podían ser mas duras, no se, o te dan mas cosas, pero luego en el examen era bastante sencillo, pero de estos exámenes que de repente van a ir a preguntar, ala ya, sabes, de algo que no hayas leído o tal, que eso no lo entiendo, nunca lo he entendido; y la práctica luego pues tiene que ser un poco más que, hablando de ello.

A: A ver, los exámenes si que es verdad que eran todos mas de, elabora un plan de entrenamiento no se que más, pues ese día tienes que llegar y proponer el entrenamiento

S: Pero si de verdad lo has entendido y sabes aplicarlo, es mejor que, cuéntame el autor de no se que de su vida y...(risas).

\section{CT: ¿Los de magisterio estáis en la misma línea?}


Ma: No, yo creo, como he dicho antes, he cursado dos asignaturas, y para mi las estrategias de evaluación he se han utilizado sí que han ido adecuadas; no había exámenes, bueno, en la de educación física en el medio natural tuvimos un examen, pero era un examen sobre todas las prácticas que habíamos llevado a cabo; se formaban grupos, cada grupo se encargaba de organizar una actividad (compartida), claro, es que es evaluación formativa y continua; tu tienes que llamar al autobús y contratar al autobús, llamar al albergue, no se que, al final lo estás haciendo tu, estás aprendiendo haciendo, que es de lo que se trata; entonces yo creo que es de la manera que se puede evaluar una asignatura así; y la otra que he cursado, pues lo mismo, nosotros realizábamos los trabajos, se dividía también la clase en grupos, tenías que ir haciendo los trabajos semanales y luego tu eras experto de un tema en concreto que tenías que exponer a todos los demás; al final estás trabajando durante todo el año, y también, tu tienes que preparar tus clases, darlas a los demás; que no es igual darles a que se lo des a un niño, no lo es, pero también estás aprendiendo a dirigirte a un grupo, a hablar, a desinhibirte, yo considero que tiene sus ventajas; que sería lo ideal ponerlo en práctica con niños, evidentemente, pero para eso tenemos el prácticum, mucho o poco.

L: Y está todo como entre iguales, entre alumnos, un alumno enseña a otro alumno, aprendes de tu compañero, por alguna razón lo aprendes y se te queda mejor, es que es así. Lo único el profesor qué hacía, pues un poco, ver como se mueve también el (grupo) y orientar un poco para donde quieres.

$\mathrm{CT}$ : Entonces entenderíais que hay que cambiar la evaluación, hay que ir a una evaluación formativa, la evaluación tradicional como la, se casa ahí, no se casa...

S: Yo creo, es que claro, es que es un poco mas, no lo se, pero, lo que veo mas complicado simplemente por el hecho que, lo que tienen que decidir antes de nada es, queremos que la carrera entera sea para que aprendas a enseñar a niños, o quieres dividirlo en ramas y que estés bien definidas las ramas, o qué; porque nosotros tenemos ahí como un barullo donde algunas asignaturas que se ha, deportes en la naturaleza, digamos, el profesor decide que sí que te quiere enseñar a enseñar a un grupo de niños, pero luego tenemos deportes colectivos donde te quiere enseñar solamente los deportes para tener la formación tu y ya está, entonces; creo que tienen que empezar con eso, decidir qué es lo que se quiere hacer en cada asignatura, porqué y luego interrelacionar todas las competencias con todas las asignaturas que se hayan decidido van hacia la educación, y allí ya poner un método de evaluación, pues eso, adaptado, por que no es I, mismo que te pregunten por todos los autores de asignatura donde solo tienes que saber la información respecto a este deporte que si tienes que enseñar a los niños sobre ello.

G: Como ha explicado mi compañera, yo creo que si que tiene razón, que nuestro caso debe, los profesores, deberían reunirse y establecer qué es lo que van a dar, a donde quieren dirigirse, porque lo que ha dicho ella, es que, unos van por un lado, otros van por otro, y yo creo que sería mejor que se pusieran ellos de acuerdo, mira yo voy a hacer esto y esto, esto puede servir para esto, por lo tanto nos estamos dirigiendo más hacia la docencia, o nos estamos dirigiendo más hacia la preparación 
física; yo creo que tendrían que juntarse más entre ellos, y si no quieren no se, pero yo creo que deberían; ahora hablar más y establecer sus criterios; yo creo que sería lo mas importante antes de empezar a hacer nada.

AL: Y yo por ejemplo a la hora de la evaluación que yo no he visto, es lo que decía el compañero, el profesor tiene que estar ahí un poco para establecer una base, el alumno que se queda con alguna duda, y si se equivoca y se desvía un poco reorientarle; y a la hora de alcanzar unos objetivos es mi trabajo, pero tú también me estás ayudando; es, también un poco pactar al final la nota; al final has conseguido esto, cómo lo ves, o como ves tu nota, es tener en cuenta también, si, nuestra opinión, al fin y al cabo, yo soy el que he seguido mi camino y el que me he comido mi propio aprendizaje; que tú has estado aquí, pues decir por aquí no vayas, por aquí si, esto está bien, esto está mal; a la hora de enfrentarte a un examen, es en plan, esta bien, esta mal, pero eso de qué es, a mi eso no me sirve de nada.

Ma: Yo no estoy totalmente en contra de hacer exámenes pero desde luego no va a ser una nota final, una nota de la asignatura la de un examen; yo considero que hay ciertas cosas que hay que preguntar en un examen, porque muchas veces también el trabajo de un grupo hay gente que se camufla ahí, y puede sacar una carrera al final sin dar palo al agua; por ejemplo, escalada, pues si tienes que saber las cadenas de seguridad, para que sirve, pues yo considero que hay ciertas cosas como esas que se pueden preguntar en un examen; que un examen igual te vale cero diez del total de la nota; o luego también ciertos trabajos individuales, pequeñas cositas, trabajar en equipo, pero también tener referencias individuales; porque ¿cómo sabes si un alumno ha alcanzado todas las competencias si está camuflado entre un grupo de seis personas?.

\section{CT: Y la pregunta sería, ¿se evalúa el trabajo en equipo?}

Ma: Se evalúa el trabajo en equipo pero también se camufla.

CT: A lo mejor no habéis entendido la pregunta. Una cosa es evaluar el trabajo en equipo y otra cosa es evaluar el resultado del trabajo en equipo

\section{A: Yo creo que no; Rotundamente no}

M: Le podemos hacer un trabajo en grupo de cualquier cosa; y es más, le lanzo una pregunta profesora, a ver si se la cuela; vamos a hacer un trabajo en grupo y el día siete presenta el grupo uno; vale, sobre bicicleta, ruta de montaña, sobre cualquier tema; somos cinco personas pero hemos venido dos; toma ahí está; luego pongo aquí los nombres, te lo lees y ¿qué?, al final hemos venido dos.

\section{CT: Pero al final la competencia es trabajo en grupo}

(barullo, hablan a la vez) 


\section{CT: ¿Cómo veríais vosotros que habría que trabajar para poder evaluar precisamente lo que quieres, no que te pase.}

Ma: Primero desde la responsabilidad de cada componente del grupo; si ya partes de que tienes en un grupo una persona irresponsable, por mucho trabajo en grupo o en equipo que quieras hacer es imposible.

G: Eso es muy complicado para los grupos; Es imposible. (A los grupos) se les escapa del alcance porque ellos te están enseñando, pero al final no son tus padres, no están ahí detrás de ti, es que este no trabaja; eso tiene que salir un poco de cada uno; para ellos es muy complicado.

AL: Yo quiero aprovechar la clase para trabajar mismamente en grupo; es como que la clase dura dos horas, y aquí os doy la teoría y luego el quiera queda después de clase para hacer le trabajo de grupo.

A: En plan realizar los trabajos en grupo, que exija algo que pueda justificar a un buen grupo, a formo par de ello pero incompleto, porque los trabajos en equipo lo que suele pasar siempre es que tu haces esta parte, tu esta, tu esta y tu esta; y luego que haya una presentación, con una presentación cualquiera pero con preguntas de cualquier cosa relacionada con tu propio trabajo que sea de la parte del compañero y ...

G: Hombre, yo creo que sería muy buena idea si por ejemplo si tienes que hacer un trabajo y te han puesto esa fecha para dentro de un mes, dos meses, pues que el profesor cada semana, pues recogiera como un diario en el cual este grupo esta semana ha hecho esto, esto y esto, y este componente y este se han dedicado a efectuar sobre esto y esto sobre esto, y bueno al final el profesor se está dando cuenta de quien está trabajando, y los del propio grupo también se están dando cuenta de quien está trabajando, y quien está colaborando; y yo creo que sería una manera buena de poder tener un control sobre eso, sobre se llega una semana antes y ya se nos come el tiempo, tu haces esto, tu esto y tu esto, y verdaderamente no hay trabajo de grupo porque así va muy separado; unos hacen una cosa, otro otra y otro otra, y ha cogido uno y lo ha juntado todo, en vez de cuantas veces ha quedado el grupo para debatir, para decir vamos a hacer esto.

Ma: Y luego si acaso no es muy sangrante muchas veces el tapar también a los compañeros; bueno, no has hecho tal, no vas a decirlo; al final el profesor no sabe que este no ha hecho esto o que no ha ido a las reuniones de grupo o que no tal; y yo he estado en asignaturas en que teníamos fichas, en expresión corporal por ejemplo, teníamos fichas en las que teníamos que reflejar las reuniones que habíamos ido, quien había faltado, quien no, y la gente no es honesta, y tu muchas veces si quieres ser honesto o si quieres decirles, mira tienes que poner esto por que al final vas a acabar mal y el trabajo en grupo ya no va a salir bien; entonces qué es trabajo en grupo, ¿ser un pringado?, ¿trabajar el doble que los demás?, y ser un pringado, es que es eso. Y si no, yo no lo veo de otra manera. A mi es una de las cosas que mas me ha molestado en la carrera; el tema del trabajo en grupo, cuando trabajas con gente trabajadora, (da gusto), genial, perfecto. Pero cuando ya tienes setas, te los comes con patatas. 
CT: No, yo lo que os voy a plantear es otra cosa, cuando tu trabajas una competencia, te puede interesar lógicamente el resultado, pero a ti lo que te interesa es que el alumnado aprenda a trabajar en grupo. ¿Pensáis que eso realmente se trabaja?

Me: Es que es muy complicado.

A. Yo creo que si, que en general los alumnos aprenden a trabajar en equipo porque después de cuatro años haciendo trabajos grupales ya conoces a tus compañeros, has visto muchas cosas, has reconocido si te has equivocado alguna vez, o deberías haberlo reconocido desde mi punto de vista, y yo creo que la base general y el respeto para trabajar en grupo, lo tienes, y si no lo tienes es porque algo has hecho mal.

S: Yo creo a mi parecer, sobre todo en los últimos años de carrera, en cuarto este año por ejemplo, si o si que lo veo mas en plan viene alguien a tu grupo de trabajo y trabaja con nosotros, y si ves que a las dos semanas no ha hecho nada, le dices, oye, venga, no de malas como al principio, que se enfada, sino que, no se, es como no me fastidies, hay confianza para decirlo ya, pero yo creo que la bases es esa,

Me: Pero hay que pedirle eso, la confianza que tienes con el compañero

A: Nosotros ahora que estamos en cuarto, estamos haciendo trabajos, y no los estamos sabiendo hacer en grupo porque no, porque coge uno y se pone en grupo a hacerlo todo y al que le cae otro, y entonces..., el trabajo concreto está siendo de todo menos grupal.

S: Al final aprendes a obrar en grupo, y aprendes a ponerte de acuerdo aunque te pongas de acuerdo diciendo que lo haga otro grupo.

(risas)

M: Yo creo que no...

S: La discusiones que tenemos a cerca del trabajo ya son mucho más civiles, pues en primero eso era una batalla campal, donde me enfado contigo porque he escrito tres párrafos mas que tu, y cosas de esas, tonterías; ahora...

A: Una mentalidad infantil también...

A: Si, a ver, pero que.... 
G: hay que aprender a trabajar en grupo, en verdad, porque en mi caso yo no he trabajado mucho en grupo; he empezado a trabajar en grupo aquí en la universidad; así se coge un poco de rodaje...

AL: Yo creo que hay algo a lo ibas que se hace a trabajar en grupo nadie te enseña, tu formas un grupo, formas un grupo, y con los miembros que forman el grupo, estableces ya tus normas de trabajo; es simple, quedamos hoy y tu te encargas de esto, de esto y de esto, y siempre va a haber gente que tire mas, es normal, dotes de líder, otro que acepte todo, otro que se lleve bien, al final son problemas que se van solucionando y es hablar un poco y tener un poco de respecto. $Y$ luego ya si no funciona el grupo, hablar, comunicar esto, esto y esto, pero fallar lo que es ya mas..., pasa aquí, pasa en una cooperativa, en un banco, en un cole..., y habrá profesores que hagan más y, ... no me importa tanto; tengo mejores cosas que hacer, cumplo y ya está.

Ma: Al final en estas evaluaciones, para mi siempre son injustas, porque hay gente que se lleva mas nota de la que se puede merecer y hay gente que se puede llevar menos también

\section{CT: Lo que pasa es que, pensar que estamos hablando de evaluar la competencia no de evaluar el trabajo}

Ma: Ya, ya; yo considero que no se evalúa el trabajo en grupo, se evalúa el resultado del trabajo en grupo

AL: Ahí yo creo se debería, lo que decía también antes, que se consensue la nota, que se preocupe el profesor, que esté mar cerca; ...y cómo os habéis organizado, qué habéis hecho, habéis quedado, y porqué no lo habéis hecho así, y porqué habéis decidido realizarlo así, y porqué, yo que se, no se, preguntar al grupo, alumno.

AL: Y claro hay que demostrar de alguna manera que todos, saben de todo el trabajo, yo creo que el trabajo en grupo que más puntualmente se ha hecho en nuestra carrera, teníamos que hacer un montaje, de, que teníamos que, tenía muchas cosas, entonces claro, cuando los enseñas, realmente, implicaba a todos por igual, a la hora de enseñarlo, y a la hora de que te lo va a ver el profesor y que te lo va a valorar, implica a todos por igual, todos se implican para hacerlo, que no es lo mismo que un trabajo que lo escribes, que ahí si que no se sabe..

Me: Yo creo que a través del trabajo en grupo pretenden evaluar otras competencias, entonces ese es un error, por ejemplo, una persona que tiene un problema en un grupo, vale, y va al profesor y se chiva, por decirlo así, ¿no?, mira, yo he tenido este problema, no nos ponemos de acuerdo entre nosotros, no conseguimos solucionarlo y queremos trabajar por separado. Ahí, ese profesor a quien se lo está contando quiere llamar a todas las partes implicadas, decir, bueno, qué ha pasado aquí: me parece lo correcto, y es buen ejemplo para enseñar a un maestro, intentar mediar y si no se puede solucionar, pues no se soluciona, pero ahí en el profesor es donde debe estar evaluando ese trabajo en grupo, cómo habla cada persona, quien quiere ponerse de 
acuerdo, quien quiere solucionarlo, quien no; el problema es que si tu vas a un profesor y le dices mira tengo este problema y no podemos trabajar juntos, estamos a estas alturas y lo primero que te dice es, uff, pues a estas alturas en qué grupo te vas a poner, y claro es que ya están todos los trabajos muy avanzados; ese yo creo que es el problema, que a través del trabajo en grupo quieren evaluar otra serie de contenidos, otra serie de competencias, entonces, al final, el trabajo en grupo no lo están teniendo en cuenta, desde mi punto de vista.

A: Las competencias yo creo que el profesor no lo sabe porque no lo ve, y aunque damos el día de mañana [...] cinco de clase y trabajamos en grupo, cooperamos, hablamos, todo es trabajo en equipo, pero al final tu lo que quieres es el documento y...

Ma: Yo también lo que he estado viendo en las clases, se juntan los grupos y trabajan, y el profesor observa, y cuando entregan el resultado final, él le vea y ponga una nota, y si ha estado bien, unos han estado trabajando más y otros han estado trabajando menos, tu tienes tal nota y tu tienes cual otra. No delante de la gente,; juntarse, oye quiero que vengas a verme porque quiero hablar del trabajo en grupo, tienes esta nota, y porqué te la han puesto tus compañeros; yo en el trabajo en grupo no te he visto colaborar, no te he visto cooperar, no te he visto implicado ene I grupo, entonces creo que no es justo que tú tengas las misma nota que tu compañero que sí le he visto preocupado, que ha venido a las tutorías cuando las habéis pedido, no se, que le he visto más implicado que tú, y hablarlo y ver si es verdad o es mentira; y con el profesor, pues es verdad que en este trabajo me merezco menos nota, porque si.

CT: Pasaría eso con el resto de competencias transversales, porque perece que las específicas, las de educación física las tenéis como más claras con respecto a la evaluación, pero con las transversales, ¿cómo lo veis?.

A: Las competencias ... que tiene que tener un maestro...

\section{CT: ¿Os recuerdo un poco las transversales?}

(risas)

Mirad, las transversales son: trabajo en equipo, el aprendizaje autónomo, las habilidades en las relaciones interpersonales, el razonamiento crítico, la adaptación a situaciones nuevas, capacidad de organización y planificación, creatividad, compromiso ético, comunicación oral y escrita en lengua nativa, capacidad de análisis y síntesis, conocimientos de informática relativos al ámbito de estudio y conocimiento de una lengua extranjera.

(risas)

Ma: pero el conocimiento ese es de modo general...

\section{CT: Esas son transversales}


Ma: ¿Cuál era la pregunta?

CT: Que si pensáis que esos problemas que estáis hablando de evaluación con el cómo se evalúa el trabajo en equipo, si sucedería con todas esas competencias transversales, que parece que como las específicas, las de vuestros estudios, a la hora de la evaluación, es el docente el que tiene esa responsabilidad, pero esas que todos los docentes tenemos que contribuir a eso...

S: Yo pienso que no se daría el mismo caso en todas, porque con lo que hemos dicho del trabajo en equipo, que es tan complicado, ver qué está haciendo quien, pero por ejemplo, saber expresarse en tu idioma nativo y escribir, pues, eso, sí que se puede ver perfectamente, haces una exposición tu solo y se ve directamente, haces un trabajo y también, entonces es algo que se ve perfectamente sin encubrirte con otro compañero, tal; y luego lo de la lengua extranjera lo mismo, hay cosas que son más individuales; pero lo del trabajo en equipo es una tapadera tras otra; y ese es el problema.

A: Yo estoy de acuerdo, yo creo que todas las que has nombrado se pueden ver mucho mas fácil que el trabajo en equipo

\section{CT: ¿Y os las evalúa alguien?}

Ma: Yo creo que no, todas esas no, a lo mejor hay alguna que si, que te expreses bien, a lo mejor dos o tres, pero todas..,

AL: A lo mejor porque viene un poco implícito con lo que haces, te van a encargar un trabajo y tu ya vas a buscar a la biblioteca, a internet, se da por hecho que lo buscas, coges la información, la analizas, la coges, seleccionas, cojo esto, lo sumo, capacidad de síntesis, tal, para expresar esto, estas ideas, y tu con lo que ves, pues bueno ya das por hecho que ese trabajo lo has tenido que aprender, pero es todo su iniciativa, mejor o peor.

$\mathrm{Ma}$ : $\mathrm{Si}$, pero a lo mejor, no te lo ponen como criterios de evaluación, ... a lo mejor no aparecen..

AL: En algunas asignaturas hay un diez por ciento que llaman de participación e implicación, ¿no?, que es como el ojo del profesor eso..

(Barullo, risas) 
G: Jugando con eso, acaba siendo un porcentaje de lo que faltaba, al final, porque.... Bueno yo lo digo desde mi experiencia, yo en ninguna asignatura que ponga eso, creo que haya dicho el profesor, va pues tu en este proyecto que estas haciendo ...

S: Si, bueno, una, la de Lenguaje corporal de primero, creo que en una exposición y se fijaba si has hecho todos los gestos y bueno, pero que aparte de eso, yo creo que no se fijaban en ninguna asignatura concretamente en todos estos detalles; obviamente tu haces una exposición y le das un tono formal un tono muy bien y ya inconscientemente el profesor ya te pone más nota que si la tratas todo correcto, pero le hablas como si fuera un colega.

G: Lo que tu dices, si se centraran mas en eso y eso se valorara de forma seria me parecería perfecto, pero ya te digo que en nuestra carrera un poco, qué asignaturas hacen eso.

Me: Participación e implicación es el ojo del profesor, mi manera de verlo, que hay ojos mejores y ojos peores, está claro, que hay ojos que no miran y ojos que si miran, es lo que creo.

\section{G: Depende del profesor también}

Me: Si porque hay profesores que, asintiéndome, sabes que vas a tener que estar un poco mas serio, normal o tal, y hay otros que les pilla todo más relajado más suelto.

S: Un tema que me parece muy interesante es el de la autoevaluación dentro del grupo, dentro del grupo tu te pones una nota para ti para el resto de tus compañeros, lo que pasa que ya ahí se mete directamente tu nota con la nota del grupo [...] pero si se da importancia a tener un diez pues todos se repartirán en plan yo un ocho, yo lo he hecho muy bien, yo un nueve, en cambio yo cuando no lo he hecho bien, pues hombre esto me ha salido un poco mal, un seis.

AL: Y otra cosa, veis por ejemplo el estado de valorado evaluable de cómo aceptar la crítica, no se si está visto, por ejemplo tu vas a exponer algo, y es algo que los maestros vamos a tener que hacer es valorar y según lo que expongas, pues eso, evaluar y (risas), es la evaluación a los compañeros; cuando alguien va a exponer un trabajo, yo pocas veces lo he hecho, así ninguna, te ha dado la oportunidad de valorar, de decir, ver lo que has fallado, pero claro es lo que vas ahí, honestamente, soy tu compañero, hecha una mano, no te voy a decir cosas malas, yo no se, ser honesto, decir la opinión, decir lo que vale, desde el uno al propio, y le digo oye yo te doy la oportunidad, el profesor te da la oportunidad, de ver lo que hace y de forma crítica te digo esto y me parecería que esto lo tendrías que cambiar.

Ma: Yo respecto a las competencias que has dicho, estaba de acuerdo con lo que decía Álvaro,; tu a la hora de realizar un trabajo, si además luego lo tienes que exponer, yo creo que va implícito casi todas las que has nombrado, que sepas investigar, redactar, síntesis, luego exponerlo, no copiar los trabajos, poner 
bibliografía, o sea, yo creo que todo va implícito en que tu hagas un bien trabajo y que lo expongas bien, pero creo que no se fijan concretamente en cada una de las cosas, que será como decía ella también, más inconsciente. Y luego lo que decía de Álvaro de evaluar, a mi también me parece muy bien si consigues un buen clima de clase que acepte esas evaluaciones a compañeros. Nosotros por ejemplo en TAFAD conseguimos un clima de clase, además desde un principio siempre nos evaluábamos, y nos decíamos los fallos y no había ningún problema, sin embargo, en la universidad, en alguna ocasión ha pasado, y ya como dijeras algo malo, "eh porqué has dicho esto", cuando en realidad estás haciendo una crítica para que la otra persona mejore.

A: Pero hay que ser también un poco realistas, si yo vengo aquí como pasaba en TAFAD, tu me dices lo que has fallado y es que yo inmediatamente, después de haber pasado sea lo que sea, es que lo acepto porque si es que tiene razón, he fallado un poco en esto, y se que lo podría haber hecho mucho mejor y además si yo estoy actuando como alumno pero si se da por hecho que el profesor, a parte que cuando vaya a ser alumno, me está evaluando a mi como alumno.

S: Yo creo que he estado viendo cierto nivel de presencia de autocrítica, bueno de crítica entre nosotros pero de manera constructiva; si, a ver, obviamente siempre hay algún caso que les va y se pican, pero es normal, pero...

Me: No se, antes si que te callabas, ¿no?, cosas

(Barullo, hablan todos a la vez)

A: Pero yo creo que por lo general sí que nos incentivan bastante, en algunas clases en otras ya pues nada, a ayudarnos unos a otros, porque sino nos perderíamos todos.

CT: Bueno, os cambio un poquito de tercio, consideráis que existe una transferencia positiva de las buenas prácticas vividas en vuestra formación inicial y los contextos de prácticas docentes, cada uno en el caso que los haya tenido, y con los compañeros y con los prácticum, o bien en...

S: ¿O sea, de lo que, las prácticas de la carrera a las de la vida diaria?

G: Yo creo que será porque [...] en una ocasión hicimos una práctica de futbol, y supuestamente el balance fue positivo, así que sin mas, tenías que saber cómo preparar, cómo llevar entrenamientos no se si era benjamín o infantil y yo estuve entrenando en infantil varios años y no se parecía en nada, es que no se parecía en nada, lo que hemos dicho antes, porque en verdad quiénes son tus niños: tus compañeros de clase, es que no puedes aplicar entrenamientos de infantil a gente de 21 años y para arriba; por eso yo te digo mi experiencia, porque son las únicas prácticas que he hecho a nivel de colectivo, fuera de la universidad.

S: En la carrera se trata todo de una manera muy utópica, claro tienes a tus compañeros como niños, tienes todas las herramientas del mundo y todo el tiempo del 
mundo, pues es que allí te salen las clases redondas; llegas al colegio, yo he estado en uno, dando atletismo, y llegas con cuarenta niños de diferentes edades, uno que le duele la tripa, otro que no se que, y quieres hacer cosas diferentes y dices, a ver, no,; hay mucho cambio y, si, yo diría que hay un contraste importante.

A: Yo veo un problema, que está un poco mal, o muy mal enfocado desde mi punto de vista; en la universidad te enseñan una cosa, como llevarla esta actividad y la haces con tus alumnos con tus compañeros de la universidad, luego la vas a llevar al centro; vale la misma porque la conocemos y la arreglamos; ahí va a fallar y pasa a un control, porque siempre pasa; y lo que no te imagines que pase pasa, y es ahí cuando ya tienes que, eh, en milésimas de segundo, adaptar, pensar, cambiar, y saber jugar con todo, y ese es la habilidad la que te tenían que enseñar un poco.

EMujer_Hu_INEF: ¿Pero eso lo hacíais dentro de la universidad?

AL: Bueno, desde el ámbito universitario esa actividad, desde el ámbito universitario, por ejemplouna actividad de ruta en bici la llevas con escolares al ámbito escolar, la haces con alumnos y siempre pasa algo, a lo mejor los de la universidad no llevan frontales pero se buscan la vida, qué haces; se me ha ido también y ha pinchado alguno; qué haces, todo eso, y es que en ese momento hay que saber, si, la teoría te la sabes, [...] pero es esa chispa, esa habilidad de, pun, rápido, la que te hace bueno o malo, y es que eso es lo que no te enseñan.

Me: Es que yo creo eso no se puede decir ya, porque pienso que es madurez y experiencia. Yo creo que eso es lo que nos agobia a todos al principio, el no saber reaccionar cuando tenemos un problema, porque al final somos responsables de unos cuantos pequeñines, entonces, yo creo que eso agobia, eso yo creo que no pueden solucionar; al final trabajamos en un ámbito de incertezas constante, entonces lo único que podemos hacer es aprender a vivir con ello y confiar en nosotros mismos.

AL: Pero hombre. lo que está claro es que desde la universidad no te vas a convertir en un experto, porque después está claro que luego todo te lo da la practica y la experiencia, pero que menos que introducirlo un poco, yo estoy hablando un poco de mas prácticas con escolares, el primer año una o dos, salidas con escolares, ...

Ma: Si hicimos los senderos escolares con los niños...

AL: ...Eso es experiencia, y estás dentro de la asignatura, y estás dentro de la universidad...

Ma: Eso es lo ideal, claro, y si cada asignatura tengas un poco de...,

G: No todas las semanas porque eso es imposible, pero cada año que hicieras algo. 
S: Una pincelada para acordarte todo el rato.

AL: Se aprende haciendo y se enseña también haciendo.

Me: Claro porque al fin y al cabo estás dentro de la carrera y estás allí con los niños, en un ambiente muy controlado porque están sus profesores, nuestros profesores, y vale que nos dejan llevarlas a cargo pero, siempre con supervisión, no estás tan agobiado de tener que [...] que siempre da bastante, luego ya controlado.

A: Yo he estado trabajando de monitora de escuela de verano y creo que es donde más he aprendido, salvo lo de la carrera; desde el primer día de escuela al último día de escuela, dije, es que el primer día ¿en qué estaba cómo hacía lo de la escuela de verano?, fíjate, y el último día estás en tu salsa; y parece que para aplicarlas pedíamos recursos que no habían dado en la carrera que si en la asignatura de juegos, pues nosotros no se qué y no se cuantos, vale, pues te dan recursos y luego ya tu , para que tu los apliques, ya te indican y todo eso

\section{G: Lo que pasa que eso es un poco el prácticum}

S: Nosotros quitando igual prácticum, lo hacemos donde sea; ... pero vamos lo que estaría bien es eso, asignaturas que tenemos encarriladas a la docencia, pues lo que dice él, introducir esas experiencias.

\section{AL: yo creo es conectar con la práctica y viceversa}

Ma: Y nosotros hemos tenido en tercer y cuarto prácticum, o sea que, hemos dado también...

Me: Yo creo que en cuarto

G: Es que cada uno tiene unas practicas

Ma: O sea, que hacemos bastante, lo que pasa es que se condensan ahí; yo lo iría metiendo desde un principio más prácticas con los centros desde el primer año.

\section{G: Desde primer año, no con muchas asignaturas}

Ma: Es también un poco complicado porque tu estás aprendiendo, e igual el primer año ya ponerte a hacer alguna actividad pues quizás no tengas la base suficiente como para poder hacerlo; y al final los niños son personas, y a lo mejor una mala experiencia le marca para el resto de sus días. 
G: Pero ya desde el comienzo lo tienes que ir controlando

Ma: Imagínate que la universidad se pone de acuerdo con ciertos centros y están supervisando con tu profesor y con el maestro, no te van a dejar si ven cualquier cosa que les vas a causar una mala experiencia.

(Barullo, hablan todos a la vez)

L: ...A ver, estaba hablando de cosas puntuales que se les queden a los niños; esa frase o cualquier cosa así es que es complicado sobre todo si no has tratado con niños antes o aunque les hayas tratado, que no les sepas hablar o por mucho que quieras..

AL: Eso al fin de al cabo, si no tratas nunca con niños te puede pasar el primer día de prácticum

L: ...pero si no tienes una base teórica es más probable que te metas en un jardín

S: Hombre, pues en Huesca por ejemplo, lo que hacen en Huesca es, hacen todo el año, primer año, de teoría y al final hacen una práctica, bastante corta, y obviamente los objetivos de esa práctica no son los mismos que una persona de cuarto,; les tiene básicamente observando, simplemente analizando la situación como trabajo para ellos mismos; y luego ya en segundo o en tercero como que se va aumentando la responsabilidad, diferentes objetivos, tal, tal, y mas tiempo, y, en fin, hasta que se llega al nivel.

$\mathrm{CT}$ : Bueno por ir cerrando un poquito, qué competencias ahora que vosotros estáis ya cerca de terminar, pensáis que se os quedan cojas, que son las mas deficitarias, que, yo es que llevo cuatro años y esto...lo hecho en falta

Me: Trabajo en equipo

A: $Y$ en la universidad yo creo que el caso del idioma

G: El tema del idioma

AL: Eso depende del currículo también, porque por ejemplo en el caso de educación física, yo he estado haciendo las prácticas en un colegio del programa british, y bueno educación física, no tenía tanto problema, no la impartes en inglés.

S: Vale, pero quiero decir, todas las carreras creo que la inmensa mayoría, el noventa por ciento, te exigen que hagas un semestre de idioma, creo; en Huesca es un "éxito", 
que es los créditos de libre elección que exigen tener al final de los cuatro años, mínimo un B1 en cualquier idioma y, ala, tira.

Ma: pero luego no vale de nada

AL: Eso sirve de bastante poco. Si tu el día de mañana, yo acabo, y lo que me estás exigiendo (es) un $\mathrm{B} 2$, si partes de un $\mathrm{B} 1$ quieres con un $\mathrm{C} 1$, prepárate, y prepárate bien.

L: No, no; que te lo den y que valga, y no tenemos que ir que hay a pagar la titulación; porque tu sabes, yo tengo compañeros que han pasado, han aprobado el supuesto B2, yo tengo el $B 2$ reconocido, y en cuanto que conoces un poco lo que es un B2 fuera, te dices, no te confundas: tienes un B1 con un poquito de B2, aunque ese curso lo llamen B2.

S: Ese es el nombre que le ponen algunos, no, con lo cual ya es un problema ponerles nombres.

$\mathrm{L}:$... entonces si tu apruebas inglés B2 tienes un B2 y la gente se cree que le tiene, y cuidado.

Me: Pero es como en cualquier lado, aquí tu te sacas el $\mathrm{C} 1$ y yo por ejemplo me saqué hace unos años el B2 o el C1 el que sea, eso es un nivel medio de ingles? (risas) y me lo saco, que guay, esto lo domino bien, y voy, voy para Inglaterra para un mes, y volví diciendo no tengo ni idea, te lo juro, yo no iba a decir nada, pero una cosa es la teoría y luego un examen con un señor que te pregunta cosas así con un acento spanenglish, y otra cosa es tener un nivel; pero ya como que, da igual, o sea, lo que te exigen es tener el título y que tengas cierta desenvoltura en el idioma, es que eso, eso es básico.

AL: el tema del idioma es un tema, bastante, bastante, cojo.

CT: La última, porque me van a regañar luego cuando hagan la transcripción, pero no me puedo quedar sin preguntar; hay una de las transferencias, perdón, de las competencias transversales, que, $y$, de las docentes que es sobre el tema de ética y "odontología" de la profesión. ¿Os suena eso de algo?

Ma: Si, lo de no copiar, y esas cosas ¿no?

A: He entendido, odontología 
(Risas)

CT: Me habré explicado mal, eh, ontología, no, odontología, no, de ética (COMPROMISO ÉTICO) ; o sea, vosotros vais a ser maestros y tenéis que tener unos principios éticos y tenéis ese código ontológico (risas), de saber un poco si esa competencia de alguna manera ... se produce...

L: No, para nada

L: Si no creas problemas en los Trabajos de Fin de Grado.

G: En serio, ¿ah si?, es que yo creo eso no se adquiere, eso o se tiene o no se tiene en tu vida

S: A ver te hacen hincapié en que durante el TFG no copiéis nada porque os van a suspender...pero siempre es como con el tono de amenaza...

Me: Siempre con ....., que es la visión negativa o mala que dan. Yo he llegado a decir, a, a mi me llegó a decir un maestro que no me valora el esfuerzo y le digo no me valoras el esfuerzo, y digo qué clase de ejemplo le estás dando a una futura maestra; pero ahí tela porque hay mucho debate de si hay que valorar el esfuerzo en la universidad, hay que valorarlo o no; porque claro, se puede valorar el esfuerzo o no; y como ese, millones de ejemplos; por ejemplo, a mi lo que me enfada muchísimo es el primer día de una asignatura encontrarme un maestro, que no es maestro, que viene de otro departamento que te dice, yo no tengo ni idea de didáctica, no se nada de didáctica, no la voy a dar, y que te da un ejemplo, desde mi punto de vista, a futuros maestros pésimo, pésimo; ya no digo de cara a contenidos, digo de cara a como persona, que todavía es más importante: yo creo que eso debería tener un control.

AL: Yo creo que la ética y la moralidad de cada persona, eso ya viene un poco desde más atrás, de cuando eres pequeño, y con toda la educación que te dan tus padres; yo creo que ya con veinte pico años quien te va a venir a dar lecciones de moralidad, de ética, de lo que está bien o lo que está mal.

So: Pero se trata de cómo poder transmitirlo cuando eres profesor en primaria,; para poder trasmitirlo a su vez a los niños

$\mathrm{CT}$ : $\mathrm{Si}$, la idea es ir, no quedarnos en la mente la ética verdadera, sino la que nos llevamos, la que tenemos que llevar después para trabajar con los niños. 
CT: Yo creo que va un poco mas orientado por lo que decía, ¿tu nombre era, perdona?, (...Luis).. de dejar marcados a los niños; tu tienes que tener por encima de todo la dignidad de los niños, entonces, ¿como veis que se abordan esos temas?

S: estas cosas, la personalidad, las emociones, como que no se le dan importancia, pero la tienen: los valores, la personalidad, todo eso

A: Depende del profesor, también. Aquí depende muchísimo del profesor, porque tan pronto tienes un profesor que dice, cuatro cosillas y tal y si (el niño) se porta mal o se te echa a llorar, ... que se calle; y luego tienes profesores que de verdad te empiezan a explicar, pues lo que podría estar pasando y, ya cómo tendrías que actuar, porqué no se pueden decir estas cosas delante de los niños por que les cuesta tal, pues...

Ma: Yo creo que ver varios casos de profesores nos ayudaría en este sentido, por ejemplo hacemos dos prácticum, conocemos dos, tres, cuatro profesores como mucho: si hiciéramos más prácticas, viéramos otros centros un día, otro día, puedes conocer diferentes casos y cómo ellos les tratan y aprender tu, de lo que tu consideras quien es el buen maestro, quien no tanto; porque por ejemplo si que he coincidido con, por ejemplo, dos que me han gustado mucho, y he coincidido también con uno que me parecía que no tenía esa ética y esa moral; no trataba bien a los alumnos; entonces yo creo que a base de verlos, nosotros podemos también adquirir esa ética y moral.

S: $Y$ también, bueno, en concreto tener como un trio en lo que sería el profesor perfecto porque cada uno pues podemos cambiar en mil cosas, pero sí unas bases claras de lo que tendría que tener un profesor; Yo que se como no... pegar a los niños (risas).

S: Claro hay muchas veces que un lenguaje que ...no saben ni que es racista pero que lo es ... y lo están usando sin darse cuenta, pues, abrir los ojos en ese sentido a tus alumnos, hacer debates, ejercicios de sociología

Me: Sí hay un problema también bastante gordo igual un poco relacionado con la ética entre los profesores y los funcionarios. Hay gente que se mete a la carrera y se mete a la carrera, o porque no te daba la nota para lo que quería, o porque trabaja de ocho a tres, porque quiere tener tres meses de vacaciones; $y$ tu hablas con gente, y hay gente que tu le dices vas a estar veinte años dando clase, la cantidad de niños que van a pasar por tus manos y cómo les puedes marcar con la mentalidad de yo trabajo de ocho a tres, me da exactamente igual, trabajar con las mismas unidades didácticas el primer año que a los veinte años, no cambio nada, no me preocupo por nada, voy doy mi clase y me voy.

Ma: También tiene que haber revisiones, que no las hay, que una plaza sea vitalicia.

AL: Yo el principal problema de los funcionarios y demás; también he visto casos en el centro en el que estaba, la profesora, siempre se alargaba y llegaba a y diez o y 
cuarto; es que los padres se quejan, los compañeros, pero es funcionaria y qué le vas a hacer...

CT: Pero vosotros también en la carrera os enseñan algo de eso, de esa ética que hay que tener. Es que eso es una competencia. Lo digo porque es una competencia, que esa competencia se trabaja

A: Yo veo que de la misma manera que ellos no evalúan nuestras competencias transversales en una prueba, nosotros tampoco nos vemos en ellos, pero es algo como muy inconsciente.

Ma: Que te lo transmite, no te lo enseñan pero te lo transmiten

AL: Tu ves un profesor que llega tarde, que esta un poco más de pasota y demás, y he tenido otro, por ejemplo, el año pasado de actividad física en el medio natural , y si yo me levanto a lo mejor a las nueve cuando me toca que hacer esta actividad, y él lleva desde las seis ... para que luego el juego de orientación salga bien ..., eso es un trabajo oculto..

S: pero que se ve la vocación

Ma: Claro, tu los ves y...dices, yo quiero ser asi también

AL: Ese es el trabajo que siempre queda: el profesor que realmente le guste (lo que hace) y que las cosas salgan bien, trabaja más de 8 horas, llega a casa, come, y queda lo que tiene que hacer, y esto no me ha gustado, esto lo cambio, y este niño ha fallado porque lo va hacer mañana, le cambio o qué...

Ma: Yo personalmente si que recuerdo que me han comentado en ciertas asignaturas, ahora no me acuerdo en cual, que el tema de la ética, de que sea vocacional, que nos dediquemos a esto por vocación, que nos formemos continuamente, que es una responsabilidad, yo sí recuerdo que me lo han dicho., de palabra directamente.

L: Yo por ejemplo, el año pasado tuve una compañera en prácticas, que estaba en un centro que daba clase de educación física, y la profesora de educación física iba en tacones, entonces ¿qué te transmite una profesora de Ef que tendría que estar con los niños yendo en tacones a clase?; que me parece perfecto pero ten tu ropa de deporte allí, tus zapatillas y cuando salgas de clase, te vistes como te da la gana, pero no estés en clase los niños, con tacones porque es educación física y tacones..

AL: Eso no, no, no se enseña, se transmite; en la universidad, si yo soy profesor de universidad, veo que llego puntual, veo he hecho mi trabajo y bien, si tienen dudas me preocupo por el alumno, al final lo transmites y sin querer lo absorbes. Y ya está, o es 
nada como enseñar, hoy voy a enseñar a como no legar tarde. Predicar con el ejemplo, y al igual que los niños nos ven a nosotros comportarnos, y tenemos que srlo, igual hemos de exigir en la universidad

L: Cuantos profesores que están en la carrera, seguro que habéis tenido algún profesor que os ha marcado para bien o para mal, y al final inconscientemente es verdad, y yo porque un poco lo he visto; el ejemplo que te ha dado un profesor con su manera de actuar, de dar clase, etc, etc, tanto para bien como para mal y que es muy complicado que te lo imparta, porque.., al final son cosas que deberían haberte enseñado tus padres, pero..., complicado, es un tema muy complicado y se ve mas en la actitud, en los hechos, que en..., no se puede copiar, no se puede no se qué...

Ma: El tener una vocación tampoco te la pueden enseñar. Yo creo que es, al final que lo vemos en la universidad, que vemos profesores que están ahí por vocación, que se desviven, otros que están por vocación y que, a lo mejor no se desviven pero bien, y otros que no están por vocación y que son nefastos.

AL: Es que sinceramente, tratas con niños, y los niños, agotan a cualquiera, y si no es vocación lo que tienes, es muy difícil dar una enseñanza de calidad y al final estás haciendo el canelo, y a saber, y eso los niños que pasan por tus manos, y como pueden, yo que se, acabar locos.

L: Además porque si los coges en primero igual son de cuarto a sexto, imagínate sin vocación, tienes una generación ahí, buena.

\section{CT: ...Último epígrafe...TFG y competencias, ahí lo dejo}

Ma: Se ponen en práctica la mayoría de ellas

\section{S: Transversales; muchas}

Ma: Las transversales todas las que has dicho se ponen en práctica; yo le he presentado ya, ya terminé, y exceptuando el trabajo en equipo lógicamente, se ponen todas de manifiesto, tienes exponer, que investigar, referenciar bien autores, no copiar, en general todo.

AL: Nada, yo estoy empezando ahora, lo mas que he avanzado es el título, a si que...

CT: Si pero ahí la compañera, la compañera, me ha parecido como que, como que...eh.

S: No, no, nada, no, es que no he empezado 
CT: ¿No has empezado?, pero bueno, las perspectivas que tu crees que hay...

Ma: Es como un parche

A: Es que, como que van temas tan diferentes que tampoco lo voy a decidir, como cada uno dice una cosa, no se muy bien lo que va a ser de mi, entonces no soy la mas indicada para opinar sobre este tema.

Me: Yo creo que en general, las competencias, todas, las transversales todas, se dan mejor y se evalúan mejor en la especialidad, que por eso quizá ellos tiene más dificultades ahora que no tienen especialización, pero yo noto que las asignaturas optativas, de especialidad, las competencias se dan mejor se evalúan mejor y espero que con el TFG sea igual

S: Claro con el TFG, digamos, te tienes que convertir como en experto

CT: Hombre se supone que el trabajo de fin de grado es para mostrar las competencias adquiridas a lo largo de los cuatro años, por eso lo pregunto

Ma: Yo sí considero que tengas que reunirlas todas para realizar un trabajo y para exponerlo

\section{CT: ¿Suficiente preparación para abordar el TFG en condiciones?}

Ma: para abordarlo, no se, bueno en mi caso es un poco especial, que he terminado hace poco, cuando empecé tenía muy pocas asignaturas, entonces, lo dejé un poco, entonces me ha costado mucho empezar. Yo no he llegado con mucho ánimo para abordar el TFG, una vez que estás dentro sí lo haces; me imagino que la gente que va en un curso normal sí lo ..hace.

CT: No pero eso es porque, al ser el digamos el colofón de todo el trabajo mas las competencias, si vosotros ahora que estáis empezando, os veis con esos recursos suficientes con esas competencias, para poder abordar con garantías...

S: Yo , si, es como un trabajo más pero muy grande; es como la selectividad de la carrera; yo es que también depende de una manera de verlo bastante optimista, porque es un trabajo muy largo y si de verdad te interesa y ser experto hay que delimitar lo que quiero.

EHombre_Hu_INEF: Si has cogido algo que no te llama puede ser un poco 
AL: Fundamental que elijáis un tema que os guste, porque sino...

$\mathrm{CT}$ : Bueno pues si alguno quiere añadir alguna cosa que se le haya quedado pendiente sobre el tema de las competencias, yo creo que hemos ido tocando prácticamente todo. Agradeceros vuestra participación, vuestra implicación. Os voy a pedir que rellenéis esta hojita con los datos, recordad poner el teléfono para que si hay haya cualquier problema os podamos, ir pasando; eh, esta, no se si la tenéis que rellenar, pero por si acaso, la rellenamos, y por último, pues hay regalo para agradeceros vuestra participación e implicación, yo creía que iba a ser para mi, me lo ha dado Víctor, y digo mira que bien, me va a dar un regalito, que no es para ti... 


\section{Anexo 5. Transcripción del GD 2}

TRANSCRIPCION REALIZADA 18 de diciembre de 2018

DINAMIZADOR (JL). Para no andar hablando de todas esas competencias que eran 13 o 14, se decidió que quizá valía la pena profundizar en las mas relevantes por las puntuaciones estadísticas obtenidas. En el estudio realizado nos han salido con las mejores y peores valoraciones del estudio que he hemos realizado a nivel nacional, con estudiantes MEPEF que han terminado la carrera y con titulados CAFyD de todo el territorio nacional. Qué nos ha salido que os puse en el documento de referencia para orientar este GD, como dato estadístico que nos diera idea de cómo se respondió de la pregunta general: cuánto y de qué forma nos han ayudado los estudios cursados para el desarrollo de estas competencias transversales. Pues lo que dicen vuestros compañeros es que organización y planificación, dentro de las llamadas competencias instrumentales, son las que mejor percepción de ayuda formativa recibida para su desarrollo se ha obtenido con un 2.59; estamos haciendo un estudio sobre 4 (máximo); este 2,59 supone sobre 4 una equivalencia a medianamente alto. Entonces vuestros compañeros consideran que la competencia para el desarrollo de la planificación y organización se ha desarrollado mucho; pero sin embargo os fijáis que la competencia informática ay la competencia para la lengua extranjera con unos promedios de 1.27 y 1.23 respectivamente, y se han desarrollado con esas valoraciones, poco. Es decir que las asignaturas que habéis cursado. según vuestros compañeros en las dos titulaciones (MEPEF y CAFyD) informática aplicada al ámbito de estudio, es decir tecnología aplicada al ámbito de la EF y lengua extranjera, obtienen valoraciones sobre la percepción de la ayuda formativa recibida para su desarrollo bastante bajas. Lo mismo para bien nos ha ocurrido con las competencias que denominamos interpersonales como el WE (trabajo en equipo) y con las HHSS (habilidades para las relaciones interpersonales), que se valoran con 3.23 el WE, porque parece que hay mucha carga de WE en los estudios cursados; y lo mismo con la percepción que se tiene sobre el desarrollo de las HHSS, habilidades en las relaciones interpersonales, con 2.79, que eso también es mucho; cunado pasa de 2.60 consideramos que es mucho; y lo mismo ocurre con la selección de las competencias sistémicas, para las que ellos nos dicen que respecto al aprendizaje autónomo al preguntarles cuanto te han ayuda los estudios cursados, asignaturas, las prácticas realizadas para desarrollar esa competencia, nos dicen que mucho también; y lo mismo para la competencia adaptativa, adaptarte a las distintas circunstancias: 2.60 también que es mucho.

JL. Vale, teniendo en consideración estas competencias seleccionadas a partir de las valoraciones estadísticas observadas, y en las que queremos profundizar, lógicamente la estadística lo que nos dice es cómo está el top, cómo está desde el punto de vista del mucho o el poco apoyo formativo recibido para su desarrollo, pero lo que no nos dice la estadística es el CÓMO; de qué forma, cuál es el funcionamiento interno de esas actividades, de esas prácticas que habéis realizado en las asignaturas, las experiencias, las materias, que nos ayuden a comprender cómo esas experiencias han ayudado al desarrollo de esas competencias. 
Entonces la primera pregunta que hacemos es qué experiencias o actividades formativas se han realizado en vuestra formación, estudios, en las asignaturas cursadas, y aquí nos entran actividades desde el punto de vista teórico prácticas, actividades de evaluación, tareas encargadas, trabajos realizados, es decir todo ese grupo de actividades que forman parte de las asignaturas cursadas, que os han ayudado A DESARROLLAR POR EMPEZAR POR ALGUNA, por ejemplo ORGANIZAR Y PLANIFICAR LA DOCENCIA, esta es la primera pregunta que lanzo.

V: básicamente las formas en las que veo hemos trabajado esta competencia ha sido prácticamente en eso, en las presentaciones con un plazo, al final tienes que organizarte con la gente de los grupos para realizar las tareas, planificar las actividades, aquí ya va más dirigido a la mención ene EF, en el momento en el que tú planificas una actividad para un pequeño grupo, el hecho de que cada uno tienen un rol al final, por ejemplo: "empiezas tu o tu porque tienes más control sobre el grupo, tú vas a llevar esa actividad; a la hora de gestionar el material pues lo mismo, al que se le de bien el tema de lo audiovisual pues se encarga de las cuestiones más audiovisuales de la tarea, el que es más manitas pues realiza las tareas de plástica, etc.

JL: vale, qué más cosas pensáis; cómo habéis aprendido a organizar y a planificar las unidades de programación.

L: yo siguiendo la misma línea que Víctor, en la asignatura de Expresión Corporal, cuando teníamos que hacer los informes semanales de contenidos por cada tema trabajado, todos asumíamos un rol, no me acuerdo muy bien, pero creo que eran secretario, coordinador, y algunos así, entonces cada uno se encargaba pues de un poco de que el trabajo saliera adelante y cada uno cumplía sus cometidos, ponía su pequeño grano de arena, para que el trabajo saliera adelante, y así cada uno hacía un epígrafe, y se iba rotando.

JL: pero fijaos que cuando hablamos de PLANIFICACIÓN Y ORGANIZACIÓN estamos hablando de una competencia que tiene que ver con cómo los docentes somos capaces de organizar toda la información que manejamos para construir unidades de programación y desde el punto de vista de la planificación cómo planificamos, cómo diseñamos, cómo gestionamos los tiempos, los materiales, etc.; esa es la competencia de organización y planificación docente, es decir, es lo que en la oposición nos piden cuando nos dicen que hagamos la programación anual que tenemos que presentar a la propia oposición, es decir, partiendo de esa base, la pregunta va más allá de lo que vosotros planteáis, esto es, rascad un poco más en vuestra memoria y pensad qué actividades habéis desarrollado aquí (en la formación universitaria), en qué asignaturas, que os hayan podido ayudar a ser mejores en esto.

VICTOR: pues por ejemplo en la asignatura de currículum en la elaboración de UD.

$\mathrm{CH}$ : Realización de unidades didácticas, organizamos una carrera (Paz), informes de expresión, de literatura, etc. La forma en la que nos ha ayudado ha sido en darnos las pautas a seguir para la correcta planificación pero en todas ellas la carga de trabajo 
era demasiado extensa. Pero aún así, me han enseñado a programar una unidad didáctica con los pasos necesarios.

JL: qué hacíais en esas materias en esas asignaturas os decían vamos a aprender a programar y a planificar y a organizar nuestra docencia; estas son las actividades que realizamos para que lo hagáis; en qué consisten esas actividades, cual es su funcionamiento interno, qué se pretendía.

V: se trataba de buscar un problema o un supuesto problema que podría ocurrir en la clase o una propuesta de necesidad de aprendizaje y, partiendo de esa necesidad, lo que se hacía al final era programar una unidad didáctica para un tiempo determinado en función de la necesidad si era más o menos grande o importante vamos a llamarlo, y a partir de ahí se iba investigando qué actividades se pueden desarrollar, cuanto tiempo se tiene y entonces lo programabas.

A: por ejemplo también en el Practicum 1 cuando ya conocías un poco la clase de destino y la profesora te dejaba hacer alguna pequeña intervención, conociendo a la clase (al alumnado), los tiempos de trabajo que requerían para realizar las tareas, para callarse y todo el tiempo que perdían, pues ahí les ibas organizando distintas actividades atendiendo a las materias que impartía el profesor del que dependías.

G: a fin de cuentas lo que me ha ayudado a mi principalmente para organizarme ha sido el Practicum tanto el 1 como el 2 sobre todo, ya que en el 1 tienes menos carga que en el 2; en el 1 no te exigen como tal una UD son más bien sesiones que te preparas y ya está, pero en el 2 te exigen dos UD bien realizadas, con todos los apartados y a fin y al cabo tienes que mirar muchos condicionantes para poder hacerlo.

JL: Quizá esa es una diferencia entre un Practicum 1 y el $2 \ldots$

L: en el practicum es donde pones en relación la teoría con la realidad porque puedes preparar un UD maravillosa pero luego aplicada a la práctica te sale un desastre.

JL: parece ser que el Practicum es lo que nos aterriza en la realidad porque las materias no lo se.

G: yo he observado una falta de experiencias reales en los cuatro años; yo pienso que en el primer y segundo año ya tienen que haber experiencias que nos acerquen a los niños, a los alumnos y aprender a ser maestros.

$\mathrm{V}$ : y de hecho es poca; yo la experiencia que tengo al acabar sigue siendo poca igualmente; al final o te buscas tu tus voluntariados o tus cosas para estar más en contacto o no ves la realidad; al final es una cuestión de programar en función a una realidad no en función a un ideal. 
JL: pensáis que tiene que ver una adecuación entre ser capaz de algo desde un punto de vista competencial y la aplicación directa a una realidad?

A: eso es importante porque por mucho que estudies y seas brillante pero las buenas calificaciones pero realmente no eres profesor hasta que no tienes la práctica y las experiencias; a lo mejor si que tenían que ser las asignaturas teóricas pero aplicando el contenido a prácticas con niños; no digo que tenga que ser todos los días pero sí poder llevar a la práctica la teoría que se ha aprendido. $Y$ además pasan cuatro años y del primero y del segundo de lo que te acuerdas es de lo que más te ha llamado la atención pero.

G: al fin de al cabo te pasas en el grado tres años en un aula y dos meses en un cuatrimestre y cuatro en otro, en total 6 meses de cuatro años que lo pasas en el colegio, me parece un porcentaje muy bajo.

V: Además hay asignaturas en las que supuestamente son en las que tienes más que programar, COA, sobre todo al final coges la teoría y dices vale, esta programación tienen que tener estos apartados, tienen que tener esto otro, pero volvemos a lo de siempre, y con esto qué?, simplemente se trata en ellas de leer y completar, ir leyendo e ir completando como un robot; yo te pongo esto de teoría, si no se muy bien le pido a un compañero de otro año y le digo más o menos que has puesto tú aquí, te ayuda, pero no te estás poniendo en una situación de lo más real.

A: yo me acuerdo de los primeros años cuando daba psicología que sí me llamó mucho la atención que hicimos un trabajo de dibujo de niños y su significado y claro cuando fui al practicum yo que era muy curiosa, y si lo aplicaba, a ver si podía alguna niña dibujar algo pero no lo hice de cara, para aprender sino a escondidas y me hubiera gustado haber profundizado más en esto en la realidad.

JL: qué pensáis un poco, terminando con esta competencia, vosotros que habéis estado en las prácticas reales, habéis visto cómo se manejan los elementos del currículum, vosotros habéis visto la realidad, hay a vuestro parecer una adecuación entre lo que os enseñamos aquí y lo que se maneja allí si es que hubiera una brecha cómo sería de grande.

L: en general no tiene nada que ver; yo he estado en un colegio público y en otro concertado; en el concertado quizá si he encontrado algo más de adecuación pero en el público no tanto; en un colegio concertado en mi experiencia a penas había niños con adaptaciones curriculares y en una clase de tres líneas..

G: y luego dependiendo también del centro público o la localidad en la que estés porque no es lo mismo estar en un pueblo como Arroyo de la Encomienda que en un barrio de Valladolid como las Delicias; ahí hay una diversidad de alumnado que te generan en un sitio si y en otro no una situación de problemática en el aula que no tienen nada que ver. 
JL: eso aquí no lo terminamos de ver en la teoría en vuestra opinión...

G/L: no, no, no, no

G: aquí es todo teórico y puede suceder o no en la realidad.

L: por ejemplo imagínate que en una clase hay un problema de comportamiento grave, aquí a nivel de teórico no te enseñan herramientas para ayudar a mejorar el comportamiento; al final si te metes ahí te las ingenias tú, si, mucha teoría y mucha metodología pero luego cuando hay un problema realmente grave que no hace que avance.

G: yo en mi caso he tenido durante la UD que he impartido en el colegio dentro del aula un alumno autista con un grado muy alto y aquí no te enseñan cómo tratar a los 21 alumnos que tienes restantes y a él mismo con sus comportamientos; él constantemente está interrumpiendo la clase pero claro pero a ti no te enseñan a actuar ante eso; tú tienes que ir improvisando a partir de lo que has ido observando en la fase de observación de practicum.

JL: siguiente competencia. COMPETENCIA INFORMÁTICA. Estamos en las dos peores valoraciones sobre la ayuda formativa recibida para el desarrollo de estas dos competencias Informática y Lengua Extranjera. En la misma línea qué consideráis vosotros desde vuestras experiencias que desde aquí y de qué manera se ha contribuido a desarrollar la COMPETENCIA TECNOLÓGICA APLICADA AL ÁMBITO DE LA EDUCACIÓN FÍSICA.

A: Hemos tenido una asignatura orientada específicamente a las nuevas tecnologías y a través de ella hemos conocido un poco más ese mundo, haciendo vídeos, Wikis, blogs, etc. Además, en otras asignaturas nos han enseñado otras formas de trabajar con los niños en clase con aplicaciones como el kahoot y el plickers.

$\mathrm{CHUCHI}$ : Esto se queda más escaso. No nos han enseñado nada nuevo a lo largo de toda la carrera. Lo único algunas aplicaciones que pueden ser utilizadas para trabajar con niños en educación física escolar como es el caso de las aprendidas en la asignatura de educación física en el medio natural: geocaching, wikiloc.

G: a mi me ha servido para reforzar los conocimientos que tenía sobre algunas aplicaciones pero no en cuanto al uso de aplicaciones que sirvan para el día a día del maestro, bueno salvo la que hemos aprendido ahora en el TFG de Atlas.ti para analizar los datos, el resto, refuerzos del power point, refuerzos del manejo del audacity para poner música en el aula.

L: también está el kahoot

A: en educación física en el medio natural ahí sí hemos aprendido herramientas tecnológicas que no sabía. 
V: yo el contacto que he tenido fue en el practicum 1 donde una profesora que tuve usaba una aplicación en donde registrando en ellas las notas le iba analizando y dando datos en relación a la evolución del alumno, le daba un especia de análisis muy completo del niño, por ejemplo si ha subido tantos puntos o ha bajado tantos otros en tal o cual momento; también contabilizada las faltas de asistencia; era realmente buena la aplicación; eso para un análisis de datos sobre tu alumnado puede servirte muy bien; pero aplicaciones educativas como tal no he usado ninguna.

JL: aquí no ha habido ninguna materia en la que os hayan enseñado herramientas tecnológicas a aplicar al ámbito de la educación primaria o al ámbito específico de la educación física...

GONZALO: yo creo que en educación física en el medio natural.

A: yo creo que también en la asignatura de TICs lo que hicimos fue repetir lo que sabíamos de antes.

G: esa asignatura de TICs fue en primero y me acuerdo que realizamos un video sobre una vivencia de tu vida.

V: yo creo que no aprendimos herramientas tecnológicas aplicadas a la educación.

A: por ejemplo en la asignatura de matemáticas sí que hemos realizado alguna práctica con el programa Excel y no relacionada con su aplicación a nuestro ámbito de la educación física.

JL: yo creo que una cosa son herramientas generalizadas del tipo office para la administración de documentos que parece sí habéis usado aquí y sí aplicables como herramientas al ámbito de la escuela, pero también preguntamos por las que son aplicables al ámbito de educación física.

L: si porque nos enseñaron en la signatura TICs a crear una página web propia de una materia, por ejemplo yo la hice sobre ciencias sociales y pienso que sí se podría llevar a cabo una página web para trabajar los contenidos de educación física.

A: a nosotros en ciencias sociales nos enseñaron a hacer una especie de cuestionario también.

V: también nos enseñaron a utilizar moodle un poco, cómo se puede hacer un cuestionario en moodle, cómo lanzar preguntas en moodle, cómo gestionar grupos. 
JL: y la dinámica formativa como era; es decir, el funcionamiento interno de esas actividades que os proponían cómo era.

V: al principio se aborda un poco a modo de aprendizaje por descubrimiento; aquí tienes esto, se entra así; nos enseñaron a crear una especie de perfil virtual del profesor, después se nos invitaba a investigar un poco y después se nos iba explicando, ya familiarizados con la aplicación, cómo realizar una encuesta; es un aprendizaje un poco por descubrimiento, se nos da una serie de pinceladas y después ya vas manejando e investigando sus posibilidades.

JL: y en AFMN que aparece ser la asignatura donde más habéis trabajado con aplicaciones tecnológicas aplicadas al campo de la EF: se hacía algún tipo de aplicación práctica de ella, sobre el terreno?

V: con un traker como la aplicación geocaching o wikiloc y códigos QR para realizar localizaciones, pero tampoco las veo; tu puedes apropiarte de ellas pero propiamente para educación yo tampoco las veo.

G: para educación física si tu llevas una programación sobre senderismo o de orientación sí las puedes utilizar, pero aun siendo aplicables a la enseñanza no son creadas para la educación, pueden ir destinadas a cualquier otro ámbito.

V: por ejemplo al final kahoot puede ser destinada para muchas cosas y es fácilmente orientable a la educación.

JL: en relación a la LENGUA EXTRANJERA; las materias que habéis cursado son facilitadoras del desarrollo de la competencia para lengua extranjera aplicable al ámbito de trabajo. Estaríamos a modo de ejemplo de asumir una plaza bilingüe en el practicum?

A: yo por ejemplo en el practicum he tenido una plaza bilingüe, mi profesora daba inglés y ciencias y yo sí que me he defendido, pero a lo mejor en el ámbito de la educación física se que a mi me cuesta mucho más.

G: yo creo sinceramente que poder asumir en el practicum una plaza bilingüe depende de tu formación anterior y no de lo que has aprendido en la universidad; si tenías formación anterior en la universidad la has seguido complementando y de puede ayudar a decidir optar para el practicum por una plaza bilingüe, pero si no estas preparado como es mi caso con lo que he aprendido en la universidad sería incapaz.

JL: en las formaciones que habéis tenido a lo largo de las materias cursadas hay una relación con el bilingüismo o tan solo hablamos de la formación recibida de una asignatura específica cursada o de dos materias especificas o.. 
V: son asignaturas en las que al final te toca rellenar ejercicios en inglés, ese es el resumen; no aprendes a hablar inglés por que aprender a hablar inglés es mucho más profundo, es por ejemplo ver una película, saber lo que te están hablando, poder tener una charla con alguien en inglés y yo personalmente no estoy en disposición de ello.

$\mathrm{CH}$ : Personalmente aún repitiendo varias veces la asignatura, en la universidad NO ME HAN ENSEÑADO nada de esta. La asignatura se limita ha hacer ejercicios, corregir y avanzar, pequeñas explicaciones, pero ya lo entenderás. Todo lo que he aprendido ha sido en academia para aprobarla, no en la universidad.

A: Para aumentar nuestro conocimiento de la lengua extranjera, hemos tenido dos asignaturas en las que nos han preparado y evaluado de todas las partes, es decir, grammar, listening, writing and reading. La parte de gramática es la que más se prepara en clase haciendo ejercicios a través de un libro, pero la mayoría del aprendizaje se lleva a cabo de forma autónoma en casa.

\section{G: Gramática, listening}

L: es verdad que casi el día a día consistía en rellenar ejercicios, pero también me acuerdo de haber aprendido, aunque a fin de cuentas es aprendizaje memorístico, un cuento en inglés y luego lo teníamos que contar al resto de la clase; también se realizaban exposiciones en inglés que yo personalmente resolvía aprendiendo de memoria porque en mi nivel de inglés no tenía tanta soltura, y después también aprendíamos a cantar una canción en inglés.

JL: abordando en clave competencial vuestro aprendizaje, vosotros pensáis que la fonación que recibís tiende a eso o se tiende a lo memorístico

L: pienso que el inglés cursado responde a un planteamiento memorístico abordando el vocabulario por ejemplo.

G: es memorístico pero porque no tengo formación previa; la formación que recibí fue en el colegio y tampoco es que se me daba muy bien el inglés.

V: la única formación que hemos tenido así menos memorística sobre le inglés han sido unas charlas, en primero y parte de segundo, que se desarrollaban en el centro de idiomas y en donde nos permitían hablar con un nativo; estabas 10 minutos con un nativo después girabas y hablabas con otro, y eso al final te estás forzando a comunicarte, es una experiencia nueva en la que te estás formando para el bilingüismo medianamente, y bueno tu intentas hablar, te intentan entender y poco a poco vas mejorando.

A: pero siempre es la misma conversación de qué tal estás, cómo te llamas, dónde vives, si tienes animales. 
V: pienso que la única forma de intentar mejorar el idioma y tender hacia al bilingüismo desde la universidad es yendo a un Erasmus o un Amity en el que te pones a hablar inglés porque no te queda otra, pero no aprendiendo a hacer ejercicios que los haces todos iguales ni aprendiendo de memoria que te suelto el rollo y he aprobado y sacado un cinco y gracias; creo que es la única forma de salir con mas nivel de inglés de la facultad y asumir puestos de trabajo bilingües.

\section{G: yo pienso lo mismo}

JL: vamos con dos competencias como más amables como las HABILIDADES EN LAS RELACIONES INTERPERSONALES; pensáis que la formación cursada y las experiencias prácticas realizadas han tendido y ayudado a desarrollaros desde el punto de vista de las habilidades sociales, interactivas de unos con otros y eso es proyectable al ejercicio docente?

$\mathrm{CH}$ : Al trabajar en equipo las relaciones interpersonales están integradas, pero al hacer los grupos aleatoriamente es cuando más las podemos trabajar (por ejemplo en expresión corporal, pero esto no ocurre en todas las materias cursadas, aun así no me parece mal que muchas dejen la libre elección de grupos como en literatura infantil, ope, curriculum... esta competencia sobre todo la hemos trabajo en la mención en la asignatura del medio natural con las salidas y el convivir juntos y en expresión corporal a la hora de estar interactuando entre nosotros constantemente.

A: Mediante los trabajos en grupo, las exposiciones que hemos hecho en la que nuestros compañeros eran nuestros alumnos y otras situaciones, han generado un aumento en nuestras relaciones interpersonales y generalmente en el compañerismo.

L: sobro todo cursando los estudios de la mención en educación física; yo cuando me matriculé en los estudios de educación física, en asignaturas como expresión corporal, que fue una de las primeras, pues yo creo que ahí experimenté las relaciones de colaboración con todos mis compañeros, porque nos fácil proviniendo de diferentes grupos, no conoces a muchos compañeros, y descubres a personas que pensabas conocías y descubres en mayor profundidad.

G: es verdad que cuando empiezas el primera año en nuestros estudios universitarios te ves obligado a relacionarte, a hacer grupos, partiendo de que nadie conoce a nadie y has de hablar con todo el mundo; durante el segundo curso ya tenemos más relaciones y ya nos conocemos aunque también surgen divisiones y prejuicios, pero la mención de educación física facilita el retomar conversaciones que se quedaron paradas durante el primer o segundo año, socializarte con los demás porque las actividades que realizamos como el senderismo, las rutas en BTT, la orientación, requieren de la colaboración, del diálogo hablando unos con otros, y pasando las actividades juntos.

L: considero que las actividades prácticas realizadas en la mención de educación física nos han hecho sentir como grupo, no así en otras menciones que según algunos 
compañeros son menos interrelacionales, como la mención en inglés en donde el ambiente de clase es más competitivo.

A: Yo dos cosas; la primera es que sí que he visto cambios en compañeros que tenía durante el primer año muchas dificultades relacionarse y hablar en público, incuso temblaba, y al final en el último curso se le ha visto más relajado y por tanto sí ha existido un cambio en favor de su capacidad de socialización. Además las materias cursadas Educación Física en el medio natural y expresión corporal sí que facilitan la unión entre compañeros, bien porque nos vamos de acampada y las relaciones interpersonales se relajan pues el contexto es más impersonal, más conocido y no tan académico; o en expresión corporal en donde el contacto físico, la experimentación con el contacto táctil, une a las personas y se forma un clima un ambiente de clase que no se consigue con los planteamientos didácticos de otras materias cursadas, 0 en otras menciones, pues sí que es verdad que hemos escuchado sobre nuestra mención lo que es envidiado el ambiente grupal que se genera. Siempre se tienen roces con los compañeros pero en general suelen salir amistades de esos grupos de trabajo en la mención generados.

V: yo creo que es la propia naturaleza de la educación física, porque al final no es estar en un aula sentado muchas veces, es estar moviéndote con un compañero, es al final como un equipo, tu al final el aula lo ves como un equipo donde estamos todos juntos y al final no importa tanto la nota final; el tema de la acampada y las actividades que te obligan a salir.

G: son actividades dinámicas y activas y al fin de al cabo son actividades generan divertimento y unión y hace que te relaciones más a tus compañeros.

JL: la acampada por ejemplo decís, las actividades físicas en el medio natural son las que más interrelaciones facilitan..

V: porque no te queda otra, porque no vas a estar haciendo senderismo mirando al suelo.

G: durante las actividades de senderismo vas a diferentes ritmos; durante el día en el senderismo o en escalada o durante las rutas en btt durante las jornadas en las que practicas vas a diferentes ritmos y por tanto te vas encontrando con distinta gente, entonces las situaciones creadas te obligan a mantener una conversación y a relacionarte con quienes coincides.

JL: qué habilidades sociales pensáis habéis desarrollado más ahora que ya estáis terminando; como tú decías antes Alexandre, alguien empieza su formación temblando por hablar en público y cómo se sale desde el punto de vista de las habilidades sociales; os pongo un ejemplo, desde el punto de vista comunicativo, es una capacidad que me facilita la interacción y que estas actividades de las que estáis hablando, favorecen esta capacidad; es decir a través de todas estas actividades expresivo corporales y de educación física en el medio natural, qué habilidades pensáis habéis desarrollado y mejorado. 
A: es que yo creo que no somos conscientes de cómo decimos las cosas comunicativamente, incluso gestualmente, y sí que es verdad que a mi me ocurrió que al participar en la asignatura de expresión corporal me daba cuenta de que a lo mejor un gesto podía significar algo para mi pero no para mi compañero; entonces a partir de ahí me he dado cuenta de mis fallos, pensando sobre ellos e incorporando en tu persona otra forma de relacionarme. Por ejemplo a lo mejor yo me relaciono con los demás de forma brusca y cortante y me he dado cuenta de que mis gestos o mis palabras muestran ese tipo de relación con los demás, y participando en las actividades de expresión corporal en las que el cuerpo también hace relaciones he conseguido ser más consciente y mejorar.

JL: algo más de habilidades sociales?; estamos hablando de algunas como la comunicación, la escucha activa, empatía, es decir todas estas cuestiones que ponemos en funcionamiento cuando interactuamos; cuando vamos de acampada ahí desplegamos una red de habilidades que nos permiten convivir, interactuar, relacionarnos, negociar, ..,; cuáles de las habilidades sociales pensáis habéis mejorado.

G: yo creo que he mejorado mucho la comunicación no verbal a la hora de expresarme con gestos; yo antes era un palo, y ahora hablo, me muevo, me expreso con las manos, asiento con la cabeza, y es verdad que no te das cuenta hasta que no te ves y es verdad que en las grabaciones de video que se hicieron sobre nuestra práctica docente en expresión corporal yo me vi y recuerdo las dos exposiciones con sorpresa sobre mi mismo y la forma de actuar que tengo y haciendo de docente con mis compañeros de la universidad dirijo la clase.

L: pero eso tienen que ver con habilidades sociales? yo pensé que eso tenía que ver con cómo interactúas con el resto a la hora de exponer.

JL: no, habilidades sociales son aquellas capacidades y habilidades que uno tiene y dispone para vivir en sociedad; son habilidades sociales por ejemplo escuchar al otro y darle el turno de palabra asintiendo con la cabeza, como él dice,

L: pero entonces también vale la mejora que has tenido cuando expones por ejemplo.

G: si yo te hablo y no me muevo a lo mejor me entiendes peor, pero si yo gestualizo quizá me entiendas mejor gracias a esos gestos.

V: yo por ejemplo, he mejorado en la asertividad; durante la elaboración de trabajos grupales acabamos peleados con algún compañero, y este año hemos intentado no repetir eso, y en cuanto hemos tenido un mínimo problema hemos intentado resolverlo pidiendo ayuda al profesor; y pienso que eso es una evolución que estamos teniendo, ya que cuando empezamos los estudios permites todo, permites echarte el trabajo encima, pero llega un momento en el que aprendes a decir hasta aquí. 
A: a mi me pasa al contrario; cuando veo que van a venir las cosas suelo ponerme a la defensiva y me quejo; no obstante este curso he intentado ofrecer más oportunidades pensando que he de ver las cosas de una forma distinta, no tan inflexible, intentando decir las cosas, la verdad, con mas tranquilidad, de forma más abierta y mas reflexiva.

L: yo coincido con Gonzalo en que mis primeras exposiciones fueron un caos, casi traumáticas en primero de carrera, pero creo que las experiencias de exponer en público me han ayudado a relajarme, a relacionarme mejor con personas que a priori no conocía de nada, y quieras o no estas experiencias no habituales en la formación anterior, te imponen.

A: pero por ejemplo en nuestra asignatura de expresión corporal si que es verdad que hay un cambio de la primera a la última sesión porque es cierto que al principio conoces a algunos pocos compañeros con los que habitualmente más te relacionas, y después vas participando en las actividades, te vas relacionando y dices me siento segura, me siento cómoda, aunque te salga fatal, pero en el fondo te sientes seguro; y sí que observo que ha habido mucho cambio en cuanto a dar una clase a muchos niños a darla a tus compañeros: ahí sí creo que es distinto.

V: otro aspecto positivo que encontré en las actividades cursadas en expresión corporal, es que los grupos se hicieron por orden de lista, lo que al final de fuerza a crear nuevas relaciones, nuevos vínculos; tu llegas de cero a un grupo y conoces solo a una persona y no sabes cómo trabaja la gente, cómo es ya no en el ámbito de trabajo sino también en el personal, con quien puedes congeniar mejor, con quien peor, entonces al final tienes que empezar de cero, y pues eso, te ayuda a tejer otra vez redes y desplegar tus habilidades personales.

JL: y que aplicas ahí para tejer esas redes, qué habéis aprendido a aplicar. esas habilidades interpersonales cuales son las que habéis aprendido a aplicar cuando llegas aun grupo nuevo

L: iniciativa por ejemplo

\section{A: Liderazgo.}

G: hablamos de habilidades aprendidas para relacionarnos en grupos nuevos de trabajo como tener iniciativa, ser empático, tener paciencia, y muchas cosas buenas y no tan buenas.

L: estar abierta a nuevas ideas.

JL: eso es; estas cosas son las que sabemos que han de ocurrir cuando nos enfrentamos a las nuevas relaciones a desarrollar cuando nos integramos en un grupo nuevo, pero cuales son las ganancias de habilidades sociales que habéis obtenido a 
través de las experiencias que habéis narrado como las de los trabajos grupales de expresión corporal.

$\mathrm{L}$ : depende mucho del grupo que te toque para realizar las tareas y en el que te tengas que integrar; en mi caso la experiencia fue positiva y lo tuve muy fácil porque todos los miembros el grupo en el que me integré éramos muy similares y trabajábamos bien; pero yo veo otros grupos y digo madre mía menos mal que yo no estoy ahí; entonces también depende del grupo y que este te facilite por ejemplo tener iniciativa y te facilite portarte bien para cumplir con Iso ideales para el desarrollo de la tarea.

V: yo he aprendido a tener iniciativa, es decir, si no arranca nadie, ya arranco yo, y lo que hago es intentar dar el primer paso muchas veces y eso lo he aprendido en la facultad porque yo antes no me mostraba tan lanzado; pero ya llega un punto en el que si tengo que trabajar soy yo el primero que da el paso y dice lo que creo tenemos que hacer, y creo que esto sí me lo han proporcionado las experiencias que he tenido en la facultad.

A: al hilo de esto recuerdo un ejemplo relacionado con una experiencia con una profesora sustituta que nos dio una asignatura que no recuerdo y se portó muy bien con nosotros porque en las exposiciones en público que teníamos que hacer, en vez de darnos los datos negativos y fallos nos dijo también los aspectos positivos que habíamos realizado y que no nos dábamos cuenta de ellos, creándonos un ambiente de seguridad, y al habernos planteado los aspectos positivos sobre nuestras habilidades sociales mostradas en las exposiciones en público, nos hacía pensar en no ser tan malos como quizá pensáramos.

V: creo que fue en la asignatura de OPE y de hecho creo que no nos dio ningún feedback negativo sino mas bien positivo; aportaba muchas valoraciones positivas y al final te ibas sintiéndote bien y pensando que en la exposición he mostrado no tantos aspectos negativos y no me ha ido tan mal.

A: por ejemplo nos daba mensajes del tipo: eres muy dulce y cuando te refieres a tus compañeros generas credibilidad en los demás.

$\mathrm{V}$ : con estos mensajes positivos, con los halagos y con aportarte un poco esa seguridad uno fluye mejor en las relaciones y se siente más seguro y facilita mejor abordar las relaciones interpersonales, ayudando a que nos tranquilizáramos más.

JL: Bueno; nos quedan tres cosas, y ya pasamos a la última. Voy a dejar la mejor para el final; vemos ahora el APRENDIZAJE AUTÓNOMO. Es la capacidad que nosotros adquirimos para ser independientes a la hora de formarnos, en el sentido de decir, yo llego a la facultad porque el contexto en el que vivo me impone que me tengo que formar, yo he de salir de la facultad nutrido a mi mismo de la formación que considero a mi me va air bien para mi formación. Cuanto de esto está presente en la formación que habéis recibido y os ha ayudado a cambiar esta forma de aprender. 
A: En muchas asignaturas hemos creado nosotros nuestros propios apuntes mediante cuadernos de campo, ampliando lo que nos daban en clase, escribiendo nuestras reflexiones personales, etc.

$\mathrm{CH}$ : Aun casi siempre trabajando en grupo también he trabajado de forma había individual. En las asignaturas que creía más importantes buscaba más información y me interesaba más por ella, como en aquellas que tratábamos patologías como en atención a la diversidad, y también en expresión corporal con todo lo relacionado con la expresión rítmica corporal o saber cosas del medio natural para enseñar a mi alumnado futuro.

G: en la facultad muchas asignaturas tenían que ver con funcionamientos grupales pero la mayoría son de funcionamiento individual y tenías que sacarte tú las castañas del fuego, y sobre todo a hora las del final Practicum y TFG, estás tú con tu tutor y nadie más te va ayudar, y eres tú el que tiene que buscar la información, eres tú quien te tienes que expresar, eres tu todo, entonces o dices, o hecho para a delante o aquí me quedo.

JL: igual vosotros (Victor, Alexandra) no tenéis aún experiencias de Practicum II y TFG y es verdad que son experiencias de mayor individualidad en su participación.

V: yo si que reconozco una diferencia en la docencia en cuanto a la experiencia en el instituto y en bachiller que ya estás como más libre y en la universidad es más yo te doy los apuntes y la explicación, pero el que tienes que ahondar y estudiar eres tú.

G: yo en cuento a eso lo pasé muy mal el primer curso de carrera porque yo vengo de un colegio concertado y después de haber hablado con otros compañeros en situaciones similares, pensamos que nos tenían demasiado tutelados, todos con el libro de texto, informándote de lo que iba a entrar en el examen, te lo estudiabas y hacías el examen y ya está; como la PAU, es todo esto lo que va a entrar en los exámenes, te lo estudias y fenomenal; pero aquí en la universidad había profesores que te daban apuntes y otros que no, entonces los que no, te tenías que buscar tu la vida, para acceder a toda esa información y elaborarla en forma de apuntes, y yo por eso el primer año lo he pasado muy mal porque no estaba acostumbrado a este sistema.

G: en la asignatura de psicología de segundo yo creo que fue la primera asignatura en la que fui capaz de obligarme a mi mismo a asistir a clase, tomar los apuntes por mi mismo, y tengo que resolver la búsqueda de la información para superar la materia por mi mismo porque entendía a mis compañeros que me decían que asistiendo ellos a clase y esforzándose no compartían los apuntes con nadie; y es un trabajo que implica muchos lunes y muchos viernes llegar a las ocho de la mañana a clase y tomar tus propios apuntes; además me ocurría que no era capaz de interpretar adecuadamente los apuntes recogidos por los demás.

$\mathrm{V}$ : o en cuanto asignaturas que me han ayudado a desarrollar mi competencia de aprender autónomamente quiero mencionar la signatura de la mención $E F$, educación 
física escolar, en donde se nos daba unos textos para la lectura y la realización de una conclusiones al respecto; además nos daba unas definiciones para nutrirte con la información que necesitas conocer pero eres tú el que has de aprovecharla para construir tu propio aprendizaje, obtener tus propias conclusiones sobre el aprovechamiento de todo el material dado para luego hacer una exposición ante los demás basada en todo ese aprovechamiento. En otra signatura de ciencias sociales no informó que seríamos examinados de todos los contenidos del área de conocimiento del medio social propios del currículo de primaria, y nosotros teníamos que crear nuestros propios apuntes buscando esa información en la propia normativa, libros de texto, lo que nos obligaba a hacer búsquedas de esa información de manera muy exhaustiva para cumplir con la responsabilidad de encontrar y elaborar la mejor información para preparar los contenidos de ciencias sociales para educación primaria ya que es uno de nuestros cometidos como docentes de primaria que vamos a ser.

G: ocurre a veces por ejemplo que en PEC tomábamos los apuntes dos compañeros quienes nos ayudábamos mutuamente para tomar esos apuntes, es decir que al final teníamos lo mismo, y en el primer examen recuerdo que saqué un cuatro y mi compañero un siete y medio, hicimos fotos al examen y teníamos a penas tres palabras cambiadas tal y como cada uno se expresa, y era prácticamente lo mismo lo aportado por los dos, y en el segundo examen de evaluación, con Iso mismo apuntes respondiendo lo mismo yo saqué un ocho y medio y mi compañero un cinco y medio; como puede cambiar tanto de los mismos apuntes de un examen a otro.

L: explica todo, porque era como un examen de conceptos; y cada concepto él te lo explicaba y luego tu te hacías tu propia definición; entonces tu compañero y tú hacíais la misma definición, pues no se..; yo por ejemplo en I primer examen saqué una nota muy baja con las mismas definiciones y en el segundo saqué una nota más alta con las mismas definiciones.

A: pienso que la capacidad de aprender autónomamente depende también en la universidad del profesor que te toque, el grupo de trabajo con el que tengas que interactuar para obtener información, la forma en la que imparte el profesor las clases, porque por ejemplo nosotros en la asignatura cambios sociales que nosotros cursamos por la tarde, pues los del grupo de la mañana nos contaron que el examen había sido tipo test después de ver un video y nosotros tuvimos que hacer un trabajo enorme, estudiamos unos textos muy largos, que recuerdo tuve que ir a la recuperación y tuve que estudiar mucho.

JL: última competencia a valorar, ADAPTACIÓN A SITUACIONES NUEVAS; estamos hablando de cuanto sois de adaptativos vosotros en vista a la formación que habéis recibido, o cuanto no sois de adaptativos por la formación que habéis recibido; me refiero a ser adaptativo en el sentido de flexibilidad, ser capaz de adaptarse a situaciones nuevas, capacidad de manejarse en situaciones que son en ocasiones difíciles.

$\mathrm{CH}$ : Esto solo lo he vivido en 3 asignaturas cursadas en la carrera. Educación para la paz con la carrera que organizamos con UNICEF, expresión corporal con todos los juegos que teníamos que hacer y la forma de evaluar las clases, que lo hacíamos entre nosotros, y por tanto debíamos aceptar los puntos de vista de los demás, o los 
errores que quedaban registrados en los videos de las sesiones que impartíamos cuando asumíamos el rol de docentes; , y en educación física en el medio natural, con todas las salidas a la naturaleza, rutas senderistas que fuimos realizando, teniendo que adaptarme a nuevas formas de participación.

A: Este aspecto lo hemos desarrollado realizando diferentes tipos de exposiciones y cambiando los grupos de trabajo regularmente. De esta manera teníamos que adaptarnos a la forma de trabajar de otras personas, a otras maneras de pensar, etc

G: yo creo que esta carrera estás constantemente adaptándote a asignaturas, a profesores, a compañeros.., es que es un cambio cada semana no pero cada mes si, porque son trabajos, son exámenes, son exposiciones, son nuevos compañeros que llegan, la mención igual, a la hora de la mención ya te estas adaptando a otro tipo de actividades distintas a las convencionales en el aula;

JL: cuáles son ese tipo de actividades que se realizan en la mención que son distintas a las habituales realizadas en la carrera.

A: en educación física en el medio natural, expresión corporal que es algo que no hemos sentido, no hemos vivido generalmente como experiencias en las asignaturas cursadas en primaria; y con ella nos hemos analizado competencialmente, que nunca lo he hecho, y no se qué proyecto quiero para mi, cómo me siento hasta que uno no lo vive, y yo si que creo que estamos en cambio continuo, en adaptación; y yo creo que el problema es claro, dura $x$ tiempo una asignatura pero te cuesta adaptarte a esa situación y cuando estás adaptado de nuevo tienes que cambiar de asignatura, y son muchas situaciones y muchas emociones, muchos compañeros, muchas cosas que pasan en muy poco tiempo que dura.

V: además si tienes que trabajar en grupo para realizar alguna tarea y quedas con los miembros del grupo y ese día tienes un problema que te preocupa, que eso pasa muchas veces, tienes que priorizar hacer ese trabajo, y claro, no van aquedar todos a trabajar menos tú, entonces venga ya alcanzo yo esto otro y me adapto a vosotros.

G: trabajos que te ponen un día para la semana siguiente, y tu veías en un grupo de tres o cuatro, madre mía, si esto es para la semana siguiente, o te pones ya no da tiempo

V: si eso es, o te pones y te adaptas a las circunstancias o se te va el tiempo; también lo haces por temas de drive y si te gusta bien, pero para mi no es lo ideal.

G: yo es que lo cierto en relación al drive los dos primeros años solíamos quedar con los del grupo de trabajo para hacer las tareas juntos, pero los dos últimos años, bueno, más ben el tercer año por que el cuarto con el practicum y el TFG no tanto, lo solíamos hacer por el drive. 
L: yo es que me di cuenta que perdía tiempo, porque uno escribo, el otro lo dicta y los otros no hacen nada.

G: a parte te reparte las tareas mejor y se hace mejor en casa.

A: interviene también mucho el grupo en el que estés y si tienes confianza y entonces no pasaría nada si un día uno no estuviera, pues entonces se permite que no haga en esa ocasión el trabajo y ya hará el siguiente y así nos vamos cubriendo, pero si te toca gente que realmente no asume el compromiso o no le importa los estudios que cursa en la carrera, entonces ocurren muchos conflictos y de algo que es totalmente académico pasa a ser algo personal; entonces los trabajos en grupo están muy bien pero con determinadas personas pero con la misma confianza y respeto, porque cuando se adolece de eso, entonces no hay más que conflictos.

$\mathrm{V}$ : de todas las maneras sin esos factores se pierde la esencia de ese trabajo colaborativo; así si divides, tu dices: tú haces la parte uno, yo la dos y tú la tres, pero o tienes tiempo y ganas y miras la parte uno y la dos y completas con tu parte y dices oye ponme algo más aquí o allí, o has perdido la esencia del trabajo colaborativo; entonces cada uno hace su parte el otro otra, lo redactamos en un documento y lo horneamos.

G: tienes toda la razón; yo me acuerdo que en un cuatrimestre los hacíamos así cada uno su parte y lo juntábamos en un documento para entregar, porque que teníamos tantos trabajos que era imposible quedar cada día para hacerlos, entonces o lo hacías tú en tu tiempo libre y cada uno cuando pudiese o era imposible quedar y vernos para hacer cada uno de ellos; me acuerdo un cuatrimestre que teníamos cinco drive abiertos y seguidos, y tenerte que poner con uno y acabarle y ponerte con otro y acabarle, y si te tienes que poner a trabajar presencialmente con todos sería imposible.

JL: ese es un poco el tema que abrimos, el TRABAJO EN EQUIPO; como habéis vivido las dinámicas en las que habéis tenido que poner en marcha esta competencia para trabajar en equipo, porque aquí como bien dices Gonzalo tareas que requieren de trabajar en grupo hay mucho. Entonces cómo habéis hecho, cuál ha sido el funcionamiento interno que habéis hecho para trabajar en equipo y asumir las tareas y responsabilidades.

A: En todas las asignaturas que he tenido en la carrera hemos trabajado en grupo, dan mucha importancia al trabajo en equipo, a ver cómo nos envolvemos en diferentes grupos, la capacidad que tenemos de organizarnos, repartirnos el trabajo y que quede adecuadamente. En algunas asignaturas hemos trabajado con el aprendizaje cooperativo desempeñando cada miembro del grupo un rol. Para mí, es el mejor método ya que si una de esas personas no hace su rol el trabajo no sale adelante. Muchas veces.

$\mathrm{CH}$ : Considero que hemos trabajado mucho la capacidad de trabajar en equipo mediante diferentes trabajos grupales. Es una de las partes positivas que he visto en 
la carrera. Podría decir que en todas las asignaturas hemos tenido que hacerlo y me parece un avance, ya que nos hace convivir, trabajar con diferentescompañeros, debatir, hablar las cosas y llegar a un acuerdo para alcanzar un fin, aunque reconozco que el método que adoptamos para abordar el trabajo nos ha generado conflictos personales entre algunos miembros de los grupos al no saber gestionar las discrepancias o tener intereses diferentes.

G: se repartía las tareas de base; yo recuerdo en la asignatura de literatura infantil, que estábamos analizando cuentos y en teoría, había que ir cambiando los roles que eran seis y había que ir asumiendo por cada cuento, pero realmente cada uno hicimos el mismo durante los siete cuentos que hubiese que analizar porque si no, ya tenías la rutina cogida, sabías qué tenías que hacer por que sino te volvías loco.

JL: y cual esa rutina de trabajo en equipo que decís aplicáis para abordar las tareas que se os encargan

L: pues sería quedar, repartir los epígrafes, luego buscabas la información cada uno en su casa, habríamos un drive común, íbamos pegando los epígrafes del trabajo y cada uno cuando pudiera iba pegando la información que había encontrado, y luego ya el resto si nos daba tiempo lo leíamos y ponías un día límite, después otro maquetaba e imprimía y ya esta el proceso.

V: yo excepto en expresión corporal, que cuando estábamos más perdidos sí decidimos quedar como grupo siempre después de la clase de los miércoles, comíamos juntos y lo hacíamos entre todos para comprobar que si había algo que alguien no sabía abordar pues lo echáramos entre todos un ojo, y nos pasábamos lo de cada uno al otro para intercambiarlo y valorarlo entre todos. $Y$ eso es lo que más cerca hemos estado para realizar un trabajo en equipo.

G: nosotros quedábamos unos días para trabajar en expresión corporal los primeros temas a realizar, pero luego ya el resto lo hacíamos por drive,... me refiero a los informes de contenidos que teníamos que elaborar.

JL: vale; yo creo que de estas no vamos a preguntar más de funcionamiento interno porque creo que habéis presentado suficiente información. Me interesa ahora que hablemos de otro asunto; a vuestro juicio de estas competencias que aparentemente vuestros compañeros han aportado esta valoración de promedio, cuales es la que vosotros daríais; es decir, según esto el ranking está en ayuda formativa para el desarrollo de la competencia de trabajo en equipo sería la que más ayuda ha recibido; después estaría el aprendizaje autónomo; después estarían las habilidades para las relaciones interpersonales, planificación, informática y lengua extranjera; Estáis de acuerdo, cual es vuestra valoración al respecto; así por ejemplo, planificación y organización, si tuvierais que definir si os han ayudado nada, algo, medianamente, mucho y muchísimo, cuál es vuestra percepción.

L: poco. 
A: tengo una duda, se refiere al trabajo en equipo al hecho de decir tenéis que hacer un trabajo o realmente enseñarnos cómo se hace un trabajo en equipo.

JL: no quiero revelaros demasiada información para no condicionaros pero una de las cosas que estamos viendo en relación al trabajo en equipo es que se hace una falsa asociación entre procesos de trabajo grupal y conciencia de desarrollo de la competencia de trabajo en equipo, porque técnicamente el trabajo en equipo formativamente requiere de unos de condicionantes que han de ponerse explícitamente en las tareas para poder desarrollar las tareas, que tal y como estáis explicando no parece estar apareciendo, por ejemplo como dices Laura, no parece tener conciencia de formación técnica, en el sentido de haber percibido que la competencia para el trabajo en equipo y se hace así ...; aquí parece que contáis que el procedimiento de trabajo grupal se realiza según contáis con un reparto interno de tareas y funciones para finalizar un producto académico y entregar, y la evaluación se hace de ese producto académico que no del proceso; eso es todo lo contrario a lo que se considera técnicamente trabajar en equipo; LO QUE PLANTEAMOS AQUÍ ES QUE EN VIRTUD DE LAS MATERIAS Y EXPERIENCIAS FORMATIVAS CURSADAS, CUAL ES LA AYUDA QUE HABÉIS RECIBIDO PARA TRABAJAR EN EQUIPO. Así lo que se percibe sobre esa ayuda recibida para desarrollar el trabajo en equipo es 3,23 que es mucho tirando a muchísimo.

\section{V: Yo no llegaría a 3}

A: es que depende mucho de las personas

JL: el 4 es que os está ayudando a trabajar en equipo mucho; el 1 sin embargo es nada.

G: yo considero que se nos ha ayudado mucho a desarrollar la competencia para el trabajo en equipo pero me quedaría con 2,6.

$\mathrm{CH}$ : considero que se nos ha ayudado muchísimo a desarrollar la capacidad de trabajar en equipo

V: yo considero que también nos han ayudado entre medianamente alto y mucho para nuestra capacidad de trabajar en equipo, 2,6 valoraría también.

A: considero que las múltiples experiencias de trabajo grupal sí han contribuido en mucha medida a tomar conciencia al menos de nuestras dificultades para trabajar en equipo, aun reconociendo su importancia: la valoración que hago es de mucha ayuda formativa recibida.

JL: En relación a la informática aplicada al ámbito de estudio, competencia tecnológica, los compañeros han valorado 1,77 que es poco.. 


\section{G: yo poco}

A: poco

JL: en relación a la competencia para el manejo de una LENGUA EXTRANJERA los compañeros hicieron una valoración de poca ayuda formativa para su desarrollo.

$\mathrm{CH}$ : la valoración que hago de la ayuda formativa recibida para aprender a manejar un alengua extranjera es de ninguna, ya que la forma de impartirnos la asignatura no pienso que sea la adecuada.

A: yo considero que la ayuda recibida para el desarrollo de nuestra capacidad de manejarnos en otro idioma ha sido moderada.

G: yo diría que para la lengua extranjera los estudios cursados en la carrera no nos han ayudado nada;

A: yo le daría una valoración de poco a la ayuda formativa para desarrollar la lengua extranjera en la carrera.

V: yo pienso también que poca ayuda formativa hemos recibido para el desarrollo de la lengua extranjera.

L: yo opino igual, poca ayuda formativa recibida a lo largo de las asignaturas cursadas para desarrollar o mejorar la lengua extranjera.

JL: los compañeros han valorado la ayuda formativa recibida para el desarrollo de las HABILIDADES EN LAS RELACIONES INTERPERSONALES pasa de 2,60 y eso $\mathrm{s}$ mucho.

$\mathrm{CH}$ : pienso que la ayuda formativa recibida a lo largo de las experiencias prácticas de la mención de educación física ha sido de mucha.

A: valoro en forma de mucho la ayuda formativa recibida a lo largo de las materias cursadas para el desarrollo de mis habilidades sociales.

G: yo valoro con mucho la ayuda recibida mediante las actividades realizadas en las asignaturas cursadas para el desarrollo de las habilidades sociales, si que le daba un 3 y algo más incluso, mucho alto. 
JL: para el APRENDIZAJE AUTÓNOMO los compañeros dicen que se les ha ayudado mucho, 2,82

$\mathrm{CH}$ : pienso que la formación recibida me ha ayudado mucho.

A: yo considero que se nos ha ayudado más que mucho mediante las actividades y tareas realizadas en la formación para desarrollar la autonomía en el estudio y en la búsqueda de información.

G: yo considero que he recibido formativamente mucha ayuda para aprender autónomamente, le pondría una valoración de 3 que es mucha la ayuda formativa recibida.

A: yo hago una valoración de mucho, pondría una puntuación de 2,82

JL: para la CAPACIDAD ADAPTATIVA aquí le dan un 2,60 que es mucho, aunque al límite con moderadamente.

V: yo creo que la valoración sobre la ayuda recibida para desarrollarnos adaptativamente a las diversas situaciones experimentadas ha sido de mucha, le pondría una puntuación de 3 sobre 4 . Yo creo que dado que nos han formado desde una constante de adaptación a metodologías, formas de estudiar, agrupaciones diversas, ambientes.

A: mi percepción sobre la ayuda que he recibido para desarrollar mi capacidad adaptativa es de moderadamente.

C: mediante las actividades de las asignaturas cursadas creo que hemos recibido mucha ayuda para desarrollar nuestra capacidad adaptativa.

JL: penúltima cuestión: EN QUÉ CREÉIS QUE PARA VOSOTROS OS PUEDE SER ÚTIL ESTAS COMPETENCIAS PARA EL USO PROFESIONAL: por ejemplo en que creéis que haberos desarrollo en la competencia para la ORGANIZACIÓN Y PLANIFICACIÓN os ha ayudado para proyectar al ejercicio profesional. La formación que yo he recibido para desarrollar mi competencia docente para la organización y planificación me ha ayudado a qué realmente?

A: En un futuro docente es muy importante ser ordenado y llevar las clases y el curso bien planificado. Hay que tener en cuenta que de nosotros depende el aprendizaje y el éxito de los niños y niñas que tengamos en el aula, por lo que nuestra responsabilidad es muy importante. 
$\mathrm{CH}$ : me puede servir sin duda para organizar unidades didácticas y sesiones prácticas para los niños.

V: nos ha ayudado a realizar una programación didáctica real, acorde a los tiempos establecidos. A ser más consciente del control de los tiempos.

G: yo discrepo a la hora de medir tiempos, porque aquí en la asignatura de expresión corporal lo podías ensayar más o menos y saber que en los 10 minutos que teníamos; pero cuando llegas practicum cuando diseñas la actividad, puedes plantear 345 actividades, puede ocurrir que desarrolles mucho más o mucho menos en función de como se presente la realidad, o sea, a mi no me sirve para medir tiempos, porque la realidad te dice otra cosa.

JL: en relación a la COMPETENCIA INFORMÁTICA, TECNOLÓGICA, DIGITAL, en qué creéis que os puede ser útil para vuestro futuro profesional en la docencia.

ANDREA: El futuro en las aulas está definido por las nuevas tecnologías por lo que tendremos que ampliar mucho más el conocimiento que tendremos sobre ellas o seguramente cuando lleguemos al aula los niños y niñas van a saber más que nosotros.

CHUCHI: Pienso que el manejo de aplicaciones tecnológicas me va a servir para aplicarlas a la enseñanza.

G: como docente pienso que la competencia tecnológica me va a servir mucho pero no por lo que he aprendido aquí en mis estudios en la universidad.

L: yo pienso que me va servir de poco, en todo caso para preparar juegos para los niños usando la tecnología, aprendan jugando, refuercen los aprendizajes realizados mediante.

G: yo creo que me a ayudar más la competencia tecnológica desde el punto de vista del docente que desde el punto de vista del docente para con el alumnado, es decir, de prepararles actividades a ellos, de llevarles a ellos a practicas con uso de tecnología; creo que me va avenir mejor a mi para analizar datos, para estadísticas, para aspectos así que no hacia ellos.

V: yo sobre la competencia tecnológica no he recibido ningún aprendizaje o refuerzo más allá de los que ya traía aplicados a la educación

A: si pienso en la formación recibida para el desarrollo de mi competencia tecnológica, he cursado la asignatura de TICs y he aprobado y ya está; no he recibido más formación que esa y ya la conocía. No veo que haya habido una formación más trascendente que esta; no obstante la dinámica formativa más común en la que he participado parte siempre de realizar trabajos con los compañeros, y el docente te dice que hagas tal trabajo y entonces te preocupas de hacerlo pero llega un punto en que 
estás tan agobiado con trabajos y entregas que tampoco piensas en incorporar a tus habilidades, es como, ya está he entregado y ya está.

V: no le veo mayor aplicabilidad futura a mi competencia tecnológica como docente de educación física que la aplicable a la propia tarea de gestión de la docencia, y no de aplicabilidad didáctica hacia el alumnado.

JL: desde el punto de vista de la LENGUA EXTRANJERA pensamos que nos va ayudar a nuestro ejercicio docente próximo?

G: si me sirve es por lo que aprenda fuera de la universidad.

V: nosotros nos estamos planteando cursar tras terminar la carrera diversos cursos de inglés porque somos conscientes de que no tenemos ningún nivel adquirido ni antes de la carrera ni después de la carrera.

A: yo recuerdo que aquí en inglés éramos muchos queriendo aprender en al carrera y una sola profesora, y claro no podía atender individualmente a cada persona que estábamos en clase, aunque sí que es verdad que si hacíamos un ejercicio y lo realizaba un compañero la profesora invertía tiempo con esa persona para realizar ese ejercicio, pero era imposible atender a tantas personas que generalmente no tenemos una base obtenida ni en educación primaria ni en secundaria, y claro, siempre estamos haciendo lo mismo en todas las etapas pero no aprendemos nada.

L: siempre en lengua extranjera estamos en clave de repaso, y siempre habrá lagunas y es porque siempre abordamos la lengua extranjera de la misma manera.

V: y en parte lo que se enseña aquí en la universidad es cosas como tiempos verbales; no me han enseñado un vocabulario específico para enseñar por ejemplo Science, decirme esto es lo que tienes que aprender para poder ser competente a la de poder impartir una clase de ciencias en la modalidad bilingüe en un centro;

JL: y para las materias de Educación Física..

G: la formación recibida para conocer terminología en inglés de educación física que nos pudiera ayudar a desenvolvernos mejor en las clases bilingües no ha existido claro.

V: yo por ejemplo no conozco el vocabulario de educación física en inglés; a mi ahora me dices cómo se dice pica en inglés y no tengo ni idea. 
L: yo creo que el bilingüismo no tiene sentido; creo que se podría plantear el inglés de otra forma y al final se pierde la esencia de la materia a impartir si se hace en inglés y no en castellano.

A: en mi experiencia en practicum, comprobé cómo en la asignatura de Science, a niños a los que daba refuerzo, la verdad no se sabía la fotosíntesis en español, entonces claro, no sabía explicarlo en inglés, y era claro, pobre porque en contexto bilingüe la va a dar por todos los lados.

G: yo sí veo sentido al aprendizaje en modalidad bilingüe en la escuela; hablo a veces con las madres, yo que soy entrenador de futbol infantil y les digo que tengo cierta envidia de sus hijos porque ojalá me hubiesen enseñado inglés desde pequeño; también es verdad que en ciencias naturales no van a aprender ese contenido adecuadamente si se hace en inglés, porque muchas veces no le entienden, pero creo que para el futuro sirve de mucho aprender el inglés.

V: yo doy clases particulares a un chico de cuarto de la ESO de historia; la asignatura de historia la tiene en inglés, el problema es que no tiene ni idea de historia, porque aprende de memoria el contenido en inglés y luego lo vuelca en el examen pero no comprende ni da la trascendencia que merece al contenido memorizado; la solución que se me ocurre es que se traduzca el tema aprendido en inglés al español, y cuando lo sepas en español aprende a decirlo en inglés pero no lo memorizas tan solo en inglés.

L: luego la formación bilingüe impartida en las escuelas hace que también se comentan faltas de ortografía en el idioma nativo y esta dimensión se desatiende.

G: mi experiencia en practicum la profesora de inglés llegaba a clase hacía una pregunta y los niños la contestaban bien, pero una con una frase de respuesta bien construida y pronunciada. Yo he estado en sus clases y he visto cómo formulaba ellas las preguntas y cómo las formulaban los niños para responder, y yo no me enteraba de nada, salvo alguna palabra que te sabes de toda la vida.

JL: avanzando algo más, de qué puedes seros útiles, o en que creéis que os beneficiará el ejercicio docente TRABAJAR EN EQUIPO y ser COMPETENTE EN LAS HABILIDADES INTERPERSONALES.

$\mathrm{CH}$ : para trabajar con el equipo docente, para hacer proyectos dentro de la escuela.

$\mathrm{V}$ : yo creo fundamental ser competente para trabajar en equipo ya que en virtud de mi experiencia en el practicum observo que como docente he de coordinarme con el resto de maestros de mi nivel; imagina que tienes un niño con ciertas necesidades especiales, pues tienes que saber cómo coordinarte con el PT, tienes que saber cómo ayudarle, pero todo eso viene de un trabajo en equipo; si vas a crear una UD que conlleve varias áreas que transversalmente aborde varios contenidos tienes que tener 
una voluntad de trabajo en equipo con el resto de compañeros especialistas, el de música el de inglés

G: tienes que llegar a mucho entendimiento, muchas conversaciones, mucho diálogo, es que es en definitiva entenderse por que es fundamental.

L: es fundamental ceder y no imponer tu criterio.

G: creo que también se aprende a trabajar en equipo en un colegio en base a la experiencia que hayas vivido; por ejemplo si ahora tuviera que atender a un niño con alguna necesidad especial, si parto de mi experiencia recibida para trabajar en equipo, a mi me costaría.

$\mathrm{CH}$ : en relación al manejo de habilidades sociales creo que como docentes nos han de servir para manejarnos mejor en situaciones con niños, con sus padres y con los propios compañeros.

JL: en qué creéis que a vosotros os parece útil el desarrollar vuestra CAPACIDAD DE APRENDIZAJE AUTÓNOMO Y ADAPTATIVA desde el punto de vista de generar vuestro perfil profesional.

A: Aunque en nuestro futuro como docentes tiene mucho peso el trabajo en equipo, una buena parte la hacemos de forma autónoma, nosotros somos los que tenemos que enfrentarnos a una clase y sacarla adelante, con todos los recursos que hemos aprendido tanto en la carrera como en nuestra experiencia.

$\mathrm{CH}$ : mediante la capacidad adaptativa pienso que podremos afrontar situaciones que se escapan de lo habitual (algún niño con algún tipo de problema, algún olvido, algún fallo) y saber qué hacer y cómo reaccionar.

G: creo que la capacidad de aprendizaje autónomo me va a servir para preparar las oposiciones; creo que es clave, porque has de prepararte los temas, buscar información distinta a la demás, programar de forma diferente a los demás, todo.

V: en relación al aprendizaje autónomo, para la vida personal es fundamental, al final aprendes solo, y nadie te dice si tienes que venir por aquí o por allí, tú decides en función de tus intereses y necesidades.

L: en mis prácticas, cuando ha habido algún accidente, he estado en ocasiones sola y a priori sin saber qué hacer al no poder dejar a los demás niños solos, o mandar a un niño que lo acompañe a secretaría para que fuera atendido, en este tipo de situaciones no me he visto muy autónoma; son cosas que vienen de repente y tampoco te han enseñado a resolver en la universidad y me agobio y no lo afronto. 
A: en mi practicum 1, los profesores te dejaban sola en clase, y decidías como creías que iría mejor al alumnado, pero realmente no sabes qué es lo que quiere el profesor, pero dado que te han dejado has de asumir una responsabilidad pero no te han enseñado en la universidad realmente a bordar estas situaciones, allí te enseñan mucha teoría pero esas cuestiones no te enseñan a manejar.

JL: ok; última pregunta; cuales son las DIFICULTADES CON LAS QUE OS HABÉIS ENCONTRADO PARA ADQUIRIR ESAS COMPETENCIAS EN VUESTRA FORMACIÓN INICIAL; habéis definido experiencias, metodologías, asignaturas, estructuras de actividad que os han ayudado a desarrollar esas competencias docentes, pero ahora os pregunto lo contrario; en esas experiencias donde están las dificultades. Así para el TRABAJO EN EQUIPO o las HABILIDADES EN LAS RELACIONES INTERPERSONALES por empezar por alguna de ellas..

A: en relación al desarrollo de mis habilidades sociales, he tenido dificultades a la hora de exponer delante de mis compañeros a los que no conocía mucho, por miedo a que me juzgaran o a equivocarme o a olvidarme de mi discurso.

V: yo creo que la gran dificultad es no distinguir lo personal con lo profesional en las relaciones con los compañeros de grupo; yo tengo un problema profesional contigo, te digo que te pongas a trabajar porque esto nos incumbe a los dos, y sabemos que es probable que so lo tome a mal; en el momento en el que instas a trabajar a un compañero de grupo se afecta a la relación interpersonal y eso afecta al trabajo grupal que se comparte.

A: yo pienso que hay un problema generalizado de asumir las responsabilidades de trabajo durante la carrera, como que nos e toma en serie el trabajo de otros compañeros.

V: yo creo que también se relaciona con un problema de objetivos; cuando trabajas con alguien quieres obtener una buena calificación, pero es posible encontrar personas que integran los grupos que se conforman con una calificación suficiente para aprobar y superar la materia y en eso tenemos un problema, porque al final sale por algún lado, porque yo no me voy a a conformar con un siete cuando el otros se quiere conformar con un cinco.

JL: estamos hablando de trabajo en equipo, es decir cómo yo me enfrento a situaciones de trabajo en equipo en mi formación y cuando me enfrento a ellas me encuentro o desde el punto de vista metodológico del planteamiento del profesor, o desde el punto de vista de cómo lo abordamos nosotros como miembros de los equipos de trabajo a los que pertenecemos para abordar las tareas encargadas, 0 desde el punto de vista de cómo nos relacionamos con los compañero, es decir, donde están en ese ejercicio de despliegue de acciones donde estéis en situación de trabajar en equipo y donde aparecen en esas situaciones los bloqueos para prosperar en el aprendizaje de ese trabajo en equipo experimentado. 
L: mi experiencia fue muy buena, sin roces con nadie, trabajábamos bien, lo cierto es que me fue siempre bien y nunca me he llevado disgusto con nadie; siempre he trabajado en el mismo grupo y me fue bien; incluso en expresión corporal me fue bien a pesar de se un grupo distinto en el que me integré distinto al habitual.

A: En relación al desarrollo de mi capacidad para trabajar en equipo, pienso que en las experiencias cursadas estaba acostumbrada a trabajar con las mismas durante el primer y el segundo año de carrera, pero se me ha hecho, a veces, difícil estos dos últimos años trabajar con otras personas., en nuevos grupos de trabajo.

$\mathrm{JL}$ : barreras encontradas cuando tratamos de desarrollar nuestra CAPACIDAD DE PLANIFICAR LAS UNIDADES DE PROGRAMACIÓN, donde están los hándicaps.

A: Estamos acostumbrados a que nos den las cosas y nos digan lo que tenemos que hacer y cómo hacerlo en cada momento, por lo que nos viene bien que de vez en cuando la capacidad de organización y planificación sea responsabilidad nuestra y lo intentemos hacer de la mejor forma posible.

G: para mi la falta de información que tenemos para realizar y aplicar una UD; a mi me da pena decirlo pero en cuarto la persona que mas me ha ayudado a desarrollar una UD ha sido Carlos como tutor de Practicum, y en cuarto. En primero, segundo y tercero, tenía una ligera idea sobre cómo hacer una UD.

A: personalmente en la asignatura de currículum creo que hemos obtenido la base para poder realizar los trabajos relacionados con la capacidad de planificar.

JL: quizá vosotros los que habéis realizado las prácticas en la especialidad, en cuarto, tenéis una visión mas certera que los que aun no lo habéis cursado, a cerca de lo que se sabe y lo que verdaderamente es.

V: lo que veo no es tanto una falta de información sino más bien una falta de experiencias, darme con un muro y aprender a soltarnos; yo creo que es un problema.

JL: problemas encontrados para la COMPETENCIA TECNOLÓGICA Y LA LENGUA EXTRANJEA creo que están definidos ya pero si alguien quiere añadir algo más??; finalmente donde están las DIFICULTADES ENCONTRADAS EN LAS EXPERIENCIAS CURSADAS PARA ADQUIRIR LAS COMPETENCIAS ADAPTATIVA Y DE APRENDIZAJE AUTÓNOMO. Donde están los hándicaps que han impedido que desarrolléis con cierta profundidad por ejemplo vuestra capacidad de adaptaros a diferentes situaciones.

$\mathrm{CH}$ : en relación a la capacidad de desarrollarme atendiendo al conocimiento de una lengua extranjera, el problema que he observado es la forma de impartir la asignatura, empleando la profesora una metodología tradicional de trabajo de la gramática y ya está, y las lagunas siempre están. 
A: en relación a las dificultades encontradas para el desarrollo de mi competencia tecnológica, lo cierto es que no soy muy partidaria de las nuevas tecnologías, el ordenador lo utilizo para las cosas necesarias y no me llama la atención por lo que las asignaturas en las que hemos tenido que utilizarlo han sido muy complicadas para mí. A pesar de ello, he de decir que he cambiado de actitud y me he superado a mí misma en muchas actividades por lo que me siento orgullosa y tengo ganas de seguir aprendiendo.

A: además las dificultades que he tenido hacia la lengua extranjera es la gramática, el tener que prepararlo por mi cuenta cuando a veces había construcciones de frases que ni entendía.

A: creo que los tiempos están muy marcados, por ejemplo, es como teoría y como que hasta el final de la asignatura antes de hacer el examen no sabes lo que te va a entrar y no estudias realmente todo, es como que te falta base porque va pasando el tiempo, después es vista de teoría y afrontar trabajos, y después hacer trabajos y acabar trabajos y luego si te da tiempo, ponerte a estudiar; es como que la estructura está generalmente muy marcada; y hasta que no acabas los trabajos no puedes ponerte a estudiar porque tampoco sabes qué estudiar realmente para no optimizar mal el tiempo, entonces es como que acabo esto, termino esto, me pongo a esto, pero realmente no te da tiempo a profundizar y reflexionar.

V: para ese aprendizaje autónomo que quiero desarrollar en mi proceso de aprendizaje explotando un tema, no lo tienes, has de metértelo como puedas para afrontar las materias.

A: en relación al desarrollo de mi capacidad para aprender autónomamente, como he dicho anteriormente nos han acostumbrado a darnos todo hecho y en algunas situaciones en las que he tenido que ampliar mis conocimientos con artículos o con otros documentos, me ha resultado bastante difícil, sobre todo el saber si lo que iba a estudiar estaba bien o no. Me creaba muchas inseguridades no tener unos apuntes fijos.

L: para mi en relación a la competencia adaptativa, vale, que es verdad que estamos en continua adaptación general durante los estudios; pero durante las prácticas, si por ejemplo mandas a los niños que hagan una rima con su nombre para el día siguiente, pero llega el día y no lo tienen, y qué haces; vale yo me puedo adaptar pero cómo, yo he necesitado como una capacidad de reacción ante ese problema concreto, aunque quizá haya tomado una decisión que perjudica a aquellos que no trajeron la tarea encomendada, pero a lo mejor tomas otra decisión que perjudica aquellos que sí tenían la rima preparada.

G: yo en esos casos me guío por la cultura que tenga marcada la tutora del colegio a quien acompaño en mis prácticas; por ejemplo ante las faltas de actitud positiva.. 
A: pero ya no eres tú, es cómo lo hace el otro; no aprendes por ti mismo, aprendes por un modelo de imitación que no sabes si esta bien o mal, y quien juzga que ese modelo está bien o mal.

L: en esta situación que he narrado, les dije a los niños que entre todos los que habían trabajado les ayudaríamos a buscar rimas, pero eso suponía invertir tiempo y no cumplir con el objetivo marcado para la UD que estábamos trabajando; pero sí pienso que hice bien para que todos se sintieran mas o menos bien.

A: por ejemplo durante el practicum cuando te dejan solo para impartir una clase te encuentras habitualmente que los niños de primaria se ponen a hablar y uno se pregunta qué hacer que sea efectivo; al final observaba a la profesora tutora par ver qué hacía, aunque no hacía nada excepcional, tal vez dejar a alguien sin recreo ante una falta de actitud; lo cierto es que hablándolo con un compañero me comentaba que lo que hacía era una técnica de tiempo sin recreo, pero a mi forma; entonces me giraba en la pizarra y escribía un $t$, una i, una e y veía que se iban callando y paraba; y hubo un momento con ese sistema, viendo cómo me giraba entonces callaban. Creo que tenemos que encontrarnos a gusto en algo que creemos nosotros, no que veamos demasiadas guías, que es necesario sin embargo tener referentes claro a modo de guía.

G: es evidente, pero es necesario pensar en la rutina que ya tienen adquirida los niños para desarrollar tu UD, y si tu aplicas una rutina nueva, a lo mejor te cuesta toda la UD que aprendan esa rutina nueva y has perdido tiempo por todos los sitios.

A: a mi me gustaría experimentar en la práctica lo que yo creo y si veo que no funciona entonces lo cambio, pero saber que sale de mi, de mi iniciativa, de mis conocimientos y experiencias.

G: yo creo en general como he ido diciendo desde le principio que este grado universitario debería de tener más experiencias para los estudiantes.

JL: muchas gracias por todo; se recuerda que es posible subsanar la información realizada. Para ello se ruega os pongáis en contacto conmigo para gestionar los cambios o eliminación de información del texto resultante. 